\section{OAK RIDGE}

NATIONAL LABORATORY

MANAGED BY UT-BATTELLE

FOR THE DEPARTMENT OF ENERGY

\title{
Durability-Based Design Criteria for a Quasi-Isotropic Carbon- Fiber Automotive Composite
}

J. M. Corum

R. L. Battiste

S. Deng

M. B. Ruggles-Wrenn

Y. J. Weitsman

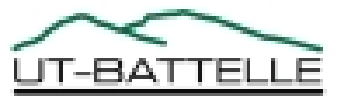




\section{DOCUMENT AVAILABILITY}

Reports produced after January 1, 1996, are generally available free via the U.S. Department of Energy (DOE) Information Bridge.

Web site http://www.osti.gov/bridge

Reports produced before January 1, 1996, may be purchased by members of the public from the following source.

National Technical Information Service

5285 Port Royal Road

Springfield, VA 22161

Telephone 703-605-6000 (1-800-553-6847)

TDD 703-487-4639

Fax 703-605-6900

E-mail info@ntis.fedworld.gov

Web site http://www.ntis.gov/support/ordernowabout.htm

Reports are available to DOE employees, DOE contractors, Energy Technology Data Exchange (ETDE) representatives, and International Nuclear Information System (INIS) representatives from the following source.

Office of Scientific and Technical Information

P.O. Box 62

Oak Ridge, TN 37831

Telephone 865-576-8401

Fax 865-576-5728

E-mail reports@adonis.osti.gov

Web site http://www.osti.gov/contact.html

This report was prepared as an account of work sponsored by an agency of the United States Government. Neither the United States Government nor any agency thereof, nor any of their employees, makes any warranty, express or implied, or assumes any legal liability or responsibility for the accuracy, completeness, or usefulness of any information, apparatus, product, or process disclosed, or represents that its use would not infringe privately owned rights. Reference herein to any specific commercial product, process, or service by trade name, trademark, manufacturer, or otherwise, does not necessarily constitute or imply its endorsement, recommendation, or favoring by the United States Government or any agency thereof. The views and opinions of authors expressed herein do not necessarily state or reflect those of the United States Government or any agency thereof. 
Metals and Ceramics Division

\title{
DURABILITY-BASED DESIGN CRITERIA FOR A QUASI-ISOTROPIC CARBON-FIBER AUTOMOTIVE COMPOSITE
}

\author{
J. M. Corum \\ R. L. Battiste \\ S. Deng \\ M. B. Ruggles-Wrenn \\ Y. J. Weitsman
}

Date Published: March 2002

\author{
Prepared by the \\ OAK RIDGE NATIONAL LABORATORY \\ Oak Ridge, Tennessee 37831 \\ managed by \\ UT-BATTELLE, LLC \\ for the \\ U.S. DEPARTMENT OF ENERGY \\ under contract DE-AC05-00OR22725
}




\section{CONTENTS}

Page

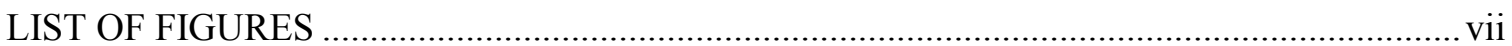

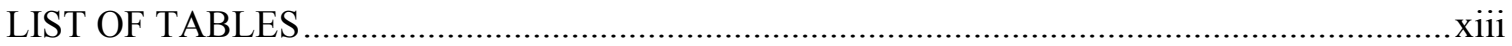

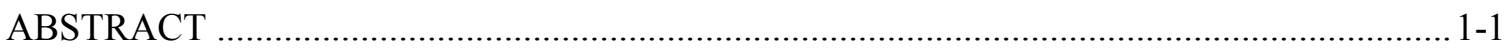

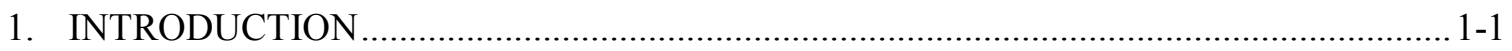

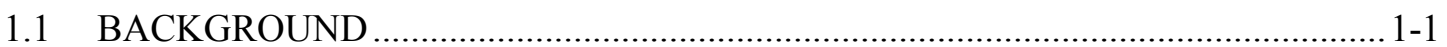

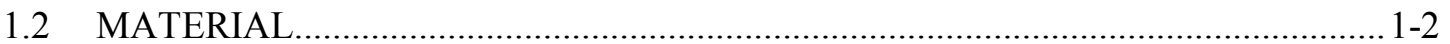

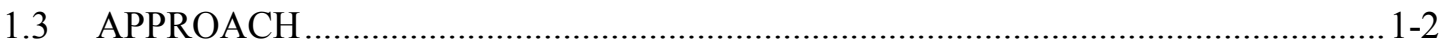

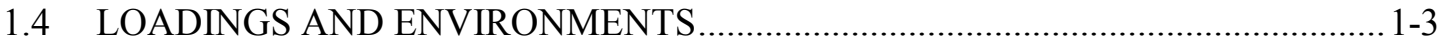

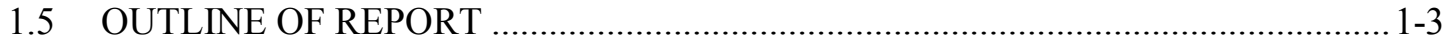

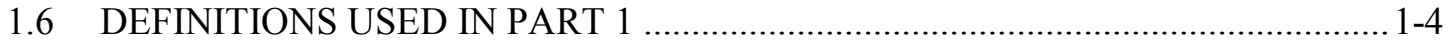

\section{PART 1. DESIGN CRITERIA}

2. ELASTIC AND CREEP PROPERTIES FOR DESIGN ANALYSIS ….............................2-1

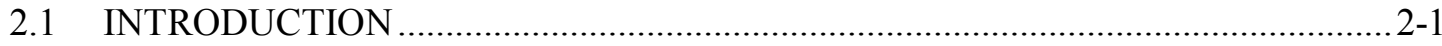

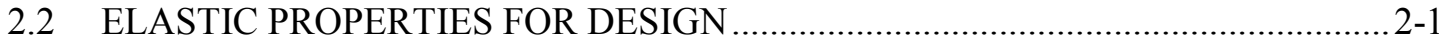

2.2.1 Effects of Temperature ............................................................................ 2-1

2.2.2 Effect of Prior Loading ................................................................................ 2-3

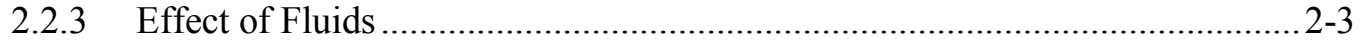

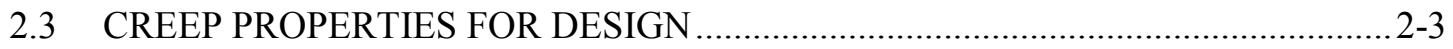

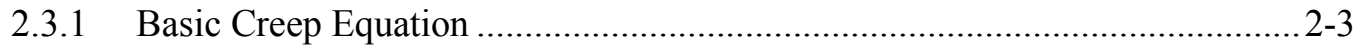

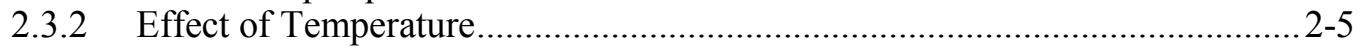

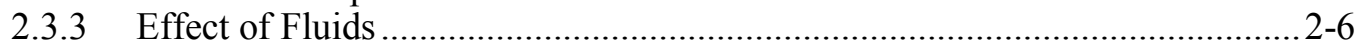

3. DESIGN ALLOWABLES FOR STATIC LOADINGS …....................................................

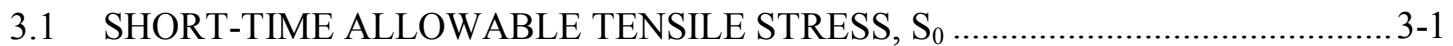

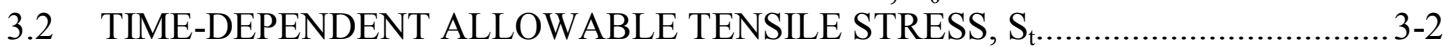

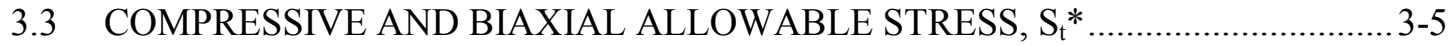

3.4 TREATMENT OF MEMBRANE AND BENDING STRESSES …........................... 3-8

3.5 TREATMENT OF INCREMENTS OF CHANGING LOADS …............................. 3-9

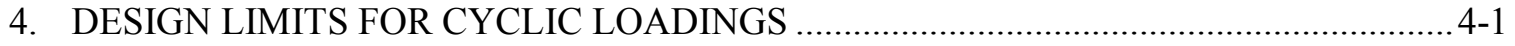

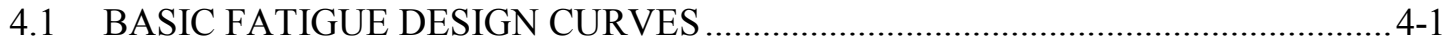

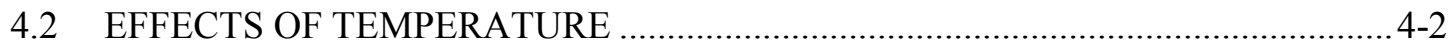

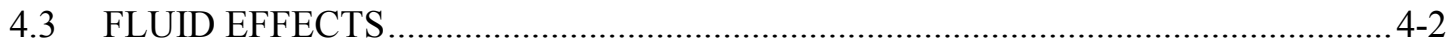

4.4 TREATMENT OF VARYING STRESS AMPLITUDES ….................................... 4-3

5. DAMAGE TOLERANCE DESIGN FOR LOW-ENERGY IMPACTS

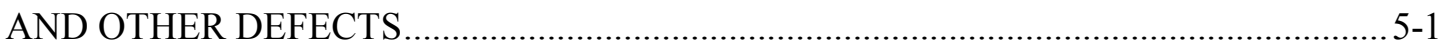

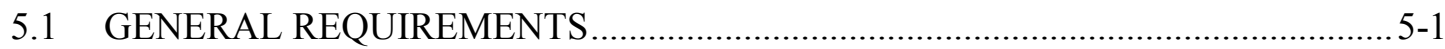

5.2 EFFECTS OF CIRCULAR HOLES …...............................................................

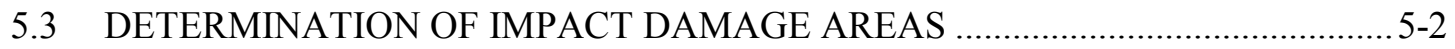

5.4. DETERMINATION OF STRENGTH AND STIFFNESS DEGRADATION ............5-3

6. SUMMARY AND COMPARISON WITH CROSSPLY CARBON-FIBER

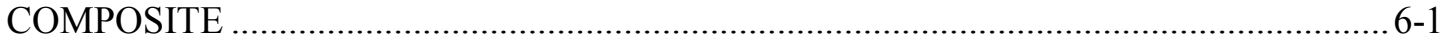

6.1 ELASTIC AND CREEP PROPERTIES FOR DESIGN ANALYSIS ….................... 6-1

6.2 ALLOWABLE STRESSES FOR STATIC LOADINGS …….................................. 6-2

6.3 ALLOWABLE STRESSES FOR CYCLIC LOADINGS ....................................... $6-3$

6.4 SIMPLIFIED SUMMARY OF ALLOWABLE STRESSES .................................... $6-4$

6.5 DAMAGE TOLERANCE EVALUATION ............................................................. $6-5$ 


\section{PART 2. BACKGROUND DATA AND MODELS}

7. BASIC TENSILE, COMPRESSIVE, AND SHEAR PROPERTIES …................................ $7-1$

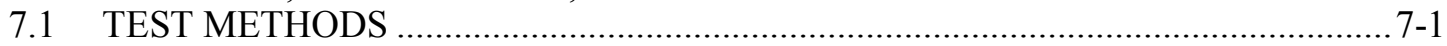

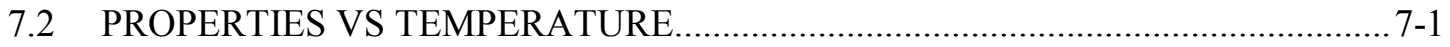

7.3 EFFECT OF PRIOR LOADING ON STIFFNESS .........................................

7.4 EFFECT OF PLAQUE THICKNESS VARIATIONS ..............................................

7.5 EFFECT OF STRAIN RATE ON TENSILE PROPERTIES.......................................

7.6 EFFECT OF THERMAL CYCLING .....................................................

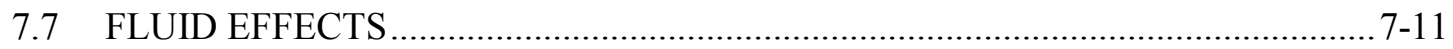

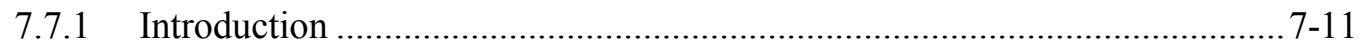

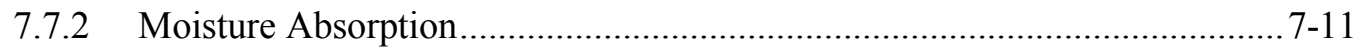

7.7.3 Windshield Washer Fluid ...................................................................... 7-14

7.7.4 Fluid Multiplication Factors for Standard Exposures.................................. 7-14

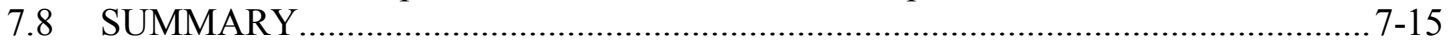

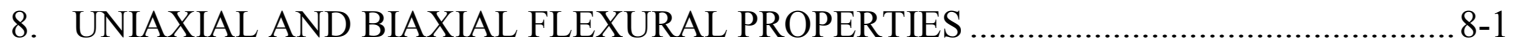

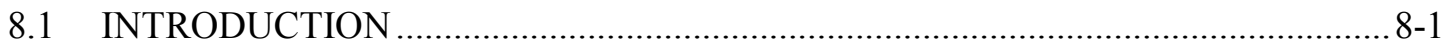

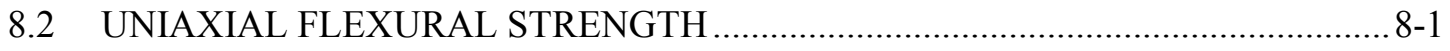

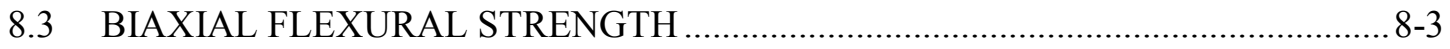

8.4 COMPARISON OF STRENGTH MULTIPLICATION FACTORS .......................... $8-5$

8.5 PREDICTABILITY OF BENDING DEFORMATIONS …....................................... $8-5$

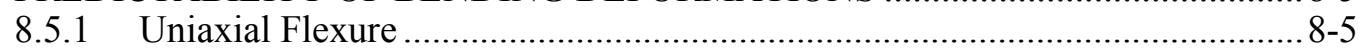

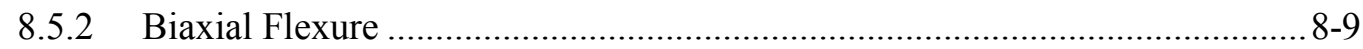

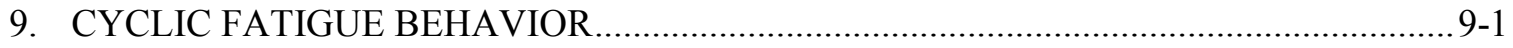

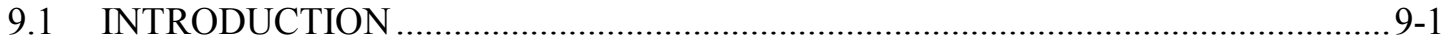

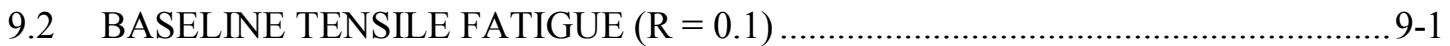

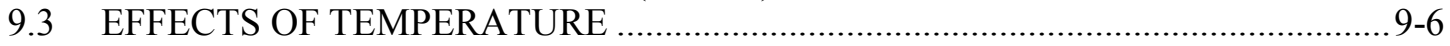

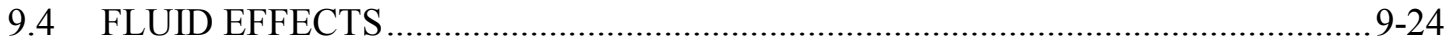

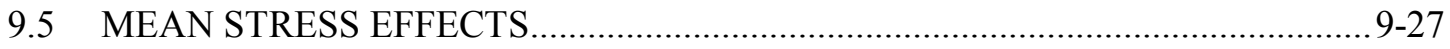

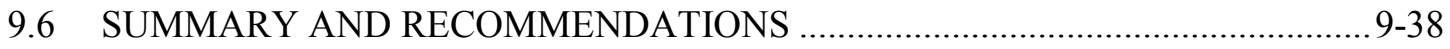

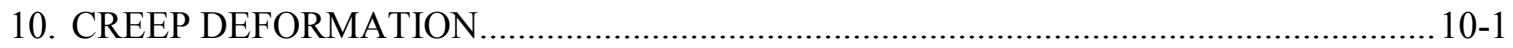

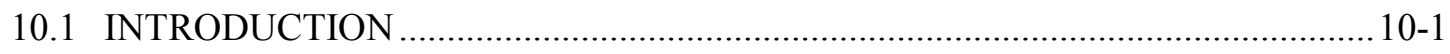

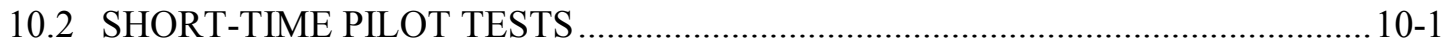

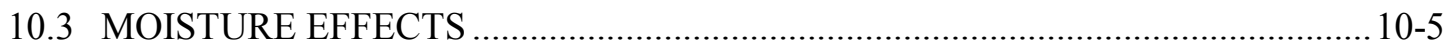

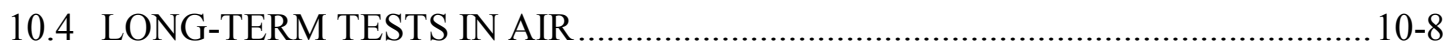

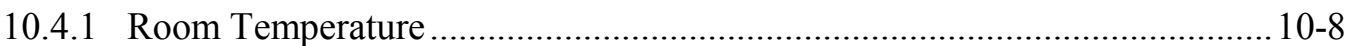

10.4.2 Elevated Temperature ........................................................................... 10-17

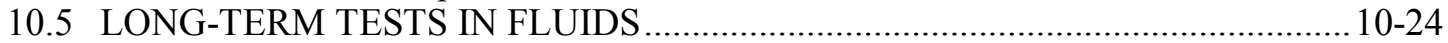

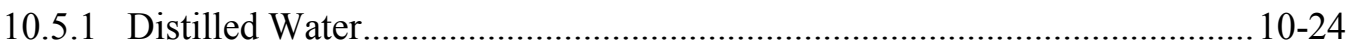

10.5.2 Windshield Washer Fluid ...................................................................... 10-27

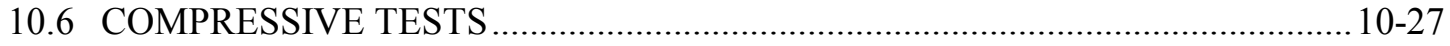

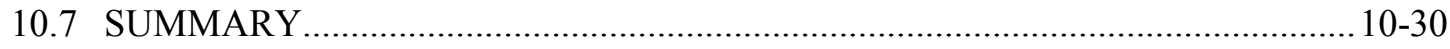

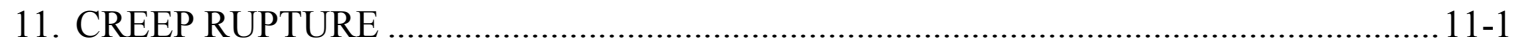

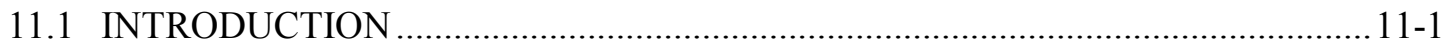

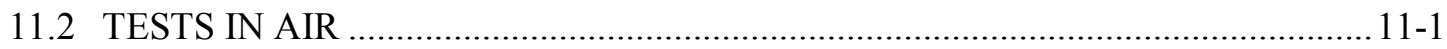

11.2.1 Room-Temperature Tensile Failures ...................................................11-1

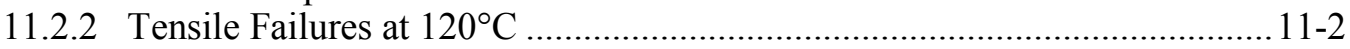

11.2.3 Compressive Failures at $120^{\circ} \mathrm{C}$.................................................................. 11-2

11.2.4 Time-Temperature Parameter ................................................................. 11-4

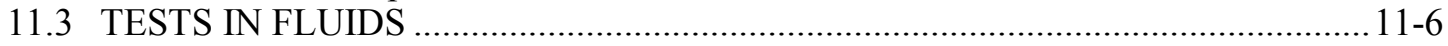

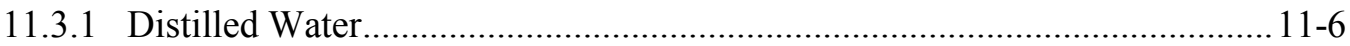

11.3.2 Windshield Washer Fluid ........................................................................ 11-6

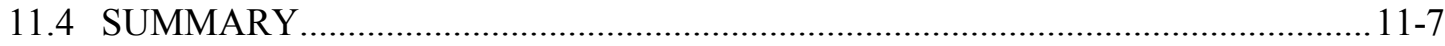


12. THE TIME-DEPENDENT AND NONLINEAR RESPONSE OF

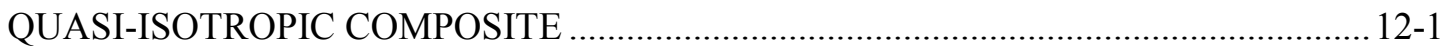

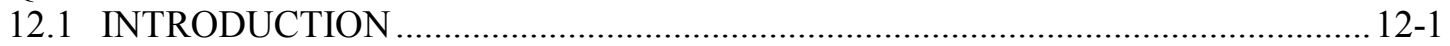

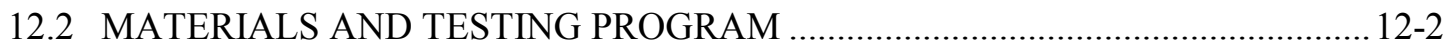

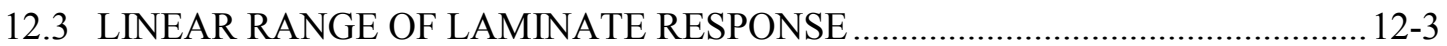

12.3.1 Basic Lamina Properties .............................................................................. 12-3

12.3.2 Tensile Properties of $\left[0 / 90^{\circ} / \pm 45^{\circ}\right]_{S}$ Laminates........................................... 12-4

12.4 STRESS-STRAIN BEHAVIOR IN THE NONLINEAR RANGE ............................ 12-6

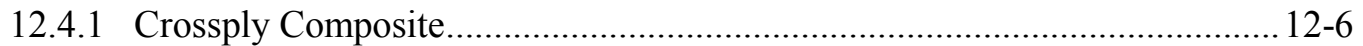

12.4.2 Quasi-Isotropic Composite .................................................................. 12-8

12.4.3 Basic Nonlinear Properties and an Approximate Model .............................12-11

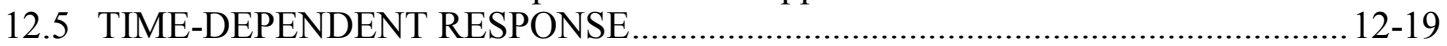

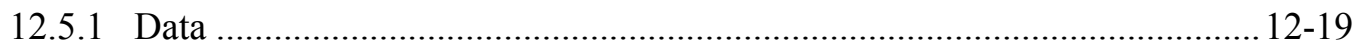

12.5.2 Data Reduction ....................................................................... 12-21

12.5.3 Correlation Between Tensile Response and Creep Behavior ....................... 12-21

12.5.4 Prediction of Creep Behavior of Quasi-Isotropic Composite Based on Crossply Viscoelastic Characterization ................................................... 12-23

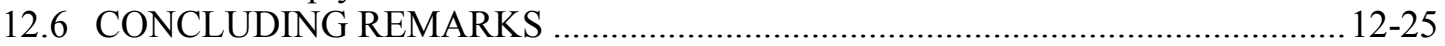

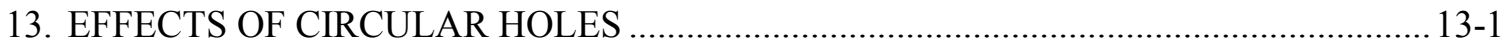

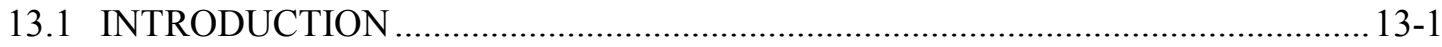

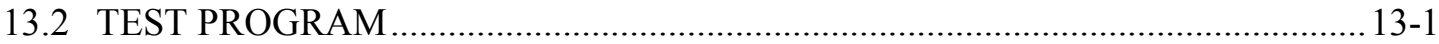

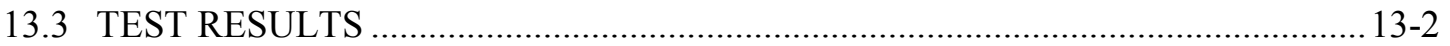

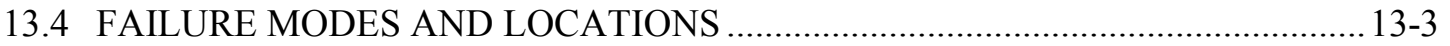

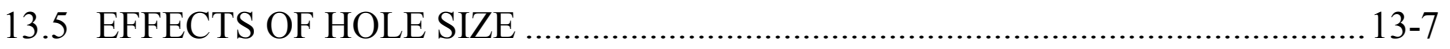

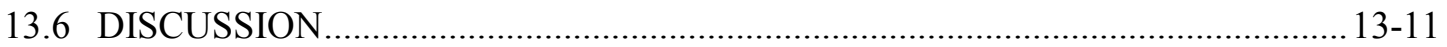

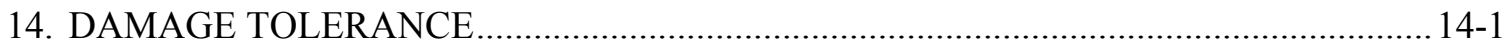

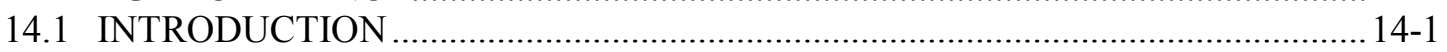

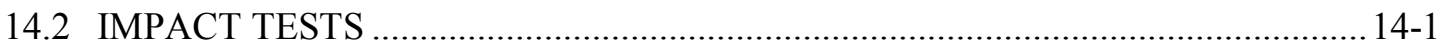

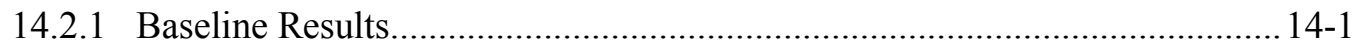

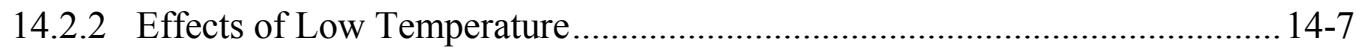

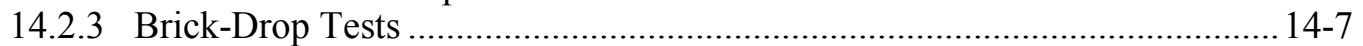

14.3 DEGRADATION OF STRENGTH PROPERTIES ........................................... 14-8

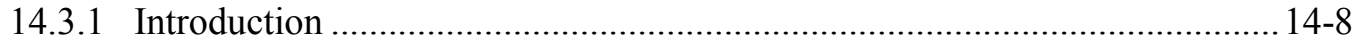

14.3.2 Compression-After-Impact ................................................................... 14-9

14.3.3 Comparison with Conventional Compressive Strength Reductions............. 14-12

14.3.4 Similarity to Hole Effects ........................................................................... 14-14

14.4 SUMMARY AND RECOMMENDATIONS …................................................ 14-15

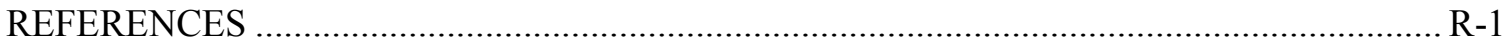

Appendix A. THE MODELING OF PLASTIC NONLINEARITY IN

POLYMERIC COMPOSITES.................................................................... A-1

Appendix B. OPTIMAL NONLINEAR LEAST-SQUARE DATA FITTING SCHEME

TO DETERMINE THE PLASTIC PARAMETERS $a$, A, AND $n$..................... B-1

Appendix C. A MATHEMATICAL DEMONSTRATION FOR THE DEPARTURE FROM QUASI-ISOTROPY CAUSED BY NONLINEARITY ......................... C-1

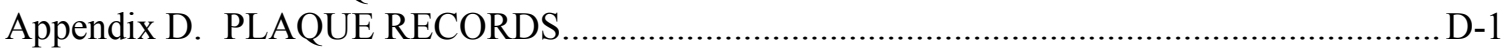




\section{LIST OF FIGURES}

Figure

Page

2.1 Multiplication factor for determining elastic in-plane modulus of elasticity at a given temperature from room-temperature value... Isochronous stress-strain curves for room-temperature ambient air Tensile creep strain multipliers for temperature effects. $2-5$

Allowable compressive and nontensile biaxial stresses, $\mathrm{S}_{\mathrm{t}}{ }^{*}$, without environmental or prior load effects

Allowable compressive and nontensile biaxial stresses, $\mathrm{S}_{\mathrm{t}}{ }^{*}$, with estimated fluid

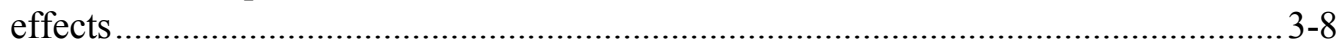

4.1 Room-temperature design fatigue curve for tensile $(\mathrm{R}=0)$ cycling..........................4-1

4.2 Room-temperature design fatigue curve for fully reversed $(\mathrm{R}=-1)$ cycling ............ 4-2

5.1 Strength reduction factor for circular holes in an infinitely wide, uniaxially

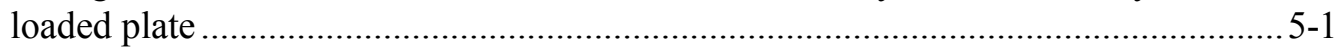

5.2 Design curve for determining impact damage area............................................ 5-3

5.3 Compressive strength degradation as a function of damage area ............................. $5-4$

7.1 Typical stress-strain curves ............................................................................ $7-3$

7.2 Temperature multiplication factors for relating stiffness and strength to room-temperature values: $(a)$ stiffness and $(b)$ strength ....................................... $7-4$

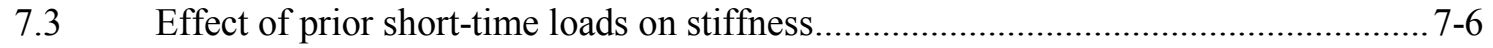

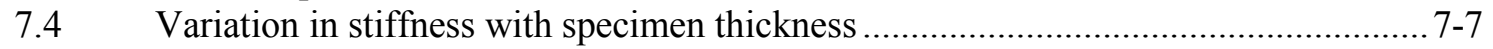

7.5 Variation in tensile strength with specimen thickness .............................................. $7-8$

7.6 Effect of strain rate on tensile stiffness ................................................................ 7-9

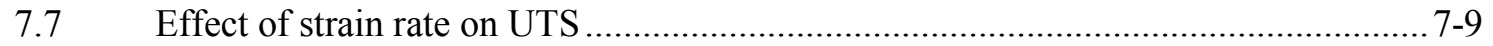

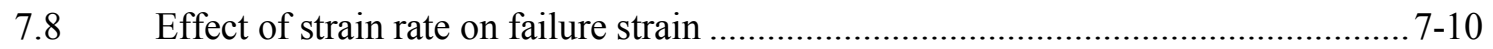

7.9 Thermal cycle .....................................................................................

7.10 Percent weight change due to exposure in room-temperature distilled water and in $70 \%$ RH air................................................................................ 7-12

7.11 Percent weight change due to exposure in room-temperature distilled water and in $70 \% \mathrm{RH}$ air, showing strength and stiffness losses corresponding to labeled times in Fig. 7.10 .......................................................................... 7-13

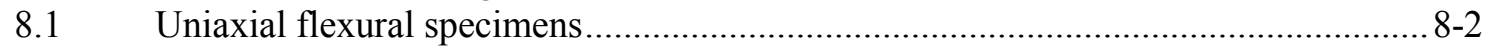

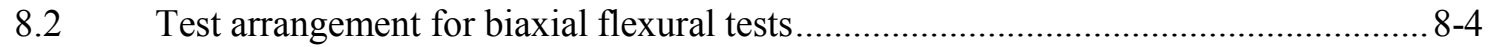

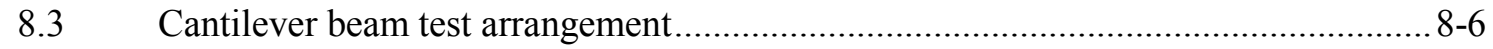

8.4 Measured and predicted center deflection in simply supported beams: $(a)$ with transverse surface fibers and $(b)$ with longitudinal surface fibers ............................ 8-7

8.5 Measured and predicted beam deflection at load in cantilever beams: $(a)$ with transverse surface fibers and $(b)$ with longitudinal surface fibers ............................ 8-8

8.6 Comparison of measured and predicted biaxial flexure specimen deflections ......... 8-10

8.7 Predicted principal stresses in bottom ply of disk at maximum load: (a) maximum,

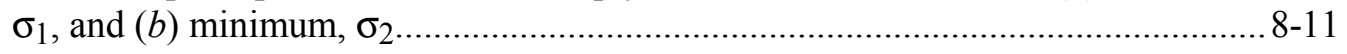


9.1 Dogbone specimen configuration used for baseline, temperature, and fluids

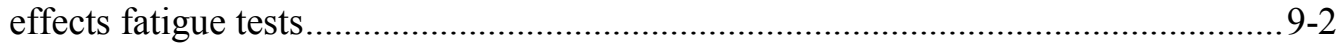

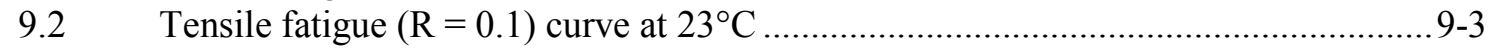

9.3 Maximum strain behavior in specimens at room temperature: $(a)$ plaque Q14

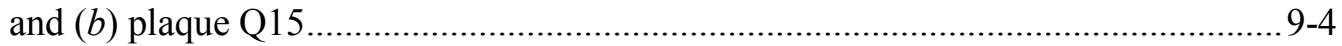

9.4 Stiffness loss vs cycle fraction, $\mathrm{n} / \mathrm{N}_{\mathrm{f}}$, for specimens at $23^{\circ} \mathrm{C}:(a)$ plaque Q14

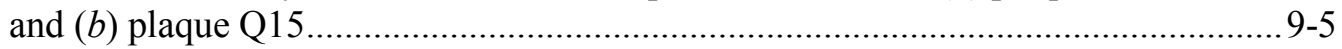

9.5 Temperature vs cycle fraction, $\mathrm{n} / \mathrm{N}_{\mathrm{f}}$, for specimens at $23^{\circ} \mathrm{C}:(a)$ plaque Q14

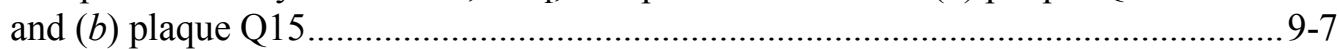

9.6 Failure location for $23^{\circ} \mathrm{C}$ tests: $(a)$ plaque Q14 and $(b)$ plaque Q15 ........................9-8

9.7 Tensile fatigue curves for plaque Q14 specimens at various temperatures ................9-9

9.8 Final tensile fatigue curves (capped by UTS values) for plaque Q14 specimens

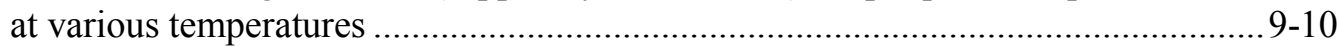

9.9 Final tensile fatigue curve for plaque Q14 specimens at $-40^{\circ} \mathrm{C}$........................... 9-11

9.10 Final tensile fatigue curve for plaque Q14 specimens at $70^{\circ} \mathrm{C} \ldots \ldots \ldots \ldots \ldots \ldots \ldots \ldots . . . . . . . . . . . . . .12$

9.11 Final tensile fatigue curve for plaque Q14 specimens at $120^{\circ} \mathrm{C} \mathrm{...............................9-13}$

9.12 Maximum strain behavior at $-40^{\circ} \mathrm{C}$ in specimens from plaque Q14 .......................9-14

9.13 Maximum strain behavior at $70^{\circ} \mathrm{C}$ in specimens from plaque Q14 ........................9-15

9.14 Maximum strain behavior at $120^{\circ} \mathrm{C}$ in specimens from plaque Q14 ....................... 9-16

9.15 Stiffness loss vs cycle fraction, $\mathrm{n} / \mathrm{N}_{\mathrm{f}}$, for plaque Q14 specimens at $-40^{\circ} \mathrm{C} \ldots \ldots \ldots \ldots . . .17$

9.16 Stiffness loss vs cycle fraction, $\mathrm{n} / \mathrm{N}_{\mathrm{f}}$, for plaque $\mathrm{Q} 14$ specimens at $70^{\circ} \mathrm{C} \ldots \ldots \ldots \ldots \ldots . . . .18-18$

9.17 Stiffness loss vs cycle fraction, $\mathrm{n} / \mathrm{N}_{\mathrm{f}}$, for plaque $\mathrm{Q} 14$ specimens at $120^{\circ} \mathrm{C} \ldots \ldots \ldots \ldots . . . . .9-19$

9.18 Temperature vs cycle fraction, $\mathrm{n} / \mathrm{N}_{\mathrm{f}}$, for plaque $\mathrm{Q} 14$ specimens at $-40^{\circ} \mathrm{C} \ldots \ldots \ldots \ldots . . . . .9-20$

9.19 Temperature vs cycle fraction, $\mathrm{n} / \mathrm{N}_{\mathrm{f}}$, for plaque $\mathrm{Q} 14$ specimens at $70^{\circ} \mathrm{C} \ldots \ldots \ldots \ldots \ldots . . . . . .9-21$

9.20 Temperature vs cycle fraction, $\mathrm{n} / \mathrm{N}_{\mathrm{f}}$, for plaque $\mathrm{Q} 14$ specimens at $120^{\circ} \mathrm{C} \ldots \ldots \ldots \ldots . . . . . .9-22$

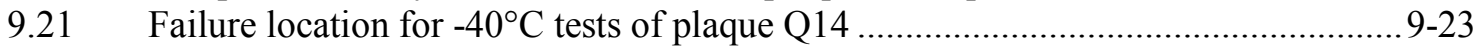

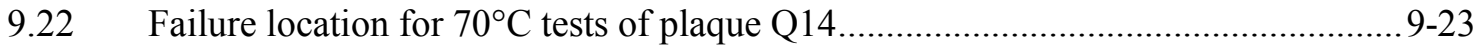

9.23 Failure location for $120^{\circ} \mathrm{C}$ tests of plaque Q14 .................................................... 9-24

9.24 Effects of fluids on room-temperature tensile fatigue strength for plaque Q15

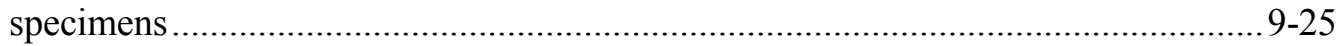

9.25 Stiffness loss vs cycle fraction, $\mathrm{n} / \mathrm{N}_{\mathrm{f}}$, for plaque Q15 specimens in $(a)$ distilled water and $(b)$ windshield washer fluid................................................................. 9-26

9.26 Extensive interlaminar cracking in long-term fluid effects tests............................. 9-27

9.27 Maximum strain behavior for plaque Q15 specimens in (a) distilled water and (b) windshield washer fluid ..................................................................... 9-28

9.28 Temperature vs cycle fraction, $\mathrm{n} / \mathrm{N}_{\mathrm{f}}$, for plaque Q15 specimens in $(a)$ distilled water and $(b)$ windshield washer fluid

9.29 Failure location for plaque Q15 specimens in $(a)$ distilled water and $(b)$ windshield

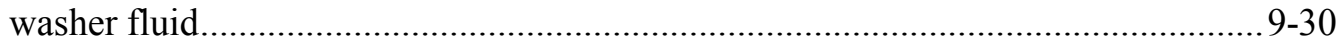

9.30 Four cyclic stress histories used to examine mean stress effects ............................ 9-31

9.31 Hourglass specimen configurations used for mean stress tests: $(a)$ original (old) specimen developed for random-glass-fiber composites and $(b)$ new specimen design intended to be more buckling resistant....

9.32 Comparison of tensile $(\mathrm{R}=0) \mathrm{S}-\mathrm{N}$ curves generated from hourglass specimens with S-N curve generated from dogbone specimens with $\mathrm{R}=0.1 \ldots \ldots \ldots \ldots \ldots \ldots \ldots \ldots . . .9-33$

9.33 Tensile $(\mathrm{R}=0)$ fatigue curve for old and new hourglass specimen data lumped together. 
9.34 Fatigue curves from four different mean-stress cycle types compared on basis of maximum stress, $\mathrm{S}_{\max }$, in cycle: $(a)$ tensile cycles and $(b)$ compressive

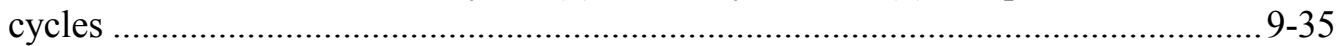

9.35 Typical failed hourglass specimens from each mean-stress cycle type ....................9-36

9.36 Fatigue curves from four different mean-stress cycle types compared on basis of alternating stress, $\mathrm{S}_{\mathrm{a}}$, in cycle: $(a)$ tensile cycles and $(b)$ compressive cycles

9.37 Fatigue curves from four different mean-stress cycle types compared on basis of stress parameter $\sqrt{\mathrm{S}_{\max } \times \mathrm{S}_{\mathrm{a}}}$ or $\sqrt{\left|\mathrm{S}_{\min }\right| \times \mathrm{S}_{\mathrm{a}}}:(a)$ tensile cycles and

(b) compressive cycles.

9.38 Comparison of Goodman predictions (based on $\mathrm{R}=-1$ correlation) with experimental data and curve for tensile mean-stress cycle types: $(a) \mathrm{R}=0$ and $(b)$ tensile mean stress of $50 \%$ UTS .

9.39 Comparison of Goodman prediction (based on $\mathrm{R}=-1$ correlation) with experimental data and curve for compressive mean-stress cycle type $(\mathrm{R}=-\infty)$

9.40 Final room-temperature design fatigue curve for tensile cycling ...........................9-41

9.41 Room-temperature design fatigue curve for fully reversed cycling......................... 9-42

10.1 Results of short-time (nominally 24-h) pilot creep tests ...................................... 10-2

10.2 Short-time test data on log-log coordinates with power-law curve fits ...................10-3

10.3 Comparison of predictions of short-time master creep equation with data............... 10-4

10.4 Long-time creep strain predictions based on short-time (24-h) data ....................... 10-5

10.5 Correlation of apparent time-dependent creep strain with temperature and humidity $10-6$

10.6 Measured strains in two specimens subjected to step changes in RH....................... 10-7

10.7 Strain-gaged room-temperature creep test specimen with accompanying unstressed piece having dummy gages for full-bridge compensation.

10.8 Bank of lever-arm creep machines used for longer term creep tests

10.9 Arrangement used for heating and obtaining full-bridge strain gage compensation in elevated-temperature tests .....

10.10 Loading strains measured in room-temperature creep tests...... $10-12$

10.11 Long-term, room-temperature creep data with individual power-law curve fits

10.12 Power-law coefficient A and exponent $\mathrm{n}$ as functions of applied stress at room temperature

10.13 Comparison of predictions of master creep equation (solid curves) with long-term, room-temperature data .....

10.14 Time-dependent, room-temperature creep strains predicted by master equation derived from long-term tests

10.15 Room-temperature isochronous stress-strain curves.......................................10-16

10.16 Loading strains measured in $120^{\circ} \mathrm{C}$ creep tests ................................................10-17

10.17 Long-term $120^{\circ} \mathrm{C}$ creep data with individual power-law curve fits........................ 10-18

10.18 Power-law coefficient $\mathrm{A}$ and exponent $\mathrm{n}$ as functions of applied stress at $120^{\circ} \mathrm{C}$

10.19 Comparison of predictions of $120^{\circ} \mathrm{C}$ master creep equation (dashed curves) with long-term data

10.20 Comparison of predicted time-dependent creep strains at room-temperature and $120^{\circ} \mathrm{C}$

10.21 Isochronous stress-strain curves at $120^{\circ} \mathrm{C}$ $10-22$ 
10.22 Results of single creep test at $70^{\circ} \mathrm{C}:(a)$ comparison of creep response with predicted room-temperature response at same stress and $(b)$ creep response on log-log scale showing power-law curve fit

10.23 Time-dependent creep strain multiplication factor vs temperature.

10.24 Arrangement used for obtaining full-bridge compensation for strain gages on specimens tested in fluids

10.25 Creep response of specimens tested in distilled water compared to predicted response in air

10.26 Expansion strains in unloaded specimen due to moisture absorption from soaking

10.27 Compensated and uncompensated time-dependent strains in specimens tested at $280 \mathrm{MPa}$ in distilled water compared to zero-stress expansion data from Fig. 10.26

10.28 Creep response of three specimens tested at $273 \mathrm{MPa}$ in windshield washer fluid compared to predicted in-air response at same stress.

10.29 Results of two one-week compressive creep tests at room-temperature compared to predicted tensile creep at same stress levels.

10.30 Compressive creep response of three specimens tested at $120^{\circ} \mathrm{C}$ compared to predicted tensile response at same temperature and stress level

11.1 Tensile creep-rupture data and curve at room temperature 11-2

11.2 Tensile creep-rupture data and curve at $120^{\circ} \mathrm{C}$ compared to room-temperature curve.

11.3 Compressive creep-rupture data and curve at $120^{\circ} \mathrm{C}$ compared with $120^{\circ} \mathrm{C}$ tensile curve

Manson-Haferd construction for tensile creep rupture

Manson-Haferd parameter curves for tension and compression.....

11.6 Creep-rupture data and curve for specimens tested in distilled water compared to in-air curve.

11.7 Creep-rupture data and curve for specimens tested in windshield washer fluid compared to in-air curve

12.1 Illustration of quasi-isotropic laminates with layup misalignment

12.2 Stiffness vs orientation angle of quasi-isotropic composite at $23^{\circ} \mathrm{C}$. $12-5$

12.3 Influence of laminate layup misalignment on the stiffness of quasi-isotropic composite

12.4 Typical stress-strain curves of crossply composite, with loads applied at orientation angle $\phi=0^{\circ}$ under two temperatures.

12.5 Typical stress-strain curves of crossply composite, with loads applied at orientation angle $\phi=45^{\circ}$ under three temperatures.

12.6 Typical stress-strain curves of quasi-isotropic composite at various orientations at $23^{\circ} \mathrm{C}$

12.7 Typical stress-strain curves of quasi-isotropic composite at various orientations at $50^{\circ} \mathrm{C}$

12.8 Typical stress-strain curves of quasi-isotropic composite at various orientations at $73^{\circ} \mathrm{C}$.

12.9 Typical stress-strain curves of quasi-isotropic composite at various orientations at $120^{\circ} \mathrm{C}$.

12.10 Comparison of stress-strain curves of quasi-isotropic composite with two different loading orientations $\left(\phi=0^{\circ}\right.$ and $\left.22.5^{\circ}\right)$ at $120^{\circ} \mathrm{C}$ 
12.11 Longitudinal and transverse stress-strain data for quasi-isotropic composite loaded at $0^{\circ}$ and $22.5^{\circ}$ about the fiber direction and for $[ \pm 45]_{3 \mathrm{~S}}$ crossply composite

12.12 Schematic drawing of strain compatibility requirements for composite laminates

12.13 Predicted and recorded values of longitudinal and transverse strains for the laminates and loading conditions noted in Fig. 12.12

12.14 Predictions for the anisotropic response of quasi-isotropic composite beyond the linear range, under loading at various orientations about the fiber direction

12.15 Predicted values of the longitudinal and transverse components of plastic strains for quasi-isotropic composite loaded at various orientations about the fiber direction and for $[ \pm 45]_{3 \mathrm{~S}}$ crossply composite

12.16 Maximum and minimum values of transverse plastic strain in the individual plies of the quasi-isotropic composite loaded at $22.5^{\circ}$ about the $0^{\circ}$ fiber direction

12.17 Typical creep-recovery curves of quasi-isotropic composite with two orientations at $73^{\circ} \mathrm{C}$.

12.18 Typical creep-recovery curves of quasi-isotropic composite with two orientations at $120^{\circ} \mathrm{C}$.

12.19 Typical creep-recovery curves of quasi-isotropic composite with different loading orientations at $23^{\circ} \mathrm{C}$

12.20 Typical stress-strain to failure response of quasi-isotropic composite at $120^{\circ} \mathrm{C}$ with loads applied at $\phi=0^{\circ}$ and $\phi=22.5^{\circ}$ about the fiber direction

12.21 Prediction of creep behavior of quasi-isotropic composite based on crossply viscoelastic characterization

13.1 Layout for four groups of specimens from a single plaque

13.2 Failure progression in 76.2-mm-wide (3-in.) quasi-isotropic specimen with 25.4-mm-diam (1-in.) hole.

13.3 Failure progression in 76.2-mm-wide (3-in.) crossply composite specimen with $0 / 90^{\circ}$ fiber orientation and 25.4-mm-diam (1-in.) hole

13.4 Failure progression in 76.2-mm-wide (3-in.) crossply composite specimen with $\pm 45^{\circ}$ fiber orientation and 25.4-mm-diam (1-in.) hole .

13.5 Notched strength (for infinite plate) vs hole diameter, with power-law curve fits

13.6 Schematic representation of predicted axial stress distributions at large and small holes in a uniaxially loaded, infinitely wide plate

13.7 Notched strength to UTS ratio vs hole radius for quasi-isotropic composite

13.8 Notched strength to UTS ratio vs hole radius for $0 / 90^{\circ}$ crossply composite

13.9 Notched strength to UTS ratio vs hole radius for $\pm 45^{\circ}$ crossply composite. Photograph of back of specimen Q24-1, impacted by pendulum 14-3

14.2

14.3

14.4 C-scan of impact specimen Q24-1 Photograph of back of specimen Q21-2, impacted by air-gun projectile.................. 14-4 Comparison of peak impact forces measured in pendulum tests of quasi-isotropic carbon-fiber composite and those of crossply carbon-fiber composite and glass-fiber composite

14.7 Baseline impact damage areas vs mass $0.535 \times \mathrm{v}$ 
14.8 Effect of test temperature of $-40^{\circ} \mathrm{C}$ on impact damage

14.9 Impact damage data for specimens subjected to brick drops compared to baseline correlations

14.10 CAI specimen and high-strength steel antibuckling face plates

14.11 CAI specimen with antibuckling face-support plates installed in hydraulic wedge grips of test machine.

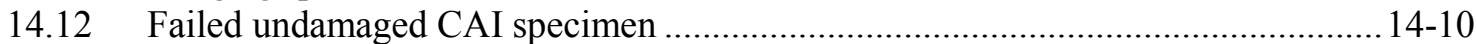

14.13 Layout used for cutting CAI specimens from impacted plate specimens ................ 14-11

14.14 Relative retained CAI strength vs damage area ............................................... 14-12

14.15 Layout used for cutting regular compressive specimens from impacted plate specimens

14.16 Relative retained conventional compressive strength compared to CAI correlations....

14.17 Comparison of strength of CAI hole specimens with CAI results for impact-damaged specimens.

14.18 Comparison of tensile and CAI compressive strengths of hole specimens

14.19 Strength reduction ratio vs hole diameter for tensile and CAI compressive tests

14.20 Curve for conservatively estimating impact damage areas ................................... 14-17

14.21 Curve for conservatively estimating strength loss ............................................ 14-17 


\section{LIST OF TABLES}

Table

Page

$2.1 \quad$ Recommended elastic properties for design analysis.............................................. 2-2

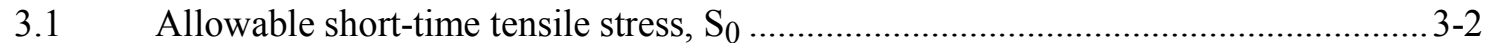

3.2 Basic $\mathrm{S}_{\mathrm{t}}(\mathrm{MPa})$ allowable stress (applicable to uniaxial tensile loadings) ................... 3-3

3.3 Allowable time-dependent uniaxial stresses, $\mathrm{S}_{\mathrm{t}}(\mathrm{MPa})$ with reductions to account for moisture/fluid effects ........................................................................... 3-4

3.4 Basic $\mathrm{S}_{\mathrm{t}} *$ (MPa) allowable stresses (applicable to compressive and nontensile biaxial stress states)............................................................................................. 3-6

3.5 Allowable time-dependent compressive and non-tensile biaxial stresses, $\mathrm{S}_{\mathrm{t}}$ * (MPa), with estimated reductions to account for fluid effects ............................ 3-7

4.1 Fatigue strength factors to account for temperature...............................................

4.2 Fatigue strength factors for two bounding fluid environments ................................. 4-3

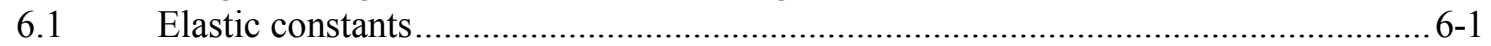

6.2 Time-dependent tensile creep strains due to $100 \mathrm{MPa}$ applied for $5000 \mathrm{~h}$

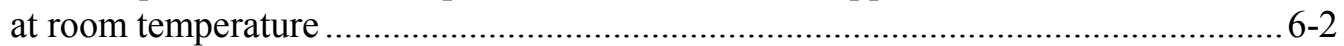

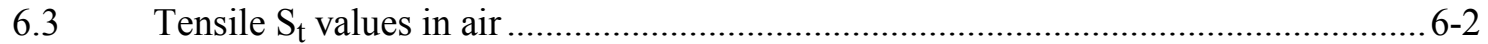

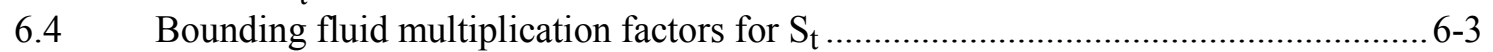

6.5 $\mathrm{S}_{\mathrm{t}} *(\mathrm{MPa})$ allowable stress applicable to nontensile biaxial stress states ...................6-3

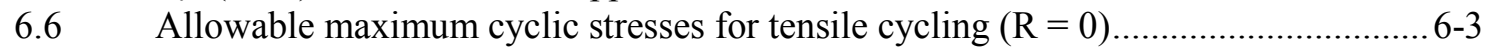

6.7 Bounding fluid multiplication factors for allowable cyclic stresses ......................... 6-4

6.8 Key allowable tensile stresses, expressed as a percentage of average

6.9 Damage areas from design curve (Fig 5.2)

6.10 Estimated strength reduction ratios caused by impact damage................................. 6-6

7.1 Average in-air room-temperature baseline properties...........................................

7.2 Average properties from temperature dependence study ......................................... 7-2

7.3 Temperature multiplication factors for determining at-temperature modulus and strength from room-temperature values ........................................... 7-3

7.4 Baseline properties at different temperatures.............................................................. $7-5$

7.5 Calculated and measured shear moduli at different temperatures.............................. 7-5

7.6 Average UTS values from groups of specimens subjected to prior

7.7 Effects of exposure in $23^{\circ} \mathrm{C}$ distilled water and in $70 \% \mathrm{RH}$ air on tensile strength and stiffness.................................................................................. $7-12$

7.8 Effects on stiffness and strength of 100-h exposure in windshield washer fluid................................................................................................. $7-14$

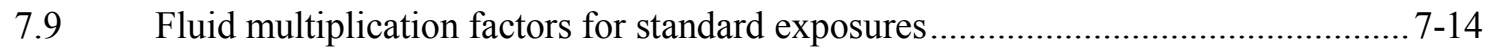

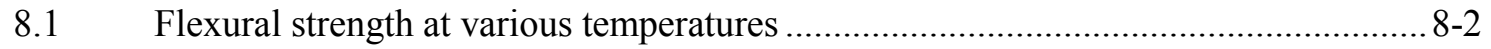

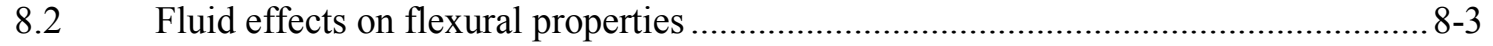

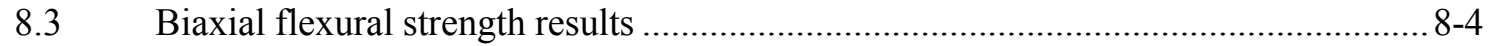

8.4 Strength reduction factors relative to in-air room-temperature values ....................... $8-5$

8.5 Comparison of average measured and predicted beam deflections for each test type, surface-fiber orientation, and load ............................................ 8-9

9.1 Fatigue strength multiplication factors for temperature ...................................... 9-10

9.2 Fatigue strength multiplication factors to account for fluid effects ........................ 9-25

9.3 Comparison of plaque Q9 with plaques Q14 and Q15 ..................................... 9-32 
10.1 Matrix of tensile creep and creep-rupture tests performed in dead-weight creep machines

11.1 Time-dependent allowable stresses at room temperature .....................................11-7

11.2 Creep-rupture strength multiplication factors (relative to in-air, room-temperature, tensile values)

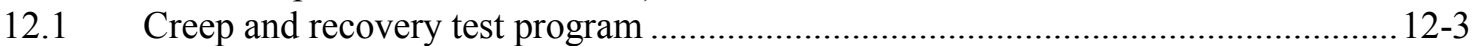

12.2 Tensile data for quasi-isotropic composite coupons loaded at various

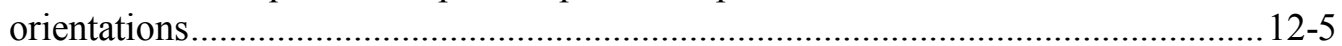

12.3 Parameters used for the simulations of the creep and recovery results $\left(\phi=0^{\circ}, 73^{\circ} \mathrm{C}\right)$

12.4 Parameters used for the simulations of the creep and recovery results $\left(\phi=22.5^{\circ}, 73^{\circ} \mathrm{C}\right)$

13.1 Average hole specimen tensile test results......................................................... 13-3

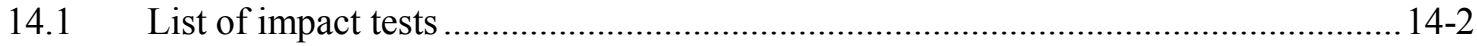

14.2 Average hole specimens compressive test results............................................ 14-14 


\title{
DURABILITY-BASED DESIGN CRITERIA FOR A QUASI- ISOTROPIC CARBON-FIBER AUTOMOTIVE COMPOSITE
}

\author{
J. M. Corum \\ M. B. Ruggles-Wrenn \\ R. L. Battiste \\ Y. J. Weitsman \\ S. Deng
}

\begin{abstract}
This report provides recommended durability-based design properties and criteria for a quasi-isotropic carbon-fiber composite for possible automotive structural applications. The composite, which was made by a rapid molding process suitable for high-volume automotive applications, consisted of continuous Thornel T300 fibers (6K tow) in a Baydur 420 IMR urethane matrix. The reinforcement was in the form of four $\pm 45^{\circ}$ stitch-bonded mats in the following layup: $\left[0 / 90^{\circ} / \pm 45^{\circ}\right]_{\mathrm{s}}$. This material is the second in a progression of three candidate thermoset composites to be characterized and modeled as part of an Oak Ridge National Laboratory project entitled Durability of Carbon-Fiber Composites. The overall goal of the project, which is sponsored by the U.S. Department of Energy's Office of Advanced Automotive Technologies and is closely coordinated with the industry Automotive Composites Consortium, is to develop durability-driven design data and criteria to assure the long-term integrity of carbonfiber-based composite systems for large automotive structural components.

This document is in two parts. Part I provides the design criteria, and Part 2 provides the underlying experimental data and models. The durability issues addressed include the effects on deformation, strength, and stiffness of cyclic and sustained loads, operating temperature, automotive fluid environments, and low-energy impacts (e.g., tool drops and kickups of roadway debris). Guidance is provided for design analysis, time-dependent allowable stresses, rules for cyclic loadings, and damage tolerance design guidance, including the effects of holes. Chapter 6 provides a brief summary of the design criteria.
\end{abstract}

\section{INTRODUCTION}

\subsection{BACKGROUND}

This report is the fourth in a series providing durability-based design data and criteria for polymeric composites suitable for producing large structural automotive components. The first two reports addressed random-glass-fiber composites - one with swirled continuous-strand-mat reinforcement and one with chopped-fiber reinforcement. ${ }^{1-4}$ The third report was the first to address a carbon-fiber composite and focused on a reference $\left[ \pm 45^{\circ}\right]_{3 \mathrm{~S}}$ crossply composite. ${ }^{4}$ This fourth report addresses a quasi-isotropic, $\left[0 / 90^{\circ} / \pm 45^{\circ}\right]_{S}$, version of the reference crossply; the matrix and individual $\pm 45^{\circ}$ stitch-bonded mats are the same in both cases. The basic ply information from the reference crossply could thus be used as a basis for predicting and better understanding the behavior of the quasi-isotropic material.

The work reported here was part of a project at Oak Ridge National Laboratory (ORNL) entitled Durability of Carbon-Fiber Composites. The project is sponsored by the U.S. Department of Energy's (DOE's) Office of Advanced Automotive Technologies and is closely coordinated with the Automotive Composites Consortium (ACC). Both the two random-glass-fiber composites and the two carbon-fiber composites were fabricated by ACC. 
The current project goal is to develop experimentally based, durability-driven design guidelines to assure the long-term (15-year) integrity of representative carbon-fiber-based, polymeric composite systems that can be used to produce large structural automotive components. Durability issues being considered include the potentially degrading effect that both cyclic and sustained loadings, exposure to automotive fluid environments, temperature extremes, holes, and low-energy impact damage from such things as tool drops and kickups of roadway debris can have on structural strength, stiffness, and dimensional stability.

The current plan for characterizing and modeling the durability of carbon-fiber composites is to focus on the following progression of thermoset materials, each of which has the same urethane matrix:

- reference $\left[ \pm 45^{\circ}\right]_{3 \mathrm{~S}}$ crossply composite,

- $\left[0 / 90^{\circ} / \pm 45^{\circ}\right]_{\mathrm{S}}$ quasi-isotropic composite, and

- chopped-fiber composite.

The chopped-carbon-fiber composite is the next to be addressed.

\subsection{MATERIAL}

The crossply and quasi-isotropic composites consisted of Thornel T300 continuous fibers (6K version) in a Baydur 420 IMR urethane matrix. The reinforcement was in the form of $\pm 45^{\circ}$ stitch-bonded mats. Six mats were used in the 3.2-mm-thick crossply composite plaques. Four mats were used in the quasi-isotropic composite, which was 2.2-mm thick. The fiber-volume content was approximately $40 \%$ in both cases. The reinforcement and matrix materials, as well as the molding process, were described in detail in Appendix A of Ref. 4.

In both cases, the 610 - by 610 -mm plaques were molded by ACC using an "InjectionCompression Procedure." For this process a preform is produced by assembling the required layup of $\pm 45^{\circ}$ mats and introducing them into a mold. The mold is left open approximately 10-15 mm. The matrix is produced via the Structural Reaction Injection Molding (SRIM) process in which the two reactive systems, polyol and polymeric isocyanate, are pumped at high pressure into an impingement mixing chamber to quickly produce a uniform mixture of the components. The reacting mixture is then pumped into the partially open mold that contains the reinforcement. The mold is then fully closed. This allows the resin to first flow, with little resistance, across the upper surface of the preform and then, under increasing closing pressure, flow into the thickness direction of the preform. This procedure results in less disturbance of the fiber orientation and produces a more uniform, void-free, distribution of resin through the carbon-fiber preform. A $2.5-\mathrm{mm}$ cure time is allowed before the mold is opened and the part ejected. Final postcure was $1 \mathrm{~h}$ in a preheated oven at $130^{\circ} \mathrm{C}$.

Inherent features of rapid-molding processes that are suitable for high-volume automotive structural applications inevitably lead to some variations in fiber spacing and orientation, as well as to variations in material thickness. The resulting variabilities in mechanical response are frequently discussed throughout this report.

The properties and characteristics of each individual quasi-isotropic plaque used in this investigation are tabulated in Appendix D.

\subsection{APPROACH}

The general project approach has been to first replicate on-road conditions in laboratory specimens to generate data to form the basis for developing correlations and models. These correlations and models are then used to formulate design criteria. In the case of the 
quasi-isotropic composite, more than 1400 individual tests were performed. The types of tests included the following:

- basic short-time tension, compression, and shear;

- uniaxial and biaxial flexure;

- cyclic fatigue, including mean stress effects;

- tensile and compressive creep and creep rupture;

- hole effects;

- low-energy impact; and

- compression-after-impact.

In most cases, characterization of the effects of temperature and fluid exposure was included in the test effort.

Despite the relatively large number of tests performed, more extensive testing would be needed in several areas to provide sufficient data for developing completely defensible correlations, models, and design criteria. The approach taken here was to first perform as many carefully planned tests as possible within time and budget constraints. Then the design criteria were developed with the philosophy of providing the best engineering design guidance possible given the limited information available. This sometimes required assumptions and extrapolations beyond the range of the existing data. Clearly, while the information in this report should be adequate for preliminary designs undertaken with this material and for comparative purposes with other materials, more information would likely be required for final design purposes.

\subsection{LOADINGS AND ENVIRONMENTS}

From a durability standpoint, it is assumed here that an automobile with a composite structure must last for 15 years $(131,000 \mathrm{~h})$ and 150,000 miles. It is further assumed that during the 15 years, the vehicle will actually be operated between 3000 and $5000 \mathrm{~h}$ (based on an average speed of 30 to $50 \mathrm{mph}$ ).

The design temperature range is taken to vary from a minimum of $-40^{\circ} \mathrm{C}$ to a maximum of $120^{\circ} \mathrm{C}$, with the higher temperatures occurring only during operation. The effects of thermal cycling are also a concern.

In addition to functional stiffness and deformation requirements, structures must support and resist a variety of live and dead loads. During operation, for example, live loads might include a combination of pothole impact, hard turn, and maximum acceleration. Dead loads during the 15-year life would include those from the weight of the vehicle or sustained loads in the bed of a light truck.

Structures will also be subjected to common vehicle fluids and operating atmospheres, and design limits must take the resulting property degradation into account. The effects of a variety of fluids and moisture conditions were examined in the case of the glass-fiber composites and in screening tests on the crossply carbon-fiber composite. Based on the combined findings, the fluids most extensively examined here were reduced primarily to distilled water and windshield washer fluid (a methanol/water mix).

\subsection{OUTLINE OF REPORT}

This report is divided into two parts, in a manner analogous to the arrangement used in the previous three reports. Part 1, which consists of five chapters, provides guidelines for (1) the properties to be used in structural analysis, (2) design allowables for static loadings, (3) design rules for cyclic loadings, and (4) damage tolerance design. A final Part 1 chapter summarizes the 
quasi-isotropic carbon-fiber composite criteria and compares the allowables with the corresponding values for the crossply composite.

Part 2, which consists of eight chapters, provides the experimental data and models on which the guidance and criteria of Part 1 are based. Those readers wishing to understand the basic behavioral characteristics of the quasi-isotropic carbon-fiber composite should read Part 2 before reading Part 1. Part 2 has chapters on basic properties, flexure, cyclic fatigue, time-dependent creep and creep rupture, hole effects, and impact. A chapter on time-dependent deformation modeling presents a constitutive model that can be used to predict not only creep strains, but recovery strains and the response to changing load levels. The chapter also demonstrates how basic information from the crossply composite can be used, together with classical lamination theory, to predict response of the quasi-isotropic composite and of more complex layups.

\subsection{DEFINITIONS USED IN PART 1}

\begin{tabular}{|c|c|}
\hline A,n & Creep law constants \\
\hline a & Hole diameter \\
\hline $\mathrm{E}$ & Elastic modulus \\
\hline $\mathrm{E}_{\mathrm{t}}$ & Time-dependent "pseudoelastic modulus" \\
\hline G & Shear modulus $[E=2 G(1+v)]$ for an isotropic material \\
\hline K & Temperature-dependent factor on allowable bending stress \\
\hline $\mathrm{k}_{\mathrm{b}}$ & Statistical factor used in determining B-basis minimum UTS \\
\hline $\mathrm{m}$ & Mass of impacting object \\
\hline $\mathrm{n}$ & Number of applied fatigue cycles of a given stress \\
\hline $\mathrm{N}_{\mathrm{d}}$ & Number of allowable design cycles for a given stress \\
\hline $\mathrm{P}$ & $\begin{array}{l}\text { Calculated membrane stress components at a point in the plane of a plate or shell } \\
\text { structure }\end{array}$ \\
\hline Q & Bending stress components at a point calculated from bending moment \\
\hline $\mathrm{R}$ & Ratio of minimum to maximum stress in a fatigue cycle \\
\hline $\mathrm{S}_{\mathrm{a}}$ & Alternating stress in a fatigue cycle \\
\hline SD & Standard deviation \\
\hline $\mathrm{S}_{\mathrm{O}}$ & Alternating stress in fully reversed fatigue cycle \\
\hline$S_{\max }$ & Maximum stress in a fatigue cycle \\
\hline $\mathrm{S}_{0}$ & Basic short-time allowable stress (time $\mathrm{t}=0$ ) \\
\hline $\mathrm{S}_{\mathrm{t}}$ & Time-dependent allowable stress \\
\hline $\mathrm{S}_{0}^{*}$ & Short-time allowable stress applicable to biaxial stresses \\
\hline $\mathrm{S}_{\mathrm{t}}^{*}$ & Time-dependent allowable stress applicable to biaxial stresses \\
\hline $\mathrm{S}_{\mathrm{r}}$ & Minimum creep-rupture strength at a given time \\
\hline $\mathrm{SCF}$ & Stress concentration factor \\
\hline t & Time at a given stress \\
\hline $\mathrm{T}_{\mathrm{d}}$ & Allowable design time at a given stress \\
\hline UTS & Ultimate tensile strength \\
\hline $\mathrm{v}$ & Velocity of impacting object \\
\hline $\mathrm{W}$ & Plate width \\
\hline$\varepsilon$ & Normal strain \\
\hline$\varepsilon_{\mathrm{c}}$ & Normal creep strain \\
\hline$\sigma$ & Normal stress \\
\hline$\sigma_{1}, \sigma_{2}$ & Principal stress components \\
\hline$\sigma_{\mathrm{m}}$ & Mean stress in fatigue cycle \\
\hline $\bar{\sigma}$ & Applied stress in plate with hole \\
\hline $\bar{\sigma}_{\infty}$ & Applied stress in infinitely wide plate with hole \\
\hline$v$ & Poisson’s ratio \\
\hline
\end{tabular}




\section{Part 1}

\section{DESIGN CRITERIA}




\section{ELASTIC AND CREEP PROPERTIES FOR DESIGN ANALYSIS}

\subsection{INTRODUCTION}

It is well known that a $\left[0 / 90^{\circ} / \pm 45^{\circ}\right]_{S}$ layup should possess in-plane isotropy, and it is shown in Chap. 12 that the quasi-isotropic composite laminate is, in fact, reasonably isotropic in the plane of the plaque, except at elevated temperatures $\left(>100^{\circ} \mathrm{C}\right)$ and stresses $(>150 \mathrm{MPa})$. At these temperatures and stresses, the stress-strain response becomes slightly nonlinear, and this nonlinearity is most pronounced at loading angles, like $22.5^{\circ}$, between fiber orientations. However, this should not be of practical concern because the stress levels involved are close to, or above, the design allowable stresses. Thus, in this chapter it is assumed that the material is isotropic in the plane of the plaque. The elastic and creep properties given in the chapter are for in-plane response to in-plane loads.

For out-of-plane bending loads, classical lamination theory coupled with beam, plate, or curved shell theories can be used to estimate bending deformations. This requires that ply properties be deduced from the crossply composite results for $0 / 90^{\circ}$ and $\pm 45^{\circ}$ fiber orientations given in Ref. 4 (see Chaps. 8 and 12). It is shown in Chap. 8 that even a classical isotropic bending analysis using just in-plane elastic properties can provide reasonable estimates of out-ofplane deformations.

\subsection{ELASTIC PROPERTIES FOR DESIGN}

For an anisotropic layup that possesses in-plane isotropy, the linearly elastic response to inplane applied loads is characterized by two constants, E and G, or alternatively, E and v, where E and $G$ are the Young's and shear moduli, and $v$ is Poisson's ratio. The constants are related by the following equation:

$$
\mathrm{G}=\frac{\mathrm{E}}{2(1+v)}
$$

Data reported in Chap. 7 confirm that this relation holds for the quasi-isotropic composite over the design temperature range from $-40^{\circ}$ to $120^{\circ} \mathrm{C}$.

The recommended average in-plane room-temperature elastic modulus and Poisson's ratio values for the quasi-isotropic composite are

$$
\begin{gathered}
\mathrm{E}=32.4 \mathrm{GPa} \\
v=0.31 .
\end{gathered}
$$

These basic values should be adjusted in accordance with the recommendations of the following subsections.

\subsubsection{Effects of Temperature}

Poisson's ratio increases slightly with temperature (see Chap. 7). The modulus of elasticity, in contrast, decreases almost linearly as the temperature increases from $-40^{\circ}$ to $120^{\circ} \mathrm{C}$. This decrease is shown in Fig. 2.1 as a multiplication factor on the above room-temperature value of 32.4 GPa. Values of both Poisson's ratio and stiffness are tabulated in Table 2.1 for specific temperatures. 


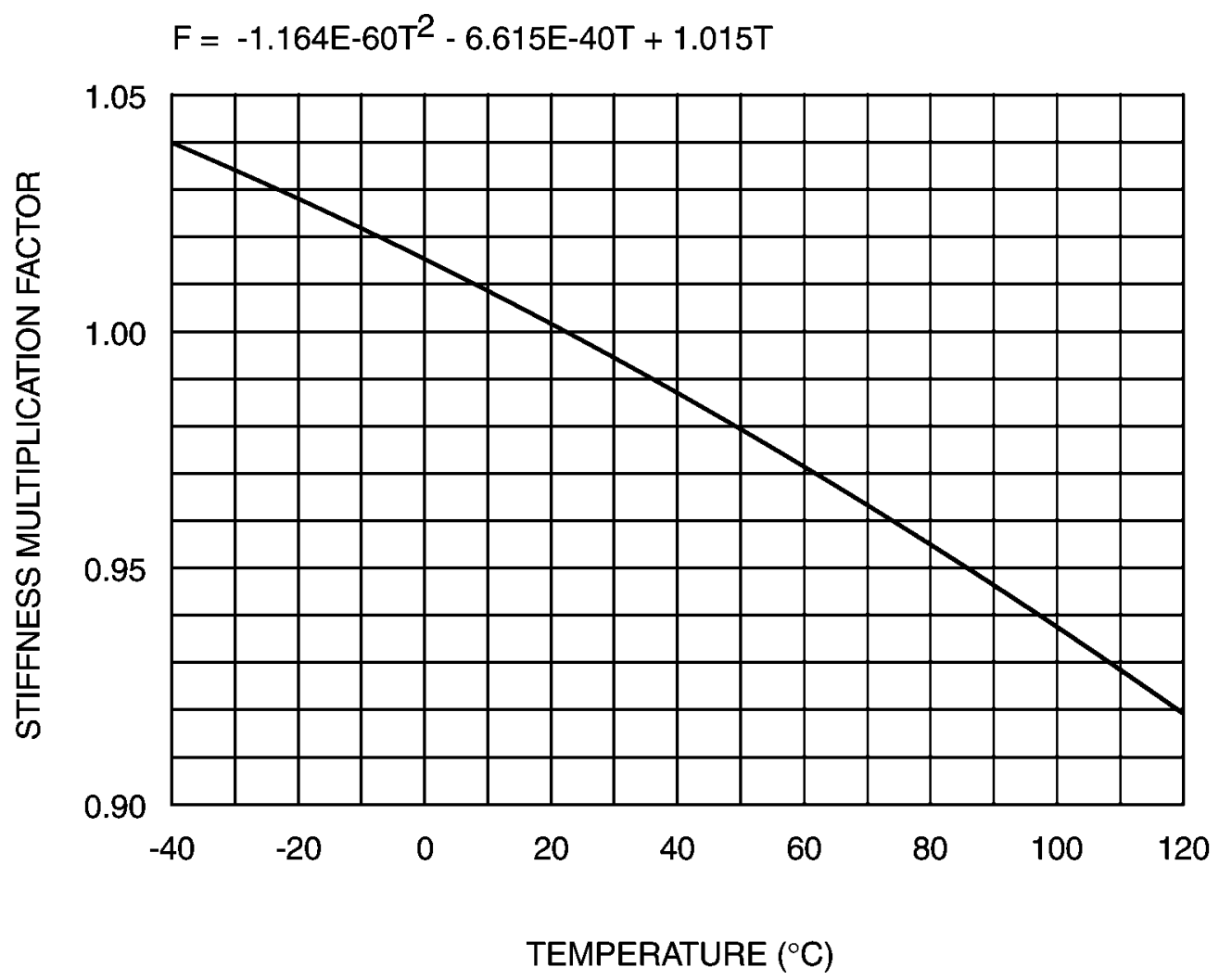

Fig. 2.1. Multiplication factor for determining elastic in-plane modulus of elasticity at a given temperature from room-temperature value.

Table 2.1. Recommended elastic properties for design analysis

\begin{tabular}{ccc}
\hline $\begin{array}{c}\text { Temperature } \\
\left({ }^{\circ} \mathbf{C}\right)\end{array}$ & $\begin{array}{c}\text { Modulus of elasticity } \\
(\mathbf{G P a})\end{array}$ & $\begin{array}{c}\text { Poisson's } \\
\text { ratio }\end{array}$ \\
\hline-40 & 33.7 & 0.31 \\
-10 & 33.0 & $0.31^{a}$ \\
23 & 32.4 & 0.31 \\
50 & 31.8 & $0.31^{a}$ \\
70 & 31.1 & 0.32 \\
120 & 29.8 & 0.34 \\
\hline
\end{tabular}

$a_{\text {Interpolated. }}$

Temperature cycling has an effect on elastic properties, as reported in Chap. 7. Tensile, compressive, and shear specimens were cycled between $-40^{\circ}$ and $120^{\circ} \mathrm{C}$ for 26 times before measuring stiffness. Tensile stiffness was little affected, compressive stiffness dropped approximately $3 \%$, but shear stiffness decreased $25 \%$. While the effect of temperature cycling on Poisson's ratio was not measured directly, Eq. (2.1) would imply a very large increase due to thermal cycling (from 0.31 to 0.74 ). This is an area of concern that should be further explored. 


\subsubsection{Effect of Prior Loading}

Prior loads tend to introduce microdamage and a resultant loss in stiffness. As shown in Chap. 7, this effect is very small in the quasi-isotropic composite. A multiplication factor of 0.99 on stiffness bounds the effect.

\subsubsection{Effect of Fluids}

Chapter 7 presents the results of several test series that assess the effects of distilled water, $70 \%$ relative-humidity (RH) air, ${ }^{*}$ and windshield washer fluid $(70 \%$ methanol $/ 30 \%$ distilled water) on stiffness. Standard exposures of $1000 \mathrm{~h}$ in distilled water and $100 \mathrm{~h}$ in windshield washer fluid were examined, but for moisture exposure (distilled water and $70 \% \mathrm{RH}$ air), the effect of exposure times up to almost $5000 \mathrm{~h}$ on tensile stiffness were assessed. In general, tensile stiffness increased slightly. For $1000 \mathrm{~h}$ in distilled water, the compressive modulus dropped $4 \%$. A stiffness multiplication factor of 0.96 is thus adopted here. This factor also conservatively covers 100-h exposure to windshield washer fluid.

\subsection{CREEP PROPERTIES FOR DESIGN}

In the case of long-term sustained loadings - either those associated with the 3000- to 5000-h operating life of an automobile or the nominally 15-year overall life - creep deformations may become an important consideration and need to be accounted for in design analysis. Guidance is given in this chapter for the inclusion of creep into design analyses at one of two levels of sophistication:

- using a time-dependent isochronous stress-strain curve to obtain a pseudo-"elastic" modulus for use in an elastic analysis or

- using a creep equation in an inelastic (elastic-creep) analysis.

A third approach would be to use the damage-based constitutive model derived in Chap. 12 that can predict the effects of changing load levels as well as recovery strains upon unloading. Unfortunately, that model is currently based on relatively short-time data, so its use for long-term predictions should be approached with caution.

\subsubsection{Basic Creep Equation}

The following equation is developed in Chap. 10 for predicting time-dependent creep strain at room temperature.

$$
\varepsilon_{\mathrm{c}}=\mathrm{At}^{\mathrm{n}},
$$

where

$$
\left.\begin{array}{l}
\mathrm{A}=7.268 \times 10^{-10} \sigma^{3}+2.614 \times 10^{-8} \sigma^{2}+2.789 \times 10^{-5} \sigma+2.960 \times 10^{-5} \\
\mathrm{n}=4.662 \times 10^{-7} \sigma^{2}-2.587 \times 10^{-4} \sigma+0.2540
\end{array}\right\}
$$

\footnotetext{
* Meteorological data show that RH averages about $70 \%$ throughout the year in most areas of the United States.
} 
Here, $\varepsilon_{\mathrm{c}}$ is time-dependent strain in percent, $\mathrm{t}$ is time in hours, and $\sigma$ is applied stress in megapascals.

Total strain is obtained by adding the creep strain predicted by Eq. (2.2) to the predicted elastic loading strain. Total strains calculated in this manner are depicted in Fig. 2.2 in the form of isochronous stress-strain curves. Each curve gives the total strain that would be accumulated at a given constant stress level over the time period for which the curve was constructed. The longesttime curve, 131,000 h, corresponds to the 15-year life of a vehicle. Note that the time-dependent strain amounts to only about $16 \%$ of the "instantaneous" elastic loading strain.

Because the curves in Fig. 2.2 are very nearly linear, the initial slope can be treated as a pseudo elastic modulus and used in an elastic analysis to approximately predict the total deformations corresponding to the time of the curve.* The time-dependent modulus (in GPa) is given by the following equation for $\mathrm{t}>0 \mathrm{~h}$.

$$
\mathrm{E}_{\mathrm{t}}=\frac{3.24}{0.1+\left[9.036 \times 10^{-4}-2.481 \times 10^{-7}(\ln \mathrm{t}) \mathrm{t}^{0.254}\right.} .
$$

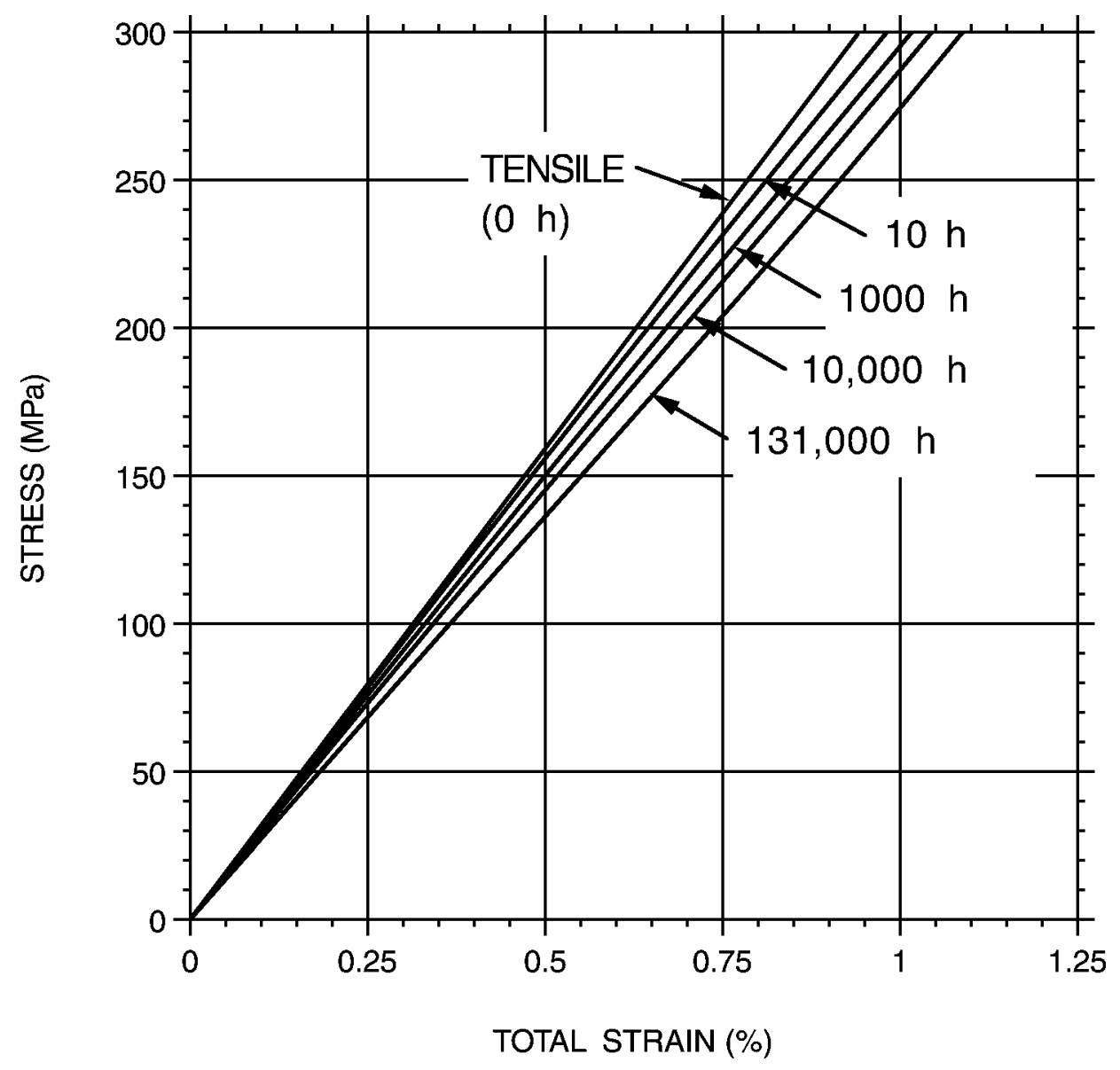

Fig. 2.2. Isochronous stress-strain curves for room-temperature ambient air.

\footnotetext{
*This approach usually gives reasonable approximations for non-time-varying loadings and providing stress redistribution is minimal.
} 
Modulus values for the curves plotted in Fig. 2.2 are tabulated below.

\begin{tabular}{|c|c|}
\hline Time (h) & $E_{t}(G P a)$ \\
\hline 0 & 32.4 \\
\hline 10 & 31.9 \\
\hline 1,000 & 30.8 \\
\hline 10,000 & 29.6 \\
\hline 131,000 & 27.5 \\
\hline
\end{tabular}

\subsubsection{Effect of Temperature}

The effect of increasing temperature on time-dependent creep strain can be accounted for by multiplying the strains predicted by Eq. (2.2) by a factor, which is plotted in Fig. 2.3. The basis for this plot, which is applicable only to creep produced by tensile stresses, is presented in Chap. 10.

Creep under compressive stresses is much more matrix-dominated, and, at least at higher temperatures and stress levels, probably involves local buckling. Limited compressive creep data presented in Chap. 10 indicate that at room temperature, compressive creep is the same as tensile creep. However, at $120^{\circ} \mathrm{C}$, compressive creep appears to be much larger than tensile creep, and the factor, rather than being constant as in the tensile case, depends on stress level. A factor of 38 times room-temperature tensile creep is reported in Chap. 10 for a stress level of $38.1 \mathrm{MPa}$; the factor increases to 77 at a stress level of $76.1 \mathrm{MPa}$. Clearly, long-term compressive loadings should be avoided at $120^{\circ} \mathrm{C}$.

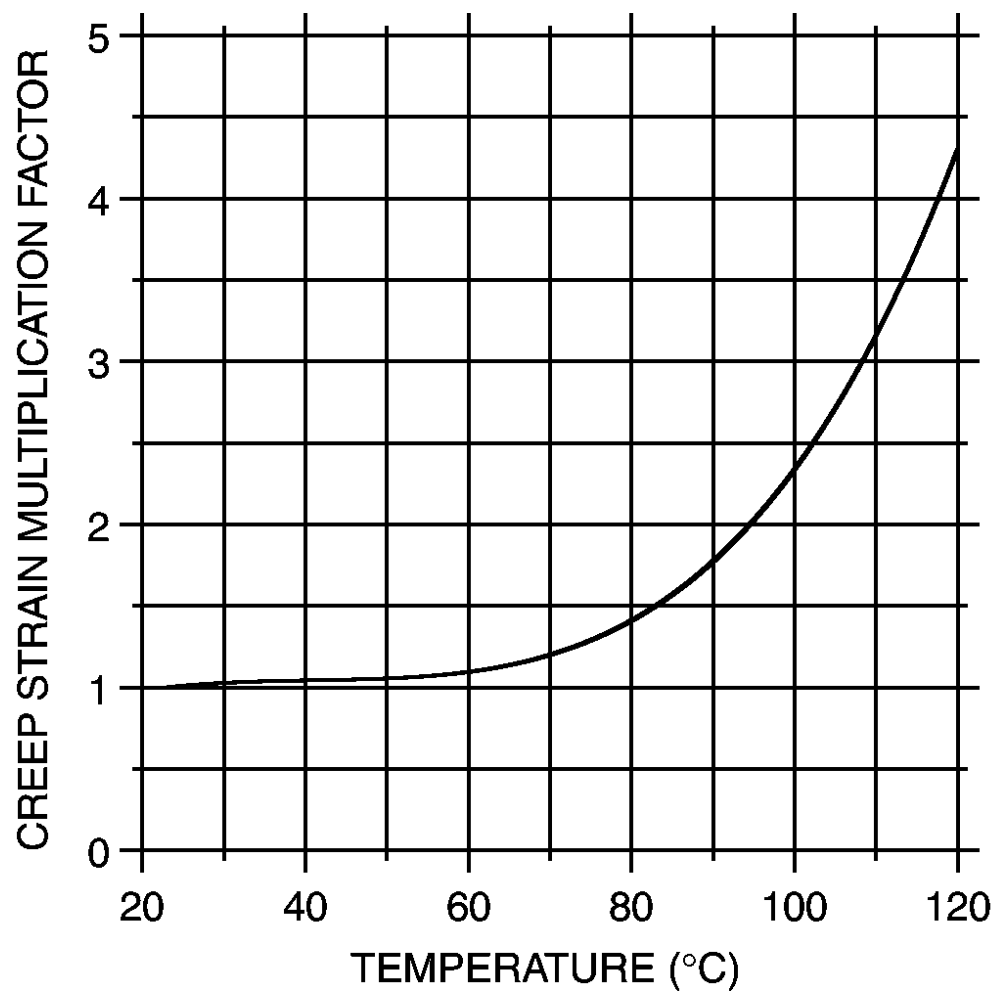

Fig. 2.3. Tensile creep strain multipliers for temperature effects. 


\subsubsection{Effect of Fluids}

The effect on creep strain of the two standard fluid exposures - 1000-h presoak in distilled water, followed by testing in distilled water, and 100-h presoak in windshield washer fluid, followed by testing in windshield washer fluid-is reported in Chap. 10. The resulting multiplication factors on room-temperature, in-air, tensile creep follow.

\begin{tabular}{|c|c|}
\hline Fluid & $\begin{array}{l}\text { Creep-st } \\
\text { multiplicatio }\end{array}$ \\
\hline Distilled water & \\
\hline
\end{tabular}

To bound the effect of fluids, the creep strains predicted by Eq. (2.2) should be multiplied by one of the above factors, as appropriate. 


\section{DESIGN ALLOWABLES FOR STATIC LOADINGS}

The basic allowable stresses, $\mathrm{S}_{0}$ and $\mathrm{S}_{\mathrm{t}}$, used in this chapter are derived from uniaxial tensile tests, both "instantaneous" and time-dependent.* They are thus directly applicable only to inplane tensile stresses. Compressive strengths, both instantaneous and time-dependent, are less than the corresponding tensile strengths. While this may be an artifact of the compression specimen configuration and imminent buckling, it must, nonetheless, be taken into account. Thus, after the tensile allowables are presented, treatment of compressive stresses and biaxial stress states is discussed. Finally, factors are given to account for fluid effects and prior thermal cycling.

\subsection{SHORT-TIME ALLOWABLE TENSILE STRESS, $\mathbf{S}_{0}$}

The basic short-time, or instantaneous, allowable stress is based on the minimum roomtemperature ultimate tensile strength (UTS), which is defined as the "B-basis stress" specified in MIL-HDBK-17.5 The minimum room-temperature value is based on statistical treatment of $\mathrm{n}=86$ UTS values, such that the survival probability at the minimum stress is $90 \%$ at a confidence level of $95 \%$. This minimum value was calculated to be 4

$$
\mathrm{UTS}_{\min }=\mathrm{UTS}_{\mathrm{avg}}-\mathrm{k}_{\mathrm{B}}(\mathrm{SD})=291 \mathrm{MPa} ;
$$

from Chap. 7, the average UTS from 86 tensile tests is $336 \mathrm{MPa}$ with a standard deviation (SD) of $29 \mathrm{MPa}$. From Ref. 5, the factor $\mathrm{k}_{\mathrm{B}}$ is 1.549 for 86 data points.

The basic time-independent allowable stress, $\mathrm{S}_{0}$, is defined as two-thirds $\mathrm{UTS}_{\min }$. At room temperature, $\mathrm{S}_{0}$ thus becomes $194 \mathrm{MPa}$, which is $58 \%$ of the average UTS. Values of $\mathrm{S}_{0}$ for other temperatures are obtained by multiplying the above room-temperature $\mathrm{S}_{0}$ value by the UTS factors plotted in Fig. 3.1 (the factors are taken from Chap. 7).

As reported in Chap. 7, UTS can be reduced by several other effects. First, prior loading sequences of $20 \%, 40 \%, 60 \%$, and $80 \%$ of the average UTS were found to reduce the subsequent UTS by $15 \%$. While $80 \%$ UTS is above $\mathrm{S}_{0}$, a prior loading to $80 \%$ UTS alone reduced the subsequent UTS by only $6 \%$, so lower stresses had a major affect. Thus prior load effects should at least be considered in design. Second, prior thermal cycling between $-40^{\circ} \mathrm{C}$ and $120^{\circ} \mathrm{C}$ reduced the subsequent UTS by almost 7\%. Finally, while the standard fluid exposures did not reduce the UTS in the quasi-isotropic composite, exposure to $70 \% \mathrm{RH}$ air did. A reduction of almost $6 \%$ bounds the latter effect for exposure times up to almost $5000 \mathrm{~h}$. If all of these reductions were applied simultaneously, the assumed effect on $\mathrm{S}_{0}$ would be

$$
\mathrm{S}_{0}=(0.85)(0.93)(0.94)(194)=144 \mathrm{MPa} \text {. }
$$

Ultimately the designer must judge which factors are appropriate for the application.

Values of $\mathrm{S}_{0}$ with no reduction factors and values with just the effect of the $70 \% \mathrm{RH}$ environment (a multiplication factor of 0.94 ) factored in are tabulated in Table 3.1.

\footnotetext{
*The allowable stress system, $\mathrm{S}_{0}$ and $\mathrm{S}_{\mathrm{t}}$, used here is the same as used for each of the three previous composites characterized in the durability studies. $1,3,4$
} 


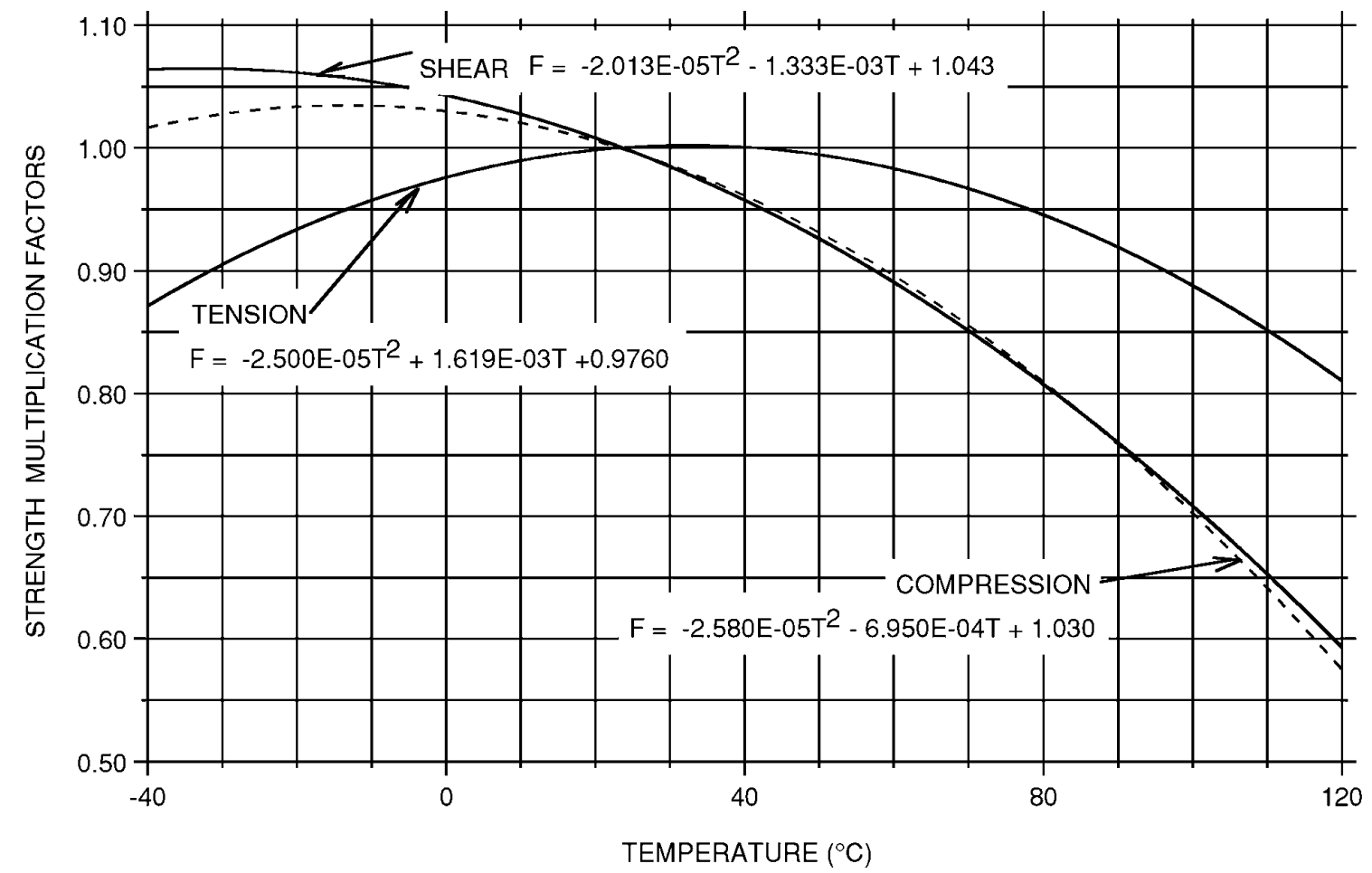

Fig. 3.1. Strength multiplication factors vs temperature.

Table 3.1. Allowable short-time tensile stress, $S_{0}(M P a)$

\begin{tabular}{ccc}
\hline $\begin{array}{c}\text { Temperature } \\
\left({ }^{\circ} \mathbf{C}\right)\end{array}$ & $\begin{array}{c}\text { Without } \\
\text { moisture effect }\end{array}$ & $\begin{array}{c}\text { With } \\
\text { moisture effect }\end{array}$ \\
\hline-40 & 169 & 159 \\
23 & 194 & 182 \\
70 & 188 & 177 \\
120 & 157 & 148 \\
\hline
\end{tabular}

Note that the values in the right-hand column are based on the assumption that there is no synergism between temperature and environmental effects, which is probably not true.

\subsection{TIME-DEPENDENT ALLOWABLE TENSILE STRESS, $\mathbf{S}_{t}$}

For sustained loadings, creep-rupture stress (see Chap. 11) is the basis for time-dependent allowable stresses, provided that $\mathrm{S}_{0}$ is not lower than the creep-rupture-derived values. The following design margin is used: $0.8 \mathrm{~S}_{\mathrm{r}}$, where $\mathrm{S}_{\mathrm{r}}$ is the minimum creep-rupture strength. Values of the allowable tensile stress $0.80 \mathrm{~S}_{\mathrm{r}}$ at room-temperature for various design lives are developed and tabulated in Chap. 11 (Table 11.1). Strength-reduction multiplication factors are then given (Table 11.2) to account for temperature, compressive loading, and fluid exposure. All of the timedependent allowable stress values are thus embodied in those two tables.

For uniaxial tension, the time-dependent allowable stress, $\mathrm{S}_{t}$, is defined as 


$$
\mathrm{S}_{\mathrm{t}} \leq\left\{\begin{array}{l}
\mathrm{S}_{0} \\
0.8 \mathrm{~S}_{\mathrm{r}}
\end{array} .\right.
$$

Values of $S_{t}$ without environmental or prior load effects are tabulated in Table 3.2 and plotted in Fig. 3.2, where both $\mathrm{S}_{0}$ and $0.8 \mathrm{~S}_{\mathrm{r}}$ are shown. Note that the time-dependent allowable stress drops below the time-independent quantity only at the higher temperatures and times. For most of the design space, $\mathrm{S}_{0}$ governs the full life of the vehicle.

Table 3.2. Basic $S_{t}(M P a)$ allowable stress (applicable to uniaxial tensile loadings)

\begin{tabular}{|c|c|c|c|c|}
\hline \multirow{2}{*}{$\begin{array}{c}\text { Time } \\
\text { (h) }\end{array}$} & \multicolumn{4}{|c|}{ Temperature $\left({ }^{\circ} \mathrm{C}\right)$} \\
\hline & -40 & 23 & 70 & 120 \\
\hline 0 & 169 & 194 & 188 & 157 \\
\hline 10 & & & & \\
\hline 100 & & & & \\
\hline 1,000 & & & & 147 \\
\hline 5,000 & & & & 142 \\
\hline 131,000 & $\nabla$ & $\nabla$ & $\downarrow$ & $130^{a}$ \\
\hline
\end{tabular}

$a_{\text {Unrealistic condition. }}$

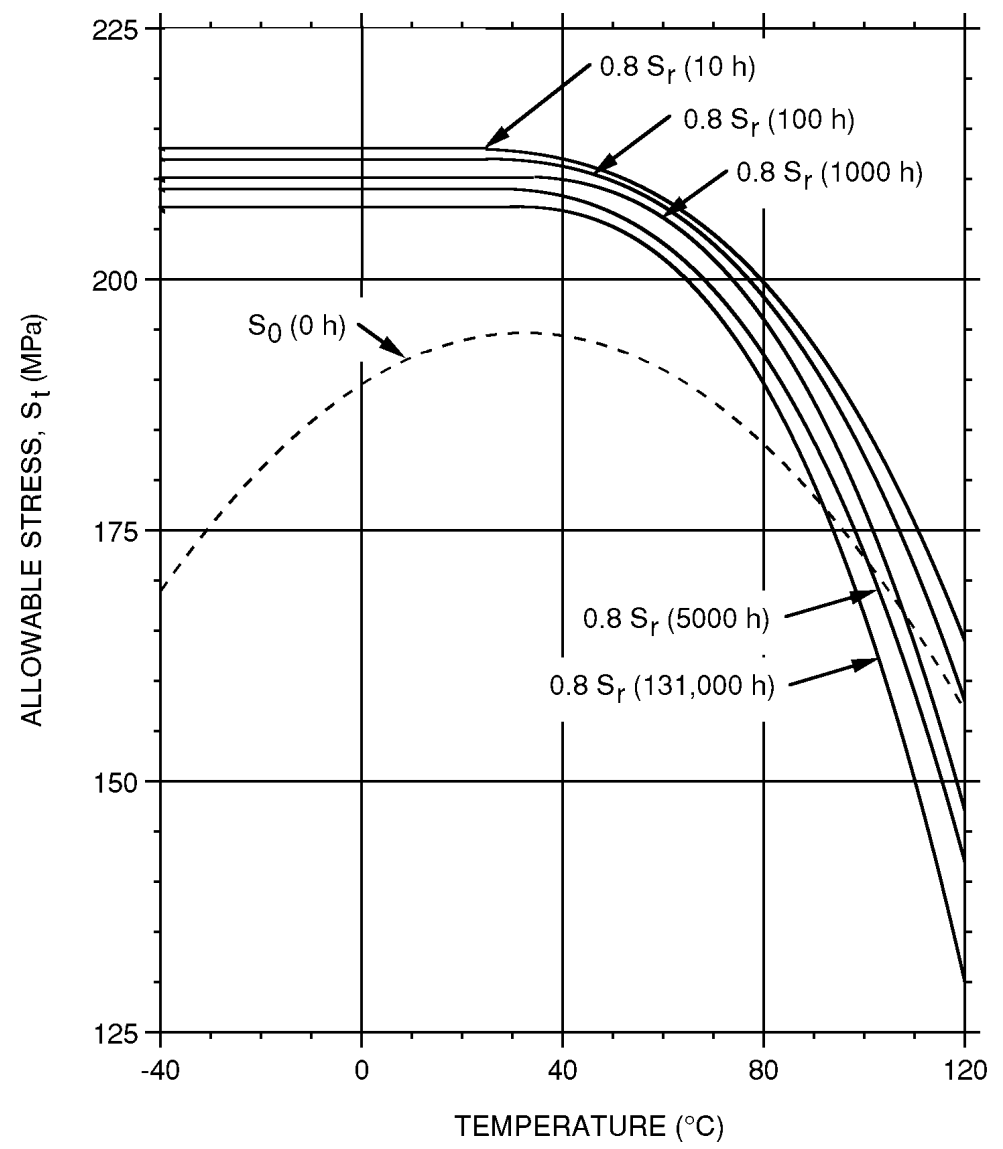

Fig. 3.2. Allowable tensile stresses, $S_{t}$, without environmental or prior load effects. Note that $S_{t}$ is the lower of $\mathrm{S}_{0}$ and $0.8 \mathrm{~S}_{\mathrm{r}}$. 
The values of $\mathrm{S}_{0}$ in the right-hand column of Table 3.1 include the 0.94 knockdown factor that accounts for the effect of a 70\% RH environment (recall that the standard fluid exposures had no effect on short-time strength). For creep rupture strength, knockdown factors for the two standard fluid exposures - testing in distilled water after a 1000-h presoak and testing in windshield washer fluid after a 100-h presoak - are given in Chap. 11 (Table 11.2). Of the two exposures, windshield washer fluid had the larger effect. Those factors were used in developing the time-dependent allowables in Table 3.3, which include moisture/fluid effects.

Table 3.3. Allowable time-dependent uniaxial stresses, $S_{t}(M P a)$ with reductions to account for moisture/fluid effects

\begin{tabular}{|c|c|c|c|c|}
\hline \multirow{2}{*}{$\begin{array}{l}\text { Time } \\
\text { (h) }\end{array}$} & \multicolumn{4}{|c|}{ Temperature $\left({ }^{\circ} \mathrm{C}\right)$} \\
\hline & -40 & 23 & 70 & 120 \\
\hline 0 & 159 & 182 & 177 & 148 \\
\hline 10 & & & & \\
\hline 100 & & & & \\
\hline 1,000 & & & & 141 \\
\hline 5,000 & & & & 135 \\
\hline 131,000 & $\nabla$ & $\downarrow$ & $\nabla$ & $122^{a}$ \\
\hline
\end{tabular}

The $\mathrm{S}_{0}$ and $0.8 \mathrm{~S}_{\mathrm{r}}$ values with moisture and fluid effects included are shown graphically in Fig. 3.3.

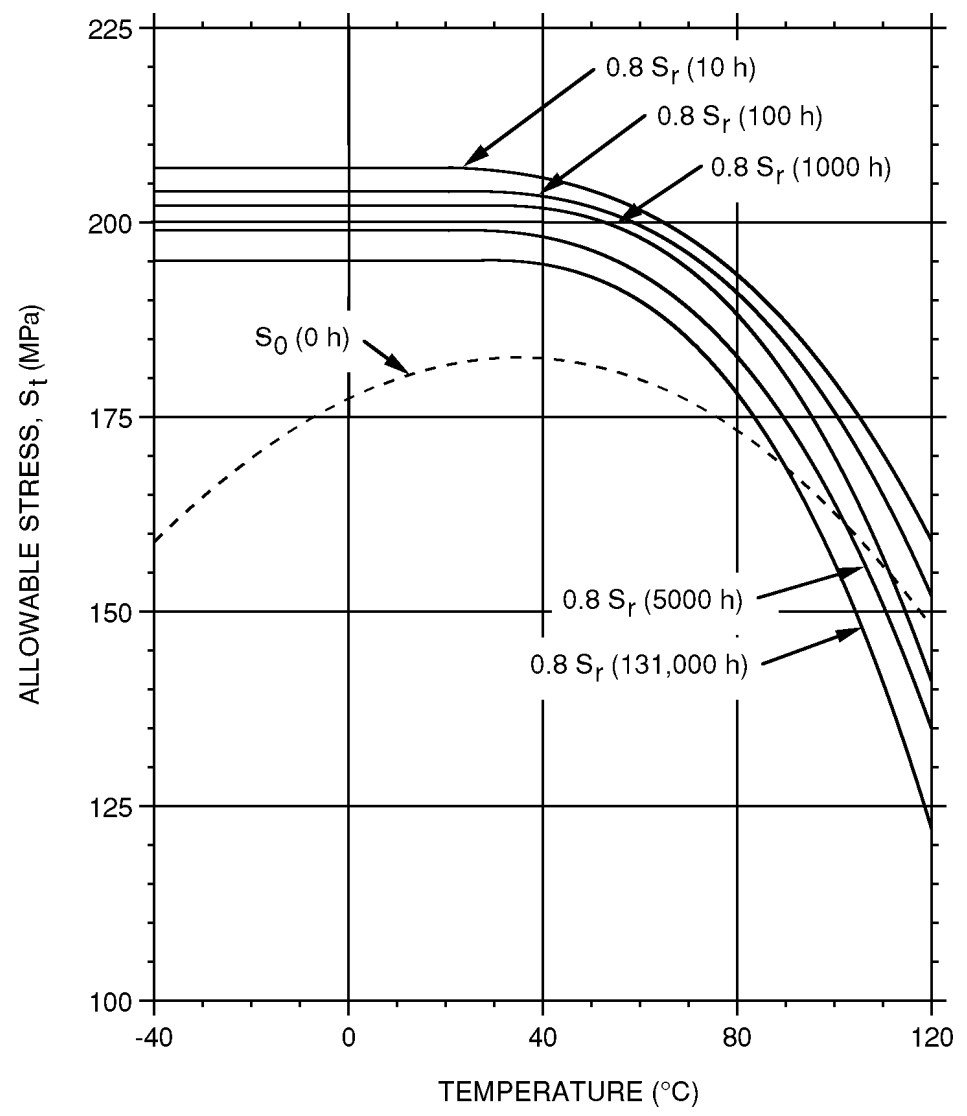

Fig. 3.3. Allowable tensile stresses, $S_{t}$, with limited moisture/fluid effects. 


\subsection{COMPRESSIVE AND BIAXIAL ALLOWABLE STRESS, $\mathrm{S}_{\mathbf{t}}$ *}

To this point, the allowable stresses are based on, and thus only apply to, uniaxial tensile stress states. In design, where other stress states will likely exist, a simple biaxial strength criterion is needed. Because the current composite is isotropic in the plane of the material, something as simple as the maximum stress criterion, which was recommended for the choppedglass-fiber composite, ${ }^{3}$ or the maximum shear stress criterion, which was recommended for the swirled-glass-fiber composite, ${ }^{1}$ may be adequate.

The available average strength data at room-temperature are plotted in principal stress space in Fig. 3.4, where they are compared with common biaxial strength theories. The solid points in the figure are from the basic tensile, compressive, and shear test results reported in Chap. 7. The open-point compressive strength comes from "baseline compression after impact" tests reported in Chap. 14. Special antibuckling face-support plates were employed in these tests. The resulting compressive strengths were nearly equal to the tensile strength, whereas the standard compressive strength was about $67 \%$ of the UTS. Of the four composites that have been addressed by the ORNL durability project, this is the first one in which the room-temperature compressive strength did not slightly exceed the tensile strength. The explanation for this difference may be that the thinner quasi-isotropic composite (nominally 2-mm thick vs 3-mm thick for the other three composites) led to buckling mechanisms in the standard compression specimen. This may have possibly resulted in some buckling in the shear specimens as well.

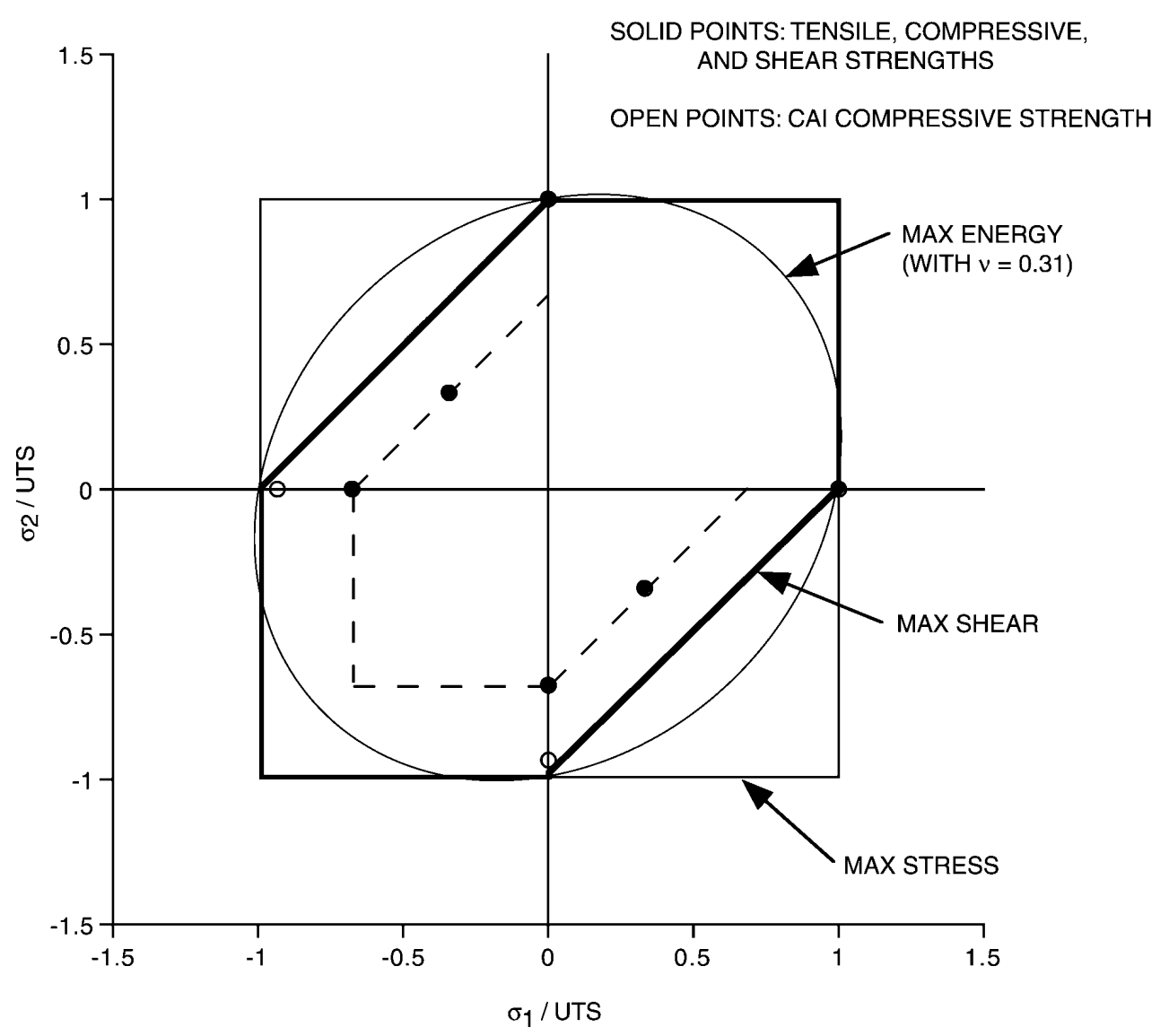

Fig. 3.4. Candidate failure criteria compared with available room-temperature failure data. Stresses are shown normalized by the UTS. 
Three common biaxial failure criteria are shown in Fig. 3.4. The maximum principal stress criterion is the square; failure is predicted when the principal stress having the largest absolute value reaches the UTS. The maximum shear stress theory is the dark hexagon; failure occurs when the algebraic difference between the maximum and minimum principal stresses reaches the UTS. Finally, the maximum energy, or von Mises, criterion is the ellipse; failure occurs when

$$
\left[\sigma_{1}^{2}-v \sigma_{1} \sigma_{2}+\sigma_{2}^{2}\right]^{1 / 2}=\mathrm{UTS}
$$

While the data in Fig. 3.4 are insufficient to make a definitive choice between the strength criteria, it would appear that the maximum shear theory could possibly give an adequate representation. Thus, in the absence of more complete biaxial data, it is recommended for tentative use for nontensile stress states.* The dashed partial hexagon represents the criterion; failure would occur when the maximum principal stress difference reaches the compressive strength. The maximum principal stress or maximum shear theory based on the UTS should be used in the first (tensile) quadrant.

Because temperature has essentially the same relative effect on both compressive and shear strengths (see Table 7.3), the previous recommendation regarding nontensile stress states holds for any temperature. Furthermore, fluids have a larger effect on compressive strength than on shear strength, so the maximum shear theory with the stress limited to the compressive strength, reduced by fluid effects, is conservative. For creep rupture, there are no available shear results, so the assumption must be made that the compressive results with the maximum shear strength criterion are still adequate.

The basic allowable stresses, $\mathrm{S}_{\mathrm{t}}{ }^{*}$, applicable to compressive and biaxial stress states are tabulated in Table 3.4 and plotted in Fig. 3.5, where both $\mathrm{S}_{0}{ }^{*}$ and $0.8 \mathrm{~S}_{\mathrm{r}}{ }^{*}$ are shown. The asterisk distinguishes the allowables applicable to nontensile stress states from those given earlier for tensile stress states.

The $70 \% \mathrm{RH}$ condition that produced the largest moisture/fluid effect on tensile strength (a multiplication factor of 0.94) was not evaluated in the case of compressive ultimate strength. However, the effects of the standard fluid exposures were evaluated; $1000 \mathrm{~h}$ in distilled water produced the largest effect on compressive strength -a multiplication factor of 0.94

Table 3.4. Basic $S_{t}$ * (MPa) allowable stresses (applicable to compressive and nontensile biaxial stress states)

\begin{tabular}{|c|c|c|c|c|}
\hline \multirow{2}{*}{$\begin{array}{c}\text { Time } \\
\text { (h) }\end{array}$} & \multicolumn{4}{|c|}{ Temperature $\left({ }^{\circ} \mathrm{C}\right)$} \\
\hline & -40 & 23 & 70 & 120 \\
\hline $0^{a}$ & 133 & 130 & 112 & 76 \\
\hline $10^{b}$ & & & & 36 \\
\hline $100^{b}$ & & & & 28 \\
\hline $1,000^{b}$ & & & & 19 \\
\hline $5,000^{b}$ & & & & 17 \\
\hline $131,000^{b}$ & $\downarrow$ & $\nabla$ & $\nabla$ & $10^{c}$ \\
\hline
\end{tabular}

$a_{\text {Allowable stress values are determined by multiplying the average compressive }}$ strength (see Table 7.4) by the ratio of the room-temperature tensile $\mathrm{S}_{0}$ value (194 MPa) to the average room-temperature UTS $(336 \mathrm{MPa})$.

$b_{0.8} \mathrm{~S}_{\mathrm{r}}{ }^{*}$ values for compression determined by multiplying the room-temperature tensile $0.8 \mathrm{~S}_{\mathrm{r}}$ values by the compression reduction factors given in Table 11.2.

${ }^{c}$ Unrealistic condition.

\footnotetext{
*Nontensile stress states are those having at least one negative principal stress component.
} 


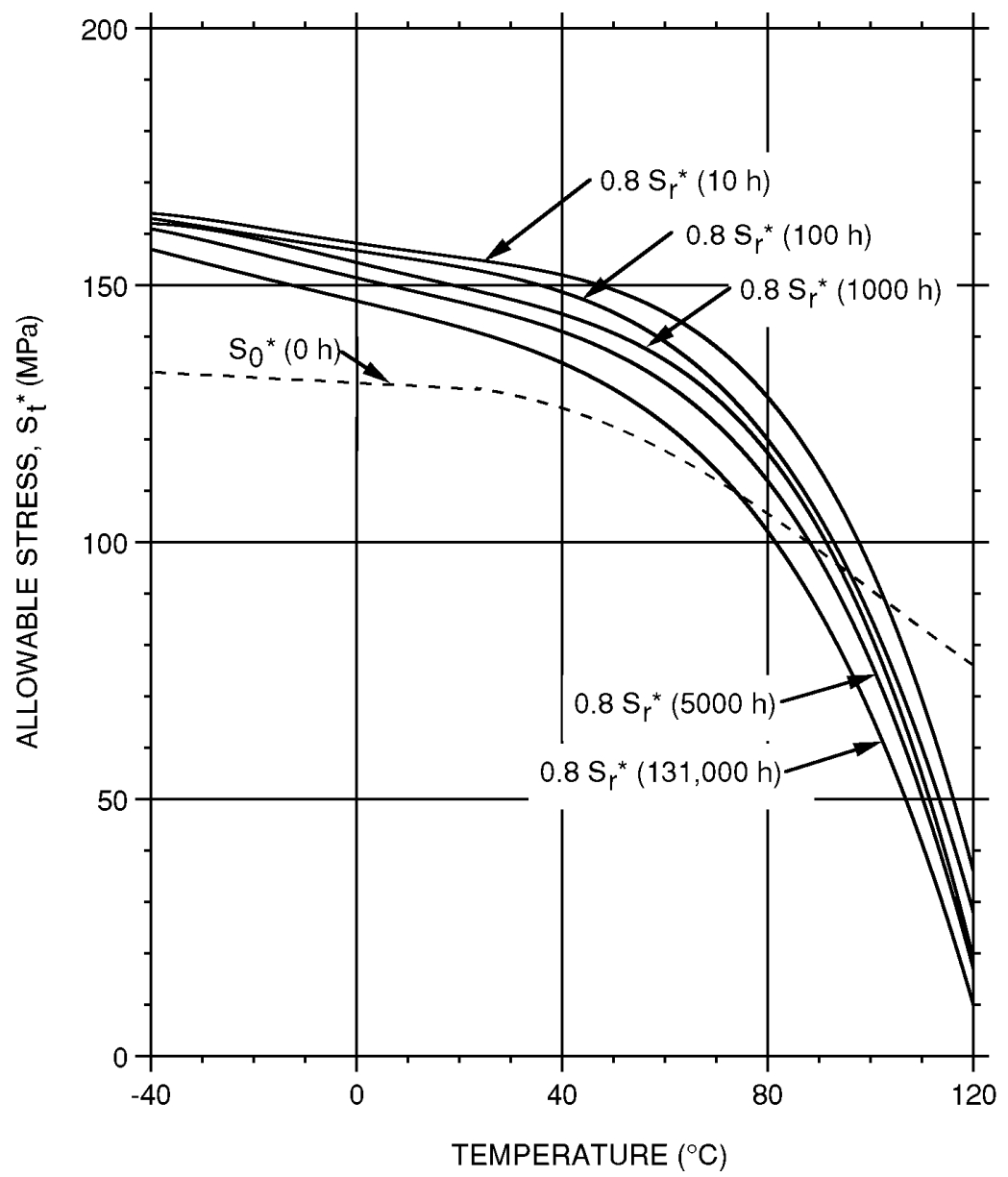

Fig. 3.5. Allowable compressive and nontensile biaxial stresses, $\mathrm{S}_{t}{ }^{*}$, without environmental or prior load effects.

(see Table 7.9). No compressive creep-rupture tests in fluids were performed; thus, the reduction ratios developed from tensile creep-rupture data (see Table 11.2) will be used also for compression. The resulting estimated time-dependent allowable compressive stresses, with reductions to account for fluid effects, are tabulated in Table 3.5 and plotted in Fig. 3.6.

Table 3.5. Allowable time-dependent compressive and non-tensile biaxial stresses, $S_{t}$ *(MPa), with estimated reductions to account for fluid effects

\begin{tabular}{|c|c|c|c|c|}
\hline \multirow{2}{*}{$\begin{array}{c}\text { Time } \\
\text { (h) }\end{array}$} & \multicolumn{4}{|c|}{ Temperature $\left({ }^{\circ} \mathrm{C}\right)$} \\
\hline & -40 & 23 & 70 & 120 \\
\hline $0^{a}$ & 125 & 122 & 105 & 71 \\
\hline $10^{b}$ & & & & 34 \\
\hline $100^{b}$ & & & & 26 \\
\hline $1,000^{b}$ & & & & 18 \\
\hline $5,000^{b}$ & & & & 16 \\
\hline $131,000^{b}$ & $\gamma$ & $\downarrow$ & $\nabla$ & $9^{c}$ \\
\hline
\end{tabular}

${ }^{a}$ Compressive $\mathrm{S}_{\mathrm{r}}$ * values multiplied by 0.94 .

${ }^{b}$ Compressive $0.8 \mathrm{~S}_{\mathrm{r}} *$ values multiplied by tensile windshield washer fluid factors given in Table 11.2.

${ }^{c}$ Unrealistic condition. 


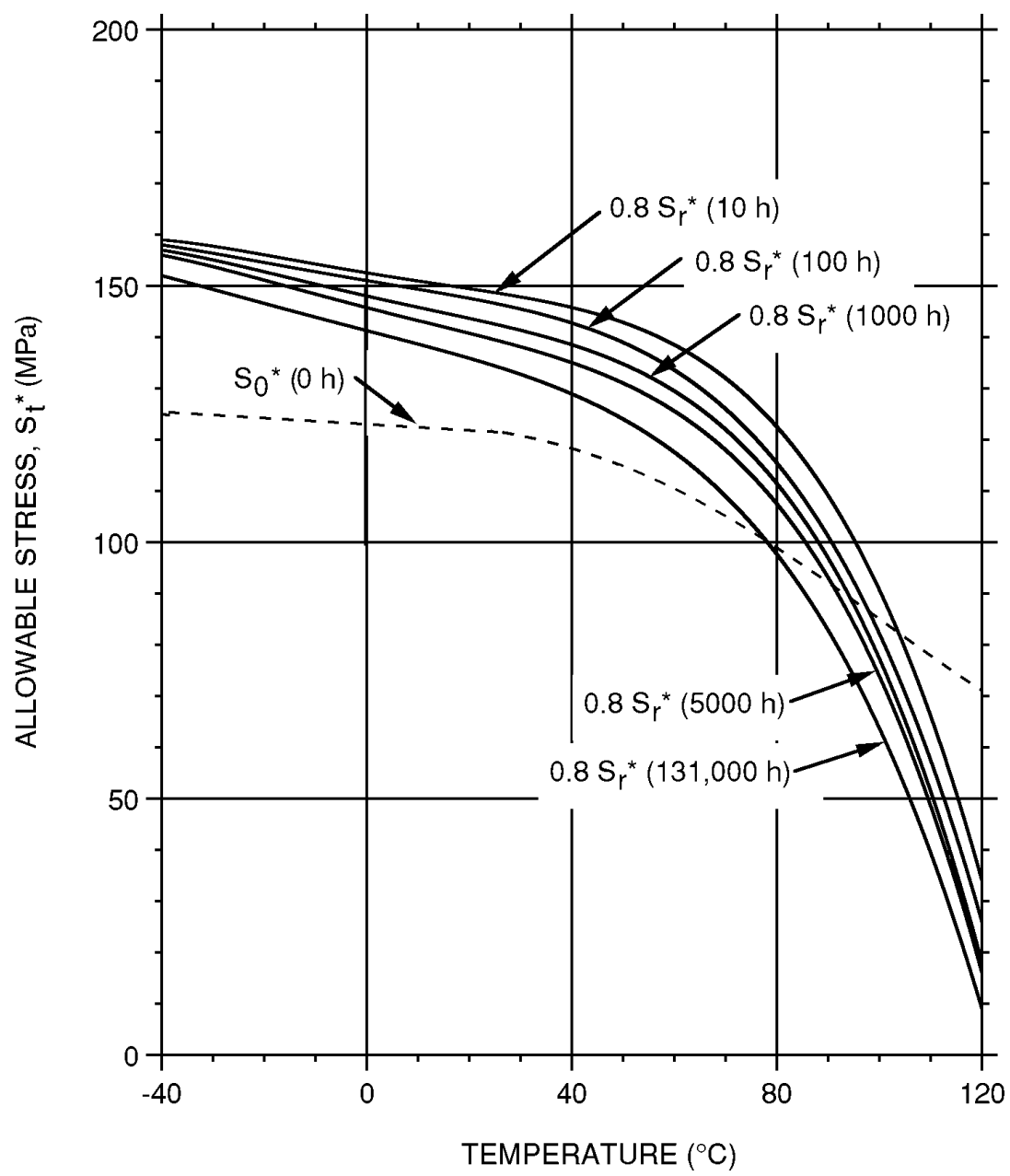

Fig. 3.6. Allowable compressive and nontensile biaxial stresses, $S_{t}{ }^{*}$, with estimated fluid effects.

\subsection{TREATMENT OF MEMBRANE AND BENDING STRESSES}

The $\mathrm{S}_{0}$ and $\mathrm{S}_{\mathrm{t}}$ (or $\mathrm{S}_{0} *$ and $\mathrm{S}_{\mathrm{t}}$ ) allowable stresses given in the previous two sections establish limits on allowable in-plane membrane stresses, P. Elastically calculated bending stresses, Q, must also be considered.* For out-of-plane bending away from structural discontinuities, the elastically calculated membrane plus bending stresses, $\mathrm{P}+\mathrm{Q}$, are limited to

$$
\mathrm{P}+\mathrm{Q} \leq \mathrm{K} \mathrm{S}_{\mathrm{t}}\left(\text { or } \mathrm{S}_{\mathrm{t}}^{*}\right)
$$

where $\mathrm{K}$ is a temperature-dependent factor, with the values tabulated as follows. ${ }^{\dagger}$

*The bending stress, Q, is calculated from a bending moment in isotropic, homogeneous beam, plate, or shell theory. It is not the ply stress calculated using classical lamination theory (see Chap. 8).

$\dagger^{\dagger}$ atios of modulus of rupture (MOR) to UTS values for three-point beam tests are listed in Table 8.1. The MOR is the elastically calculated maximum bending stress. The $\mathrm{K}$ values are based on the MOR/UTS ratios. Although MOR/UTS ratios greater than 1.5 were obtained experimentally, the K values are capped at 1.5 . 


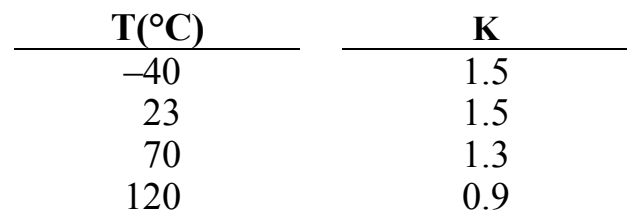

The flexure test results on which the $\mathrm{K}$ factors are based are given in Chap. 8 (Table 8.1). The values come from specimens with surface fibers transverse to the beam axis (specimens with surface fibers parallel to the beam axis gave slightly higher factors). It should be reemphasized that the factors above apply to bending stresses elastically calculated assuming an isotropic, homogeneous material.

Geometric discontinuities include corners and bends. At such locations, the fiber distribution across the thickness of a composite plate or shell structure is likely to be less uniform. More importantly, new failure modes (i.e., delaminations) can be introduced. Equation (3.2) and the K factors do not apply at these locations.

As is shown in Chap. 8 (see Tables 8.2 and 8.3), fluid effects on bending strength are close to those for in-plane compressive strength. In the latter case, a multiplication factor of 0.94 on short-time strength bounds the standard fluid effects. From tests of beams with transverse surface fibers, the corresponding factor for bending is 0.93 .

\subsection{TREATMENT OF INCREMENTS OF CHANGING LOADS}

For changing stress levels, the time-fraction summation method should be used to assess cumulative damage. The sum of the use fractions associated with the primary plus bending stresses for all increments of loading should not exceed a value of 1.0:

$$
\sum_{i}\left(\frac{t}{T_{d}}\right)_{i} \leq 1.0 .
$$

Here, $t_{i}$ is the specified duration of a given load increment $i$, and $T_{d_{i}}$ is the allowable time for the stress associated with that load increment. 


$$
\text { 3-10 }
$$




\section{DESIGN LIMITS FOR CYCLIC LOADINGS}

\subsection{BASIC FATIGUE DESIGN CURVES}

Two room-temperature, ambient-air design fatigue curves are provided in this chapter. The first, shown in Fig. 4.1, applies to cycles in which the stress varies from zero to a maximum tensile value (ratio, $\mathrm{R}$, of minimum to maximum tensile stress equals zero). The maximum stress, $\mathrm{S}_{\max }$, in the cycle is shown in Fig. $4.1 \mathrm{vs}$ the allowable number of design cycles. The second curve is shown in Fig. 4.2. It applies to fully reversed cycles $(\mathrm{R}=-1)$ where the stress varies from a tensile stress to an equal, but opposite, compressive stress. The alternating stress, $S_{a}$, in the cycle is shown in Fig. 4.2 vs the allowable number of design cycles. The curve in Fig. 4.2 may be used with the Goodman relation, given below, to determine the allowable lives for cycles with other tensile or compressive mean stress values.

As explained in Chap. 9, these design curves were derived from fatigue failure curves by first placing a margin of 20 on cycles to failure and then multiplying stress by an additional reduction factor of 0.90 . The latter factor is the ratio of the minimum to average UTS. It provides an extra margin to cover data scatter.

For cycles with a mean stress, $\sigma_{\mathrm{m}}$, other than zero, Eq. (4.1) can be used to determine the allowable alternating stress, $\mathrm{S}_{\mathrm{a}}$, corresponding to a required cyclic life $\mathrm{N}_{\mathrm{d}}$.

$$
\mathrm{S}_{\mathrm{a}}=\mathrm{S}_{\mathrm{o}}\left(1-\frac{\sigma_{\mathrm{m}}}{\mathrm{UTS}}\right)
$$

Here, $S_{o}$ is the allowable alternating stress determined from Fig. 4.2 for a given design life $\mathrm{N}_{\mathrm{d}}$. The average room-temperature UTS value of $336 \mathrm{MPa}$ should be used in Eq. (4.1). For a compressive mean stress, the absolute value should be used in Eq. (4.1).

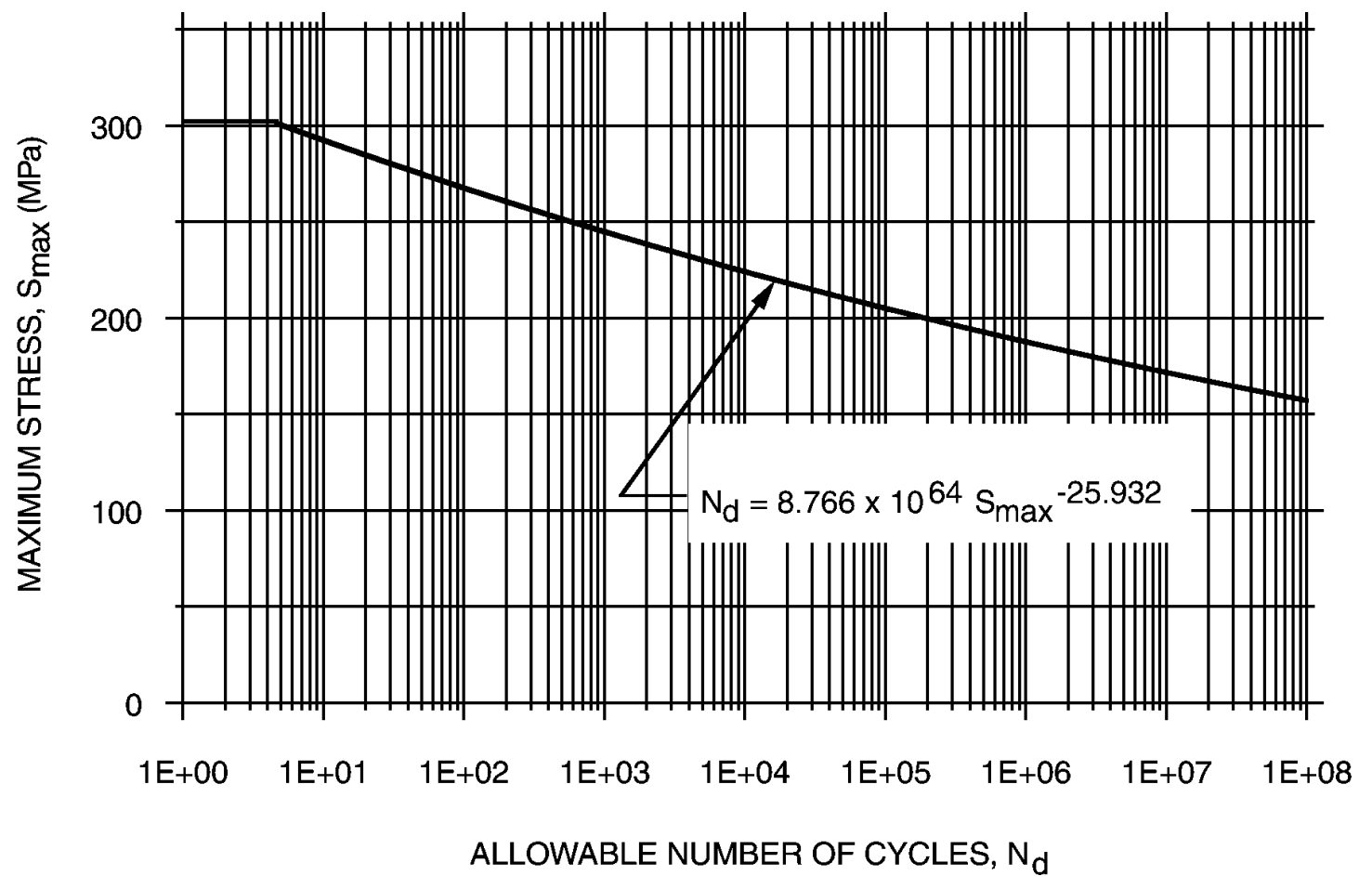

Fig. 4.1. Room-temperature design fatigue curve for tensile $(R=0)$ cycling. 


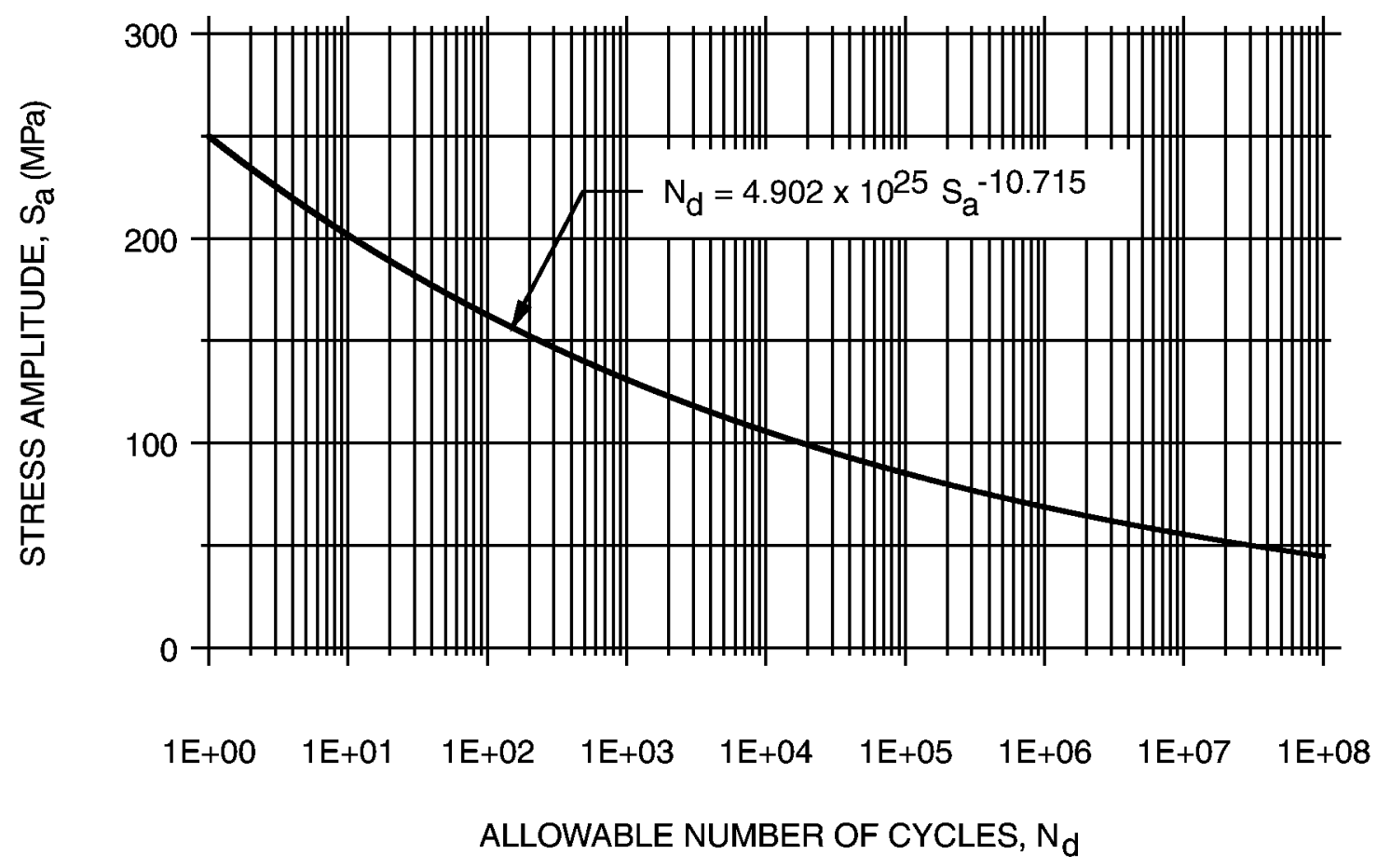

Fig. 4.2. Room-temperature design fatigue curve for fully reversed $(R=-1)$ cycling. This curve can be used with the Goodman relation, Eq. (4.1), for cycles having various mean stresses.

In the absence of definitive biaxial fatigue test data, it is assumed that, just as in the case of short-time static loadings, maximum principal stresses govern tensile fatigue cycles while the maximum shear stress criterion governs compressive fatigue cycles. A compressive fatigue cycle is one in which any principal stress goes into compression.

\subsection{EFFECTS OF TEMPERATURE}

The design fatigue curves in Figs. 4.1 and 4.2 are for room temperature. For other temperatures, fatigue strength multiplication factors, developed in Sect. 9.3, should be used. The factors are repeated here in Table 4.1.

Table 4.1. Fatigue strength factors to account for temperature

\begin{tabular}{ccccc}
\hline \multirow{2}{*}{$\begin{array}{c}\text { Temperature } \\
\left({ }^{\circ} \mathbf{C}\right)\end{array}$} & $\mathbf{1 0}^{\mathbf{2}}$ & $\mathbf{1 0}^{\mathbf{4}}$ & $\mathbf{1 0}^{\mathbf{6}}$ & $\mathbf{1 0}^{\mathbf{8}}$ \\
\cline { 2 - 5 } Cycles & 0.89 & 1.03 & 0.96 & 0.88 \\
23 & 1.00 & 1.00 & 1.00 & 1.00 \\
70 & 1.00 & 0.97 & 0.89 & 0.82 \\
120 & 0.97 & 0.78 & 0.62 & 0.50 \\
\hline
\end{tabular}

\subsection{FLUID EFFECTS}

Fluid effects on fatigue strength are discussed in Sect. 9.4. The two standard exposures discussed earlier were used for fatigue: 
- specimens soaked for $1000 \mathrm{~h}$ at room temperature and then tested in distilled water, and

- specimens soaked for $100 \mathrm{~h}$ at room temperature and then tested in windshield washer fluid (70\% methanol $/ 30 \%$ distilled water).

The fatigue strength multiplication factors are tabulated in Table 4.2. Values greater than 1.00 are reduced to 1.00 in the table. Like the temperature effects factors, the fluid factors were derived from tension-tension fatigue data. In the absence of other data, it is assumed that they apply to other uniaxial and biaxial conditions as well.

Table 4.2. Fatigue strength factors for two bounding fluid environments

\begin{tabular}{lcccc}
\hline \multirow{2}{*}{ Environment } & \multicolumn{4}{c}{ Cycles } \\
\cline { 2 - 5 } & $\mathbf{1 0}^{\mathbf{2}}$ & $\mathbf{1 0}^{\mathbf{4}}$ & $\mathbf{1 0}^{\mathbf{6}}$ & $\mathbf{1 0}^{\mathbf{8}}$ \\
\hline Water, 100-h presoak & 0.92 & 0.91 & 0.97 & 1.00 \\
Windshield washer & 0.97 & 0.92 & 0.95 & 0.98 \\
fluid, 100-h presoak & & & & \\
\hline
\end{tabular}

\subsection{TREATMENT OF VARYING STRESS AMPLITUDES}

Cumulative damage under varying stress amplitudes is an important consideration in designing for cyclic loadings. For the random-glass-fiber composites previously evaluated, Miner's rule was recommended. ${ }^{1-3}$ The choice for the glass composites was based on a very limited number of block loading tests in each case and was thus not well based statistically.

No block loading tests have been performed for either the crossply or quasi-isotropic carbonfiber composite. It is recommended that in the absence of definitive data, Miner's rule again be adopted. For a design to be acceptable, the fatigue damage should satisfy the following relation:

$$
\sum_{\mathrm{i}}\left(\mathrm{n} / \mathrm{N}_{\mathrm{d}}\right)_{\mathrm{i}} \leq 1.0
$$

where $n_{i}$ is the number of specified cycles of type $i$, and $N_{d i}$ is the number of design-allowable cycles for cycle i determined from one of the design curves in Figs. 4.1 or 4.2. These curves should be adjusted to correspond to the maximum temperature of the cycle and to account for the environment. 


\section{DAMAGE TOLERANCE DESIGN FOR LOW-ENERGY IMPACTS AND OTHER DEFECTS}

\subsection{GENERAL REQUIREMENTS}

A two-part design assessment procedure is recommended.

1. Assume the presence of a 6.4-mm-diam circular hole in the worst possible location of the structure, and demonstrate, through analysis or use of experimental data and models, that the structure maintains its integrity. This evaluation will ensure that the structure can tolerate minor impacts and structural flaws at least up to a size of $6.4 \mathrm{~mm}$ in diameter or length, no matter where they are located. Guidance for this evaluation is provided in the next section.

2. For specific low-energy impacts such as kickups of roadway debris, tool drops, or load drops in a pickup truck box, the procedures described in Sects. 5.3 and 5.4 may be used to assess damage tolerance for damage areas larger than that corresponding to a 6.4 -mm-diam hole $\left(32 \mathrm{~mm}^{2}\right)$.

\subsection{EFFECTS OF CIRCULAR HOLES}

Results of tensile tests of specimens containing circular holes are presented in Chap. 13. Compressive tests of specimens with circular holes are reported in Chap. 14. A key observation is that the effective stress concentration factor (SCF) is not nearly as high as theoretically predicted.* Furthermore, the smaller the hole, the smaller the effective SCF. Figure 5.1, which is

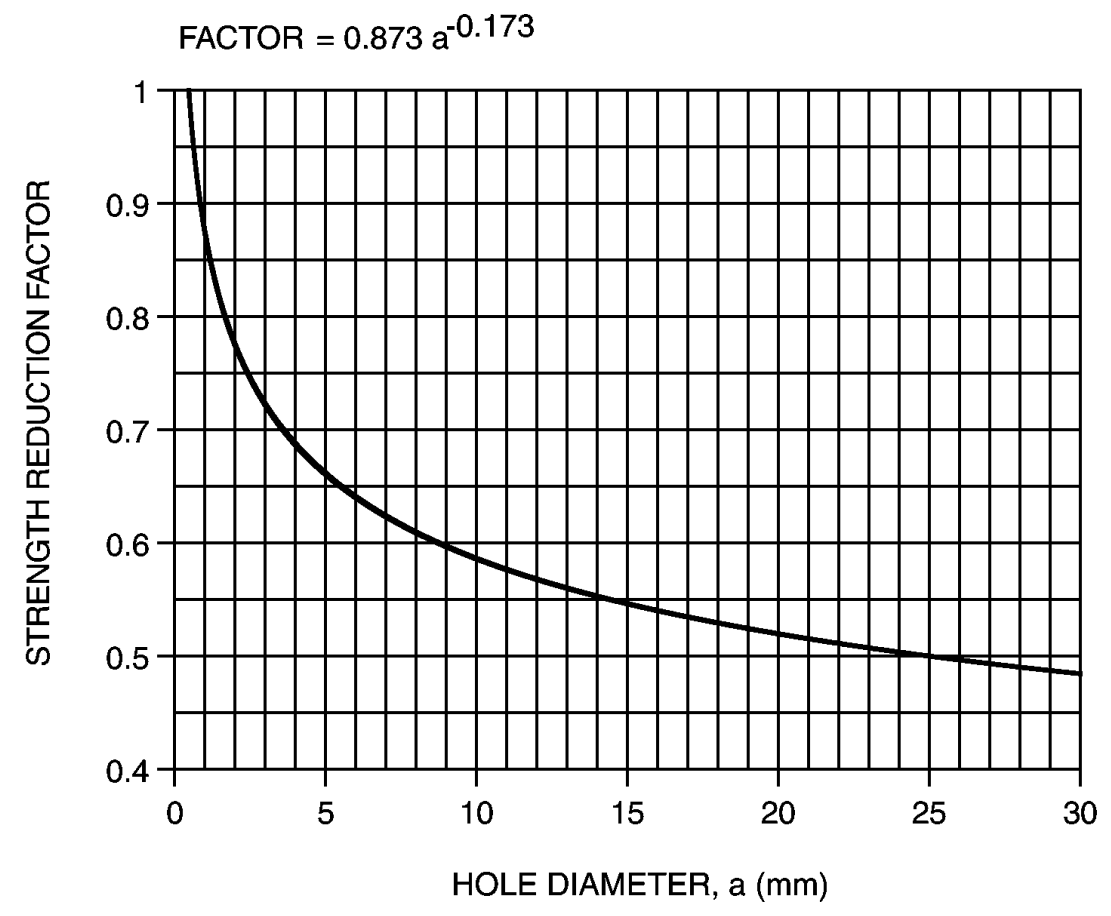

Fig. 5.1. Strength reduction factor for circular holes in an infinitely wide, uniaxially loaded plate. Curve is derived from tensile tests of quasi-isotropic composite plates with circular holes of various diameters. The curve conservatively represents compressive test data as well.

\footnotetext{
*This is a common characteristic of composites, observed in each of the three previously characterized automotive composites.
} 
based on tensile test results from specimens with circular holes, can be used for design evaluations. The ordinate gives the gross stress at failure in an infinitely wide, uniaxially loaded plate with a circular hole as a fraction of the strength of a plate with no hole- the UTS. For the standard 6.4-mm-diam hole, the reduction is 0.63 compared to a theoretical reduction of 0.33 for the quasi-isotropic composite.

While Fig. 5.1 is for an infinitely wide plate, real structures will have sections where the width to hole diameter is relatively small. In those cases, the following equation (from Chap. 13) can be used to determine the applied failure-causing stress, $\bar{\sigma}$, in a finite-width plate that corresponds to an applied failure-causing stress, $\bar{\sigma}_{\infty}$, in an infinitely wide plate:

$$
\frac{\bar{\sigma}}{\bar{\sigma}_{\infty}}=\frac{3(1-\mathrm{a} / \mathrm{w})}{2+(1-\mathrm{a} / \mathrm{w})^{3}},
$$

where $\mathrm{w}$ is the plate width, and $\mathrm{a}$ is the hole diameter. This equation is only accurate for values of $\mathrm{a} / \mathrm{w} \leq 1 / 2$.

The compressive test results presented in Chap. 14 show the compressive strength reduction factor to be above the tensile factor (see Fig. 14.19). Thus, Fig. 5.1 can be conservatively used for compressive stress states.

While no fatigue or creep-rupture test results were generated on quasi-isotropic composite specimens with circular holes, such tests were performed in the case of the chopped-glass-fiber composite. ${ }^{3}$ Tensile, fatigue, and creep-rupture results showed about the same strength reduction. Thus, it is assumed that Fig. 5.1 can also be applied to fatigue and creep rupture, as well as to the short-time failures.

To reliably predict stiffness reductions in structures with circular holes, finite-element analyses should be employed. In addition to stiffness effects, the analyses will predict stresses for comparison with allowable stresses. However, the peak predicted stresses at the hole can be adjusted downward using Fig. 5.1 and Chap. 13 as guides.

\subsection{DETERMINATION OF IMPACT DAMAGE AREAS}

For a given impacting object (e.g., roadway debris or dropped tool) of mass, m, impacting a structure with velocity, $\mathrm{v}$, in the most highly stressed location, away from structural discontinuities, the impact damage should be estimated from the "design" curve in Fig. 5.2. This curve is the upper bound of data generated from air-gun and pendulum impact tests on clamped 203-mm-diam by 2.2-mm-thick circular plates. Development of this design curve and its applicability to real events, typified by bricks dropped in a pickup box, are discussed in Chap. 14 of Part 2. Also, it is shown in Chap. 14 that the curve applies to impacts on specimens at a temperature of $-40 \mathrm{C}$. Although tests were not performed on specimens given the standard fluid presoaks, tests were performed on the crossply-carbon-fiber composite following a 1000-h exposure in distilled water. The fluid exposure had no deleterious effect.

Once the impact damage area has been estimated, the procedures recommended in the following section can be used to assess the likely effect on properties and structural integrity. 


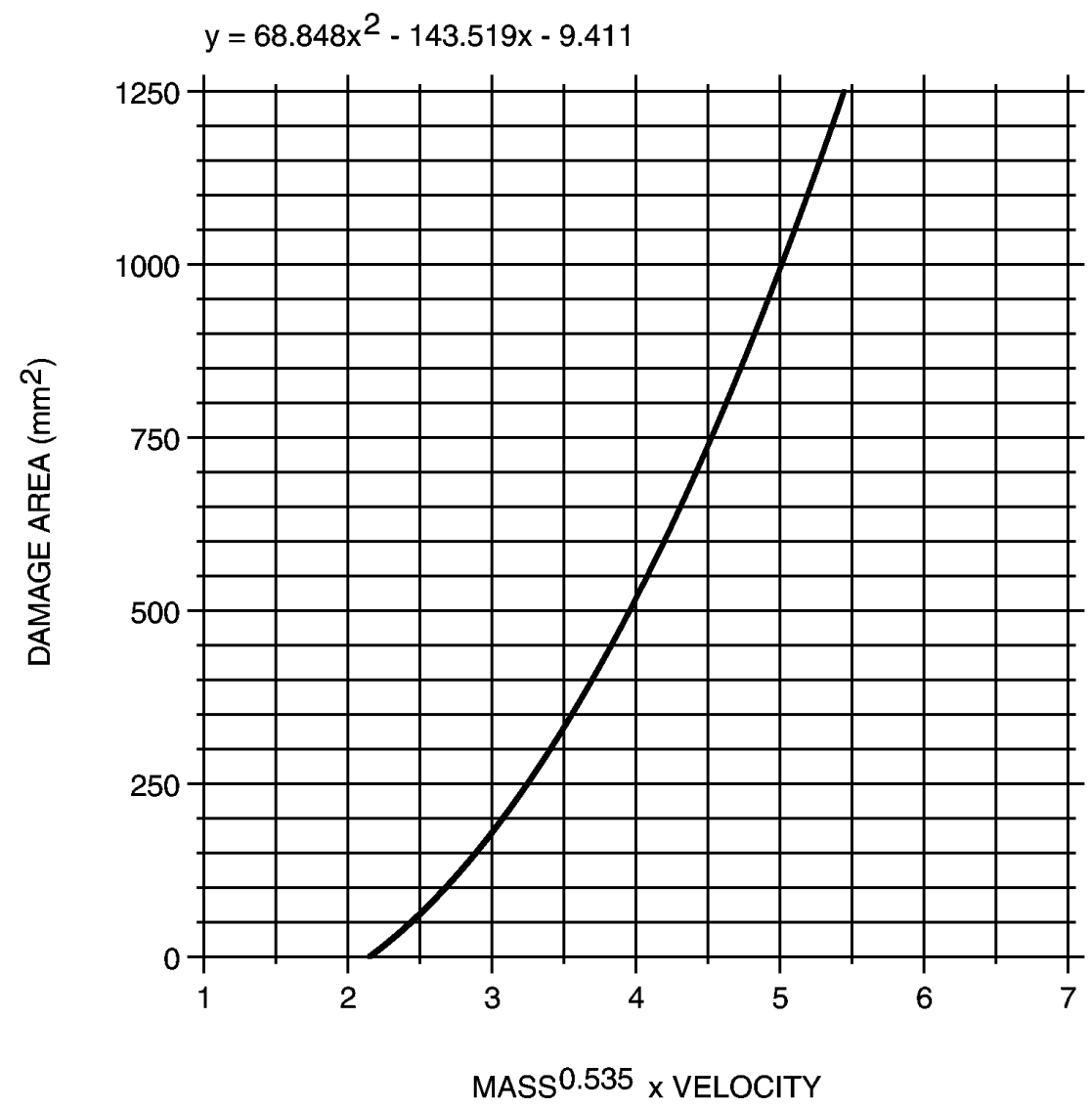

Fig. 5.2. Design curve for determining impact damage area. Mass, $m$, is in kilograms, and velocity, $\mathrm{v}$, is in meters per second.

\subsection{DETERMINATION OF STRENGTH AND STIFFNESS DEGRADATION}

The procedures recommended here depend, in part, on the observation made in Chap. 14 that impact damage area can be conservatively represented by a circular hole of equivalent area. Damage areas can either be factored into the structural evaluation as a circular hole, or the degradation in strength can be estimated as specified in the following paragraph. Structural stiffness degradation can best be estimated, conservatively, by the equivalent circular hole method.

For a given predicted damage area, the degradation in compressive strength can be estimated using Fig. 5.3.* This curve was derived from test data obtained from 76.2-mm-wide compressionafter-impact (CAI) specimens cut from impacted plates (see Chap. 14).

In using Fig. 5.3 to estimate strength reductions, it should be kept in mind that the curves are for finite-width specimens. To approximately convert the results to an infinitely-wide plate or to other finite widths, Eq. (5.1) can be used (again treating the damage area as a circular hole).

* Compressive strength is usually the major concern in impact damage because of delaminations produced by the impact. Consequently, only compression after impact was evaluated for the quasi-isotropic composite. For the previously evaluated crossply-carbon-fiber composite, both tensile and compressive residual strength evaluations were performed. The degradation in tensile strength was just very slightly greater than for compression. 


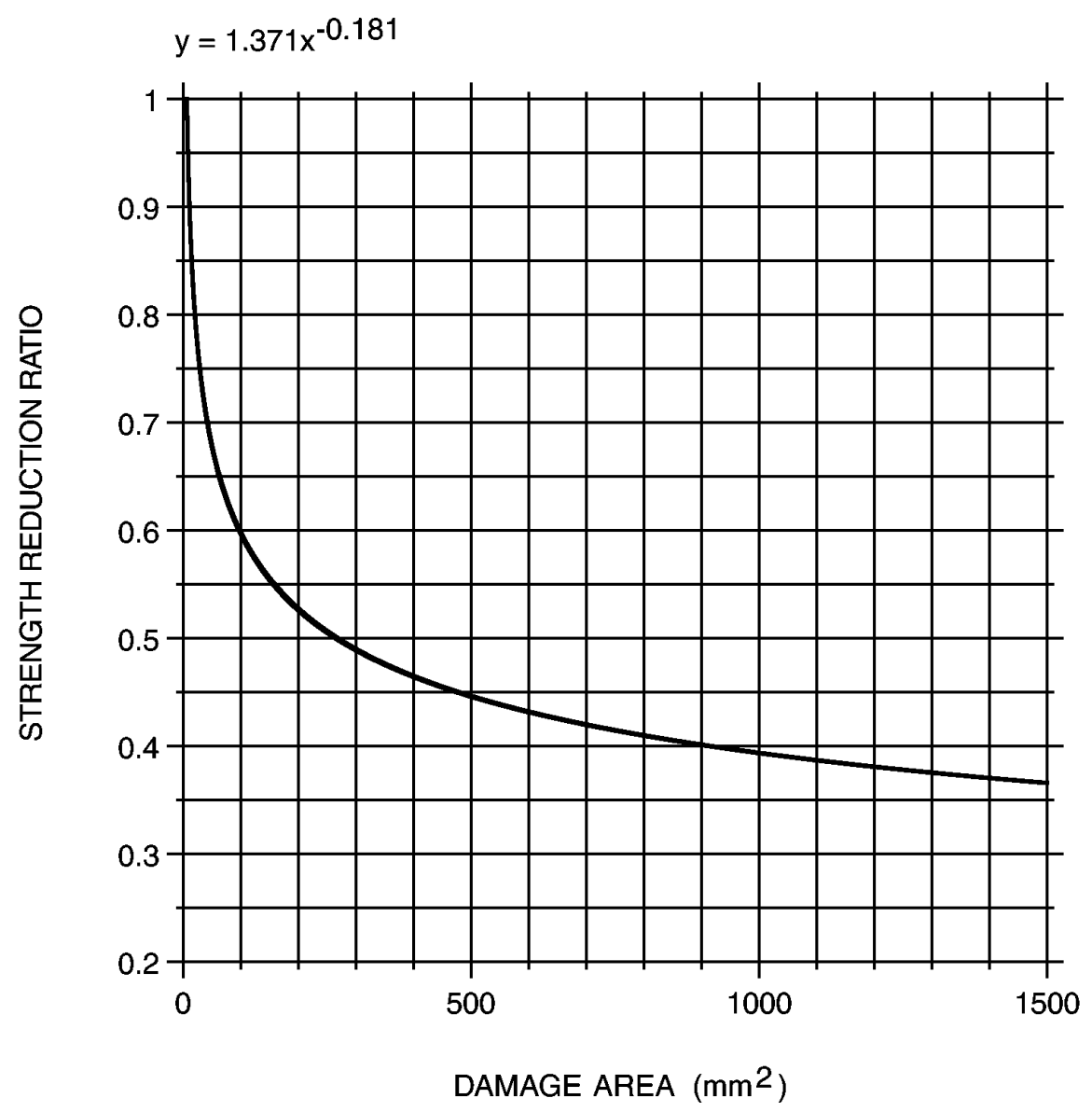

Fig. 5.3. Compressive strength degradation as a function of damage area. This figure applies directly only to a 76.2 -mm-wide specimen. 


\section{SUMMARY AND COMPARISON WITH CROSSPLY CARBON-FIBER COMPOSITE}

This chapter briefly summarizes the guidance and criteria presented in the previous four chapters for the quasi-isotropic carbon-fiber composite. The various properties, allowables, and factors are compared with the corresponding crossply composite values for the $0 / 90^{\circ}$ fiber orientation. ${ }^{4}$

In Sect. 6.4, the allowable stresses for static and cyclic loadings are reduced to a simplified table of values expressed as a percentage of the room-temperature, ambient air, UTS value. Values for the crossply composite with $0 / 90^{\circ}$ fiber orientation are also shown in the simplified table to facilitate direct comparisons between the two materials.

\subsection{ELASTIC AND CREEP PROPERTIES FOR DESIGN ANALYSIS}

Unlike the highly anisotropic crossply composite, the quasi-isotropic composite is essentially isotropic in the plane. In-plane elastic constants for the quasi-isotropic composite are given in Table 6.1, in which they are compared with the $0 / 90^{\circ}$ crossply values. The quasiisotropic composite stiffness is about $69 \%$ of the $0 / 90^{\circ}$ crossply composite value at room temperature, and it is just slightly less affected by an increase in temperature to $120^{\circ} \mathrm{C}$ than is the $0 / 90^{\circ}$ crossply.

Table 6.1. Elastic constants

\begin{tabular}{|c|c|c|}
\hline $\begin{array}{l}\text { Temperature } \\
\left({ }^{\circ} \mathrm{C}\right)\end{array}$ & $\begin{array}{l}\text { Elastic modulus } \\
\text { (GPa) }\end{array}$ & $\begin{array}{l}\text { Poisson's } \\
\text { ratio }\end{array}$ \\
\hline \multicolumn{3}{|c|}{ Quasi-isotropic composite } \\
\hline 23 & 32.4 & 0.31 \\
\hline 120 & 29.8 & 0.34 \\
\hline \multicolumn{3}{|c|}{$0 / 90^{\circ}$ crossply composite } \\
\hline 23 & 46.7 & 0.05 \\
\hline 120 & 42.0 & 0.04 \\
\hline
\end{tabular}

A multiplication factor of 0.96 was chosen to bound the effect of fluid exposure on the stiffness of the quasi-isotropic composite. The effect on the $0 / 90^{\circ}$ crossply was slightly larger; there the bounding multiplication factor was 0.94 .

Prior temperature cycling had little effect on tensile stiffness of either composite. It had a very significant effect (a loss of $25 \%$ in the quasi-isotropic composite*) on shear stiffness, which is matrix- and interface-dominated.

Room-temperature time-dependent creep strains in both the quasi-isotropic and the $0 / 90^{\circ}$ crossply composite are very small. This is illustrated by the tabulation in Table 6.2 of timedependent creep strains predicted to result from application of a 100-MPa stress for $5000 \mathrm{~h}$ at room temperature. The difference in creep compliance at room temperature between the two composites is much less than the difference in elastic compliance. Predicted creep at $120^{\circ} \mathrm{C}$ is actually less for the quasi-isotropic composite than for the $0 / 90^{\circ}$ crossply composite.

\footnotetext{
*In-plane shear stiffness after thermal cycling was not measured in the crosssply composite. However, tensile stiffness for the $\pm 45^{\circ}$ crossply, which is a measure of interlaminar shear stiffness, was reduced $16 \%$ by prior thermal cycling.
} 
Table 6.2. Time-dependent tensile creep strains due to $100 \mathrm{MPa}$ applied for $5000 \mathrm{~h}$ at room temperature

\begin{tabular}{lcc}
\hline \multicolumn{1}{c}{ Composite } & $\begin{array}{c}\text { Creep strain } \\
\mathbf{( \% )}\end{array}$ & $\begin{array}{c}\text { Temperature multiplication } \\
\text { factor at } \mathbf{1 2 0} \mathbf{C}\end{array}$ \\
\hline Quasi-isotropic & 0.026 & $4.3^{a}$ \\
$0 / 90^{\circ}$ crossply & 0.022 & 6.3 \\
\hline
\end{tabular}

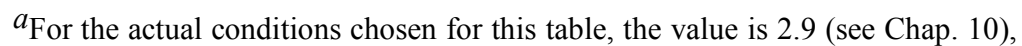
but 4.3 was chosen as a single bounding factor applicable to a range of conditions.

A creep-strain multiplication factor of 1.7 bounds the effects of the standard fluid exposures on the quasi-isotropic composite. The corresponding factor was 4.0 for the $0 / 90^{\circ}$ crossply composite.

In summary, both the elastic and creep responses of the quasi-isotropic composite are less affected by temperature and fluids than was the $0 / 90^{\circ}$ crossply composite.

\subsection{ALLOWABLE STRESSES FOR STATIC LOADINGS}

The basic time-dependent allowable stress quantity used in Chap. 3 is the same as that used in Ref. 1 for the crossply composite:

$$
\mathrm{S}_{\mathrm{t}} \leq\left\{\begin{array}{l}
\mathrm{S}_{0} \\
0.8 \mathrm{~S}_{\mathrm{r}}
\end{array}\right.
$$

Here $S_{t}$ is the time-dependent allowable stress applicable to tensile stress components, $S_{0}$ is the short-time (time-independent) allowable stress, and $\mathrm{S}_{\mathrm{r}}$ is the minimum creep-rupture strength corresponding to time $t$. Representative values of $S_{t}$ are tabulated in Table 6.3 for both the quasiisotropic composite and the $0 / 90^{\circ}$ crossply composite. For the quasi-isotropic composite, the time-dependent allowables do not drop below the time-dependent $\mathrm{S}_{0}$ value at room temperature, but they do at $120^{\circ} \mathrm{C}$. They never drop below the $\mathrm{S}_{0}$ values for the $0 / 90^{\circ}$ crossply.

Table 6.3. Tensile $S_{t}$ values in air (MPa)

\begin{tabular}{cccc}
\hline \multirow{2}{*}{$\begin{array}{c}\text { Temperature } \\
\left({ }^{\circ} \mathbf{C}\right)\end{array}$} & $\mathbf{0} \mathbf{~}$ & $\mathbf{5 0 0 0} \mathbf{~ h}$ & $\mathbf{1 5}$ years \\
\cline { 2 - 4 } & Quasi-isotropic \\
23 & 194 & 194 & 194 \\
120 & 157 & 142 & $130^{a}$ \\
23 & $\mathbf{0 / 9 0 ^ { \circ } \text { crossply }}$ \\
120 & 265 & 265 & 265 \\
& 217 & 217 & $217^{a}$ \\
\hline
\end{tabular}

${ }^{a}$ Unrealistic condition.

Bounding allowable stress multiplication factors for moisture/fluid effects are tabulated in Table 6.4 for both composites. The factors for the quasi-isotropic composite are just slightly lower than those for the $0 / 90^{\circ}$ crossply composite.

For tensile biaxial stress states, the maximum principal stress theory is recommended for design; the maximum tensile stress is limited to $\mathrm{S}_{\mathrm{t}}$. For compressive and other nontensile biaxial stress states, the maximum shear stress theory is recommended; there, the maximum principal 
Table 6.4. Bounding fluid multiplication factors for $S_{t}$

\begin{tabular}{lccc}
\hline \multirow{2}{*}{ Composite } & \multicolumn{3}{c}{ Time } \\
\cline { 2 - 4 } & $\mathbf{0 ~ h}$ & $\mathbf{5 0 0 0} \mathbf{~ h}$ & $\mathbf{1 5}$ years \\
\hline Quasi-isotropic & 0.94 & 0.95 & 0.94 \\
$0 / 90^{\circ}$ crossply & 0.96 & 0.95 & 0.95 \\
\hline
\end{tabular}

stress difference is limited to the quantity $\mathrm{S}_{\mathrm{t}}{ }^{*}$, which is based on compressive strength and compressive creep-rupture tests. Representative $\mathrm{S}_{\mathrm{t}}{ }^{*}$ values are tabulated in Table 6.5 for the quasi-isotropic composite. These values are significantly lower than the tensile allowables in Table 6.3, largely because of the buckling mechanisms associated with compressive failures of the thin (2-mm) quasi-isotropic composite.

Table 6.5. $S_{t} *(M P a)$ allowable stress applicable to nontensile biaxial stress states

\begin{tabular}{crcc}
\hline \multirow{2}{*}{$\begin{array}{c}\text { Temperature } \\
\left({ }^{\circ} \mathbf{C}\right)\end{array}$} & \multicolumn{3}{c}{ Time } \\
\cline { 2 - 4 } & $\mathbf{0 ~ h}$ & $\mathbf{5 0 0 0} \mathbf{h}$ & $\mathbf{1 5}$ years \\
\hline 23 & 130 & 130 & 130 \\
120 & 76 & 17 & $10^{a}$ \\
\hline
\end{tabular}

$a_{\text {Unrealistic condition. }}$

\subsection{ALLOWABLE STRESSES FOR CYCLIC LOADINGS}

Two room-temperature design fatigue $(\mathrm{S}-\mathrm{N})$ curves are used for the quasi-isotropic composite —one for tensile $(\mathrm{R}=0)$ cycling and one for fully-reversed $(\mathrm{R}=-1)$ cycling. The latter curve can be used with the Goodman relation for cycles having various mean stress levels. The stress parameter for the tensile-cycling curve is $S_{\max }$ : for the second curve the parameter is $S_{a}$, the alternating stress component. Both curves have a margin of 20 on cycles to failure and an additional multiplication reduction factor of 0.9 on stress to approximately account for the difference between average and minimum strengths. Tables of factors are provided to account for temperature and fluid effects.

Table 6.6 compares representative allowable cyclic stresses for the quasi-isotropic and $0 / 90^{\circ}$ crossply composites subjected to tensile $(\mathrm{R}=0)$ cycling. The quasi-isotropic composite is seen to be significantly less resistant to cycling than was the $0 / 90^{\circ}$ crossply composite (as judged by the strength drop between $10^{2}$ and $10^{8}$ cycles). It should be borne in mind, however, that while the

Table 6.6. Allowable maximum cyclic stresses for tensile cycling $(\mathbf{R}=\mathbf{0})$

\begin{tabular}{ccc}
\hline \multirow{2}{*}{$\begin{array}{c}\text { Temperature } \\
\left({ }^{\circ} \mathbf{C}\right)\end{array}$} & \multicolumn{2}{c}{ Maximum stress $(\mathbf{M P a})$} \\
\cline { 2 - 3 } $\mathbf{1 0}^{\mathbf{2}}$ cycles & $\mathbf{1 0}^{\mathbf{8}}$ cycles \\
\hline \multirow{3}{*}{ Quasi-isotropic } \\
120 & 267 & 157 \\
& 259 & 79 \\
23 & $\mathbf{0 / 9 0}^{\circ}$ crossply & \\
120 & 389 & 301 \\
& 311 & 211 \\
\hline
\end{tabular}


quasi-isotropic composite exhibits nearly identical behavior in all directions, the crossply composite is decidedly weaker when the load is oriented at off-angles to the fibers.

Bounding fluid effects multiplication factors for the two composites are tabulated in Table 6.7. The factors are about the same for the two materials.

Table 6.7. Bounding fluid multiplication factors for allowable cyclic stresses

\begin{tabular}{lcc}
\hline \multicolumn{1}{c}{ Composite } & $\mathbf{1 0}^{\mathbf{2}}$ cycles & $\mathbf{1 0}^{\mathbf{8}}$ cycles \\
\hline Quasi-isotropic & 0.92 & 0.98 \\
$0 / 90^{\circ}$ crossply & 0.93 & 0.97 \\
\hline
\end{tabular}

\subsection{SIMPLIFIED SUMMARY OF ALLOWABLE STRESSES}

As a way of further simplifying and summarizing the allowable design stresses for static and cyclic loadings, Table 6.8 gives the key allowable stress values for various conditions as a percentage of the average room-temperature UTS values-336 $\mathrm{MPa}$ for the quasi-isotropic composite and $477 \mathrm{MPa}$ for the $0 / 90^{\circ}$ crossply composite. As expected, the table shows that time, temperature, and cyclic loading had a greater negative effect on the quasi-isotropic composite allowables than on those of the $0 / 90^{\circ}$ crossply composite. The strength of the latter derives almost entirely from the axial fibers; in the quasi-isotropic composite, the $\pm 45^{\circ}$ plies also contribute, although to a lesser degree than the $0^{\circ}$ fibers, through an interaction with the matrix.

Table 6.8. Key allowable tensile stresses, expressed as a percentage of average room-temperature $\mathrm{UTS}^{a}$

\begin{tabular}{|c|c|c|c|c|}
\hline \multirow{2}{*}{ Stress allowable } & \multicolumn{2}{|c|}{ Without fluid effects } & \multicolumn{2}{|c|}{ With fluid effects $b$} \\
\hline & $23^{\circ} \mathrm{C}$ & $120^{\circ} \mathrm{C}$ & $23^{\circ} \mathrm{C}$ & $120^{\circ} \mathrm{C}$ \\
\hline \multicolumn{5}{|c|}{ Quasi-isotropic } \\
\hline $\mathrm{S}_{0}$ & 58 & 47 & 54 & 44 \\
\hline \multicolumn{5}{|l|}{$\mathrm{S}_{\mathrm{t}}$} \\
\hline $5000 \mathrm{~h}$ & 58 & 42 & 54 & 40 \\
\hline 15 years & 58 & $39^{c}$ & 54 & $36^{c}$ \\
\hline \multicolumn{5}{|l|}{$\mathrm{S}_{\max }(\mathrm{R}=0)$} \\
\hline $10^{2}$ cycles & 79 & 77 & 73 & 71 \\
\hline $10^{8}$ cycles & 47 & 24 & 46 & 23 \\
\hline \multicolumn{5}{|c|}{$0 / 90^{\circ}$ crossply } \\
\hline $\mathrm{S}_{0}$ & 56 & 45 & 53 & 44 \\
\hline \multicolumn{5}{|l|}{$\mathrm{S}_{\mathrm{t}}$} \\
\hline $5000 \mathrm{~h}$ & 56 & 45 & 53 & 44 \\
\hline 15 years & 56 & $45^{c}$ & 53 & $44^{c}$ \\
\hline \multicolumn{5}{|l|}{$\mathrm{S}_{\max }(\mathrm{R}=0)$} \\
\hline $10^{2}$ cycles & 82 & 65 & 76 & 60 \\
\hline $10^{8}$ cycles & 63 & 44 & 61 & 43 \\
\hline
\end{tabular}

${ }^{a}$ Quasi-isotropic $\mathrm{UTS}_{\mathrm{avg}}=336 \mathrm{MPa} ; 0 / 90^{\circ}$ crossply $\mathrm{UTS}_{\mathrm{avg}}=477 \mathrm{MPa}$.

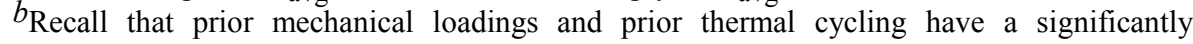
degrading effect on the UTS, and hence $\mathrm{S}_{0}$. These reductions are not included in these values.

${ }^{c}$ Unrealistic condition. 
A strain limit of 0.3 to $0.4 \%$ has often been used, at least for glass-fiber composites, for design of composite automotive structures. ${ }^{*}$ The strain limit is intended to cover all effects. For both the quasi-isotropic and $0 / 90^{\circ}$ crossply carbon-fiber composites, strain limits of 0.3 and $0.4 \%$ correspond to 29 and $39 \%$ of the average room-temperature UTS, respectively. Comparison of these stress levels with the allowable values in Table 6.8 shows that, for the quasi-isotropic composite, the limits would cover all the realistic conditions except for high-cycle fatigue at $120^{\circ} \mathrm{C}$. For the $0 / 90^{\circ}$ crossply, all conditions would be covered by the limits.

The strain limits are overly conservative in large regions of Table 6.8. The limits given in Part 1 of this report put the design allowables on a more rational and defensible basis, and they avoid the overconservatism and underconservatism associated with the simplified strain limit of approach.

\subsection{DAMAGE TOLERANCE EVALUATION}

For specific low-energy impacts such as roadway kickups, tool drops, and load drops in a pickup box, experimentally derived correlations are given for (1) estimating the damage area from the mass and velocity of the impacting object and (2) determining, from the estimated damage area, the resulting degradation in strength. While these correlations are clearly tied to the specific sizes and geometries of the impacted plate specimens and of the specimens used for mechanical property evaluations, it is thought that they do provide useful information. This is particularly true when comparing the relative response of two different composites.

Table 6.9 gives the predicted damage for four representative combinations of impactor mass and velocity and for both the quasi-isotropic and the $0 / 90^{\circ}$ crossply composites. Both sets of damage areas in Table 6.9 include surface ply delaminations, but these were much more prevalent in the crossply composite. Despite this fact, damage in the quasi-isotropic composite is more than twice that in the crossply. This is attributable to the quasi-isotropic composite being thinner than the crossply.

Table 6.9. Damage areas from design curve (Fig. 5.2)

\begin{tabular}{|c|c|c|c|}
\hline \multirow{2}{*}{$\begin{array}{l}\text { Mass } \\
(\mathrm{kg})\end{array}$} & \multirow{2}{*}{$\begin{array}{c}\text { Velocity } \\
(\mathrm{m} / \mathrm{s})\end{array}$} & \multicolumn{2}{|c|}{ Damage area $\left(\mathrm{mm}^{2}\right)$} \\
\hline & & Quasi-isotropic & $0 / 90^{\circ}$ crossply \\
\hline 11.52 & 0.8 & 168 & 72 \\
\hline 11.52 & 1.3 & 891 & 338 \\
\hline 0.0227 & 22.4 & 168 & 84 \\
\hline 0.0227 & 36.4 & 891 & 396 \\
\hline
\end{tabular}

In the quasi-isotropic composite, only compression-after-impact strength was determined. For the crossply composite, residual tensile strength was also measured; the loss in tensile strength was just slightly larger than the compressive strength loss. Table 6.10 gives comparative values of strength loss for both composites for two arbitrary damage areas. Because the specimens used to determine strength loss differed in width for the two composites, both sets of original values in the table were adjusted to those of an infinitely wide plate to make them more comparable. This was done using the approximate relation given by Eq. (5.1) for a circular hole (having the same area as the impact damage area).

\footnotetext{
*In the aerospace industry, fixed wing and rotorcraft composite structures have been successfully designed to operate at strains up to $0.4 \%{ }^{6}$
} 
Table 6.10. Estimated strength reduction ratios caused by impact damage

\begin{tabular}{|c|c|c|c|c|}
\hline \multirow{3}{*}{$\begin{array}{c}\text { Damage area } \\
\left(\mathrm{mm}^{2}\right)\end{array}$} & \multicolumn{4}{|c|}{ Strength reduction ratio } \\
\hline & \multicolumn{2}{|c|}{ Quasi-isotropic $^{a}$} & \multicolumn{2}{|c|}{$0 / 90^{\circ}$ crossply $b$} \\
\hline & $\begin{array}{l}\text { 76.2-mm } \\
\text { width }\end{array}$ & $\begin{array}{l}\text { Infinite } \\
\text { width }\end{array}$ & $\begin{array}{l}\text { 25.4-mm } \\
\text { width }\end{array}$ & $\begin{array}{l}\text { Infinite } \\
\text { width }\end{array}$ \\
\hline 50 & 0.68 & 0.69 & 0.60 & 0.68 \\
\hline 125 & 0.57 & 0.59 & 0.43 & 0.61 \\
\hline
\end{tabular}

$a_{\text {Compression. }}$

$b_{\text {Tension. }}$

When related to an infinitely wide plate, the strength reduction values are similar in the two composites. 
Part 2

BACKGROUND DATA AND MODELS 


\title{
7. BASIC TENSILE, COMPRESSIVE, AND SHEAR PROPERTIES
}

\author{
M. B. Ruggles-Wrenn
}

\subsection{TEST METHODS}

Basic properties were established from stiffness, tensile, compressive, and shear tests. Untabbed dogbone-shaped tensile specimens were used ${ }^{7}$ in all stiffness and tensile tests, which were performed according to the test method described in Ref. 7. Flat specimens with tabs were used in compression tests. ${ }^{7}$ The tab material was G-11 composite, an epoxy reinforced with woven fiberglass cloth. The adhesive used for bonding the tabs to the test specimens was Hysol's EA-93009NA for the $-40^{\circ} \mathrm{C}$ and $23^{\circ} \mathrm{C}$ tests and EA-9394 for the $120^{\circ} \mathrm{C}$ tests. Compression tests employed an IITRI fixture (Procedure B in ASTM D 3410 ${ }^{8}$ ). The test method was as described in Ref. 7. The V-notched beam (Iosipescu) shear specimens and shear test method were as described in Ref. 7. The tab material and adhesive used for bonding the tabs were the same as for the compression specimens. Poisson's ratio measurements were carried out using five specimens according to the test method described in Ref. 7. All tension and compression specimens were cut so that the surface fibers were at $90^{\circ}$ to the specimen axis, thus placing a weaker ply at the specimen surface. All shear specimens were cut so that the surface fibers were at $0^{\circ}$ to the specimen axis.

In addition to presenting baseline properties at room temperature, this chapter provides strength and stiffness properties for $-40,70$, and $120^{\circ} \mathrm{C}$. Multiplication factors for determining elastic constants and strength properties at different temperatures from room-temperature values are developed. Furthermore, effects of prior loading, thickness variations, strain rate, and thermal cycling on properties are discussed. Finally, fluid effects are considered, and fluid multiplication factors for exposures in distilled water and windshield washer fluid are presented.

\subsection{PROPERTIES VS TEMPERATURE}

In-air room-temperature tensile properties were established from 456 stiffness tests and 86 tensile tests on specimens from 19 different plaques. Compressive properties were based on 40 tests on specimens from 9 plaques, and shear properties were based on 6 Iosipescu shear tests on specimens from a single plaque. Baseline room-temperature properties are summarized in Table 7.1 with the corresponding percent coefficients of variation (COVs) given in parentheses.

Table 7.1. Average in-air room-temperature baseline properties

\begin{tabular}{lccc}
\hline \multicolumn{1}{c}{ Property } & Tension & Compression & Shear \\
\hline Modulus, GPa & $32.4(6.3)$ & $32.1(10.4)$ & $12.2(9.2)$ \\
Poisson's ratio & 0.31 & & \\
Strength, MPa & $336(8.7)$ & $225(9.6)$ & $226(6.2)$ \\
Failure strain, \% & $1.02(6.8)$ & $0.72(16.9)$ & $2.32^{a}(5.0)$ \\
\hline
\end{tabular}

$a_{\text {Engineering shear strain. }}$

Tensile and compressive strength and stiffness obtained for the quasi-isotropic (Q) composite are lower than those obtained for the crossply $(\mathrm{C})$ carbon-fiber composite when tested with the $0 / 90^{\circ}$ fiber orientation. For the $\mathrm{C}$ composite, the $0 / 90^{\circ}$ fiber orientation tensile stiffness 
and strength were $46.7 \mathrm{GPa}$ and $477 \mathrm{MPa}$; compressive stiffness and strength were $53.3 \mathrm{GPa}$ and $429 \mathrm{MPa}$. The failure strain in tension closely matches that of the crossply composite in the $0 / 90^{\circ}$ direction because both are limited by the carbon-fiber ductility. Failure strain in compression is also comparable to that for the $\mathrm{C}$ composite, $0 / 90^{\circ}$ case $(1.12 \%)$. Shear modulus is about one-half that obtained for the $\pm 45^{\circ}$ case $(24.2 \mathrm{GPa})$, while shear strength exceeds that obtained for either fiber orientation $\left(95.0 \mathrm{MPa}\right.$ for the $0 / 90^{\circ}$ and $191 \mathrm{MPa}$ for the $\left.\pm 45^{\circ}\right)$. Shear strain to failure is higher than that for the $\pm 45^{\circ}(0.88 \%)$ but considerably lower than that for the $0 / 90^{\circ}$ case $(11.9 \%)$.

Note that for the $\mathrm{C}$ composite (both fiber orientations) strength in compression is comparable to the UTS. However, compressive strength for the Q composite is only $67 \%$ of the UTS. The lower value of compressive strength is probably due to a significant decrease in specimen thickness compared to the materials studied previously. A thinner compression specimen is much more likely to fail in a buckling mode* at a lower stress.

The baseline properties were used to assess whether classical lamination theory (CLT), developed for laminates formed of plies reinforced by straight unidirectional fibers, can be used to determine the longitudinal modulus for the Q composite. Ply stiffnesses for the $0^{\circ}$ and $45^{\circ}$ layers were obtained from crossply data that are derived in Ref. 9 and updated in Sect. 12.3.1: $\mathrm{Q}_{11}=88.6 \mathrm{GPa}, \mathrm{Q}_{22}=2.1 \mathrm{GPa}, \mathrm{Q}_{12}=3.10 \mathrm{GPa}$, and $\mathrm{Q}_{66}=3.30 \mathrm{GPa}$. Using basic CLT to calculate stiffnesses of a quasi-isotropic laminate from ply stiffnesses and then calculating longitudinal modulus from laminate stiffnesses, we obtain $\mathrm{E}_{\text {calc }}=34.9 \mathrm{GPa}$, which compares reasonably well to the average experimental value of $32.4 \mathrm{GPa}$.

Tensile tests conducted at $-40,-10,23,50,70$, and $120^{\circ} \mathrm{C}$ were employed to quantify the effects of temperature. Six specimens were tested at each temperature. All specimens were cut from a single plaque (Q11). Compressive and shear tests were conducted at $-40,23,70$, and $120^{\circ} \mathrm{C}$. Six compression tests each were performed at 23 and $120^{\circ} \mathrm{C}$. Five compression tests each were carried out at -40 and at $70^{\circ} \mathrm{C}$. Six shear tests were performed at $23^{\circ} \mathrm{C}$ and five tests at each of the other temperatures. All compression and shear specimens were cut from plaque Q18. The average properties from the temperature dependence study are summarized in Table 7.2 with the corresponding COVs given in parentheses.

Table 7.2. Average properties from temperature dependence study

\begin{tabular}{ccccccc}
\hline \multirow{2}{*}{ Property } & \multicolumn{5}{c}{ Temperature } \\
\cline { 2 - 7 } & $-\mathbf{4 0}^{\circ} \mathbf{C}$ & $-\mathbf{1 0}^{\circ} \mathbf{C}$ & $\mathbf{2 3}^{\circ} \mathbf{C}$ & $\mathbf{5 0}^{\circ} \mathbf{C}$ & $\mathbf{7 0}^{\circ} \mathbf{C}$ & $\mathbf{1 2 0}^{\circ} \mathbf{C}$ \\
\hline Tension & & & & & \\
Modulus, GPa & $32.6(9.1)$ & $31.4(8.6)$ & $32.8(4.8)$ & $30.9(8.8)$ & $31.2(4.1)$ & $29.4(5.5)$ \\
Strength, MPa & $296(8.3)$ & $313(12.6)$ & $358(8.0)$ & $301(13.7)$ & $327(6.5)$ & $288(7.5)$ \\
Poisson's ratio & 0.31 & & 0.31 & & 0.32 & 0.34 \\
& & & & & \\
Compression & & $31.3(12.6)$ & & $30.0(1.4)$ & $26.8(10.1)$ \\
Modulus, GPa & $31.4(6.8)$ & & $221(7.2)$ & & $197(10.8)$ & $125(9.0)$ \\
Strength, MPa & $231(7.8)$ & & & & $11.9(1.7)$ & $11.0(2.4)$ \\
& & & $12.2(9.2)$ & & $192(5.7)$ & $132(4.2)$ \\
Shear & & & $226(6.2)$ & & \\
$\quad$ Modulus, GPa & $12.3(2.3)$ & & & & & \\
$\quad$ Strength, MPa & $247(7.2)$ & &
\end{tabular}

\footnotetext{
*Compression tests reported in Chap. 14 on specimens with antibuckling plates produced strengths much closer to the UTS.
} 
Typical stress-strain curves at different temperatures are shown in Fig. 7.1. Note that all stress-strain curves, particularly those at room temperature, exhibit a slight stiffening as the loading progresses. This phenomenon may be due to straightening of carbon fibers during the test.

Based on data in Table 7.2, percent changes from room-temperature values were calculated for each property and plotted as functions of temperature. As a result, correlations between percent changes in properties and temperature were developed. These correlations were specifically formulated to give $0 \%$ change at room temperature. Based on these correlations, properties at different temperatures and the corresponding multiplication factors were calculated. Correlations between multiplication factors and temperature were developed so that multiplication factors for any temperature within range can be established. Multiplication factors are presented in Table 7.3.

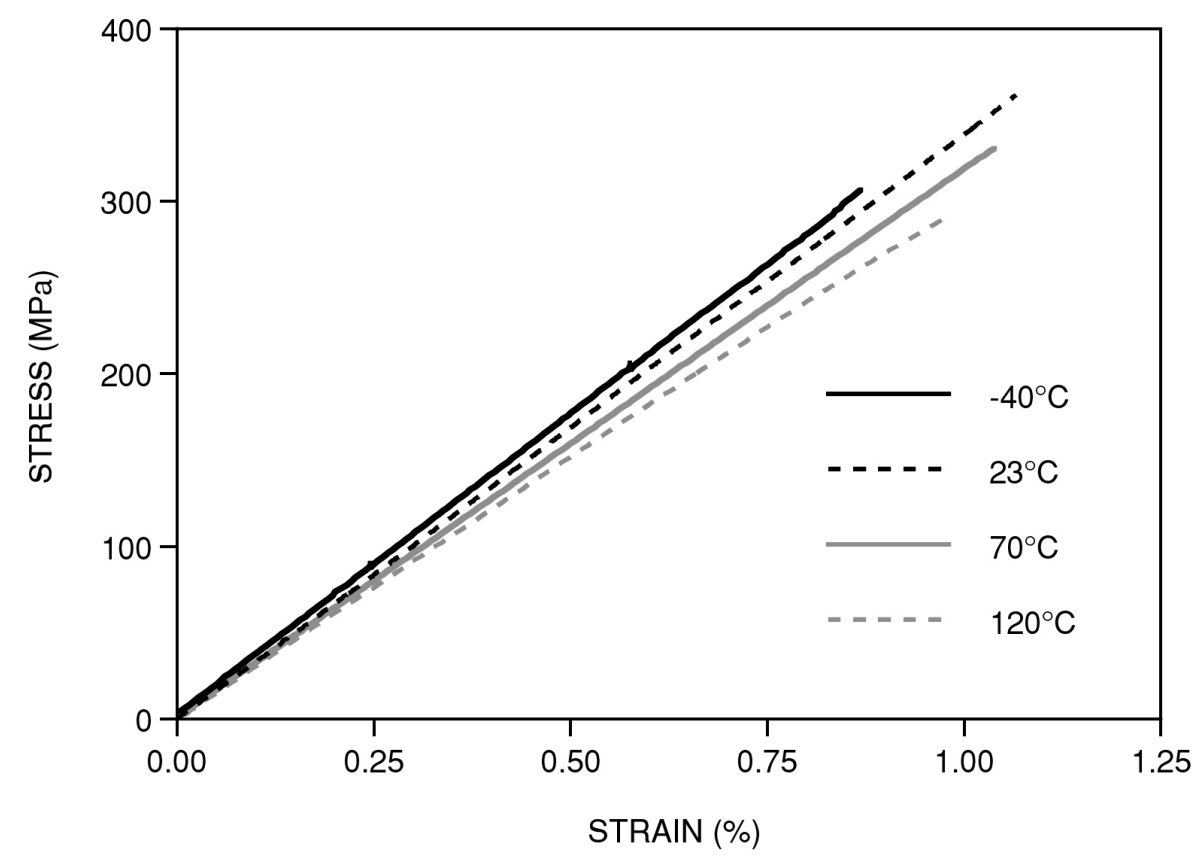

Fig. 7.1. Typical stress-strain curves.

Table 7.3. Temperature multiplication factors for determining at-temperature modulus and strength from room-temperature values

\begin{tabular}{lcccccc}
\hline \multirow{2}{*}{ Property } & \multicolumn{5}{c}{ Temperature } \\
\cline { 2 - 7 } & $\mathbf{- 4 0}^{\circ} \mathbf{C}$ & $\mathbf{- 1 0}^{\circ} \mathbf{C}$ & $\mathbf{2 3}^{\circ} \mathbf{C}$ & $\mathbf{5 0}^{\circ} \mathbf{C}$ & $\mathbf{7 0}^{\circ} \mathbf{C}$ & $\mathbf{1 2 0}^{\circ} \mathbf{C}$ \\
\hline Tension & & & & & & \\
Modulus & 1.04 & 1.02 & 1.00 & 0.98 & 0.96 & 0.92 \\
Strength & 0.87 & 0.96 & 1.00 & 0.99 & 0.97 & 0.81 \\
& & & & & & \\
Compression & & & 1.00 & & 0.95 & 0.85 \\
$\quad$ Modulus & 1.02 & & 1.00 & & 0.86 & 0.58 \\
Strength & 1.02 & & & & & \\
& & & & & 0.97 & 0.89 \\
Shear & 0.99 & & 1.00 & & 0.85 & 0.59 \\
Modulus & 1.06 & & 1.00 & & & \\
Strength & & & & & & \\
\hline
\end{tabular}


The multiplication factors are also plotted in Fig. 7.2. Tensile tests at $-10^{\circ} \mathrm{C}$ and at $50^{\circ} \mathrm{C}$ were added to better define the changes in properties with temperature, in particular, to confirm a decrease in tensile strength for temperatures below $23^{\circ} \mathrm{C}$. Thus, the shape of the temperature factor curve is well-defined for tensile strength. However, in the case of compression and shear, temperature factors are based on experimental results obtained at $-40,23,70$, and $120^{\circ} \mathrm{C}$ only.

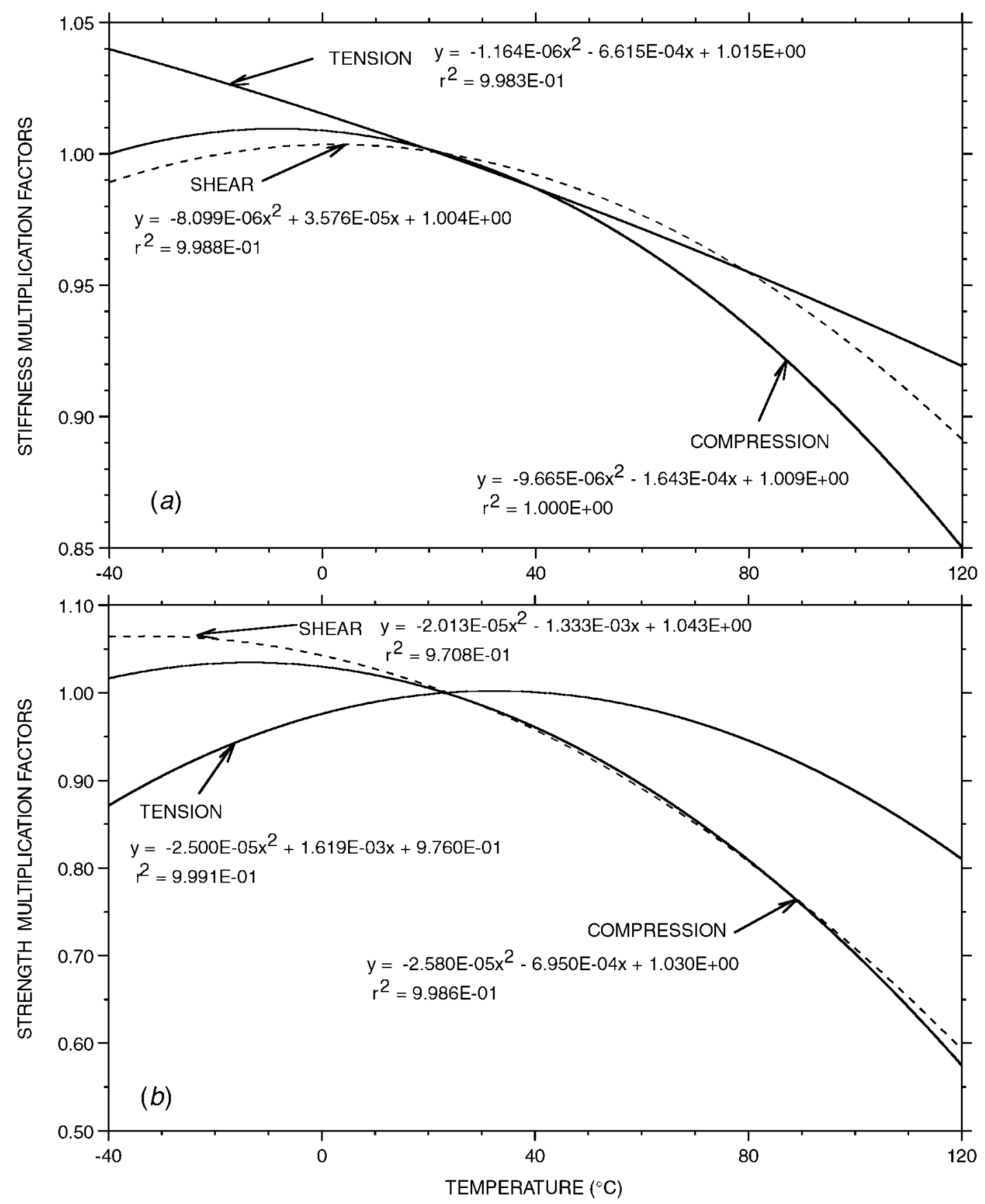

Fig. 7.2. Temperature multiplication factors for relating stiffness and strength to roomtemperature values: $(a)$ stiffness and $(b)$ strength. 
Therefore, the slightly arched shape of the temperature factor curves for compression and shear may be an artifact of the data fit. In the case of tension and compression, multiplication factors for temperatures above $23^{\circ} \mathrm{C}$ are similar to those obtained for the $\mathrm{C}$ composite, $0 / 90^{\circ}$ fiber orientation. Conversely, tensile strength for the $\mathrm{Q}$ composite decreases as the temperature drops below $23^{\circ} \mathrm{C}$. In the case of shear, the $\mathrm{Q}$ composite is considerably less temperature sensitive than was the $\mathrm{C}$ composite.

Finally, the temperature multiplication factors were applied to the baseline roomtemperature properties (Table 7.1) to obtain the at-temperature properties presented in Table 7.4. With the exception of Poisson's ratio, all properties in Table 7.4 were derived by multiplying the average room-temperature properties in Table 7.1 by the factors from Table 7.3. The Poisson's ratio values are averages from actual at-temperature tests of the same specimens as used to obtain the room-temperature values. Very low loads were used to ensure that damage was not introduced at each temperature.

The tensile modulus, E, shear modulus, G, and Poisson's ratio, $v$, in an isotropic material are related by the expression

$$
\mathrm{G}=\mathrm{E} / 2(1+v)
$$

Using this expression with the values of $\mathrm{E}$ and $v$ in Table 7.4, values of shear modulus, $\mathrm{G}$, were calculated for the different temperatures. Results, summarized in Table 7.5, show good agreement between calculated and experimental values of shear modulus for all temperatures considered.

Table 7.4. Baseline properties at different temperatures

\begin{tabular}{lcccccc}
\hline \multirow{2}{*}{ Property } & \multicolumn{5}{c}{ Temperature } \\
\cline { 2 - 7 } & $\mathbf{- 4 0}^{\circ} \mathbf{C}$ & $\mathbf{- 1 0}^{\circ} \mathbf{C}$ & $\mathbf{2 3}^{\circ} \mathbf{C}$ & $\mathbf{5 0}^{\circ} \mathbf{C}$ & $\mathbf{7 0}^{\circ} \mathbf{C}$ & $\mathbf{1 2 0}^{\circ} \mathbf{C}$ \\
\hline Tensile & & & & & & \\
Modulus, GPa & 33.7 & 33.0 & 32.4 & 31.8 & 31.1 & 29.8 \\
Poisson's ratio & 0.31 & & 0.31 & & 0.32 & 0.34 \\
Strength, MPa & 292 & 323 & 336 & 333 & 323 & 272 \\
& & & & & & \\
Compressive & & & & & & \\
Modulus, GPa & 32.7 & & 32.1 & & 30.5 & 27.3 \\
Strength, MPa & 230 & & 225 & & 194 & 131 \\
& & & & & & \\
Shear & & & 12.2 & & 11.8 & 10.9 \\
Modulus, GPa & 12.1 & & 226 & & 192 & 133 \\
Strength, MPa & 240 & &
\end{tabular}

Table 7.5. Calculated and measured shear moduli at different temperatures

\begin{tabular}{ccccc}
\hline Temperature $\left({ }^{\circ} \mathbf{C}\right)$ & $\boldsymbol{v}$ & $\mathbf{E}(\mathbf{G P a})$ & $\mathbf{G}_{\text {calc }}(\mathbf{G P a})$ & $\mathbf{G}_{\mathbf{e x p}}(\mathbf{G P a})$ \\
\hline-40 & 0.31 & 33.7 & 12.9 & 12.1 \\
23 & 0.31 & 32.4 & 12.4 & 12.2 \\
70 & 0.32 & 31.1 & 11.8 & 11.8 \\
120 & 0.34 & 29.8 & 11.1 & 10.9 \\
\hline
\end{tabular}




\subsection{EFFECT OF PRIOR LOADING ON STIFFNESS}

Subjecting a specimen to a short-time tensile load can cause microstructural damage that is subsequently reflected in a loss of residual stiffness. To quantify this effect, 16 specimens were subjected to sequentially increasing loadings followed by unloadings. Four specimens were each subjected to sequential loads of 20,40,60, and $80 \%$ of the UTS. After each target load was reached, the specimen was unloaded, and the stiffness was checked. Finally, each specimen was loaded to failure. Additional groups of four specimens were subjected to load sequences starting with 40,60 , and $80 \%$ of the UTS. Results are summarized in Fig. 7.3. Changes in stiffness were calculated with respect to the virgin stiffness of individual specimens.

As seen in Fig. 7.3, stiffness appears to be unaffected by prior loading history. Specimens subjected to sequential loads of $20,40,60$, and $80 \%$ and those loaded directly to $80 \%$ of the UTS exhibit similar stiffness loss. Stiffness loss was less than $1 \%$ in all tests except one, which produced a stiffness loss less than $1.3 \%$. Note that stiffness loss at the basic allowable stress level, $\mathrm{S}_{0}$, of $194 \mathrm{MPa}$ (see Sect. 3.1) is less than $1 \%$.

For the crossply carbon fiber composite, $0 / 90^{\circ}$ fiber orientation, all reductions in stiffness were less than $1 \%$. For the $\pm 45^{\circ}$ fiber orientation, the average stiffness loss corresponding to a maximum prior load of $80 \%$ of the UTS was $18.1 \%$. As stated above, each specimen in each group of four replicate tests was ultimately tested to failure. Comparison of the average UTS values from these groups with the average UTS produced by six virgin specimens from the same plaque provides insight into the effects of prior short-time loads on the UTS. These average values are presented in Table 7.6.

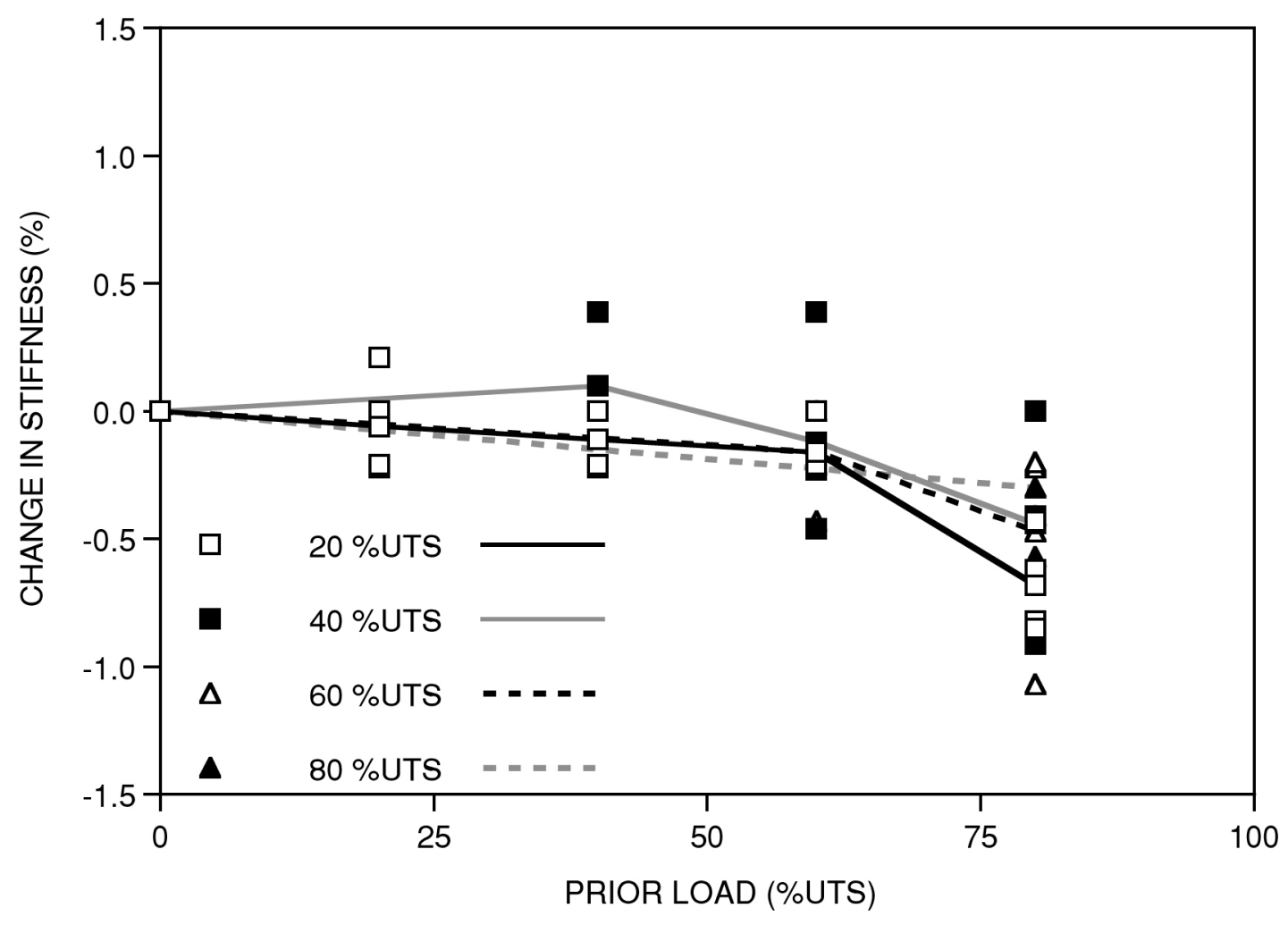

Fig. 7.3. Effect of prior short-time loads on stiffness. 
Table 7.6. Average UTS values from groups

of specimens subjected to prior

short-time static loads

\begin{tabular}{lc}
\hline $\begin{array}{c}\text { Prior loads } \\
(\% \text { UTS })\end{array}$ & $\begin{array}{c}\text { Average subsequent UTS } \\
\text { (MPa) }\end{array}$ \\
\hline 0 (virgin $^{a}$ & 358 \\
$20,40,60,80$ & 305 \\
$40,60,80$ & 314 \\
60,80 & 320 \\
80 & 336 \\
\hline \multicolumn{2}{c}{$a_{\text {Six reference tensile specimens were tested. }}$}
\end{tabular}

Results in Table 7.6, demonstrate that prior short-time static loads degrade the strength. Average UTS values drop considerably (15\%) for specimens subjected to prior loads. The reduction in strength appears to depend on prior history; UTS decreases as the number of loading/unloading segments increases. Specimens loaded directly to $80 \%$ of the UTS produced a strength closest to that of the virgin specimens. The lowest average UTS was produced by the group loaded to $20,40,60$, and $80 \%$ of the UTS. For the C composite, prior loadings resulted in higher UTS values than those of virgin specimens.

\subsection{EFFECT OF PLAQUE THICKNESS VARIATIONS}

Basic room-temperature tensile stiffness and strength information was evaluated together with plaque thickness data to establish correlations between tensile properties and plaque thickness. The relatively low COVs in Table 7.1 demonstrate that tensile stiffness and strength vary little. This observation agrees well with the fact that thickness variations within plaques were also relatively small. The thickness COV for the entire specimen population used in the stiffness tests was a low 3.7\%. The thickness COV for the specimens used in the reference tensile tests was $4.2 \%$. Stiffness and strength are plotted vs specimen thickness in Figs. 7.4 and 7.5, respectively. Both stiffness and strength decrease slightly, as expected, with increasing thickness.

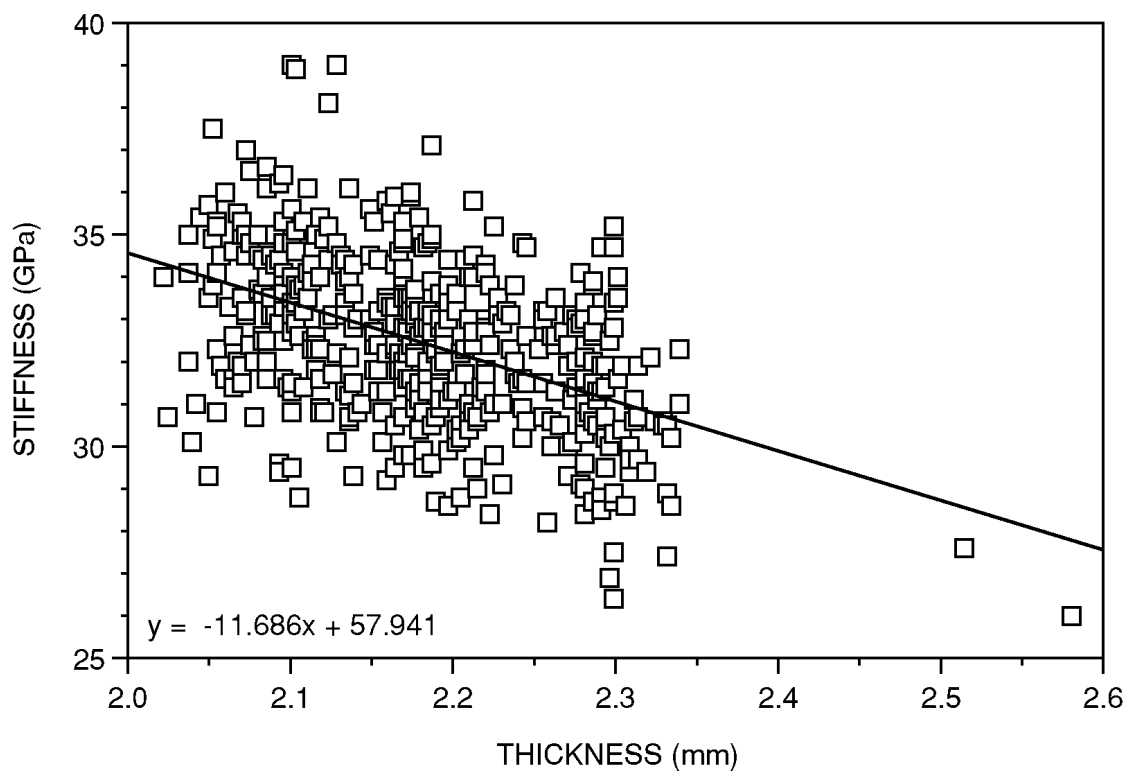

Fig. 7.4. Variation in stiffness with specimen thickness. 


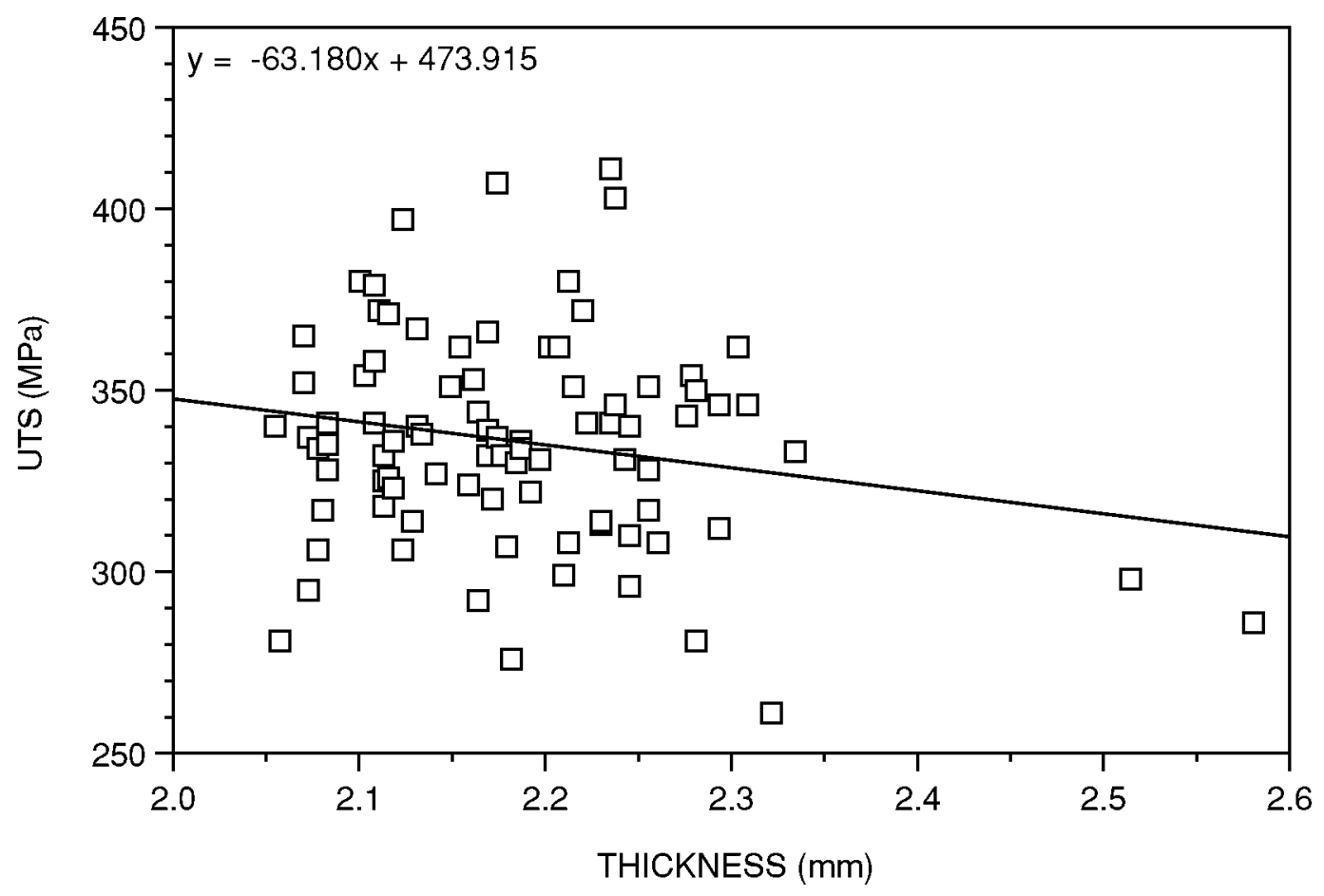

Fig. 7.5. Variation in tensile strength with specimen thickness.

For the crossply composite, tensile stiffness and strength also decreased linearly with increasing specimen thickness for both fiber orientations. Furthermore, for both fiber orientations, strength and stiffness were found to depend linearly on fiber volume content. The dependence was more pronounced for the $0 / 90^{\circ}$ fiber orientation properties.

\subsection{EFFECT OF STRAIN RATE ON TENSILE PROPERTIES}

The effect of strain rate on tensile behavior was investigated in 16 tests conducted at the following constant strain rates: $10^{-6}, 10^{-4}, 10^{-2}$, and $10 \mathrm{~s}^{-1}$. At these rates, the durations of the tensile tests varied from about $3 \mathrm{~h}$ to just a fraction of a second. Four tests were performed at each strain rate. Note that the displacement rate of $0.001 \mathrm{in} . / \mathrm{s}$ that was used in the baseline tensile tests is equivalent to an average strain rate of $10^{-4} \mathrm{~s}^{-1}$. Results are summarized in Figs. 7.6-7.8, where modulus, UTS, and failure strain, respectively, are plotted vs strain rate. Strain rate effects are seen to be relatively small except at the very fast rate. The variations of stiffness and strength with strain rate are small except at the strain rate of $10 \mathrm{~s}^{-1}$, where stiffness drops by $26 \%$. Failure strain appears to decrease continuously as rate increases, finally dropping by $14 \%$ at the strain rate of $10 \mathrm{~s}^{-1}$. Note that some time-dependent creep strains are present at the lowest strain rate. The effects of strain rate observed for the Q composite are similar to those reported for the crossply, $0 / 90^{\circ}$ fiber orientation, especially in the case of the UTS. 


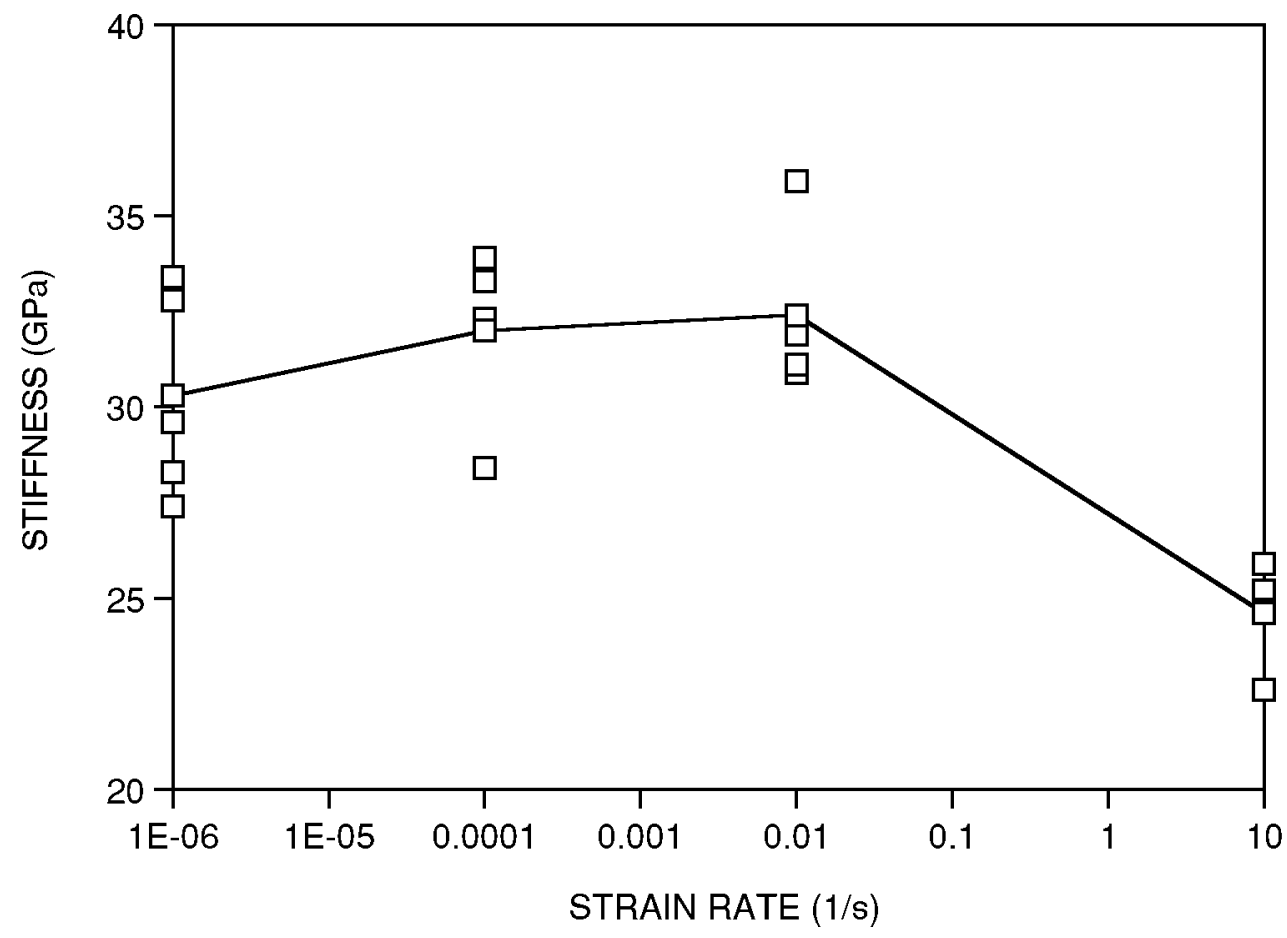

Fig. 7.6. Effect of strain rate on tensile stiffness.

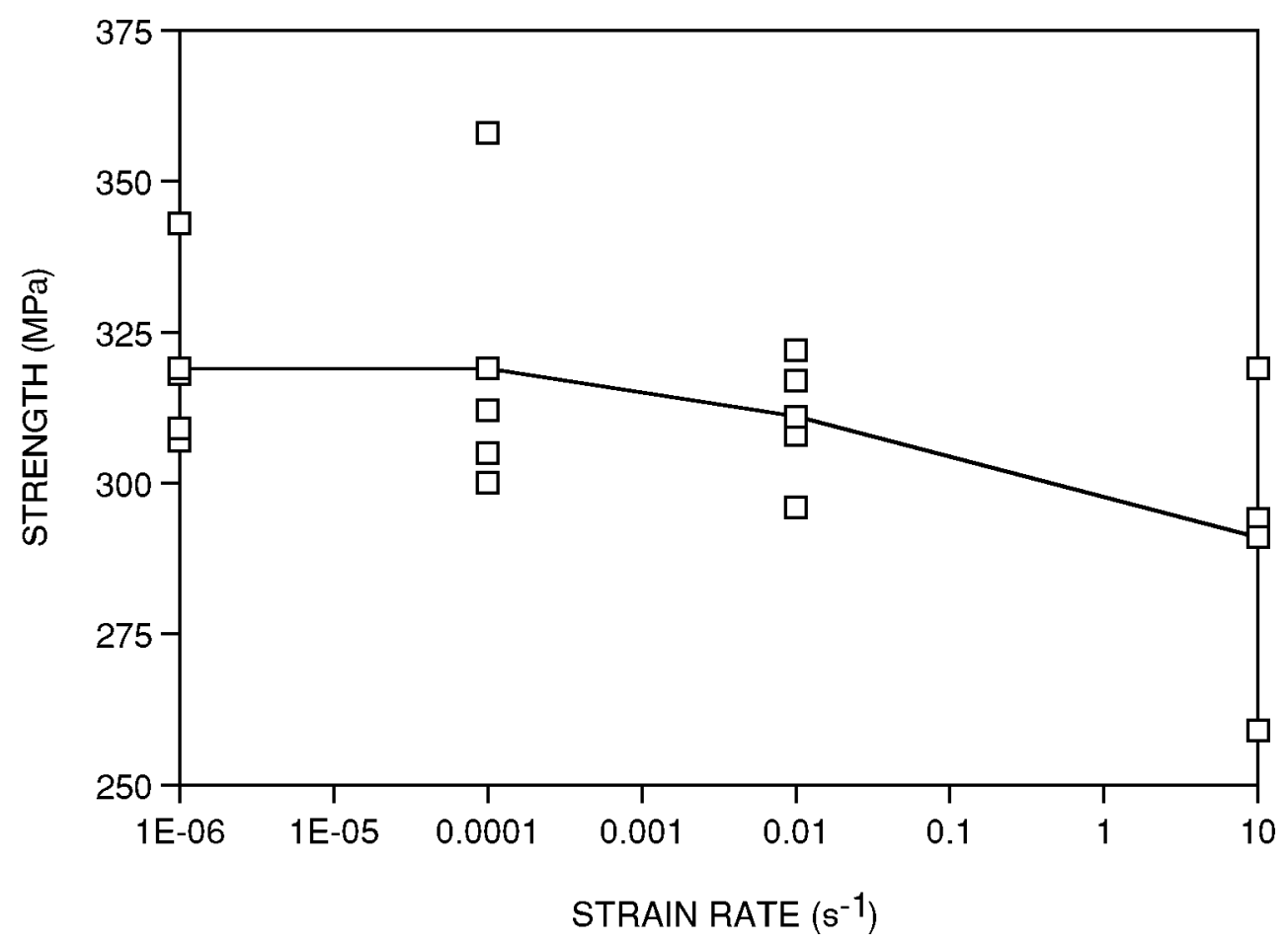

Fig. 7.7. Effect of strain rate on UTS. 


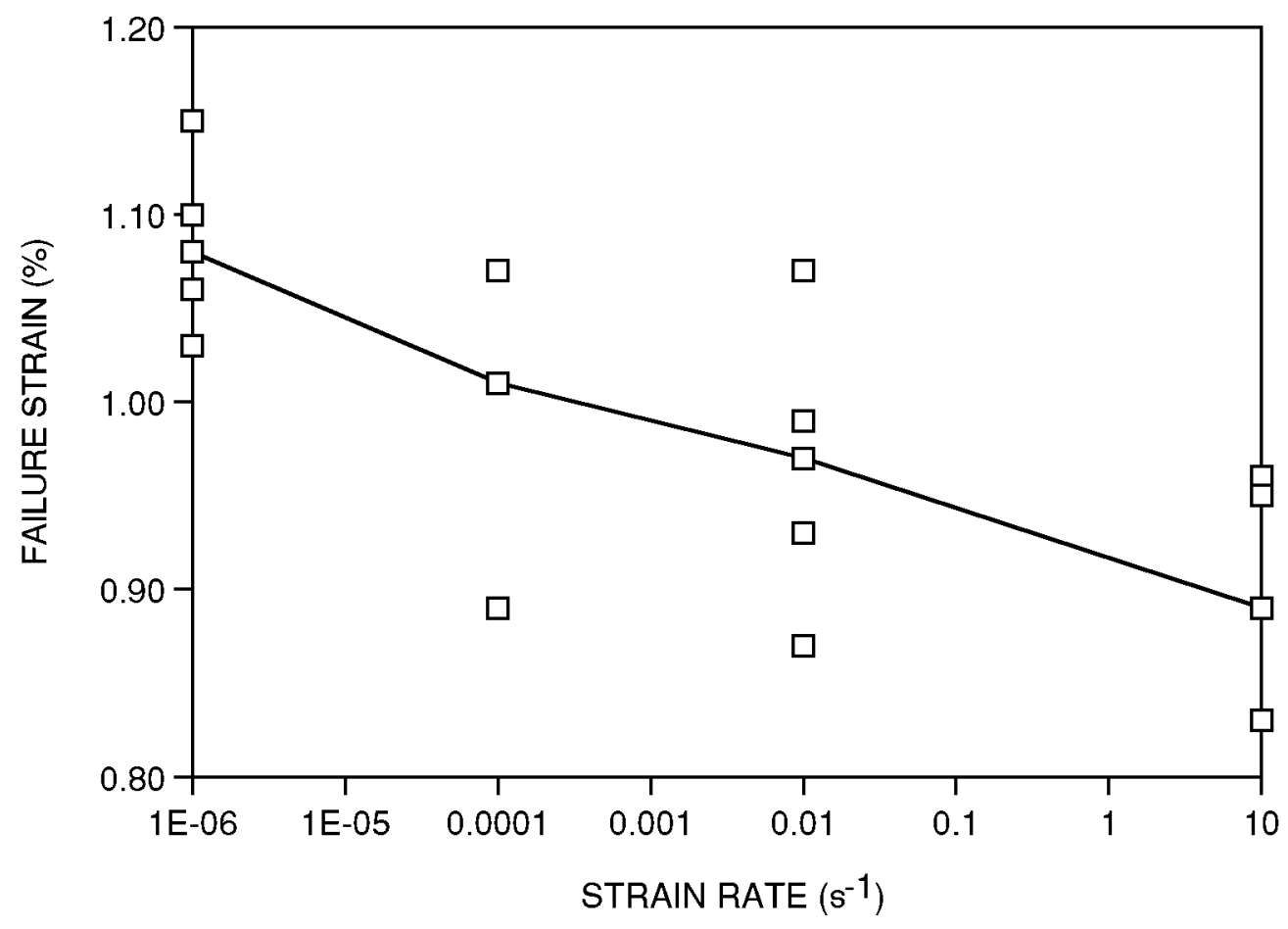

Fig. 7.8. Effect of strain rate on failure strain.

\subsection{EFFECT OF THERMAL CYCLING}

Thermal cycling is a concern because of the significant mismatch between the coefficient of thermal expansion (CTE) of the matrix and that of the fiber.* The mismatch could lead to microstructural damage under significant temperature changes.

The effects of thermal cycling were investigated in six tensile, four compressive, and four shear tests. Prior to testing, specimens were subjected to 26 thermal cycles. A thermal cycle between -40 and $120^{\circ} \mathrm{C}$, schematically shown in Fig. 7.9, was chosen to reflect the automotive design temperature range.

In tension, a stiffness loss of $0.3 \%$ and a strength loss of $6.6 \%$ were observed. In compression, the stiffness loss was $2.9 \%$, but strength improved by $19.7 \%$. Conversely, loss of shear stiffness was considerable (25.1\%), while shear strength dropped only by $3.4 \%$. It appears that thermal cycling has no significant effect on fiber-dominated properties. Note that the fairly considerable changes in compressive strength and shear stiffness are well founded. Both in the case of compressive strength and in the case shear stiffness, all test specimens produced consistent results, and data scatter was small. The same observation holds for the compression and shear reference specimens. Furthermore, all test specimens were well distributed throughout the plaque; none of the test groups came from a single specific location.

For the $0 / 90^{\circ}$ fiber orientation of the crossply composite, tensile and compressive properties were not significantly affected by thermal cycling. However, for the $\pm 45^{\circ}$ fiber orientation, tensile

\footnotetext{
${ }^{*}$ Unpublished ACC data indicate a CTE for Baydur 420 IMR neat resin of $79.8 \times 10^{-6} /{ }^{\circ} \mathrm{C}\left(30\right.$ to $\left.80^{\circ} \mathrm{C}\right)$. The handbook value for T300 carbon fiber is $-0.54 \times 10^{-6} /{ }^{\circ} \mathrm{C}$. ACC obtained an average value of $2.73 \times 10^{-6} /{ }^{\circ} \mathrm{C}$ for the quasi-isotropic carbon-fiber composite. ${ }^{10}$
} 


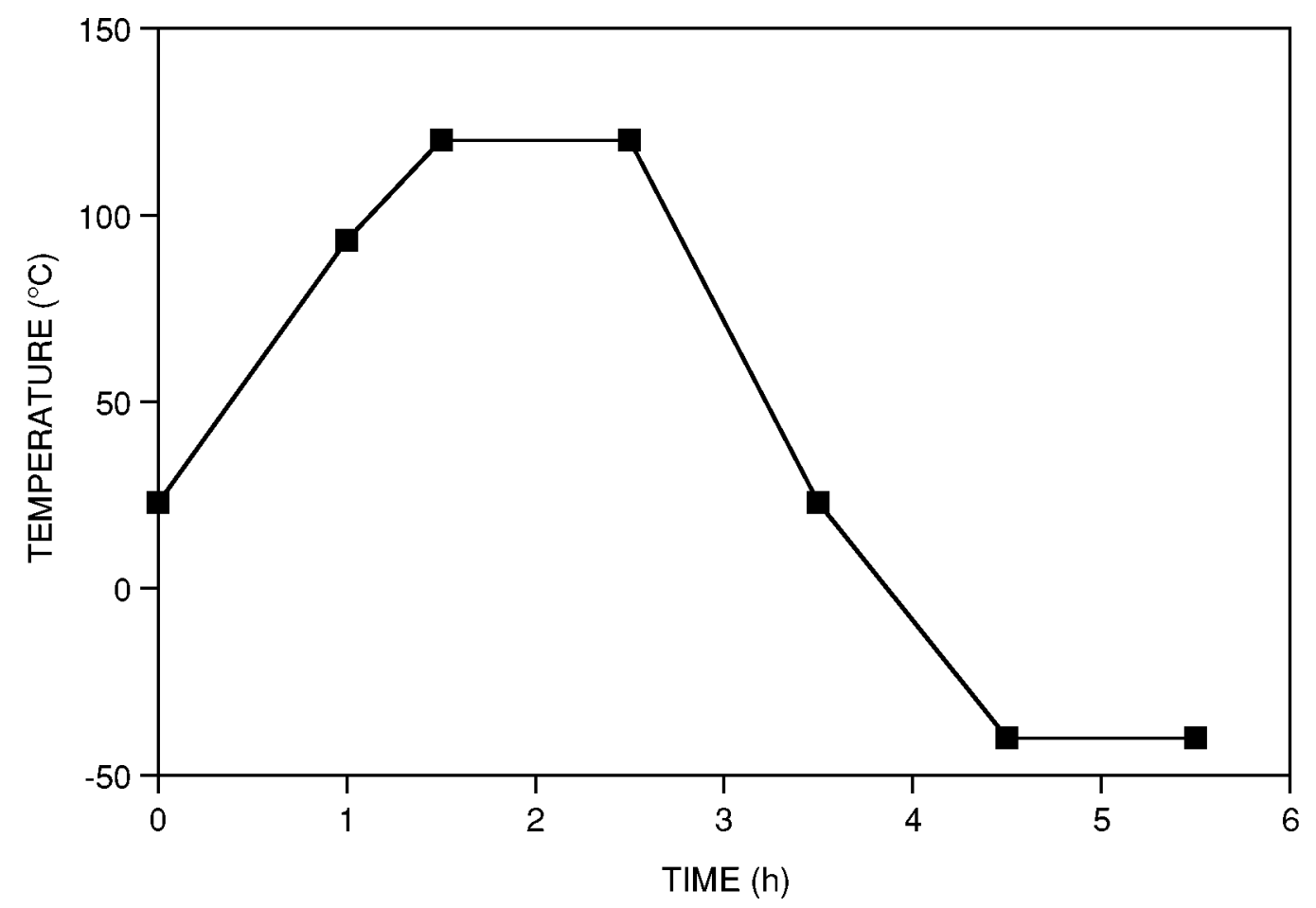

Fig. 7.9. Thermal cycle.

stiffness dropped by $15.5 \%$, and tensile strength improved by $1.8 \%$; while compressive stiffness dropped by $0.3 \%$ and compressive strength increased by $6.1 \%$.

\subsection{FLUID EFFECTS}

\subsubsection{Introduction}

From a durability standpoint, it is assumed that structures will be subjected to common vehicle fluids and operating atmospheres; therefore, design limits must take the resulting property degradation into account. The effects of a variety of fluids and moisture conditions were examined in the case of the glass-fiber composites and in screening tests on the carbon-fiber crossply composite. Based on the combined findings, the fluids most extensively examined were reduced primarily to distilled water and windshield washer fluid (a methanol/water mix). Exposure times of $1000 \mathrm{~h}$ for distilled water and of $100 \mathrm{~h}$ for the windshield washer fluid were judged to be representative of realistic service conditions. Furthermore, choosing standard exposures provides a direct comparison with previous materials in the durability study.

\subsubsection{Moisture Absorption}

Moisture absorption in the Q composite was investigated with the purpose of establishing correlations between exposure time and weight change, and subsequently with strength and stiffness. A broad range of exposure conditions was chosen to provide a better understanding of moisture effects. One group of specimens was exposed in $23^{\circ} \mathrm{C}$ distilled water. Another group was exposed in $70 \% \mathrm{RH}$ air. The $70 \% \mathrm{RH}$ condition is of particular interest because typical 
meteorological year data show that humidity averages about $70 \%$ for most of the year in most places in the United States. All specimens were kept in 40\% RH air for 1 week prior to exposure.

The study included exposure times of up to $4818 \mathrm{~h}$. Percent weight change as a function of the square root of exposure time is shown in Fig. 7.10. Weight change is calculated with reference to weight at the time of immersion. Note that for both types of exposure, the weight increases and reaches a maximum after about $3000 \mathrm{~h}$ of exposure, at which point the absorption process becomes saturated for both distilled water and 70\% RH. The curves in Fig. 7.10 suggest that absorption follows the classical Fick's diffusion relation. The saturation level for soaking in distilled water in Fig. 7.10 is somewhat higher than for the crossply composite, but that depends on the moisture content at test initiation.

Effects of exposure on tensile properties are summarized in Table 7.7, where the average values of percent change in strength and stiffness are given for different exposure times (each average is based on at least six specimens). The change in stiffness is calculated with reference to virgin stiffness of each individual specimen. The change in strength, however, is calculated with reference to the plaque average strength. Thus the somewhat greater percent changes in strength for the $70 \% \mathrm{RH}$ exposure may result from strength data scatter.

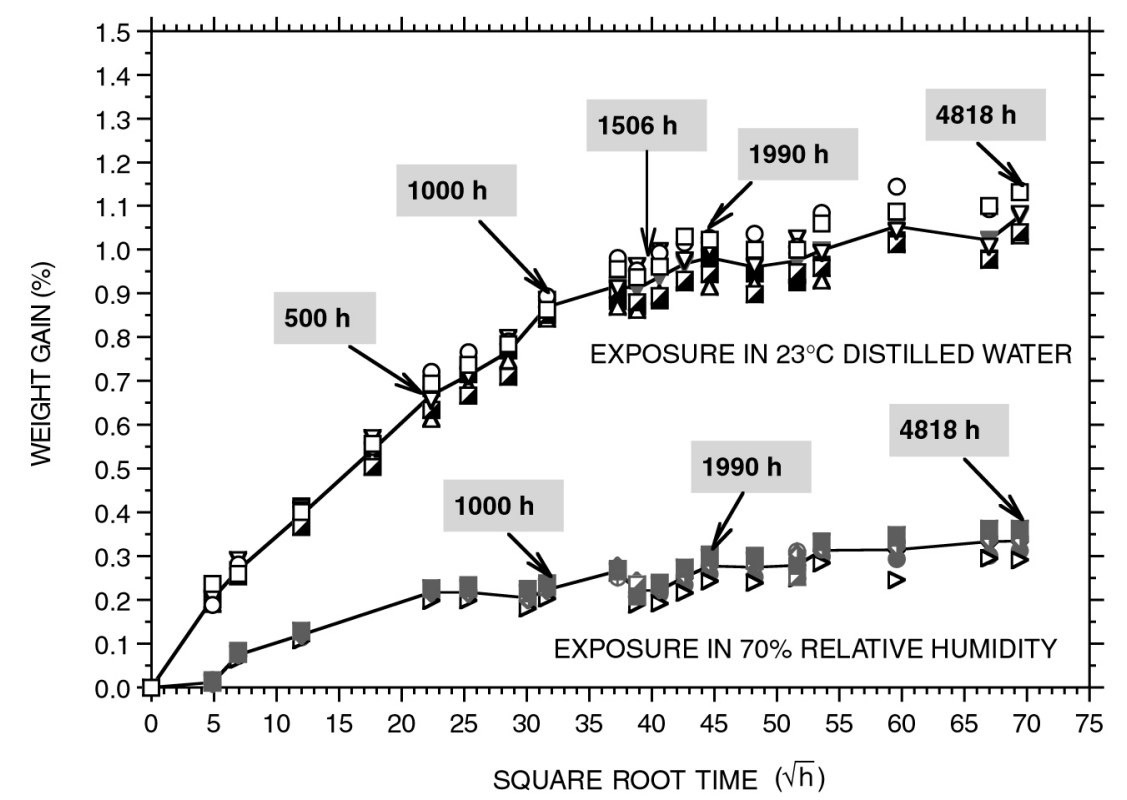

Fig. 7.10. Percent weight change due to exposure in room-temperature distilled water and in $70 \%$ RH air.

Table 7.7. Effects of exposure in $23^{\circ} \mathrm{C}$ distilled water and in $70 \% \mathrm{RH}$ air on tensile strength and stiffness

\begin{tabular}{cccccc}
\hline \multirow{2}{*}{$\begin{array}{c}\text { Exposure time } \\
\text { (h) }\end{array}$} & \multicolumn{2}{c}{ Change in stiffness (\%) } & & \multicolumn{2}{c}{ Change in strength (\%) } \\
\cline { 2 - 3 } \cline { 5 - 6 } & $\mathbf{2 3}^{\circ} \mathbf{C}$ distilled water & $\mathbf{7 0 \%} \mathbf{~} \mathbf{H}$ & & $\mathbf{2 3}^{\circ} \mathbf{C}$ distilled water & $\mathbf{7 0 \%} \mathbf{~ R H}$ \\
\hline 500 & 2.6 & & & -0.8 & \\
1000 & 1.4 & 0.8 & & 0.1 & -4.0 \\
1506 & 0.8 & -0.6 & & -0.5 & \\
1990 & 3.2 & 1.2 & & -3.3 & -5.7 \\
4818 & 0.1 & & & \\
\hline
\end{tabular}


Effects of moisture exposure on stiffness and strength are illustrated in Fig. 7.11. Shown in Fig. 7.11 is percent weight gain vs square root of exposure time with labels specifying property changes corresponding to different exposure times and percent weight changes. Note that property changes are small and somewhat scattered. Thus, it is important to select a bounding factor, which is done below for the standard exposures.

Note that for the $\mathrm{C}$ composite, moisture exposure appeared to be significantly more damaging. Following $1000 \mathrm{~h}$ of exposure in $23^{\circ} \mathrm{C}$ distilled water, stiffness loss was $6.1 \%$ and $4.1 \%$ for the $0 / 90^{\circ}$ and $\pm 45^{\circ}$ fiber orientations, respectively. Corresponding reductions in strength were $3.9 \%$ for the $0 / 90^{\circ}$ and $3.5 \%$ for the $\pm 45^{\circ}$ fiber orientations. Stiffness reductions for the 4241-h exposure were $7.6 \%\left(0 / 90^{\circ}\right)$ and $4.9 \%\left( \pm 45^{\circ}\right)$, while corresponding reductions in strength were $6.4 \%\left(0 / 90^{\circ}\right)$ and $8.3 \%\left( \pm 45^{\circ}\right)$. Results of exposure in $70 \% \mathrm{RH}$ air are more comparable for the two carbon fiber composites. The $\mathrm{C}$ composite, $0 / 90^{\circ}$ fiber orientation, exhibited only slight reductions in stiffness $(0.8 \%)$ and strength $(0.2 \%)$ following $3968 \mathrm{~h}$ of exposure. Reductions in stiffness and strength corresponding to $4271 \mathrm{~h}$ of exposure for the $\pm 45^{\circ}$ fiber orientation were $2.3 \%$ and $6.8 \%$, respectively.

Prolonged exposure in $23^{\circ} \mathrm{C}$ distilled water represents an important bounding condition, which was studied and evaluated to gain a better understanding of environmental material and property degradation. However, it should be recognized that the 4818-h exposure in roomtemperature distilled water hardly represents a typical service condition for an automotive composite. A 1000-h exposure is judged to be a more representative bounding moisture exposure likely to be encountered under normal operating conditions. Thus, here and throughout this report, a 1000-h exposure in room-temperature distilled water is chosen as the most representative bounding condition (standard exposure). However, note that the 1000-h exposure in distilled water does not bound tensile strength degradation due to prolonged exposure in $70 \% \mathrm{RH}$ air. This was addressed in Chap. 3.

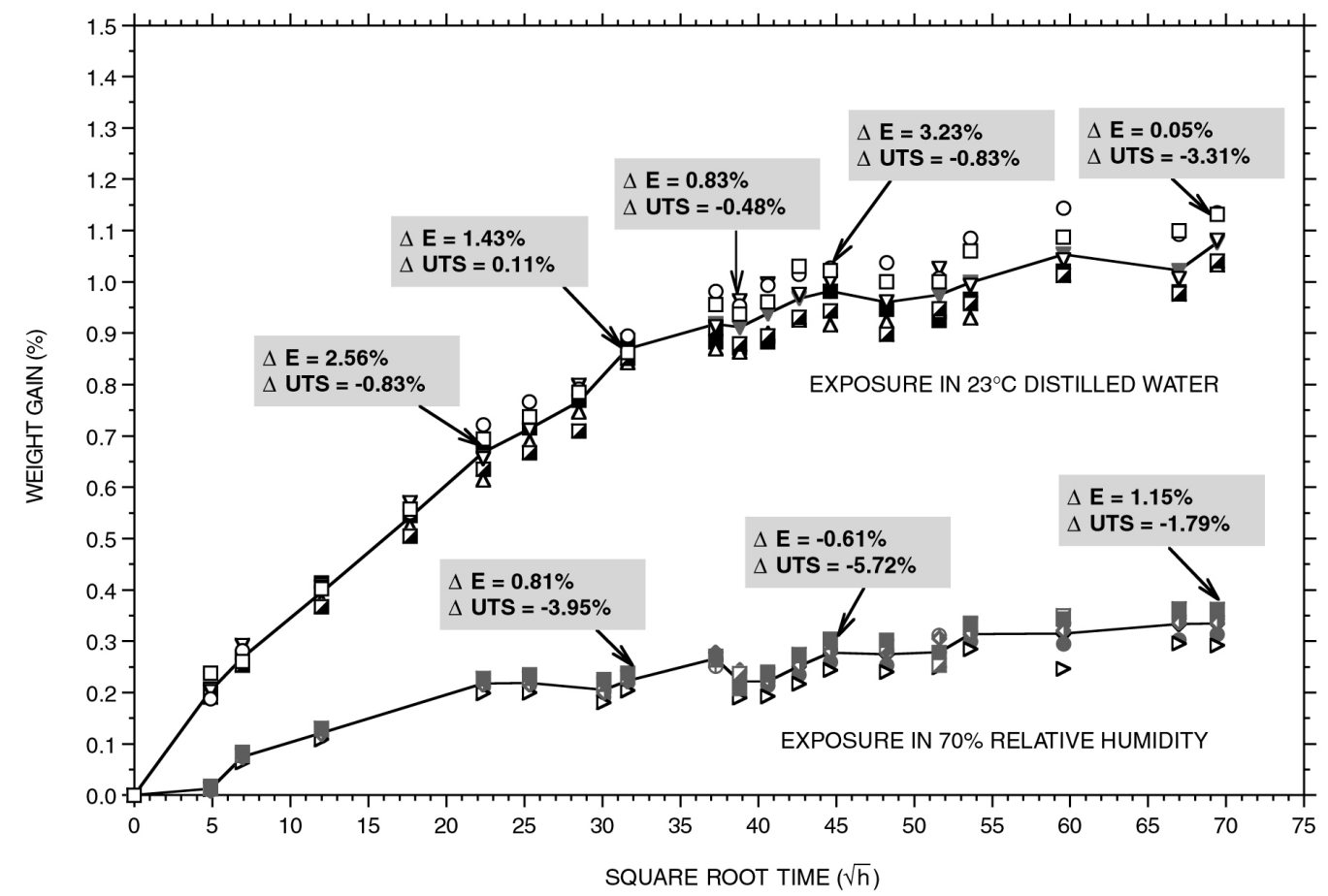

Fig. 7.11. Percent weight change due to exposure in room-temperature distilled water and in 70\% RH air, showing strength and stiffness losses corresponding to labeled times in Fig. 7.10. 


\subsubsection{Windshield Washer Fluid}

The effects of exposure in windshield washer fluid (30\% distilled water and $70 \%$ methanol) were investigated. Windshield washer fluid was selected as a practical exposure condition because methanol in windshield washer fluid is a "lighter molecule." Exposure time was $100 \mathrm{~h}$. Results are summarized in Table 7.8. All multiplication factors are based on a minimum of six tests.

Stiffness reductions were established with reference to the virgin stiffness for each specimen. Strength reductions were established relative to plaque average UTS values. Tensile stiffness shows little degradation. Likewise, strength is little affected for all loading types. The crossply carbon fiber composite appears to be slightly more sensitive to exposure in windshield washer fluid. For the crossply composite, $100 \mathrm{~h}$ in windshield washer fluid caused a stiffness loss of $0.8 \%$ and a strength loss of $2.3 \%$. Note that $100 \mathrm{~h}$ was chosen as the bounding condition (or standard exposure) for windshield washer fluid.

Table 7.8. Effects on stiffness and strength of 100-h exposure in windshield washer fluid

\begin{tabular}{lcccc}
\hline & $\begin{array}{c}\text { Change in } \\
\text { stiffness (\%) }\end{array}$ & $\begin{array}{c}\text { Stiffness } \\
\text { multiplication } \\
\text { factor }\end{array}$ & $\begin{array}{c}\text { Change in } \\
\text { strength (\%) }\end{array}$ & $\begin{array}{c}\text { Strength } \\
\text { multiplication } \\
\text { factor }\end{array}$ \\
\hline Tension & 0.7 & 1.01 & 0.5 & 1.01 \\
Compression & - & - & -1.8 & 0.98 \\
Shear & - & - & 0.7 & 1.01 \\
\hline
\end{tabular}

\subsubsection{Fluid Multiplication Factors for Standard Exposures}

Fluid multiplication factors for standard exposures in room-temperature distilled water $(1000 \mathrm{~h})$ and in windshield washer fluid $(100 \mathrm{~h})$ are summarized in Table 7.9.

Table 7.9. Fluid multiplication factors for standard exposures

\begin{tabular}{|c|c|c|}
\hline & $\begin{array}{c}\text { Stiffness multiplication } \\
\text { factor }\end{array}$ & $\begin{array}{c}\text { Strength multiplication } \\
\text { factor }\end{array}$ \\
\hline \multicolumn{3}{|c|}{$1000 \mathrm{~h}$ in distilled water } \\
\hline Tension & 1.01 & 1.00 \\
\hline Compression & 0.96 & 0.94 \\
\hline Shear & 0.99 & 0.98 \\
\hline \multicolumn{3}{|c|}{$100 \mathrm{~h}$ in windshield washer fluid } \\
\hline Tension & 1.01 & 1.01 \\
\hline Compression & - & 0.98 \\
\hline Shear & - & 1.01 \\
\hline
\end{tabular}

Note that the strength multiplication factor of 0.94 obtained for distilled water in compression can be used to represent the effects of the standard exposure in either fluid. Furthermore, the factor of 0.94 covers the largest strength reduction caused by exposure in $70 \%$ $\mathrm{RH}$. This multiplication factor is comparable to the multiplication factors of 0.92 and 0.93 used to bound standard exposures for the crossply composite, $0 / 90^{\circ}$ and $\pm 45^{\circ}$ fiber orientations, respectively. 


\subsection{SUMMARY}

Basic elastic constants and strength properties were summarized previously. Roomtemperature stiffness values in tension and compression are comparable. Room-temperature tensile strength is approximately 1.5 times compressive strength. The low compressive strength is most likely due to specimen geometry. Thin compressive specimens are likely to fail in a buckling mode at a lower stress. Compression specimens with antibuckling plates (see Chap. 14) produced strengths much closer to the UTS.

It was demonstrated that, using ply stiffnesses from crossply material data, Classical Lamination Theory predicts the tensile modulus for the Q composite reasonably well. Temperature factors for determining baseline properties at different temperatures from roomtemperature values were established. Furthermore, at all temperatures it was demonstrated that elastic modulus, shear modulus, and Poisson's ratio can be related using the established expression for isotropic homogeneous materials.

Effects of prior loads were investigated and found to have little effect on stiffness. Likewise strain rate effects are relatively small, except at the very fast rate. Stiffness and strength decrease with increasing plaque thickness, but the correlation is weak. Prior thermal cycling was found to have a significant effect on matrix-dominated properties.

The study of fluid effects revealed that the moisture absorption process reaches saturation at about $3000 \mathrm{~h}$ for both room-temperature distilled water and for $70 \% \mathrm{RH}$. A single reduction factor of 0.94 can be used to bound the effects of both standard exposures (1000 h in roomtemperature distilled water and $100 \mathrm{~h}$ in windshield washer fluid) on stiffness and strength. 


\title{
8. UNIAXIAL AND BIAXIAL FLEXURAL PROPERTIES
}

\author{
M. B. Ruggles-Wrenn, A. Ionita, ${ }^{*}$ and J. M. Corum
}

\subsection{INTRODUCTION}

Because it is almost impossible to avoid bending in composite structures, there is a need to explore flexural behavior experimentally. This chapter focuses primarily on (1) uniaxial flexural tests of simply supported beams and (2) biaxial flexural tests of simply supported circular plates. These tests produced bending strength data for various temperatures and fluid exposure conditions. They also produced approximate deflection data. A third group of uniaxial flexural tests — on cantilever beams — was performed explicitly to provide deflection data for assessing the predictability of bending deformations in the quasi-isotropic composite.

The next three sections of this chapter focus on uniaxial and biaxial flexural strength. Then there is a section that addresses just the predictability of bending deformations. Analysis methods examined range from the finite-element method (ABAQUS), incorporating (CLT), to simple beam bending and plate bending theory analyses that ignore the inhomogeneity and anisotropy of the composite material.

\subsection{UNIAXIAL FLEXURAL STRENGTH}

The uniaxial flexural strength tests were performed in accordance with the three-point bend test method specified in the American Society for Testing and Materials (ASTM) Standard D 790.1 (Ref. 11). The specimen used is depicted in Fig. 8.1( $a$ ). The overall specimen length was $76.2 \mathrm{~mm}$. The loading rollers had a radius of $4.4 \mathrm{~mm}$.

Seventy-two specimens were tested. All came from a single plaque, Q19. The UTS for this plaque was determined to be $346 \mathrm{MPa}$. Thirty-six specimens were cut so that the surface fibers were longitudinal (at an angle of $0^{\circ}$ relative to the beam axis). These are referred to as $\mathrm{L}$ beams. The other 36 beams were cut with transverse surface fibers, and they are consequently referred to $\mathrm{T}$ beams.

The strength values reported in this section are modulus of rupture (MOR) values. They are the maximum elastically calculated outer-fiber bending stress at rupture for an isotropic, homogeneous beam. As such, the values are somewhat qualitative, but they do provide for some comparison with similarly calculated elastic stresses from a preliminary design analysis, and they may be used to establish environmental and temperature multiplication factors.

The MOR values at $-40,23,70$, and $120^{\circ} \mathrm{C}$ were established based on 6 tests on $\mathrm{L}$ beams and 6 tests on $\mathrm{T}$ beams at each temperature (a total of 48 tests). Results are presented in Table 8.1.

The multiplication factors in the table give the MOR at each temperature in terms of the room-temperature MOR value. The values of the ratio of MOR to UTS are based on an average room-temperature UTS value of $346 \mathrm{MPa}$ for plaque Q19. The UTS values for other temperatures were obtained from the room-temperature value by using the temperature multiplication factor developed in Chap. 7.

Surprisingly, the $\mathrm{T}$ beams consistently produced a slightly higher MOR at a given temperature than did the L beams. At room temperature, the ratio of the MOR for L beams to the MOR for $\mathrm{T}$ beams is 0.95 . At $23^{\circ} \mathrm{C}$, the ratio of MOR to the UTS is 1.80 and 1.71 for the

\footnotetext{
*Department of Mechanical and Aerospace Engineering and Engineering Science, The University of Tennessee, Knoxville, and Metals and Ceramics Division, Oak Ridge National Laboratory.
} 

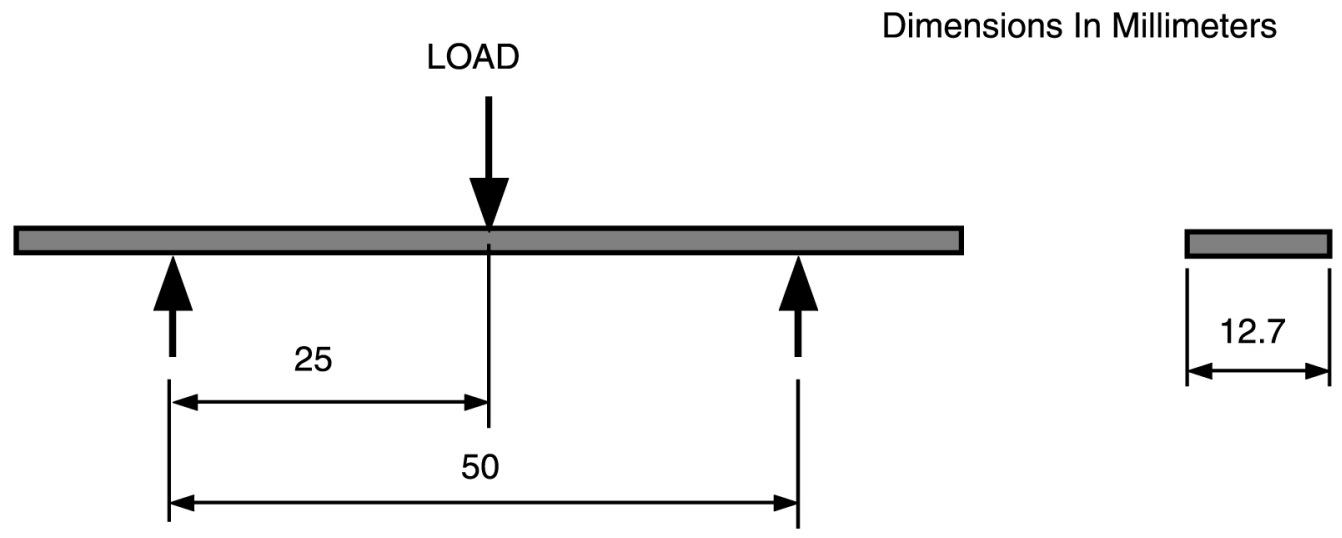

(a) SIMPLY-SUPPORTED BEAM
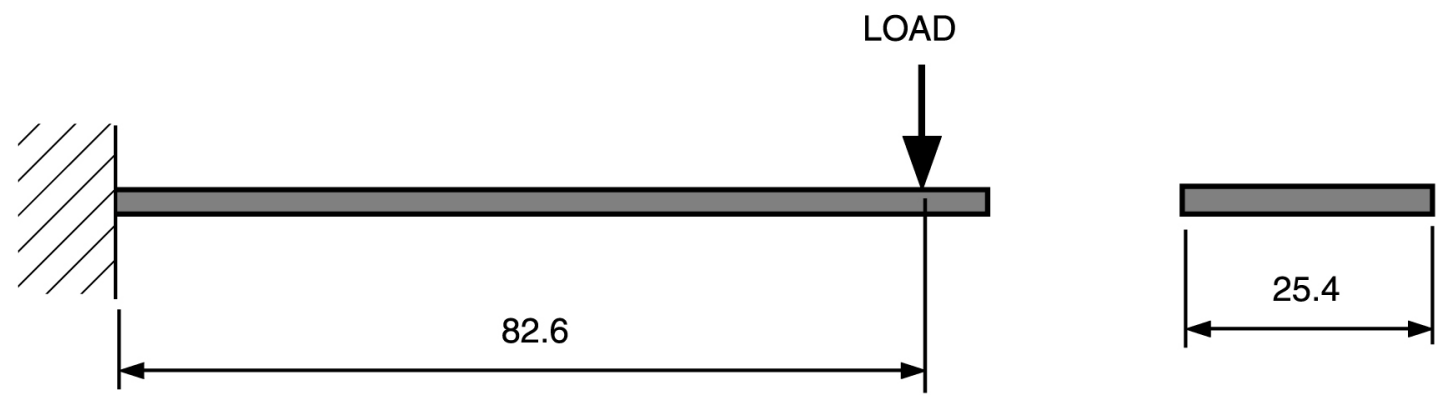

(b) CANTILEVER BEAM

Fig. 8.1. Uniaxial flexural specimens.

Table 8.1. Flexural strength at various temperatures

\begin{tabular}{|c|c|c|c|c|c|c|c|}
\hline \multirow[b]{2}{*}{$\begin{array}{c}\text { Temperature } \\
\left({ }^{\circ} \mathrm{C}\right)\end{array}$} & \multicolumn{3}{|c|}{ T beams } & \multicolumn{3}{|c|}{ L beams } & \multirow{2}{*}{$\begin{array}{c}\text { Ratio } \\
\text { of } \\
\text { L to T } \\
\text { MOR } \\
\end{array}$} \\
\hline & $\begin{array}{l}\text { MOR } \\
\text { (MPa) }\end{array}$ & $\begin{array}{c}\text { MOR } \\
\text { multiplication } \\
\text { factor }\end{array}$ & $\begin{array}{c}\text { Ratio of } \\
\text { MOR } \\
\text { to UTS } \\
\end{array}$ & $\begin{array}{l}\text { MOR } \\
\text { (MPa) }\end{array}$ & $\begin{array}{c}\text { MOR } \\
\text { multiplication } \\
\text { factor } \\
\end{array}$ & $\begin{array}{l}\text { Ratio of } \\
\text { MOR to } \\
\text { UTS } \\
\end{array}$ & \\
\hline-40 & 615 & 0.99 & 2.04 & 597 & 1.01 & 1.98 & 0.97 \\
\hline 23 & 622 & 1.00 & 1.80 & 591 & 1.00 & 1.71 & 0.95 \\
\hline 70 & 533 & 0.86 & 1.59 & 433 & 0.73 & 1.29 & 0.81 \\
\hline 120 & 317 & 0.51 & 1.13 & 261 & 0.44 & 0.93 & 0.82 \\
\hline
\end{tabular}

$\mathrm{T}$ beams and the $\mathrm{L}$ beams, respectively. However, at $120^{\circ} \mathrm{C}$, the load-carrying capacity in bending is only 1.13 and 0.93 times that indicated by the UTS for the T beams and L beams, respectively. For the crossply composite, $0 / 90^{\circ}$ fiber orientation, the ratio of the MOR to the UTS was 1.7 at $23^{\circ} \mathrm{C}$ and 1.2 at $120^{\circ} \mathrm{C}$. 
The effects of fluids on flexural properties were assessed using the standard exposures in windshield washer fluid and room-temperature distilled water. For each standard exposure, six $\mathrm{L}$ beams and six $\mathrm{T}$ beams were tested. The resulting fluid strength-multiplication factors are presented in Table 8.2 together with the corresponding fluid strength-multiplication factors from Chap. 7 for tension and compression.

The results in Table 8.2 demonstrate that a single multiplication factor of 0.93 may be used to represent the effects of $1000 \mathrm{~h}$ in distilled water or $100 \mathrm{~h}$ in windshield washer fluid on uniaxial flexural strength. For the crossply composite as well, a single environmental multiplication factor $\left(0.96\right.$ for the $0 / 90^{\circ}$ fiber orientation and 0.97 for the $\pm 45^{\circ}$ fiber orientation) was found to represent the effects of the standard exposures on flexure.

Table 8.2. Fluid effects on flexural properties

\begin{tabular}{lcccc}
\hline \multicolumn{1}{c}{ Environment } & $\begin{array}{c}\text { MOR } \\
\text { (MPa) }\end{array}$ & $\begin{array}{c}\text { MOR } \\
\text { multiplication } \\
\text { factor }\end{array}$ & $\begin{array}{c}\text { Tensile strength } \\
\text { multiplication } \\
\text { factor }\end{array}$ & $\begin{array}{c}\text { Compressive } \\
\text { strength } \\
\text { multiplication factor }\end{array}$ \\
\hline T beams & & & & \\
$\quad \begin{array}{l}\text { 1000 h in distilled water } \\
\text { 100 h in windshield washer fluid }\end{array}$ & 592 & 0.95 & 1.00 & 0.94 \\
L beams & 631 & 1.01 & 1.01 & 0.98 \\
$\quad \begin{array}{l}1000 \mathrm{~h} \text { in distilled water } \\
100 \mathrm{~h} \text { in windshield washer fluid }\end{array}$ & 552 & 0.93 & 1.00 & 0.94 \\
\hline
\end{tabular}

\subsection{BIAXIAL FLEXURAL STRENGTH}

The test specimen and support and loading arrangement used for biaxial flexural tests is depicted in Fig. 8.2. The circular specimen had an outside diameter of $94 \mathrm{~mm}$. The support-ring diameter was $88.9 \mathrm{~mm}$, while the load-ring diameter was $38.1 \mathrm{~mm}$.

Determination of the stresses in the circular specimen is complicated both by the fact that the specimen is an anisotropic composite and that geometric nonlinearities occur during loading.* The original concept of this test was based on the fact that for a homogeneous, isotropic specimen, classical small-deflection plate bending theory predicts that the bending stresses are everywhere equibiaxial over the area inside the load ring. Here, no attempt was made to use predicted stresses at failure because the distribution of these stresses is complicated. Rather, the failure load is reported and used to determine temperature and fluid multiplication factors for biaxial flexure.

Six "as-received" specimens were tested at room temperature. In addition, six tests were performed at $120^{\circ} \mathrm{C}$. To explore fluid effects, six specimens presoaked for $100 \mathrm{~h}$ in windshield washer fluid and six specimens presoaked for $1000 \mathrm{~h}$ in room-temperature distilled water were also tested. All tests were conducted in a laboratory air environment. The results are summarized in Table 8.3, where the multiplication factors are the ratios of the average failure load, for each set of tests, to the average for the as-received room-temperature tests.

The maximum load produced at room temperature in air was somewhat lower than that for the crossply composite $(12,380 \mathrm{~N})$. However, the multiplication factors in Table 8.3 follow the same trend as those obtained for the crossply composite, with the lowest multiplication factor corresponding to $120^{\circ} \mathrm{C}(0.55$ for the crossply composite $)$.

\footnotetext{
*This topic is discussed further in Sect. 8.5, where the results of a geometrically nonlinear ABAQUS CLT analysis are presented.
} 


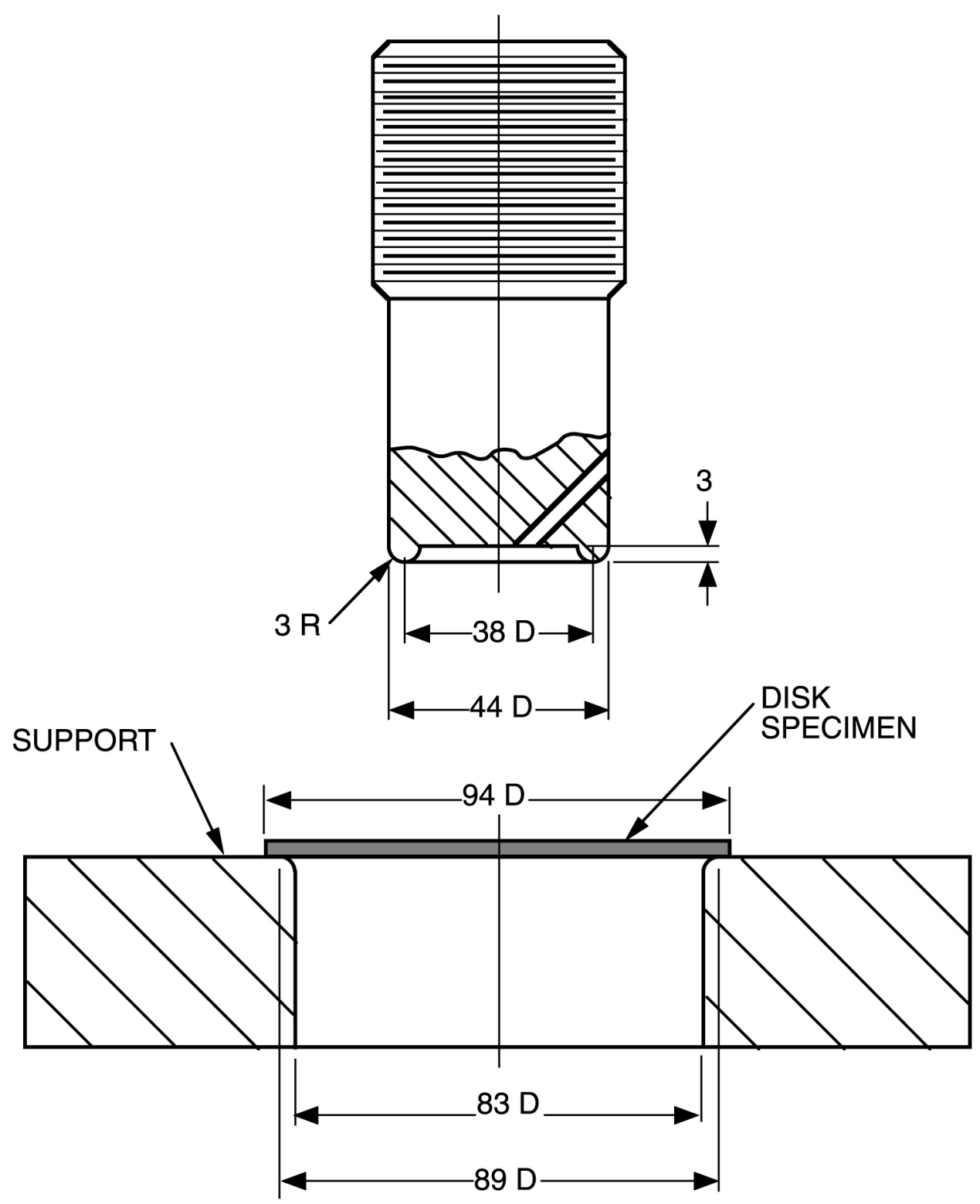

Fig. 8.2. Test arrangement for biaxial flexural tests. Dimensions are in millimeters.

Table 8.3. Biaxial flexural strength results

\begin{tabular}{lccc}
\hline \multicolumn{1}{c}{ Specimen and test condition } & $\begin{array}{c}\text { Maximum } \\
\text { load (N) }\end{array}$ & COV (\%) & $\begin{array}{c}\text { Multiplication } \\
\text { factor }\end{array}$ \\
\hline As received, room temperature & 9740 & 4.2 & 1.00 \\
As received, $120^{\circ} \mathrm{C}$ & 4317 & 10.0 & 0.44 \\
100-h presoak in windshield washer & 9016 & 5.2 & 0.93 \\
$\begin{array}{l}\text { fluid } \\
\text { 1000-h presoak in distilled water }\end{array}$ & 9588 & 4.2 & 0.98 \\
\hline
\end{tabular}




\subsection{COMPARISON OF STRENGTH MULTIPLICATION FACTORS}

Strength multiplication factors obtained in the biaxial flexural tests are compared with those obtained under various other stress states in Table 8.4. At $120^{\circ} \mathrm{C}$, the biaxial flexural strength multiplication factor of 0.44 compares well with the uniaxial flexural strength multiplication factor of 0.44 for the L beams. In the case of the 1000-h distilled water soak, the biaxial flexural strength multiplication factor of 0.93 again compares well with the factor of 0.93 for the L beams. In the case of a 100-h exposure in windshield washer fluid, the biaxial flexural strength reduction factor of 0.98 compares fairly well with that for the uniaxial flexure, $\mathrm{T}$ beams (1.01). The corresponding strength multiplication factor for the L beams, however, is a lower 0.93. It is further seen that the fluid effects are fairly small for all states of stress considered, with multiplication factors ranging from 0.93 to 1.01 . For the crossply composite, environmental strength multiplication factors ranged from 0.92 (produced in compression on specimens presoaked for $100 \mathrm{~h}$ in windshield washer fluid) to 0.99 .

Table 8.4. Strength reduction factors relative to in-air room-temperature values

\begin{tabular}{lccc}
\hline \multirow{2}{*}{ Stress state } & \multicolumn{3}{c}{ Test condition } \\
\cline { 2 - 4 } & $\begin{array}{c}\mathbf{1 0 0 0} \mathbf{h} \text { in distilled } \\
\text { water }\end{array}$ & $\begin{array}{c}\mathbf{1 0 0} \mathbf{h} \text { in windshield } \\
\text { washer fluid }\end{array}$ & $\mathbf{1 2 0}^{\circ} \mathbf{C}$ \\
\hline Tension & 1.00 & 1.01 & 0.81 \\
Compression & 0.94 & 0.98 & 0.58 \\
Shear & 0.98 & 1.01 & 0.59 \\
Biaxial flexure & 0.93 & 0.98 & 0.44 \\
Uniaxial flexure, T beams & 0.95 & 1.01 & 0.51 \\
Uniaxial flexure, L beams & 0.93 & 0.93 & 0.44 \\
\hline
\end{tabular}

Results in Table 8.4 demonstrate that at $120^{\circ} \mathrm{C}$ the governing temperature multiplication factor corresponds to flexure. For the crossply carbon-fiber composite, both fiber orientations, the shear multiplication factor was the governing parameter.

\subsection{PREDICTABILITY OF BENDING DEFORMATIONS}

\subsubsection{Uniaxial Flexure}

While the quasi-isotropic composite is isotropic in the plane (for membrane stress states), it is anisotropic for bending stress states. The more plies a quasi-isotropic composite has, the smaller the bending anisotropy. The question of predictability of bending deformations arose relative to the design analysis guidance given in Chap. 2. Are bending deformations predicted well by CLT? How well do predictions of simple isotropic, homogeneous beam-bending theory match measured deformations?

To answer these questions, the deflections of the simply supported beams tested at room temperature, as well as of cantilever beams tested at room temperature, were predicted by several types of analyses, and the results were compared with the measured values. The cantilever beam test arrangement, which emphasized accurate loading deflection measurements, is depicted in Fig. 8.1(b) and Fig. 8.3. Six cantilever beams with longitudinal surface fibers, and six with transverse surface fibers, were tested. All of the beams came from plaque Q1, and the virgin in-plane stiffness for each was measured prior to the bend test. 


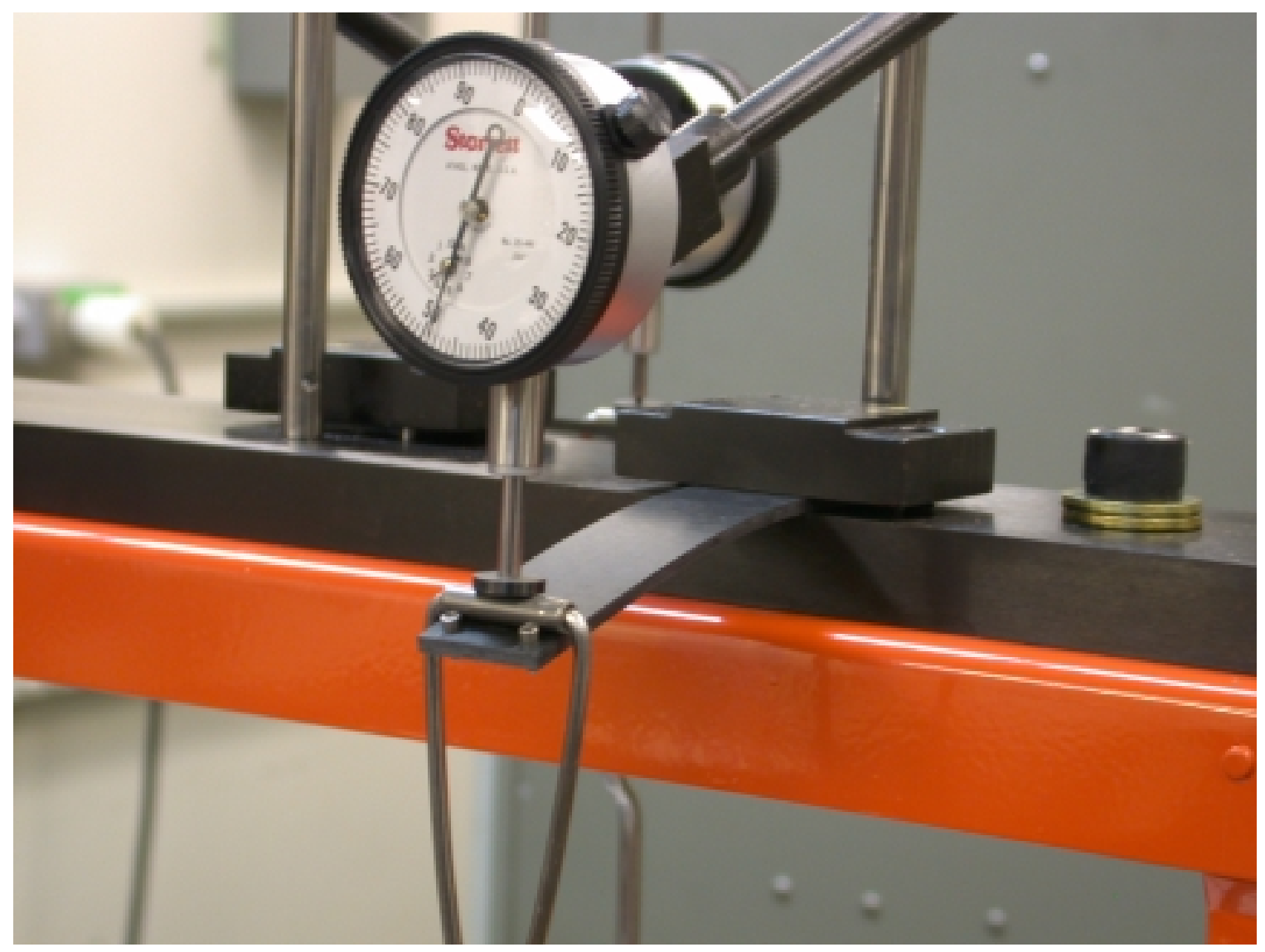

Fig. 8.3. Cantilever beam test arrangement.

Four analyses were performed on each individual beam:

1. a finite-element analysis (using the ABAQUS computer program) based on plate elements with transverse shear and incorporating CLT,

2. beam theory with shear and incorporating CLT,

3. classical isotropic, homogeneous beam-bending theory (without shear), and

4. classical isotropic, homogeneous cylindrical-bending plate theory, which accounts for the fact that the beam is wide by substituting $\mathrm{E} /\left(1-v^{2}\right)$ for the stiffness, $\mathrm{E}$, in beam theory ( $v$ is Poisson's ratio).

The measured deflections, in both types of beams, were essentially linear with load. Thus, elastic analyses suffice. In the CLT-based analyses, the CLT stiffnesses $\mathrm{Q}_{\mathrm{ij}}$, were taken from Ref. 9, but they were adjusted, up or down, by the ratio of the measured modulus of elasticity of the specimen to the in-plane modulus of elasticity from Ref. 9. For the simply supported beams, the specimen value was taken as the average plaque Q19 stiffness. For the cantilever beams, the virgin stiffness of each individual beam was used.

The predictions are compared with measured results in Figs. 8.4 and 8.5 for the simply supported beams and cantilever beams, respectively. Each individual test and the corresponding predictions are shown to convey an idea of trends and scatter. As expected, the deflection of beams with transverse surface fibers is larger than that of those with longitudinal surface fibers.

In an attempt to draw some conclusions from Figs. 8.4 and 8.5, the results are averaged and compared in Table 8.5. The deflection of beams with transverse surface fibers appears to be more 

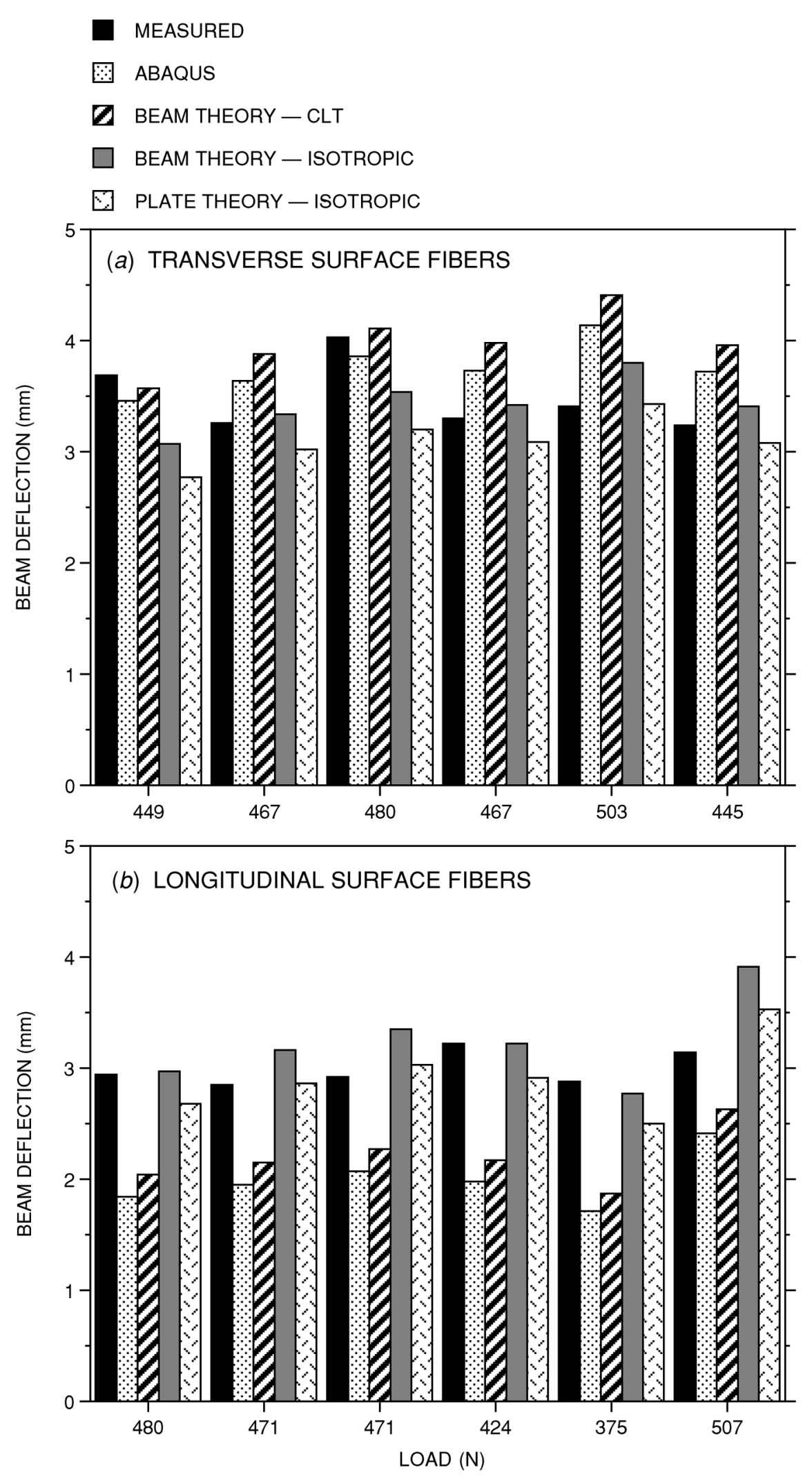

Fig. 8.4. Measured and predicted center deflection in simply supported beams: $(a)$ with transverse surface fibers and $(b)$ with longitudinal surface fibers. 

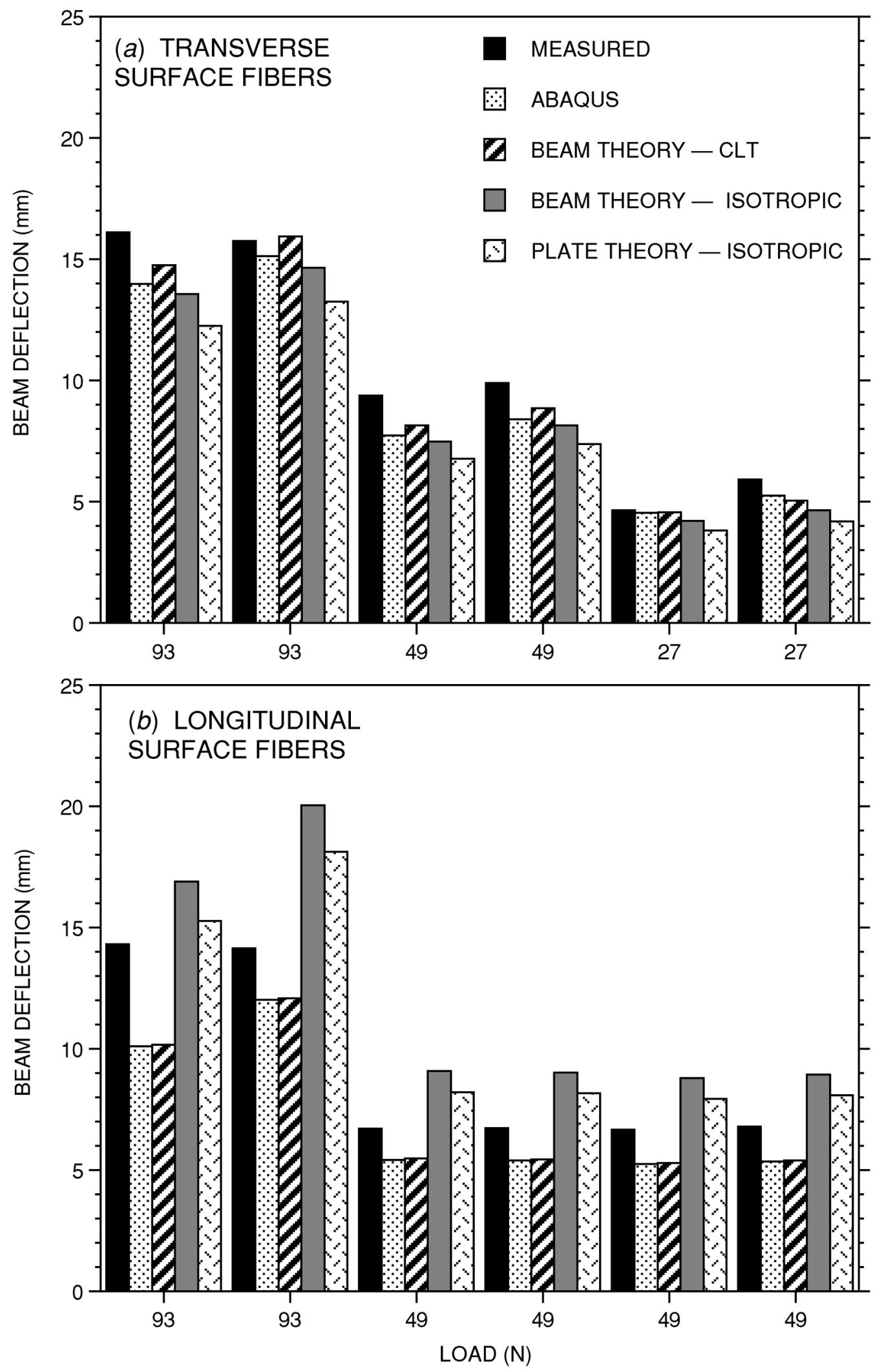

Fig. 8.5. Measured and predicted beam deflection at load in cantilever beams: (a) with transverse surface fibers and $(b)$ with longitudinal surface fibers. 
Table 8.5. Comparison of average measured and predicted beam deflections for each test type, surface-fiber orientation, and load

\begin{tabular}{|c|c|c|c|c|}
\hline \multirow{2}{*}{ Orientation/load } & \multicolumn{4}{|c|}{ Predictions, over/under (\%) } \\
\hline & Beam/CLT & ABAQUS/CLT & Beam & Plate \\
\hline \multicolumn{5}{|c|}{ 3-point beam } \\
\hline Transverse (6) & 16.3 & 8.9 & 0 & 8.9 \\
\hline Longitudinal (6) & -27.3 & $\begin{array}{c}-33.7 \\
\text { Cantilever beam }\end{array}$ & 7.3 & -3.0 \\
\hline Transverse & & & & \\
\hline $21 \mathrm{~N}(2)$ & -3.6 & -8.7 & -11.4 & -19.9 \\
\hline $11 \mathrm{~N}(2)$ & -11.7 & -16.3 & -18.9 & -26.7 \\
\hline $6 \mathrm{~N}(2)$ & -9.1 & -7.4 & -16.3 & -24.4 \\
\hline \multicolumn{5}{|l|}{ Longitudinal } \\
\hline $21 \mathrm{~N}(2)$ & -21.8 & -22.3 & 29.8 & 17.3 \\
\hline $11 \mathrm{~N}(4)$ & -19.8 & -20.4 & 33.3 & 20.5 \\
\hline
\end{tabular}

$a_{\text {Number of test results in average. }}$

predictable than that of beams with longitudinal surface fibers. Overall, the predictions of the more rigorous analyses based on CLT do not appear to be any more accurate than those of simple isotropic, homogeneous beam-bending theory based only on in-plane properties ( $\mathrm{E}$ and $\mathrm{v})$. The latter would probably be adequate for predicting bending deflections for preliminary design purposes. For complex structures, the finite-element method would appear to do equally well.

\subsubsection{Biaxial Flexure}

The load deflection response of the circular disks quickly became nonlinear as the load was increased. A geometrically nonlinear ABAQUS finite-element analysis with CLT was thus performed on the disks. Because the disks were from plaque Q19, the same as the simply supported beams, the average $\mathrm{Q}_{\mathrm{ij}}$ coefficients used for the beams were used for the plate analysis. The result of the analysis is plotted in Fig. 8.6, where it is compared with the measured deflections from the six room-temperature plate tests. The agreement is reasonably good.

The dashed line in Fig. 8.6 is a linear prediction based on simple isotropic, homogeneous plate-bending theory. It appears to agree fairly well with the initial slope of the measured results. This illustrates once again that, in the absence of nonlinearities, simple isotropic, homogeneous plate theory (and probably shell theory) can provide acceptable estimates of bending deformations.

Figure 8.7 shows the predicted principal stress contours in the bottom ply of the disk (on the side opposite the load). The surface-ply fibers run horizontally in these plots. The highest predicted stress, located on the horizontal axis opposite the 38.1-mm-diam load ring, is $1337 \mathrm{MPa}$, which is several times higher than the measured uniaxial UTS of $346 \mathrm{MPa}$ for plaque Q19 and higher than the MOR of $591 \mathrm{MPa}$ calculated from the L beam results. This is consistent with expectations. The MOR and the bending stress denoted by Q in Chap. 3 of Part 1 are calculated from resultant moments as if stress varied linearly across the thickness. 


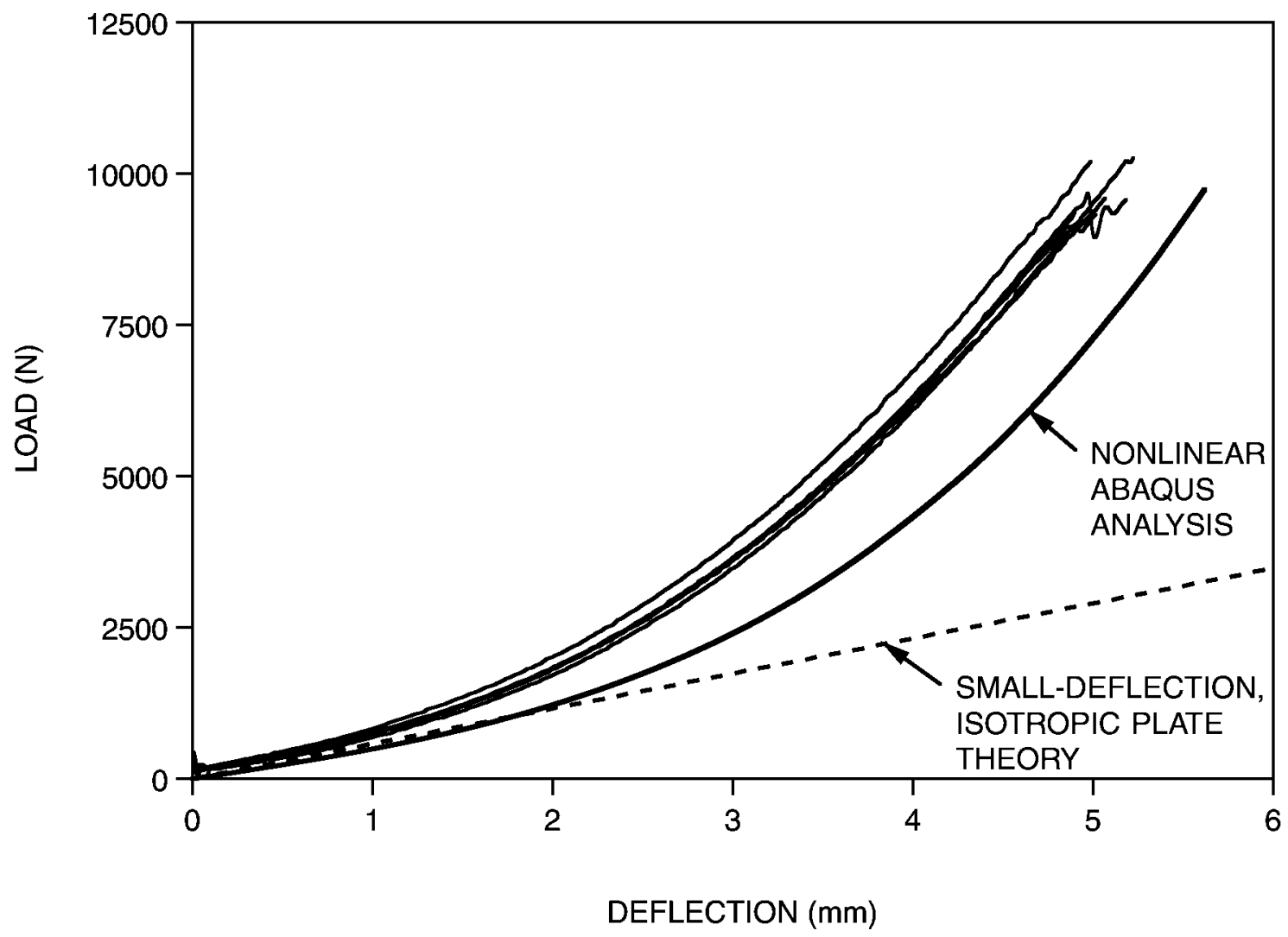

Fig. 8.6. Comparison of measured and predicted biaxial flexure specimen deflections. The deflections shown are at the 38.1-mm-diam load ring. 


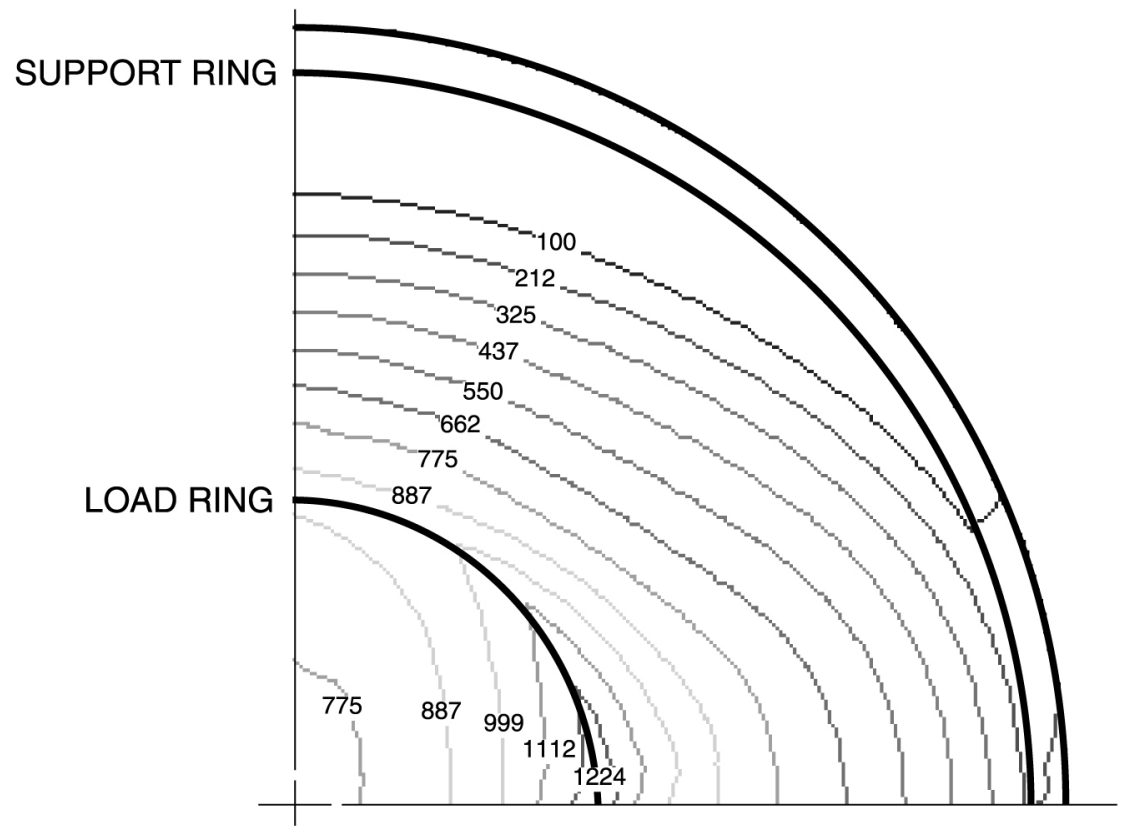

(a)

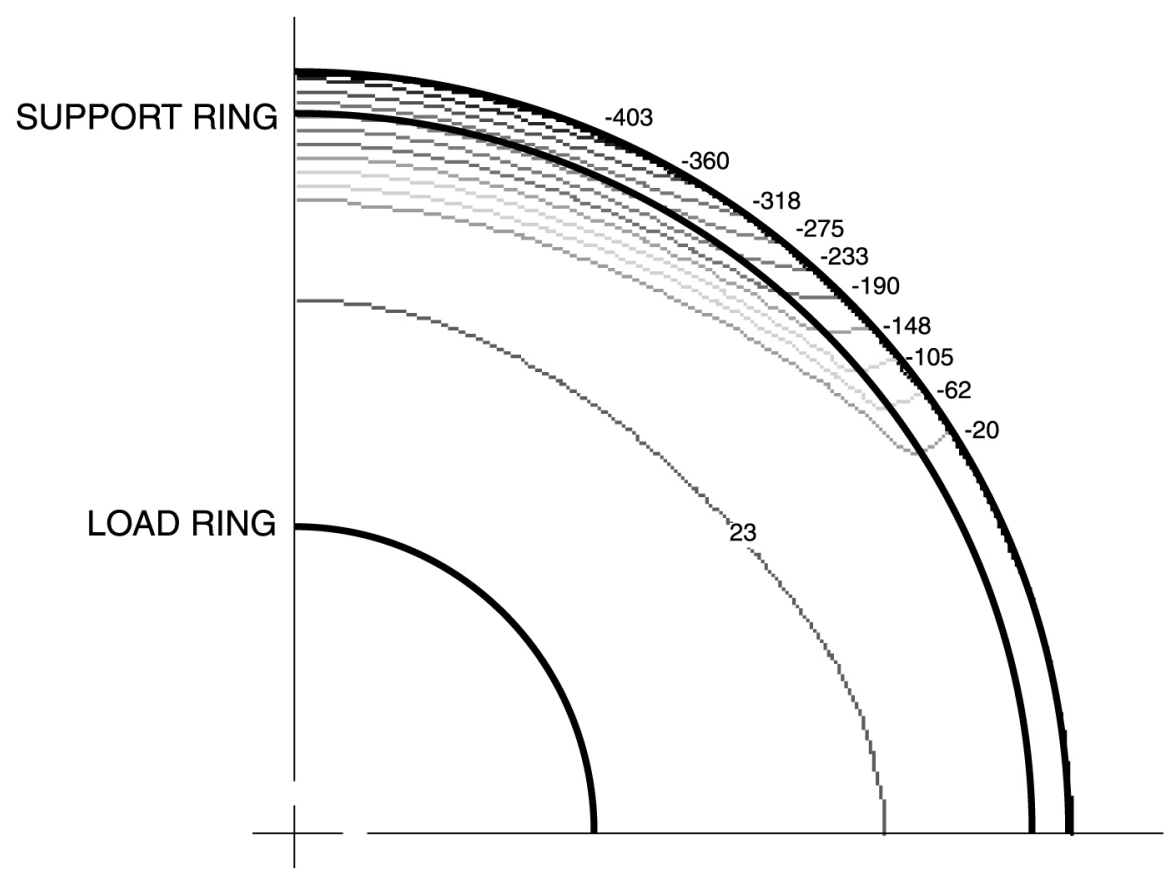

(b)

Fig. 8.7. Predicted principal stresses in bottom ply of disk at maximum load: (a) maximum, $\sigma_{1}$, and $(b)$ minimum, $\sigma_{2}$. The fiber direction is horizontal in these plots. 


$$
\text { 8-12 }
$$




\title{
9. CYCLIC FATIGUE BEHAVIOR
}

\author{
R. L. Battiste and J. M. Corum
}

\subsection{INTRODUCTION}

Several series of cyclic fatigue tests, leading to stress vs cyclic life curves, were carried out for the quasi-isotropic material. In most cases, maximum and minimum cyclic strains and cyclic stiffness (elastic modulus) values were monitored and recorded. The test series included the following:

- baseline in-air tensile fatigue tests at $23^{\circ} \mathrm{C}$ on specimens from two different plaques,

- tensile fatigue tests at $-40,23,70$, and $120^{\circ} \mathrm{C}$ on specimens from a single plaque to establish how fatigue strength varies with temperature,

- tensile fatigue tests on presoaked specimens in distilled water (1000-h presoak) and windshield washer fluid (100-h presoak) to establish fluid effects, and

- mean stress effects tests using two different specimen designs and four different cycle types.

Twenty-one room-temperature baseline tests were performed. In all the other tensile fatigue series, a minimum of eight tests per condition was generally conducted.

All of the tests, except the mean stress ones, used the standard dogbone tensile-type specimen (see Fig. 9.1) and a tensile cycle in which the ratio, $R$, of minimum to maximum stress was $0.1 .^{7}$ The mean stress tests used two hourglass specimen designs, one design previously employed for mean stress tests and a new second design thought to be more resistant to buckling. The specimens for the various fatigue series came from a total of three plaques (see Appendix D).

Each of the above test series is discussed in the following sections. Conclusions and recommendations for developing fatigue design curves are presented in the last section of the chapter.

\subsection{BASELINE TENSILE FATIGUE $(\mathrm{R}=0.1)$}

Baseline in-air, load-controlled tests were performed at a nominal temperature of $23^{\circ} \mathrm{C}$. Specimens came from plaques Q14 and Q15. A haversine waveform was used. The frequency varied with stress in accordance with the following relation, recommended by ACC: ${ }^{7}$

$$
\mathrm{f}=\left(\mathrm{k} \mathrm{S}_{\mathrm{ult}}\right) /\left(\mathrm{S}_{\max }-\mathrm{S}_{\min }\right)
$$

where $\mathrm{k}=3 \mathrm{~Hz}$ was used, $\mathrm{S}_{\mathrm{ult}}$ is the at-temperature UTS of the material, $\mathrm{S}_{\max }$ is the maximum stress in the cycle, and $\mathrm{S}_{\min }$ is the minimum cyclic stress $\left(\mathrm{S}_{\min }=0.1 \mathrm{~S}_{\max }\right)$.

The baseline results are plotted in Fig. 9.2, which shows cycles to failure as a function of the maximum cyclic stress. A power law curve was fit to the data. Note that the curve is bounded above by the UTS of the composite (average UTS $=336 \mathrm{MPa}$ ); no lower bound is shown. ${ }^{12}$ This average UTS was obtained experimentally from eight (four per plaque) reference specimens from plaques Q14 and Q15. This average also happens to be equal to the average for all the plaques, as reported in Chap. 7.

Maximum peak cyclic strain and loss of stiffness values are of interest as measures of damage development. These parameters were monitored during each test. An in-house computer control program stopped the normal fatigue cycling at specified cycle intervals and imposed a slow $(0.1-\mathrm{Hz})$ reduced load-level cycle to assess stiffness reductions. Data generated at the 

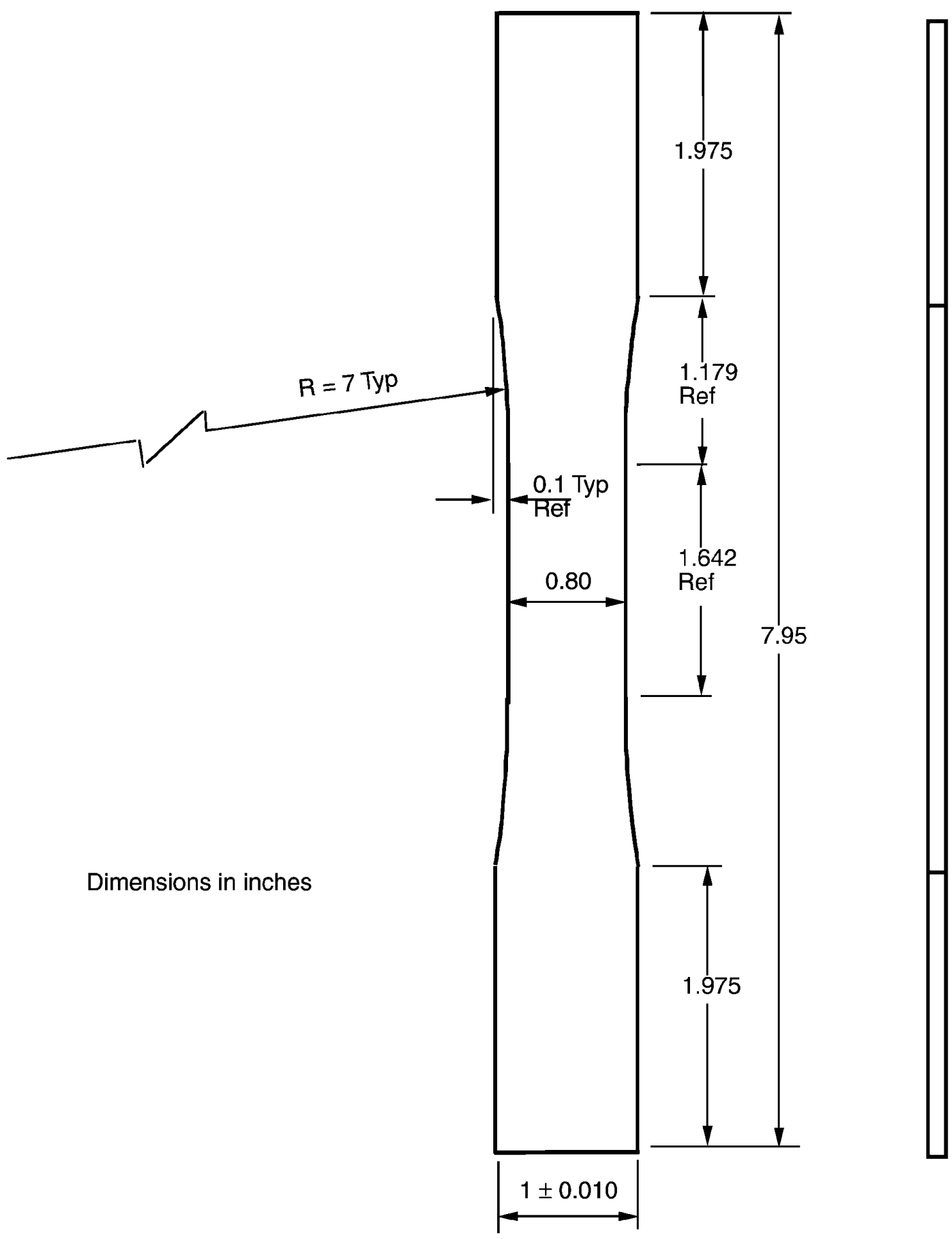

Fig. 9.1. Dogbone specimen configuration used for baseline, temperature, and fluids effects fatigue tests $(1$ in. $=25.4 \mathrm{~mm})$. 


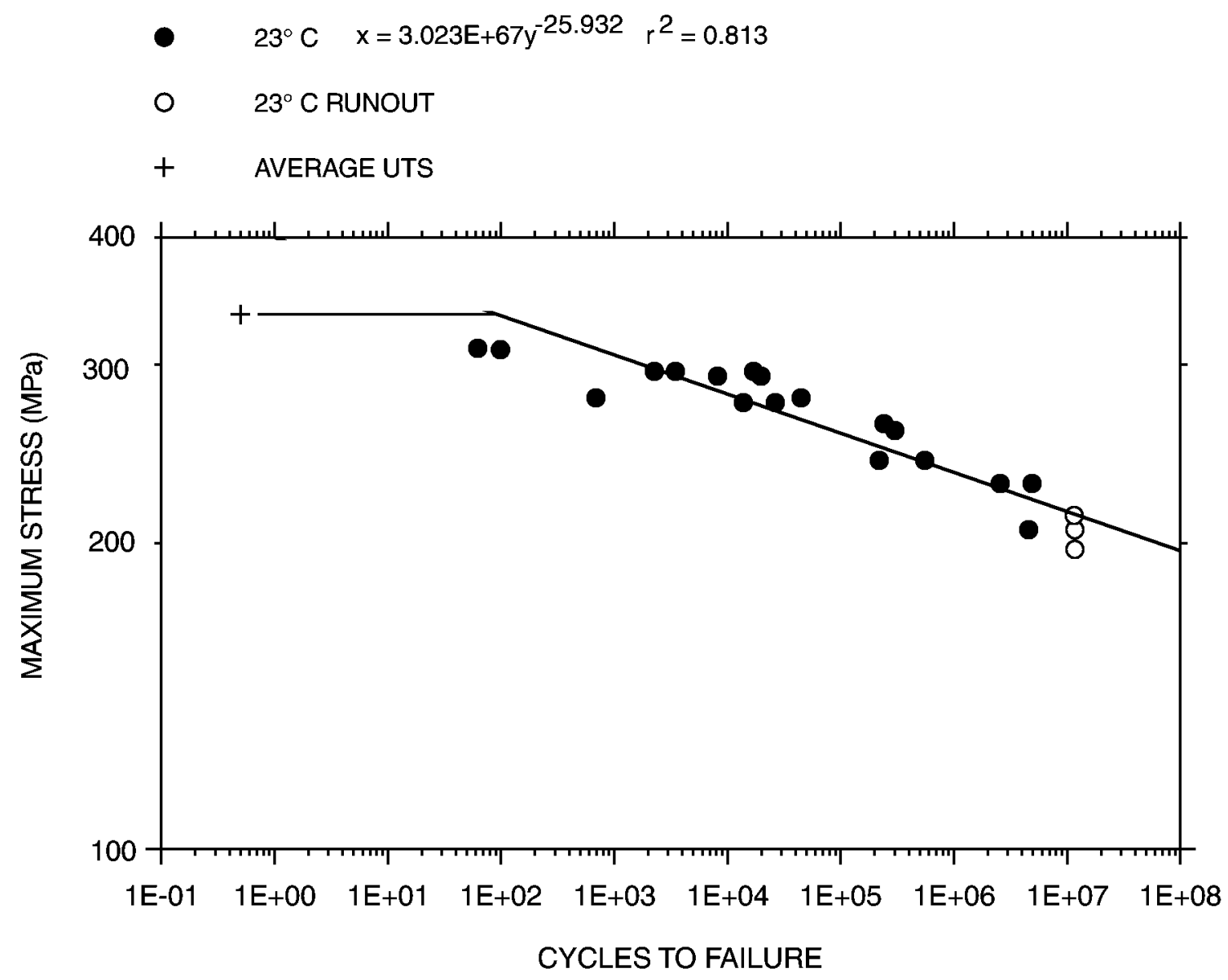

Fig. 9.2. Tensile fatigue $(R=0.1)$ curve at $23^{\circ} \mathrm{C}$.

specified intervals were saved only if stiffness changed by $1 \%$ or more. In addition to the specified intervals, the program automatically saved fatigue and stiffness data for even log-cycle numbers. Normally, the program was run in a manual mode for the first 300 cycles. During this manual mode, a stiffness check cycle was imposed every tenth fatigue cycle and the data saved, independent of the change in stiffness criteria. Various types of MTS extensometers were employed to measure strain; all had a 25.4-mm gage length. Figure 9.3 shows the maximum strain for the fatigue cycles as a function of cycle number for tests on specimens from plaques Q14 and Q15, respectively. Note that in two tests in Fig. 9.3(a), the first ten cycles of data were lost because of an intermittent error in the computer control program. The curves appear more like the chopped-glass-fiber material in shape and magnitude than the crossply-carbon-fiber material tested earlier. ${ }^{3,4}$ The initial small linear increase of strain with cycle number probably reflects the buildup of some microstructural damage with perhaps some strain increase due to time-dependent creep strain (due to the positive tensile mean stress). The turn upward at the end of the tests indicates the development of more significant damage mechanisms.

Of particular importance in cyclic fatigue is the reduction in stiffness, reflecting the accumulation of damage with cycling. Ideally, this loss should not exceed $10 \%$ over the design allowable life. The reduction in stiffness in percent change from the initial stiffness as a function of cyclic life fraction, $n / \mathrm{N}_{\mathrm{f}}$, is shown in Fig. 9.4. With the factor of 20 design margin $\left(\mathrm{n} / \mathrm{N}_{\mathrm{f}}=\right.$ 0.05) on cyclic life that is recommended later in this chapter, the room-temperature stiffness loss 

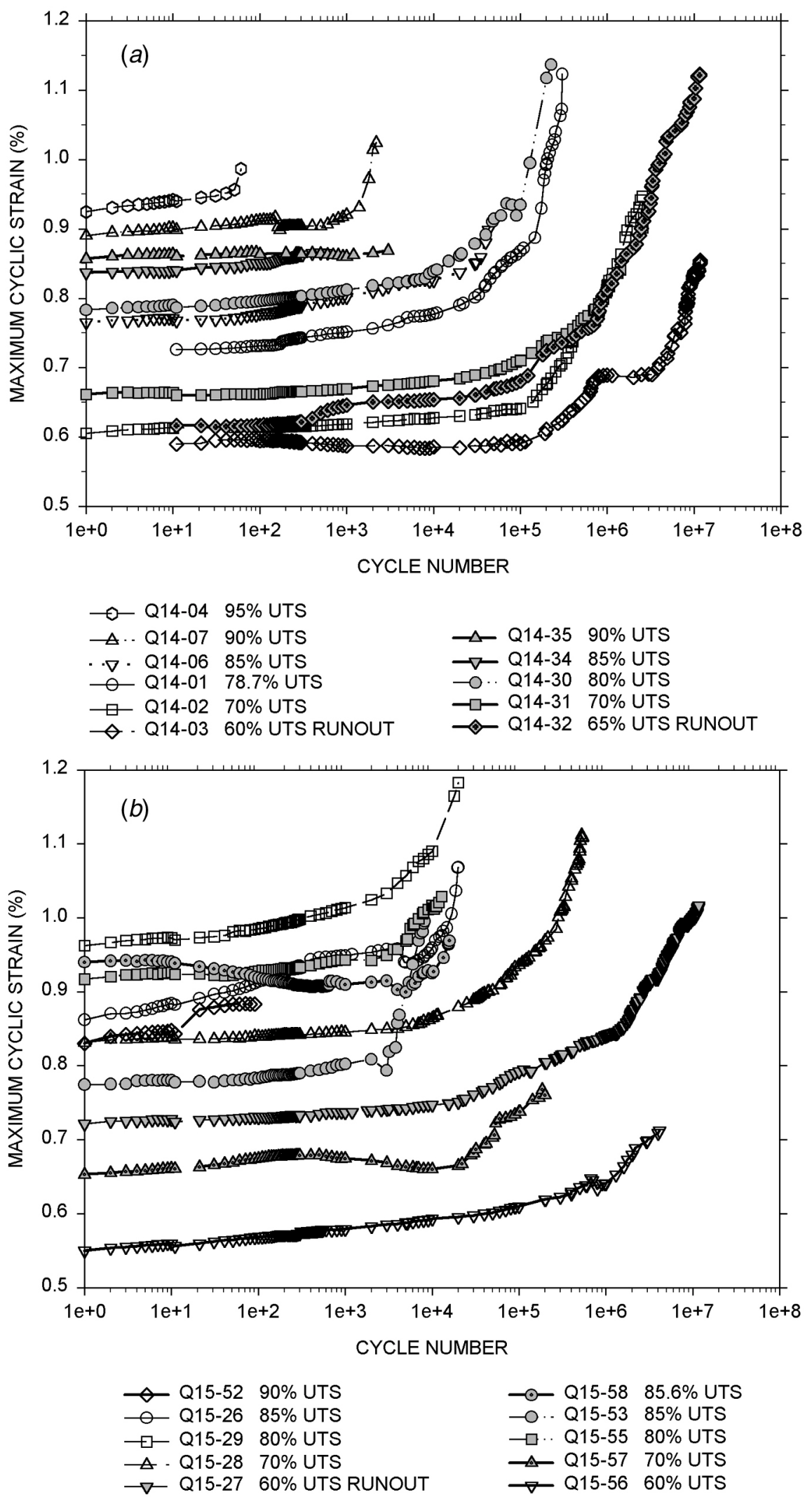

Fig. 9.3. Maximum strain behavior in specimens at room temperature: (a) plaque Q14 and (b) plaque Q15. 

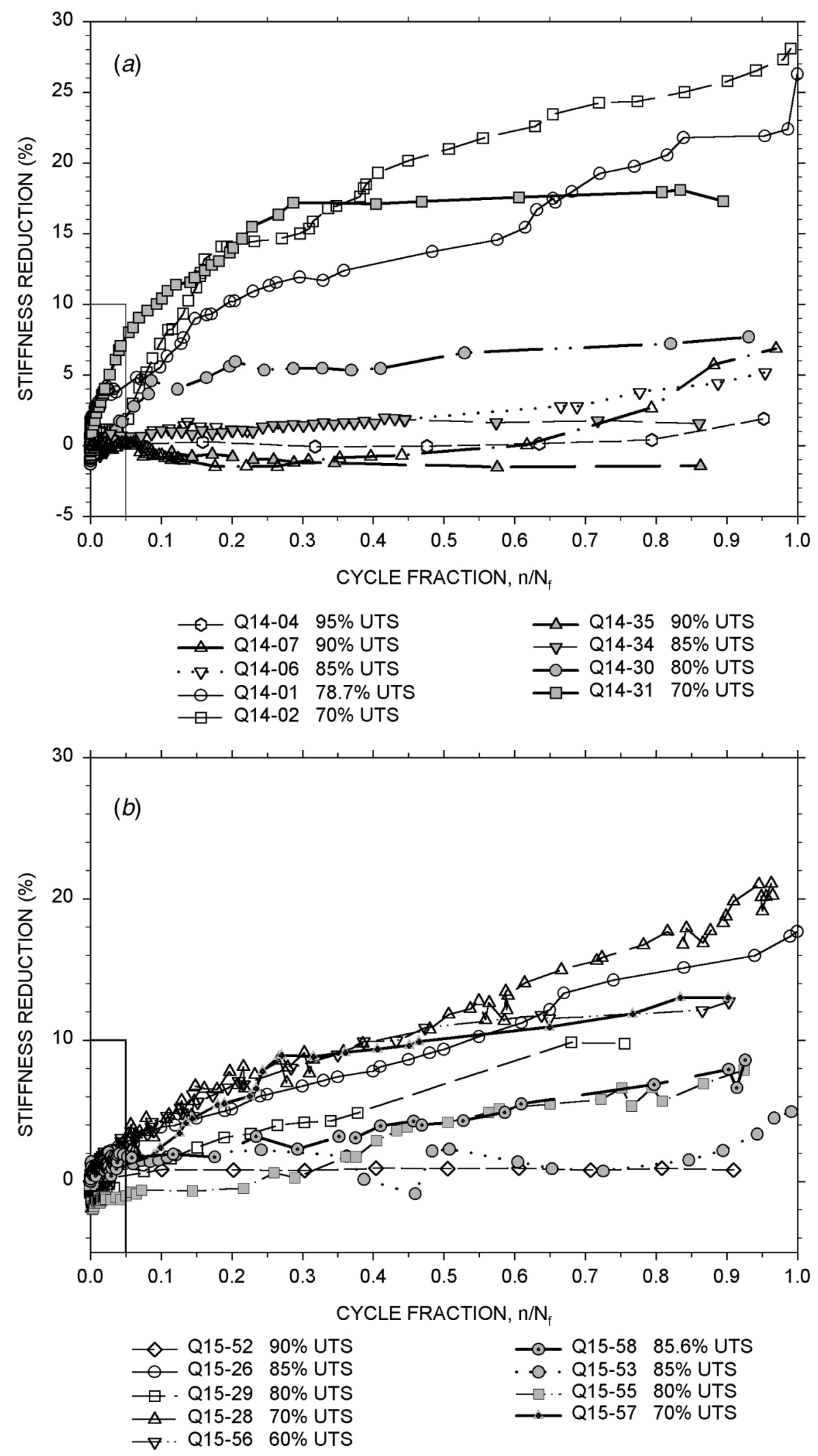

Fig. 9.4. Stiffness loss vs cycle fraction, $n / \mathbf{N}_{\mathrm{f}}$, for specimens at $23^{\circ} \mathrm{C}$ : (a) plaque $\mathrm{Q} 14$ and (b) plaque Q15. 
is seen to be less than $10 \%$ for all tests. ${ }^{*}$ A trend in both Fig. 9.4 plots appears to be a decrease in stiffness reduction with increasing stress levels. Of course, the higher stress levels accumulated fewer cycles to failure. This observation is consistent with the small loss of stiffness (less than $1 \%$ ) associated with prior tensile loading of up to $80 \%$ UTS reported in Chap. 7.

To help validate the above fatigue test results, the specimen temperature was monitored throughout each test using a type-K thermocouple. Mylar adhesive tape was used to fasten the thermocouple at the specimen centerline. The thermocouple assembly was inspected after each test to ensure that physical contact between the thermocouple and specimen surface had been maintained. Figure 9.5 shows specimen temperature as a function of life fraction. In this case, specimen temperature is defined as the average of generally 200 evenly spaced data points recorded during a given fatigue cycle. The curves show only small temperature changes (about $4^{\circ} \mathrm{C}$ ) throughout the entire test life, with the major portion of that increase occurring during the first $2 \%\left(\mathrm{n} / \mathrm{N}_{\mathrm{f}}=0.02\right)$ of life. This temperature behavior is opposite to the behavior of the $\pm 45^{\circ}$ crossply-carbon-fiber material, which displayed large temperature increases (up to $35^{\circ} \mathrm{C}$ ), mostly near the end of life. ${ }^{4}$

Figure 9.6 shows the failure locations referenced to the specimen centerline along with the maximum stresses as a percent of UTS for each specimen. Because about two-thirds of the failures occur within, or just outside of the specimen gage length, the specimen design and the alignment of each test machine appear to have been adequate. Finite-element analysis predicted about a 5\% increase in stress at the gage length to radius junction. However, the failure locations appear random with cyclic stress amplitude.

\subsection{EFFECTS OF TEMPERATURE}

The following procedure was used to develop a consistent set of fatigue strength values over the -40 to $120^{\circ} \mathrm{C}$ temperature range for the quasi-isotropic material. A single plaque (Q14) was used to generate tensile $(\mathrm{R}=0.1) \mathrm{S}-\mathrm{N}$ curves at $-40,23,70$, and $120^{\circ} \mathrm{C}$. Continuous, oncethrough heated air was used to maintain specimen temperature in the 70 and $120^{\circ} \mathrm{C}$ tests. Liquid nitrogen vapor with on/off control was used for the $-40^{\circ} \mathrm{C}$ tests. For each temperature, factors were developed relating the fatigue strength curve to the corresponding room-temperature curve. These factors were then applied to the baseline room-temperature curve to obtain the final fatigue strengths.

Figure 9.7 shows the power-law curve fits and corresponding data points along with their respective UTS data points (shown as + signs). All test specimens came from plaque Q14. The UTS values for $-40,70$, and $120^{\circ} \mathrm{C}$ were calculated using the average UTS for plaque Q14 $(328 \mathrm{MPa})$ at $23^{\circ} \mathrm{C}$ and the static strength multiplication factors given earlier in this report (see Sect. 7.2). The data scatter at $-40,70$, and $120^{\circ} \mathrm{C}$ made completely satisfactory curve fitting difficult, as reflected by the low coefficients of determination, $\mathrm{r}^{2}$, for the curve fits. Figure 9.8 shows the final curves and equations, incorporating the respective UTS values. The corresponding fatigue strength multiplication factors are listed in Table 9.1. Note that the factors do not vary monotonically with cycles because of capping each curve at the corresponding UTS. The factors are those used in Sect. 4.2 of Part 1. Figures 9.9-9.11 show the curve, equation, and data points for each individual temperature of $-40,70$, and $120^{\circ} \mathrm{C}$, respectively, for clarity. The runouts are, in each case, all above the failure curves, indicating that the curves are conservative representations at high cycles.

\footnotetext{
*Actually, the total recommended reduction exceeds the factor of 20 because the stress is also reduced (see Sect. 9.6).
} 

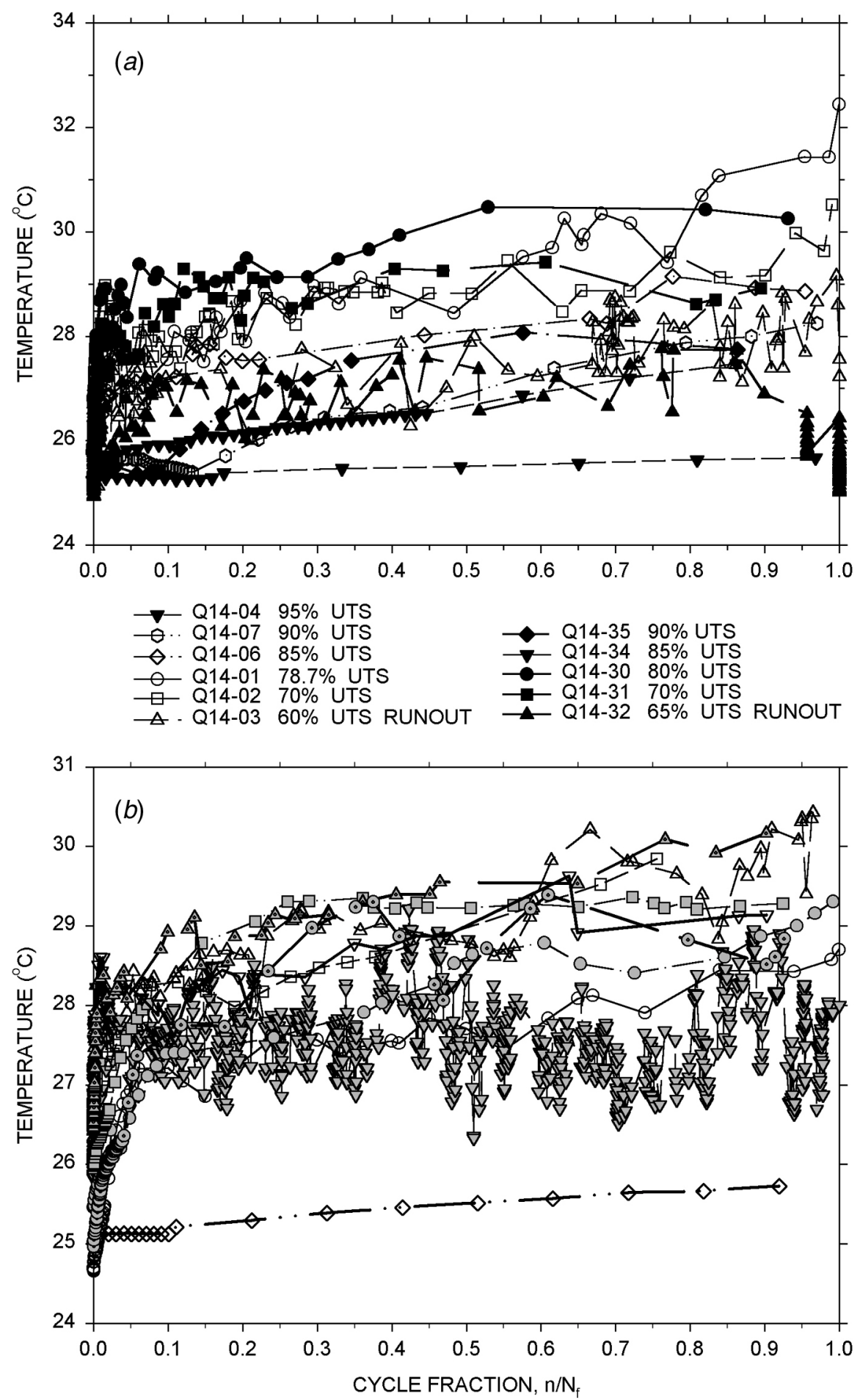

$\begin{array}{llll}\text { Q15-52 } & 90 \% \text { UTS } & \text { Q15-58 } & 85.6 \% \text { UTS } \\ \text { Q15-26 } & 85 \% \text { UTS } & \text { Q15-53 } & 85 \% \text { UTS } \\ \text { Q15-29 } & 80 \% \text { UTS } & \text { Q15-55 } & 80 \% \text { UTS } \\ \text { Q15-28 } & 70 \% \text { UTS } & \text { Q15-57 } & 70 \% \text { UTS } \\ \text { Q15-27 } & 60 \% \text { UTS RUNOUT } & \text { Q15-56 } & 60 \% \text { UTS }\end{array}$

Fig. 9.5. Temperature vs cycle fraction, $n / \mathrm{N}_{\mathrm{f}}$, for specimens at $23^{\circ} \mathrm{C}$ : (a) plaque $\mathrm{Q} 14$ and (b) plaque Q15. 


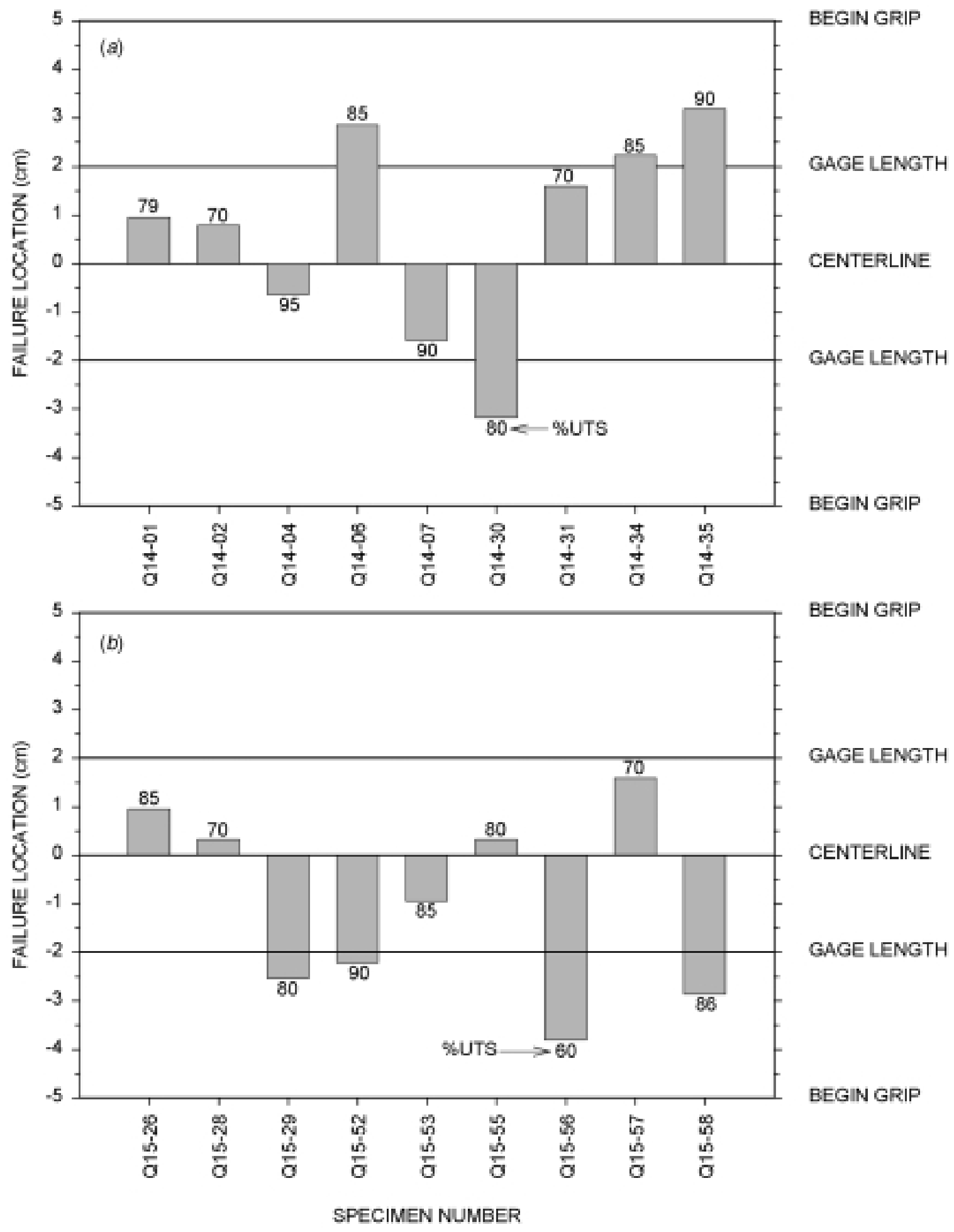

Fig. 9.6. Failure location for $23^{\circ} \mathrm{C}$ tests: (a) plaque Q14 and (b) plaque Q15. 


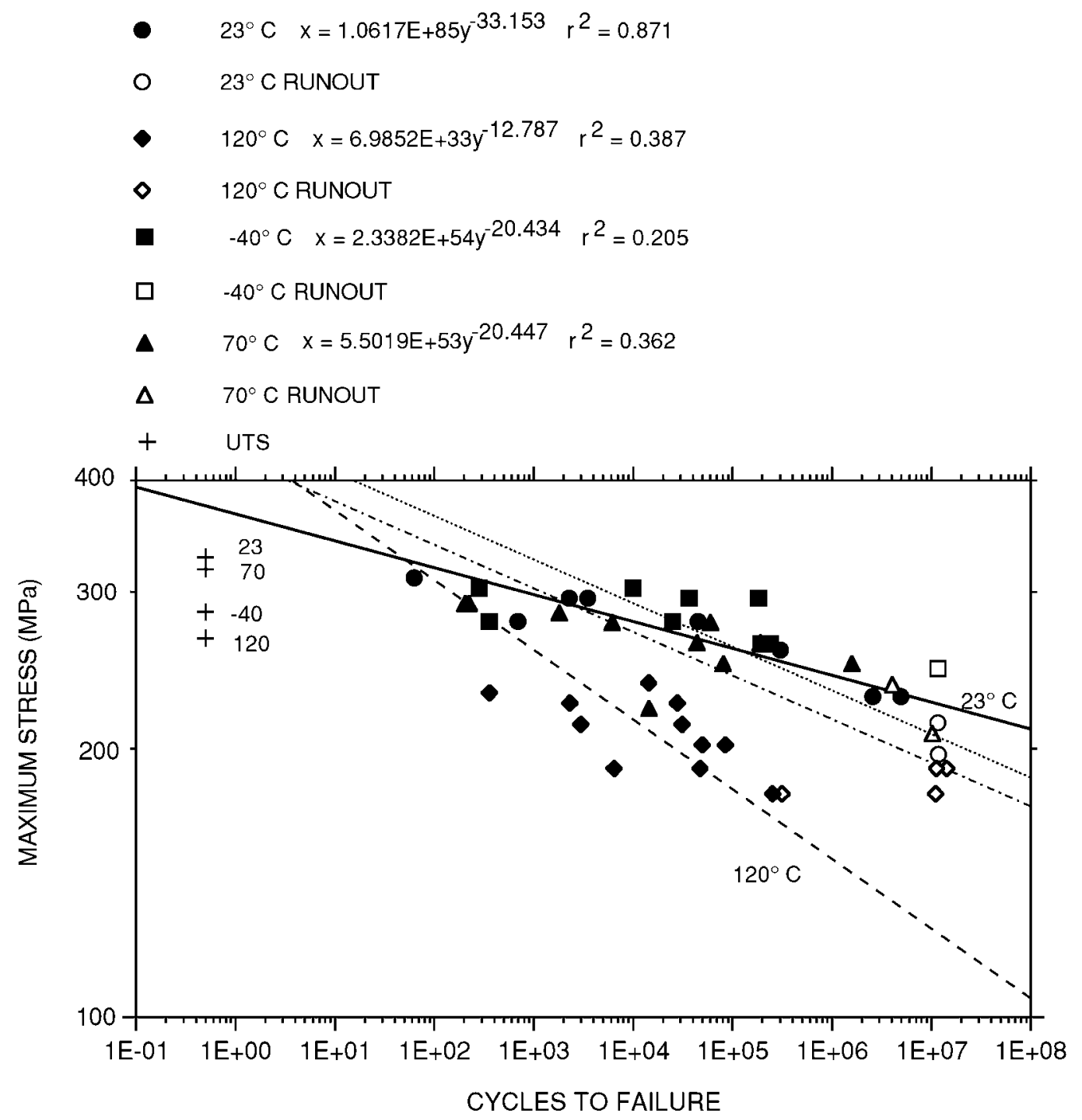

Fig. 9.7. Tensile fatigue curves for plaque Q14 specimens at various temperatures. 


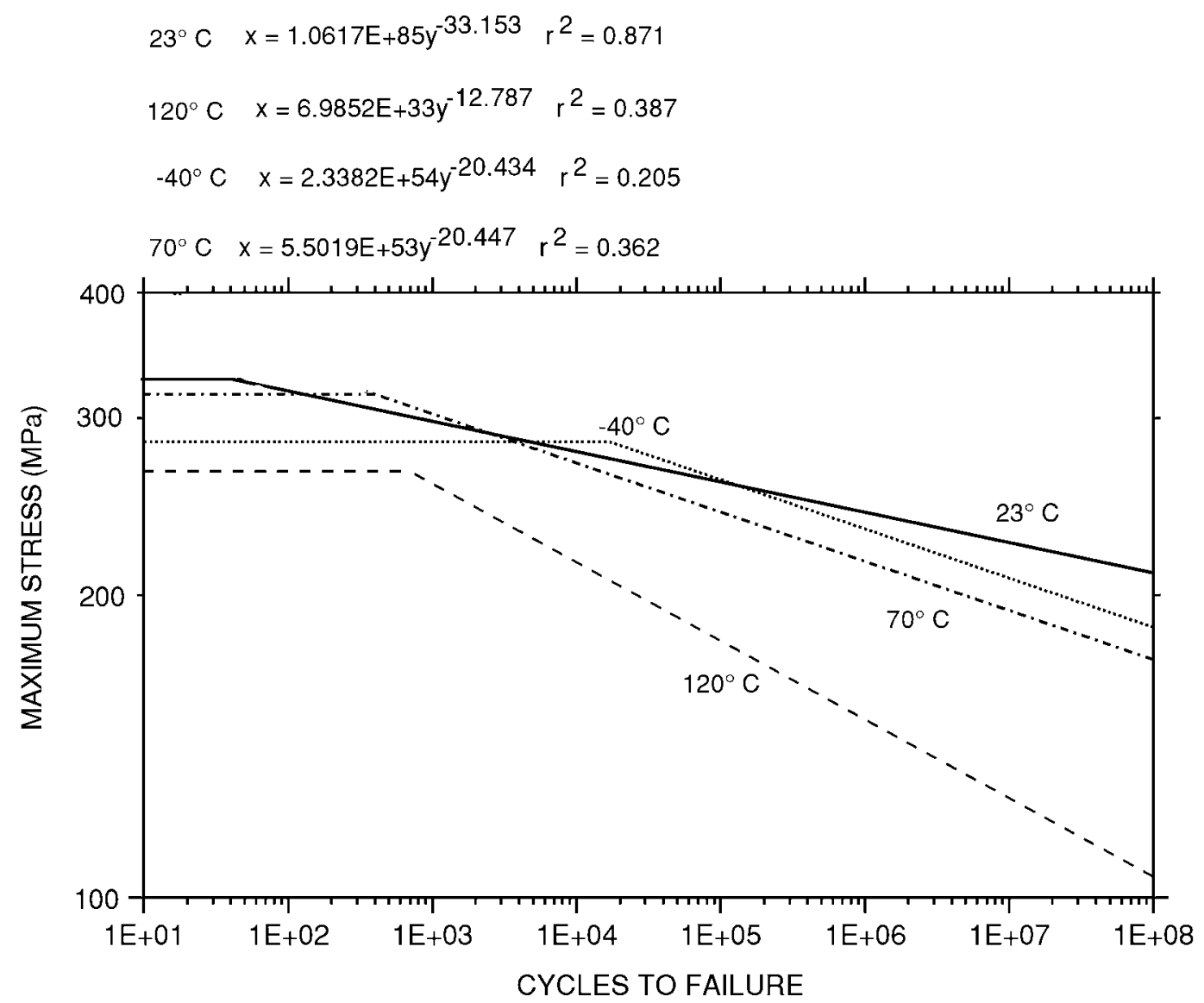

Fig. 9.8. Final tensile fatigue curves (capped by UTS values) for plaque Q14 specimens at various temperatures.

Table 9.1. Fatigue strength multiplication factors for temperature

\begin{tabular}{ccccc}
\hline \multirow{2}{*}{ Temperature $\left({ }^{\circ} \mathbf{C}\right)$} & \multicolumn{4}{c}{ Cycles to failure } \\
\cline { 2 - 5 } & $\mathbf{1 0}^{\mathbf{2}}$ & $\mathbf{1 0}^{\mathbf{4}}$ & $\mathbf{1 0}^{\mathbf{6}}$ & $\mathbf{1 0}^{\mathbf{8}}$ \\
\hline-40 & 0.89 & 1.03 & 0.96 & 0.88 \\
23 & 1.00 & 1.00 & 1.00 & 1.00 \\
70 & 1.00 & 0.97 & 0.89 & 0.82 \\
120 & 0.97 & 0.78 & 0.62 & 0.50 \\
\hline
\end{tabular}




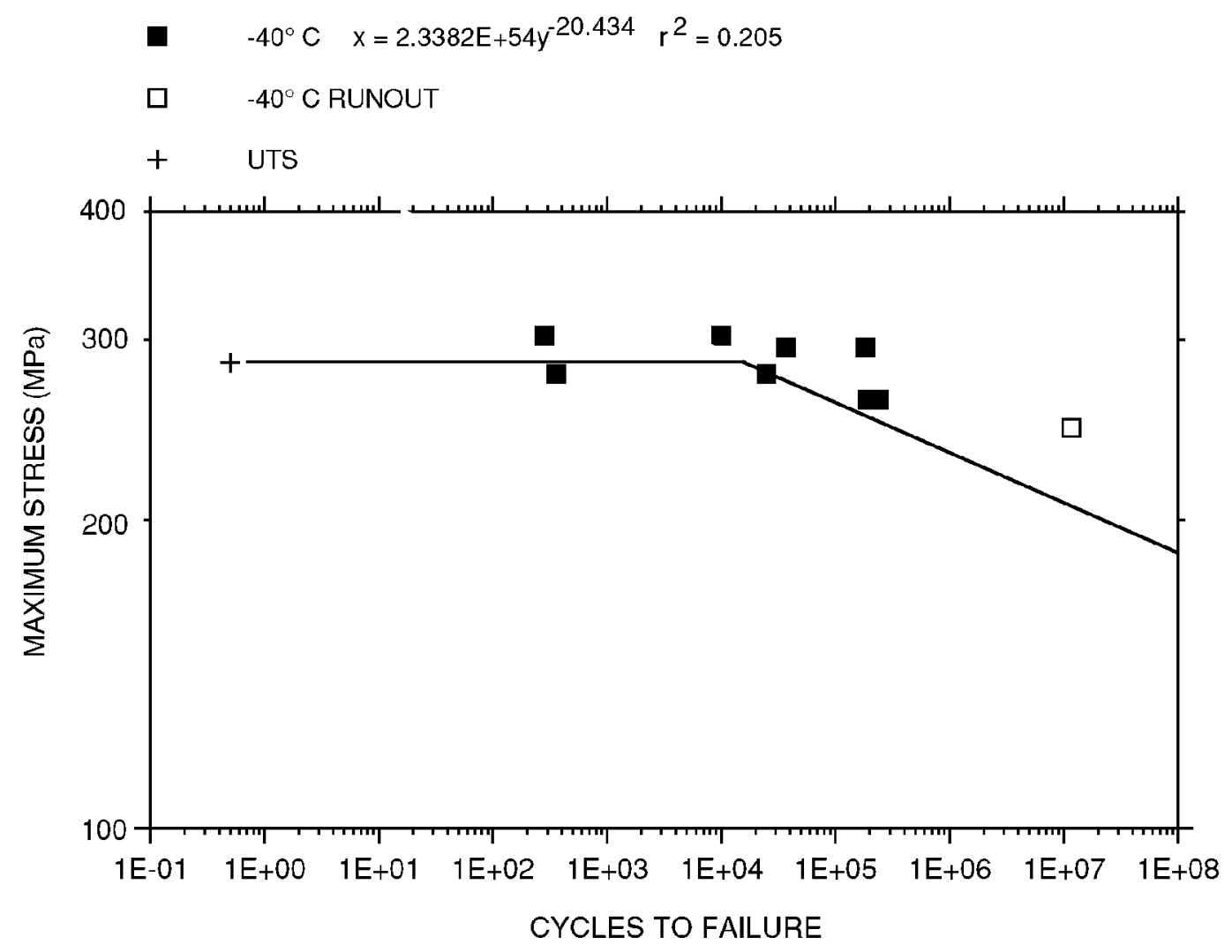

Fig. 9.9. Final tensile fatigue curve for plaque $Q 14$ specimens at $-40^{\circ} \mathrm{C}$. The nominal UTS value of $292 \mathrm{MPa}$ at $-40^{\circ} \mathrm{C}$ (see Table 7.4) came from several plaques. Some of the applied cyclic stresses were actually above this value. 


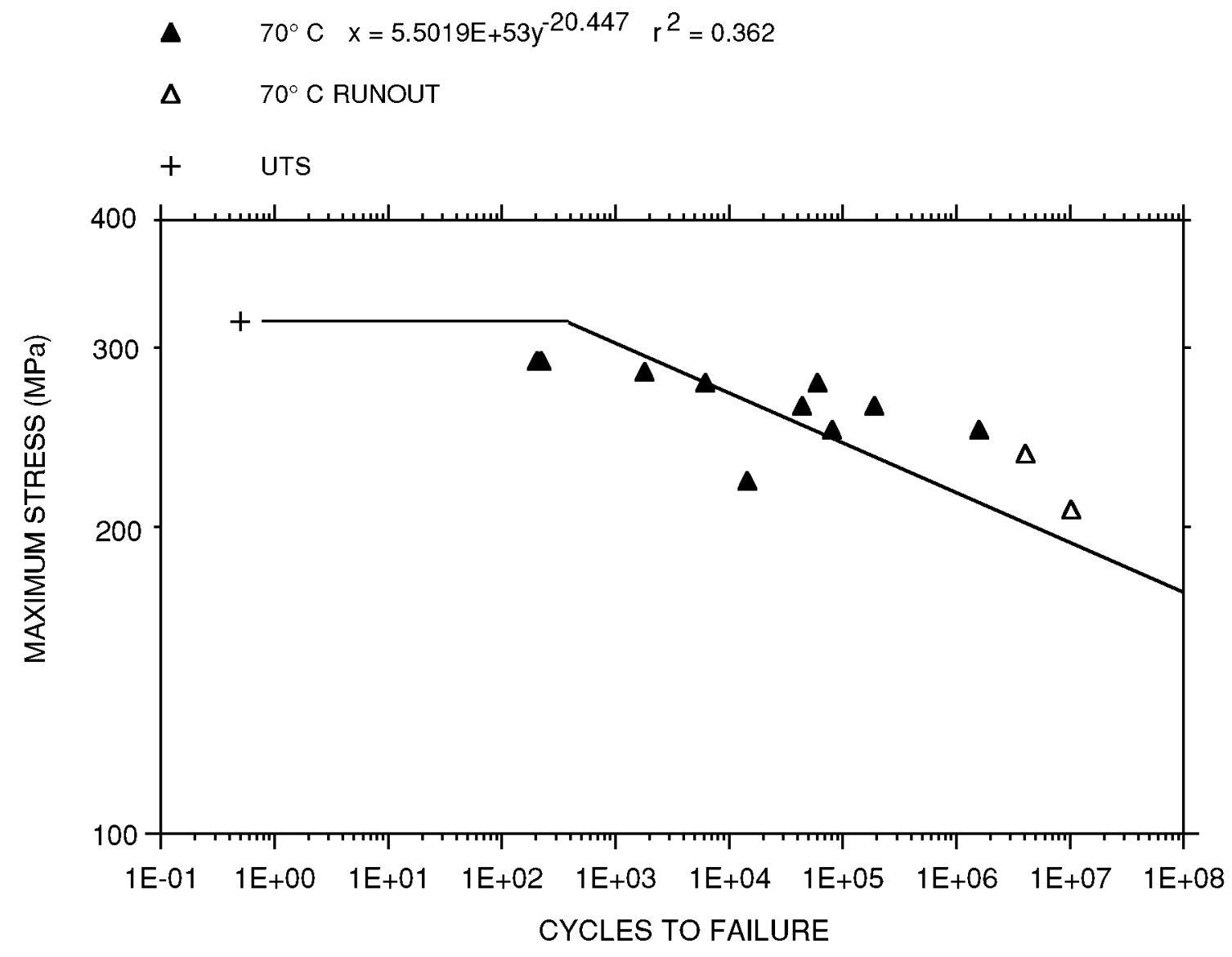

Fig. 9.10. Final tensile fatigue curve for plaque $Q 14$ specimens at $70^{\circ} \mathrm{C}$. 


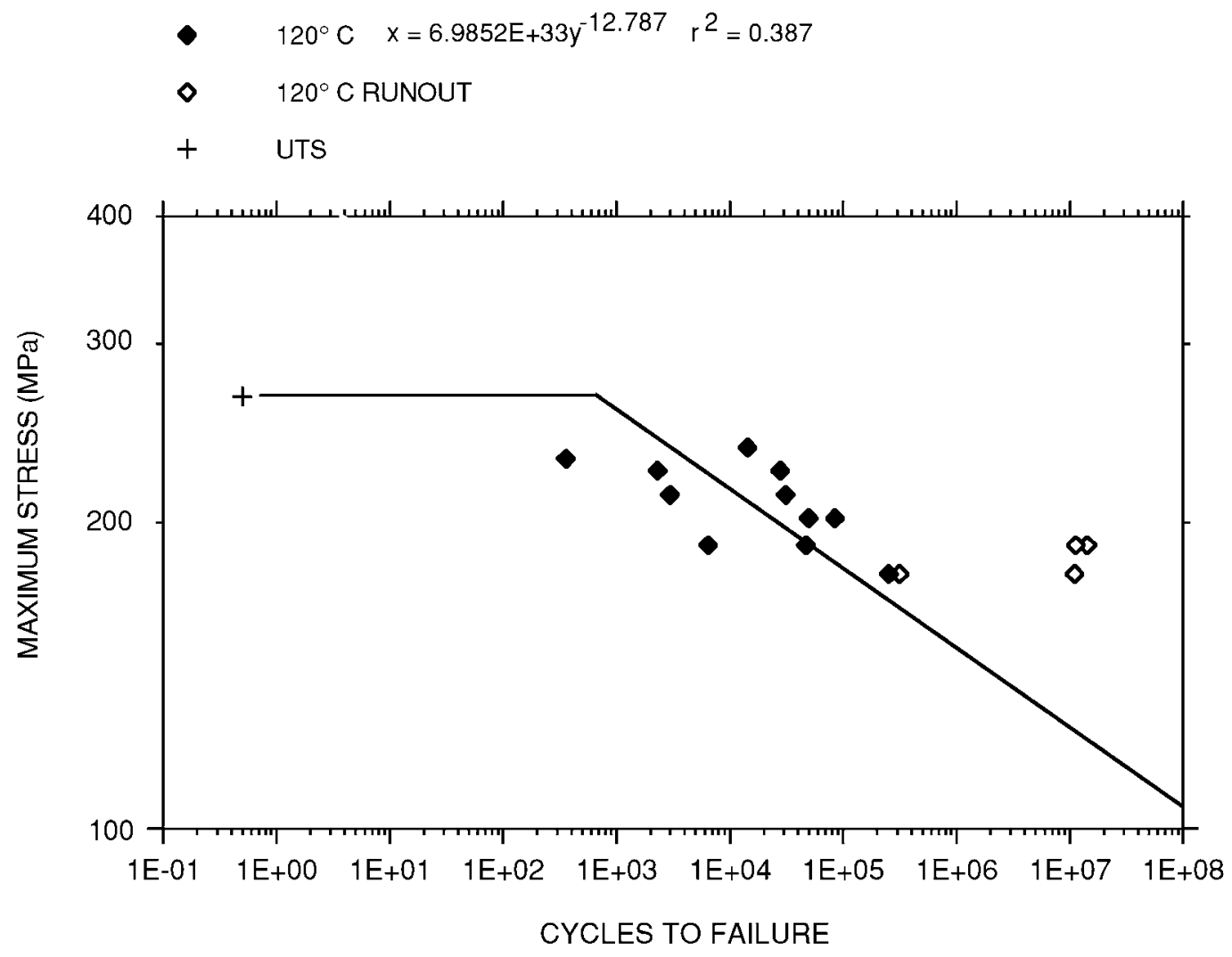

Fig. 9.11. Final tensile fatigue curve for plaque $\mathrm{Q} 14$ specimens at $120^{\circ} \mathrm{C}$.

The maximum cyclic strain and stiffness reduction were investigated and displayed to ensure integrity of the above results. The maximum cyclic strain as a function of cycle number for the $-40,70$, and $120^{\circ} \mathrm{C}$ tests are shown in Figs 9.12-9.14. As in the case of the $23^{\circ} \mathrm{C}$ tests, a relatively long slow linear increase during the early portions of the tests and a moderate upturn toward the end of the tests is observed. This behavior is again more consistent with the choppedglass-fiber material in shape and magnitude than with that of the $\pm 45^{\circ}$ fiber orientation or $0 / 90^{\circ}$ fiber orientation of the crossply-carbon-fiber material tested earlier. ${ }^{3,4}$ The stiffness reduction vs cycle fraction for the $-40,70$, and $120^{\circ} \mathrm{C}$ tests are shown in Figs. 9.15-9.17. The stiffness losses for all of the tests are seen to be less than $10 \%$ with the recommended factor of 20 design margin $\left(\mathrm{n} / \mathrm{N}_{\mathrm{f}}=0.05\right)$ on cyclic life.

The average test temperatures as a function of cycle fraction for the three test series are shown in Figs. 9.18-9.20 and reveal a very tight temperature variation band of about $2^{\circ} \mathrm{C}$. The same method of temperature measurement as for the room-temperature test series, previously described, was employed. Figures 9.21-9.23 show the failure locations referenced to the specimen centerline along with the maximum stresses as a percent of UTS for each specimen for the three series. As in the case of the room-temperature test series, most of the failures occurred within the desired region of the specimen, and there appears to be no clear correlation between failure location and stress amplitude. 


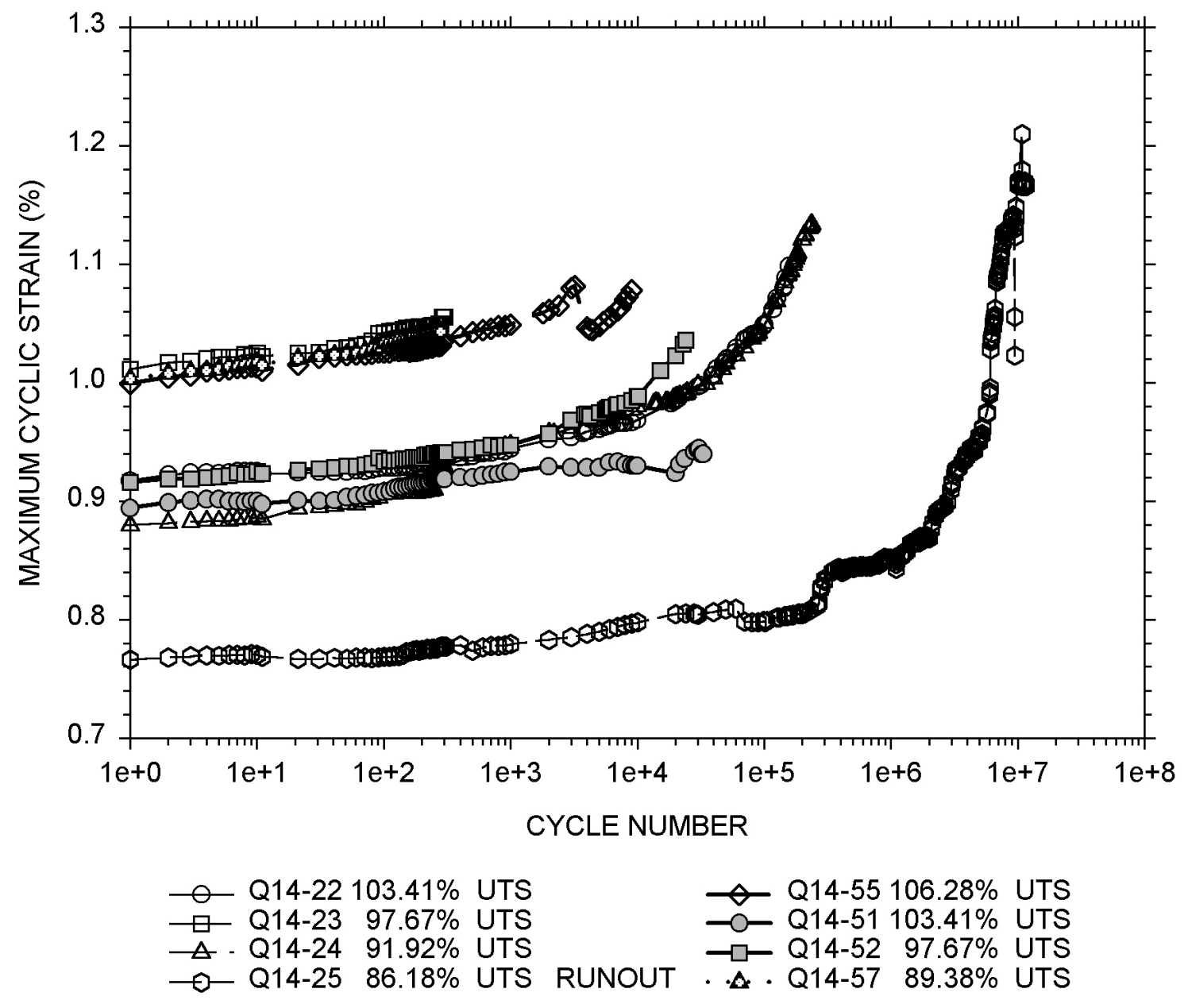

Fig. 9.12. Maximum strain behavior at $-40^{\circ} \mathrm{C}$ in specimens from plaque Q14. 


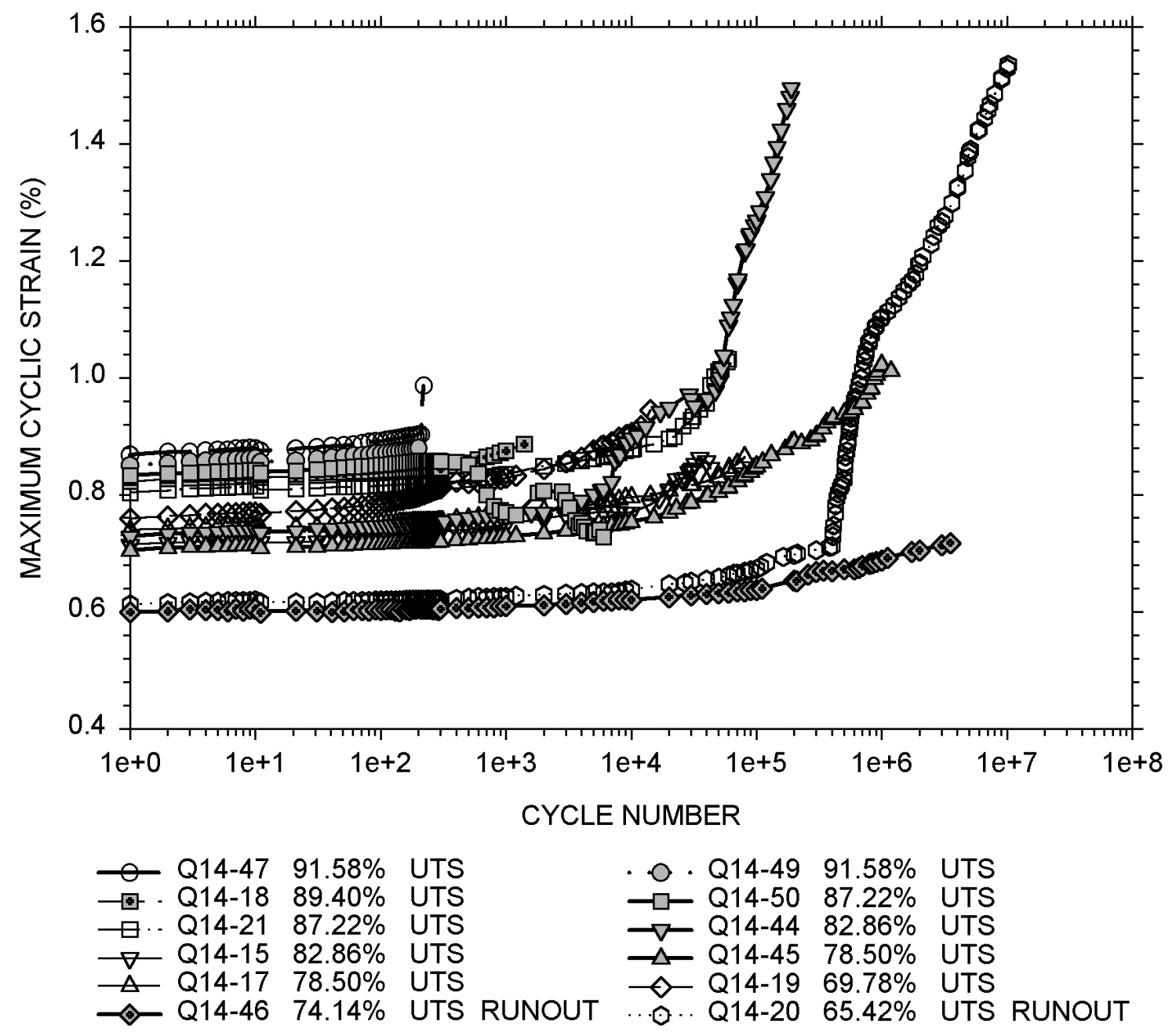

Fig. 9.13. Maximum strain behavior at $70^{\circ} \mathrm{C}$ in specimens from plaque $Q 14$. 


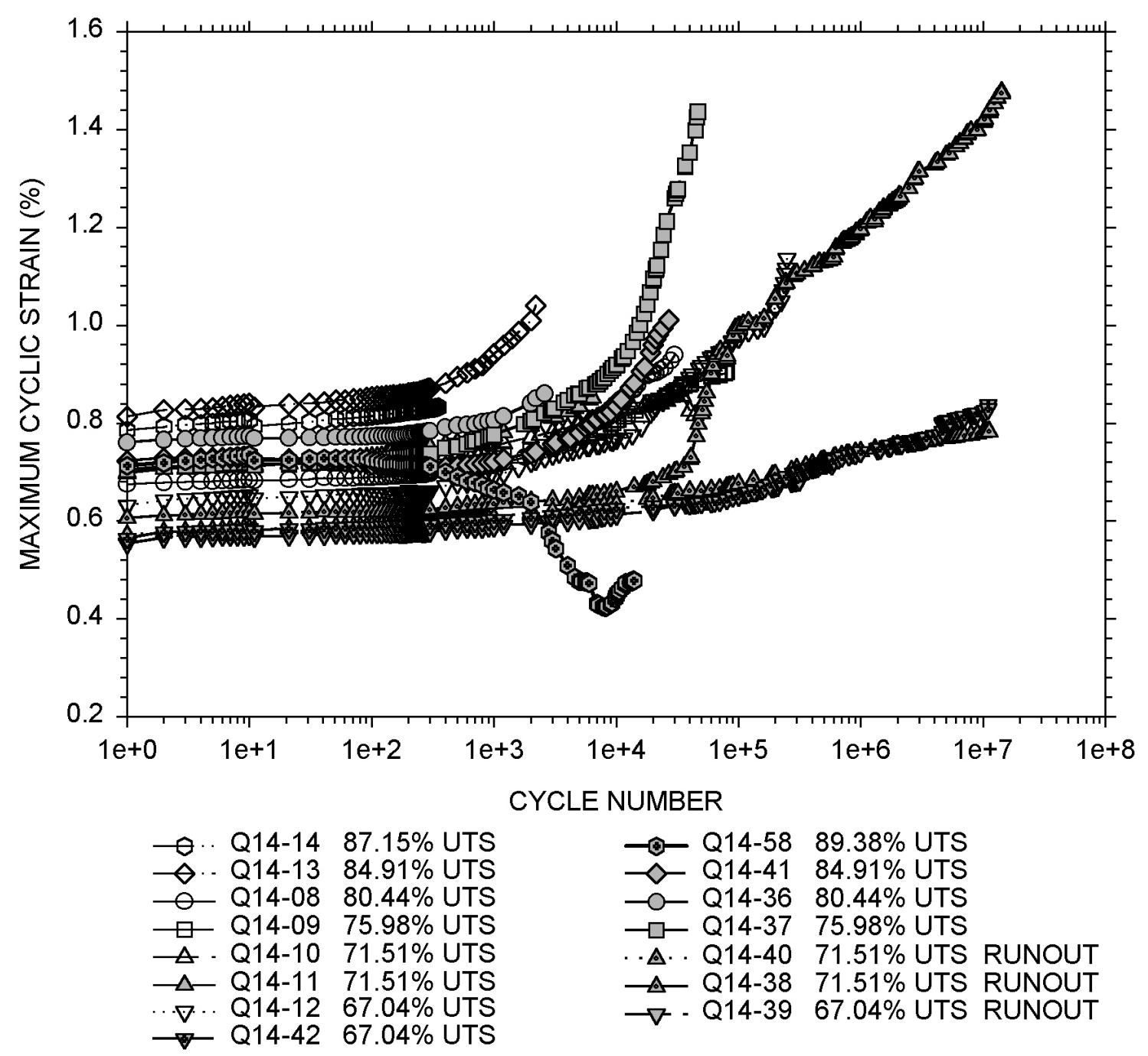

Fig. 9.14. Maximum strain behavior at $120^{\circ} \mathrm{C}$ in specimens from plaque $\mathrm{Q} 14$. 

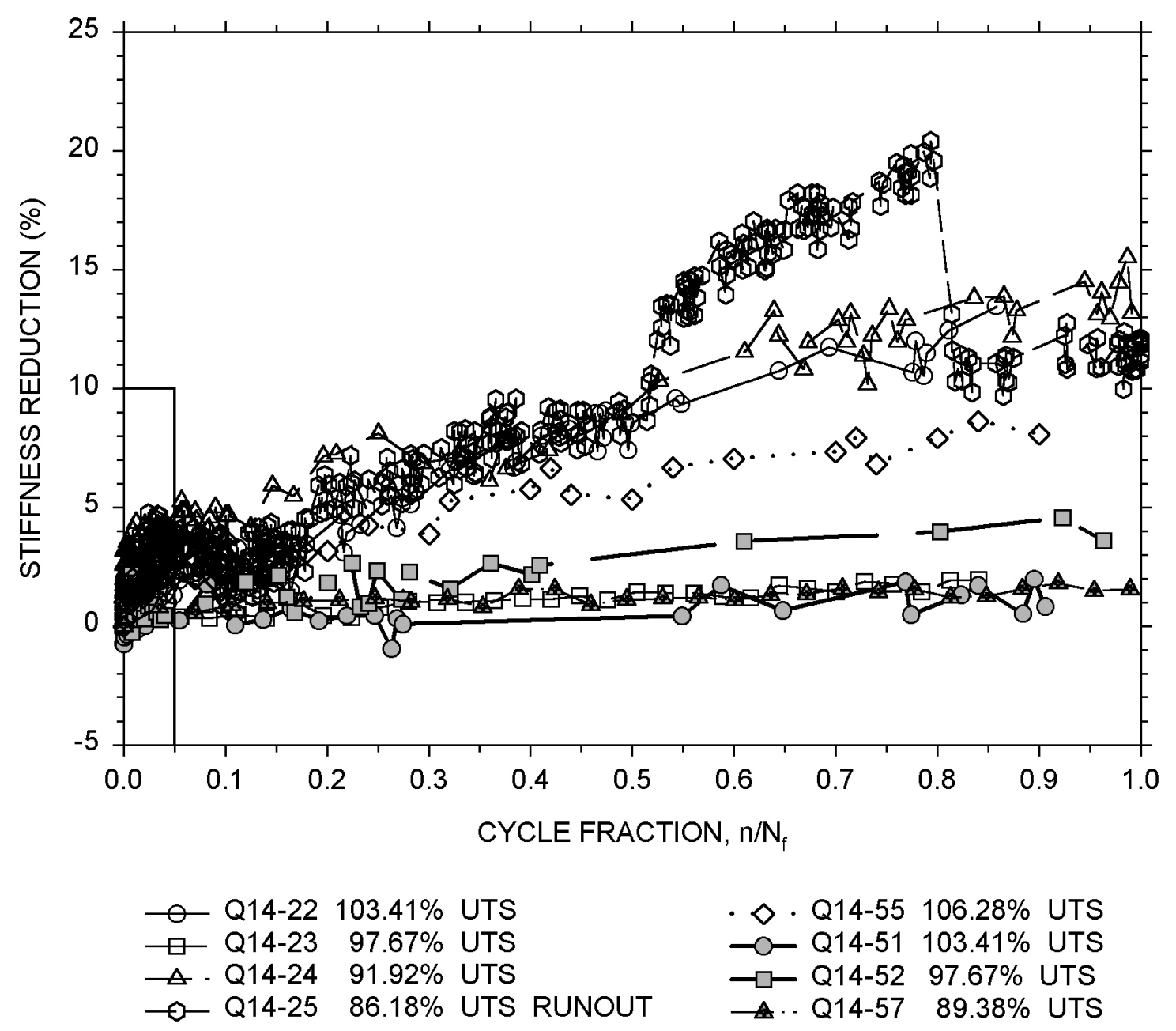

Fig. 9.15. Stiffness loss vs cycle fraction, $n / N_{f}$, for plaque $Q 14$ specimens at $-40^{\circ} \mathrm{C}$. 

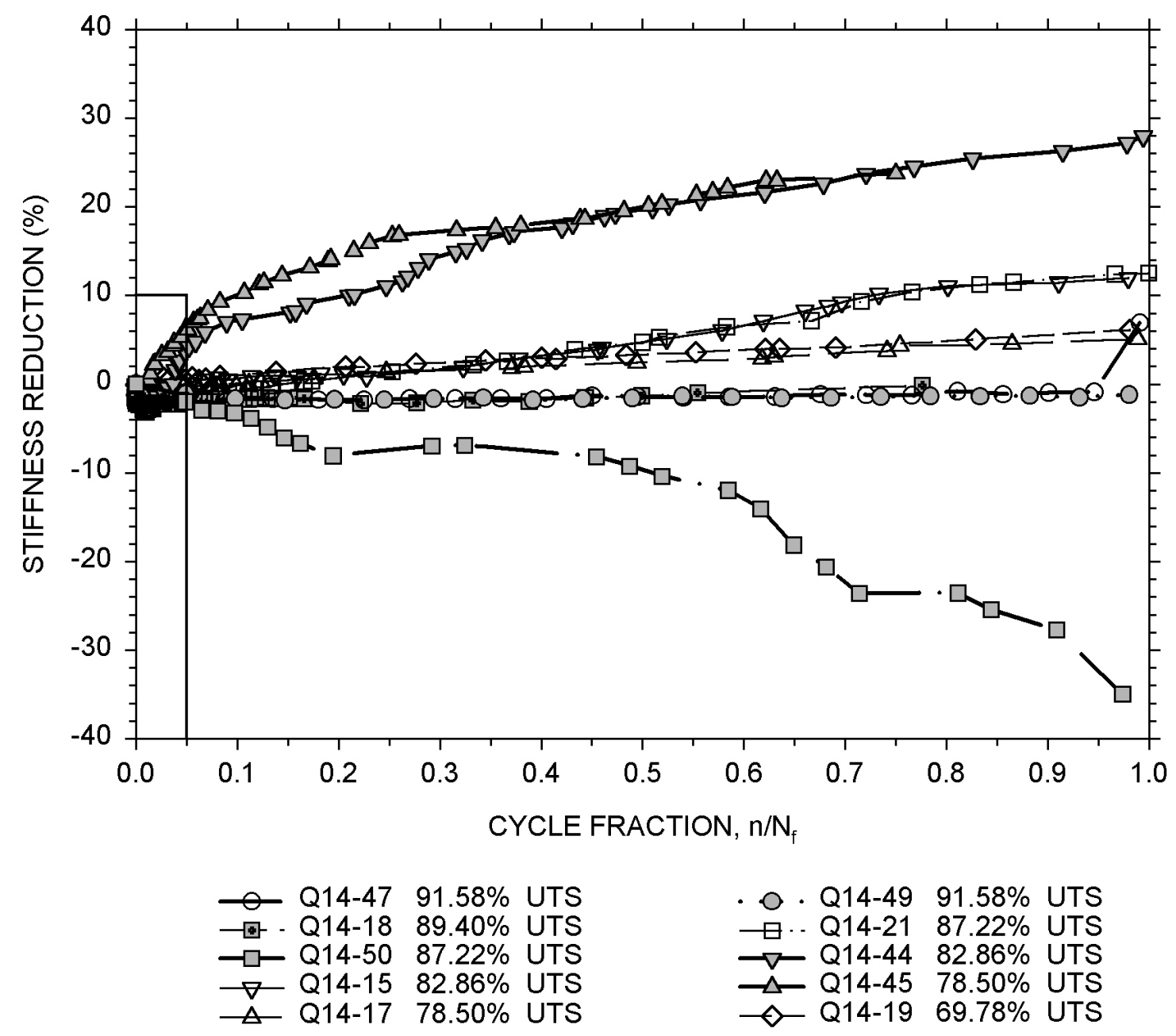

$$
\begin{aligned}
& \text {. o. Q14-49 } 91.58 \% \text { UTS } \\
& \text { ‥ Q14-21 } 87.22 \% \text { UTS } \\
& \rightarrow \text { Q14-44 } 82.86 \% \text { UTS } \\
& \triangle-\text { Q14-45 } 78.50 \% \text { UTS } \\
& \diamond \text { Q14-19 } 69.78 \% \text { UTS }
\end{aligned}
$$

Fig. 9.16. Stiffness loss vs cycle fraction, $\mathbf{n} / \mathbf{N}_{\mathrm{f}}$, for plaque $\mathrm{Q} 14$ specimens at $70^{\circ} \mathrm{C}$. 


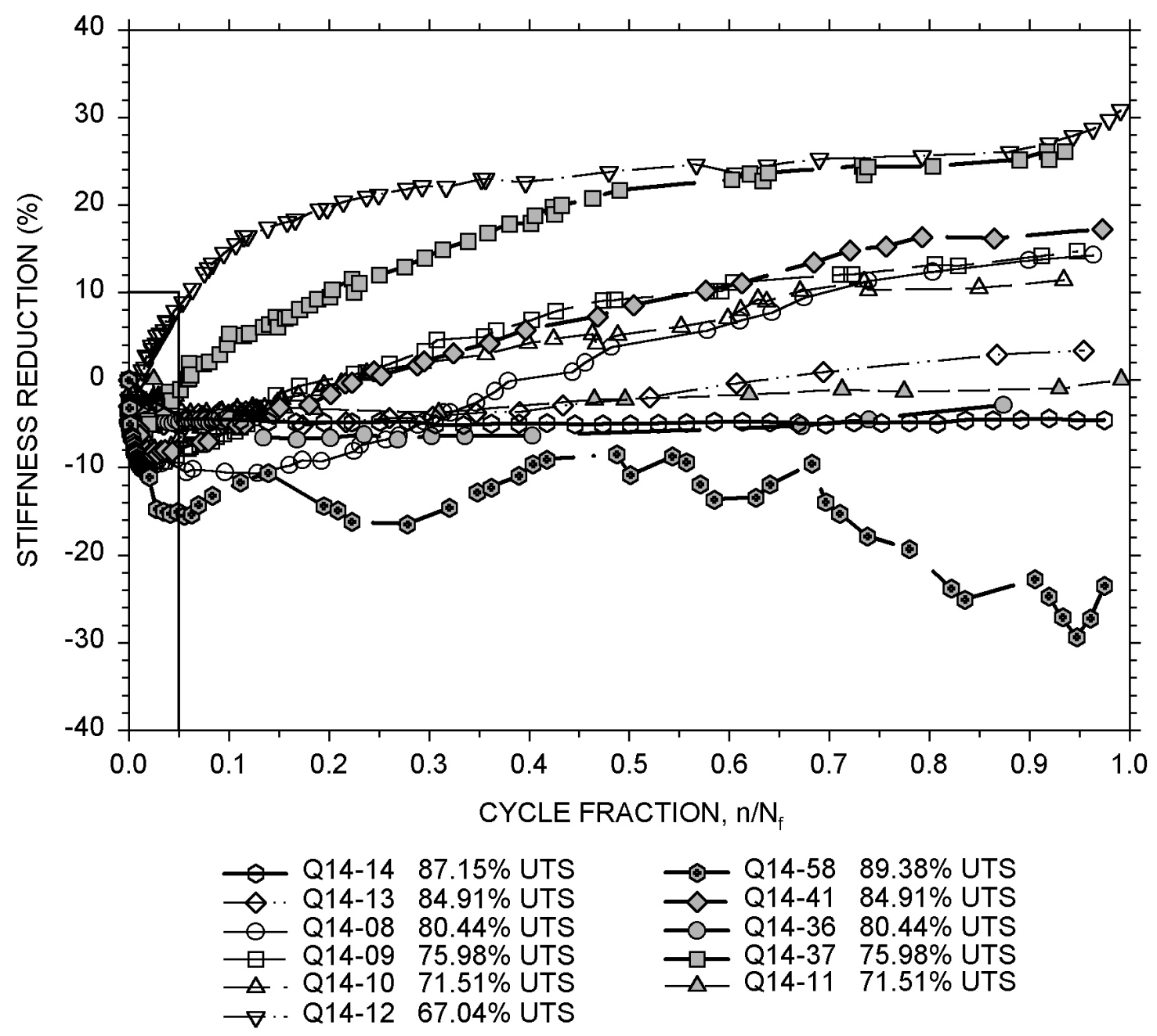

Fig. 9.17. Stiffness loss vs cycle fraction, $n / N_{f}$, for plaque $Q 14$ specimens at $120^{\circ} \mathrm{C}$. 


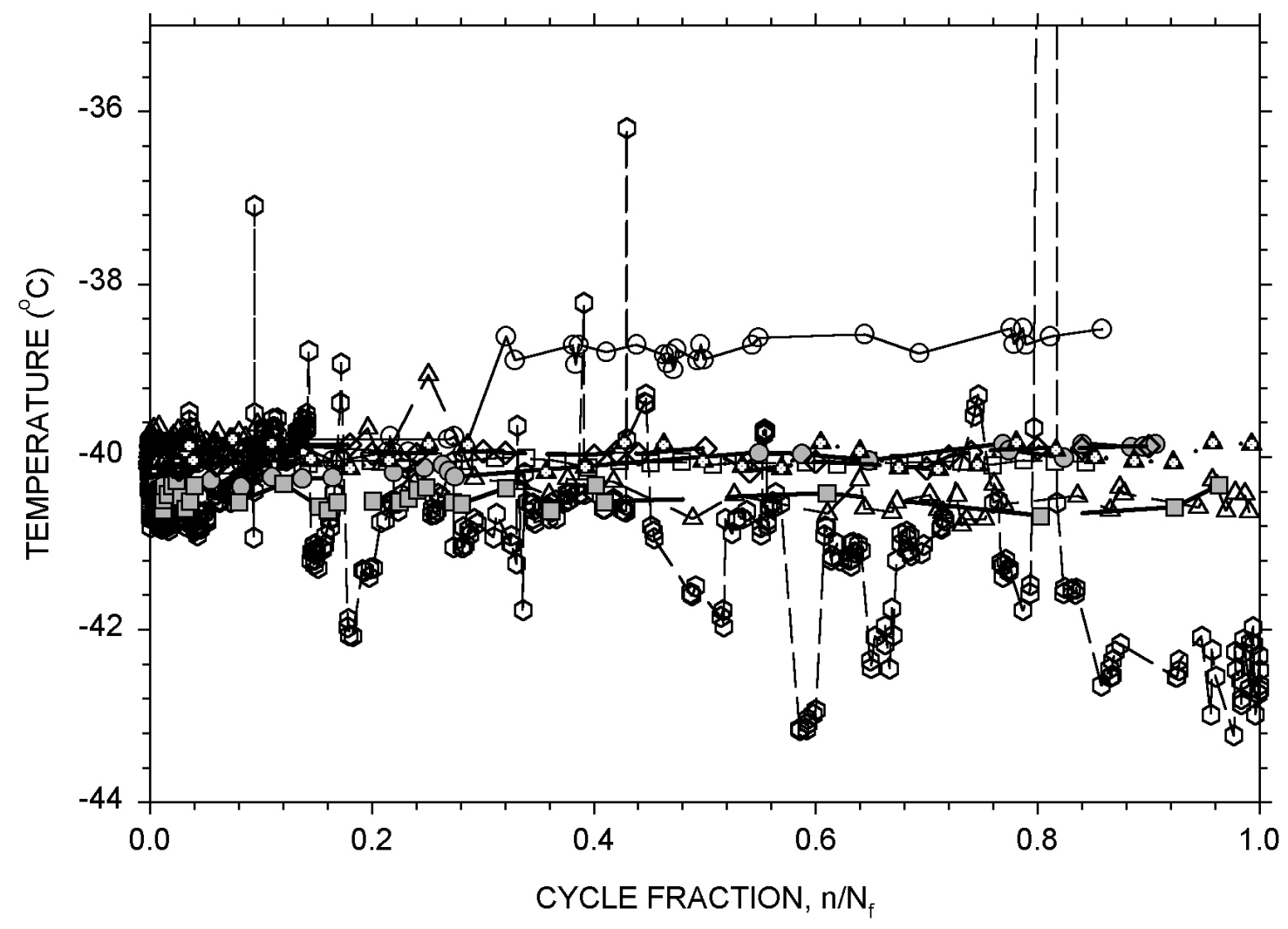

Q14-22 103.41\% UTS Q14-23 $97.67 \%$ UTS Q14-24 $91.92 \%$ UTS Q14-25 $86.18 \%$ UTS RUNOUT

Q14-55 106.28\% UTS Q14-51 $103.41 \%$ UTS Q14-52 $97.67 \%$ UTS Q14-57 $89.38 \%$ UTS

Fig. 9.18. Temperature vs cycle fraction, $n / N_{f}$, for plaque $Q 14$ specimens at $-40^{\circ} \mathrm{C}$. 

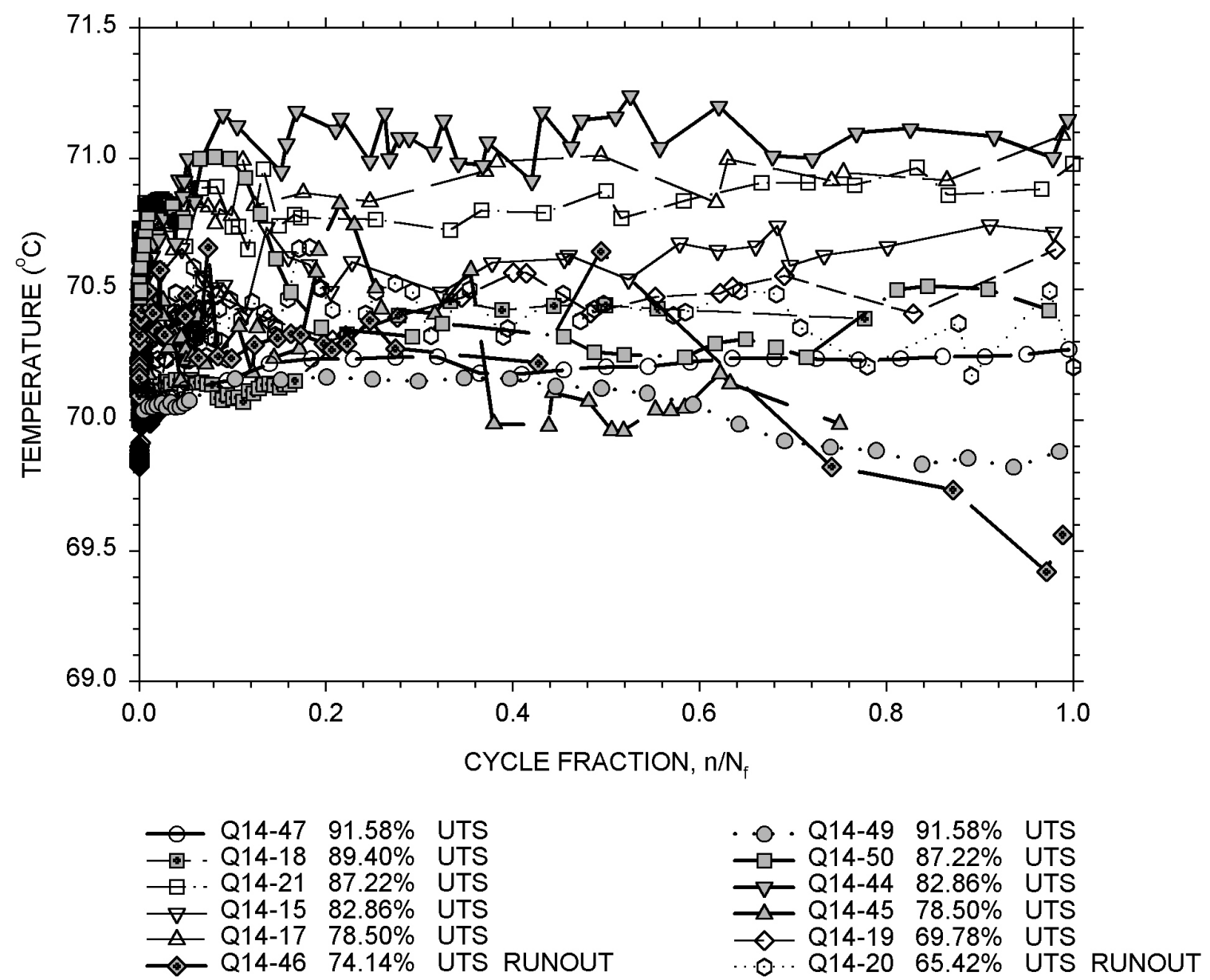

Fig. 9.19. Temperature vs cycle fraction, $n / N_{f}$, for plaque $Q 14$ specimens at $70^{\circ} \mathrm{C}$. 


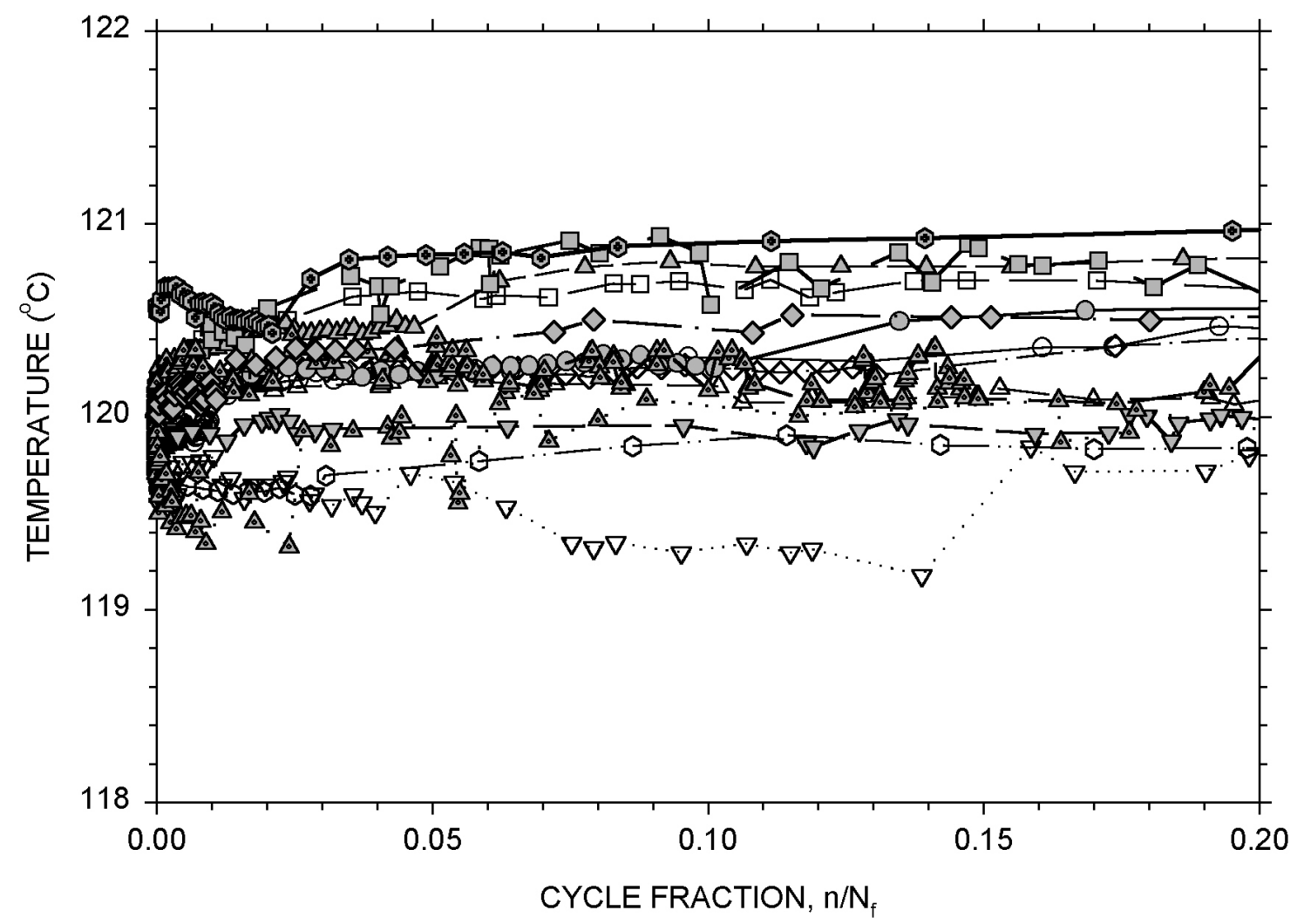

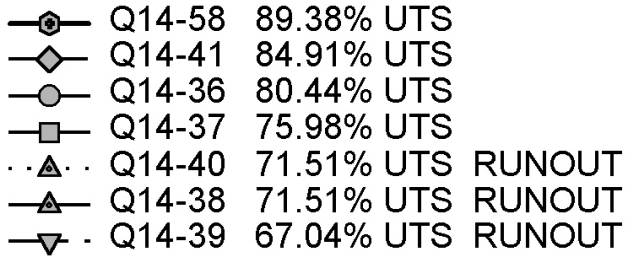

Fig. 9.20. Temperature vs cycle fraction, $n / N_{f}$, for plaque $Q 14$ specimens at $120^{\circ} \mathrm{C}$. 


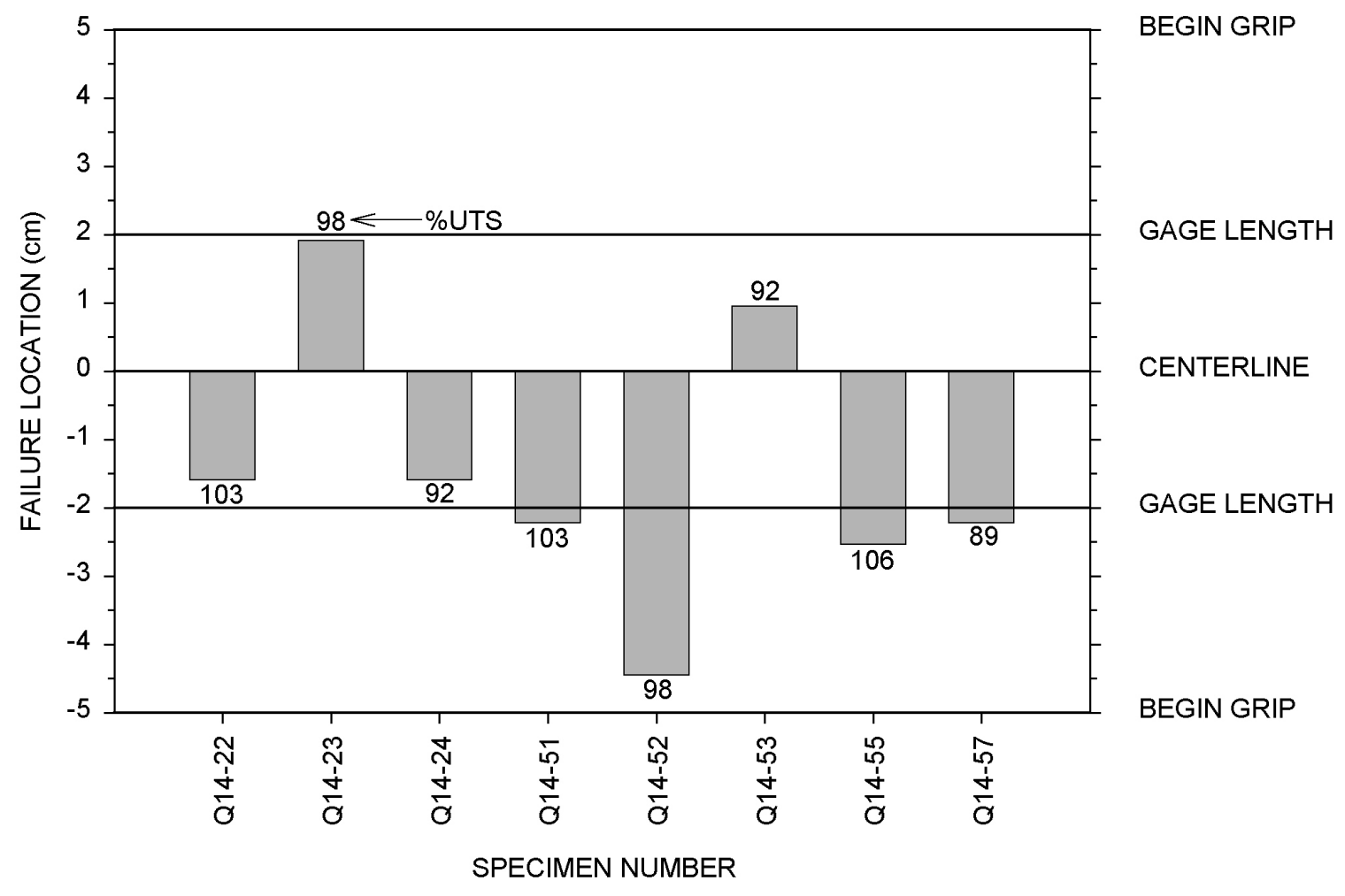

Fig. 9.21. Failure location for $-40^{\circ} \mathrm{C}$ tests of plaque $\mathrm{Q} 14$.

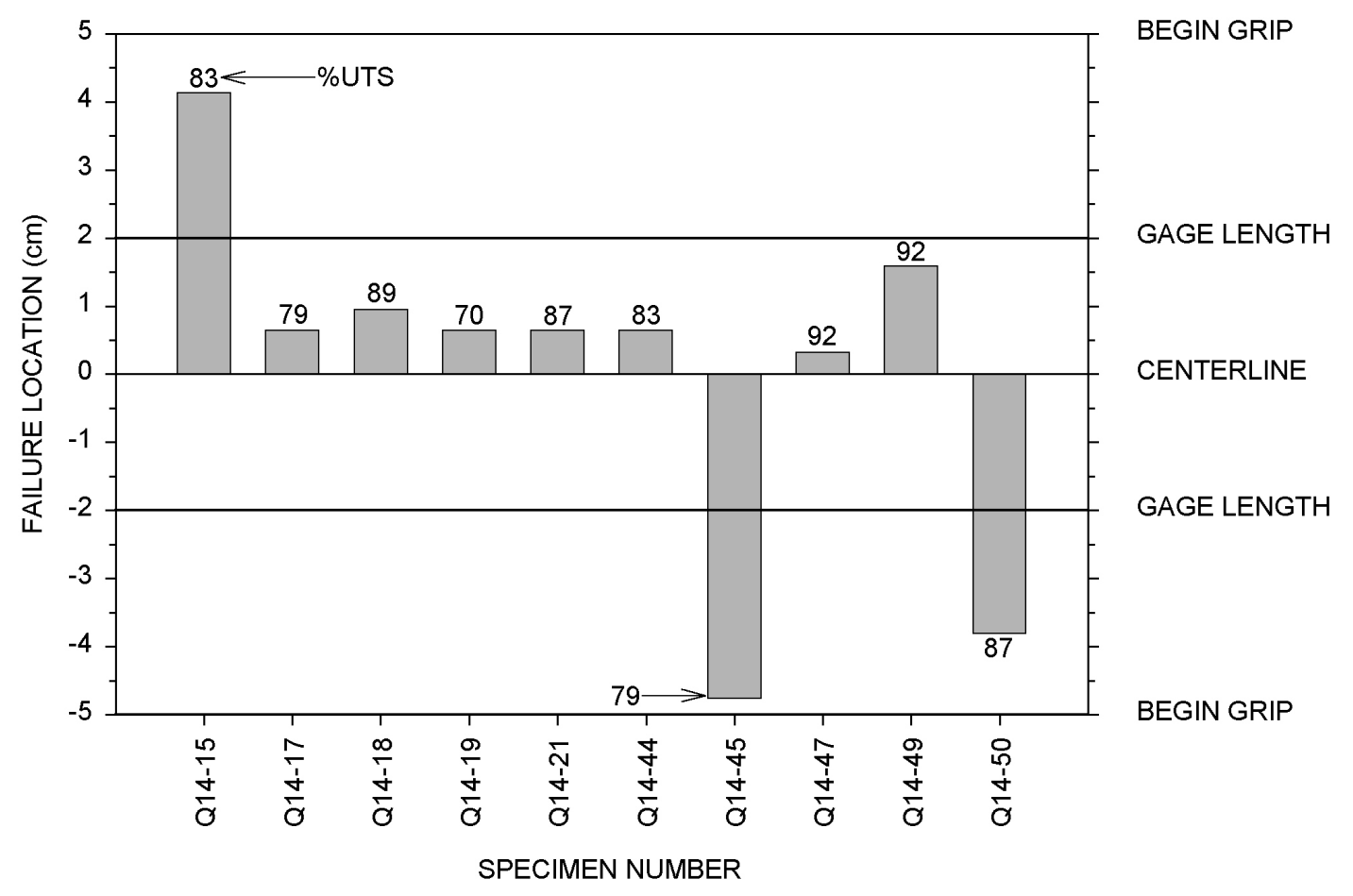

Fig. 9.22. Failure location for $70^{\circ} \mathrm{C}$ tests of plaque $\mathrm{Q} 14$. 


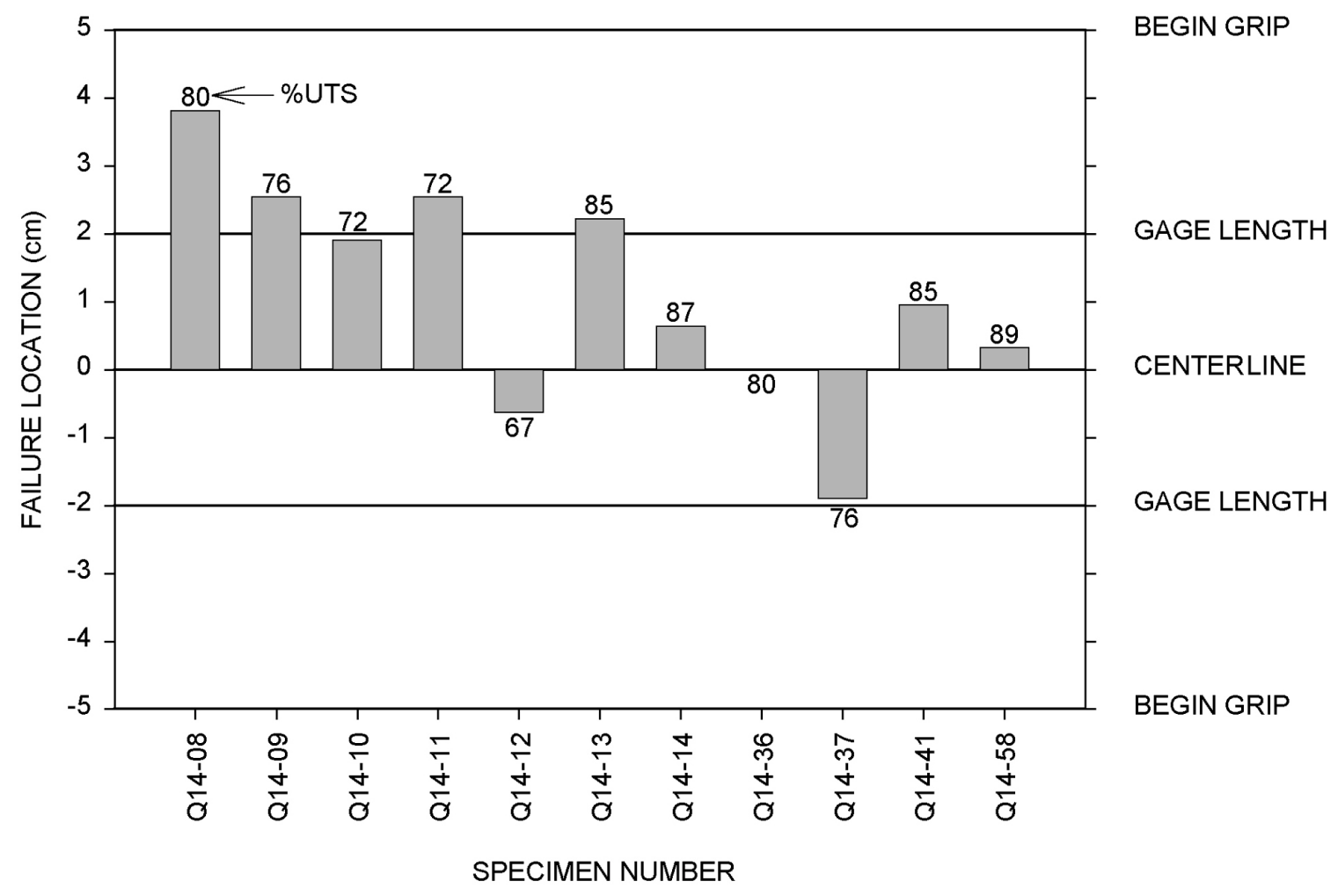

Fig. 9.23. Failure location for $120^{\circ} \mathrm{C}$ tests of plaque $Q 14$.

\subsection{FLUID EFFECTS}

Fatigue strength multiplication factors to account for fluid effects were developed in a similar manner to the temperature factors. The following two standard fluid conditions were examined:

- $\quad$ specimens soaked for $1000 \mathrm{~h}$ and then tested in distilled water, and

- specimens soaked for $100 \mathrm{~h}$ and then tested in windshield washer fluid (70\% methanol/30\% distilled water).

All of these room-temperature tensile fatigue $(\mathrm{R}=0.1)$ tests were carried out on specimens from a single plaque (Q15). In addition to the two fluid exposures, a baseline in-air test series was performed, and a resulting fatigue curve was also developed. The ratio of the fatigue strength from a fluid curve to the corresponding strength from the in-air curve provided the fluid reduction factors.

The S-N results of all three fatigue series are plotted in Fig. 9.24. The coefficients of determination, $\mathrm{r}^{2}$, for all three data sets are reasonably good, especially for the in-air and distilled water tests. The curve-fit equations shown in the figure were used to calculate the fluid multiplication factors. The resulting fluid factors are listed in Table 9.2 and were used in Sect. 4.3 of Part 1. In general, the factors in Table 9.2 are higher than the corresponding factors for the chopped-glass-fiber composite, but lower than the corresponding factors for the crossply carbonfiber composite (all had the same matrix). ${ }^{3,4}$ There appears to be less of a strength enhancement at the higher cycles than with the previous composite materials. 


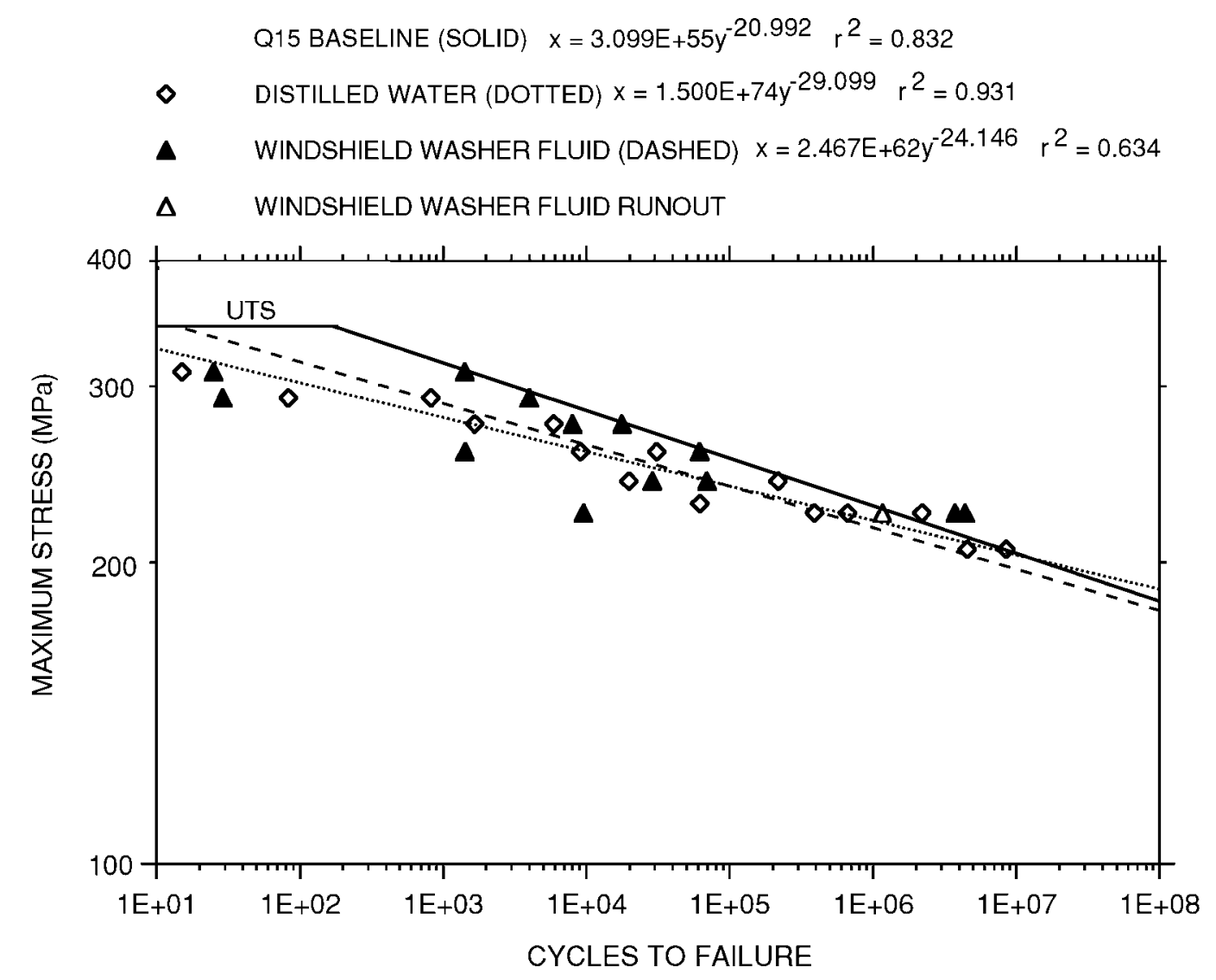

Fig. 9.24. Effects of fluids on room-temperature tensile fatigue strength for plaque Q15 specimens.

Table 9.2. Fatigue strength multiplication factors to account for fluid effects

\begin{tabular}{ccccc}
\hline \multirow{2}{*}{ Fluid condition } & \multicolumn{4}{c}{ Cycles to failure } \\
\cline { 2 - 5 } & $\mathbf{1 0}^{\mathbf{2}}$ & $\mathbf{1 0}^{\mathbf{4}}$ & $\mathbf{1 0}^{\mathbf{6}}$ & $\mathbf{1 0}^{\mathbf{8}}$ \\
\hline $\begin{array}{c}\text { 1000-h presoak in distilled } \\
\text { water }\end{array}$ & 0.92 & 0.91 & 0.97 & 1.03 \\
$\begin{array}{c}\text { 100-h presoak in windshield } \\
\text { washer fluid }\end{array}$ & 0.97 & 0.92 & 0.95 & 0.98 \\
\hline
\end{tabular}

Figure 9.25 shows the measured stiffness loss for the distilled water and windshield washer fluid specimens. The stiffness losses for all of the tests, except one, are seen to be less than $10 \%$ with the recommended factor of 20 design margin $\left(\mathrm{n} / \mathrm{N}_{\mathrm{f}}=0.05\right)$ on cyclic life. The circumstances surrounding the one test (Q15-7), and others, are complicated by a problem with the fluid containment system. The higher cycle, lower stress tests in both fluids presented a problem not encountered with the previous composites. Most, but not all, of the long-term (60 and 65\% UTS) stress tests developed fluid leaks relatively early in life. The specific tests were Q15-7, -11, -37 and -39. In two tests, Q15-7 and -35, the leaks increased to the point that fluid replacement during testing was not practical. Extensive interlaminar cracking from the gage length all the way through the radius region of the specimen proved to be the cause of the leaking. Figure 9.26 

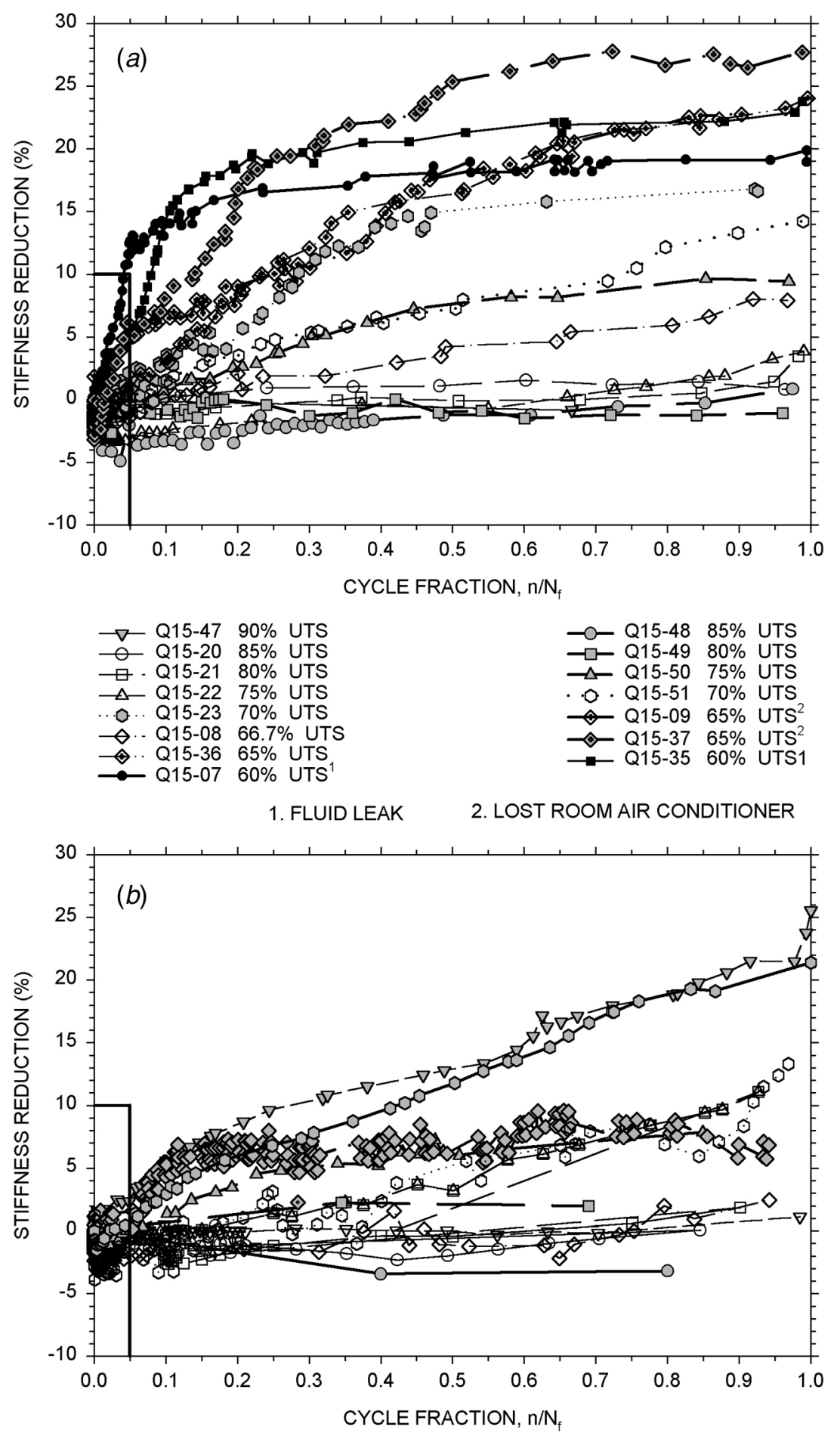

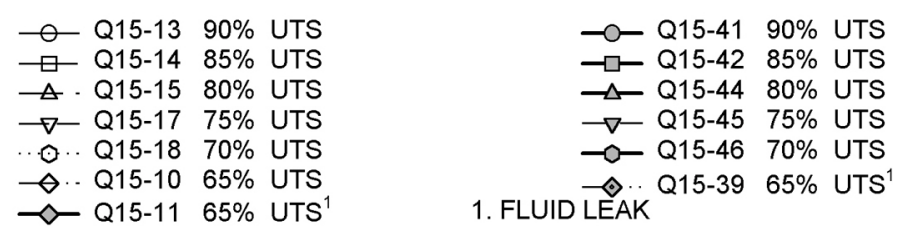

Fig. 9.25. Stiffness loss vs cycle fraction, $n / \mathbf{N}_{\mathbf{f}}$, for plaque $Q 15$ specimens in (a) distilled water and (b) windshield washer fluid. 


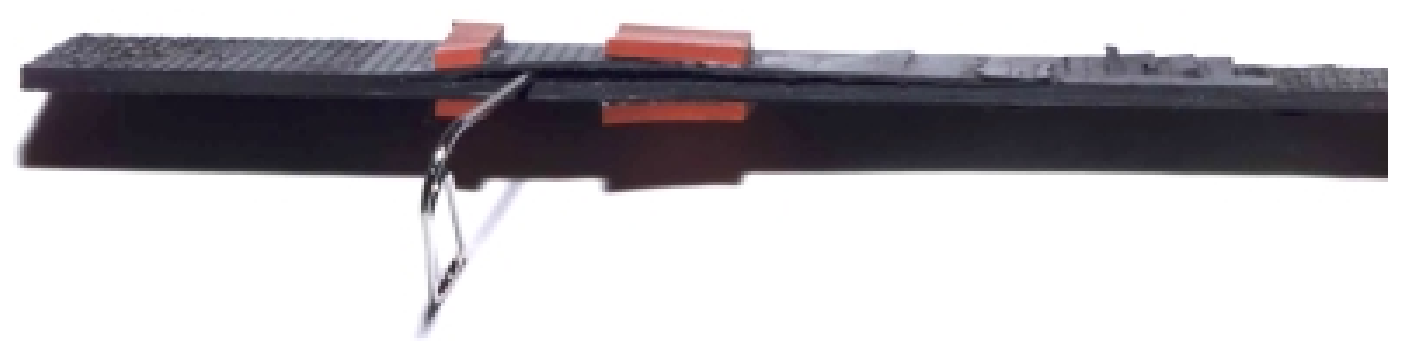

Fig. 9.26. Extensive interlaminar cracking in long-term fluid effects tests.

shows one edge of specimen Q15-7 with a paper clip holding the main crack open. Rubber pads glued on the specimen sides indicate the position and depth of two silicone caulk seals. The crack allowed the fluid to essentially bypass the seals. In the future, a new fluid containment system, which includes at least part of the lower grip and employs an immersible extensometer, appears to be the most technically correct method to successfully test this material at low stresses. The strain measurement accuracy may have been compromised on at least tests Q15-7 and -35, so the more than $10 \%$ reduction shown in Fig. 9.25 may not be totally attributable to normal material behavior.

The maximum cyclic strain vs cycle number for the tests in both fluids is shown in Fig. 9.27. The curves appear much the same as the in-air $23^{\circ} \mathrm{C}$ case that was shown in Fig. 9.3(b). The average cyclic temperatures as a function of cycle fractions for both series are shown in Fig. 9.28. In the case of these fluid tests, the thermocouple measured the fluid temperature just off the specimen surface and at the centerline. Tape was not used because it might impede fluid migration into the specimen during fatigue cycling. The small step jumps in temperature of tests Q15-9 and -37 are due to the loss of the laboratory air conditioner. Neither of these perturbations can be seen in the stiffness reduction or maximum strain plots. Figure 9.29 shows the failure locations referenced to the specimen centerline, along with the maximum stresses as a percent of UTS for each specimen for the two series. A slightly larger percentage of the failures occurred within the desired portion of the specimen than in the case of the room-temperature, in-air test series, and there appears to be no clear correlation between failure location and stress.

\subsection{MEAN STRESS EFFECTS}

While tensile cycling with $\mathrm{R}=0$, which leads to fatigue lives very similar to those for $\mathrm{R}=$ 0.1 discussed previously in this chapter, is likely to commonly occur in automotive structural components, other types of cycles, with various mean stresses, are equally likely. Consequently, design guidance cannot be limited to tensile cycling only; provisions are needed for assessing other cycle types as well.

To address this need for the quasi-isotropic composite, a limited series of mean-stress fatigue tests was conducted. Four cycle types, depicted in Fig. 9.30, were used. Two of them- $\mathrm{R}=0$ tension and the cycle with a tensile mean stress of $50 \%$ of the UTS - involved only tensile stresses. The other two cycle types-fully-reversed loading, $\mathrm{R}=-1$, and zero to a compressive loading, $\mathrm{R}=-\infty$-involved compressive stresses.

Because compressive loadings, and thus the potential for buckling failure modes, were involved in two of the four cycle types, hourglass-shaped specimens were used for all four. 

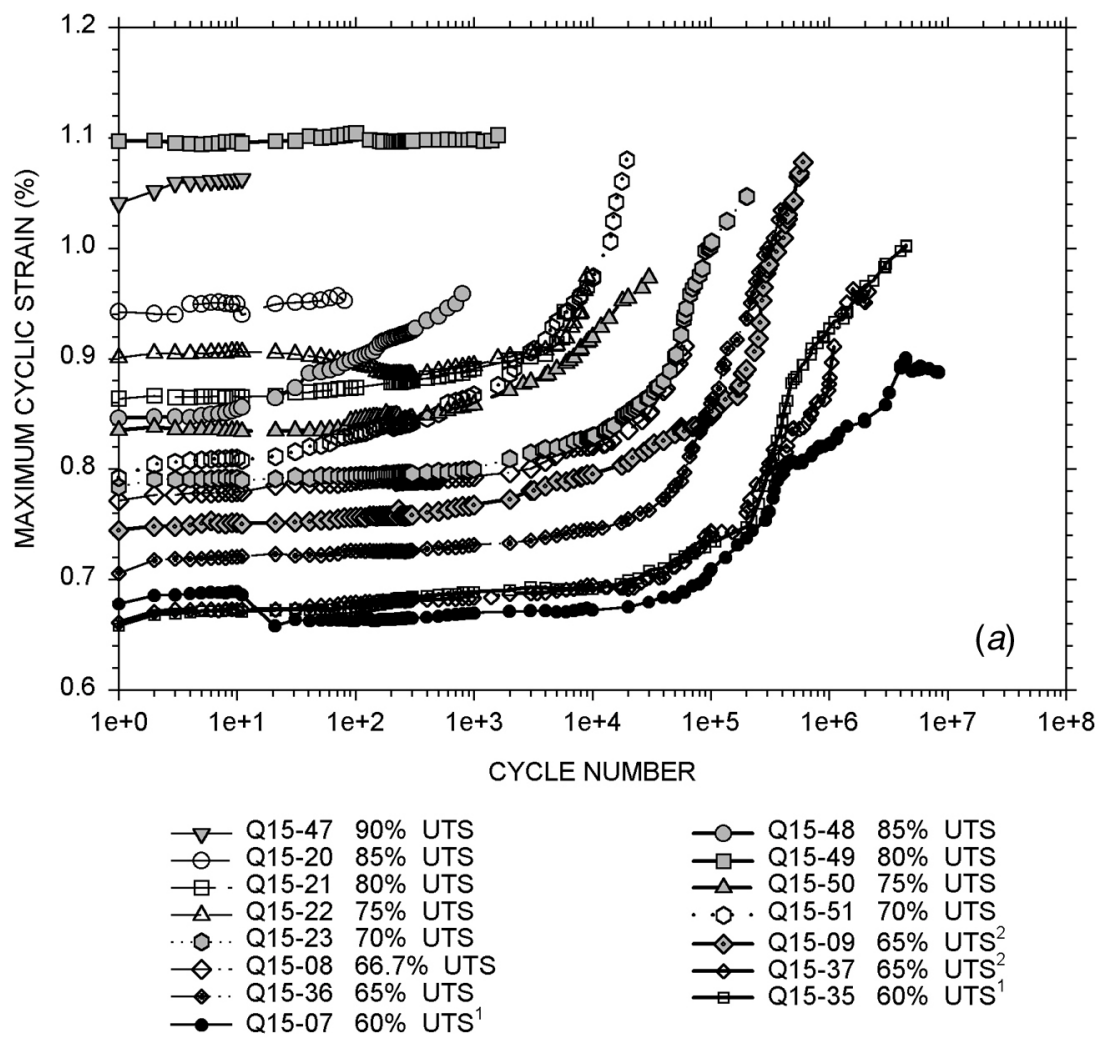

-0- Q15-48 85\% UTS

$\rightarrow \square-Q 15-49 \quad 80 \%$ UTS

$\rightarrow \square$ Q15-50 $75 \%$ UTS

- $\bigcirc$. Q15-51 70\% UTS

$\therefore-$ Q15-09 65\% UTS

$\leadsto$ Q15-37 65\% UTS

$\rightarrow$ Q15-36 $65 \%$ UTS

$\begin{array}{ll}\text { 1. FLUID LEAK } & \text { 2. LOST ROOM AIR CONDITIONER }\end{array}$

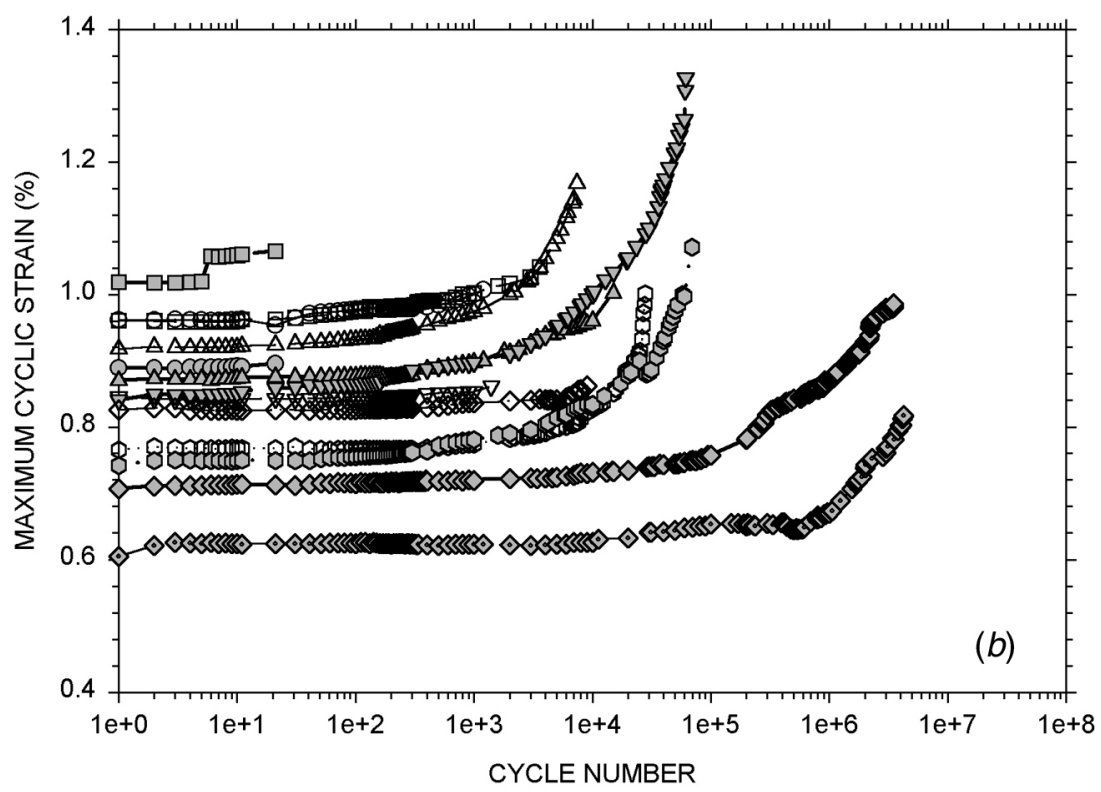

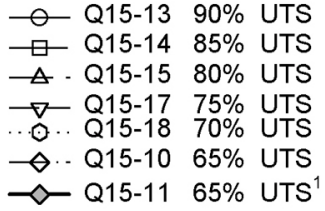

- - Q15-41 $90 \%$ UTS

$\rightarrow-$ Q15-42 $85 \%$ UTS

$\triangle \quad$ Q15-44 80\% UTS

$\rightarrow$ Q15-45 75\% UTS

. . Q15-46 70\% UTS

$\therefore$ Q15-39 $65 \%$ UTS $^{1}$

1. FLUID LEAK

Fig. 9.27. Maximum strain behavior for plaque Q15 specimens in (a) distilled water and (b) windshield washer fluid. 

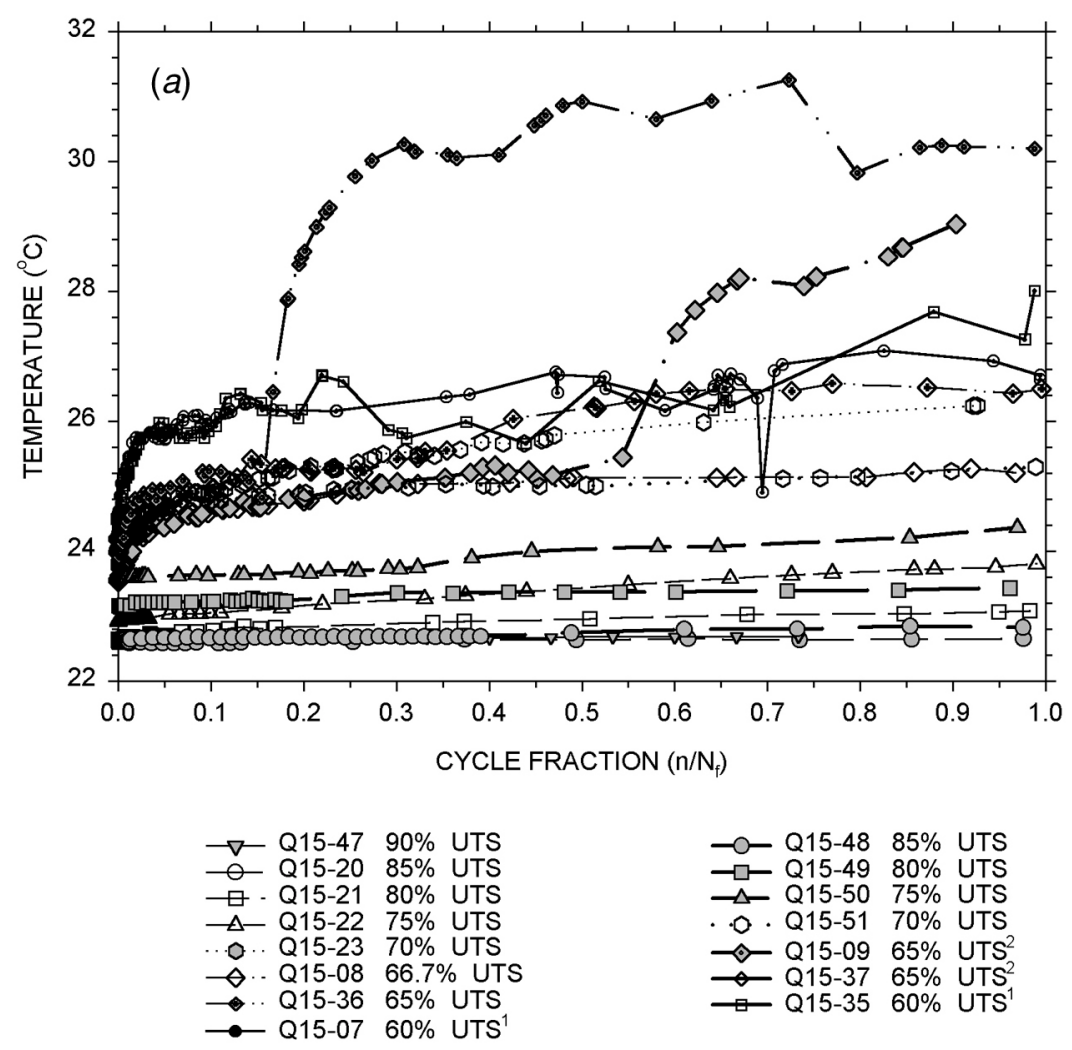

1. FLUID LEAK

2. LOST ROOM AIR CONDITIONER

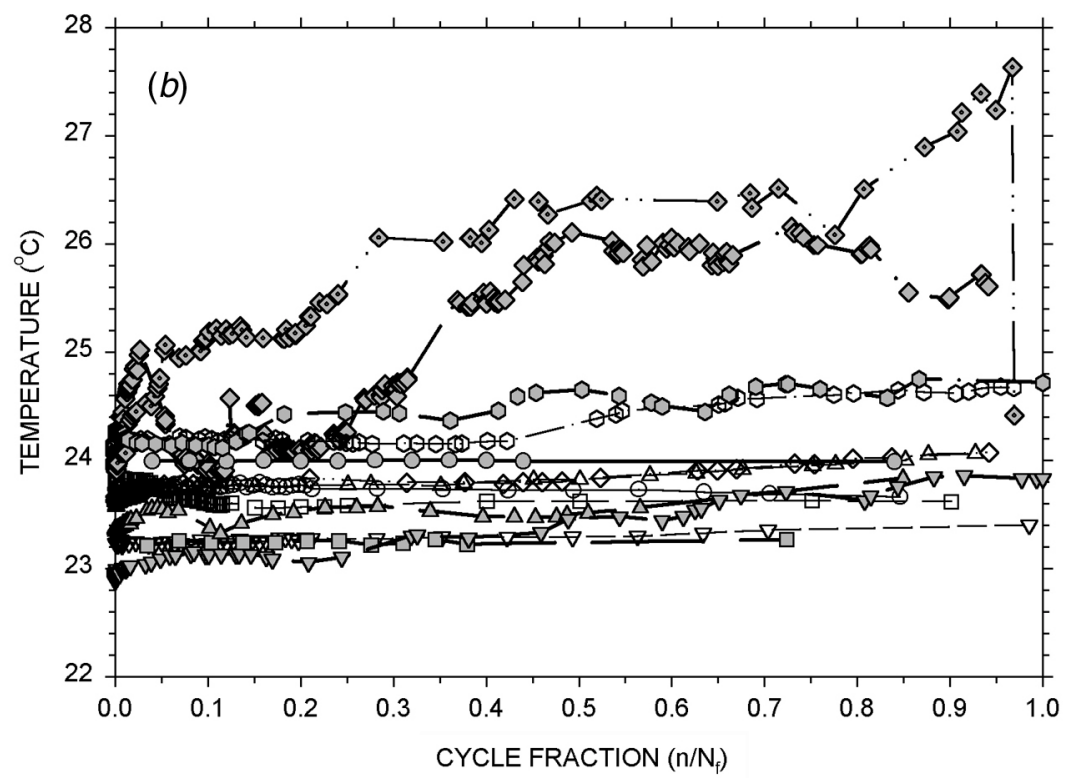

-O- Q15-41 90\% UTS $\rightarrow \square-Q 15-42 \quad 85 \%$ UTS $\triangle$ Q15-44 80\% UTS $\rightarrow-Q 15-45 \quad 75 \%$ UTS -O- Q15-46 70\% UTS $\curvearrowright$ Q15-39 65\% UTS ${ }^{1}$

1. FLUID LEAK

Fig. 9.28. Temperature vs cycle fraction, $\mathbf{n} / \mathbf{N}_{\mathbf{f}}$, for plaque $Q 15$ specimens in (a) distilled water and $(b)$ windshield washer fluid. 

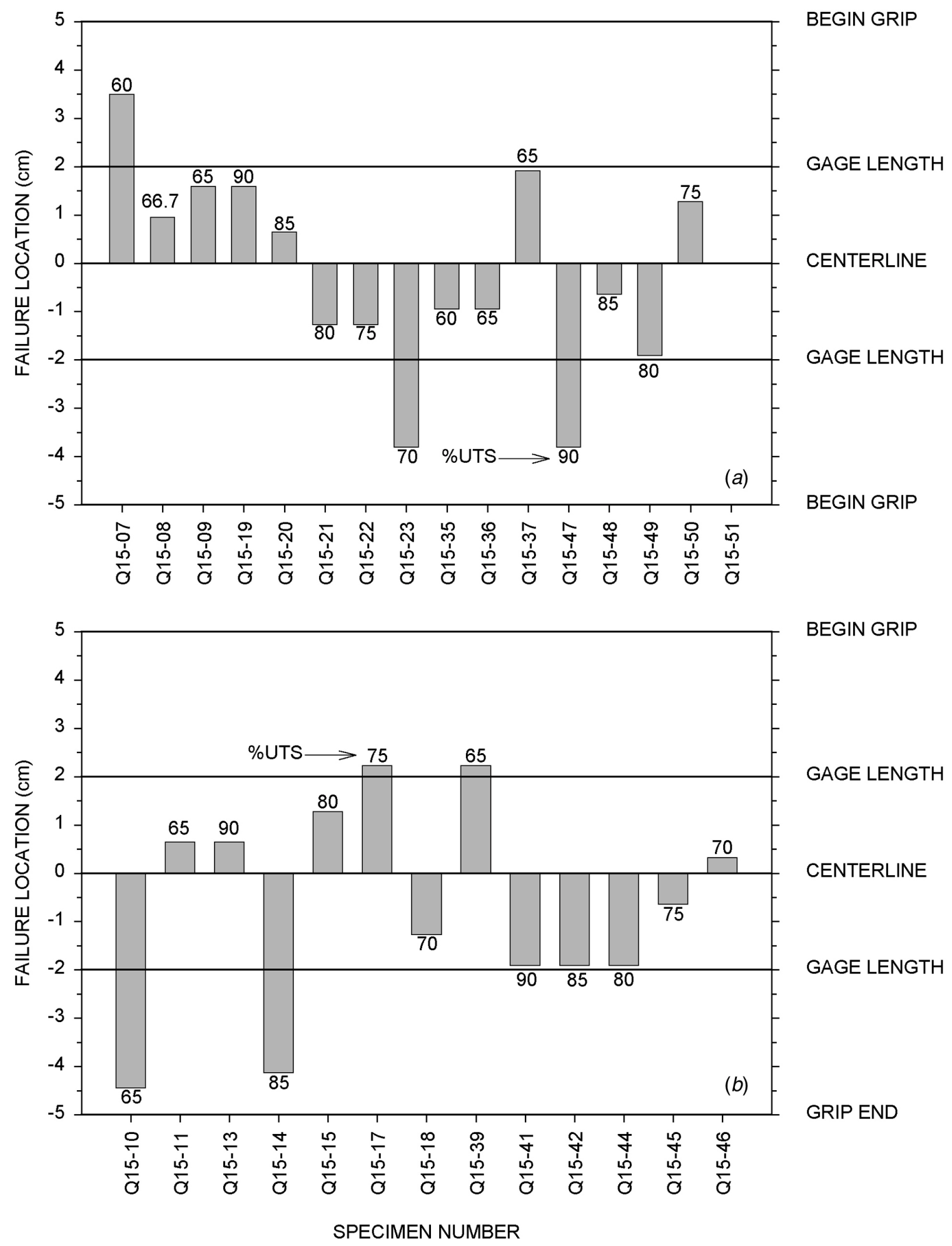

Fig. 9.29. Failure location for plaque $Q 15$ specimens in (a) distilled water and (b) windshield washer fluid. 

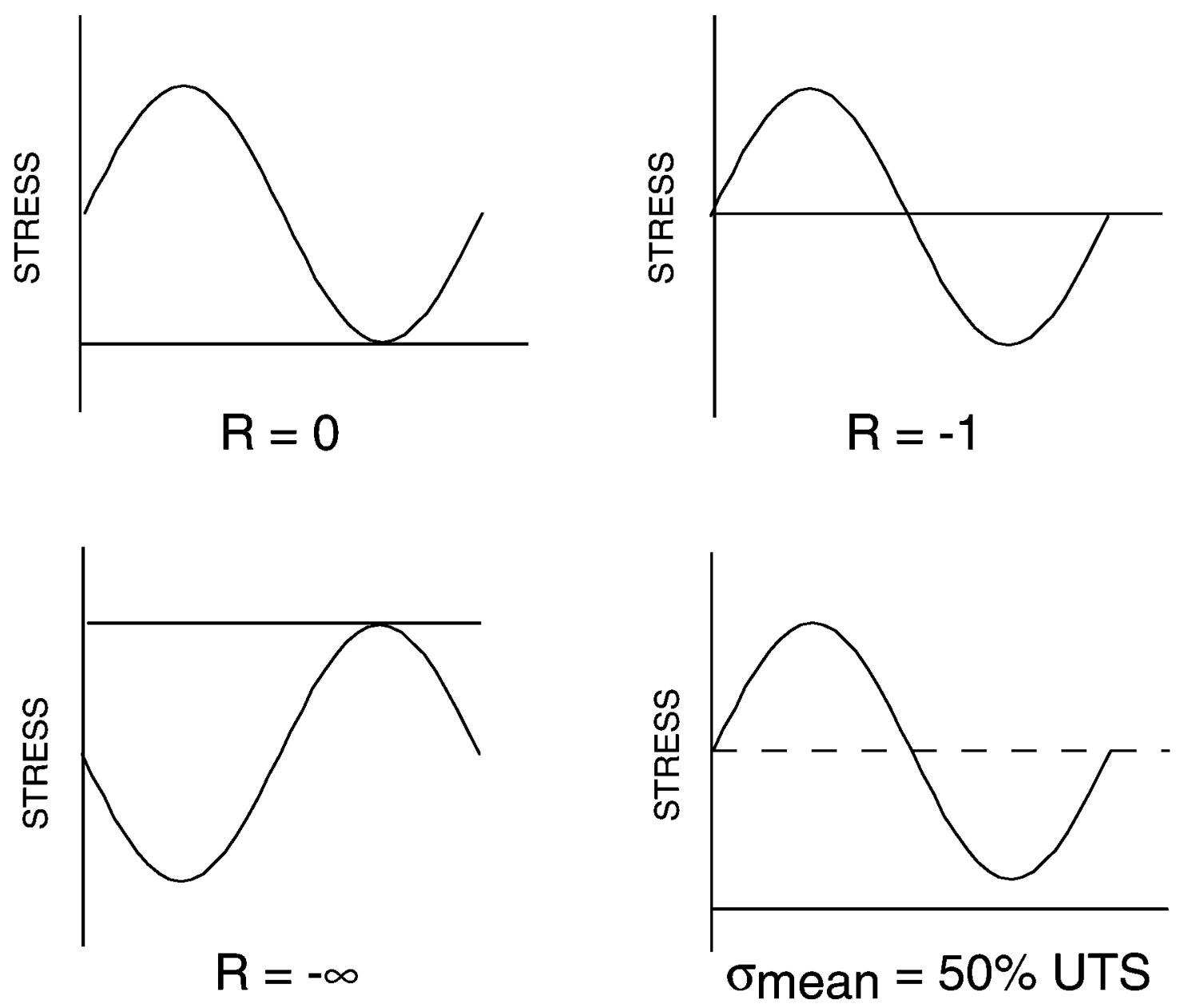

Fig. 9.30. Four cyclic stress histories used to examine mean stress effects.

Actually, two slightly different specimen designs, as shown in Fig. 9.31, were used for each cycle type. The first design, Fig. 9.31(a), was that used for tests on each of the previous three composite materials. $^{2-4}$ Because the quasi-isotropic material is thinner than the previous three composites - $2 \mathrm{~mm}$ vs $3 \mathrm{~mm}$ - and because future materials may be even thinner and even more prone to buckling, it was decided to evaluate a modified specimen having a shorter length and smaller radius in the hourglass section. This "new" specimen is shown in Fig. 9.31(b). While the new specimen may be somewhat more resistant to buckling, the stress concentration that is inherent in an hourglass specimen is greater than in the "old" specimen. Finite-element analyses of both specimens show that the axial stress at the edges in the middle of the hourglass section is $3.5 \%$ higher than the average axial stress in the old specimen and $10.4 \%$ higher in the new specimen.

All of the mean-stress test specimens came from a single plaque (Q9), and there were an equal number of specimens of the "old" and of the "new" designs. Six to eight tests were nominally performed on each specimen design for each of the four cycle types.

Plaque Q9, from which the hourglass specimens came, was somewhat thicker and weaker than plaques Q14 and Q15, from which the dogbone fatigue specimens were obtained. These differences are quantified in Table 9.3. 

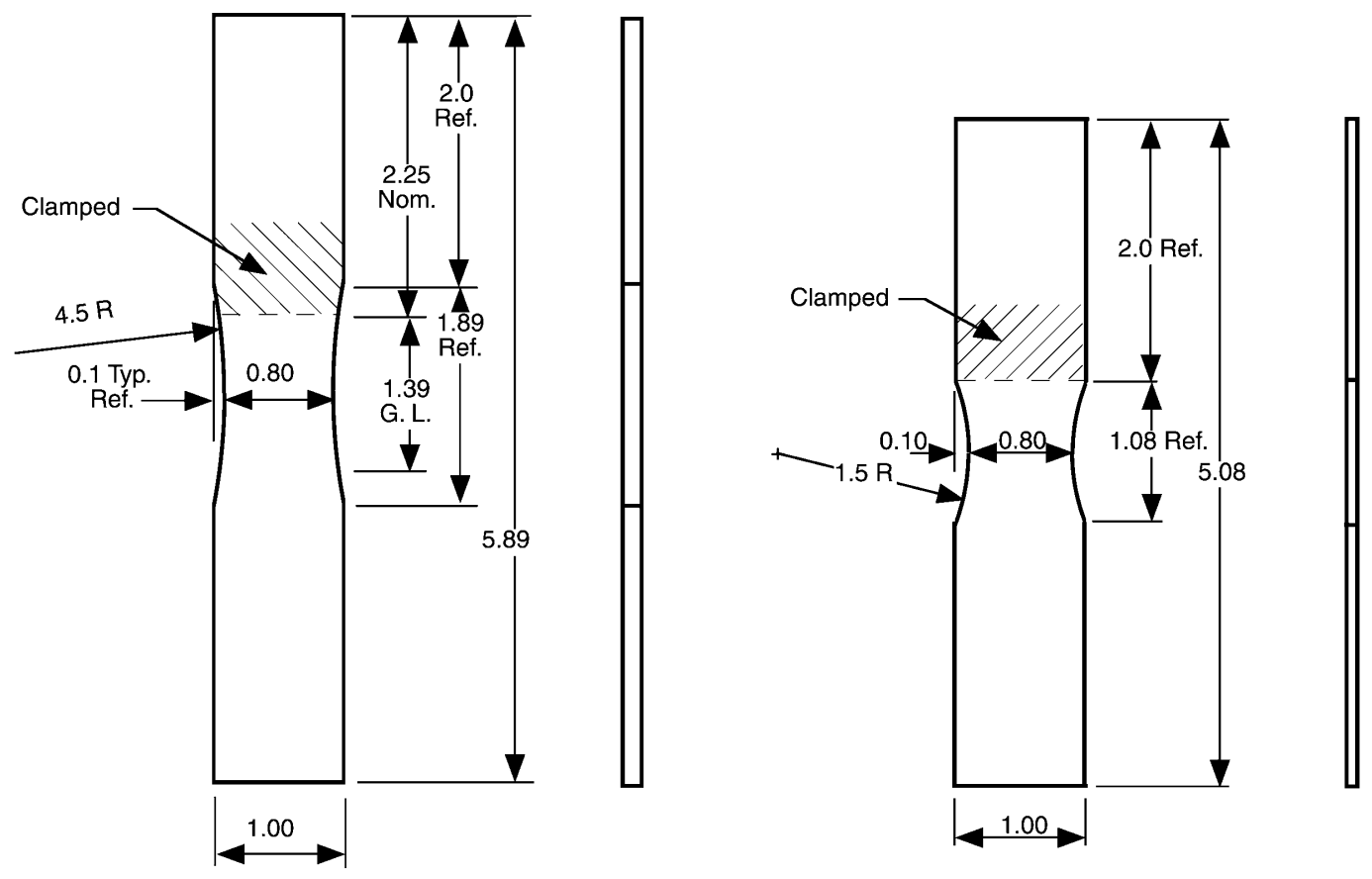

Dimensions in inches

(a)

(b)

Fig 9.31. Hourglass specimen configurations used for mean stress tests: (a) original (old) specimen developed for random-glass-fiber composites and $(b)$ new specimen design intended to be more buckling resistant $(1 \mathrm{in} .=\mathbf{2 5 . 4} \mathbf{~ m m})$.

Table 9.3. Comparison of plaque Q9 with plaques Q14 and Q15

\begin{tabular}{ccccc}
\hline Plaque No. & $\begin{array}{c}\text { Modulus of } \\
\text { elasticity } \\
\text { (GPa) }\end{array}$ & UTS (MPa) & $\begin{array}{c}\text { Average } \\
\text { thickness } \\
\text { (mm) }\end{array}$ & $\begin{array}{c}\text { Maximum to } \\
\text { minimum } \\
\text { thickness } \\
\text { variation (\%) }\end{array}$ \\
\hline 9 & 30.6 & 299 & 2.35 & 29.5 \\
14 & 32.9 & 328 & 2.19 & 12.1 \\
15 & 32.2 & 344 & 2.18 & 15.5 \\
\hline
\end{tabular}

Tensile fatigue $(\mathrm{R}=0)$ results for the two hourglass specimen designs are shown in Fig. 9.32, where they are compared with the previously presented dogbone specimen tensile $(\mathrm{R}=$ 0.1 ) results. The new specimen results are close to the $R=0.1$ results and exhibit somewhat longer fatigue lives than the old specimen results. The latter observation is true for all four cycle types; the new specimen design gave slightly longer lives. This is despite the fact that stress concentrations are higher in the new specimen. The increased cyclic life is probably due to the increased lateral restraint in the shorter new specimen.

Because mean stress data are limited and because the difference in old and new specimen results is not too large, it was decided to lump the two sets of data together for analysis in each case. The result for the tensile $\mathrm{R}=0$ case is shown in Fig. 9.33, where the data and resulting 


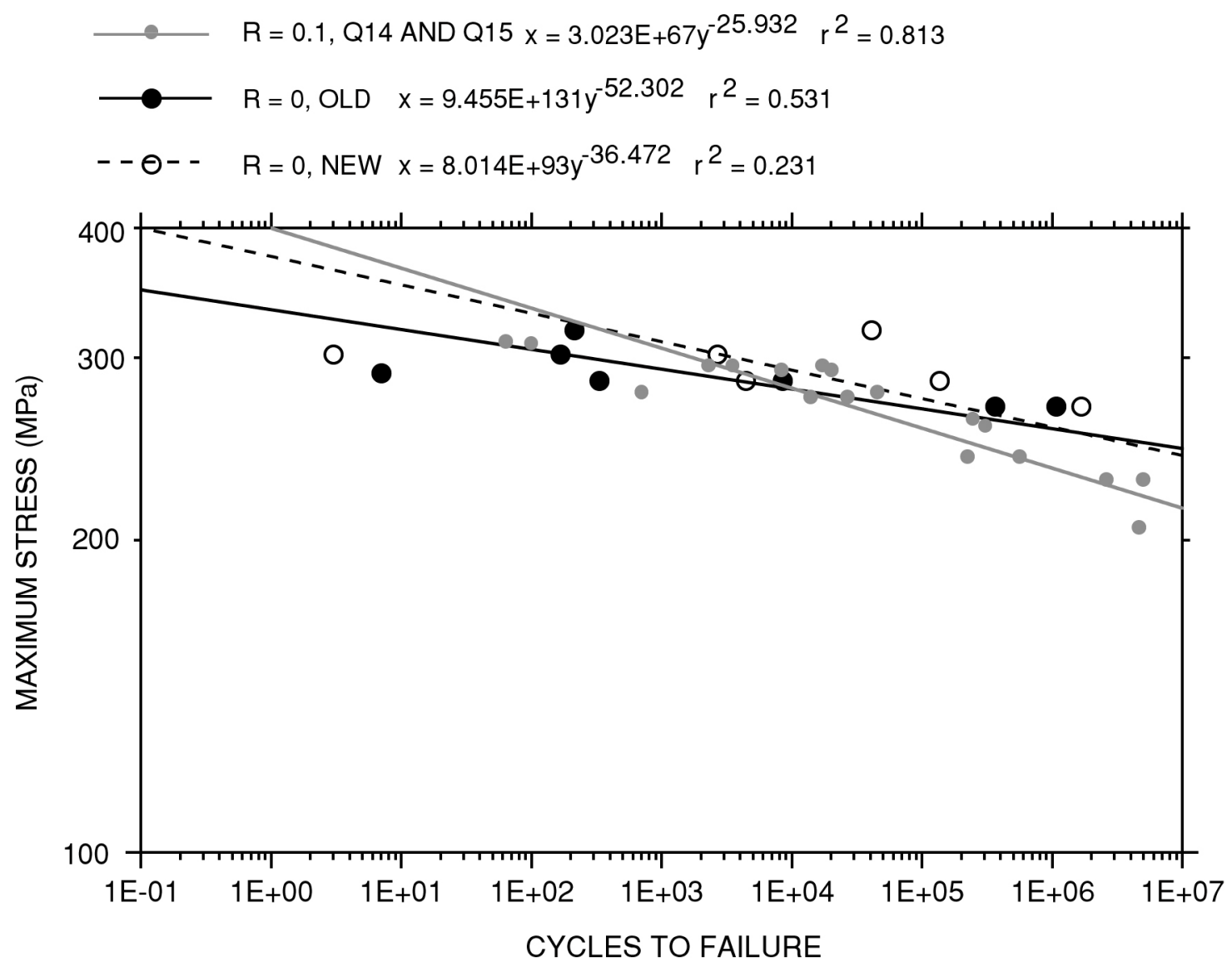

Fig. 9.32. Comparison of tensile $(R=0) \mathrm{S}-\mathrm{N}$ curves generated from hourglass specimens with S-N curve generated from dogbone specimens with $R=0.1$. The dogbone specimen data and curve are shown in gray. 


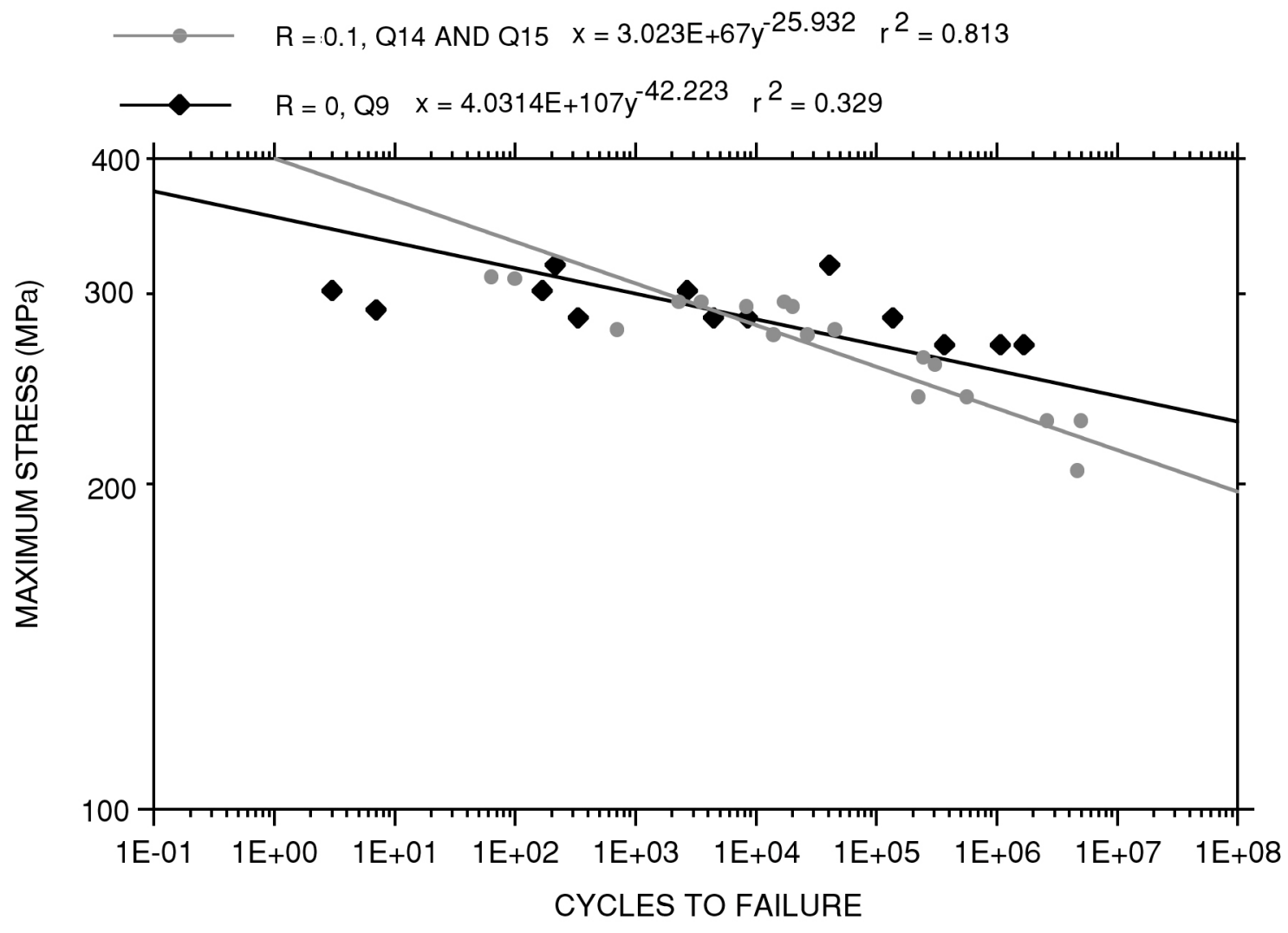

Fig. 9.33. Tensile $(R=0)$ fatigue curve for old and new hourglass specimen data lumped together. The dogbone specimen data and curve $(R=0.1)$ are again shown in gray for reference.

power-law $\mathrm{S}-\mathrm{N}$ curve are again compared with the tensile $\mathrm{R}=0.1$ data and curve from dogbone specimens cut from plaques Q14 and Q15. The hourglass specimen curve is slightly more shallow than the dogbone specimen curve when plotted on a maximum stress basis. This may result, at least in part, from the lower tensile strength of plaque Q9, compared to that of Q14 and Q15.

Figure 9.34 shows the S-N curves for all four cycle types compared on the basis of the maximum stress, $S_{\max }\left(\right.$ or $\left.\left|S_{\min }\right|\right)$, reached in the cycle. Clearly $S_{\max }$ does not correlate the results well; the two cycle types that went into compression have a steeper slope.

Several investigators ${ }^{13,14}$ have noted the difference in the results from tensile cycles and those from cycles that go into compression. The failure mode is different, and the S-N curves have different slopes. In the case of the current results, there is a marked difference in failure mode, as illustrated in Fig. 9.35. Tensile specimens - either those corresponding to $\mathrm{R}=0$ or to a $50 \%$ UTS mean stress - broke into two pieces, with a clean transverse break in the outer surface plies (recall that the surface fibers are transverse to the specimen axis). The compressive specimens $-\mathrm{R}=-\infty$ and $\mathrm{R}=-1$ - developed a major delamination, generally not at the center of the specimen thickness. The thinner of the two intact layers then began to buckle and crack upon each cyclic loading, presumably caused by overall bending and buckling of the thicker layer. This buckling occurred in both old and new specimen designs.

Figure 9.36 shows the data and resulting curves using the alternating stress component, $\mathrm{S}_{\mathrm{a}}$, rather than the maximum stress as the correlating parameter. The results for all four cases are grouped more closely than they were in Fig. 9.34, but a significant discrepancy still exists in the slopes. 


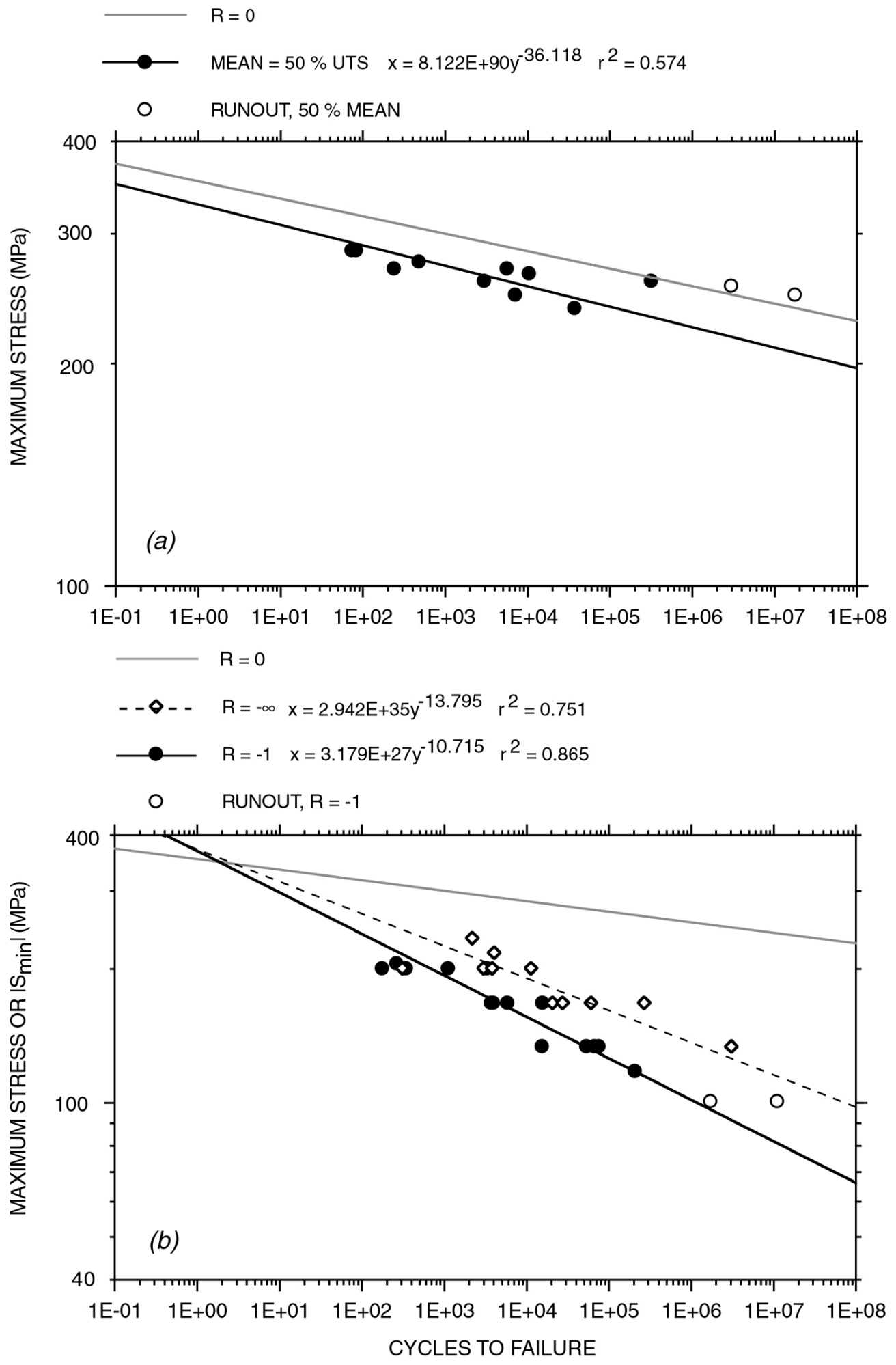

Fig. 9.34. Fatigue curves from four different mean-stress cycle types compared on basis of maximum stress, $S_{\max }$, in cycle: $(a)$ tensile cycles and (b) compressive cycles. 


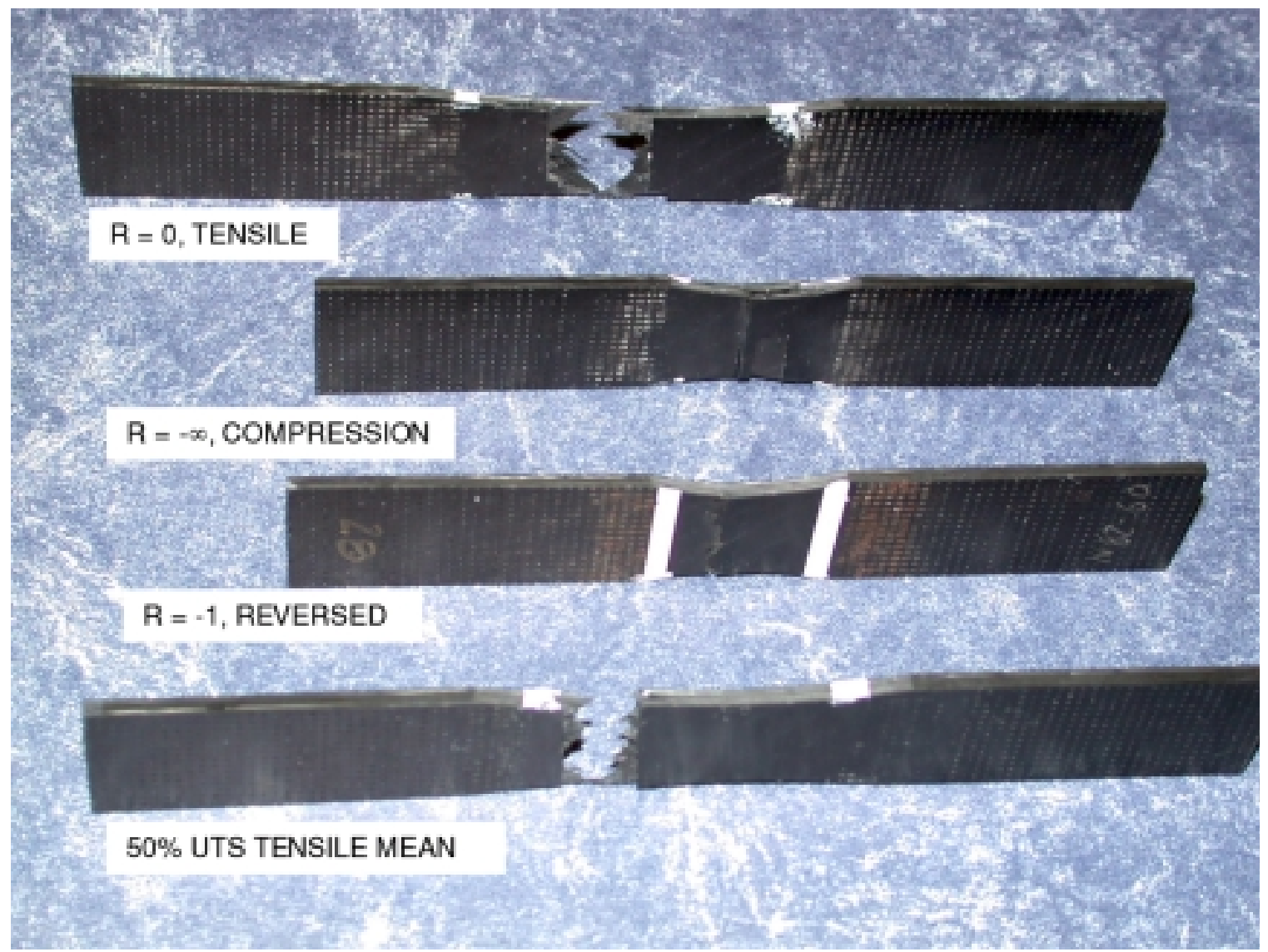

Fig. 9.35. Typical failed hourglass specimens from each mean-stress cycle type. 


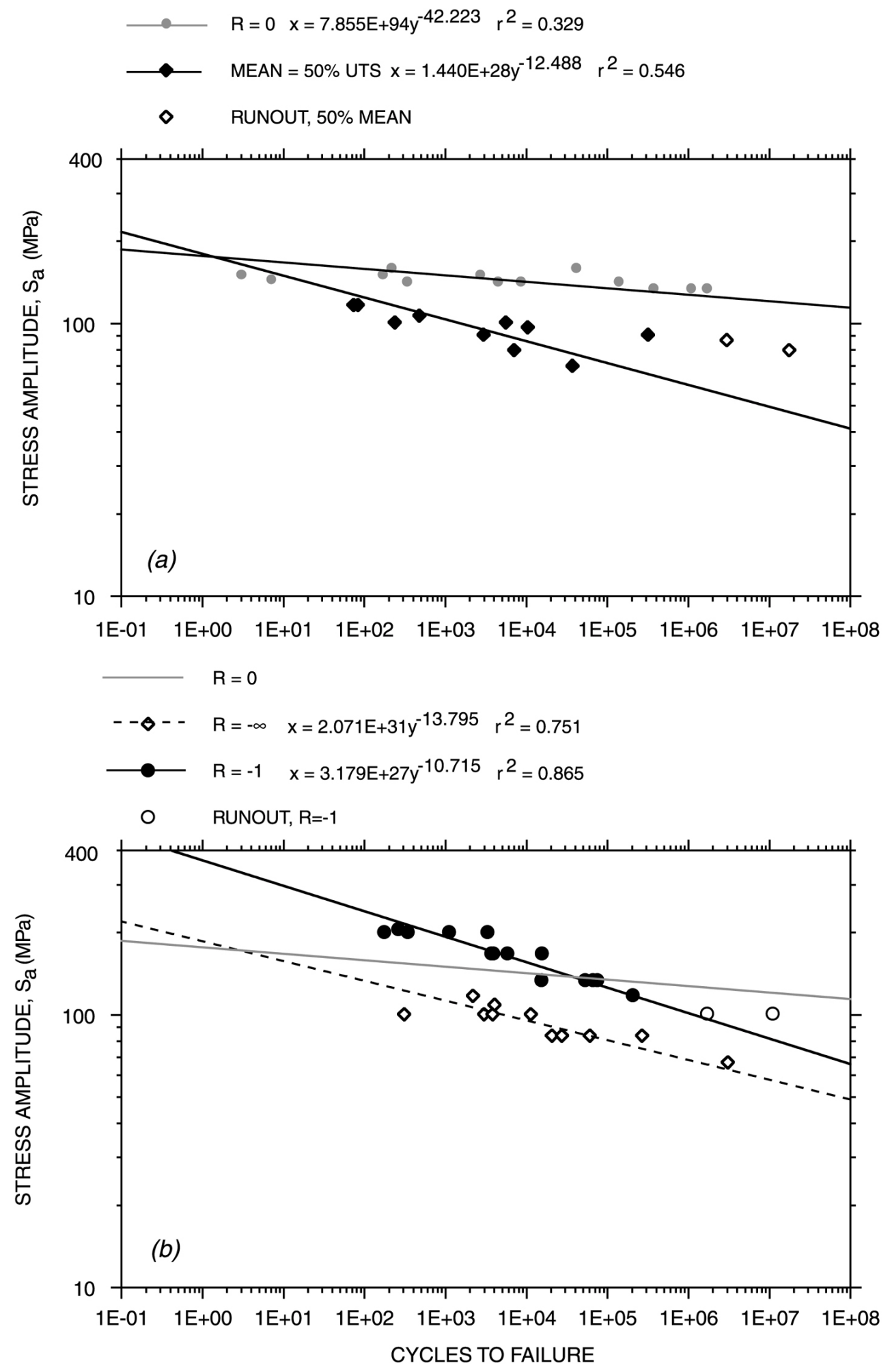

Fig. 9.36. Fatigue curves from four different mean-stress cycle types compared on basis of alternating stress, $S_{a}$, in cycle: $(a)$ tensile cycles and $(b)$ compressive cycles. 
One final stress parameter tried was that suggested by Conle and Ingall. ${ }^{13}$

$$
\mathrm{S}=\sqrt{\mathrm{S}_{\max } \times \mathrm{S}_{\mathrm{a}}} .
$$

They observed that several sets of data from the literature could be correlated with this parameter, provided that tension and compression were treated separately. The parameter was successfully used previously for both the chopped-glass-fiber composite and the crossply carbon-fiber composite. ${ }^{3,4}$ It does not work well here, however, as shown in Fig. 9.37.*

Owen and Smith ${ }^{14}$ suggested several forms of the Goodman relation for correlating composite fatigue results from tests with various mean stresses. The simplest of these, shown below, was found to work reasonably well for the quasi-isotropic composite.

$$
\mathrm{S}_{\mathrm{a}}=\mathrm{S}_{\mathrm{o}}\left(1-\frac{\sigma_{\mathrm{m}}}{\mathrm{UTS}}\right)
$$

Here, $S_{a}$ is the alternating stress in a cycle having mean stress $\sigma_{m}$, and $S_{o}$ is the alternating stress in a fully-reversed cycle $(R=-1)$ at a given cyclic life (i.e., the predicted value of $S_{a}$ is for the same cyclic life as that corresponding to $S_{o}$ in the fully-reversed cycle).

With Eq. (9.3) and the expression relating cyclic life to alternating stress component for the $\mathrm{R}=-1$ test series [Fig. 9.36(b)], $\mathrm{S}_{\mathrm{a}}$ for any of the other three test series can be predicted. The resulting predictions are compared with the data in Figs. 9.38 and 9.39, for tension and compression, respectively. With the exception of the tensile $\mathrm{R}=0$ case, where the prediction is conservatively low at lower stress levels, the agreement between measured and predicted fatigue lives is good. $\dagger^{\dagger}$ Thus, use of Eq. (9.3) is recommended for the design guidance in Chap. 4 of Part 1 .

\subsection{SUMMARY AND RECOMMENDATIONS}

The purpose of this section is to summarize and draw conclusions from the cyclic fatigue information that has been presented and to develop recommendations on which the fatigue design guidance in Chap. 4 of Part 1 is based.

The design approach recommended in Chap. 4 of Part 1 for $\mathrm{R}=0$ tensile loading makes use of a room-temperature design curve based on tensile $(\mathrm{R}=0.1)$ cycling. The construction of that curve is shown in Fig. 9.40. The baseline data and power law curve fit to the data are shown. The tick mark labeled " $\mathrm{S}_{0}$ " in Fig. 9.40 represents the basic allowable tensile stress value determined earlier for $23^{\circ} \mathrm{C}$ (see Sect. 3.1 of Part 1). Because the range of the design fatigue curve includes the basic allowable stress, fatigue is seen to be a significant consideration for this material. Even though the cyclic stiffness data presented in this chapter indicate that a design margin of 20 on cycles is sufficient to limit stiffness loss to $10 \%$ or less at room temperature, an additional multiplication factor of $\mathrm{UTS}_{\min } / \mathrm{UTS}_{\mathrm{avg}}=0.90$ was applied to stress to obtain the final design curve. This was judged to be necessary because of the significant scatter in fatigue life.

A second design curve, based on fully reversed $(\mathrm{R}=-1)$ cycling, is provided in Chap. 4, along with the Goodman relation in Eq. (9.3), for all other loading cycles involving mean stresses. This second curve, which is shown in Fig. 9.41, was developed by applying the same

\footnotetext{
*Note in Fig. 9.37(a) that the data for the 50\% UTS tensile mean stress case are too limited and scattered to provide a well-defined fit. Using $\mathrm{y}=\mathrm{f}(\mathrm{x})$ to fit the data would likely result in a better fit and in the two curves in the figure being more parallel.

$\dagger$ Note that in the compressive $(\mathrm{R}=-\infty)$ cycle, the absolute value of negative mean stress was used in Eq. (9.3). A compressive mean stress does not increase strength, contrary to reported results for some other composites.
} 


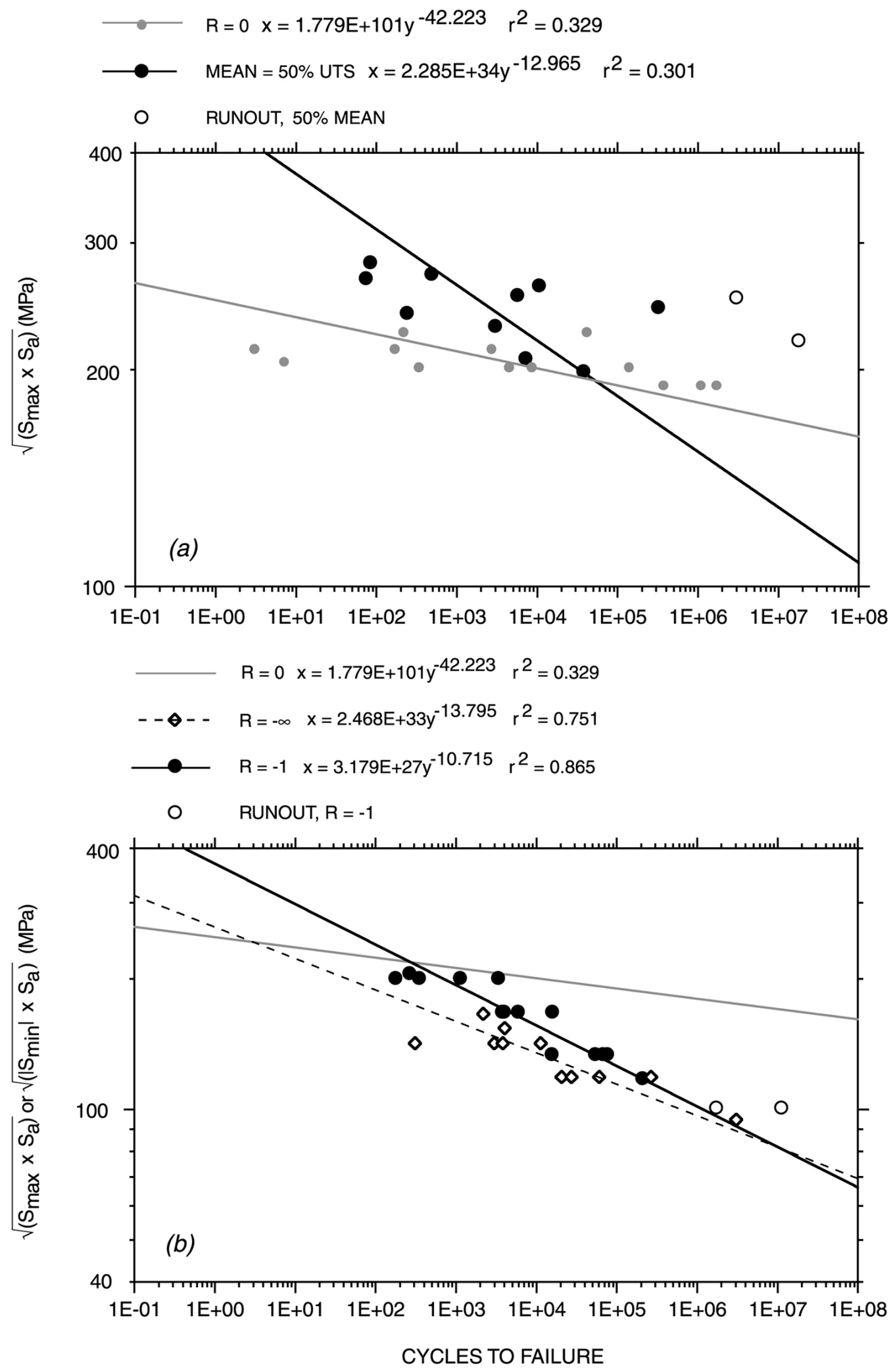

Fig. 9.37. Fatigue curves from four different mean-stress cycle types compared on basis of stress parameter $\sqrt{S_{\max } \times S_{a}}$ or $\sqrt{\left|S_{\min }\right| \times S_{a}}:(a)$ tensile cycles and (b) compressive cycles. 


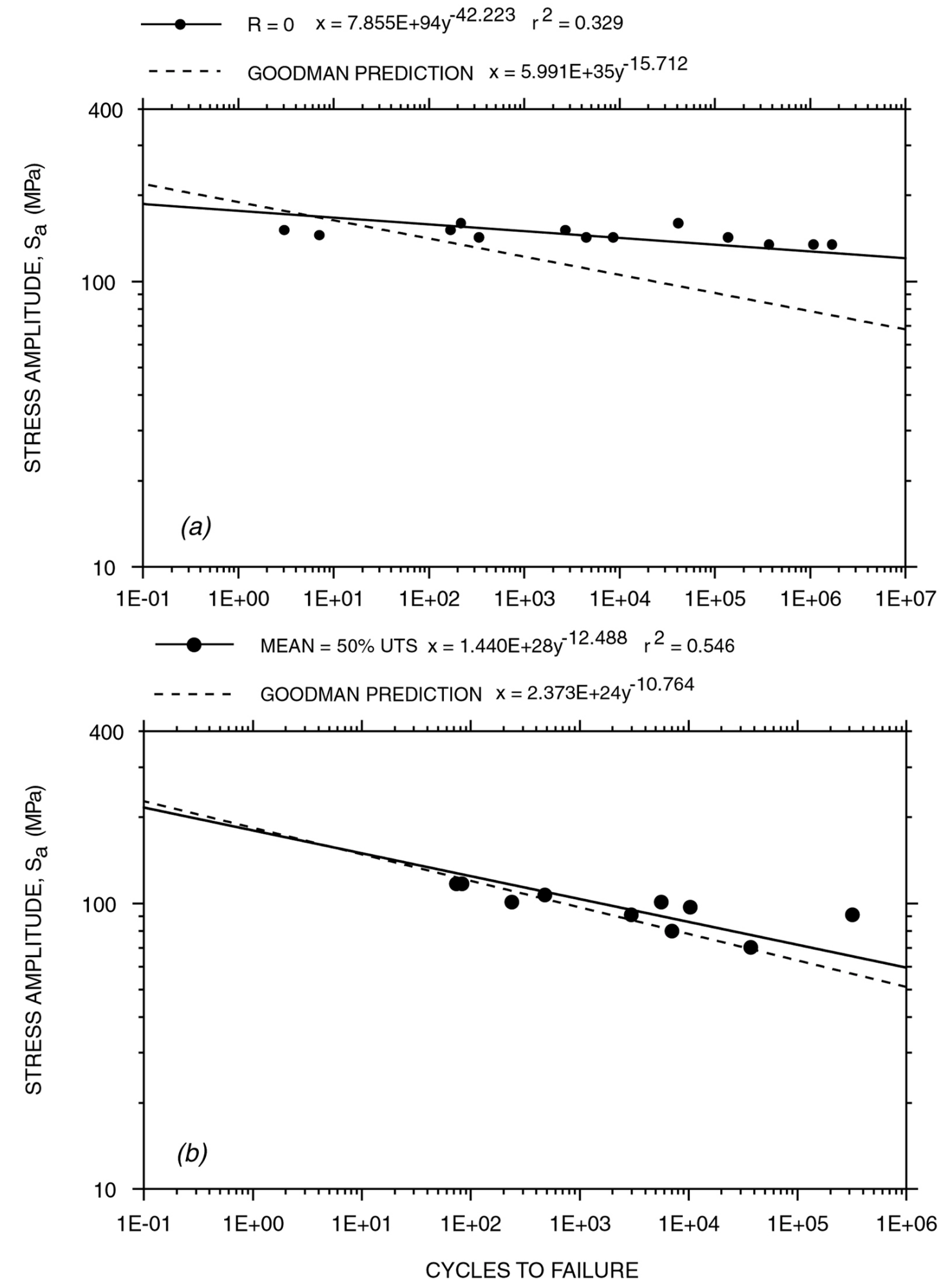

Fig. 9.38. Comparison of Goodman predictions (based on $\mathbf{R}=-1$ correlation) with experimental data and curve for tensile mean-stress cycle types: $(a) R=0$ and $(b)$ tensile mean stress of $50 \%$ UTS. 


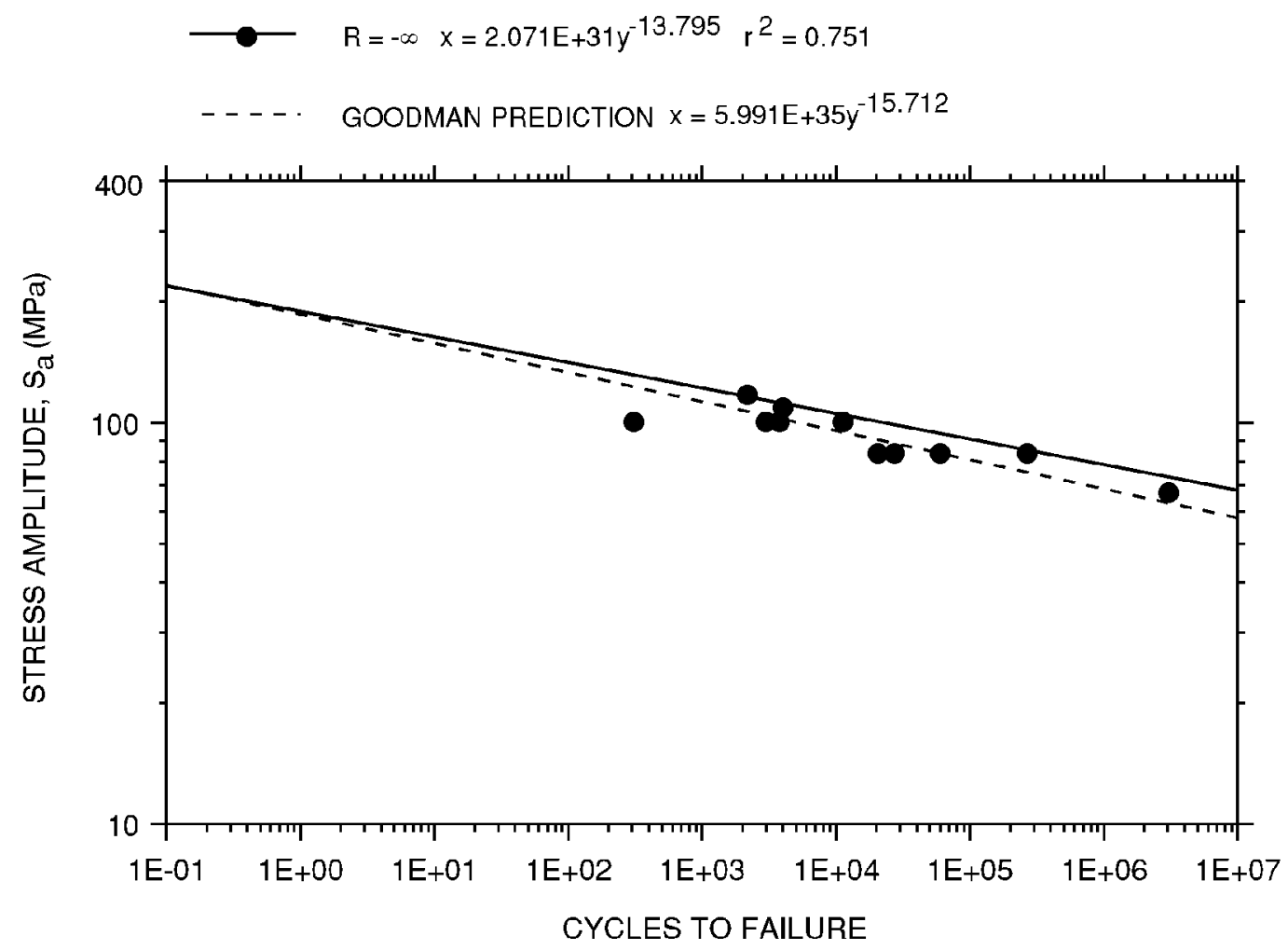

Fig. 9.39. Comparison of Goodman prediction (based on $R=-1$ correlation) with experimental data and curve for compressive mean-stress cycle type $(R=-\infty)$.

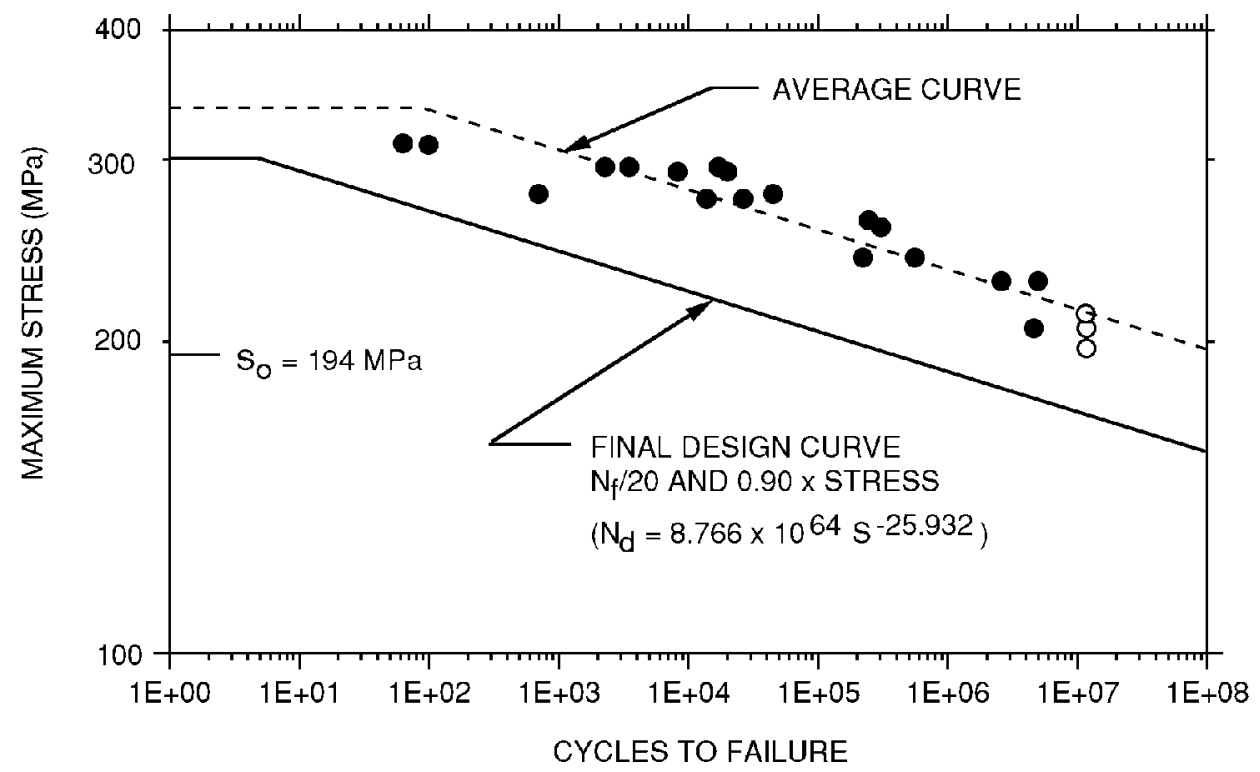

Fig. 9.40. Final room-temperature design fatigue curve for tensile cycling. 


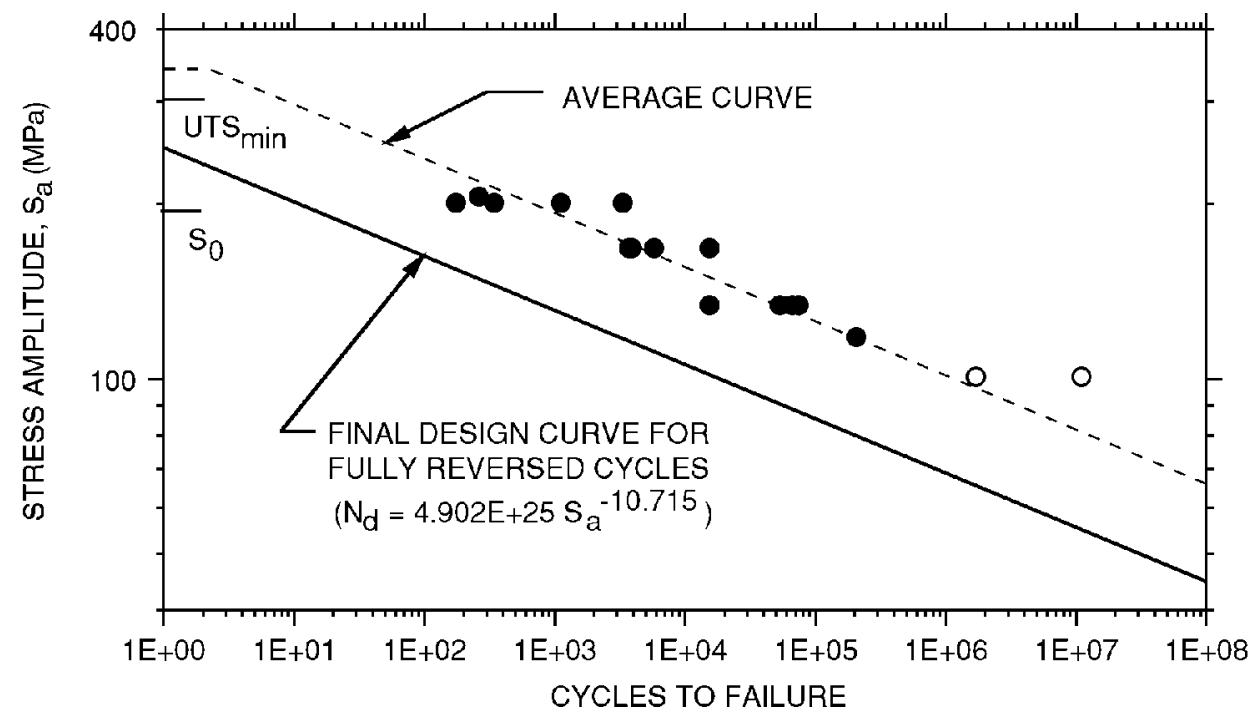

Fig. 9.41. Room-temperature design fatigue curve for fully reversed cycling.

two design factors, used in the previous paragraph for tensile $(\mathrm{R}=0)$ cycling, to the $\mathrm{R}=-1 \mathrm{~S}-\mathrm{N}$ curve given in Fig. 9.36(b).

Multiplication factors on the room-temperature fatigue strength values were developed to handle both temperature and fluid effects. These factors are applied to both design fatigue curves in Chap. 4. The fatigue factors are generally similar to those observed for the chopped-glass-fiber composite and the $0 / 90^{\circ}$ crossply carbon-fiber composite previously characterized. 3,4 The significant exception is the $120^{\circ} \mathrm{C}$ case. The fatigue strength reduction factor at $120^{\circ} \mathrm{C}$ is less (greater reduction) for the glass-fiber composite at low cycles but significantly greater at high cycles. In the case of fluid effects, the carbon-fiber composite generally exhibited greater resistance than did the glass-fiber composite and almost identical resistance to that of the $0 / 90^{\circ}$ crossply carbon-fiber composite. 


\title{
10. CREEP DEFORMATION
}

\author{
J. M. Corum, R. L. Battiste, and M. B. Ruggles-Wrenn
}

\subsection{INTRODUCTION}

Constant-load tensile creep-deformation tests were performed both in air at room temperature and elevated temperature and in fluids (distilled water with a 1000-h presoak and windshield washer fluid with a 100-h presoak). A few compressive creep tests were also performed in air at room temperature and elevated temperature. Elevated temperature tests were primarily at $120^{\circ} \mathrm{C}$. The approach was to develop a room-temperature tensile creep equation, well supported by experimental data, and to then develop creep multiplication factors to approximately characterize the effects of temperature, fluids, and compressive loadings in terms of the roomtemperature in-air response.

These steps are described in the following sections of this chapter. First, however, the results from a series of short-time pilot tests will be described. Also, because time-dependent creep strains in the quasi-isotropic composite are small, expansion and contraction strains due to the ingress and egress of moisture in a specimen are relatively large, even those due to changes in RH. These effects will be discussed before presenting the main results on which the roomtemperature creep equation and the factors are based.

\subsection{SHORT-TIME PILOT TESTS}

A series of short-time (nominally 24-h) pilot tensile creep tests was performed in an MTS hydraulic test machine using an averaging MTS extensometer. The 25.4-mm-gage length extensometer was mounted on the two edges of a standard 20.3-mm-wide dogboned tensile specimen. These tests were meant to serve a twofold purpose. First, they helped to scope the expected response in longer-term tests performed on dead-weight creep machines and thus helped in the choice of stress levels to be used. Second, they allowed a tentative creep equation to be established, based just on 24-h test data. The feasibility of basing a creep equation just on shorttime data was then later assessed by comparing the predictions with long-term data.

Figure 10.1 shows the results of the short-time tests. Stress levels are expressed as a percentage of the average UTS, $329 \mathrm{MPa}$, for the two plaques used in the creep studies-Q10 $(\mathrm{UTS}=325 \mathrm{MPa})$ used for short-time tests and Q16 (UTS $=333 \mathrm{MPa})$ used for long-term tests. One $30 \%$ test, two $40 \%$ tests, four $60 \%$ tests, and two $80 \%$ tests are shown. Data from each individual test were fit with a power-law equation of the following form, which is the basis for the solid curves in the figure.

$$
\varepsilon_{\mathrm{c}}=\mathrm{At}^{\mathrm{n}} \text {. }
$$

Figure 10.2 shows the same data and curve fits as in Fig. 10.1, but on a log-log scale. Here the power laws are straight lines with slopes $n$. It can be seen from the data that the slope in each test decreases with time. At the lower stresses a longer time is required to reach a constant slope. The final slope appears to decrease with increasing stress level. As can be seen from Fig. 10.2, the power laws were fit only to the latter part of each set of data, where the slope appeared to approach a constant value. From the log-log plot, it appears that $24 \mathrm{~h}$ may be insufficient to reach constant values of $n$, particularly at the lower stress levels.

The coefficients, A, and exponents, $\mathrm{n}$, from the individual power-law curve fits were plotted as functions of stress. Curve fit expressions for $\mathrm{A}$ and $\mathrm{n}$ were then obtained and substituted into 


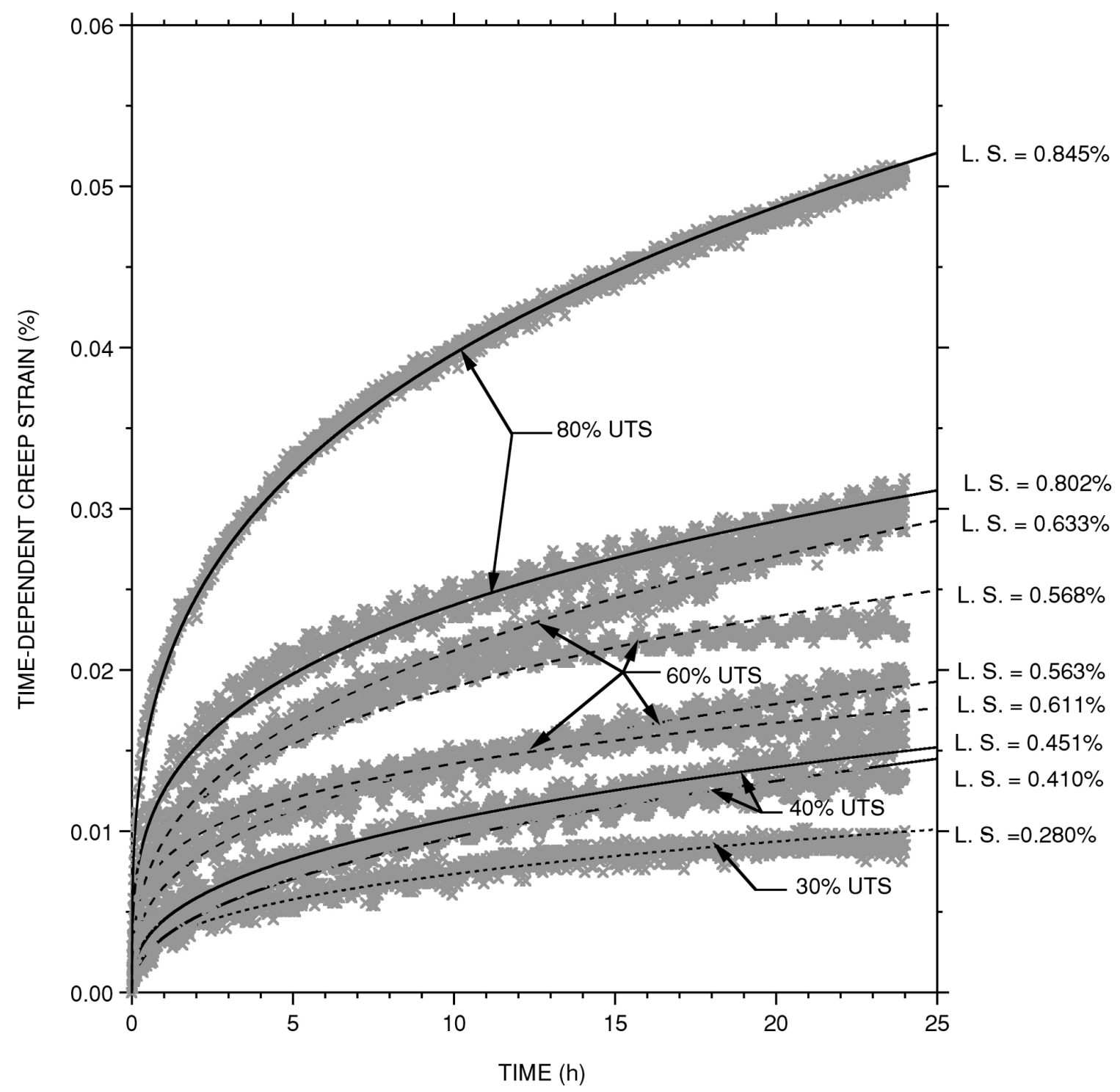

Fig. 10.1. Results of short-time (nominally 24-h) pilot creep tests. The values to the right of the plot are the measured loading strains. 


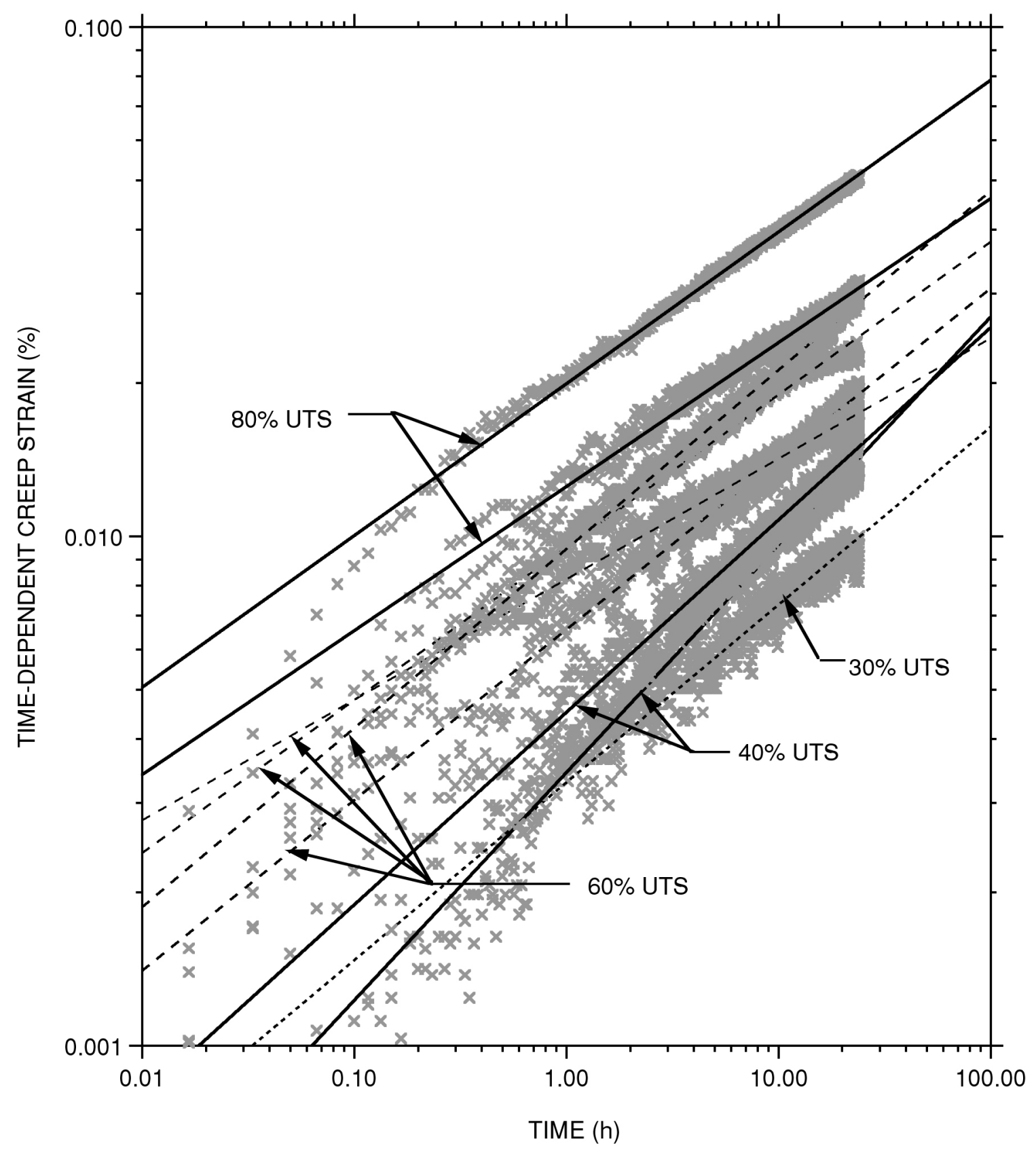

Fig. 10.2. Short-time test data on log-log coordinates with power-law curve fits.

Eq. (10.1) to obtain a "master" creep equation based on the short-time data. Predictions of the master equation are compared in Fig. 10.3 with the original data. The representation is good, particularly at the lower stress levels. The data become increasingly scattered as the stress increases because of the random development of damage, particularly in the outer plies of transverse fibers, which affects the measured strain.

Figure 10.4 shows predictions of long-term creep response by the master equation based on short-time data. These curves will be compared later in this chapter with predictions based on long-term data. 


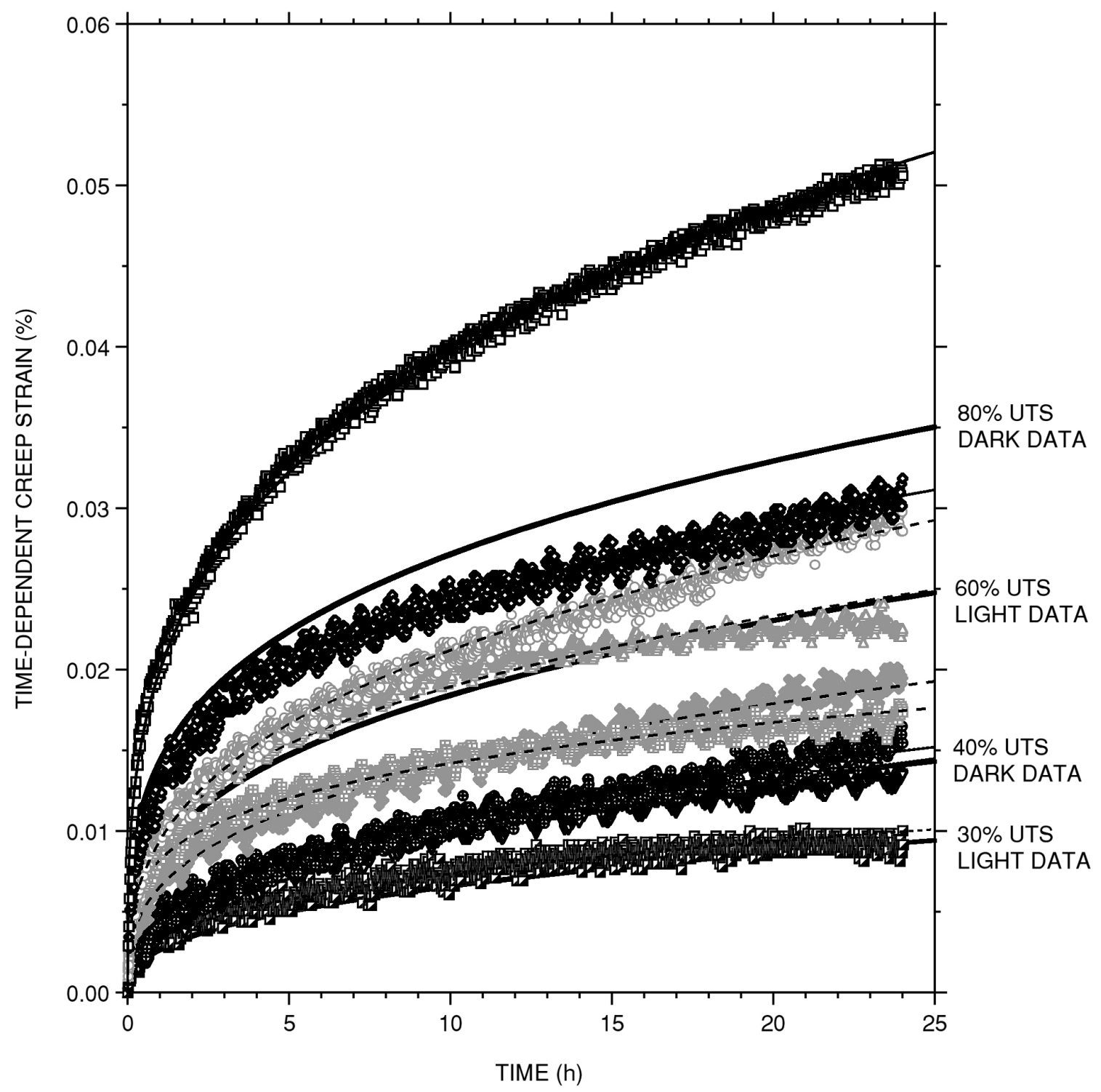

Fig. 10.3. Comparison of predictions of short-time master creep equation with data. 


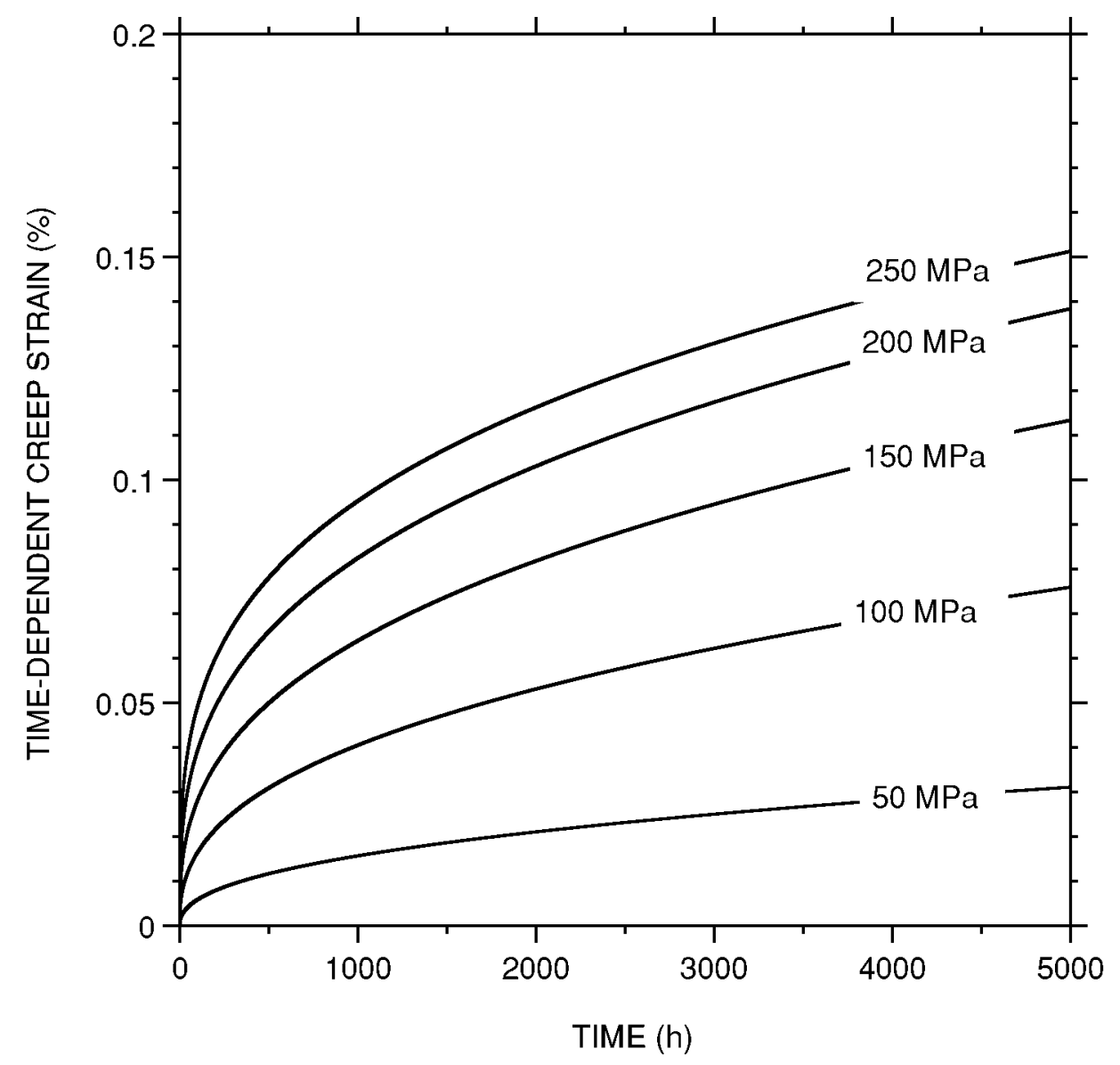

Fig. 10.4. Long-time creep strain predictions based on short-time (24-h) data.

\subsection{MOISTURE EFFECTS}

In three separate cases, 24-h creep tests were allowed to continue over a weekend during which a major drop in outside temperature occurred. This led to an interesting behavioral revelation, as illustrated by the typical results shown in Fig. 10.5. The measured time-dependent strain is shown as a function of time, along with the outside temperature and RH variation.* The laboratory RH was recorded a couple of times on Friday and again on Monday. The curve through these points illustrates that the indoor laboratory humidity dropped over the weekend; the laboratory temperature remained reasonably constant throughout the test period.

During the first $24 \mathrm{~h}$ of the test, the outside temperature was warm and essentially constant. Near the end of the 24 -h test, the outside humidity rose to nearly $100 \%$, followed by the appearance of a cold front. The temperature dropped over Friday night, rose slightly on Saturday, and dropped further Saturday night. This led to the drop in laboratory humidity and to a slightly delayed drop in specimen strain as moisture was lost from the specimen.

* Meteorological data are recorded and maintained for various sites around the Oak Ridge Reservation. The data plotted in Fig. 10.5 are from a station close to the building where the creep tests were performed. 


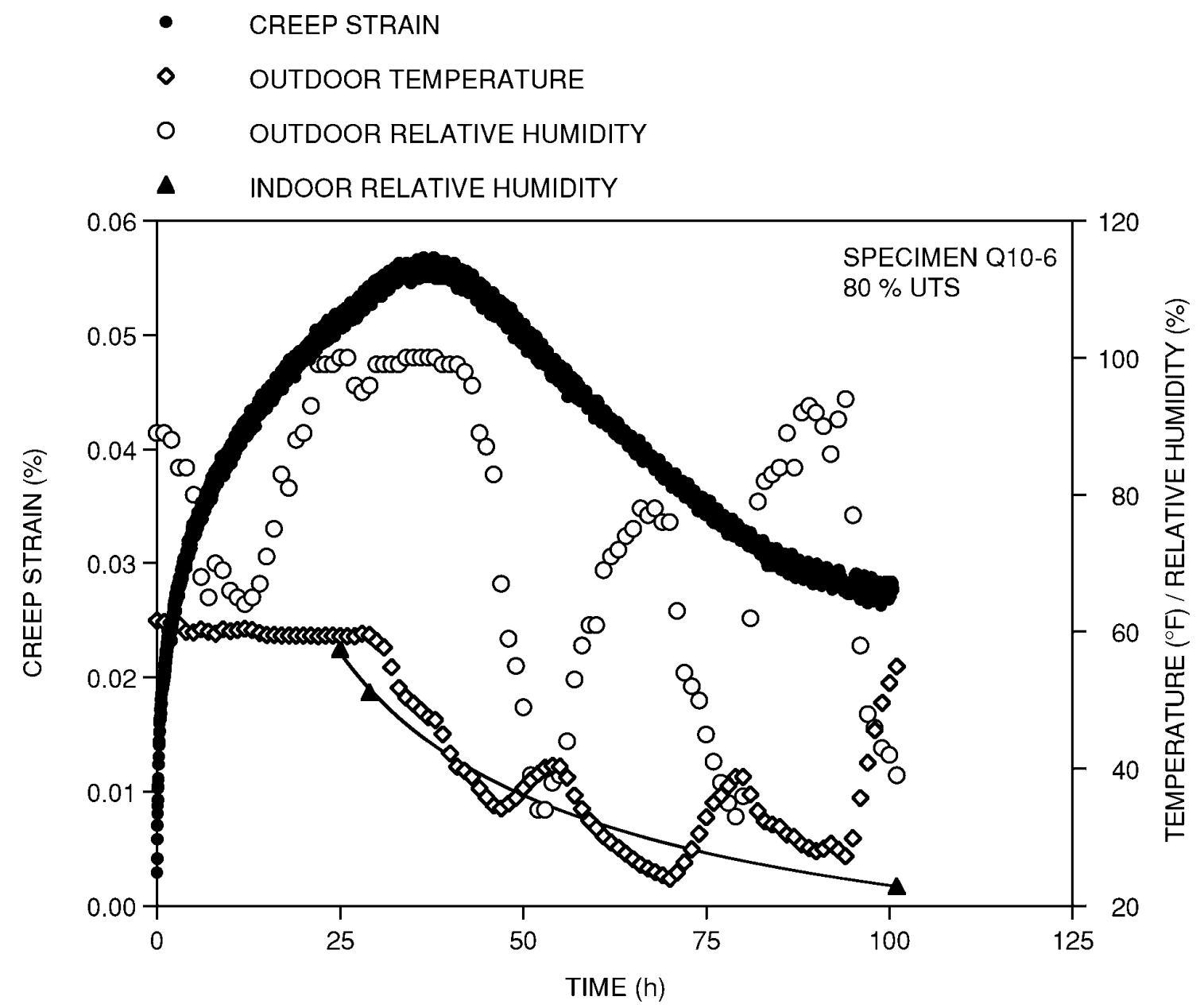

Fig. 10.5. Correlation of apparent time-dependent creep strain with temperature and humidity. Inside humidity, and thus specimen moisture content, drops with decreasing outside temperature.

The contraction of the specimen occurs surprisingly quickly as the humidity drops. ${ }^{*}$ To further explore the effects of humidity change, two unstressed specimens were subjected to a history of step changes in RH, as shown in Fig. 10.6(a). One (A) had two strain gages wired individually to measure the moisture-induced strains on each face [Fig. 10.6(b)]. Gages on the two faces of the other specimen (B) were wired in a full bridge with two "dummy" gages on the faces of a third unstressed specimen that was subjected to the same humidity history. As intended, moisture-induced strain changes were eliminated from the B specimen strain output [Fig. 10.6(b)].

Strains indicated by the specimen A gages track the humidity level well. Note in particular that the expansion due to the first incremental increase of $20 \% \mathrm{RH}$ is significantly less than that due to the second $20 \%$ incremental increase. This has been observed by others. The higher the humidity, the larger the moisture effect. ${ }^{16}$

Because strains due to changes in moisture content are so significant relative to measured time-dependent creep strains, it was decided to use full-bridge strain gage compensation in all of

\footnotetext{
* It should be emphasized that the specimen in Fig. 10.5 was under stress, which accelerates moisture migration. 15
} 

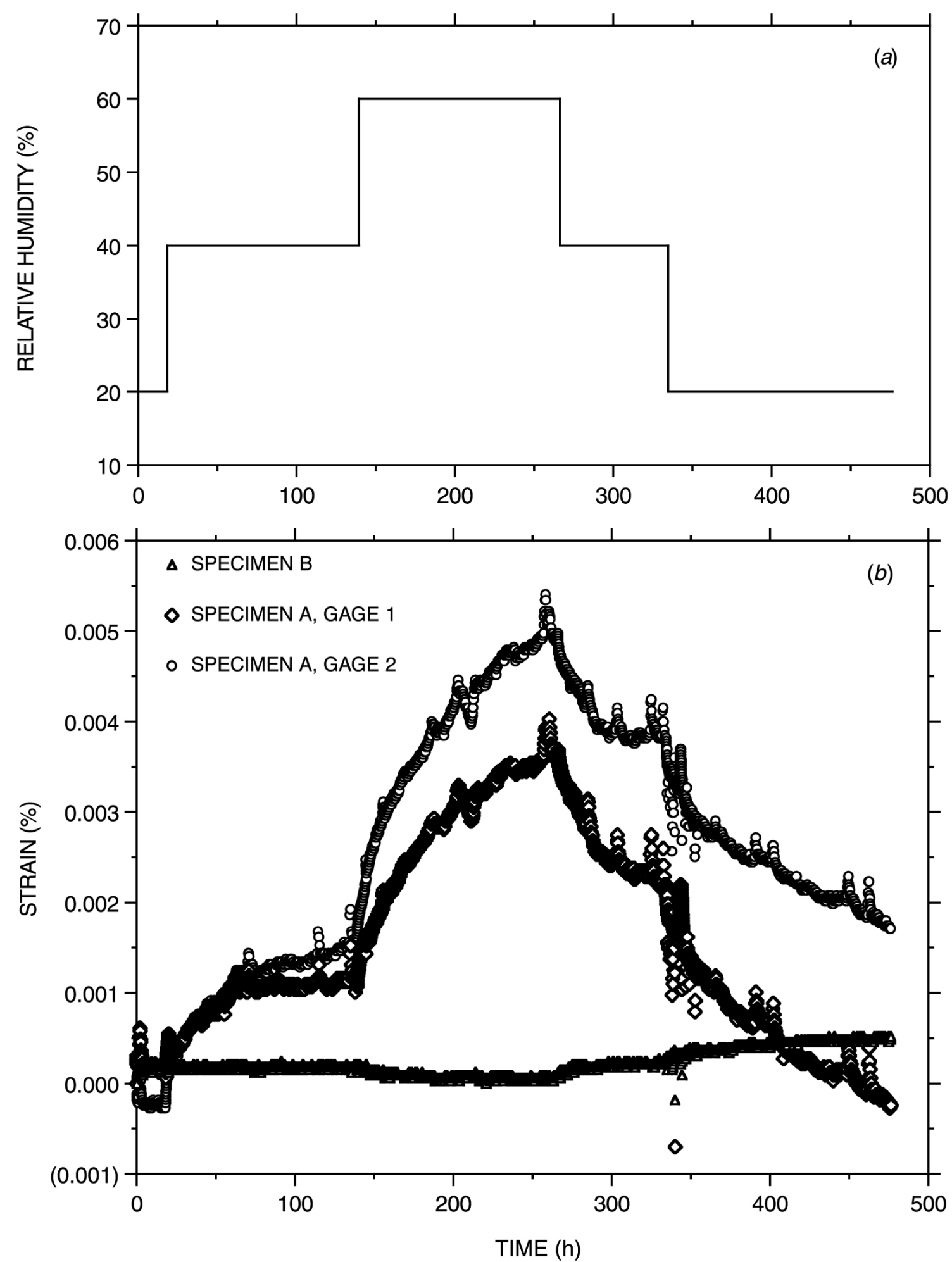

Fig. 10.6. Measured strains in two specimens subjected to step changes in RH. Specimen B was instrumented with compensated strain gages (full bridge). Specimen A gages were not compensated, so strains due to moisture ingress/egress were measured. 
the long-term creep tests reported in the following sections. This effectively eliminated spurious strain readings resulting from moisture and temperature changes. Note that although strains caused by moisture-induced expansion/contraction were eliminated, creep compliance itself is still affected by moisture level and, perhaps, by moisture migration.

\subsection{LONG-TERM TESTS IN AIR}

Forty-five tensile creep tests were performed in dead-weight creep machines. Eighteen were room-temperature tests in air; one was at a temperature of $70^{\circ} \mathrm{C}$; eleven were at $120^{\circ} \mathrm{C}$; nine were in distilled water (seven with a 1000-h presoak); and six were in windshield washer fluid (70\% methanol $/ 30 \%$ distilled water, 100 -h presoak). The detailed test matrix is given in Table 10.1. The table lists the applied stress, both in megapascals and as a percentage of the applicable UTS (the latter values were all obtained from the room-temperature plaque average of $329 \mathrm{MPa}$ by applying the factors developed in Chap. 7), and it tabulates the key results. Tests of specimens with no strain gages were aimed specifically at obtaining creep-rupture failures.

Because specimen thickness and/or stiffness have often been found to have a significant influence, they are shown also. The adjusted stress in the table is the actual stress multiplied by the ratio of average stiffness to the specimen virgin stiffness. A weaker specimen with a lower stiffness, which usually means a thicker specimen, thus has a higher adjusted stress. Use of adjusted stress values did not generally lead to improved creep-rupture correlations, so they are not used herein.

Figure 10.7 shows a typical strain-gaged room-temperature specimen under test. MicroMeasurements gages (CEA-06-500UW-350) having a gage length of $12.7 \mathrm{~mm}$ were used. Gages on the front and back of each specimen eliminated bending effects, while dummy gages on the associated unstressed piece provided the full-bridge compensation to eliminate expansion/ contraction effects.

Figure 10.8 shows a bank of lever-arm creep machines with specimens under test. Seventeen lever-arm machines and two direct-load machines were used. The latter two machines were used for the two room-temperature tests at an applied stress level of $30 \%$ of the UTS.

Figure 10.9 shows the heating arrangement used for the elevated temperature tests. The specimen, the associated unstressed strain-gaged piece, and a similar piece used to maintain good heat balance over all were encapsulated in silicon rubber. This was, in turn, sandwiched between assemblies that contained small heat blankets, metal plates for rigidity and uniform heat distribution, and insulation.

\subsubsection{Room Temperature}

The short-time loading strains measured in the room-temperature tests are plotted against stress in Fig. 10.10. The solid line is a linear curve fit to the data points, while the dashed line represents the average plaque Q16 modulus of elasticity. The stiffness indicated by the loading strains appears to be somewhat greater than that measured on the Q16 virgin specimens. There may be two contributors to this difference. First, the usual variability, and second, the fact that the material stiffness does naturally increase with loading as fibers straighten and become better aligned with the loading. The virgin stiffness measurements were made at very small load levels near the origin.

Time-dependent, room-temperature creep strains are shown in Fig. 10.11 as a function of time. Only the long-term test data are plotted for use in developing a creep equation (two longterm tests developed strain gage problems and are not included). Data from each test were fit with a power-law curve of the form given in Eq. (10.1), with coefficient A and exponent $n$. Only those 
Table 10.1. Matrix of tensile creep and creep-rupture tests performed in dead-weight creep machines

\begin{tabular}{|c|c|c|c|c|c|c|c|c|c|c|c|c|c|}
\hline Specimen & $\begin{array}{l}\text { Thickness } \\
\text { (in.) }\end{array}$ & $\begin{array}{c}\text { Virgin } \\
\text { stiffness } \\
(\text { GPa }) \\
\end{array}$ & $\begin{array}{r}\mathbf{E}_{\text {avg. }}{ }^{\prime} \\
\text { E }_{\text {spec. }}\end{array}$ & $\begin{array}{c}\text { UTS } \\
(\mathrm{MPa})^{b}\end{array}$ & $\begin{array}{c}\text { Stress } \\
\text { (\% UTS) }\end{array}$ & $\begin{array}{c}\text { Actual } \\
\text { stress } \\
(\mathrm{MPa}) \\
\end{array}$ & \begin{tabular}{|c|} 
Adjusted \\
stress \\
(MPa)
\end{tabular} & $\begin{array}{c}\text { Adjusted } \\
\% \text { UTS }\end{array}$ & \begin{tabular}{||c|} 
Loading \\
strain \\
$(\%)$ \\
\end{tabular} & $\begin{array}{c}\text { Creep } \\
\text { strain } \\
(\%) \\
\end{array}$ & $\begin{array}{c}\text { Total } \\
\text { strain } \\
(\%)\end{array}$ & \begin{tabular}{|c}
$\begin{array}{c}\text { Rupture } \\
\text { time } \\
\text { (h) }\end{array}$ \\
\end{tabular} & Notes ${ }^{c}$ \\
\hline \multicolumn{14}{|c|}{ Room temperature } \\
\hline Q16-2 & 0.0842 & 32.8 & 0.979 & 329 & 82.5 & 271 & 266 & 80.74 & 0.782 & & & & Discontinued (5407 h) \\
\hline Q16-4 & 0.0847 & 32.7 & 0.982 & 329 & 30 & 99 & 97 & 29.45 & 0.294 & & & & Discontinued (4633 h) \\
\hline Q16-7 & 0.0861 & 33.1 & 0.970 & 329 & 82.5 & 271 & 263 & 80.01 & 0.765 & & & & Discontinued (5425 h) \\
\hline Q16-9 & 0.0864 & 32.4 & 0.991 & 329 & 85 & 280 & 277 & 84.21 & 0.81 & & & & Discontinued (5406 h) \\
\hline Q16-10 & 0.0863 & 30.9 & 1.039 & 329 & 90 & 296 & 308 & 93.50 & 0.9 & - & - & 0.12 & \\
\hline Q16-11 & 0.0863 & 31.9 & 1.006 & 329 & 60 & 197 & 199 & 60.38 & 0.578 & & & & Discontinued $(4638 \mathrm{~h})$ \\
\hline Q16-32 & 0.0870 & 30.4 & 1.056 & 329 & 86 & 283 & 299 & 90.81 & & & & 588.8 & No gages \\
\hline Q16-33 & 0.0868 & 32.2 & 0.997 & 329 & 88 & 290 & 289 & 87.73 & & & & 858.7 & No gages \\
\hline Q16-35 & 0.0865 & 33.8 & 0.950 & 329 & 85.6 & 282 & 268 & 81.32 & 0.81 & & & & $\begin{array}{l}\text { Extensometer, } \\
\text { discontinued }(1736 \mathrm{~h})\end{array}$ \\
\hline Q16-38 & 0.0860 & 32.0 & 1.003 & 329 & 88.5 & 291 & 292 & 88.78 & & & & 6.2 & No gages \\
\hline Q16-40 & 0.0864 & 32.0 & 1.003 & 329 & 88.5 & 291 & 292 & 88.78 & & & & & $\begin{array}{l}\text { No gages, discontinued } \\
(2885 \mathrm{~h})\end{array}$ \\
\hline Q16-41 & 0.0867 & 30.4 & 1.056 & 329 & 85 & 280 & 295 & 89.75 & & & & 0.09 & No gages \\
\hline Q16-44 & 0.0882 & 31.5 & 1.019 & 329 & 30 & 99 & 101 & 30.57 & 0.3 & & & & Discontinued (4587 h) \\
\hline Q16-45 & 0.0888 & 33.0 & 0.973 & 329 & 60 & 197 & 192 & 58.36 & 0.568 & & & & Discontinued (4592 h) \\
\hline Q16-46 & 0.0888 & 30.7 & 1.046 & 329 & 80 & 263 & 275 & 83.65 & 0.805 & & & & Discontinued $(4279 \mathrm{~h})$ \\
\hline Q16-47 & 0.0896 & 31.4 & 1.022 & 329 & 86 & 283 & 289 & 87.92 & 0.838 & & & & Discontinued $(4279 \mathrm{~h})$ \\
\hline Q16-49 & 0.0898 & 31.6 & 1.016 & 329 & 80 & 263 & 267 & 81.27 & 0.756 & $>0.059$ & $>0.816$ & 736.87 & \\
\hline Q16-51 & 0.0898 & 30.7 & 1.046 & 329 & 85 & 280 & 292 & 88.88 & 0.852 & 0.232 & 1.084 & 0.161 & \\
\hline \multicolumn{14}{|c|}{$70^{\circ} \mathrm{C}$} \\
\hline Q16-27 & 0.0874 & 31.8 & 1.009 & 319 & 80 & 255 & 258 & 80.75 & 0.79 & & & & Discontinued $(4060 \mathrm{~h})$ \\
\hline \multicolumn{14}{|c|}{$120^{\circ} \mathrm{C}$} \\
\hline Q16-20 & 0.0847 & 31.8 & 1.009 & 266 & 80 & 213 & 215 & 80.75 & 0.74 & $>0.306$ & $>1.046$ & 21.9 & \\
\hline Q16-21 & 0.0874 & 32.7 & 0.982 & 266 & 60 & 160 & 157 & 58.90 & 0.547 & $>0.067$ & $>0.614$ & 4205.2 & \\
\hline Q16-22 & 0.0873 & 31.4 & 1.022 & 266 & 75 & 200 & 204 & 76.67 & 0.666 & 0.223 & 0.889 & 2345.5 & \\
\hline Q16-24 & 0.0872 & 30.6 & 1.049 & 266 & 15.3 & 41 & 43 & 16.09 & 0.1506 & & & & Discontinued $(192 \mathrm{~h})$ \\
\hline Q16-50 & 0.0898 & 29.6 & 1.084 & 266 & 80 & 213 & 231 & 86.76 & 0.792 & $>0.315$ & $>1.107$ & 463.5 & \\
\hline Q16-52 & 0.0898 & 31.0 & 1.035 & 266 & 90 & 239 & 248 & 93.19 & 0.85 & 0.177 & 1.027 & 0.276 & \\
\hline Q16-53 & 0.0896 & 32.0 & 1.003 & 266 & 85 & 226 & 227 & 85.27 & 0.802 & $>0.242$ & $>1.044$ & 81.45 & \\
\hline Q16-55 & 0.0898 & 33.0 & 0.973 & 266 & 80 & 213 & 207 & 77.82 & 0.725 & $>0.202$ & $>0.927$ & 315.1 & \\
\hline Q16-56 & 0.0895 & 31.1 & 1.032 & 266 & 90 & 239 & 247 & 92.89 & 0.836 & 0.161 & 0.997 & 0.138 & \\
\hline Q16-57 & 0.0894 & 31.9 & 1.006 & 266 & 85 & 226 & 228 & 85.53 & 0.807 & 0.221 & 1.028 & 0.358 & \\
\hline Q16-58 & 0.0892 & 30.5 & 1.052 & 266 & 80 & 213 & 224 & 84.20 & 0.765 & $>0.312$ & $>1.077$ & 19.83 & \\
\hline
\end{tabular}


Table 10.1. (continued)

\begin{tabular}{|c|c|c|c|c|c|c|c|c|c|c|c|c|c|}
\hline Specimen & $\begin{array}{l}\text { Thickness } \\
\text { (in.) }\end{array}$ & $\begin{array}{c}\text { Virgin } \\
\text { stiffness } \\
(\mathrm{GPa}) \\
\end{array}$ & $\begin{array}{c}\text { Evvg./ }_{a} \\
\text { Espec. }^{\text {and }}\end{array}$ & $\begin{array}{c}\text { UTS } \\
(\text { MPa })^{b}\end{array}$ & $\begin{array}{c}\text { Stress } \\
\text { (\% UTS) }\end{array}$ & \begin{tabular}{|l|} 
Actual \\
stress \\
(MPa) \\
\end{tabular} & \begin{tabular}{|c|} 
Adjusted \\
stress \\
(MPa)
\end{tabular} & \begin{tabular}{|c|}
$\begin{array}{c}\text { Adjusted } \\
\% \text { UTS }\end{array}$ \\
\end{tabular} & \begin{tabular}{|c|} 
Loading \\
strain \\
$(\%)$ \\
\end{tabular} & \begin{tabular}{|c|} 
Creep \\
strain \\
$(\%)$ \\
\end{tabular} & $\begin{array}{c}\text { Total } \\
\text { strain } \\
(\%) \\
\end{array}$ & \begin{tabular}{|c|}
$\begin{array}{c}\text { Rupture } \\
\text { time } \\
\text { (h) }\end{array}$ \\
\end{tabular} & Notes $c$ \\
\hline \multicolumn{14}{|c|}{ Distilled water } \\
\hline Q16-1 & 0.0840 & 31.3 & 1.026 & 329 & 82.88 & 273 & \begin{tabular}{|l|}
280 \\
\end{tabular} & 85.00 & 0.79 & $>0.053$ & $>0.843$ & $\sim 24$ & \\
\hline Q16-6 & 0.0857 & 33.3 & 0.964 & 329 & 0 & 0 & 0 & 0.00 & 0 & & & & No presoak, discontinued \\
\hline Q16-8 & 0.0863 & 33.6 & 0.955 & 329 & 85 & 280 & 267 & 81.21 & 0.812 & $>0.273$ & $>1.085$ & 460.9 & No presoak \\
\hline Q16-12 & 0.0859 & 32.8 & 0.979 & 329 & 85 & 280 & 274 & 83.19 & 0.808 & $>0.041$ & $>0.849$ & 2.6 & \\
\hline Q16-14 & 0.0861 & 29.6 & 1.084 & 329 & 80.24 & 264 & 286 & 87.00 & 0.84 & $>0.074$ & $>0.914$ & 41 & \\
\hline Q16-25 & 0.0875 & 33.8 & 0.950 & 329 & 82 & 270 & 256 & 77.88 & & & & & $\begin{array}{l}\text { No gages, discontinued } \\
(917 \mathrm{~h})\end{array}$ \\
\hline Q16-26 & 0.0875 & 32.4 & 0.991 & 329 & 81 & 266 & 264 & 80.25 & & & & & $\begin{array}{l}\text { No gages, discontinued } \\
(917 \mathrm{~h})\end{array}$ \\
\hline Q16-30 & 0.0871 & 32.4 & 0.991 & 329 & 77.5 & 255 & 253 & 76.78 & 0.726 & & & & Discontinued $(2115 \mathrm{~h})$ \\
\hline Q16-31 & 0.0871 & 32.7 & 0.982 & 329 & 75 & 247 & \begin{tabular}{|l|}
242 \\
\end{tabular} & 73.62 & 0.694 & & & & Discontinued $(2115 \mathrm{~h})$ \\
\hline \multicolumn{14}{|c|}{ Windshield washer fluid } \\
\hline Q16-3 & 0.0848 & 31.3 & 1.026 & 329 & 82.88 & 273 & \begin{tabular}{|l|}
280 \\
\end{tabular} & 85.00 & 0.84 & $>1.653$ & $>2.493$ & 695 & \\
\hline Q16-13 & 0.0863 & 31.1 & 1.032 & 329 & 84.29 & 277 & 286 & 87.00 & 0.888 & $>0.027$ & $>0.915$ & 0.221 & \\
\hline Q16-15 & 0.0858 & 31.1 & 1.032 & 329 & 86.23 & 284 & 293 & 89.00 & 0.907 & $>0.025$ & $>0.932$ & 0.204 & \\
\hline Q16-17 & 0.0857 & 33.1 & 0.970 & 329 & 83 & 273 & 265 & 80.49 & 0.78 & & & & Discontinued $(4130 \mathrm{~h})$ \\
\hline Q16-18 & 0.0852 & 32.9 & 0.976 & 329 & 83 & 273 & 266 & 80.98 & 0.789 & $>0.034$ & $>0.823$ & 18.8 & \\
\hline Q16-28 & 0.0874 & 31.7 & 1.013 & 329 & 80 & 263 & 267 & 81.01 & & & & 872 & No gages \\
\hline Average & 0.0872 & 31.9 & 1.006 & & & & & & & & & & \\
\hline
\end{tabular}

${ }^{a}$ Overall average room-temperature $\mathrm{E}=32.1 \mathrm{GPa}$ is also average for plaques $\mathrm{Q} 10$ and Q16; Q16 value is $31.9 \mathrm{GPa}$

$b_{\text {Room-temperature UTS }}=329 \mathrm{MPa}$ is average for plaques Q10 and Q16; Q16 value is $333 \mathrm{MPa}$.

${ }^{c}$ Times shown for "discontinued" tests are approximate test durations at time of writing this report. 


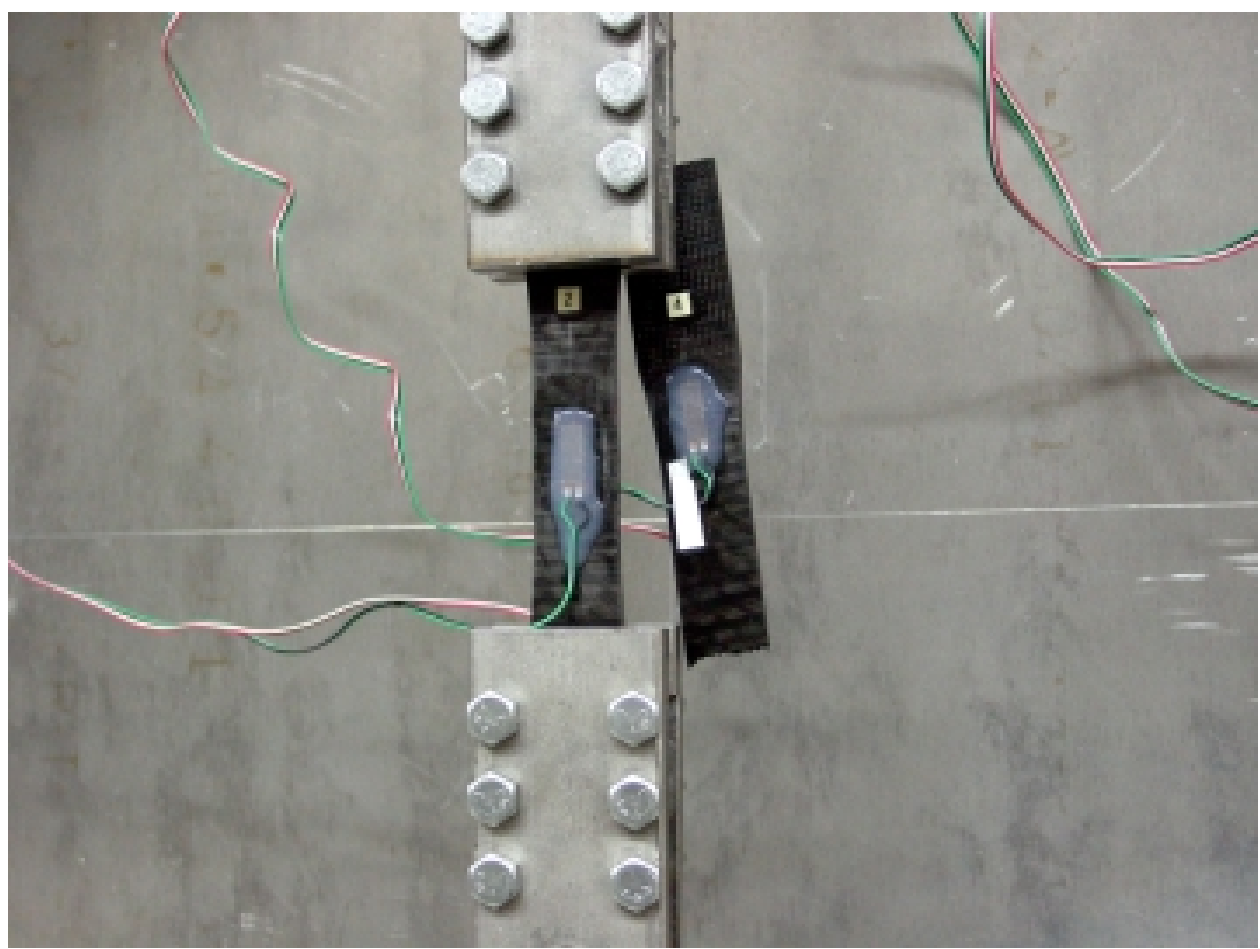

Fig. 10.7. Strain-gaged room-temperature creep test specimen with accompanying unstressed piece having dummy gages for full-bridge compensation.

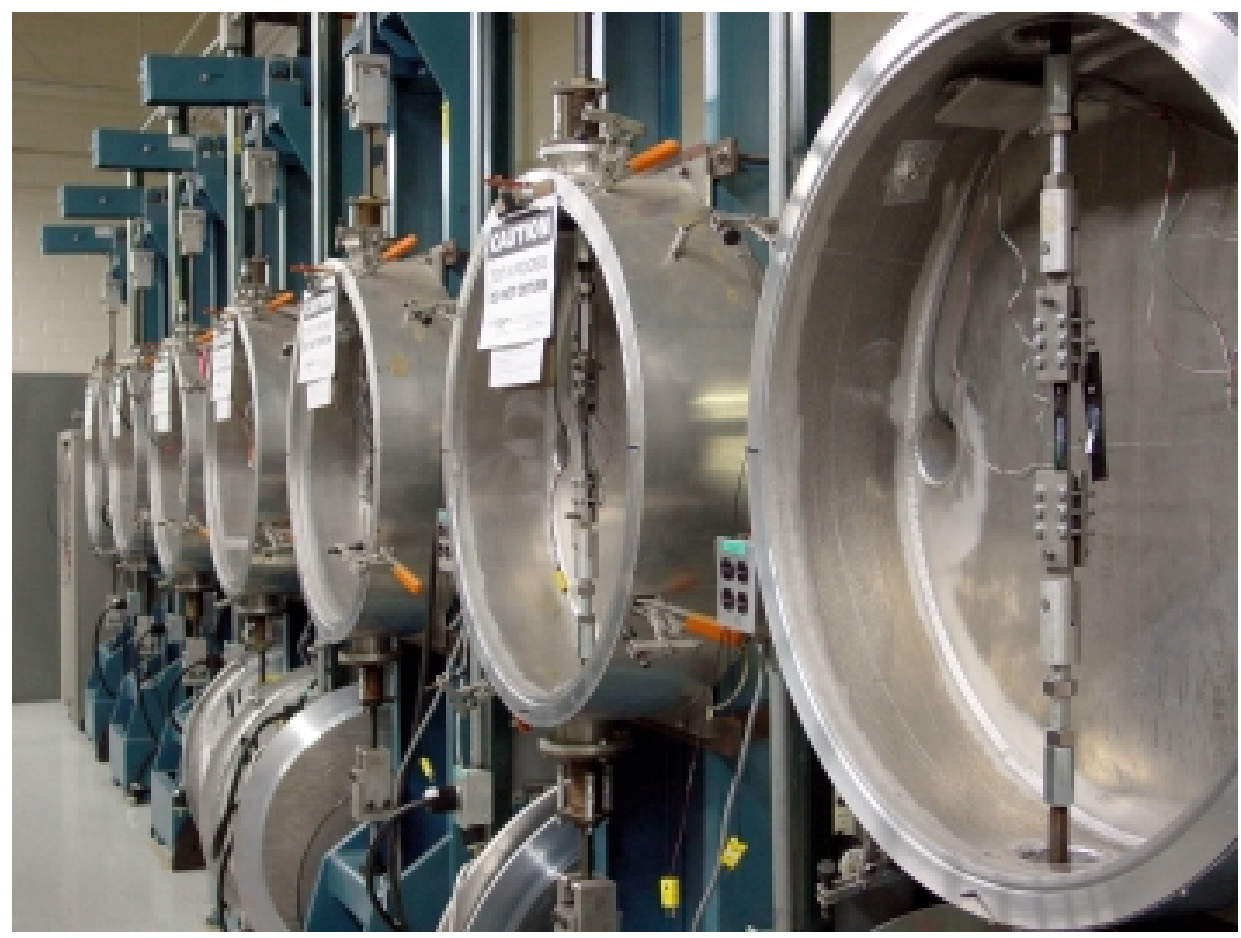

Fig. 10.8. Bank of lever-arm creep machines used for longer term creep tests. 


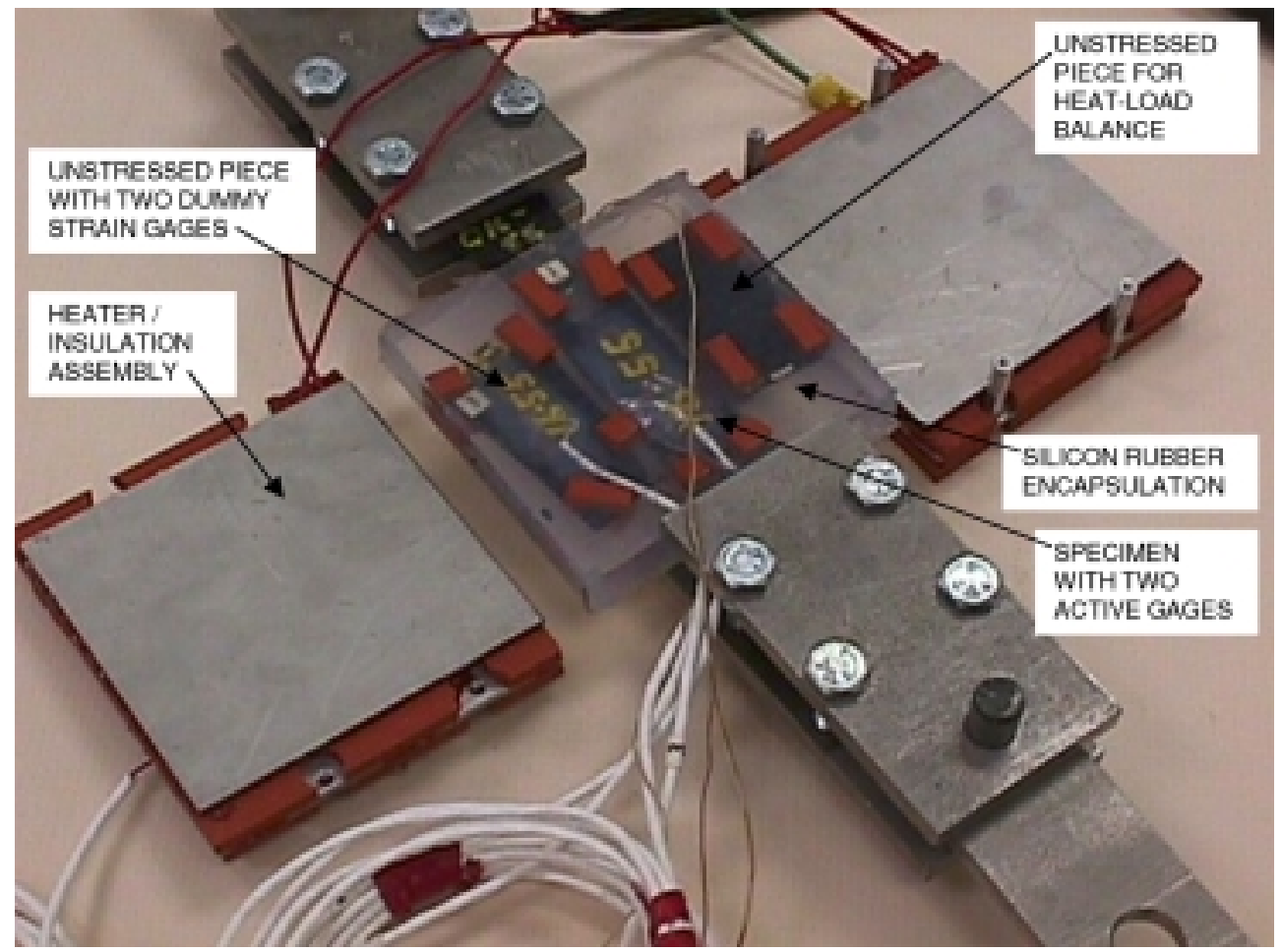

Fig. 10.9. Arrangement used for heating and obtaining full-bridge strain gage compensation in elevated-temperature tests.

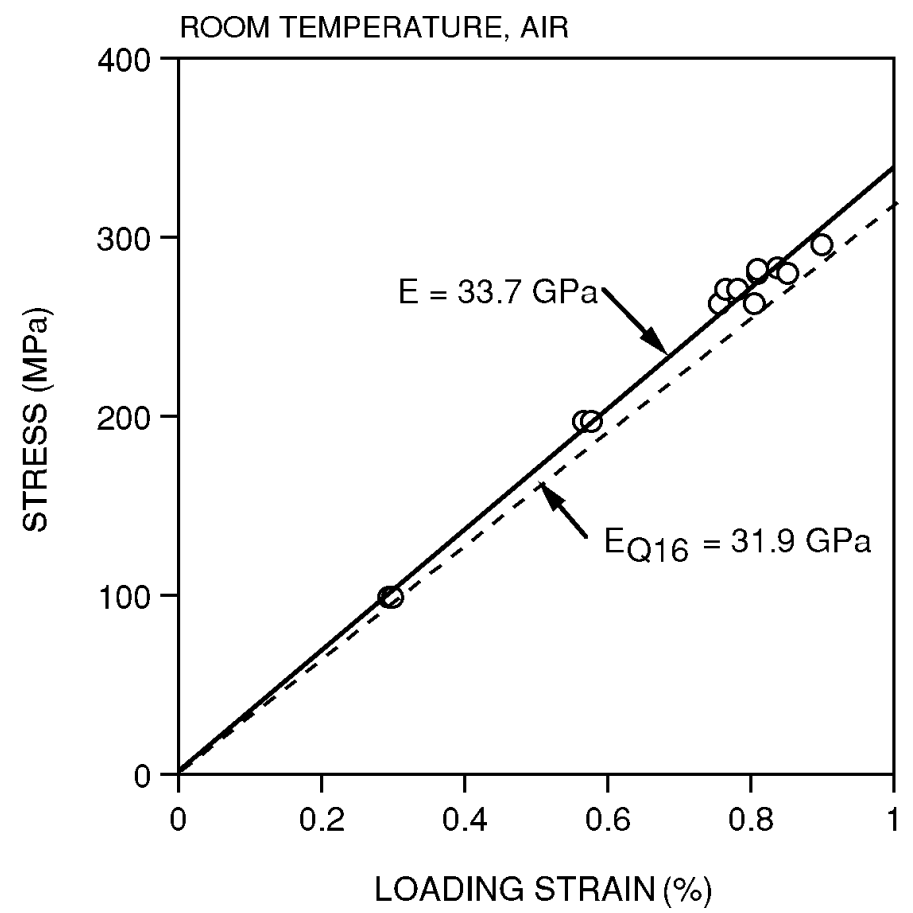

Fig. 10.10. Loading strains measured in room-temperature creep tests. Note that the apparent stiffness based on the measured loading strains is, as expected, slightly greater than the average virgin modulus of elasticity of the plaque Q16 specimens. 


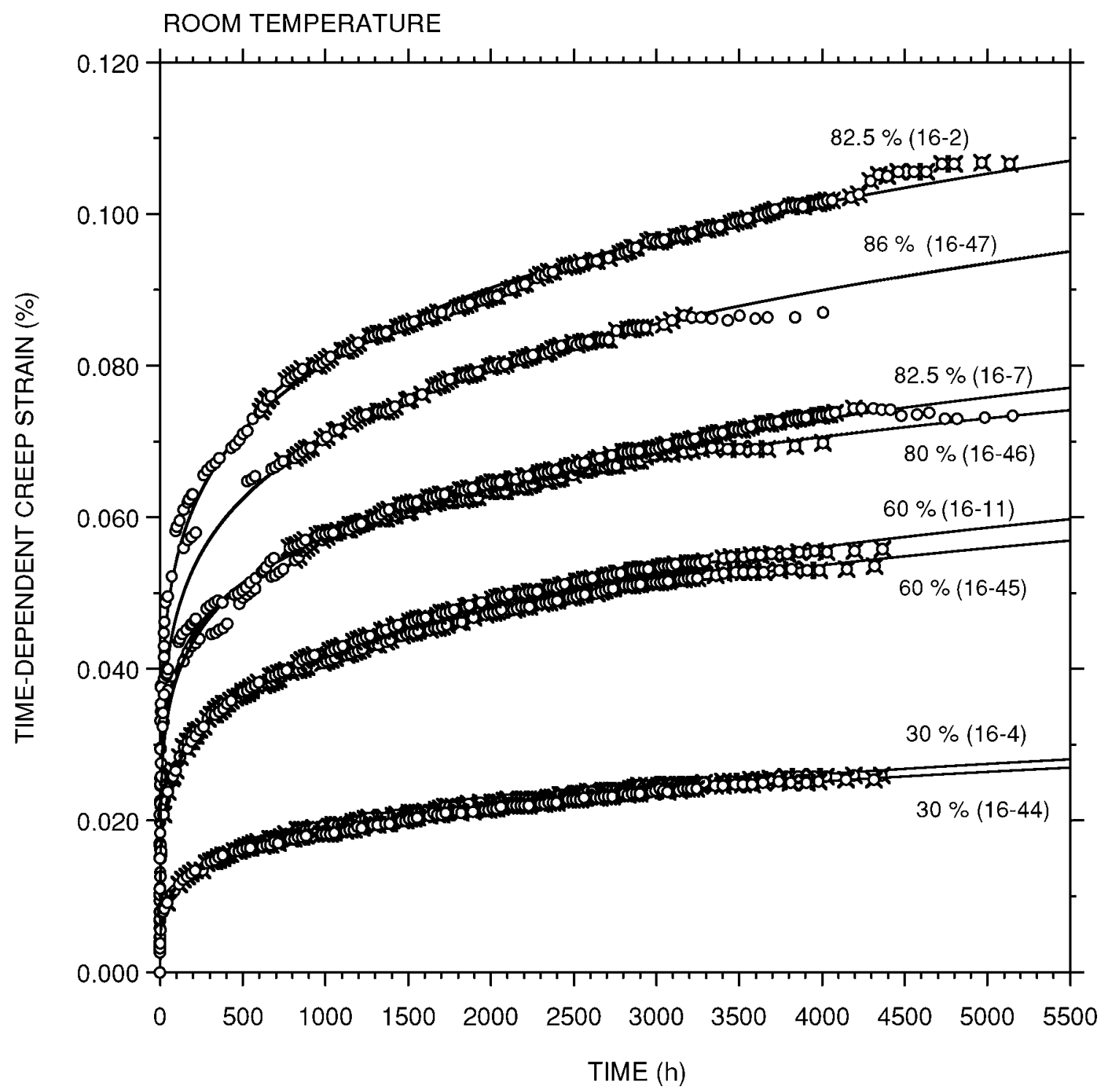

Fig. 10.11. Long-term, room-temperature creep data with individual power-law curve fits. Only data points with an " $x$ " behind them were used in the curve fits.

data points with an " $x$ " behind them were used in the curve fits." The coefficients $A$ and exponents $\mathrm{n}$ from the curve fits are, as shown in Fig. 10.12, functions of applied stress. Despite the increasing scatter at high stress, caused by random damage, it was possible to derive polynomial expressions for $\mathrm{A}$ and $\mathrm{n}$. The resulting room-temperature master creep equation is thus given by

$$
\varepsilon_{\mathrm{c}}=\mathrm{At}^{\mathrm{n}}
$$

*As discussed in Sect. 10.2, on a log-log basis the creep data points eventually fall on a straight line. Only data from that point in time forward were used for curve fitting. 

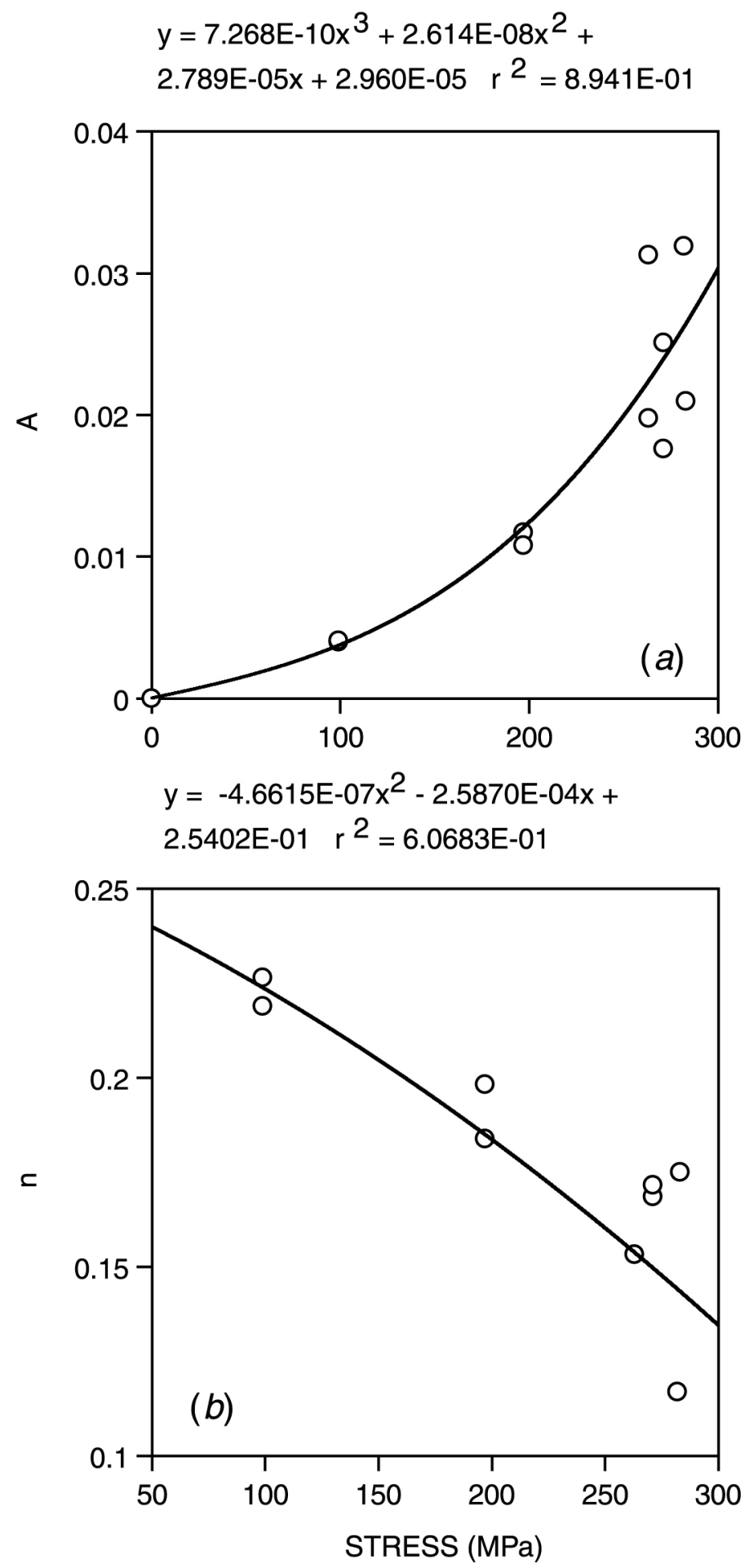

Fig. 10.12. Power-law coefficient $A$ and exponent $n$ as functions of applied stress at room temperature. 
where

$$
\left.\begin{array}{c}
\mathrm{A}=7.268 \times 10^{-10} \sigma^{3}+2.614 \times 10^{-8} \sigma^{2} \\
+2.789 \times 10^{-5} \sigma+2.960 \times 10^{-5} \\
\mathrm{n}=-4.662 \times 10^{-7} \sigma^{2}-2.587 \times 10^{-4} \sigma \\
+0.2540
\end{array}\right\}
$$

Here, $\varepsilon_{\mathrm{c}}$ is time-dependent creep strain in percent, $\mathrm{t}$ is time in hours, and $\sigma$ is stress in megapascals. Note that there is a negligible inconsistency in Eq. (10.2). The coefficient A is not precisely zero when stress is zero [see Fig. 10.12(a)].

Predictions of the master room-temperature equation are compared in Fig. 10.13 with the original data. At stresses equal to 30 and $60 \%$ of the UTS, the agreement is good. The prediction for $82.5 \%$ of the UTS is between the corresponding two sets of data, and the prediction for $86 \%$ of the UTS is a good representation of the data. Equation (10.2) is thus adopted as an adequate representation of the room-temperature time-dependent creep for the quasi-isotropic composite.

Figures 10.14 and 10.15 graphically summarize the expected creep deformation at room temperature. In Fig. 10.14, a set of predicted creep curves is plotted out to $5500 \mathrm{~h}$. A comparison of these predictions derived from long-term data with those that were derived from short-time

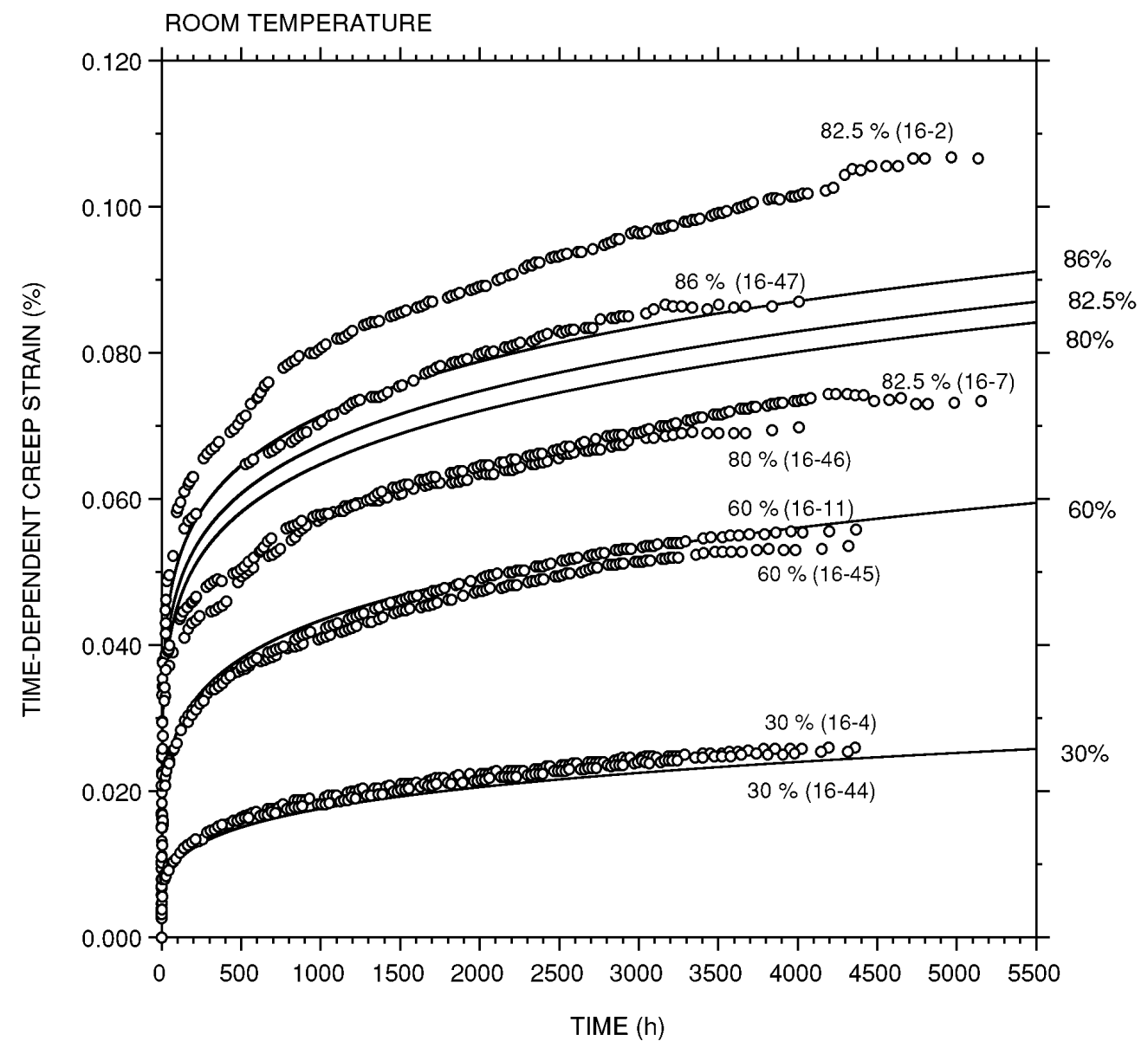

Fig. 10.13. Comparison of predictions of master creep equation (solid curves) with long-term, room-temperature data. 


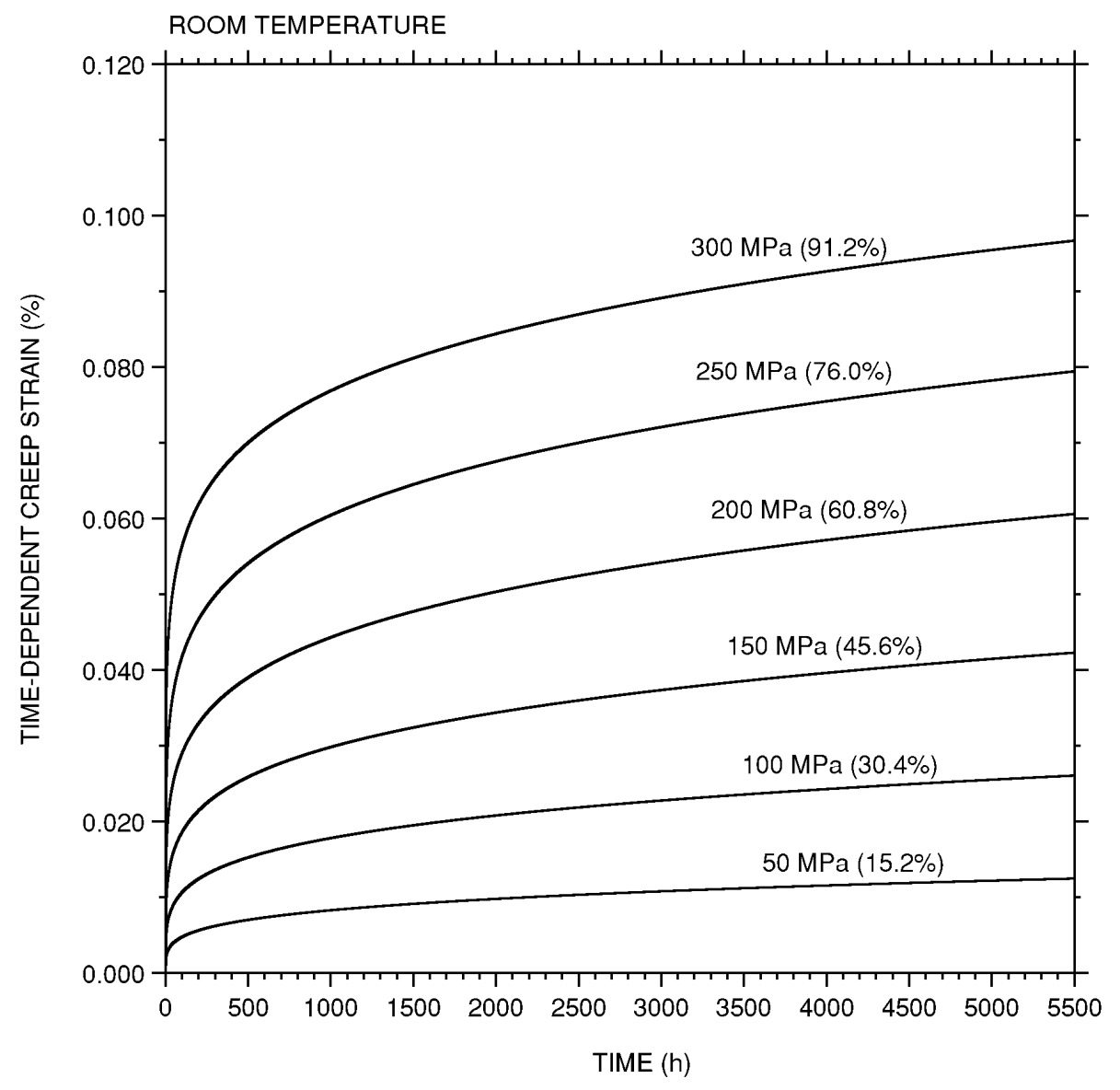

Fig. 10.14. Time-dependent, room-temperature creep strains predicted by master equation derived from long-term tests.

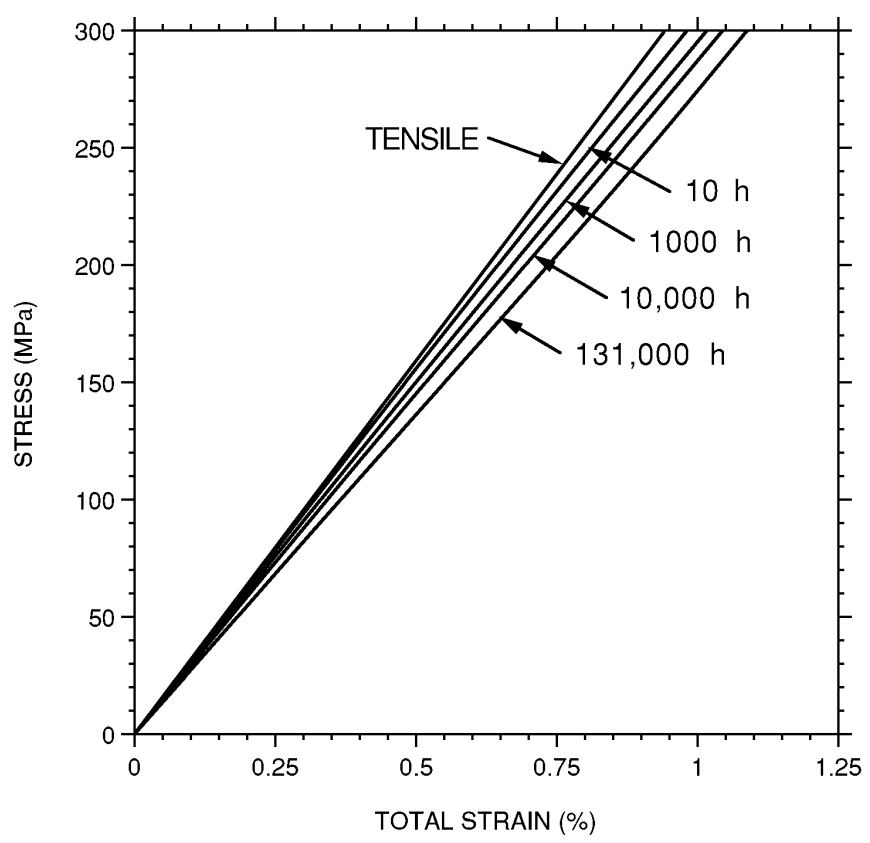

Fig. 10.15. Room-temperature isochronous stress-strain curves. 
24-h data (see Fig. 10.4) shows that the latter overpredicts the strains at $5000 \mathrm{~h}$ by a factor of 2 to almost 3. This confirms that test durations longer than $24 \mathrm{~h}$ are required to develop a creep equation valid for long times.

Figure 10.15 shows the predicted time-dependent deformations as isochronous curves. These curves depict the total strain that would be accumulated in a specified time at a constant stress. The "tensile" curve, which is just the short-time stress-strain curve, corresponds to zero time. The curve labeled $131,000 \mathrm{~h}$ corresponds to 15 years, the assumed life of a vehicle. At $300 \mathrm{MPa}$, which is about $90 \%$ of the UTS of the composite, the creep strain at 15 year is just $16 \%$ of the elastic loading strain. Comparison of the isochronous curves for the quasi-isotropic composite with those for the crossply composite in the two principal fiber orientations ${ }^{4}$ shows that the elastic and creep deformations of the quasi-isotropic composite are almost 50\% larger than those of the crossply composite with a $0 / 90^{\circ}$ fiber orientation, but they are many times less than those of the crossply composite with a $\pm 45^{\circ}$ fiber orientation.

\subsubsection{Elevated Temperature}

The loading strains measured in creep tests at a temperature of $120^{\circ} \mathrm{C}$ are plotted in Fig. 10.16, where they are compared with the estimated $120^{\circ} \mathrm{C}$ elastic modulus of plaque Q16. The agreement is very good. Measured time-dependent creep strains for various stress levels are plotted in Fig. 10.17. Each set of test data was fit with a power-law expression, and each curve is labeled with the stress level, as a percentage of the $120^{\circ} \mathrm{C}$ UTS. Note that the $60 \%$ and $75 \%$ UTS tests extended to $4205 \mathrm{~h}$ and $2346 \mathrm{~h}$ before failing. Clearly the scatter at the higher stress levels,

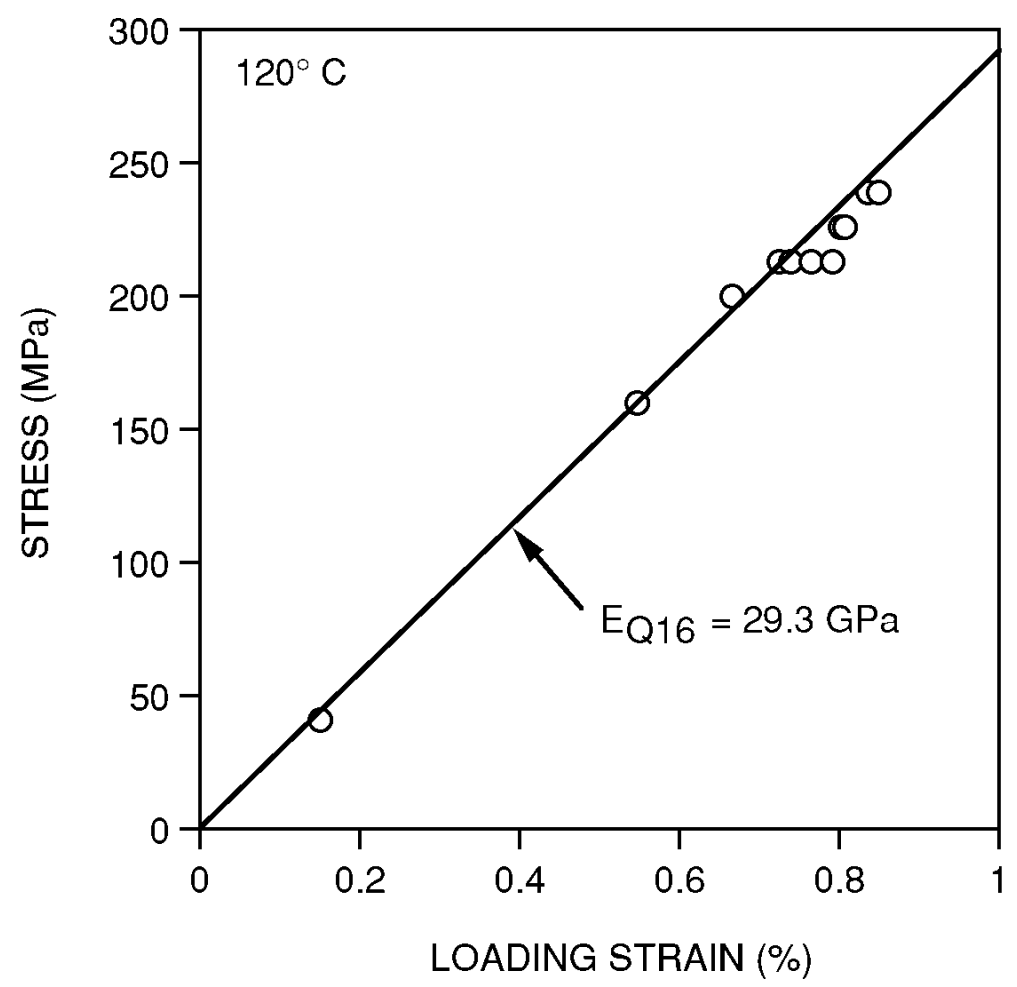

Fig. 10.16. Loading strains measured in $120^{\circ} \mathrm{C}$ creep tests. Solid line represents the estimated average plaque Q16 modulus of elasticity at $120^{\circ} \mathrm{C}$, which is determined by multiplying the Q16 average room-temperature value by the stiffness temperature-reduction factor given in Chap. 7 . 


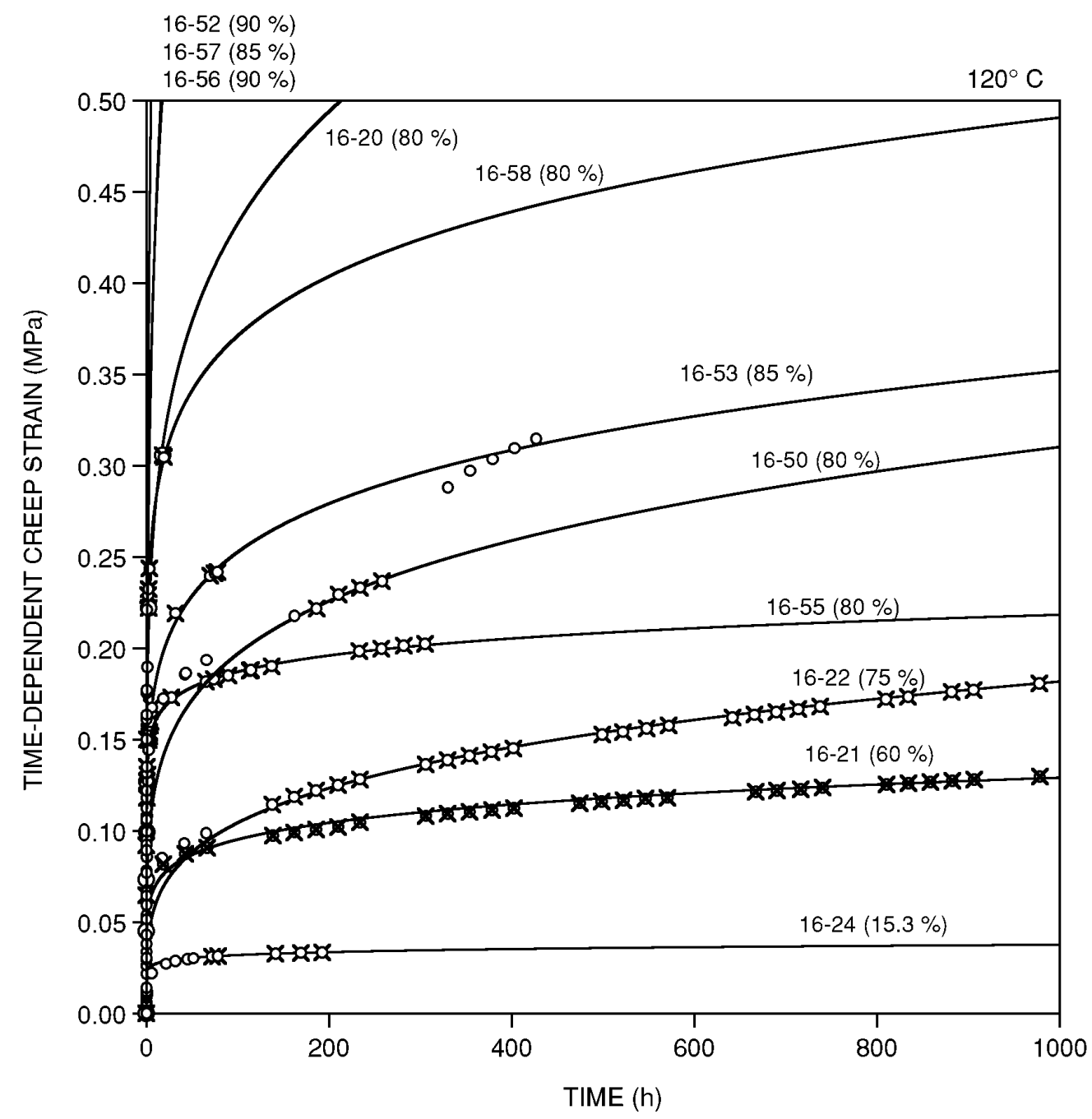

Fig. 10.17. Long-term $120^{\circ} \mathrm{C}$ creep data with individual power-law curve fits. Only data points with an " $\times$ " behind them were used in the curve fits.

where damage is prominent, is greater at $120^{\circ} \mathrm{C}$ than at room temperature, viz. the four tests at $80 \%$ UTS and the two tests at $85 \%$ UTS.

The coefficients A and exponents $\mathrm{n}$ from the curve fits of the $120^{\circ} \mathrm{C}$ test data are plotted as functions of stress in Fig. 10.18. In both cases, exponential equations appeared to provide the best fits to the plotted data. Note, again, that the coefficient A does not go to zero as stress goes to zero. The coefficients of determination, $\mathrm{r}^{2}$, are low, however, because of the scatter at the high stresses. The resulting $120^{\circ} \mathrm{C}$ creep equation becomes

$$
\varepsilon_{\mathrm{c}}=\mathrm{At}^{\mathrm{n}}
$$

where

$$
\left.\begin{array}{l}
\mathrm{A}=0.01051 \times 10^{0.005158 \sigma} \\
\mathrm{n}=0.004960 \times 10^{0.002672 \sigma}
\end{array}\right\}
$$

Again, strain is in percent, time in hours, and stress in megapascals. 

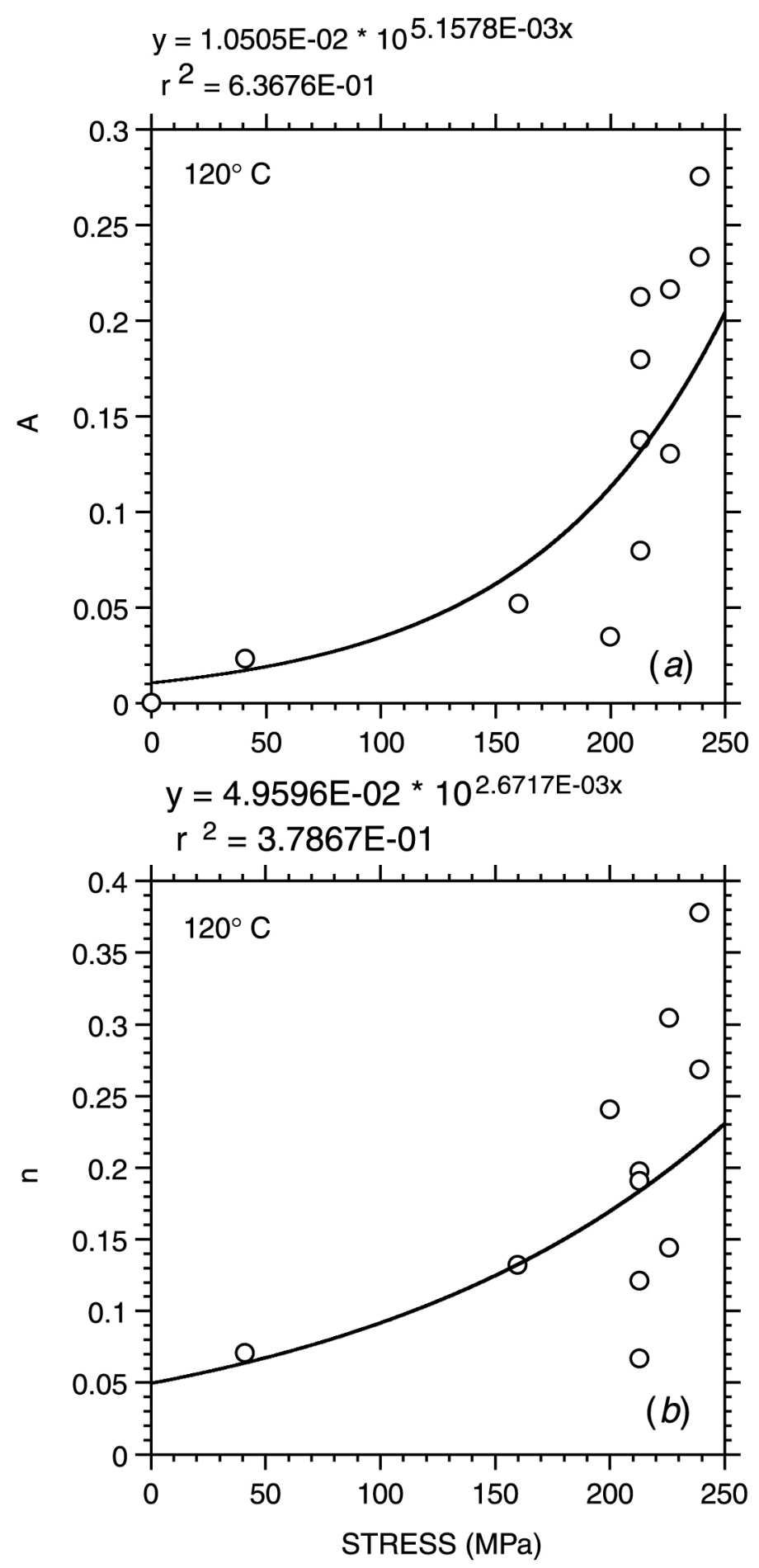

Fig. 10.18. Power-law coefficient $A$ and exponent $n$ as functions of applied stress at $120^{\circ} \mathrm{C}$. 
Predictions of Eq. (10.3) are compared in Fig. 10.19 with the measured $120^{\circ} \mathrm{C}$ creep strains. Considering the scatter at the higher stresses, the predictions appear to be reasonable. The comparison shown in Fig. 10.20 of predicted $120^{\circ} \mathrm{C}$ creep strains with predicted roomtemperature creep strains provides the basis for the multiplication factor that was given in Chap. 2 of Part 1 . At $5000 \mathrm{~h}$, the ratio of predicted $120^{\circ} \mathrm{C}$ creep strain to room-temperature creep strain varies with stress, as tabulated below.

\begin{tabular}{ccc} 
Stress (MPa) & & Ratio \\
\cline { 1 - 1 } 25 & & 3.9 \\
50 & & 2.9 \\
100 & & 2.9 \\
150 & & 4.3 \\
200 & & 8.1
\end{tabular}

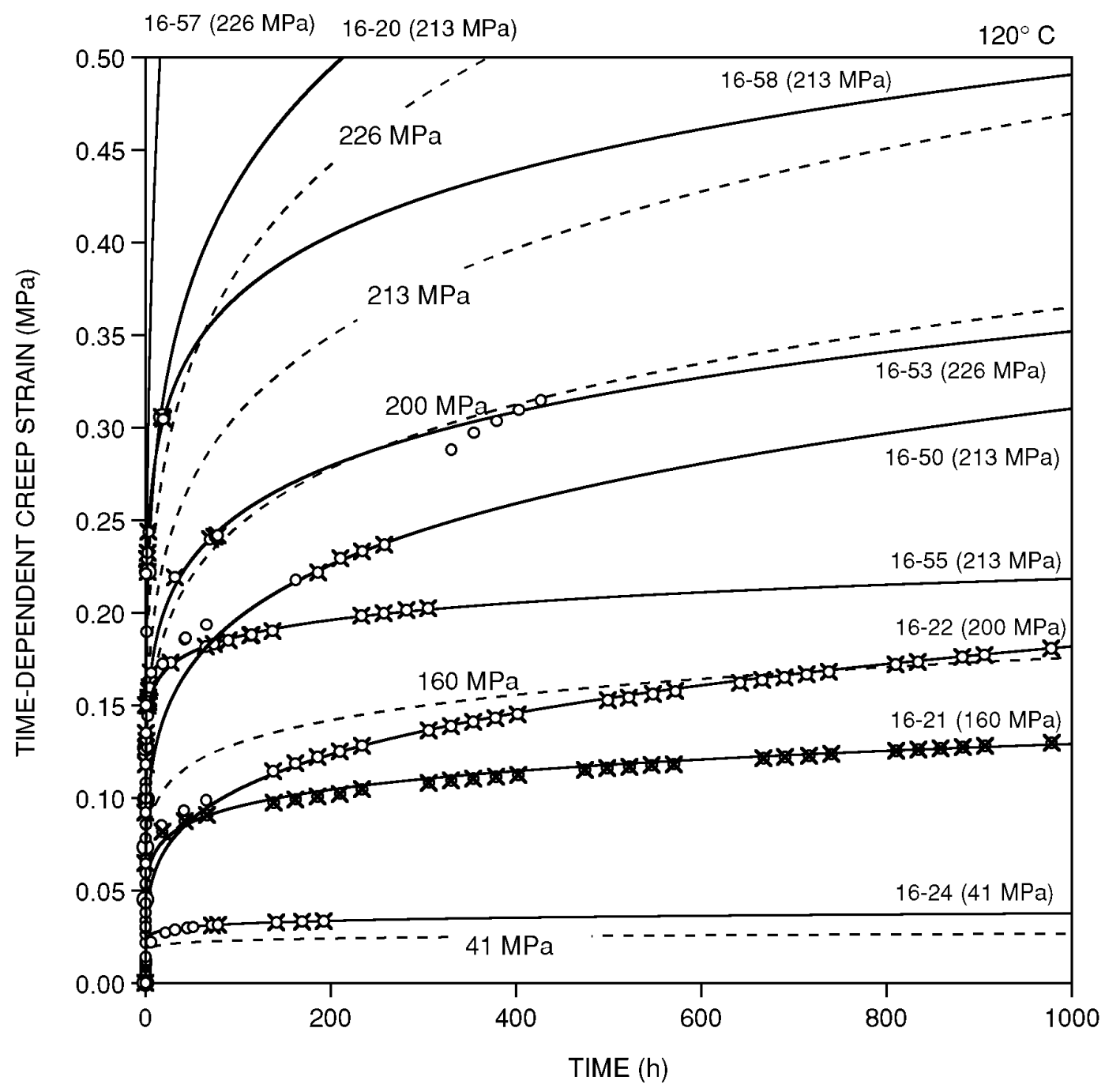

Fig. 10.19. Comparison of predictions of $120^{\circ} \mathrm{C}$ master creep equation (dashed curves) with long-term data. Solid curves are individual power-law curve fits from Fig. 10.17. 


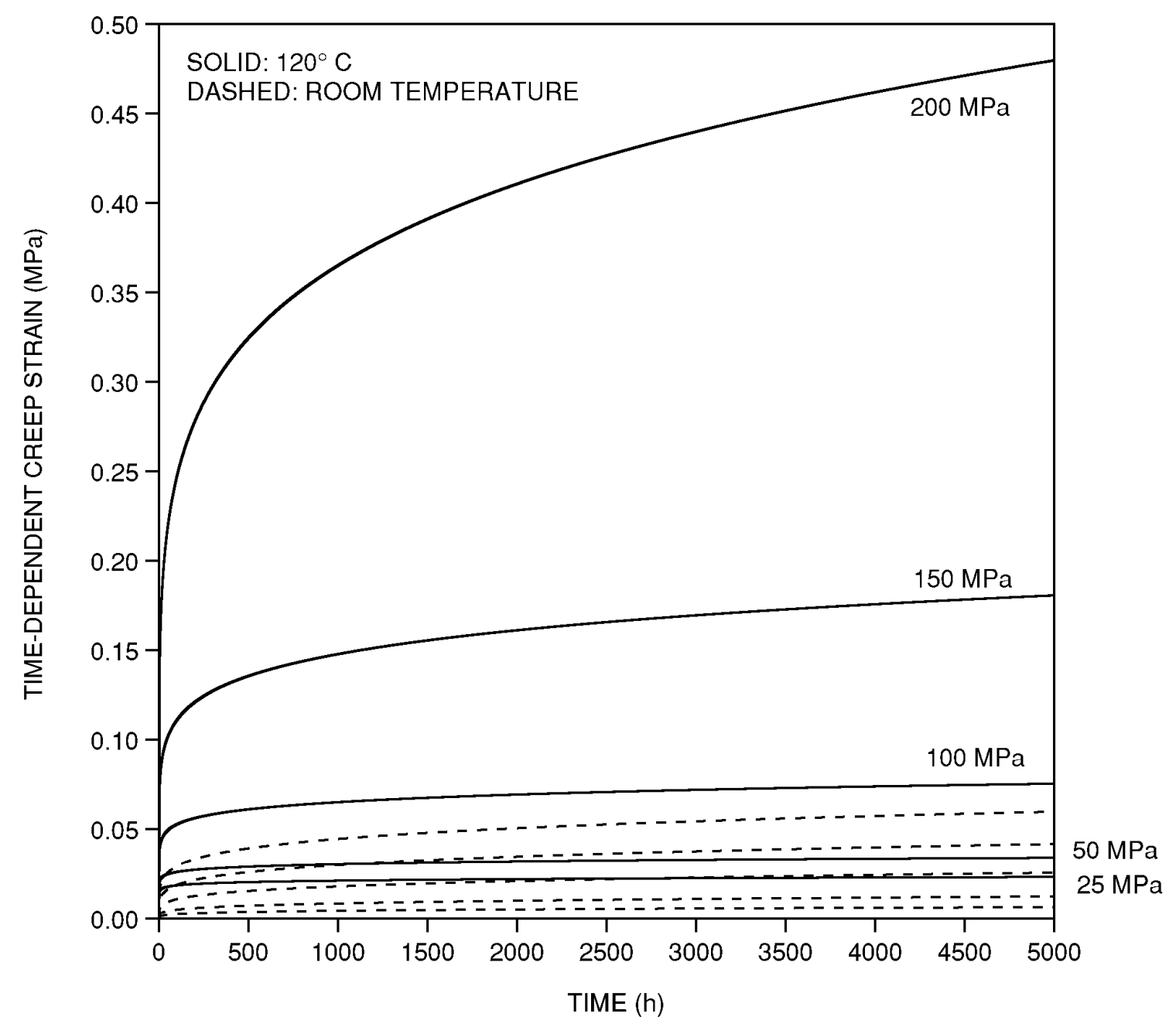
$120^{\circ} \mathrm{C}$.

Fig. 10.20. Comparison of predicted time-dependent creep strains at room-temperature and

A factor of 4.3, which is adequate up to a stress of 150 , was chosen for use in Part 1. The corresponding ratio for the $0 / 90^{\circ}$ crossply composite was 6.3 . The ratio was about 41 for the $\pm 45^{\circ}$ fiber orientation. ${ }^{4}$

Although not used in Part 1, a set of $120^{\circ} \mathrm{C}$ isochronous stress-strain curves was generated using Eq. (10.3). The resulting curves, shown in Fig. 10.21, illustrate the increased significance of time-dependent creep strains relative to elastic loading strains at the higher stresses.

As was shown in Table 10.1, a single creep test was performed at $70^{\circ} \mathrm{C}$. The results are shown in Fig. 10.22(a) and $(b)$ on linear and log scales, respectively. The latter provides a good illustration of the choice of data range used for power-law curve fitting. Referring to Fig. 10.22(a), which shows the corresponding predicted room-temperature creep curve, the ratio of $70^{\circ} \mathrm{C}$ creep strain at $5000 \mathrm{~h}$ to the corresponding room-temperature creep strain is 1.2 . Figure 10.23 shows the resulting curve, used in Part 1, for estimating elevated-temperature creep from that predicted at room temperature. 


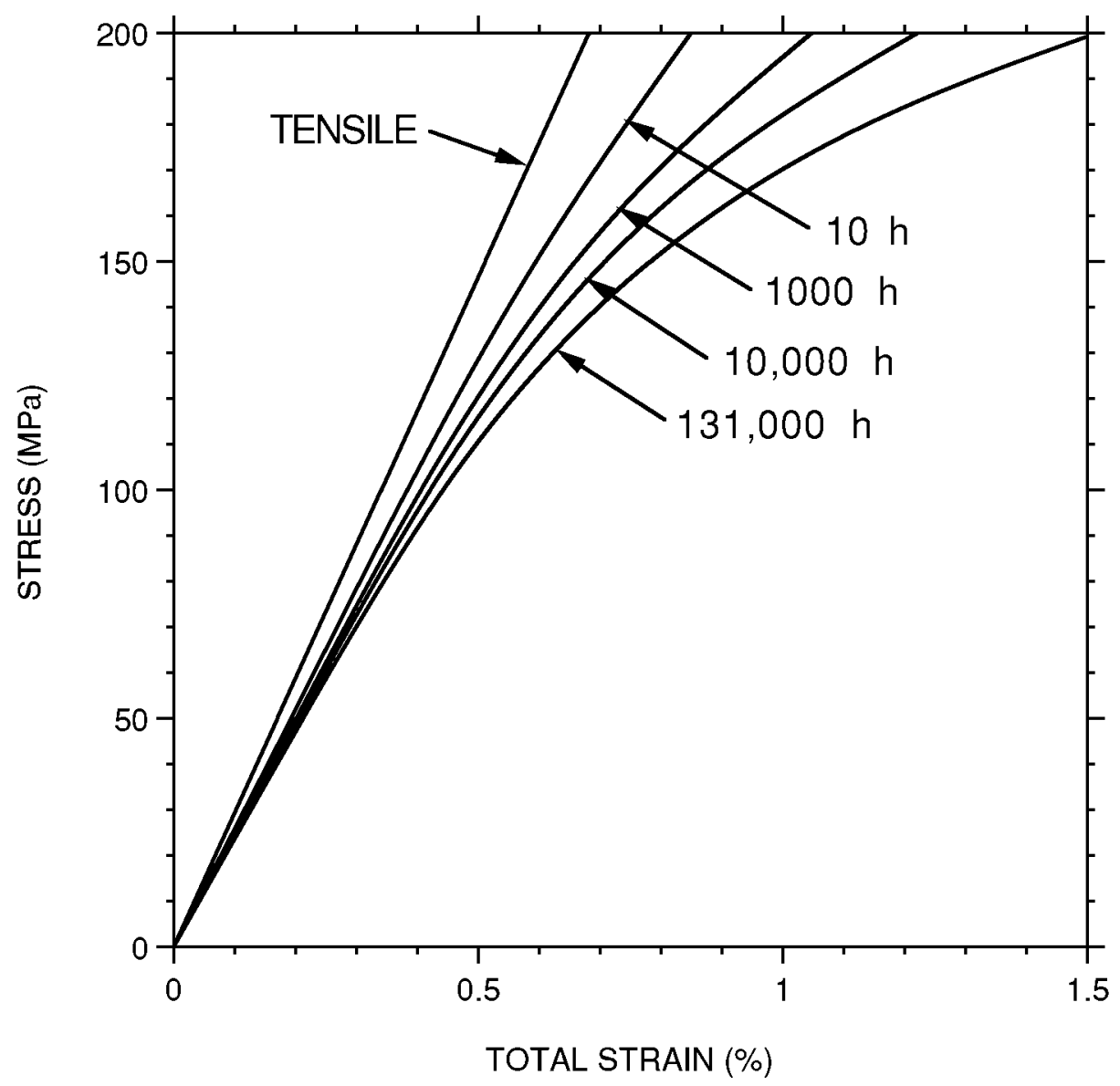

Fig. 10.21. Isochronous stress-strain curves at $120^{\circ} \mathrm{C}$. 

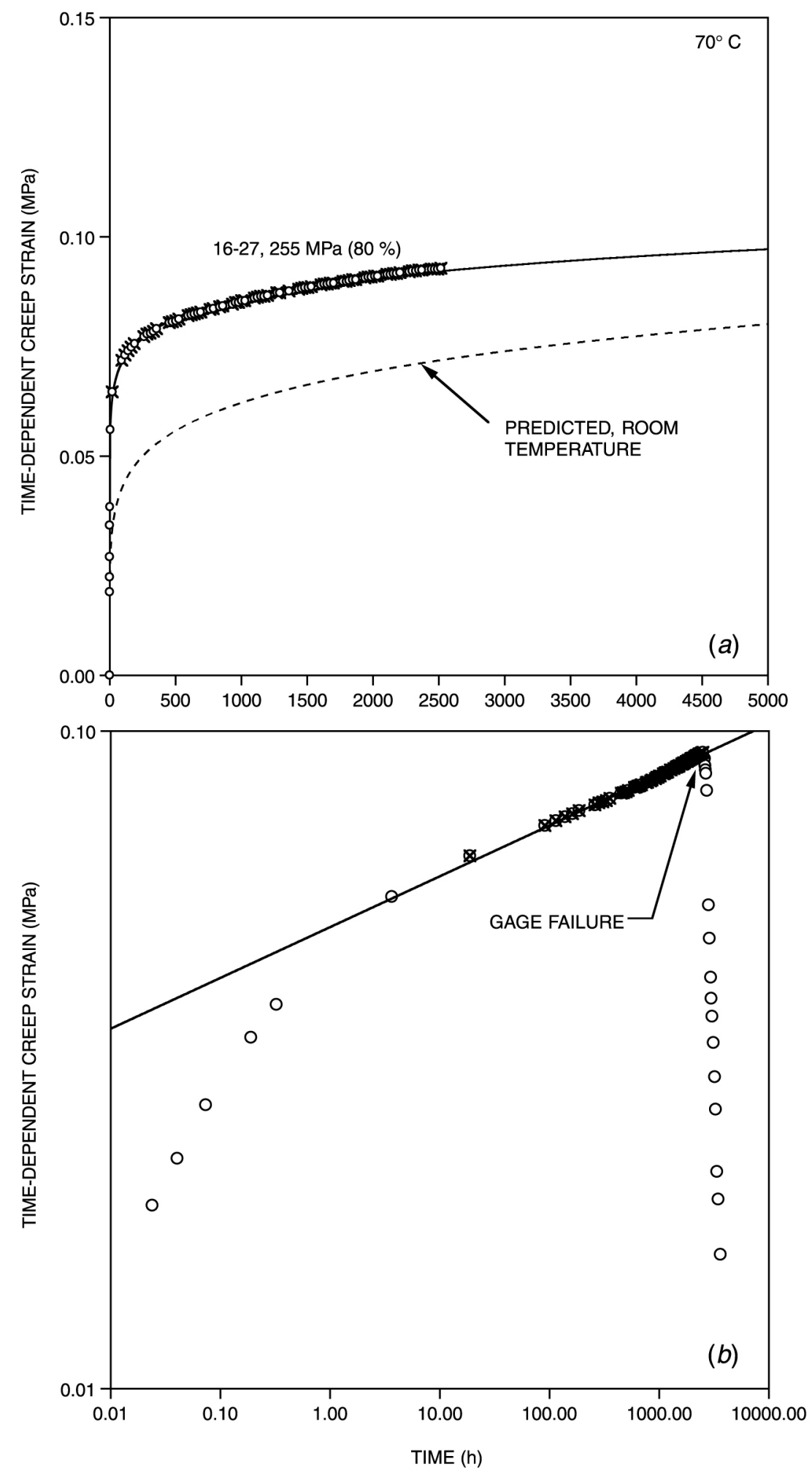

Fig. 10.22. Results of single creep test at $70^{\circ} \mathrm{C}$ : (a) comparison of creep response with predicted room-temperature response at same stress and $(b)$ creep response on log-log scale showing power-law curve fit. 


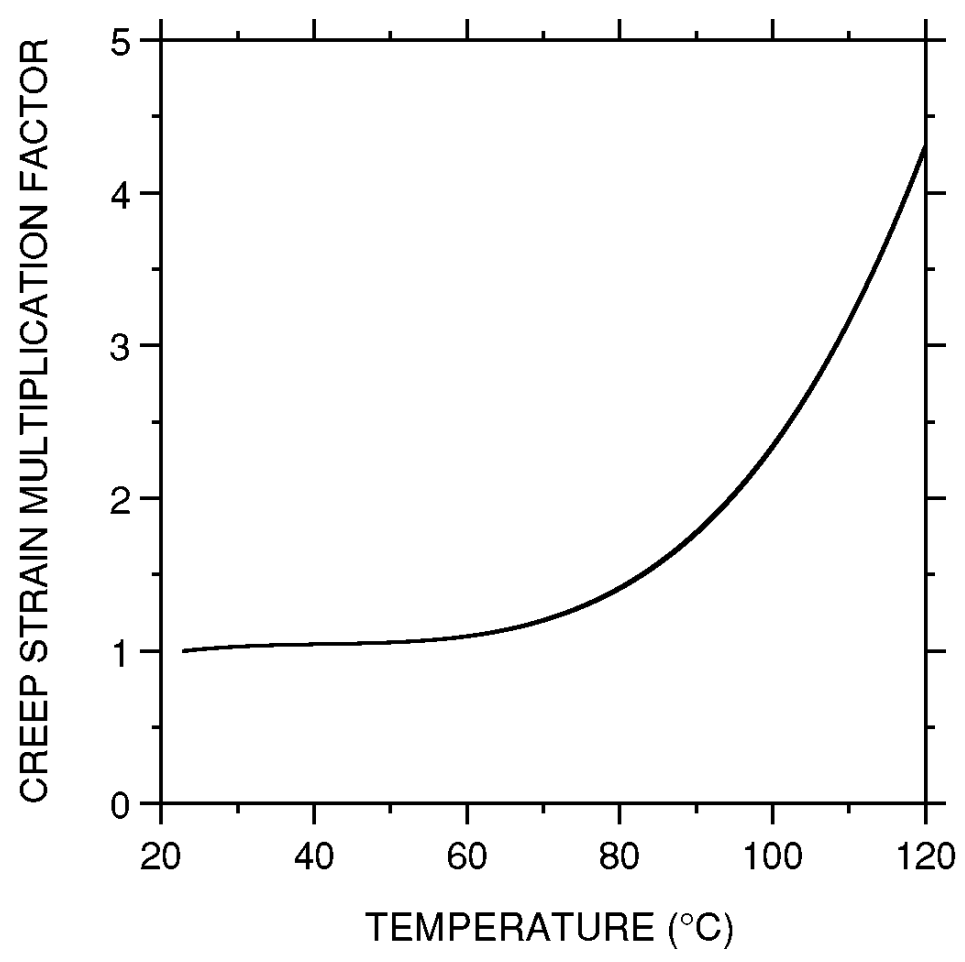

Fig. 10.23. Time-dependent creep strain multiplication factor vs temperature.

\subsection{LONG-TERM TESTS IN FLUIDS}

Figure 10.24 depicts the arrangement used to perform creep tests in fluids - either distilled water, generally with a 1000 -h presoak, or windshield washer fluid with a 100 -h presoak. As was done for the fatigue tests reported in Chap. 9, an acrylic pipe section with silicon-rubber end plugs was used to contain the fluid over the reduced-width section of the dogboned tensile specimens. The specimen shown in Fig. 10.24 has full-bridge strain-gage compensation, which requires a second container for the unstressed piece with dummy strain gages.

\subsubsection{Distilled Water}

The creep curves resulting from four tests in distilled water (all with a nominal 1000-h presoak) are plotted in Fig. 10.25, where they are fitted with power-law curves and compared to the corresponding in-air creep curves predicted by Eq. (10.2). Ratios of the distilled-water creep strains to the predicted in-air strains vary from 1.2 to 2.1 (the latter corresponding to the 264-MPa test). A ratio of 1.7 (which adequately covers the other tests) is recommended for design and is used in Chap. 2 of Part 1.

To further explore the effects of distilled water on specimen strain, the three tests given in Table 10.1 on specimens Q16-6, 16-8, and 16-12 were performed. In the test of 16-6, expansion strain due to moisture absorption alone was measured; the specimen was not loaded, there was no presoak, and full-bridge strain-gage compensation was not used. The resulting expansion strain is plotted as a function of time in Fig. 10.26. For comparison purposes, the expansion strain is about equivalent to the predicted room-temperature creep strain incurred at a stress of $100 \mathrm{MPa}$. Also, 


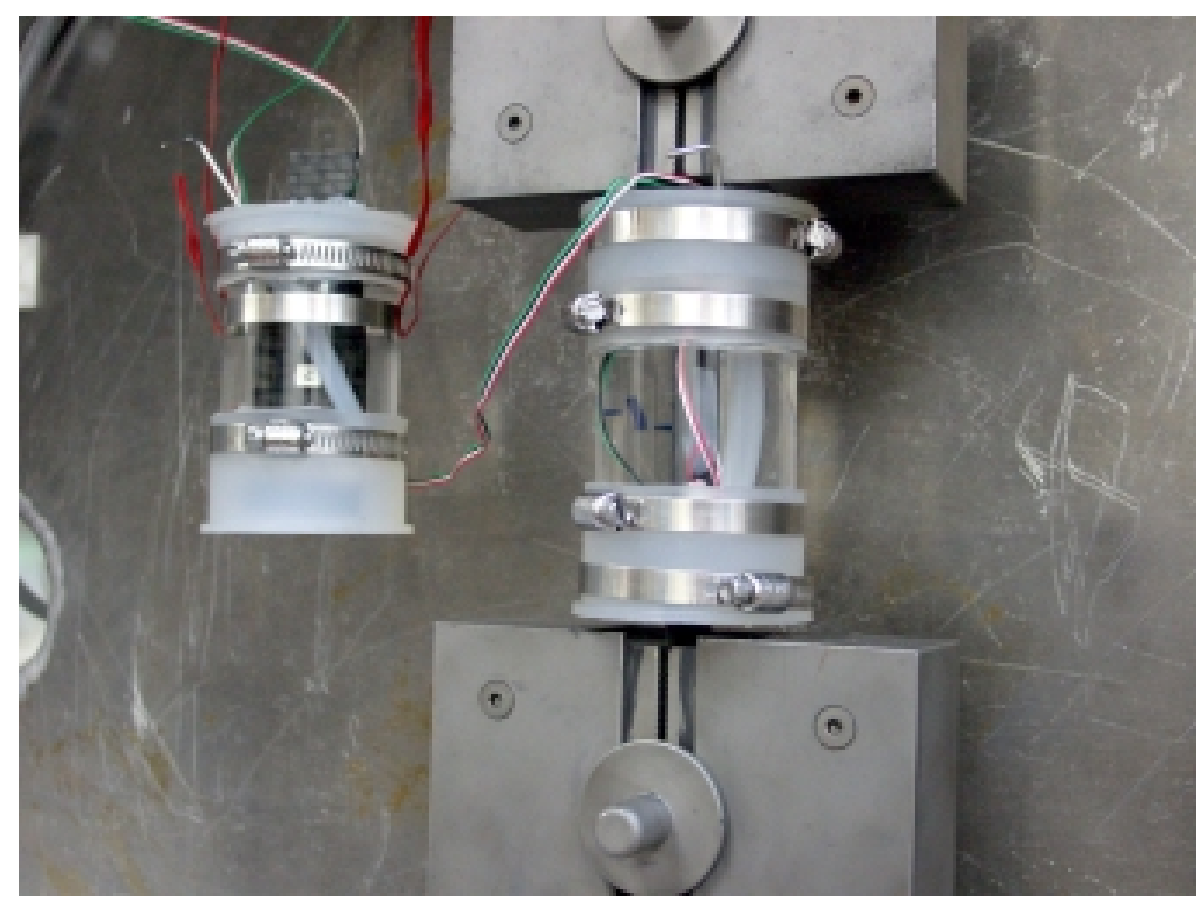

Fig. 10.24. Arrangement used for obtaining full-bridge compensation for strain gages on specimens tested in fluids.

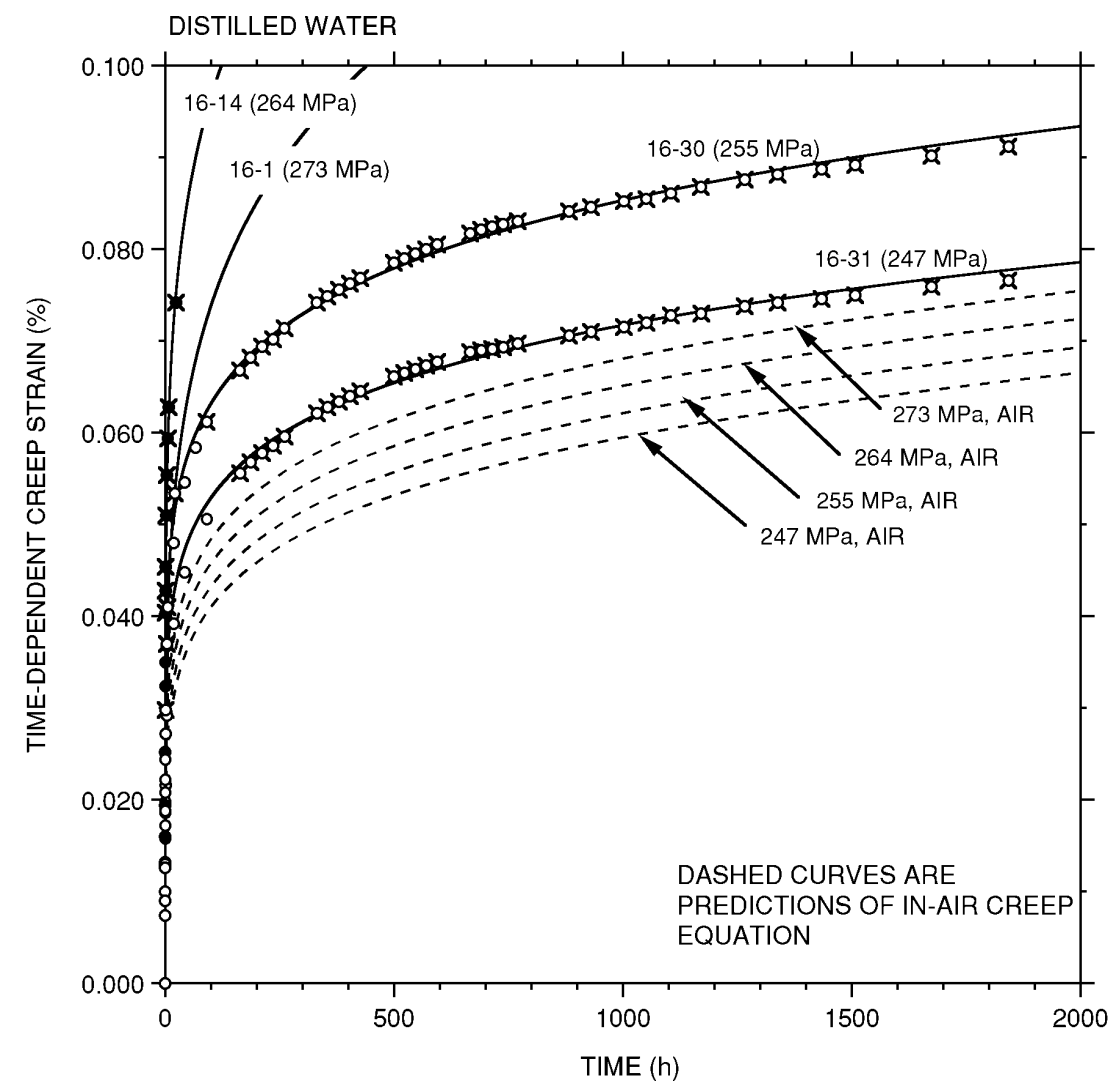

Fig. 10.25. Creep response of specimens tested in distilled water compared to predicted response in air. Solid curves are power-law fits using data points with an " $x$ " behind them. 


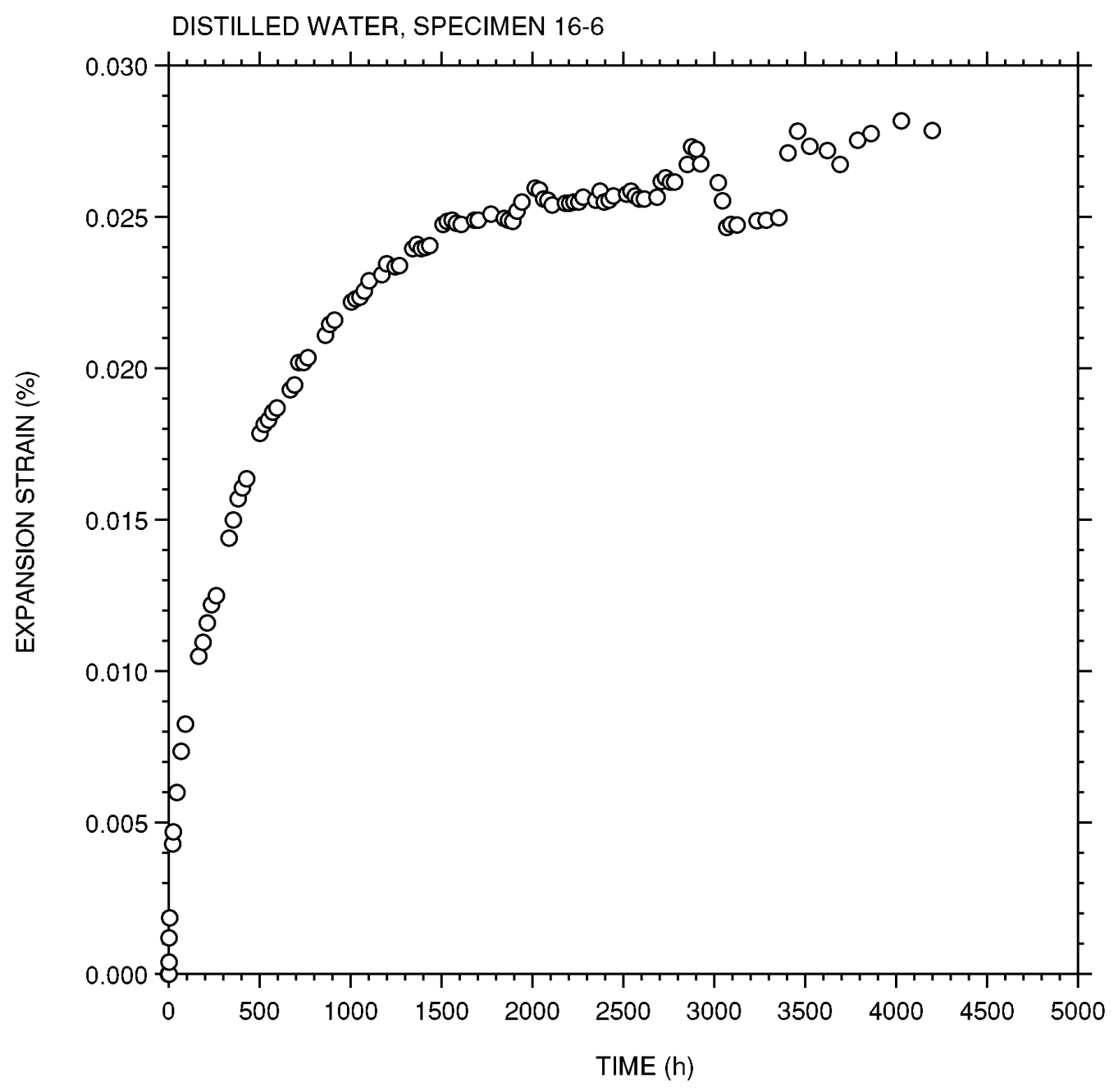

Fig. 10.26. Expansion strains in unloaded specimen due to moisture absorption from soaking.

the maximum creep strain is approximately equivalent to the thermal expansion produced by a temperature change of $100^{\circ} \mathrm{C}$.

The expansion strain due to moisture absorption in the presence of creep would be expected to be higher than in Fig. 10.26 due to the effect of load. A comparison test was performed at a stress of $280 \mathrm{MPa}$ (no presoak and no strain gage compensation). The resulting time-dependent strain (moisture expansion plus creep) is plotted in Fig. 10.27, along with the results from Fig. 10.26. Here, the strain is considerably larger than would be expected from creep alone. The creep strain alone from a second test at $280 \mathrm{MPa}$ is also shown in Fig. 10.27. While the measured strain from this test is lower, the test (Q16-12) failed in just $2.6 \mathrm{~h}$, so no definitive comparison was possible. More data clearly would be needed to sort out the moisture contribution at various loads.

\footnotetext{
*ACC measurements produced an average coefficient of linear thermal expansion of $2.7 \times 10^{-6} /{ }^{\circ} \mathrm{C}$ for the quasiisotropic composite. ${ }^{10}$
} 


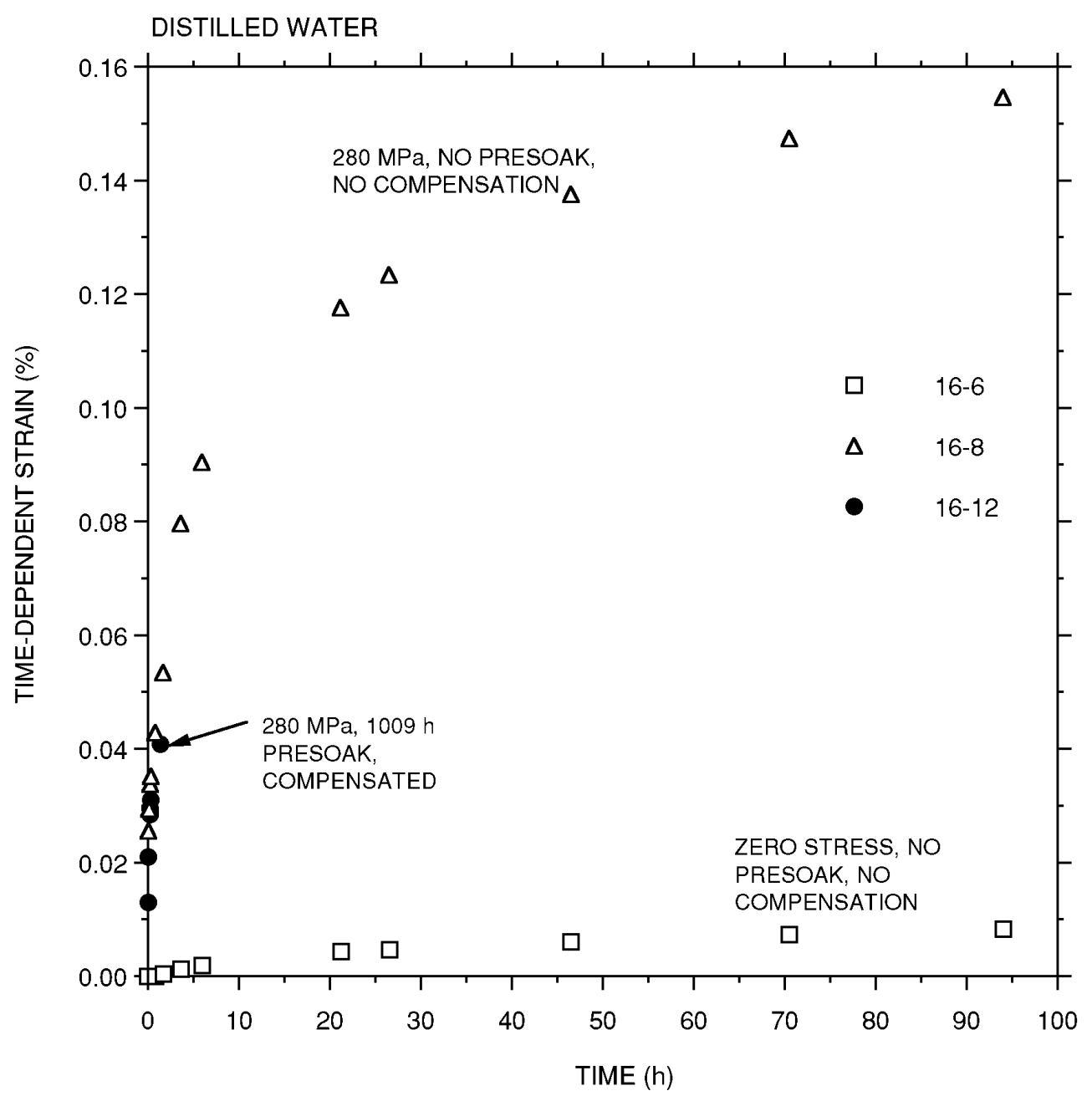

Fig. 10.27. Compensated and uncompensated time-dependent strains in specimens tested at 280 MPa in distilled water compared to zero-stress expansion data from Fig. 10.26.

\subsubsection{Windshield Washer Fluid}

The creep curves resulting from three tests at a stress of $273 \mathrm{MPa}$ in windshield washer fluid (all with a nominal 100-h presoak) are plotted in Fig. 10.28, where they are fitted with power-law curves and compared with the corresponding predicted in-air curve. The cause of the upturn in the 16-3 and 16-7 tests is not known for sure. While specimen 16-3 failed at $695 \mathrm{~h}$, specimen 16-17 was discontinued after more than $4000 \mathrm{~h}$ of test time. It may be, at least in the latter case, that microcracks in the transverse surface plies occurred under the strain gages.

If the anomalous strain behavior is ignored and only the curve fits are considered, a ratio of 1.5 between creep in windshield washer fluid and creep in air covers the three sets of data. This value was used in the design guidance in Chap. 2 of Part 1.

\subsection{COMPRESSIVE TESTS}

Several qne week creep tests were performed at room-temperature and at $120^{\circ} \mathrm{C}$ using standard compression specimens and the standard ITRI compression test fixture (see Chap. 7). 
WINDSHIELD WASHER FLUID

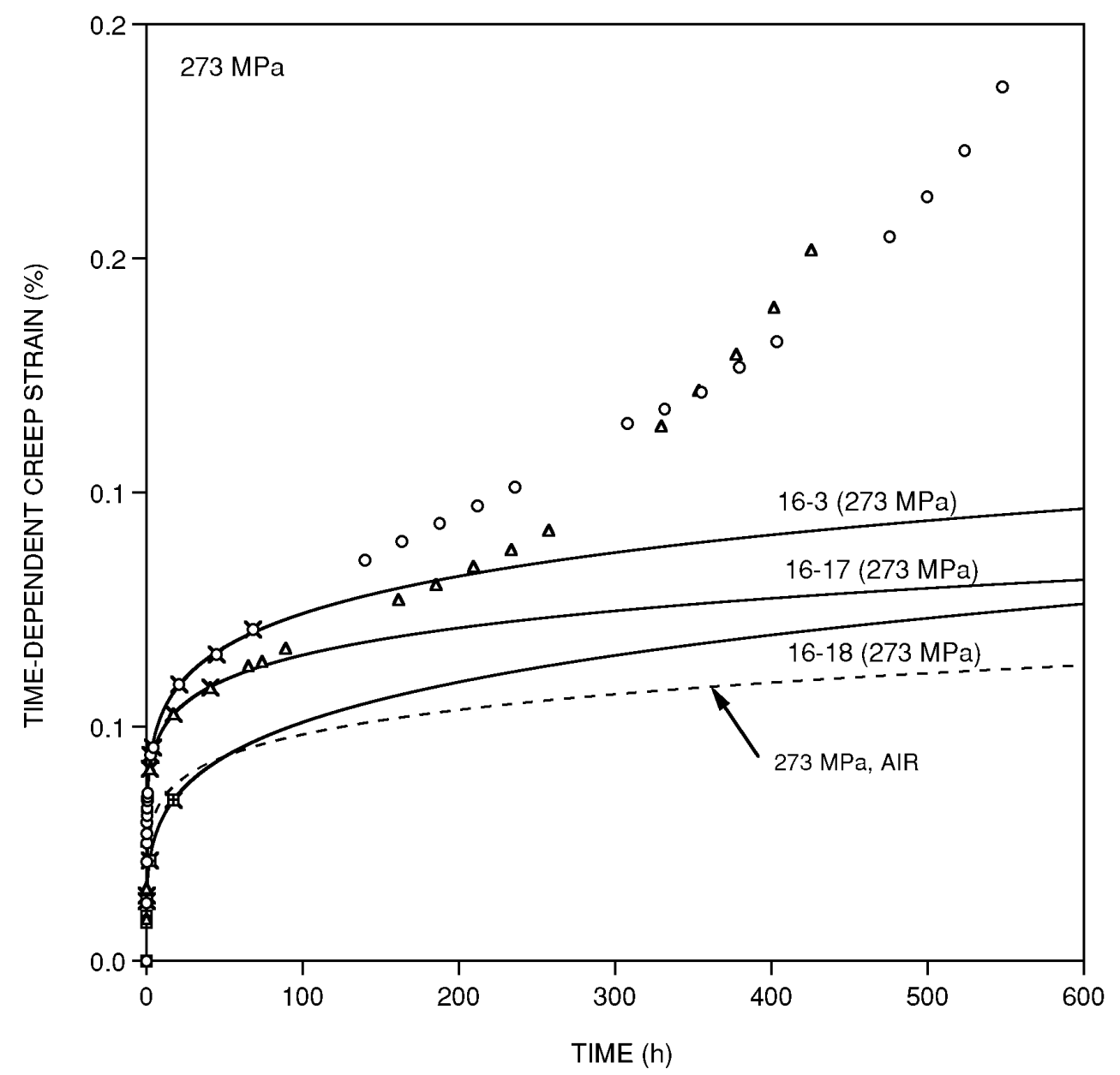

Fig. 10.28. Creep response of three specimens tested at $273 \mathrm{MPa}$ in windshield washer fluid compared to predicted in-air response at same stress.

Specimens were strain-gaged, but full-bridge gage compensation was not used. While humidity changes, which were discussed earlier in this chapter, significantly affected the room-temperature results, data at both temperatures were sufficient to draw tentative conclusions regarding the magnitude of compressive creep relative to tensile creep. All specimens were from plaque Q18, which had a significantly higher stiffness than did Q16, from which the tensile creep specimens were taken. To make the compressive results more comparable to the tensile results, the stresses were multiplied by 0.93 , the ratio of Q16 stiffness to Q18 stiffness.

Results of two room-temperature compressive tests at different stress levels are plotted in Fig. 10.29, where the corresponding predicted tensile creep strains are shown for comparison. At first look, the data appear unusable, particularly those from the lower stress level test. However, comparisons with the corresponding site meteorological data make the results more plausible. Consider the results of the higher stress test first. The upward swing seen in the last three data points corresponds to a significant drop in outside temperature; the inside humidity dropped, and the specimen shrank as moisture migrated out. The last three points were consequently not used in the power-law curve fit represented by the upper solid curve. 


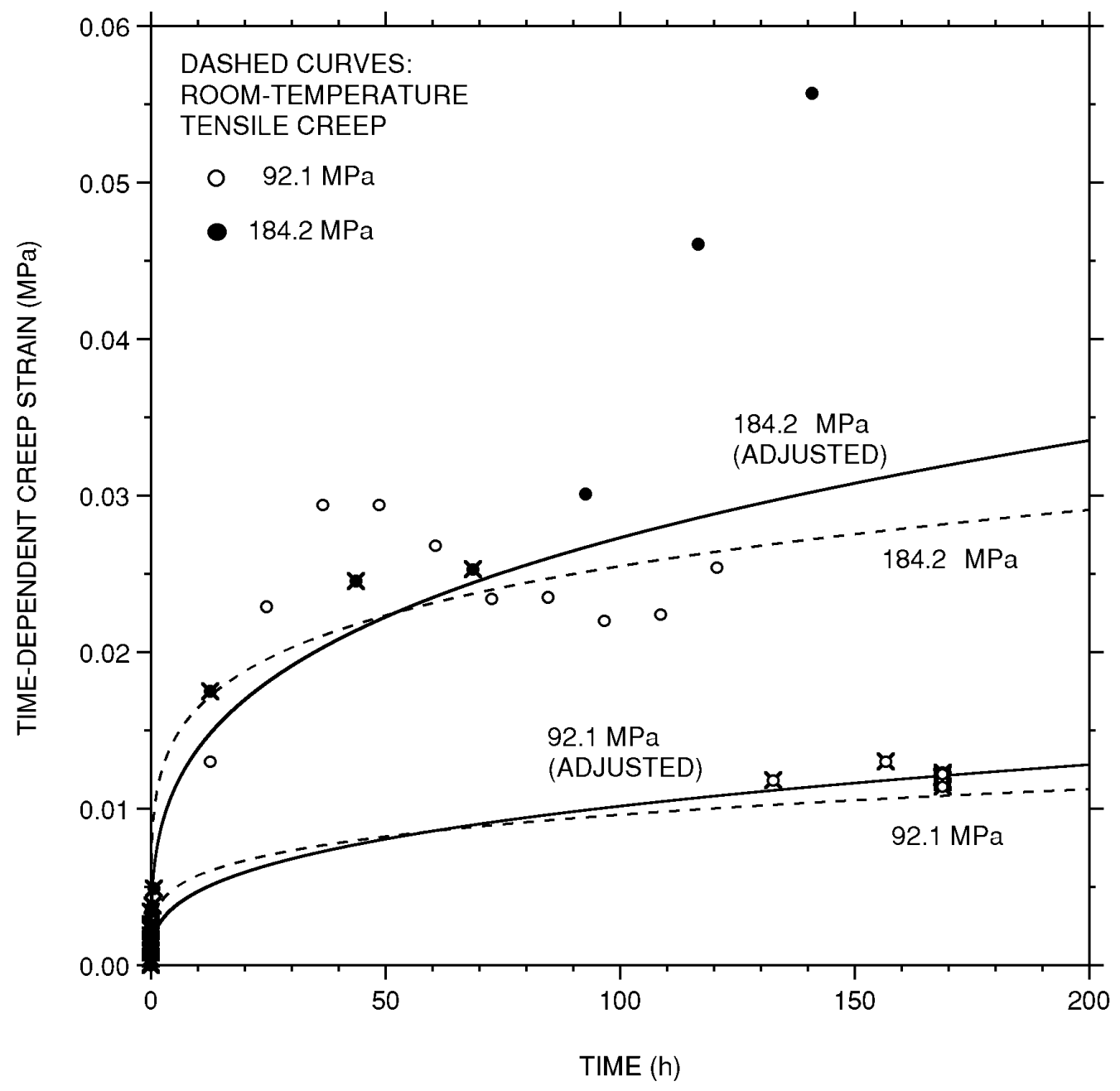

Fig. 10.29. Results of two one-week compressive creep tests at room-temperature compared to predicted tensile creep at same stress levels. The errant response in both cases correlates with outside temperature and thus laboratory humidity level.

The results of the lower stress test were similarly affected. In the early days of the test, the outside temperature dropped, but in the latter stages of the test the outside warmed back up to about the level that existed at the beginning of the test. Thus, the upward excursion was an artifact of outside temperature changes. Only the initial and final data points were used in the power-law curve fit represented by the lower solid curve.

Comparison of the compressive and tensile curves at each of the two stress levels leads to the tentative conclusion that tensile and compressive creep are about the same at room temperature.

Three $120^{\circ} \mathrm{C}$ compressive tests were successfully completed. Humidity changes did not dominate the results as they did in the room-temperature case because moisture is relatively quickly driven out of the specimen at elevated temperature. The $120^{\circ} \mathrm{C}$ results are plotted in Fig. 10.30. Again, the corresponding predicted tensile creep curves (dashed) are shown for comparison. The solid curves are power-law fits to portions of the data determined from the corresponding log-log plot. On the basis of the curves, it appears that at $120^{\circ} \mathrm{C}$ compressive creep varies from 7.8 times tensile creep at $38.1 \mathrm{MPa}$ to 18 times at $76.1 \mathrm{MPa}$. While buckling 


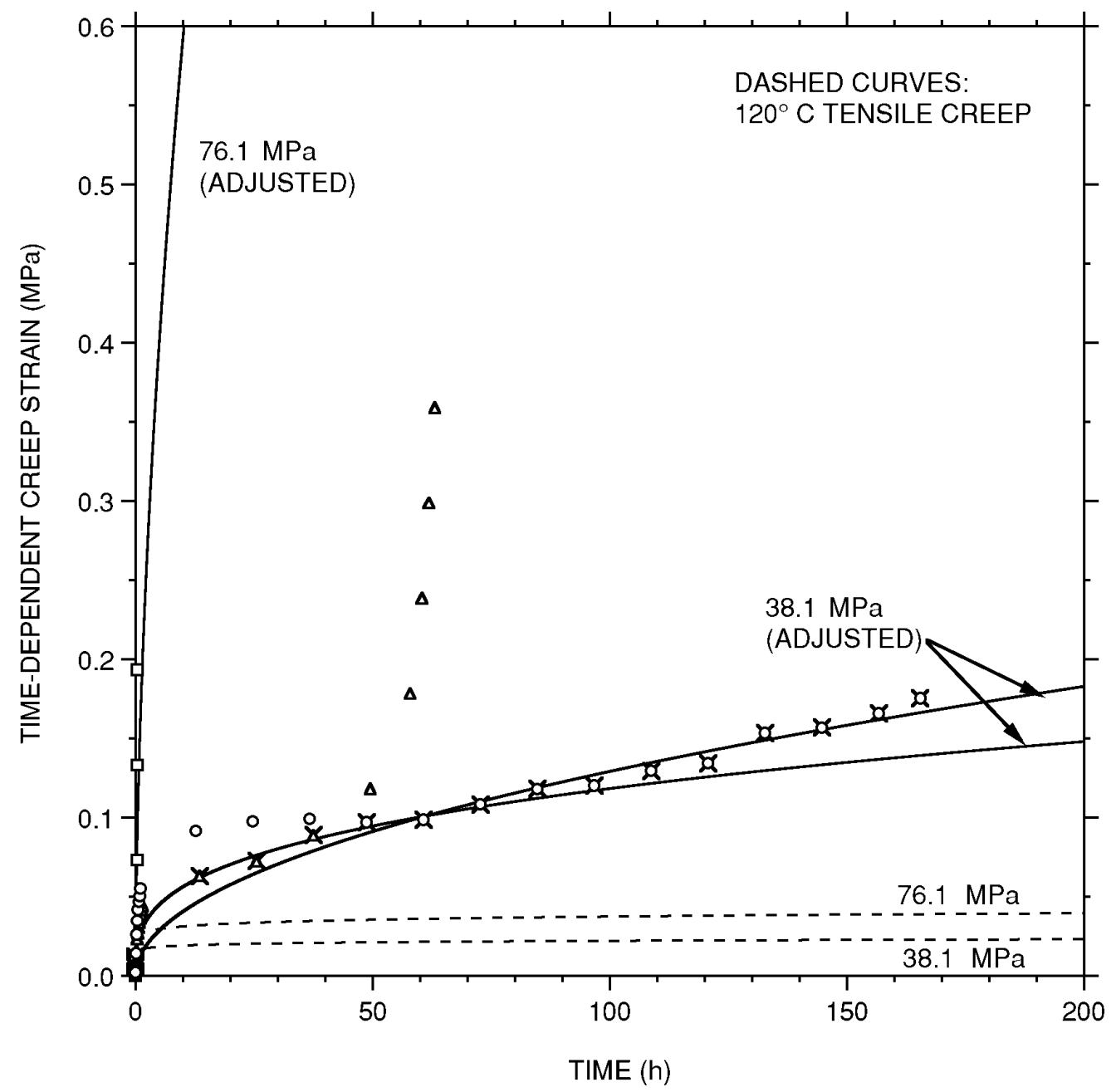

Fig. 10.30. Compressive creep response of three specimens tested at $120^{\circ} \mathrm{C}$ compared to predicted tensile response at same temperature and stress level.

mechanisms are probably involved in these high deformations, it is obvious that long-term compressive loadings should be avoided at $120^{\circ} \mathrm{C}$.

\subsection{SUMMARY}

The overall strategy was to develop a well-based equation that described room-temperature, time-dependent, tensile creep strains as a function of time and applied stress. Multiplication factors were then derived to account for the effects of temperature, fluids, and compressive loadings. It was found that long-term creep can be adequately described by a power law of the form $\varepsilon_{\mathrm{c}}=A \mathrm{t}^{\mathrm{n}}$, where $\mathrm{A}$ and $\mathrm{n}$ are functions of stress. To determine $\mathrm{A}$ and $\mathrm{n}$ for a given test, the test must be allowed to continue sufficiently long for the data to reach and clearly define a straight line on $\log \varepsilon_{\mathrm{c}}$ vs $\log \mathrm{t}$ coordinates.

Creep strains for the quasi-isotropic carbon-fiber composite are small at room temperature; after 15 years at a given stress, they amount to only about $16 \%$ of the corresponding elastic loading strain. Because the time-dependent creep strains are small, expansion and contraction caused by significant changes in humidity can dominate the indicated strains. For this reason, 
full-bridge strain-gage compensation was used in long-term tests. This effectively eliminated spurious strains caused by temperature and humidity changes.

Equation (10.2) is the master equation for predicting room-temperature in-air creep strains. To estimate creep strains for other conditions, the strains predicted by Eq. (10.2) should be multiplied by the factors tabulated below.

\begin{tabular}{lcc}
\multicolumn{1}{c}{ Condition } & Creep multiplication factor \\
\cline { 1 - 1 } $10^{\circ} \mathrm{C}$ in air & 1.2 \\
$120^{\circ} \mathrm{C}$ in air & 4.3 \\
Distilled water & 1.7 \\
Windshield washer fluid & 1.5 \\
Compression at room temperature & 1.0 \\
Compression at $120^{\circ} \mathrm{C}$ & $7.8 \times 4.3=34$ at $38.1 \mathrm{MPa}$ \\
& $18 \times 4.3=77$ at $76.1 \mathrm{MPa}$
\end{tabular}

Compressive loadings at elevated temperatures should clearly be avoided. 
$10-32$ 


\title{
11. CREEP RUPTURE
}

\author{
J. M. Corum, R. L. Battiste, and M. B. Ruggles-Wrenn
}

\subsection{INTRODUCTION}

The tensile creep tests that were listed in Table 10.1 included those tests that resulted in failure and that are thus used in this chapter. The table also shows the times at which tests were discontinued. These discontinued tests are, where appropriate, considered as runouts in this chapter.

Tensile creep-rupture curves are presented in this chapter for an air environment at room temperature and $120^{\circ} \mathrm{C}$, as well as for the distilled water and windshield washer fluid environments. Two of the compression creep tests at $120^{\circ} \mathrm{C}$ discussed in Chap. 10 resulted in failure, so a creep-rupture correlation for that condition is also provided. A time-temperature parameter approach is used to estimate failure behavior at temperatures for which no experimental data were generated.

The strategy followed in this chapter is to first develop a room-temperature creep-rupture design curve, which is the basis for the room-temperature time-dependent allowable stress values given in Chap. 3 of Part 1. By comparing the creep-rupture curves for other environments and loadings to the room-temperature curve, creep-rupture strength reduction factors are established. These were used in Chap. 3 of Part 1 to appropriately reduce the time-dependent allowable stresses.

\subsection{TESTS IN AIR}

\subsubsection{Room-Temperature Tensile Failures}

Seven of the room-temperature tests listed in Table 10.1 ended in creep-rupture failure. In addition, six of the "discontinued" tests were at similar stress levels but had not failed at the time of writing this report.* All of these data points are plotted in Fig. 11.1. Only the failure points were used, however, in developing the solid creep-rupture curve. The data are very scattered relative to time, with rupture life only slightly dependent on stress. As a result, the coefficient of determination, $\mathrm{r}^{2}$, is low. ${ }^{\dagger}$

As was done for the previous glass- and carbon-fiber composites investigated, a design curve was developed by taking $80 \%$ of the minimum creep-rupture strength. ${ }^{1,3,4}$ Because of the paucity of failure data, the "minimum" curve was established by simply shifting the original solid curve down to bound all of the data points.

Note that the allowable short-time stress, $\mathrm{S}_{0}$, defined as two-thirds of the minimum UTS, is $194 \mathrm{MPa}$ at room temperature. This value is less than the time-dependent design allowable over the entire life of a vehicle. Thus, as was specified in Chap. 3, time-dependent allowable stresses do not govern at room-temperature.

\footnotetext{
*Four discontinued tests were at stresses well below those expected to ever result in rupture.

$\dagger$ Note that the curve fit expresses stress as a function of time, when in fact time is the dependent variable. This choice of variables was necessary to obtain a reasonable fit to the data.
} 


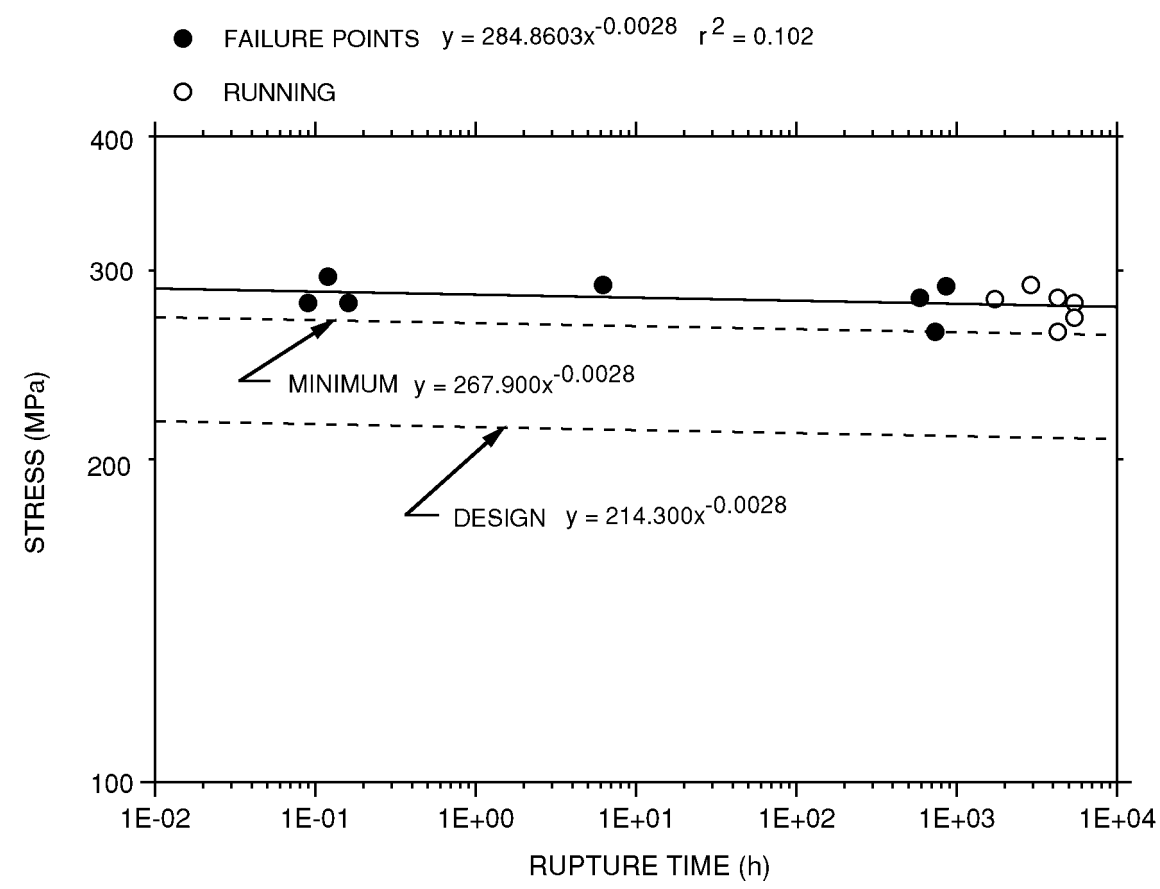

Fig. 11.1. Tensile creep-rupture data and curve at room temperature. The "minimum" curve is a visual minimum based on the available data. The "design" curve is based on $80 \%$ of the minimum creeprupture strength.

\subsubsection{Tensile Failures at $120^{\circ} \mathrm{C}$}

All of the $120^{\circ} \mathrm{C}$ creep tests listed in Table 10.1 , except for one very low-stress one, resulted in creep rupture. The ten failure points are plotted in Fig. 11.2, where they are again represented by a power-law curve fit. The room-temperature curve from Fig. 11.1 is shown for comparison. The slope of the $120^{\circ} \mathrm{C}$ curve is significantly greater than that of the room-temperature curve, and the coefficient of determination for the curve fit is larger.

By using the curve-fit equations in Figs. 11.1 and 11.2, the ratio of the creep-rupture strength at $120^{\circ} \mathrm{C}$ to that at room temperature can be calculated for various times. The resulting values are tabulated in the "Summary" (Sect. 11.4) at the end of the chapter. Multiplying stress values from the room-temperature design curve by the corresponding ratio yields a design curve for $120^{\circ} \mathrm{C}$.

\subsubsection{Compressive Failures at $120^{\circ} \mathrm{C}$}

Two of the three compressive creep tests at $120^{\circ} \mathrm{C}$ described in Chap. 10 failed within the specified one-week test period. The two room-temperature tests did not fail.

The $120^{\circ} \mathrm{C}$ tests are tabulated below, and the results are plotted in Fig. 11.3, where they are compared with the corresponding tensile curve from Fig. 11.2. The basis for adjusting the stresses was discussed in Sect. 10.6. Ratios of the $120^{\circ} \mathrm{C}$ compressive creep-rupture strength to the roomtemperature tensile strength are tabulated in Sect. 11.4.

$\begin{array}{ccc}\text { Adjusted stress (MPa) } & & \text { Failure time (h) } \\ 38.1 & \text { Runout (166 h) } \\ 38.1 & 63.1 \\ 76.1 & 0.4\end{array}$




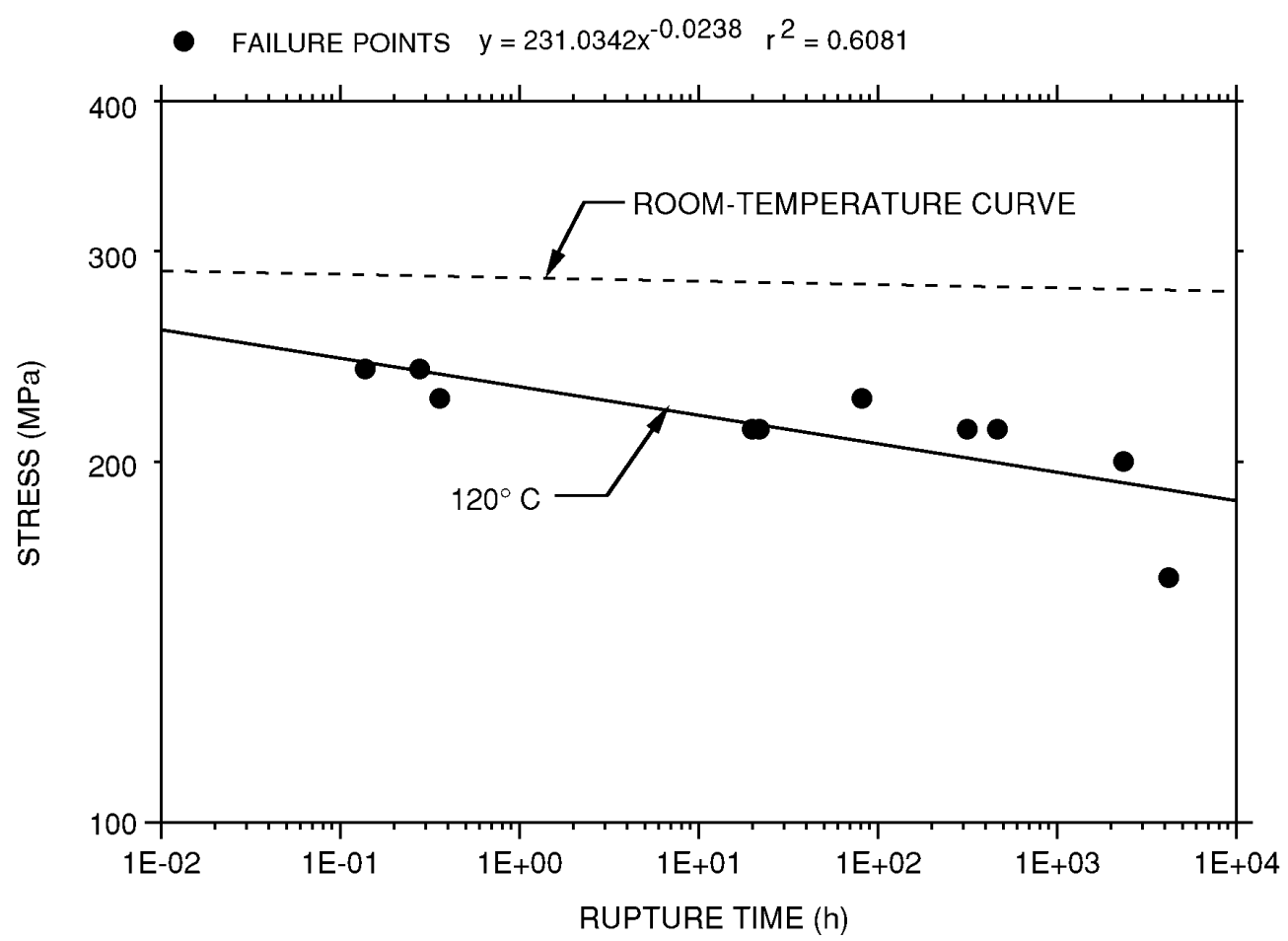

Fig. 11.2. Tensile creep-rupture data and curve at $120^{\circ} \mathrm{C}$ compared to room-temperature curve.

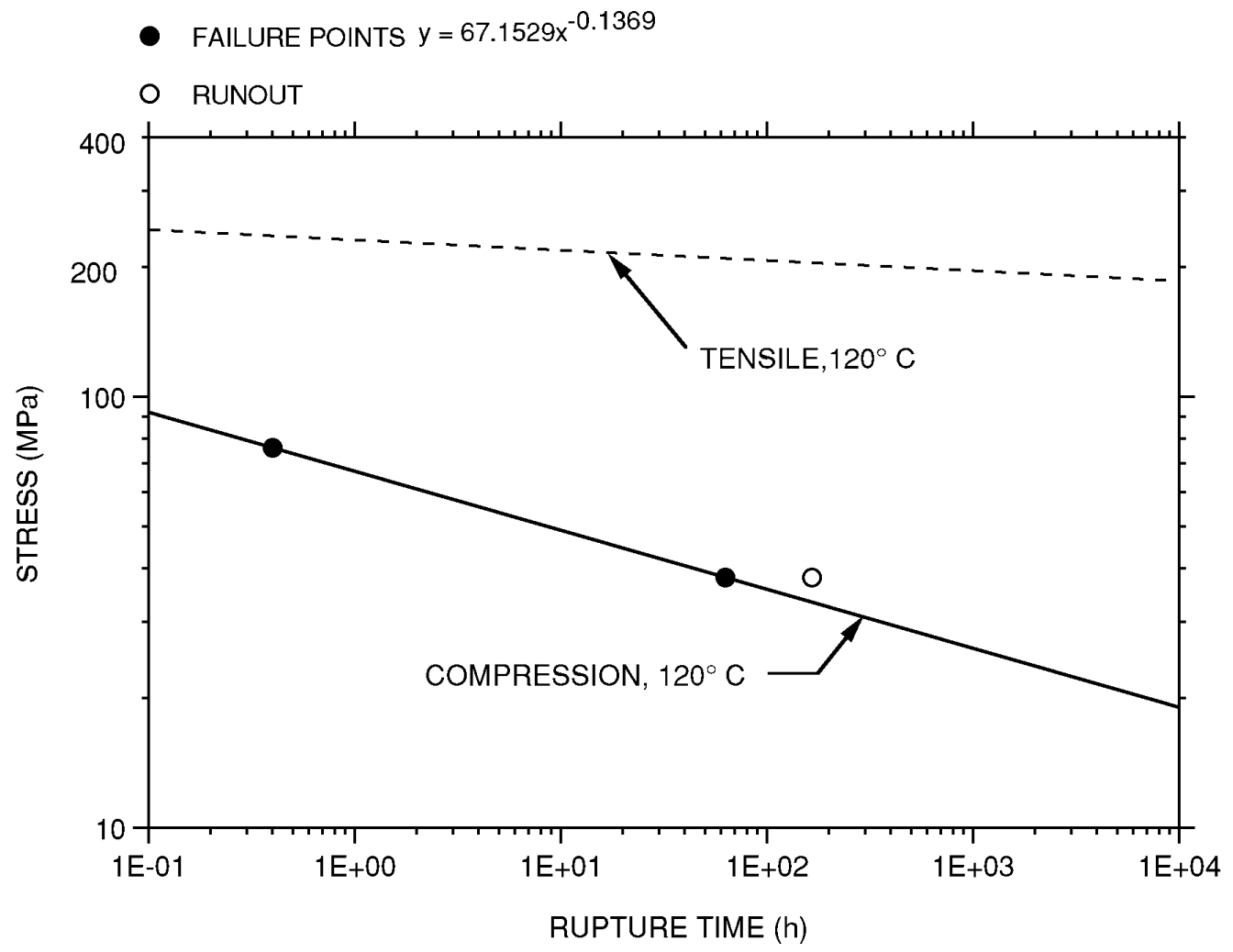

Fig. 11.3. Compressive creep-rupture data and curve at $120^{\circ} \mathrm{C}$ compared with $120^{\circ} \mathrm{C}$ tensile curve. 


\subsubsection{Time-Temperature Parameter}

The goal of a time-temperature parameter in creep rupture is to merge creep-rupture curves at different temperatures into a single curve by using a temperature-compensated abscissa (i.e., the abscissa is a function of both temperature and time). The time-temperature parameter is needed here so that rupture stresses can be developed for all of the temperatures $(-40,23,70$, and $120^{\circ} \mathrm{C}$ ) for which allowable stresses are tabulated in Chap. 3 of Part 1.

Probably the most widely used parameter is Larson-Miller. It is based on two assumptions: 17 (1) the temperature dependence of creep rate is governed by the Arrhenius equation, and (2) creep-rupture time multiplied by minimum creep rate is a constant. ${ }^{*}$ The resulting LarsonMiller parameter is expressed as

$$
\mathrm{P}_{\mathrm{LM}}(\sigma)=\mathrm{T}\left(\mathrm{C}+\log _{10} \mathrm{t}_{\mathrm{r}}\right)
$$

where $\mathrm{T}$ is absolute temperature, usually expressed in degrees Rankine, and $\mathrm{t}_{\mathrm{r}}$ is rupture time in hours. The constant $C$ is found by plotting lines of $\log _{10} t_{r} v s 1 / T$ for constant stress levels. The lines should converge at

$$
1 / \mathrm{T}=0, \quad \log _{10} \mathrm{t}_{\mathrm{r}}=-\mathrm{C} .
$$

They do not converge at this point for the quasi-isotropic material, so the Larson-Miller parameter is inadequate. Manson-Haferd replaced Larson-Miller's constant $\mathrm{C}$ with a somewhat more general intersection point $\left(\mathrm{T}_{\mathrm{a}}, \mathrm{t}_{\mathrm{a}}\right)$ on a plot of $\mathrm{T} v \log _{10} \mathrm{t}_{\mathrm{r}}$ (Ref. 17). The resulting MansonHaferd parameter is expressed as

$$
\mathrm{P}_{\mathrm{MH}}(\sigma)=\frac{\mathrm{T}-\mathrm{T}_{\mathrm{a}}}{\log _{10} \mathrm{t}_{\mathrm{r}}-\log _{10} \mathrm{t}_{\mathrm{a}}} .
$$

If pairs of $\left(\sigma, \mathrm{t}_{\mathrm{r}}\right)$ data points are determined from the power-law creep-rupture expressions at room-temperature and $120^{\circ} \mathrm{C}$, they can be used to construct the plot of $\mathrm{T}$ vs $\log _{10} \mathrm{t}_{\mathrm{r}}$ in Fig. 11.4. These curves, for three different stresses, do approximately converge at a common point $\left(\mathrm{T}_{\mathrm{a}}, \mathrm{t}_{\mathrm{a}}\right)$. With these values, Eq. (11.2) becomes

$$
\mathrm{P}_{\mathrm{MH}}(\sigma)=\frac{1.8 \mathrm{~T}-265}{\log _{10} \mathrm{t}_{\mathrm{r}}+7.0}
$$

where $\mathrm{T}$ is now in degrees Celsius.

The room-temperature and $120^{\circ} \mathrm{C}$ tensile creep-rupture data are plotted in Fig. 11.5 as a function of the Manson-Haferd parameter given in Eq. (11.3). The resulting master curve was drawn by eye through the data. Creep-rupture stresses for various times at temperatures of -40 , 23,70 , and $120^{\circ} \mathrm{C}$ were determined from the master curve and used, in turn, to determine reduction ratios of the stresses at each temperature relative to those at room temperature $\left(23^{\circ} \mathrm{C}\right)$. The resulting $120^{\circ} \mathrm{C}$ ratios agree, as they should, reasonably well with those determined directly from the original creep-rupture curves. The latter are used in the table of ratios in Sect. 11.4; but at -40 and $70^{\circ} \mathrm{C}$, the ratios are those estimated from Fig. 11.5.

The master curve for compression shown in Fig. 11.5 has a much more tenuous basis than does that for tension. There are only two data points, both at $120^{\circ} \mathrm{C}$. The following assumptions were used to draw the curve shown. First, it was assumed that the Manson-Haferd constants developed from the tensile data hold also for compression. Second, for high values of $\mathrm{P}_{\mathrm{MH}}$, the

\footnotetext{
* It was seen in Chap. 10 that the quasi-isotropic composite does not exhibit a discernable steady minimum creep rate, so, strictly speaking, one of the bases for the time-temperature parameter is violated.
} 


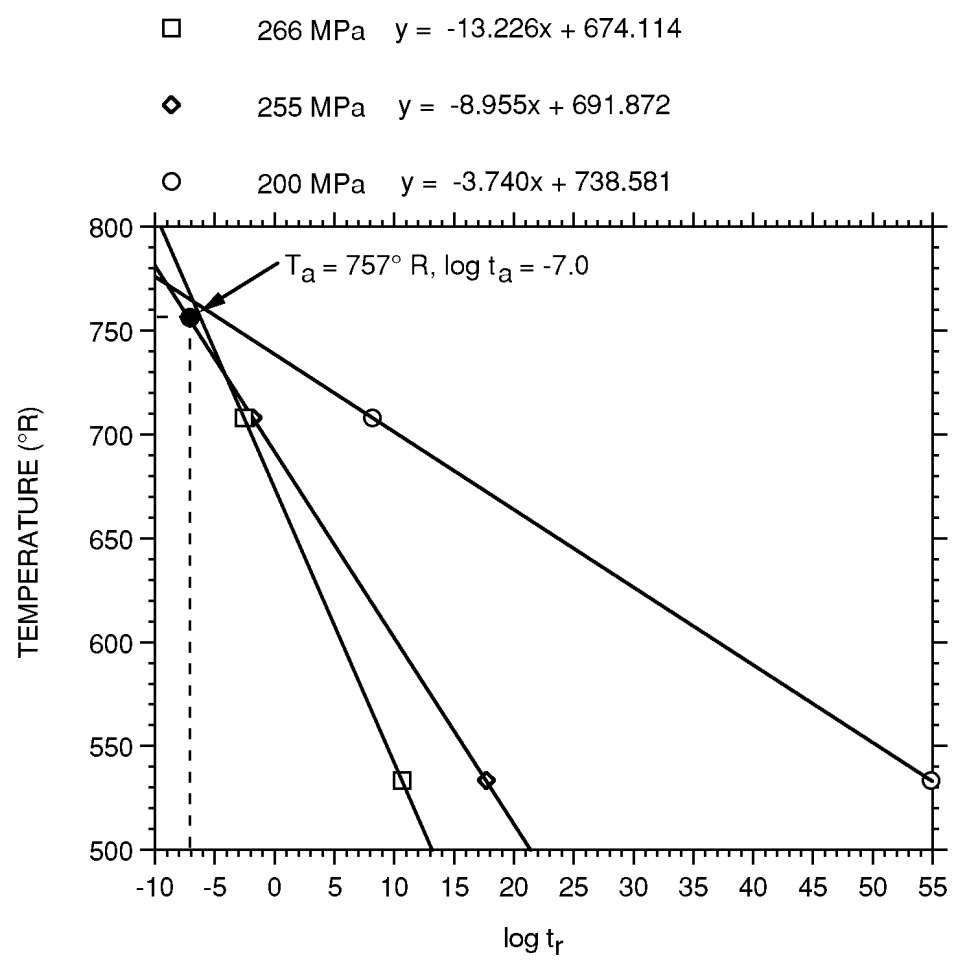

Fig. 11.4. Manson-Haferd construction for tensile creep rupture. Note that data points are calculated from room-temperature and $120^{\circ} \mathrm{C}$ creep-rupture curve fits (see Figs. 11.1 and 11.2).

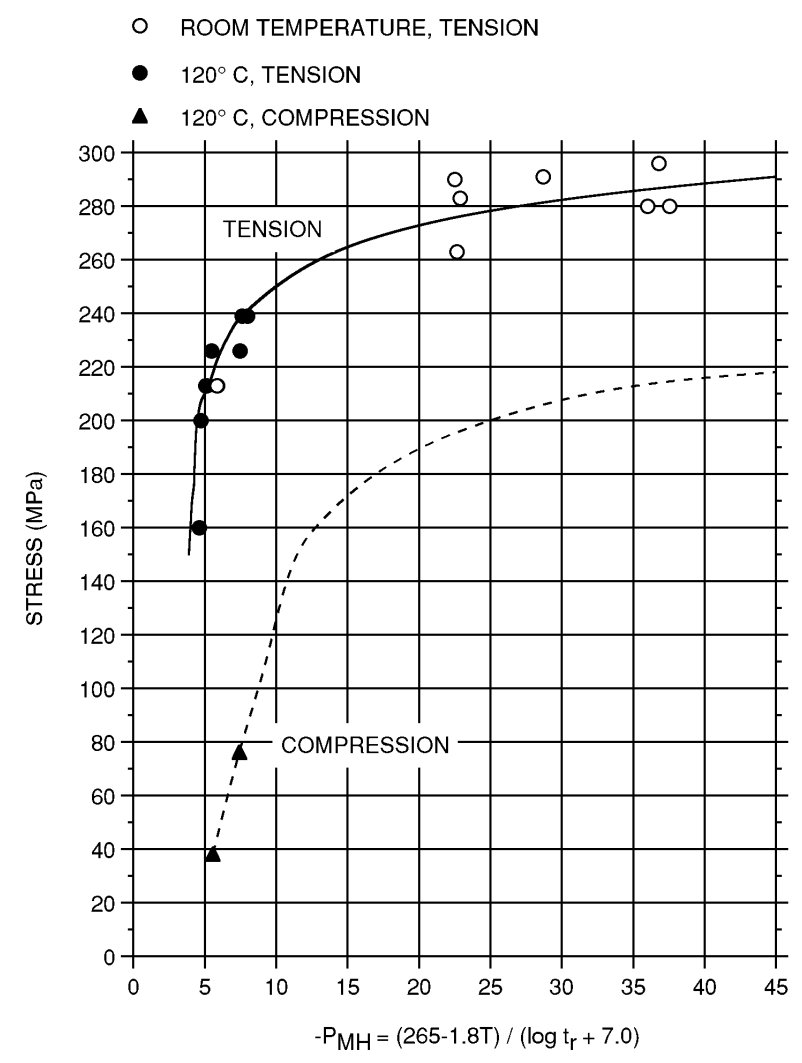

Fig. 11.5. Manson-Haferd parameter curves for tension and compression. 
stress is limited by the ultimate compressive strength at room temperature, $225 \mathrm{MPa}$. With these two assumptions, the two data points were plotted and the curve drawn.

In the same way as the tensile creep-rupture strengths and ratios were determined from Fig. 11.5, ratios of the compressive creep-rupture strengths at $-40,23,70$, and $120^{\circ} \mathrm{C}$ to the corresponding room-temperature strengths were determined. The $120^{\circ} \mathrm{C}$ ratios agreed well with those determined directly from the creep-rupture curves. The latter are used in Sect. 11.4; but at $-40,23$, and $70^{\circ} \mathrm{C}$, the ratios are those estimated from Fig. 11.5.

\subsection{TESTS IN FLUIDS}

\subsubsection{Distilled Water}

Four of the eight tensile creep tests listed in Table 10.1 for distilled water (with a 1000-h presoak) resulted in creep-rupture failure. These four points, along with four runouts, are plotted in Fig. 11.6, where the failure data are fitted with a power law. The resulting curve has a barely perceptible slope, and the coefficient of determination is almost zero. The data are again compared with the room-temperature, creep-rupture curve. Strength reduction ratios relative to the latter were calculated and are tabulated in Sect. 11.4.

\subsubsection{Windshield Washer Fluid}

Figure 11.7 depicts the results of the five tensile failure tests, tabulated in Table 10.11, of specimens tested in windshield washer fluid (with a 100-h presoak). Ratios of failure stresses in windshield washer fluid to those in air are tabulated in Sect. 11.4.

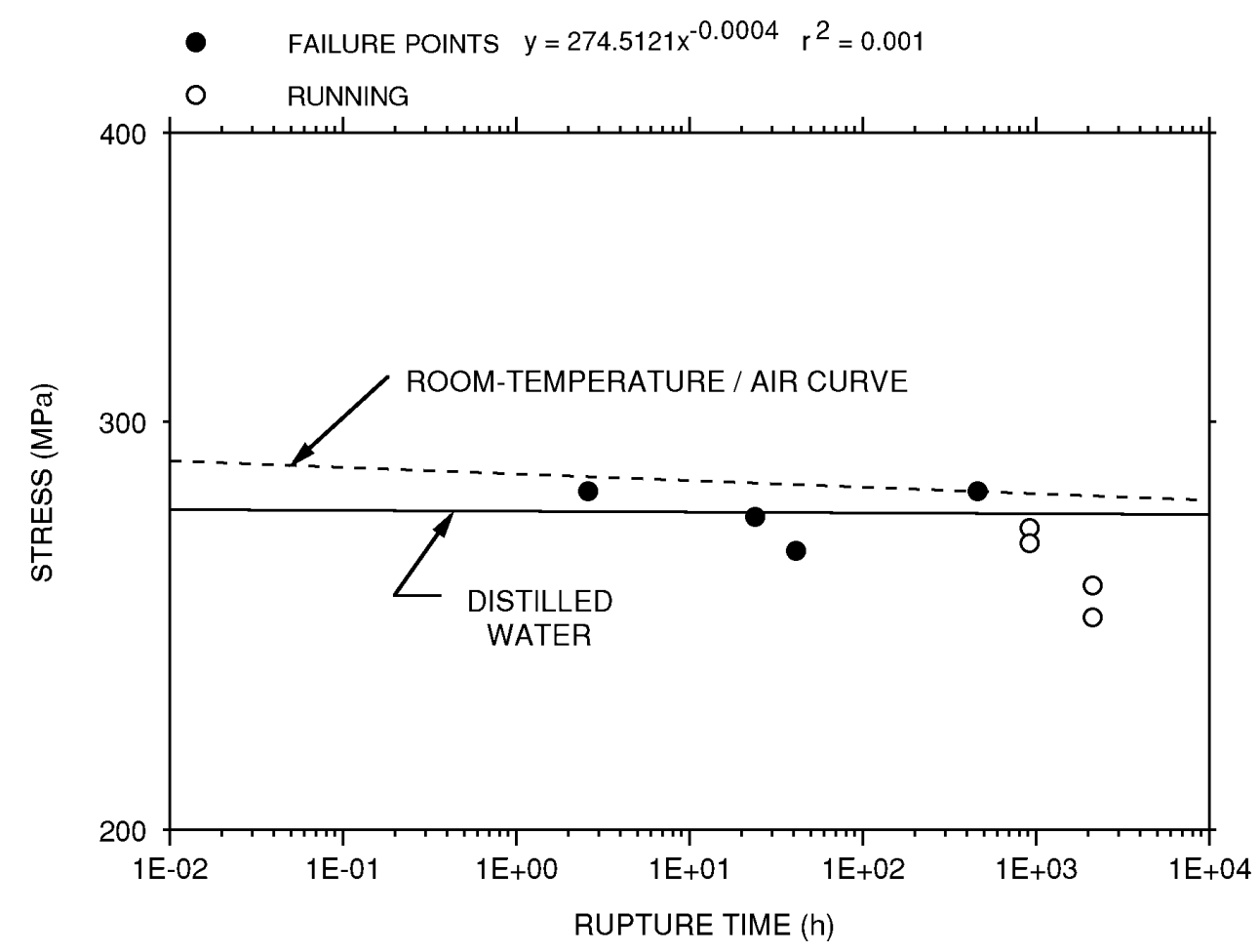

Fig. 11.6. Creep-rupture data and curve for specimens tested in distilled water compared to in-air curve. 


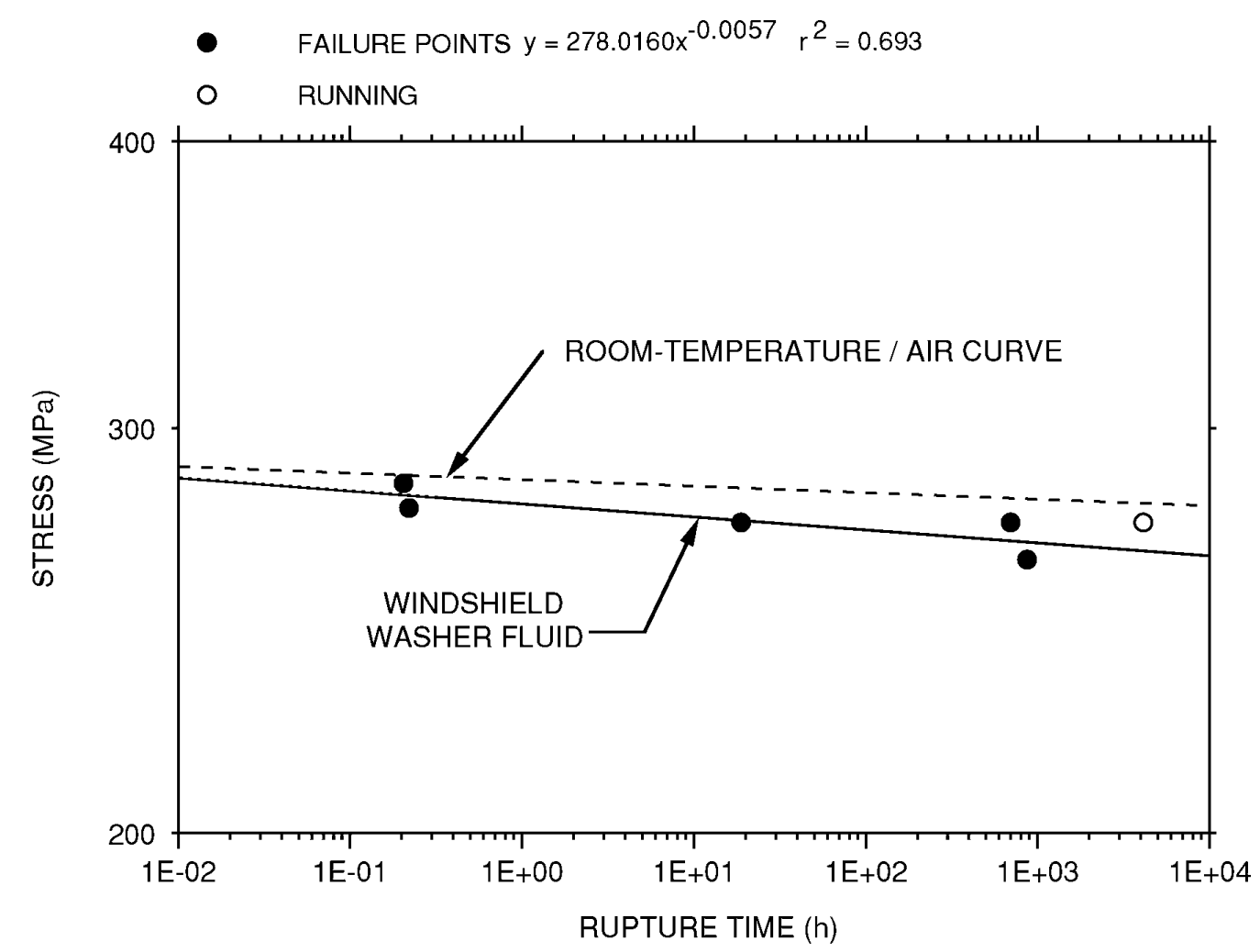

Fig. 11.7. Creep-rupture data and curve for specimens tested in windshield washer fluid compared to in-air curve.

\subsection{SUMMARY}

Tensile creep-rupture data were generated in air at room temperature and at $120^{\circ} \mathrm{C}$. Compressive data were generated at $120^{\circ} \mathrm{C}$ only. These limited in-air data were then used with a Manson-Haferd time-temperature parameter to estimate failure stresses at various times for temperatures of $-40,23,70$, and $120^{\circ} \mathrm{C}$. Creep-rupture data were also generated in distilled water and in windshield washer fluid (70\% methanol $/ 30 \%$ distilled water).

The room-temperature, in-air tensile creep-rupture curve, which is the baseline to which results for the other temperature, fluid, and loading conditions are compared, was shown in Fig. 11.1. Also shown was a design curve, which was based on $80 \%$ of the minimum creeprupture strength and which is the basis for the time-dependent allowable stresses in Chap. 3 of Part 1. Values of time-dependent allowable stress from the room-temperature design curve are given in Table 11.1.

Table 11.1. Time-dependent allowable stresses at room temperature

\begin{tabular}{lccccc}
\hline & \multicolumn{7}{c}{ Time (h) } \\
\cline { 2 - 6 } & $\mathbf{1 0}$ & $\mathbf{1 0 0}$ & $\mathbf{1 0 0 0}$ & $\mathbf{5 0 0 0}$ & $\mathbf{1 3 1 , 0 0 0}$ \\
\hline Stress, MPa & 213 & 212 & 210 & 209 & 207 \\
\hline
\end{tabular}


Table 11.2 tabulates ratios of the creep-rupture strengths for various conditions to the corresponding tensile strengths in air at room temperature. These ratios were applied to the design values in Table 11.1 to obtain the time-dependent allowable stresses tabulated in Chap. 3 of Part 1 .

Table 11.2. Creep-rupture strength multiplication factors (relative to in-air, room-temperature, tensile values)

\begin{tabular}{lccccc}
\hline \multirow{2}{*}{ Condition } & \multicolumn{5}{c}{ Time (h) } \\
\cline { 2 - 5 } & $\mathbf{1 0}$ & $\mathbf{1 0 0}$ & $\mathbf{1 0 0 0}$ & $\mathbf{5 0 0 0}$ & $\mathbf{1 3 1 , 0 0 0}$ \\
\hline In-air tension & & & & & \\
$-40^{\circ} \mathrm{C}^{a}$ & 1.00 & 1.00 & 1.00 & 1.00 & 1.00 \\
$23^{\circ} \mathrm{C}$ & 1.00 & 1.00 & 1.00 & 1.00 & 1.00 \\
$70^{\circ} \mathrm{C}^{a}$ & 0.96 & 0.96 & 0.96 & 0.95 & 0.95 \\
$120^{\circ} \mathrm{C}$ & 0.77 & 0.74 & 0.70 & 0.68 & 0.63 \\
In-air compression & & & & & \\
$-40^{\circ} \mathrm{C}^{a}$ & 0.77 & 0.77 & 0.77 & 0.77 & 0.76 \\
$23^{\circ} \mathrm{C}^{a}$ & 0.73 & 0.72 & 0.71 & 0.70 & 0.68 \\
$70^{\circ} \mathrm{C}^{a}$ & 0.65 & 0.62 & 0.61 & 0.59 & 0.55 \\
$120^{\circ} \mathrm{C}$ & 0.17 & 0.13 & 0.09 & 0.08 & 0.05 \\
Distilled water & 0.97 & 0.97 & 0.98 & 0.98 & 0.99 \\
$(1000$-h presoak) & & & & & \\
Windshield-washer fluid & 0.97 & 0.96 & 0.96 & 0.95 & 0.94 \\
$(100$-h presoak) & & & & & \\
\hline$a_{\text {From Manson-Haferd correlations. }}$ & & &
\end{tabular}




\title{
12. THE TIME-DEPENDENT AND NONLINEAR RESPONSE OF QUASI-ISOTROPIC COMPOSITE
}

\author{
Shiqiang Deng, ${ }^{*}$ Xiaoming Li, ${ }^{*}$ and Y. Jack Weitsman*
}

\subsection{INTRODUCTION}

The characterization and modeling of the crossply, stitched T300 mat/urethane IMR composite were reported in several earlier reports and articles. ${ }^{9,18-20}$ A comprehensive listing of material properties was also published. ${ }^{21}$ This material is reinforced by continuous fiber strands and injected very rapidly with the urethane resin. The rapidity of the injection process may cause nonuniform distribution and incomplete penetration of the resin phase. Stitching was applied to maintain fiber alignments, but misorientations may still occur. Because no unidirectionally reinforced plies could be processed, it was necessary to backtrack the basic lamina stiffnesses from crossply stress-strain data by means of laminate theory and micromechanics. In view of inherent data scatter attributable to the processing imperfections, the above stiffnesses could be determined to within approximately $\pm 3 \%$.

As expected, the response of the crossply composite was highly sensitive to the orientation of the load about the fiber directions. Detailed creep and recovery data, accompanied by a data reduction effort, enabled the formulation of a predictive model for the time-dependent behavior of crossply specimens loaded at various stress levels, under different temperatures, and at discrete load orientations and durations. Typically, the time-dependent response could be represented in power-law form, with an additional, time-dependent, irreversible component. The incorporation of the foregoing additional factors, namely time, temperature, as well as orientation, amplitude, and duration, brought about a substantial increase in data scatter. This scatter, which became ever larger at higher stresses and temperature, widened the range of uncertainty of the predictive model.

Most of the orientational dependence was eliminated in the case of the quasi-isotropic $\left[0 / 90^{\circ} / \pm 45^{\circ}\right]_{S}$ composite. These layups were manufactured by processing stitched crossply pairs that were subsequently placed at $45^{\circ}$ about each other. However, the above orientation could not always be accurately maintained, and variations, estimated at up to $5^{\circ}$, did occur. The above discrepancies resulted in data scatter of about $\pm 10 \%$ at room temperature, attaining a level of $\pm 17 \%$ at $120^{\circ} \mathrm{C}$. Although such scatter could obscure the effects of mechanical and environmental input parameters, it was nevertheless possible to discern some consistent trends in the stress-strain response and the time-dependent behavior of the quasi-isotropic composite. Specifically, both of the above aspects of material behavior exhibited an unmistakable dependence on load orientation in the high-stress regime, which was further accentuated at elevated temperatures. Consequently, it was possible to employ both viscoelasticity and plasticity theories to model the behavior of the quasi-isotropic composite, by associating both inelastic aspects with the response of the resin phase.

*Department of Mechanical and Aerospace Engineering and Engineering Science, University of Tennessee, Knoxville, and Metals and Ceramics Division, Oak Ridge National Laboratory. 


\subsection{MATERIALS AND TESTING PROGRAM}

Three T300 stitched mat/urethane 420 IMR laminate plaques with $\left[0 / 90^{\circ} / \pm 45^{\circ}\right]_{\mathrm{S}}$ (quasiisotropic) layups were used for specimens. These quasi-isotropic plaques had in-plane dimensions $610 \mathrm{~mm}$ by $610 \mathrm{~mm}$ and were of varying thickness, averaging between 2.0 and $2.4 \mathrm{~mm}$.

Test coupons measuring $203.2 \mathrm{~mm}$ in length and $25.4 \mathrm{~mm}$ in width were cut from the above plaques at different angles, $\phi$, relative to the fiber direction in the top ply, as shown in Fig. 12-1. Crossply glass fiber laminates with a thickness of $1.6 \mathrm{~mm}$ were used as tabs. These tabs were glued near the two ends of test coupons, using high-strength epoxy, to prevent any possible damage caused by the grips of the testing machine.

Tensile tests were conducted using an 810 MTS Material Testing System with a loading rate of $1.02 \mathrm{~mm} / \mathrm{min}$ at four different temperatures $\left(23,50,73\right.$, and $\left.120^{\circ} \mathrm{C}\right)$. An axial extensometer and several strain gages were used for recording the strains in both the longitudinal and transverse directions of the test coupons. At least three replicate specimens were tested for each case.

Additional test coupons, with the same features as mentioned above, were employed to conduct creep and recovery tests. The short-term creep and recovery tests were performed on the 810 MTS Material Testing System at various levels of fixed stresses under load-control mode.

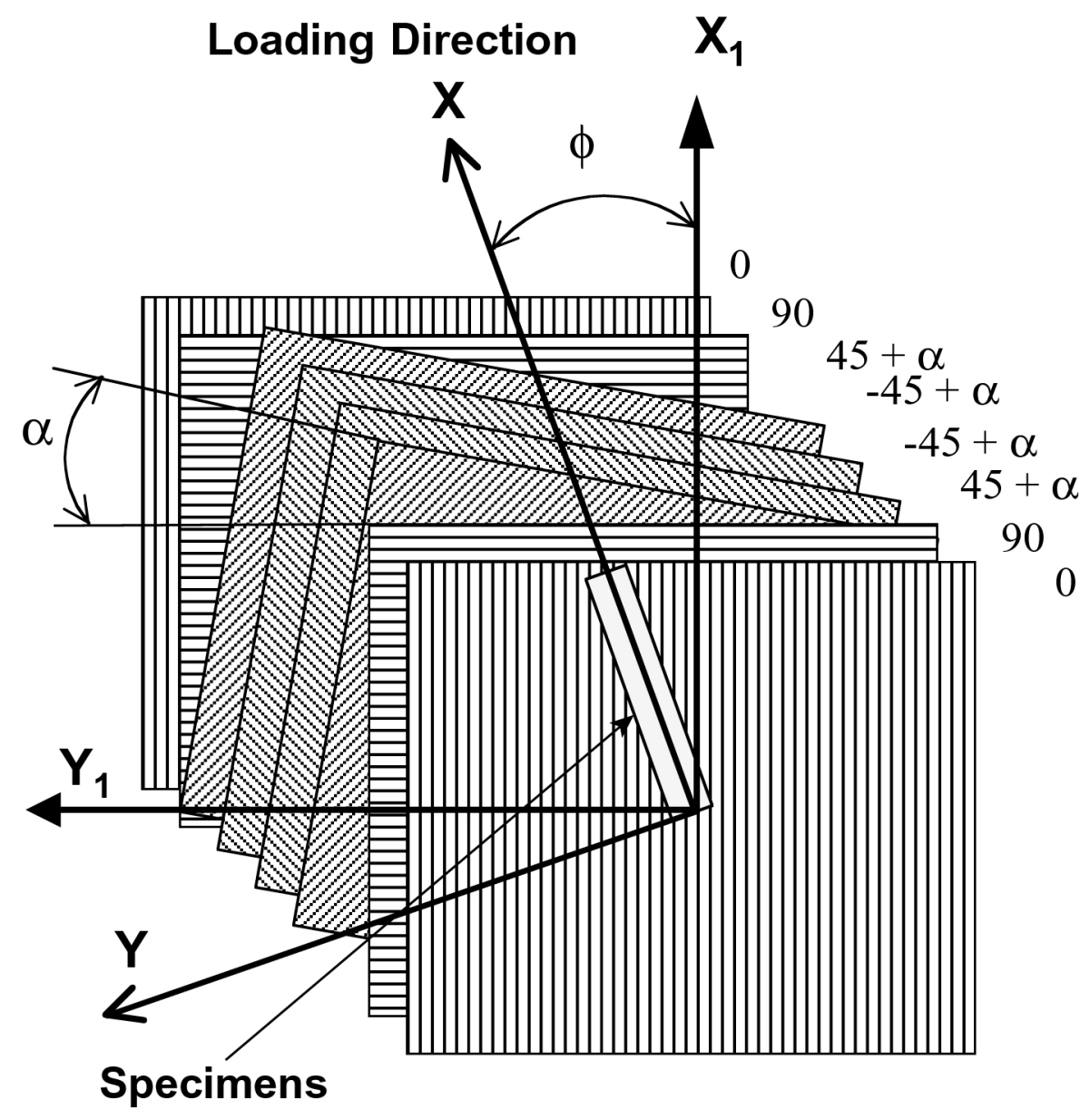

Fig. 12.1. Illustration of quasi-isotropic laminates with layup misalignment.

*In that figure some ply groups are misaligned. The observable effects of such misalignment are discussed later. 
One extensometer and several strain gages were attached to the surfaces of test coupons to record the deformation response during creep loading, followed by recovery upon unloading. The foregoing tests involved $24 \mathrm{~h}$ of creep followed by $48 \mathrm{~h}$ of strain recovery. Tests were performed at three temperature levels $\left(23,73\right.$, and $\left.120^{\circ} \mathrm{C}\right)$. Residual strain values at the end of the recovery period were considered to represent permanent deformation. The creep and recovery test program is listed in Table 12.1.

Table 12.1. Creep and recovery test program

\begin{tabular}{|c|c|c|c|c|c|}
\hline $\begin{array}{c}\text { Creep stress } \\
\sigma_{0}(\mathrm{MPa})\end{array}$ & $\begin{array}{l}\text { Creep/recovery } \\
\text { times } t_{0} /(r-1) t_{0} \\
\text { (h) }\end{array}$ & $\begin{array}{c}\text { Number } \\
\text { of test } \\
\text { specimens }\end{array}$ & $\begin{array}{c}\text { Creep stress } \\
\sigma_{0}(\mathrm{MPa})\end{array}$ & $\begin{array}{c}\text { Creep/recovery } \\
\text { times } t_{0} /(r-1) t_{0} \\
(h)\end{array}$ & $\begin{array}{c}\text { Number } \\
\text { of test } \\
\text { specimens }\end{array}$ \\
\hline \multicolumn{3}{|c|}{$\phi=0^{\circ}, T={73^{\circ} \mathrm{C}}^{\circ}$} & \multicolumn{3}{|c|}{ 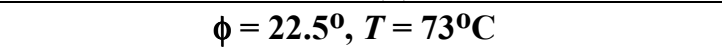 } \\
\hline 59.2 & $24 / 48$ & 2 & 59.2 & $24 / 48$ & 2 \\
\hline 88.8 & $24 / 48$ & 3 & 88.8 & $24 / 48$ & 2 \\
\hline 118.4 & $24 / 48$ & 3 & 118.4 & $24 / 48$ & 2 \\
\hline 148 & $24 / 48$ & 2 & 148 & $24 / 48$ & 2 \\
\hline 177.6 & $24 / 48$ & 2 & 177.6 & $24 / 48$ & 3 \\
\hline \multicolumn{3}{|c|}{$\phi=0^{\circ}, T=120^{\circ} \mathrm{C}$} & \multicolumn{3}{|c|}{$\phi=22.5^{\circ}, T=120^{\circ} \mathrm{C}$} \\
\hline 59.2 & $24 / 48$ & 1 & 59.2 & $24 / 48$ & 4 \\
\hline 88.8 & $24 / 48$ & 1 & 88.8 & $24 / 48$ & 2 \\
\hline 118.4 & $24 / 48$ & 1 & 118.4 & $24 / 48$ & 4 \\
\hline 148 & $24 / 48$ & 1 & 148 & $24 / 48$ & 4 \\
\hline 148 & $72 / 48$ & 1 & 177.6 & $24 / 48$ & 2 \\
\hline 177.6 & $24 / 48$ & 1 & & & \\
\hline \multicolumn{3}{|c|}{$\phi=0^{0}, T=23^{\circ} \mathrm{C}$} & \multicolumn{3}{|c|}{$\phi=90^{\circ}, T=23^{\circ} \mathrm{C}$} \\
\hline \multirow[t]{2}{*}{118.4} & $24 / 48$ & 1 & 118.4 & $24 / 48$ & 1 \\
\hline & \multicolumn{2}{|l|}{$\phi=4^{\circ}, T=2^{\circ} \mathrm{C}$} & \multirow[t]{2}{*}{148} & \multirow[t]{2}{*}{$24 / 48$} & \multirow[t]{2}{*}{1} \\
\hline 177.6 & $24 / 48$ & 1 & & & \\
\hline \multicolumn{3}{|c|}{$\phi=45^{\circ}, T=73^{\circ} \mathrm{C}$} & \multicolumn{3}{|c|}{ 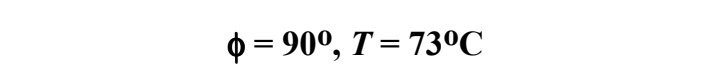 } \\
\hline \multirow[t]{3}{*}{59.2} & \multirow[t]{2}{*}{$24 / 48$} & \multirow[t]{3}{*}{2} & 59.2 & $24 / 48$ & 2 \\
\hline & & & 118.4 & $24 / 48$ & 2 \\
\hline & $=67.5^{\circ}, T=23^{\circ} \mathrm{C}$ & & 177.6 & $24 / 48$ & 1 \\
\hline \multirow[t]{2}{*}{118.4} & $24 / 48$ & 1 & & & \\
\hline & $\mathrm{P}=67.5^{\circ}, T=73^{\circ} \mathrm{C}$ & & \multicolumn{3}{|c|}{$\phi=90^{\circ}, T=120^{\circ} \mathrm{C}$} \\
\hline 148 & $24 / 48$ & 2 & 177.6 & $24 / 48$ & 1 \\
\hline 177.6 & $24 / 48$ & 2 & & & \\
\hline
\end{tabular}

\subsection{LINEAR RANGE OF LAMINATE RESPONSE}

\subsubsection{Basic Lamina Properties}

As noted in a previous work, ${ }^{9}$ difficulties encountered during the manufacturing of the T300/urethane composites prevented the processing of unidirectionally reinforced laminae, thereby necessitating the production of stitched crossply pairs. 
It was therefore necessary to backtrack the values of the basic lamina properties from stressstrain data on crossply laminates, oriented at various angles about the load direction, with the aid of lamination theory and micromechanics.

Omitting the details, which were given in the aforementioned work, ${ }^{9}$ the best estimates for these basic properties at room temperature are listed below:

$$
Q_{11}=89.6 \mathrm{GPa}, Q_{22}=2.1 \mathrm{GPa}, Q_{12}=3.1 \mathrm{GPa} \text {, and } Q_{66}=3.3 \mathrm{GPa} .
$$

Note these values have been updated somewhat from those reported in Ref. 9.

\subsubsection{Tensile Properties of $\left[0 / 90^{\circ} / \pm 4^{\circ}\right]_{S}$ Laminates}

With the foregoing properties at hand, it was readily possible to evaluate the longitudinal stiffness $E_{x}$ of the quasi-isotropic laminate under uniaxial tension. ${ }^{22}$

$$
E_{x}=\frac{1}{n_{p} h_{o}}\left(\frac{N_{x}}{\varepsilon_{x}}\right)=\frac{1}{n_{p} h_{o}}\left(A_{11}-\frac{A_{12}^{2} A_{66}+A_{66} A_{16}^{2}-2 A_{12} A_{16} A_{26}}{A_{22} A_{66}-A_{26}^{2}}\right)
$$

where $A_{\mathrm{ij}}$ are the in-plane laminate stiffnesses expressed in Eq. (12.2), $h_{o}$ denotes ply thickness, and $n_{p}$ is the total number of plies. For the quasi-isotropic laminate under consideration, $h_{o}=$ $0.28 \mathrm{~mm}$, and $n_{p}=8$.

Obviously, for a perfect quasi-isotropic layup, $E_{x}$ should not depend on load orientation.

Nevertheless, actual room-temperature experimental data, which are listed in Table 12.2 and depicted in Fig. 12.2, indicate the presence of angular dependence in $E_{x}$, even within the linear range of stress-strain response. This departure from quasi-isotropy can be traced to reported layup misalignments during the manufacturing process, when adjacent, stitched crossply pairs could not be stacked precisely at $\pm 45^{\circ}$ to each other, as desired.

To assess the effect of such misalignments, consider the circumstance where the inner $\left[ \pm 45^{\circ}\right]$ ply groups were tilted by a common angle $\alpha$ about their proper directions during the manufacturing process, as shown in Fig. 12.1. Straightforward manipulations of laminate equations $^{22}$ yield the following expressions (where $\alpha=0$ corresponds to a perfect quasi-isotropic layup):

$$
\begin{aligned}
A_{11}= & A_{22}=2 h_{o}\left(Q_{11}+Q_{22}\right)\left\{\cos ^{4} \phi+\sin ^{4} \phi+\frac{1}{2}+\frac{1}{2} \sin ^{2}[2(\alpha+\phi)]\right\} \\
& +2 h_{o}\left(Q_{12}+2 Q_{66}\right)\left\{\sin ^{2}(2 \phi)+\cos ^{2}[2(\alpha+\phi)]\right\} \\
A_{12}= & 2 h_{o}\left(Q_{11}+Q_{22}-4 Q_{66}\right) \frac{1}{2}\left\{\sin ^{2}(2 \phi)+\cos ^{2}[2(\alpha+\phi)]\right\} \\
& +4 h_{o} Q_{12}\left\{\cos ^{4} \phi+\sin ^{4} \phi+\frac{1}{2}+\frac{1}{2} \sin ^{2}[2(\alpha+\phi)]\right\} \\
A_{16}= & -A_{26}=2 h_{o}\left(Q_{11}-Q_{22}-2 Q_{12}-4 Q_{66}\right) \frac{1}{4}\{\sin (4 \phi)-\sin [4(\alpha+\phi)]\} \\
A_{66}= & 2 h_{o}\left(Q_{11}+Q_{22}-2 Q_{12}\right) \frac{1}{2}\left\{\sin ^{2}(2 \phi)+\cos ^{2}[2(\alpha+\phi)]\right\}+4 h_{o} Q_{66}\left\{\cos ^{2}(2 \phi)+\sin ^{2}[2(\alpha+\phi)]\right\} .
\end{aligned}
$$


Table 12.2. Tensile data for quasi-isotropic composite coupons loaded at various orientations

\begin{tabular}{cccccc}
\hline $\begin{array}{c}\text { Orientation } \\
\text { angle } \\
(\mathbf{d e g})\end{array}$ & $\begin{array}{c}\text { Temperature } \\
\left({ }^{\mathbf{}} \mathbf{C}\right)\end{array}$ & $\begin{array}{c}\text { Stiffness } \\
\mathbf{( G P a )}\end{array}$ & $\begin{array}{c}\text { Tensile strength } \\
\mathbf{( M P a )}\end{array}$ & $\begin{array}{c}\text { Failure strain } \\
\mathbf{( \% )}\end{array}$ & $\begin{array}{c}\text { Poisson's } \\
\text { ratio }\end{array}$ \\
\hline 0 & 23 & $30.8 \pm 0.7$ & $306.0 \pm 10.0$ & $0.98 \pm 0.05$ & $0.305 \pm 0.05$ \\
& 50 & $29.8 \pm 1.3$ & $291.6 \pm 43.5$ & $0.94 \pm 0.12$ & \\
& 73 & $31.2 \pm 1.5$ & $284.6 \pm 37.3$ & $0.94 \pm 0.18$ & \\
15 & 120 & $26.7 \pm 2.3$ & $260.5 \pm 44.9$ & $0.98 \pm 0.12$ & $0.343 \pm 0.02$ \\
22.5 & 23 & $28.9 \pm 0.5$ & $239.5 \pm 28.6$ & $0.86 \pm 0.11$ & \\
& 23 & $29.0 \pm 2.7$ & $254.5 \pm 21.3$ & $0.92 \pm 0.10$ & $0.355 \pm 0.05$ \\
& 50 & $32.1 \pm 0.8$ & $306.8 \pm 4.6$ & $0.97 \pm 0.04$ & \\
& 73 & $31.4 \pm 1.2$ & $273.5 \pm 12.3$ & $0.87 \pm 0.11$ & \\
30 & 120 & $25.8 \pm 4.1$ & $218.1 \pm 27.4$ & $1.00 \pm 0.14$ & $0.393 \pm 0.02$ \\
45 & 23 & $26.9 \pm 0.8$ & $277.7 \pm 5.0$ & $1.09 \pm 0.03$ & \\
67.5 & 23 & $32.2 \pm 0.8$ & $295.0 \pm 15.9$ & $0.92 \pm 0.04$ & \\
& 23 & $29.9 \pm 0.5$ & $289.7 \pm 23.7$ & $1.01 \pm 0.11$ & \\
& 50 & $30.6 \pm 0.1$ & $298.8 \pm 9.1$ & $1.04 \pm 0.02$ & \\
90 & 73 & $27.5 \pm 0.4$ & $288.5 \pm 2.1$ & $1.02 \pm 0.05$ & \\
& 120 & $24.3 \pm 0.3$ & $205.2 \pm 4.7$ & $1.16 \pm 0.2$ & \\
& 23 & $30.2 \pm 1.0$ & $294.1 \pm 7.4$ & $0.96 \pm 0.03$ & \\
& 50 & $30.7 \pm 2.5$ & $288.9 \pm 5.4$ & $0.92 \pm 0.06$ & \\
& 73 & $30.2 \pm 0.5$ & $303.0 \pm 2.1$ & $0.99 \pm 0.03$ & \\
\hline
\end{tabular}

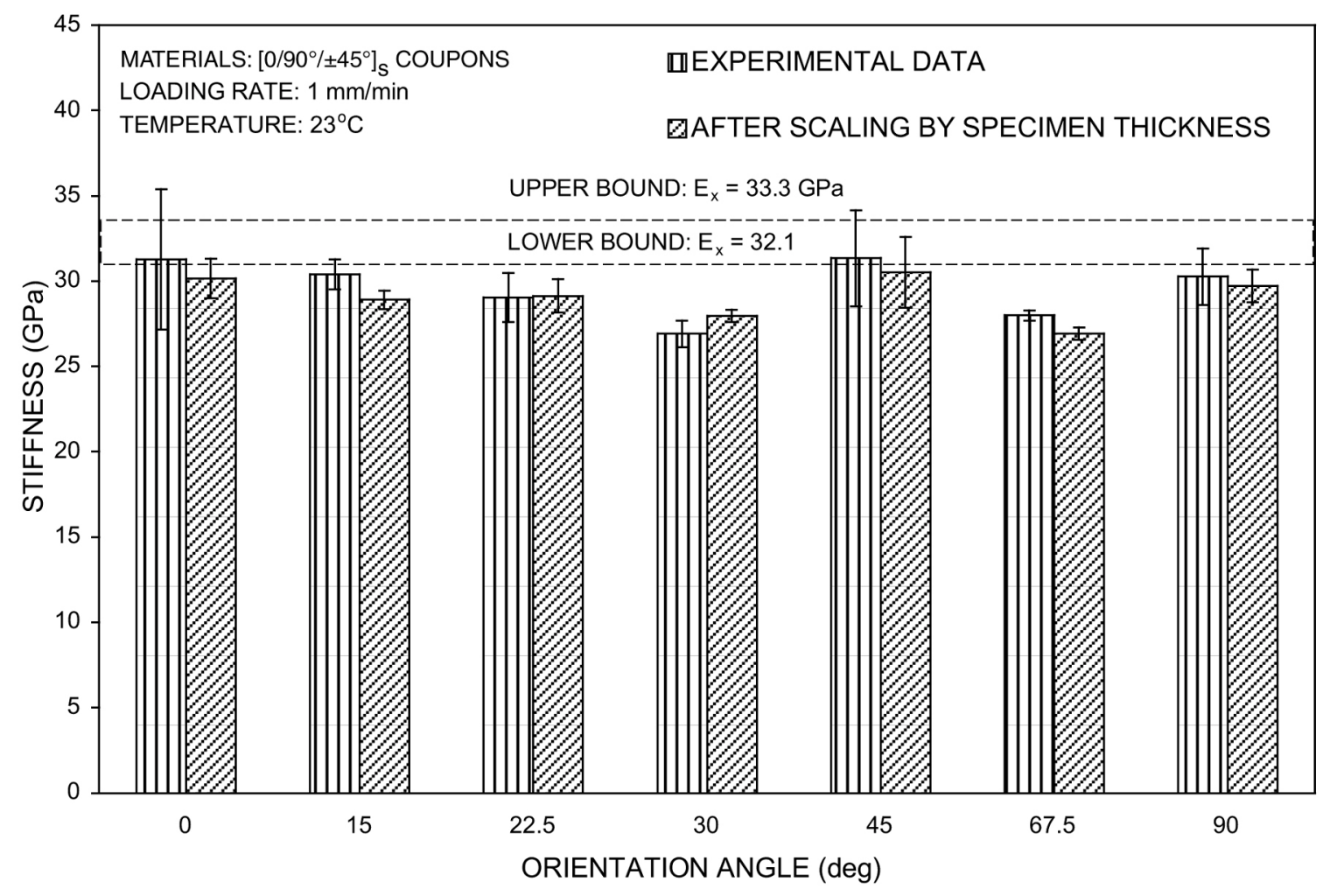

Fig. 12.2. Stiffness vs orientation angle of quasi-isotropic composite at $23^{\circ} \mathrm{C}$. The dashed line denotes the values of ideal quasi-isotropic laminates, calculated according to laminate theory. 
The resulting departure from quasi-isotropy can be evaluated by combining Eqs. (12.1) and (12.2). Results are depicted in Fig. 12.3, where $E_{x}$ at different orientations $\phi$ is plotted vs the misalignment angle $\alpha$, with $\alpha$ varying between $0^{\circ}$ and $20^{\circ}$. It is evident that departures from quasi-isotropy increase with $\alpha$.

Note, however, that the results shown in Fig. 12.3 correspond to the assumed misaligned configuration depicted in Fig. 12.1. This configuration may or may not correspond to the actual misalignments that occur during the layup process. Because of practical limitations, it is only possible to measure the angular orientations of outer layers of the laminate, while the directions of the inner plies may be estimated with some uncertainty with the aid of X-ray photographs. Nevertheless, an analysis of the idealized misaligned layup shown in Fig. 12.1 can provide a reasonable estimate for the magnitude of misalignment angles that occurred during the actual layup processes*. For the actual ratio of $E_{\min } / E_{\max }$ that was recorded experimentally, it appears that a reasonably good estimate is $\alpha \sim 5^{\circ}$.

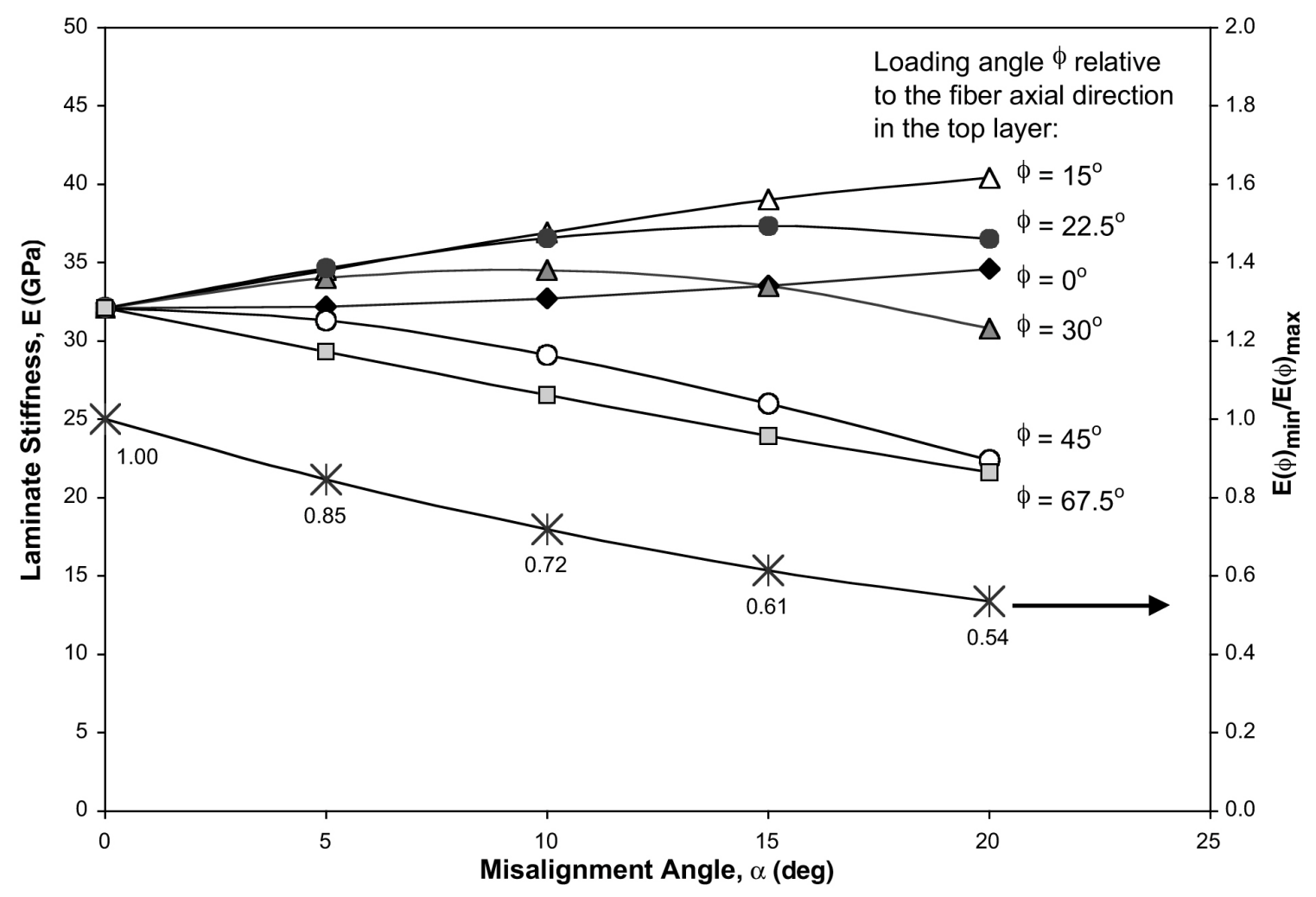

Fig. 12.3. Influence of laminate layup misalignment on the stiffness of quasi-isotropic composite.

\subsection{STRESS-STRAIN BEHAVIOR IN THE NONLINEAR RANGE}

\subsubsection{Crossply Composite}

For the crossply composite, the stress-strain response is highly orientation dependent. For loading orientations $\phi=0^{\circ}$ and $90^{\circ}$, which are parallel to fiber directions, the stress-strain curves

\footnotetext{
*Although a wide scope of possibilities exists for the locations and orientations of the misaligned plies, the inplane stiffnesses of the laminate are highly insensitive to any particular ordering of those locations within the laminate.
} 
are nearly linear up to failure, as shown in Fig. 12.4. However, that linear range diminishes monotonically, and nonlinearity tends to prevail as the angle between load and fiber direction increases. This angular dependence becomes most pronounced at $\phi=45^{\circ}$. The nonlinearity becomes further accentuated with temperature, as shown in Fig. 12.5.

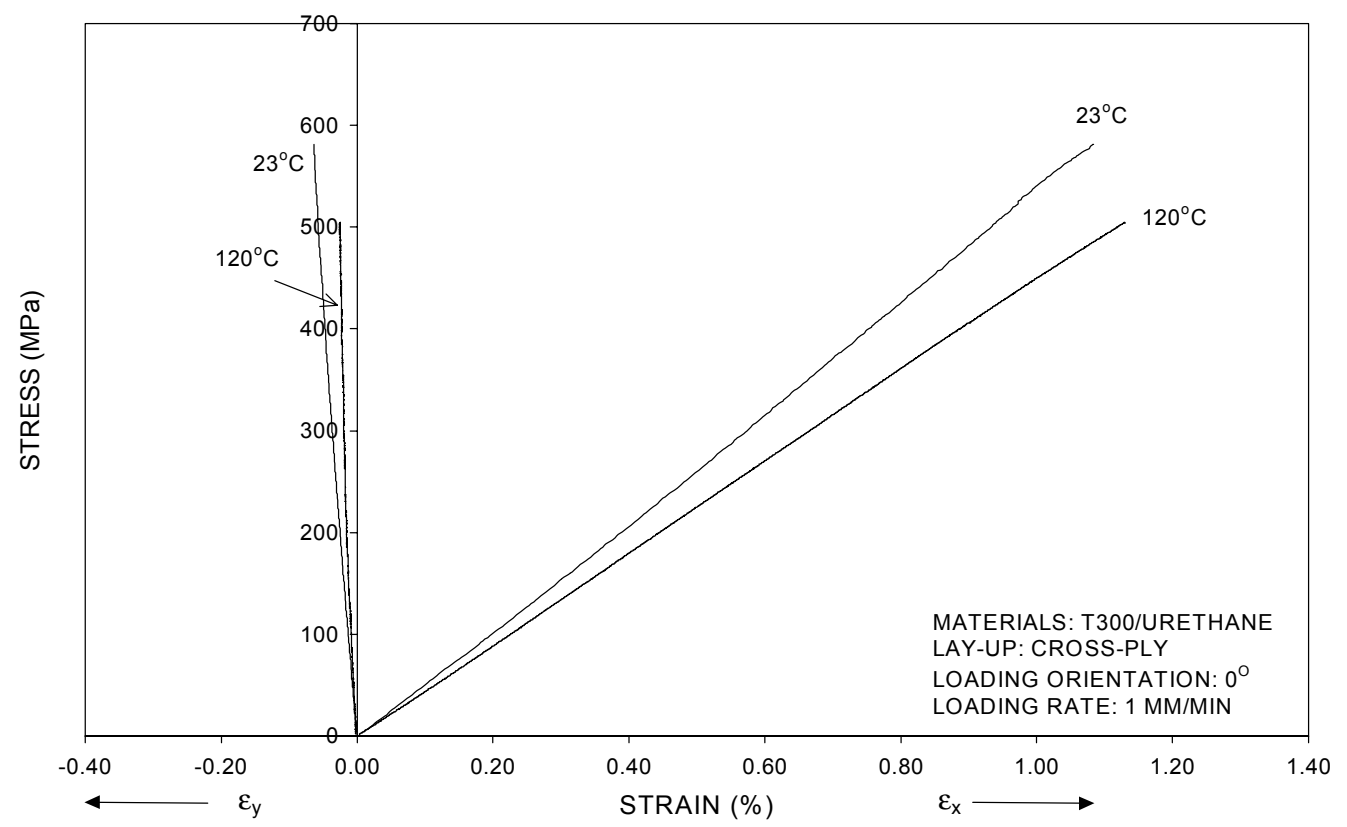

Fig. 12.4. Typical stress-strain curves of crossply composite, with loads applied at orientation angle $\phi=0^{\circ}$ under two temperatures.

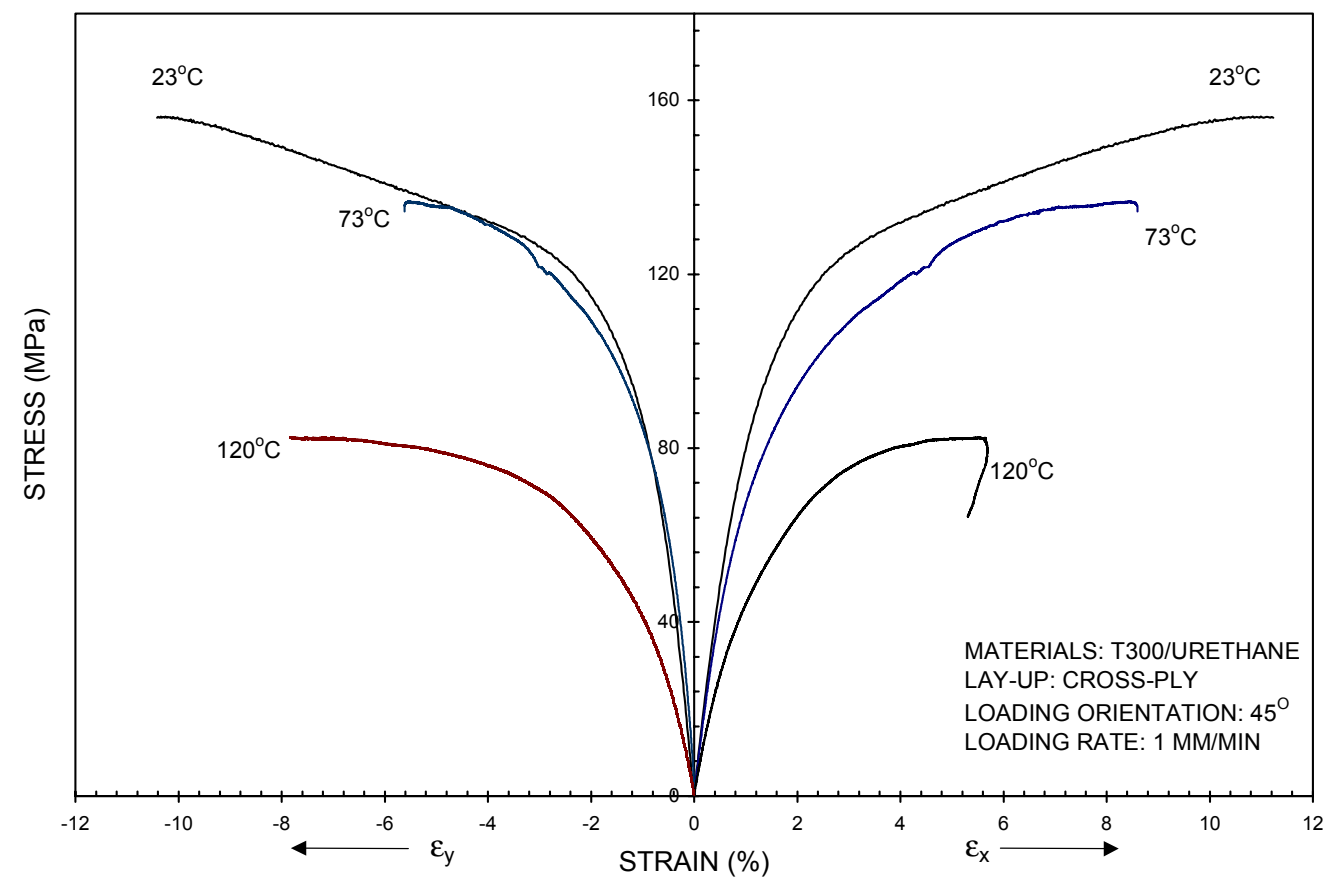

Fig. 12.5. Typical stress-strain curves of crossply composite, with loads applied at orientation angle $\phi=45^{\circ}$ under three temperatures. 


\subsubsection{Quasi-Isotropic Composite}

The main purpose of this section is to provide a rational mechanics-based explanation for the consistently observed dependence of the stress-strain response of the quasi-isotropic composite on load orientation at the elevated stress range.

Typical stress-strain to failure curves for quasi-isotropic coupons tested at various orientations are shown in Figs. 12.6 to 12.9. These figures exhibit consistent departures between the response of coupons tested in orientations $\phi$, such as $0^{\circ}, 45^{\circ}$, and $90^{\circ}$, which are parallel to fiber directions, and the softer behavior of samples tested in intermediate orientations $\widetilde{\phi}$ such as $15^{\circ}, 22.5^{\circ}, 30^{\circ}$, and $67.5^{\circ}$. Clearly, the response at angles $\tilde{\phi}$ is nonlinear, with nonlinearity increasing with both stress and temperature. Note that, ideally, all stress-strain curves should coalesce toward a common straight line near the origin. However, this may not occur in all circumstances, because of the layup misalignments, as discussed in Sect. 12.3.2. A specific example for a departure between the response at $\phi=0^{\circ}$ and the behavior at $\widetilde{\phi}=22.5^{\circ}$, which emanates from the origin of the stress and strain coordinates, is shown in Fig. 12.10. Obviously, in this case some of the plies in the sample tested at $\widetilde{\phi}=22.5^{\circ}$ are misaligned about their designated quasi-isotropic orientations, and the effects of nonlinearity and misalignment compound each other.

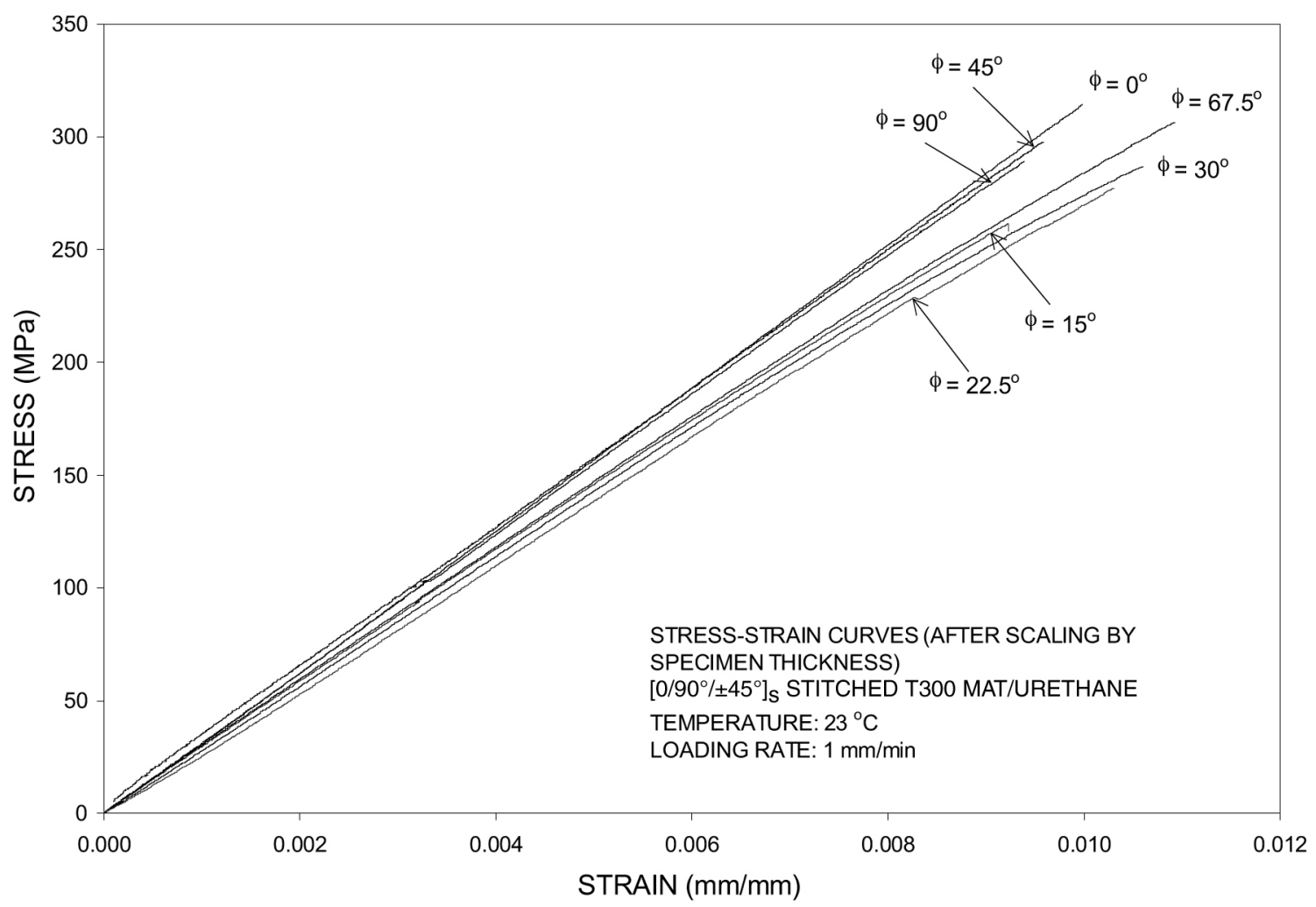

Fig. 12.6. Typical stress-strain curves of quasi-isotropic composite at various orientations at $23^{\circ} \mathrm{C}$. 


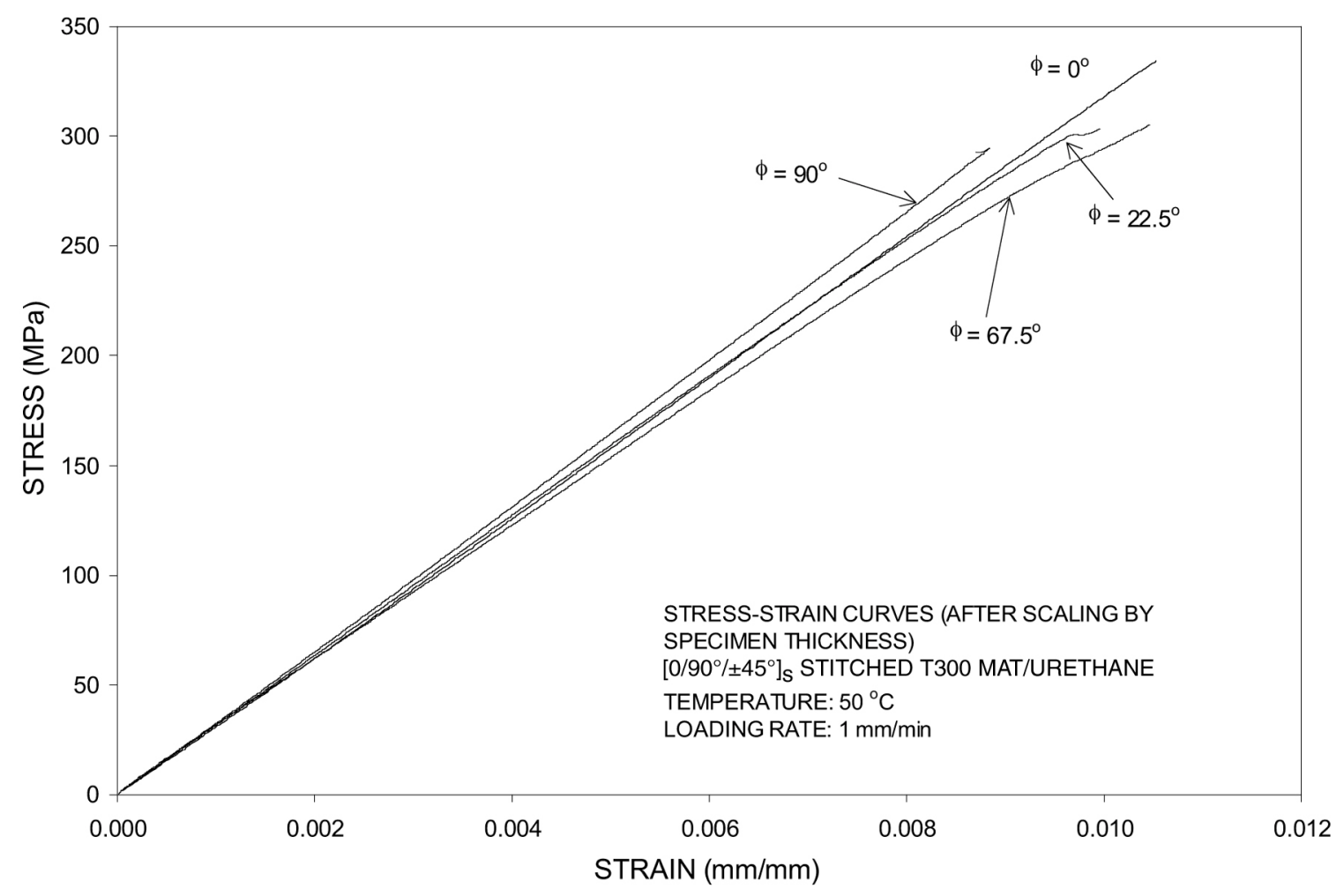

Fig. 12.7. Typical stress-strain curves of quasi-isotropic composite at various orientations at $50^{\circ} \mathrm{C}$.

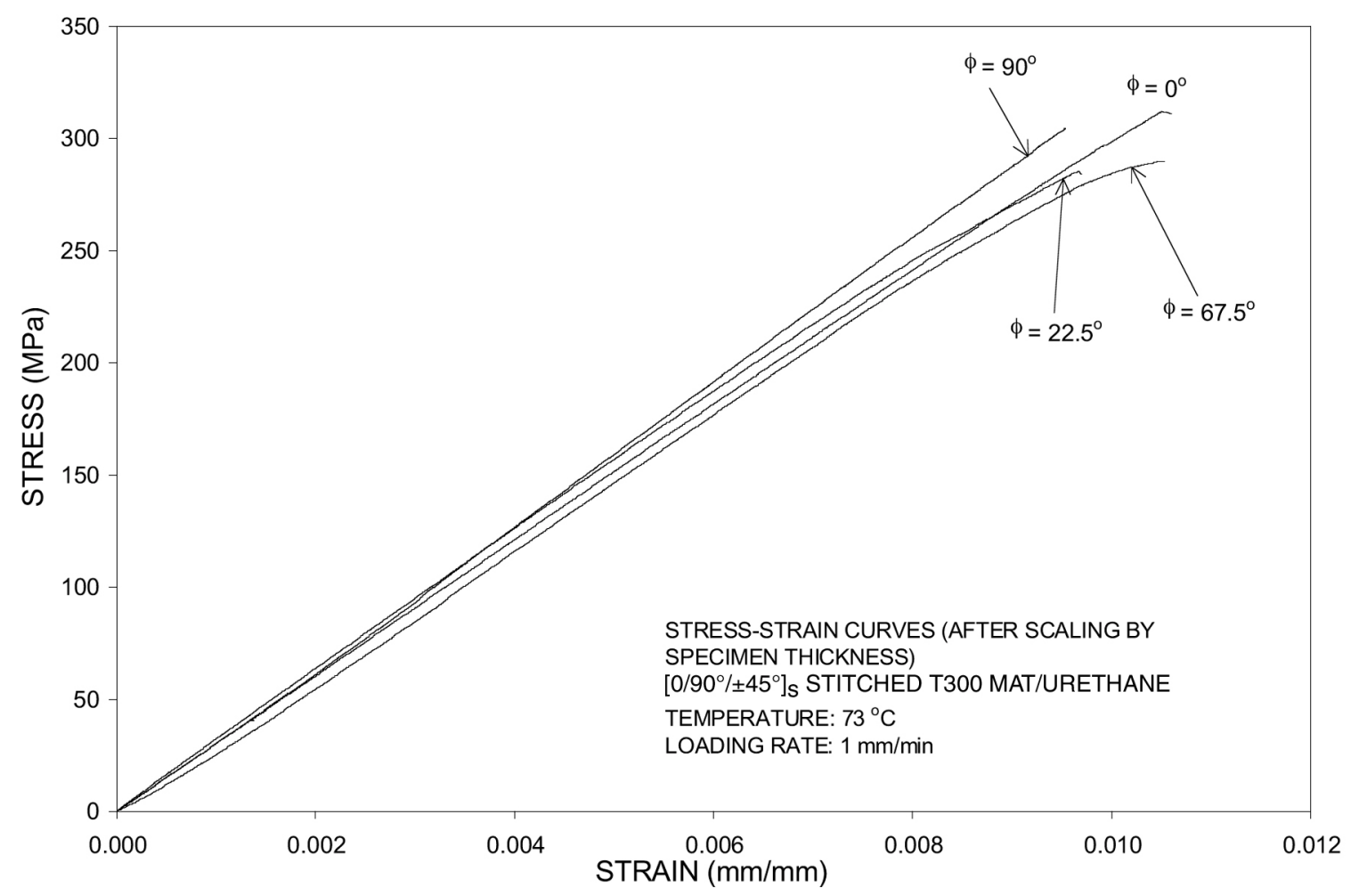
$73^{\circ} \mathrm{C}$.

Fig. 12.8. Typical stress-strain curves of quasi-isotropic composite at various orientations at 


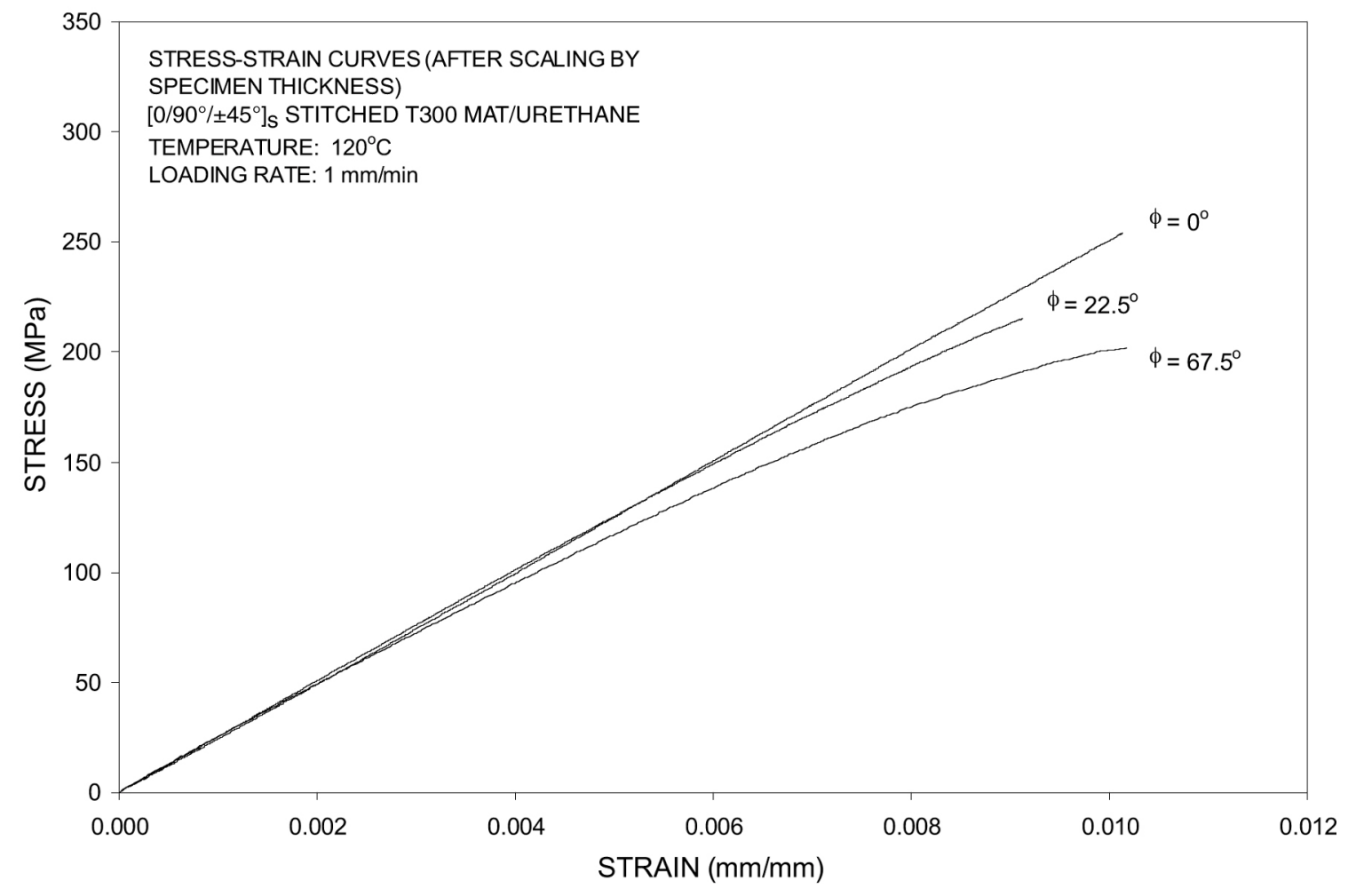

Fig. 12.9. Typical stress-strain curves of quasi-isotropic composite at various orientations at $120^{\circ} \mathrm{C}$.

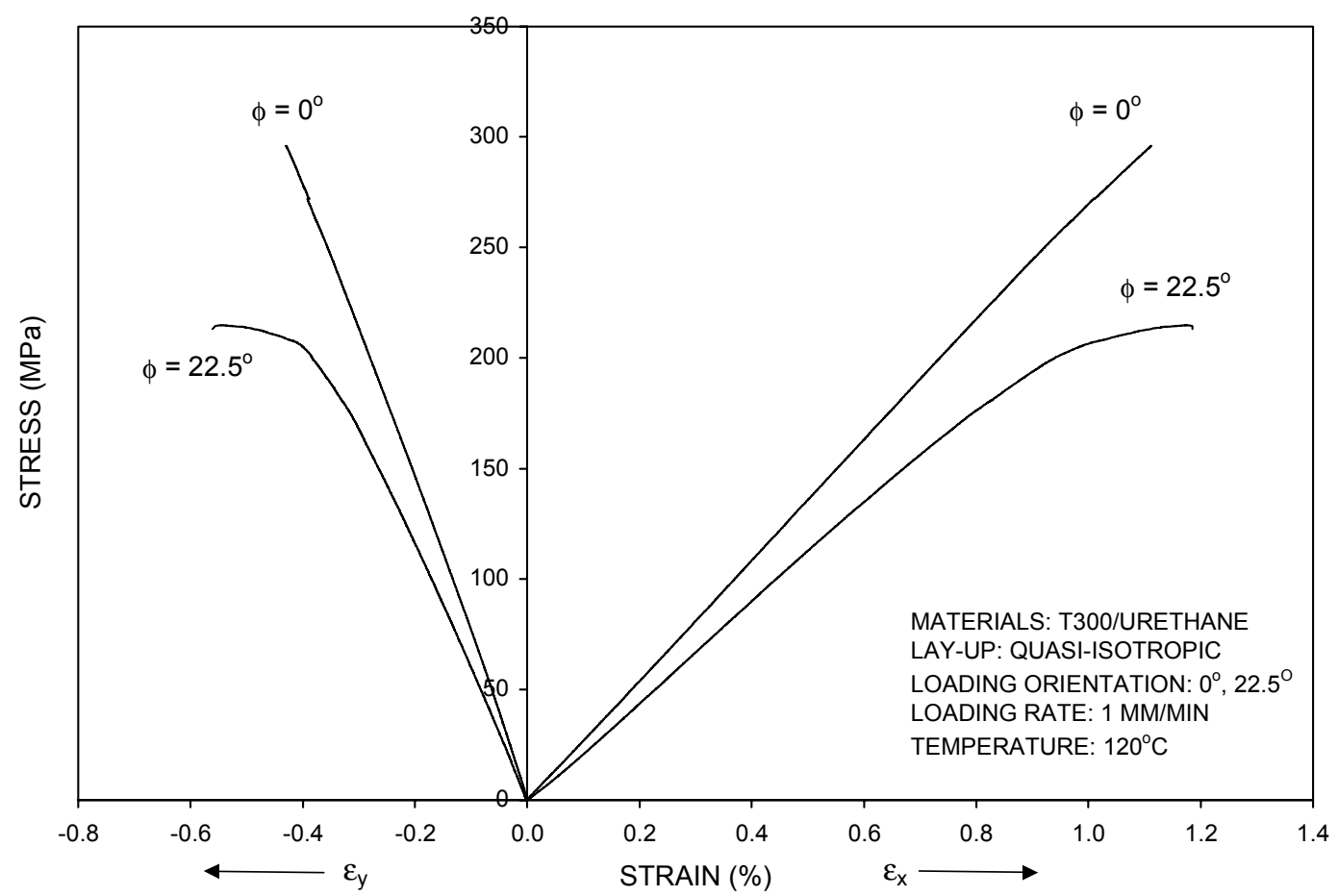

Fig. 12.10. Comparison of stress-strain curves of quasi-isotropic composite with two different loading orientations $\left(\phi=0^{\circ}\right.$ and $\left.22.5^{\circ}\right)$ at $120^{\circ} \mathrm{C}$. 


\subsubsection{Basic Nonlinear Properties and an Approximate Model}

It is possible to account for the nonlinear behavior of fiber-reinforced polymeric composites by means of plasticity and viscoplasticity theories. ${ }^{23-25}$ The formulation involves the association of the effective stress $\bar{\sigma}$ with the effective plastic strain $\bar{\varepsilon}^{p}$ within the larger context of plasticity theory. Because a negligible amount of nonlinearity occurs parallel to the fiber direction, $\mathrm{x}_{1}$, the normal stress $\sigma_{11}$ is assumed to play no role in $\bar{\sigma}$. Thereby, in a two-dimensional case, the effective stress $\bar{\sigma}$ is associated with shear stress, $\tau_{12}$, and the stress normal to the fiber direction, $\sigma_{22}$, through the expression

$$
\bar{\sigma}=\left[\frac{3}{2}\left(\sigma_{22}^{2}+2 a \tau_{12}^{2}\right)\right]^{1 / 2}
$$

Furthermore, in most circumstances, $\bar{\sigma}$ and $\bar{\varepsilon}^{p}$ were related by the empirical expression $\bar{\varepsilon}^{p}=\mathrm{A} \bar{\sigma}^{n}$. The details are reproduced in Appendix A [Eq. (A.8)].

The determination of the parameters $a, A$ and $n$ requires the employment of a comprehensive experimental program that uses unidirectionally reinforced off-axis plies at various off-axis orientations, $\theta$, although it appears that balanced $\pm \theta$ angle plies could also be used. Unfortunately, such samples were not available for the composite at hand.

It was therefore decided to assess the values of $a, A$, and $n$ from the quasi-isotropic data by means of an approximate approach and subsequently to verify the validity of those parameters by using them to predict the nonlinear response of the $[ \pm 45]_{3 \mathrm{~S}}$ crossply samples with an incremental computational method. The rationale behind the current approach is that because the quasiisotropic layups exhibited only a limited amount of plasticity, a nonincremental representation of their nonlinear stress-strain behavior would simplify the evaluation of the parameters $a, A$, and $n$, while keeping the errors within acceptable limits. However, in view of the significant nonlinearity in the response of the $[ \pm 45]_{3 \mathrm{~S}}$ crossply samples, the prediction of their behavior by means of the more accurate model would establish the validity of the parametric values.

For a single off-axis unidirectional composite under monotonically increasing load $N_{x}$, the increment of the total strain can be decomposed into elastic and plastic portions:

$$
\begin{aligned}
& d \varepsilon_{x}=d \varepsilon_{x}^{e}+d \varepsilon_{x}^{p} . \\
& d \varepsilon_{y}=d \varepsilon_{y}^{e}+d \varepsilon_{y}^{p} .
\end{aligned}
$$

As mentioned earlier, the stress-strain response of the quasi-isotropic composite exhibited only small to moderate nonlinearity, as shown in Fig. 12.11. Thereby, it was decided to avoid a step-by-step, incremental, laminate analysis for this layup and, as an approximation, to integrate Eqs. (12.4) and (12.5) directly, thereby obtaining for each individual ply

$$
\begin{gathered}
\varepsilon_{x}=\bar{s}_{11} \sigma_{x}+[h(\theta)]^{n+1} A \sigma_{x}{ }^{n} . \\
\varepsilon_{y}=\bar{s}_{12} \sigma_{x}+v_{x y}^{p}[h(\theta)]^{n+1} A \sigma_{x}{ }^{n} .
\end{gathered}
$$

In Eqs. (12.6) and (12.7), $\bar{s}_{11}$ and $\bar{s}_{12}$ are the off-axis elastic compliance components of unidirectional lamina; $A, n$, and $h(\theta)$ are the plastic parameters and transformation function 


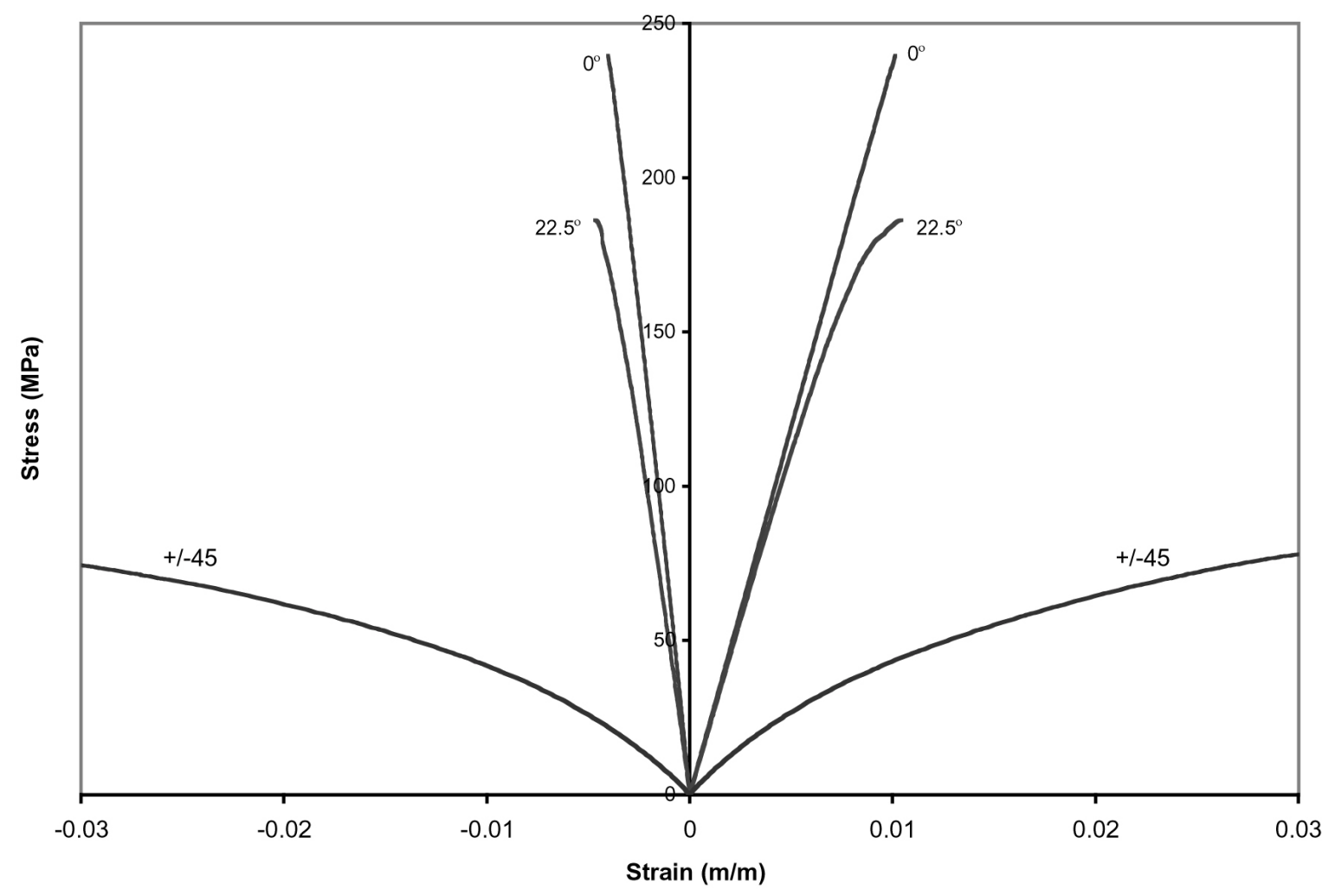

Fig. 12.11. Longitudinal and transverse stress-strain data for quasi-isotropic composite loaded at $0^{\circ}$ and $22.5^{\circ}$ about the fiber direction and for $[ \pm 45]_{3 \mathrm{~S}}$ crossply composite.

detailed in Appendix A [Eq. (A.13)]. Furthermore, the plastic Poisson's ration $v_{x y}^{p}$ can be expressed as 23

$$
v_{x y}^{p}=-\frac{1-2 a}{2 a+\tan ^{2} \theta}
$$

Because the longitudinal plastic strain must have a common value for each and every ply in the laminate at all stress levels, as shown in Fig. 12.12, Eq. (12.6) yields

$$
[h(\theta)]_{1}^{n+1} A \sigma_{x, 1}^{n}=[h(\theta)]_{2}^{n+1} A \sigma_{x, 2}^{n}=\cdots=[h(\theta)]_{N}^{n+1} A \sigma_{x, N}^{n}=\varepsilon_{x}^{p},
$$

where $N$ is the number of plies of the laminate. For plies of equal thickness $t$, the average stress $\sigma_{\mathrm{x}}$ is given by

$$
\sigma_{x}=\frac{N_{x}}{H}=\frac{t}{H}\left(\sigma_{x, 1}+\sigma_{x, 2}+\cdots+\sigma_{x, N}\right)
$$




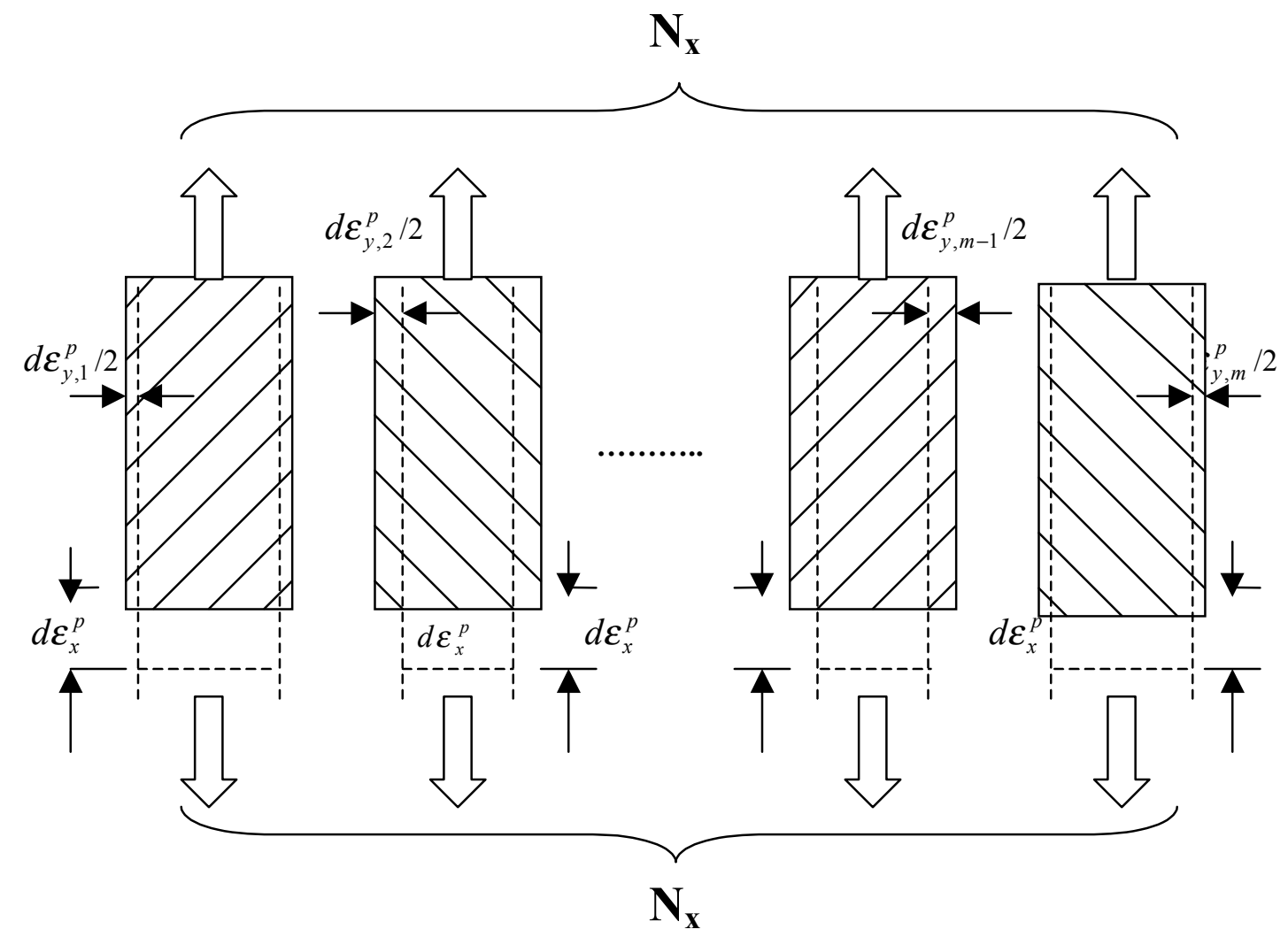

Fig. 12.12. Schematic drawing of strain compatibility requirements for composite laminates.

where $H=N t$ is the laminate thickness, and all ply stresses $\sigma_{\mathrm{x}, \mathrm{i}}$ must satisfy Eq. (12.9). Note that the total number of plies of the laminate is $N=H / t$; thus the average stress $\sigma_{\mathrm{x}}$ may be expressed as

$$
\begin{aligned}
\sigma_{x} & =\frac{1}{N}\left\{\left(\frac{\varepsilon_{x}^{p}}{A}\right)^{\frac{1}{n}} \frac{1}{[h(\theta)]_{1}^{1+\frac{1}{n}}}+\left(\frac{\varepsilon_{x}^{p}}{A}\right)^{\frac{1}{n}} \frac{1}{[h(\theta)]_{2}^{1+\frac{1}{n}}}+\cdots+\left(\frac{\varepsilon_{x}^{p}}{A}\right)^{\frac{1}{n}} \frac{1}{[h(\theta)]_{N}^{1+\frac{1}{n}}}\right\} \\
& =\frac{1}{N}\left\{\sum_{i=1}^{N} \frac{1}{[h(\theta)]_{i}^{1+\frac{1}{n}}}\right\}\left(\frac{\varepsilon_{x}^{p}}{A}\right)^{\frac{1}{n}},
\end{aligned}
$$

which leads to 


$$
\varepsilon_{x}^{p}=N^{n} \frac{A}{\left\{\sum_{i=1}^{N} \frac{1}{[h(\theta)]_{i}^{1+\frac{1}{n}}}\right\}^{n}} \sigma_{x}^{n} .
$$

Similarly, the average value of the transverse plastic strain can be approximated by

$$
\begin{aligned}
\varepsilon_{y}^{p} & =\frac{1}{N}\left(\varepsilon_{y, 1}^{p}+\varepsilon_{y, 2}^{p}+\cdots+\varepsilon_{y, N}^{p}\right) \\
& =\frac{1}{N}\left(v_{x y, 1}^{p}+v_{x y, 2}^{p}+\cdots+v_{x y, N}^{p}\right) \varepsilon_{x}^{p},
\end{aligned}
$$

which results in an averaged plastic Poisson's ratio

$$
\boldsymbol{v}_{x y}^{p}=\frac{1}{N} \sum_{i=1}^{N} \boldsymbol{v}_{x y, i}^{p}
$$

The total strain-stress relation may thus be expressed as:

$$
\begin{aligned}
& \varepsilon_{x}=H a_{11} \sigma_{x}+N^{n} \frac{A}{\left\{\sum_{i=1}^{N} \frac{1}{[h(\theta)]_{i}^{1+\frac{1}{n}}}\right\}^{n}} \sigma_{x}^{n} . \\
& \varepsilon_{y}=H a_{12} \sigma_{x}+N^{n-1} \frac{A\left[\sum_{i=1}^{N} v_{x y, i}^{p}\right]}{\left\{\sum_{i=1}^{N} \frac{1}{[h(\theta)]_{i}^{1+\frac{1}{n}}}\right\}^{n}} .
\end{aligned}
$$

The first terms on the right sides of Eqs. (12.15) and (12.16) account for the elastic portions of $\varepsilon_{\mathrm{x}}$. In those equations, $a_{11}$ and $a_{12}$ are the well-known linear laminate-level compliances. Denote the elastic coefficients $\eta_{\mathrm{x}}$ and $\eta_{\mathrm{y}}$ as $\eta_{\mathrm{x}}=H a_{11}$ and $\eta_{\mathrm{y}}=H a_{12}$, and let the plastic coefficients $\xi_{\mathrm{x}}$ and $\xi_{\mathrm{y}}$ be 


$$
\begin{gathered}
\xi_{x}=N^{n} \frac{A}{\left\{\sum_{i=1}^{N} \frac{1}{[h(\theta)]_{i}^{1+\frac{1}{n}}}\right\}^{n}} . \\
\xi_{y}=N^{n-1} \frac{A\left[\sum_{i=1}^{N} v_{x y, i}^{p}\right]}{\left\{\sum_{i=1}^{N} \frac{1}{[h(\theta)]_{i}^{1+\frac{1}{n}}}\right\}^{n}} .
\end{gathered}
$$

Equations (12.15) and (12.16) are then reduced to

$$
\begin{aligned}
& \varepsilon_{x}=\eta_{x} \sigma_{x}+\xi_{x} \sigma_{x}^{n} . \\
& \varepsilon_{y}=\eta_{y} \sigma_{x}+\xi_{y} \sigma_{x}^{n} .
\end{aligned}
$$

The elastic and plastic coefficients $\eta_{\mathrm{x}}, \eta_{\mathrm{y}}, \xi_{\mathrm{x}}, \xi_{\mathrm{y}}$ and the parameter $n$ in Eqs. (12.19) and (12.20) may be evaluated by fitting experimental data. This was accomplished by means of a nonlinear optimization scheme that was designed to determine the $\eta_{\mathrm{x}}, \eta_{\mathrm{y}}, \xi_{\mathrm{x}}, \xi_{\mathrm{y}}$, and $n$ values that correspond to the best least-square fit against both $\varepsilon_{\mathrm{x}}$ and $\varepsilon_{\mathrm{y}}$ vs $\sigma_{\mathrm{x}}$ data sets. An outline of this scheme is given in Appendix B.

Once the plastic parameter $n$ and coefficients $\xi_{\mathrm{x}}$ and $\xi_{\mathrm{y}}$ were determined by the optimization procedure, the remaining plastic parameters $\mathrm{A}$ and $a$ [the parameter $a$ is embedded in the function $h(\theta)$ ] can be determined by correlating Eqs. (12.15), (12.16), and (A.13). ${ }^{*}$

Note that the present approximation inherently discards any nonlinearity that occurs in the quasi-isotropic composite loaded in any of the fiber directions because by Eq. (A.13), $h(0)=0$, and thereby both $\xi_{\mathrm{x}}$ and $\xi_{\mathrm{y}}$ vanish. This deficiency results from the assumption inherent in the current approximation, which overlooks the requirement of ply-by-ply uniformity of the transverse strain $\varepsilon_{\mathrm{y}}$ throughout the laminate. As noted earlier, the approximation is not admissible for crossply laminates loaded in off-axis directions because in those circumstances nonlinearity dominates the response.

The optimization scheme was employed to fit the stress-strain data for the quasi-isotropic composite loaded at $22.5^{\circ}$ about the $0^{\circ}$ fiber direction, at $120^{\circ} \mathrm{C}$. The scheme yielded the values of $n=6.619, a=3.983$, and $A=8.923 \times 10^{-19}\left(\mathrm{MPa}^{-n}\right)$. The resulting predictions, for both $\sigma_{\mathrm{x}} \mathrm{vs}$ $\varepsilon_{\mathrm{x}}$ and $\sigma_{\mathrm{y}} \mathrm{vs} \varepsilon_{\mathrm{y}}$, are plotted in Fig. 12.13, where they are compared against the experimental data. In view of the previous remarks, these values are approximate. Nevertheless, note that the values of $\eta_{\mathrm{x}}$ and $\eta_{\mathrm{y}}$ came in close agreement with the laminate values $H a_{11}$ and $H a_{22}$.

\footnotetext{
*See Appendix A for Eq. (A.13).
} 


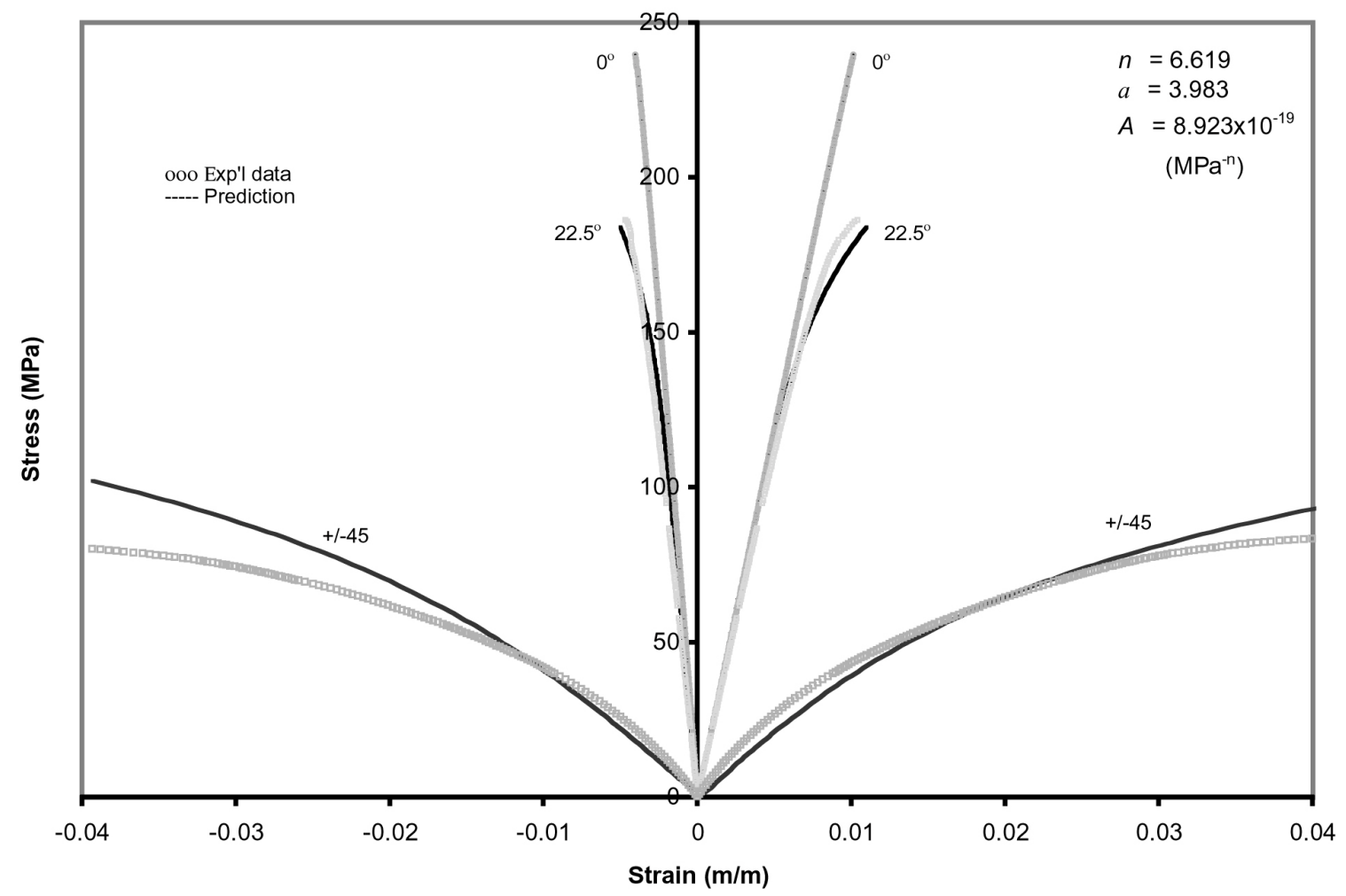

Fig. 12.13. Predicted and recorded values of longitudinal and transverse strains for the laminates and loading conditions noted in Fig. 12.12. Predictions based upon elasto-plastic behavior with $n=6.619, a=3.983$, and $A=8.923 \times 10^{-19} \mathrm{MPa}^{-\mathrm{n}}$.

To assess the validity of the approximate values of $n, a$, and $A$, these parameters were employed to predict the response of the $[ \pm 45]_{3 S}$ crossply composite by means of a detailed incremental scheme, that ascertained uniformity of both longitudinal and transverse strains.

The plasticity strain-stress expression from Appendix A, when applied to each $i$ th ply, reads

$$
\varepsilon_{x, i}^{p}=[h(\theta)]_{i}^{n+1} A \sigma_{x, i}^{n}
$$

which can be written as

$$
\sigma_{x, i}=\left\{\frac{1}{[h(\theta)]_{i}^{n+1} A}\right\}^{\frac{1}{n}}\left(\varepsilon_{x, i}^{p}\right)^{\frac{1}{n}} .
$$

Differentiation of Eq. (4.19) gives the incremental relationship

$$
d \sigma_{x, i}=\frac{1}{n[h(\theta)]_{i}^{1+\frac{1}{n}} A^{\frac{1}{n}}}\left(\varepsilon_{x, i}^{p}\right)^{\frac{1}{n}-1} d \varepsilon_{x, i}^{p} .
$$

Because, by hypothesis, all $\varepsilon_{x, i}^{p}$ and $d \varepsilon_{x, i}^{p}$ have common values for all plies, the summation of all increments $d \sigma_{x, i}$ yields the following expression for the average stress increment 


$$
d \sigma_{x}=\frac{1}{N}\left\{\sum_{i=1}^{N} \frac{1}{n[h(\theta)]_{i}^{1+\frac{1}{n}} A^{\frac{1}{n}}}\right\}\left(\varepsilon_{x}^{p}\right)^{\frac{1}{n}-1} d \varepsilon_{x}^{p}
$$

Consequently, the incremental relationship between laminate-level incremental plastic strain $d \varepsilon_{x}^{p}$ and stress $d \sigma_{x}$ reads

$$
d \varepsilon_{x}^{p}=\left\{\frac{N n A^{\frac{1}{n}}}{\sum_{i=1}^{N} \frac{1}{[h(\theta)]_{i}^{1+\frac{1}{n}}}}\right\}\left(\varepsilon_{x}^{p}\right)^{1-\frac{1}{n}} d \sigma_{x}
$$

Note also that in view of Eq. (12.8), $v_{x y}^{p}$ has a common value for all plies in the special case of the $\left[ \pm 45^{\circ}\right]_{3 \mathrm{~S}}$ layup. Consequently, the requirement of uniformity of transverse strains is automatically satisfied in the present circumstance. Equation (12.24) was solved numerically for stress increments $\Delta \sigma_{\mathrm{x}}=1 \mathrm{MPa}$. The computations employed the same value of $n, a$, and $A$ as those selected, matching the quasi-isotropic data. Results for both $\varepsilon_{\mathrm{x}}$ and $\varepsilon_{\mathrm{y}}$ vs $\sigma_{\mathrm{x}}$ are also shown in Fig. 12.13, where good agreement is exhibited between computational prediction and experimental data for the crossply composite.

Nevertheless, the current computation scheme does not address the requirement that the plastic component of shear stress, namely $\gamma_{x y}^{p}$, should also be common to all plies. It is reasonable to expect that the accounting for this latter requirement would further reduce the level of $\sigma_{\mathrm{x}}$ that corresponds to a prescribed level of $\varepsilon_{\mathrm{x}}$, thus leading to an even better fit between data and predictions for the response of the $\left[ \pm 45^{\circ}\right]_{3 \mathrm{~S}}$ crossply composite shown in Fig. 12.13.

Turning back to the quasi-isotropic specimens, note that the stress-strain data for the $22.5^{\circ}$ load orientation exhibit a certain amount of "kinking" prior to failure, as can be seen in Fig. 12.13. A similar behavior was noticed by other researchers; ${ }^{26}$ such kinking was attributed to the formation of damage, the representation of which falls beyond the scope of the plasticity formulation employed herein.

Using the aforementioned values of $a, A$, and $n$ and the approximate computational scheme, it was possible to predict the departure from quasi-isotropy at increasing stress levels, as loads continue to be directed away from the fiber directions. Results are shown in Fig. 12.14.

The plastic components of strain, $\varepsilon_{x}^{p}$ and $\varepsilon_{y}^{p}$, are shown in Fig. 12.15 for both the $\left[0 / 90^{\circ} / \pm 45^{\circ}\right]_{\mathrm{S}}$ quasi-isotropic, as loads are directed away from the fiber directions, and the $[ \pm 45]_{3 \mathrm{~S}}$ crossply composites. It can be observed that for the quasi-isotropic composite, the effect of nonlinearity is negligible for stresses below $120 \mathrm{MPa}$. Above $120 \mathrm{MPa}$ nonlinearity becomes significant, and the stress-strain response is no longer isotropic. For the crossply composite, nonlinearity appears to occur even at the low stress range and subsequently induces large in-plane deformation.

An estimate of the error associated with the approximate computation of the quasi-isotropic response at a loading orientation of $22.5^{\circ}$, which discarded the required commonality of transverse strains, is exhibited by the curves displayed in Fig. 12.16. The thin lines in that figure represent the maximum and minimum values of $\varepsilon_{y, i}^{p}$ in individual plies, while the thicker line exhibits the average value of $\varepsilon_{y, i}^{p}$ computed by the approximate method. It can be seen that the 


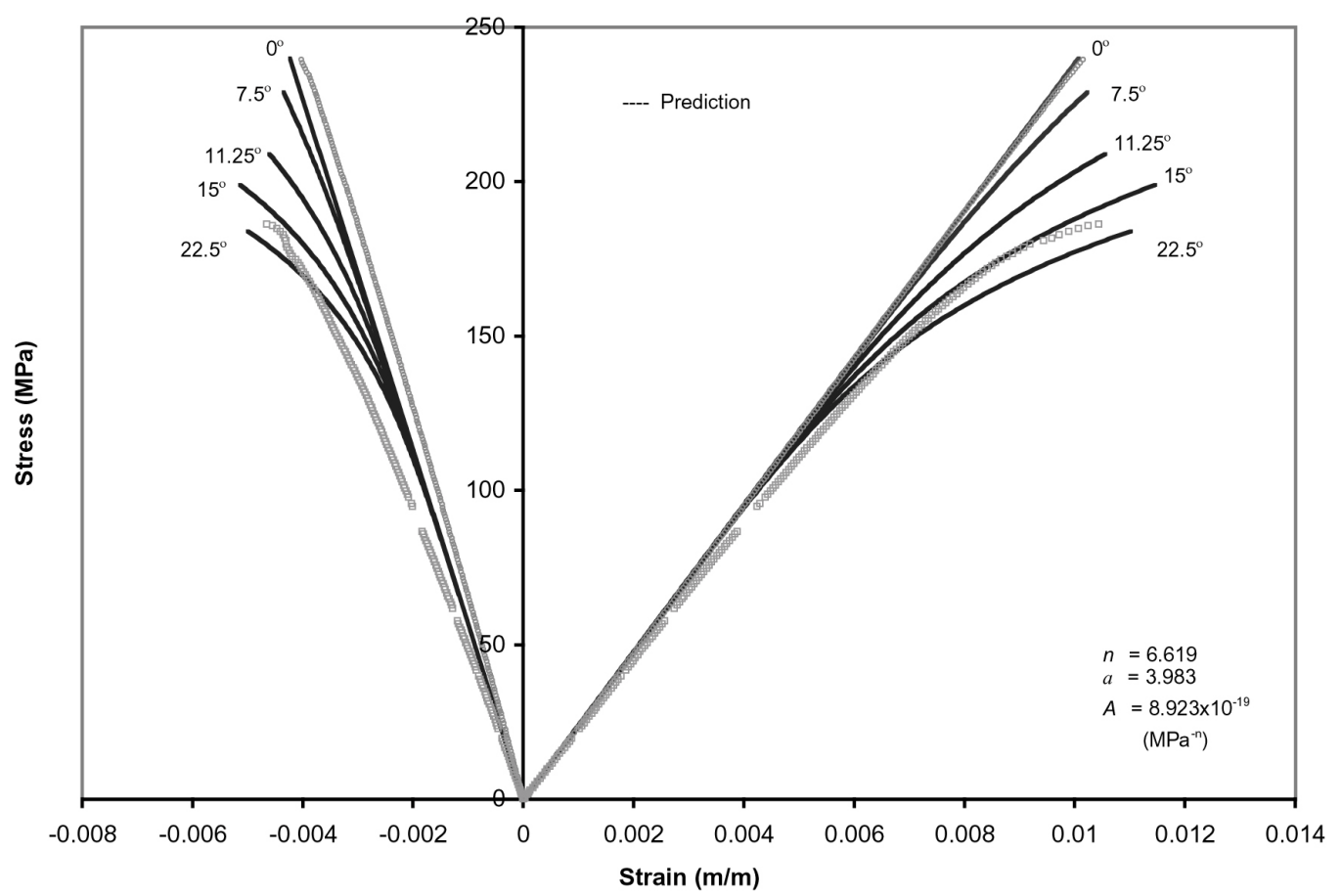

Fig. 12.14. Predictions for the anisotropic response of quasi-isotropic composite beyond the linear range, under loading at various orientations about the fiber direction.

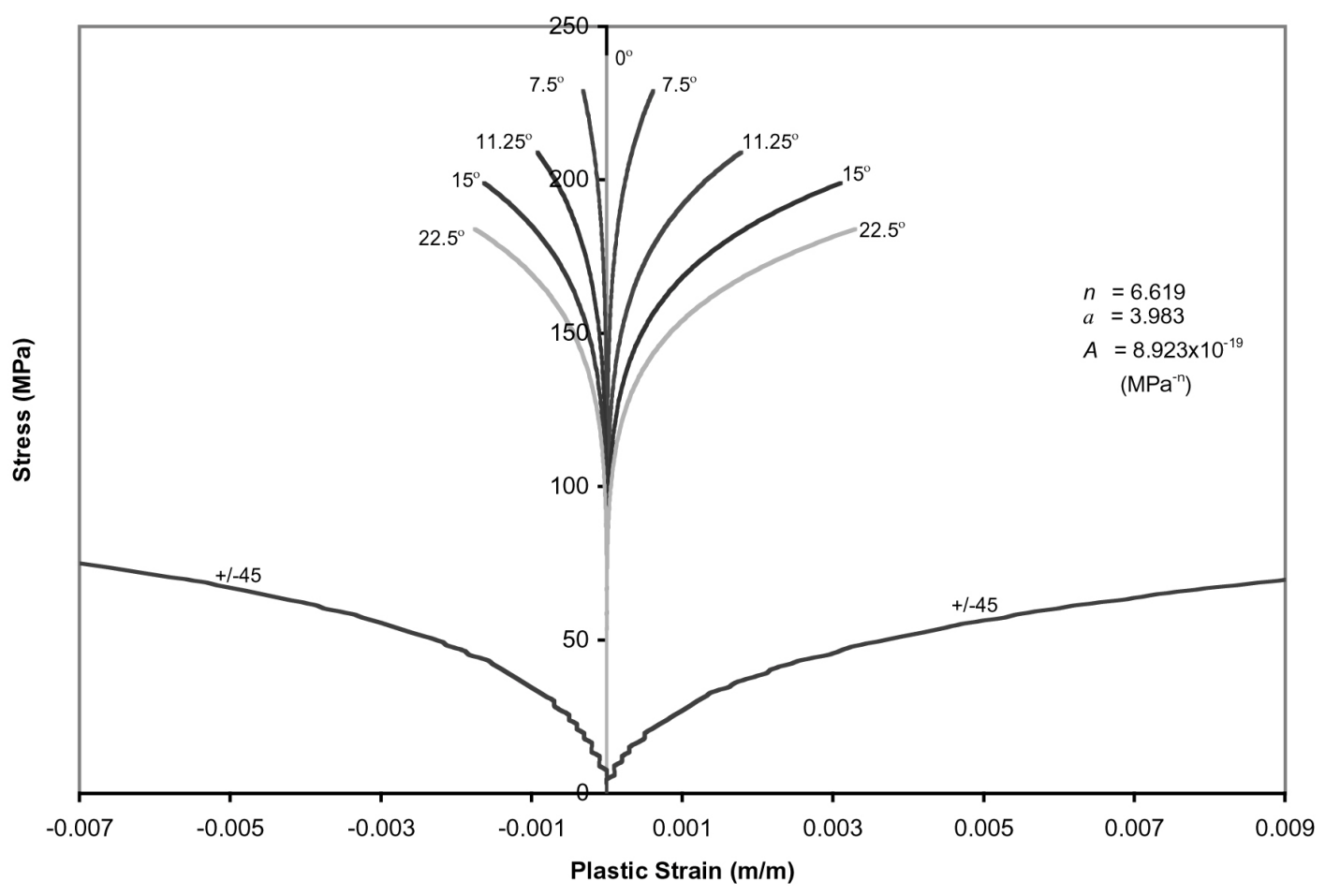

Fig. 12.15. Predicted values of the longitudinal and transverse components of plastic strains for quasi-isotropic composite loaded at various orientations about the fiber direction and for $[ \pm 45]_{3} \mathrm{~S}$ crossply composite. 


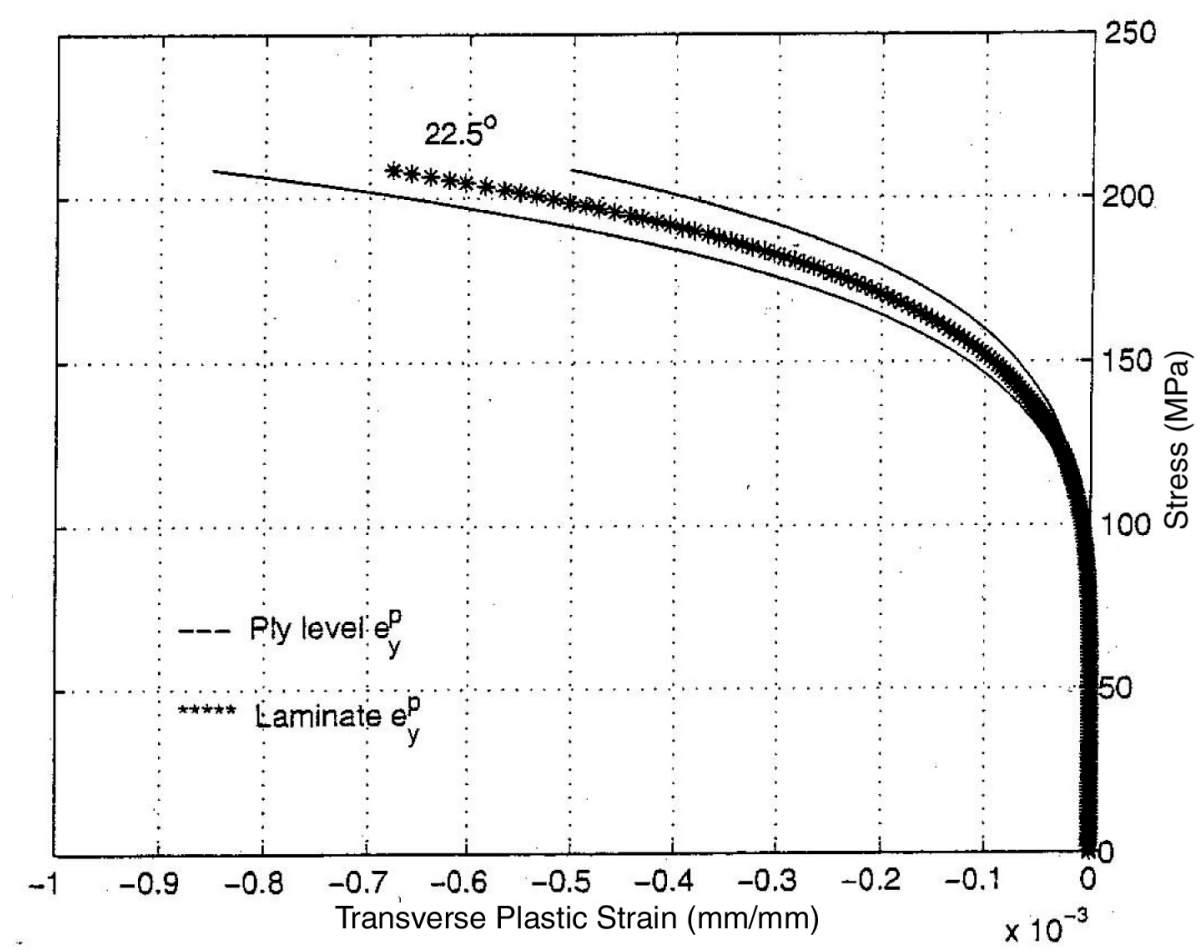

Fig. 12.16. Maximum and minimum values of transverse plastic strain in the individual plies of the quasi-isotropic composite loaded at $22.5^{\circ}$ about the $0^{\circ}$ fiber direction. The disparity provides an error estimate for the approximate scheme.

width of the error band increases with stress and reaches the range of up $\pm 20 \%$ at failure. The resulting discrepancy for the $\sigma_{\mathrm{x}}$ vs $\varepsilon_{\mathrm{x}}$ plot would obviously be smaller.

\subsection{TIME-DEPENDENT RESPONSE}

\subsubsection{Data}

Similarly to the case of tensile tests, the creep and recovery behavior of quasi-isotropic composite coupons was found to depend on the load orientation angle $\phi$, and this dependence was further accentuated with increasing stress amplitudes. Typical creep and recovery curves of quasiisotropic coupons under various creep stresses at loading angles $\phi=0^{\circ}$ and $\phi=22.5^{\circ}$ are shown in Figs. 12.17 and 12.18 , at temperatures of $73^{\circ} \mathrm{C}$ and $120^{\circ} \mathrm{C}$, respectively. Similar results are shown in Fig. 12.19 for room temperature $\left(23^{\circ} \mathrm{C}\right)$, in which case only five specimens were tested in view of the minimal amount of creep at that temperature level. Nevertheless, even in this case there is a discernible difference between the creep at the "off-axis" direction of $67.5^{\circ}$ and the case where loads are applied parallel to a fiber direction, such as $0^{\circ}$ or $90^{\circ}$. Furthermore, Figs. 12.17 to 12.19 show that the permanent deformation also depends on load orientation angle $\phi$ and increases with stress and temperature. 


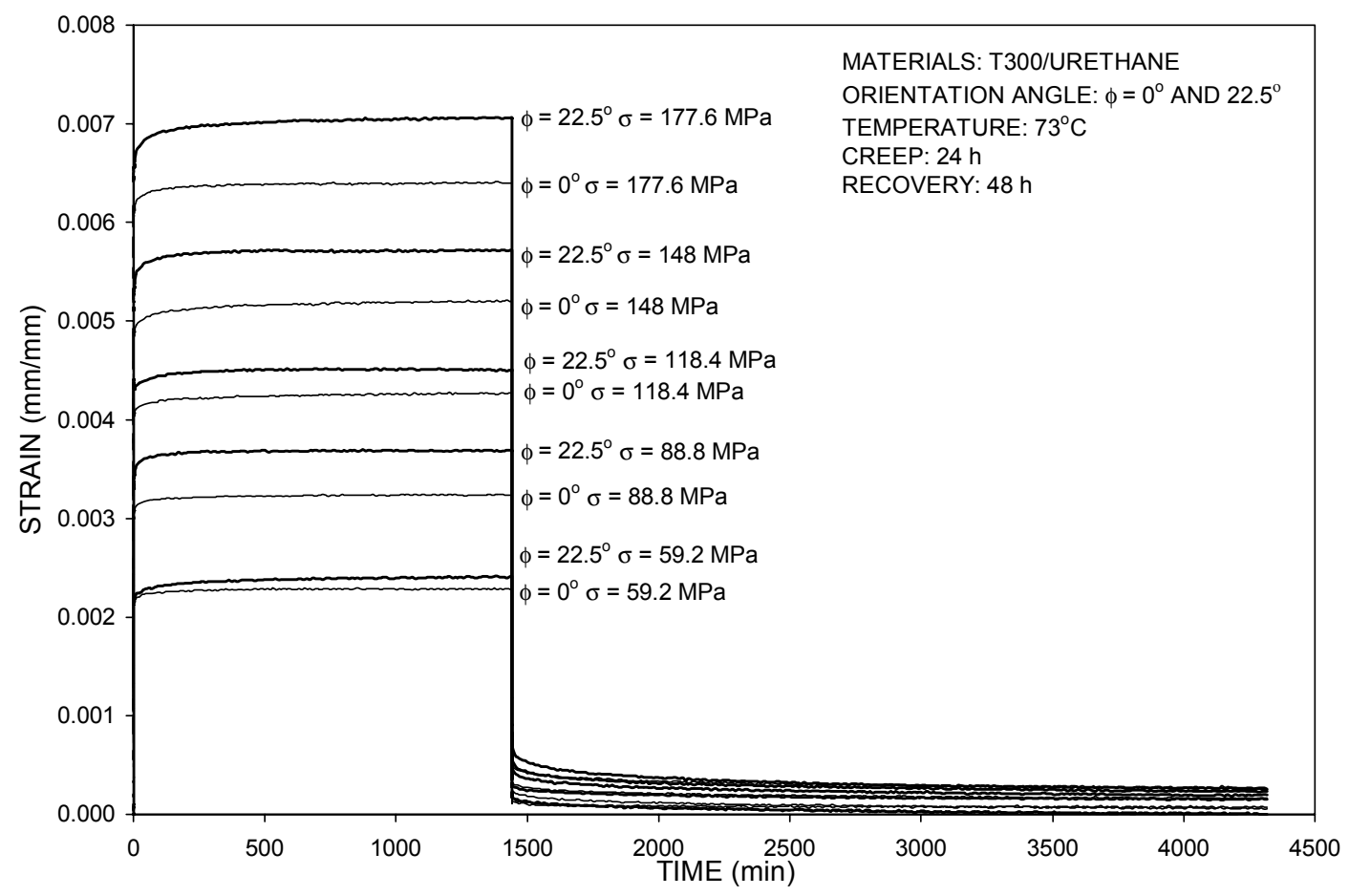

Fig. 12.17. Typical creep-recovery curves of quasi-isotropic composite with two orientations at $73^{\circ} \mathrm{C}$.

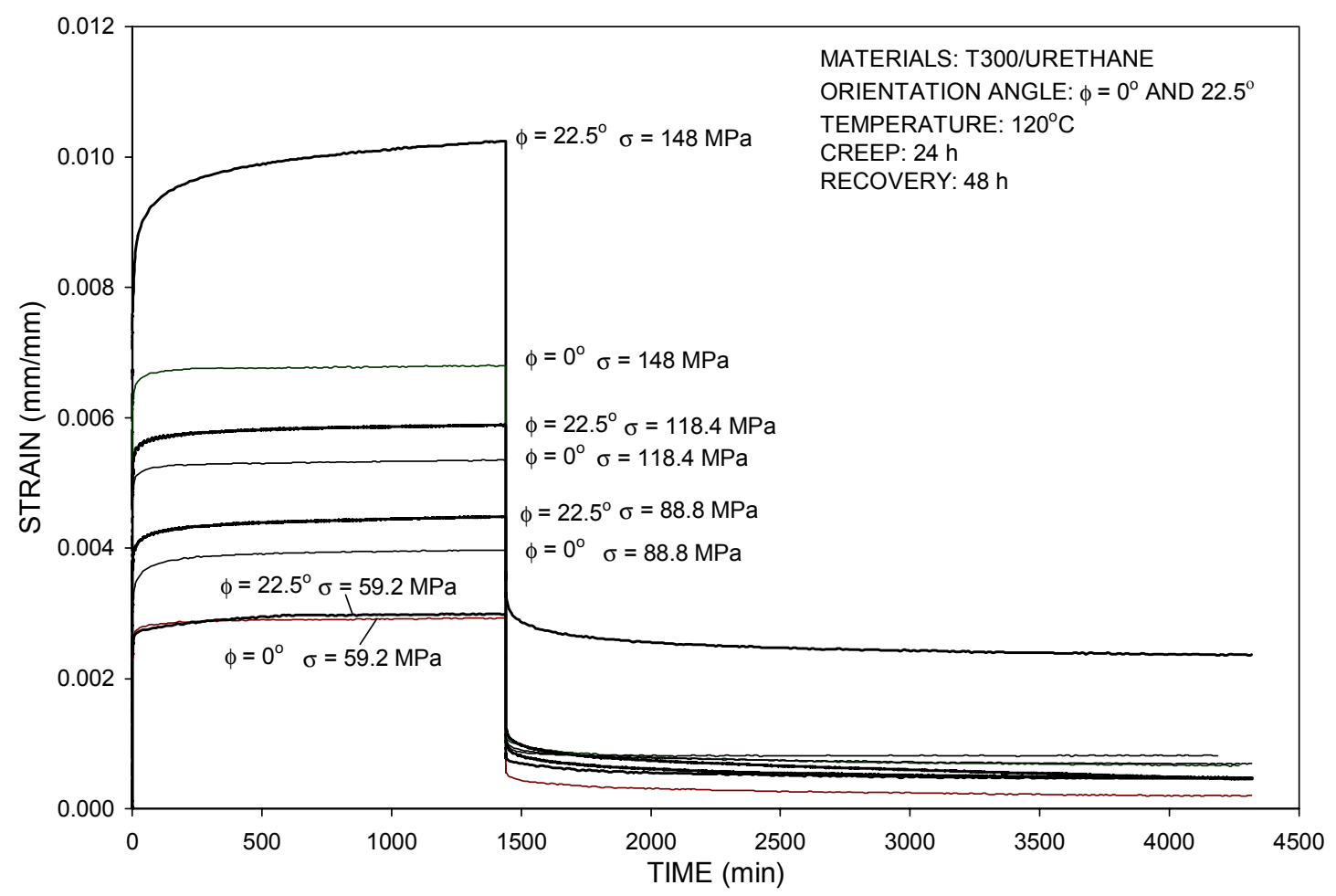

Fig. 12.18. Typical creep-recovery curves of quasi-isotropic composite with two orientations at $120^{\circ} \mathrm{C}$. 


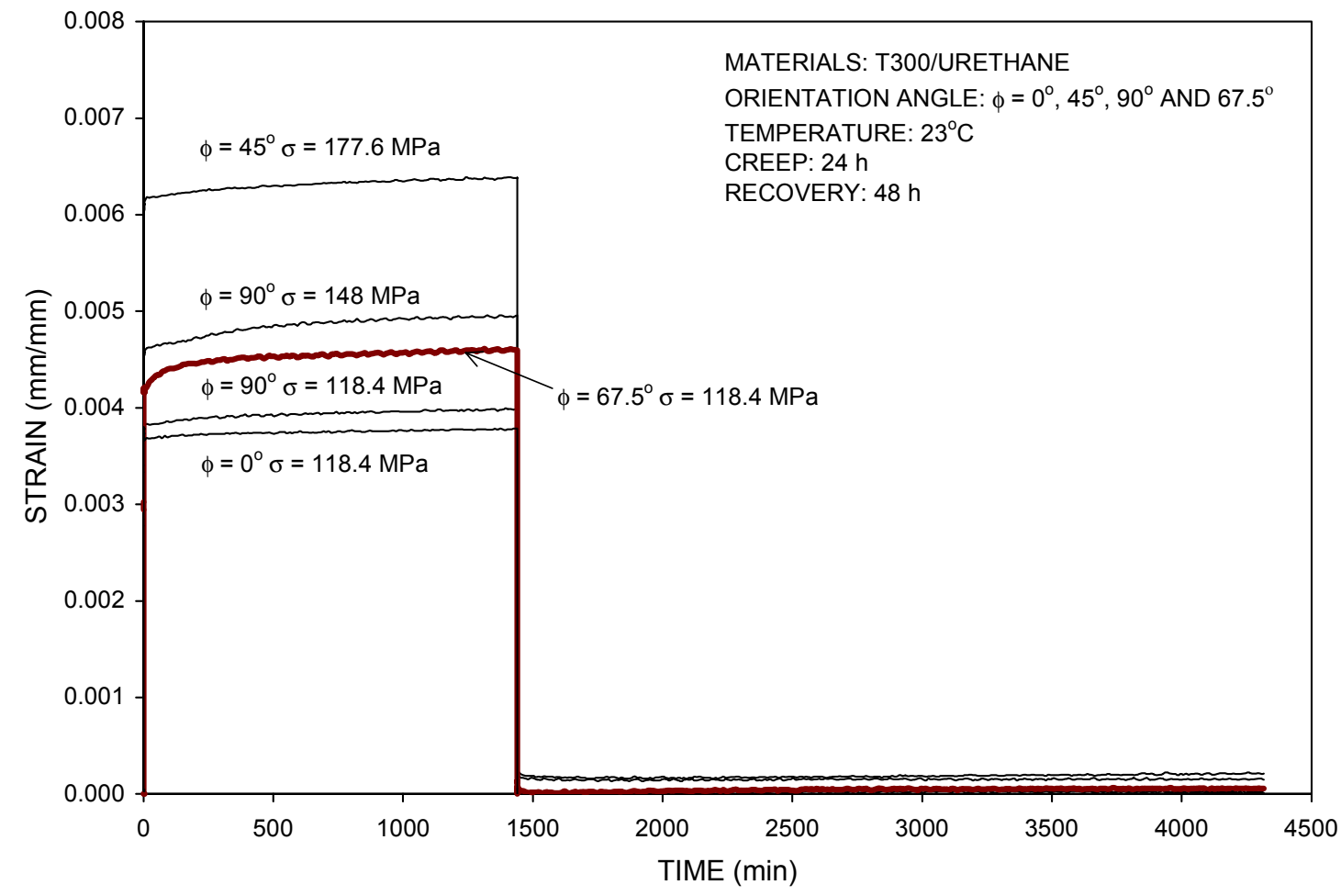

Fig. 12.19. Typical creep-recovery curves of quasi-isotropic composite with different loading orientations at $23^{\circ} \mathrm{C}$.

\subsubsection{Data Reduction}

By fitting the creep data with a power-law expression, namely

$$
\varepsilon_{v}=\left(D_{o}+D_{1} t^{n}\right) \sigma_{o},
$$

one can obtain the parameters $D_{\mathrm{o}}, D_{1}$, and $n$ as listed in Tables 12.3 and 12.4.

These tables suggest that, for these short tests, $D_{0}$ and $D_{1}$ are essentially independent of stress and orientation angle $\phi$. However, the power $n$ appears to be higher for $\phi=22.5^{\circ}$ than for $\phi=0^{\circ}$.

\subsubsection{Correlation Between Tensile Response and Creep Behavior}

The creep and recovery responses under different loading angles for the quasi-isotropic coupons appear to be consistent with the behavior observed in the tensile tests. Namely, both creep and residual permanent strains were larger at load orientation of $\phi=22.5^{\circ}$ than those that occurred when loads were applied parallel to any of the quasi-isotropic fiber directions. Such differences can be attributed to irreversible (plastic) nonlinearity, as depicted by the additional deformation $(\Delta \varepsilon)$ that develops within the coupons loaded at $\phi=22.5^{\circ}$ shown in Fig. 12.20. As noted earlier, the quantity $\Delta \varepsilon$ was found to increase with stress and temperature. 
Table 12.3. Parameters used for the simulations of the creep and recovery results $\left(\phi=0^{\circ},{\left.73^{\circ} \mathrm{C}\right)}^{\circ}\right.$

\begin{tabular}{cccccc}
\hline $\begin{array}{c}\boldsymbol{\sigma}_{\mathbf{0}} \\
\mathbf{M P a})\end{array}$ & $\begin{array}{c}\text { Creep time } \\
\mathbf{( h )}\end{array}$ & $\begin{array}{c}\text { Recovery } \\
\mathbf{t i m e} \\
\mathbf{( h )}\end{array}$ & $\begin{array}{c}\mathbf{D}_{\mathbf{0}} \\
\left(\mathbf{M P a}^{\mathbf{- 1}}, \times \mathbf{1 0}^{-\mathbf{5}}\right)\end{array}$ & $\begin{array}{c}\mathbf{D}_{\mathbf{1}} \\
\left(\mathbf{M P a}^{-\mathbf{n}_{\mathbf{m i n}}} \mathbf{- \mathbf { n }}, \times \mathbf{1 0}^{-\mathbf{6}}\right)\end{array}$ & $\mathbf{n}$ \\
\hline 59.2 & 24 & 48 & 3.43 & 1.44 & 0.045 \\
59.2 & 24 & 48 & 3.58 & 2.01 & 0.045 \\
88.8 & 24 & 48 & 3.34 & 3.31 & 0.050 \\
88.8 & 24 & 48 & 3.93 & 2.20 & 0.045 \\
88.8 & 24 & 48 & 3.34 & 2.20 & 0.045 \\
118.4 & 24 & 48 & 3.51 & 1.78 & 0.045 \\
118.4 & 24 & 48 & 3.45 & 1.08 & 0.045 \\
118.4 & 24 & 48 & 3.51 & 2.15 & 0.080 \\
148 & 24 & 48 & 3.28 & 1.53 & 0.060 \\
148 & 24 & 48 & 3.84 & 1.48 & 0.060 \\
177.6 & 24 & 48 & 3.58 & 4.00 & 0.050 \\
177.6 & 24 & 48 & 2.96 & 6.20 & 0.040 \\
\hline
\end{tabular}

Table 12.4. Parameters used for the simulations of the creep and recovery results $\left(\phi=22.5^{\circ}, 7^{\circ} \mathrm{C}\right)$

\begin{tabular}{|c|c|c|c|c|c|}
\hline $\begin{array}{c}\sigma_{0} \\
(\mathbf{M P a})\end{array}$ & $\begin{array}{l}\text { Creep time } \\
\text { (h) }\end{array}$ & $\begin{array}{l}\text { Recovery } \\
\text { time } \\
\text { (h) }\end{array}$ & $\frac{\mathrm{D}_{\mathrm{o}}}{\left(\mathrm{MPa}^{-1}, \times 10^{-5}\right)}$ & $\begin{array}{c}\mathrm{D}_{1} \\
\left(\mathrm{MPa}^{-\mathrm{n}_{\mathrm{min}^{-n}}}, \times 10^{-6}\right)\end{array}$ & n \\
\hline 59.2 & 24 & 48 & 3.49 & 2.95 & 0.080 \\
\hline 59.2 & 24 & 48 & 3.61 & 2.50 & 0.080 \\
\hline 88.8 & 24 & 48 & 3.74 & 3.05 & 0.045 \\
\hline 88.8 & 24 & 48 & 2.93 & 4.80 & 0.055 \\
\hline 118.4 & 24 & 48 & 3.44 & 2.14 & 0.080 \\
\hline 118.4 & 24 & 48 & 3.70 & 0.65 & 0.080 \\
\hline 148 & 24 & 48 & 3.87 & 3.41 & 0.045 \\
\hline 148 & 24 & 48 & 3.51 & 1.60 & 0.090 \\
\hline 177.6 & 24 & 48 & 3.53 & 1.00 & 0.050 \\
\hline 177.6 & 24 & 48 & 3.53 & 1.68 & 0.045 \\
\hline 177.6 & 24 & 48 & 3.59 & 2.35 & 0.070 \\
\hline
\end{tabular}




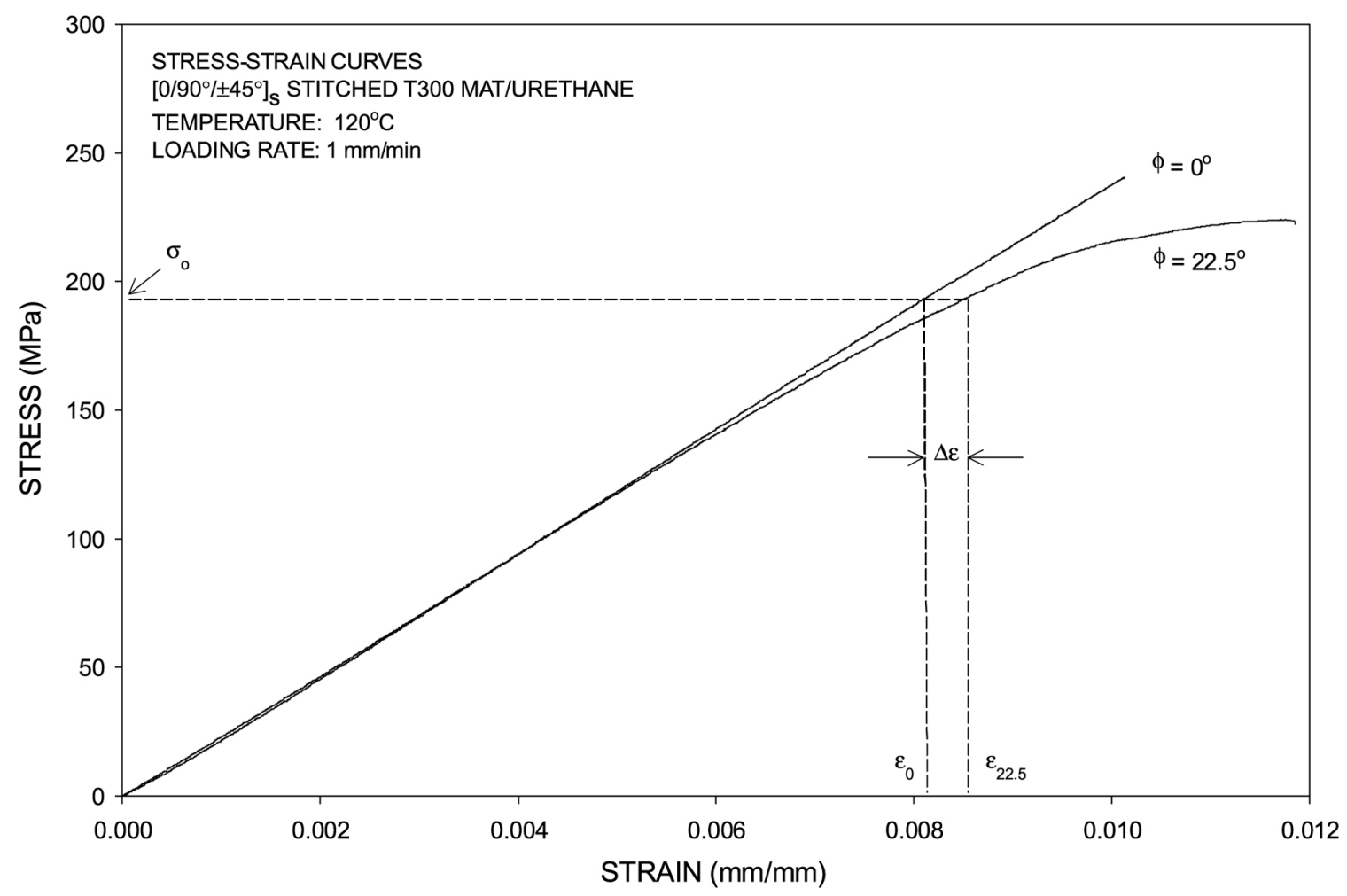

Fig. 12.20. Typical stress-strain to failure response of quasi-isotropic composite at $120^{\circ} \mathrm{C}$ with loads applied at $\phi=0^{\circ}$ and $\phi=22.5^{\circ}$ about the fiber direction.

\subsubsection{Prediction of Creep Behavior of Quasi-Isotropic Composite Based on Crossply Viscoelastic Characterization}

For the quasi-isotropic layup, the in-plane laminate stiffnesses $A_{i j}$ are independent of the loading orientation $\phi$ within the linear range. The following expressions for $A_{i j}$ can be obtained from Eq. (12.2) upon setting $\alpha=0$ :

$$
\begin{aligned}
& A_{11}=A_{22}=h_{o}\left[3\left(Q_{11}+Q_{22}\right)+2 Q_{12}+4 Q_{66}\right] \\
& A_{12}=h_{o}\left[\left(Q_{11}+Q_{22}\right)+6 Q_{12}-4 Q_{66}\right] \\
& A_{16}=A_{26}=0 \\
& A_{66}=h_{o}\left[\left(Q_{11}+Q_{22}\right)-2 Q_{12}+4 Q_{66}\right] .
\end{aligned}
$$

Subsequently, Eq. (12.1) yields the following relationship between longitudinal strain $\varepsilon_{x}$ and stress $\sigma_{x}$ :

$$
\varepsilon_{x}=n_{p} \frac{3\left(Q_{11}+Q_{22}\right)+2 Q_{12}+4 Q_{66}}{\left[3\left(Q_{11}+Q_{22}\right)+2 Q_{12}+4 Q_{66}\right]^{2}-\left[\left(Q_{11}+Q_{22}\right)+6 Q_{12}-4 Q_{66}\right]^{2}} \sigma_{x} .
$$


In the above, only $Q_{22}$ and $Q_{66}$ incorporate the properties of the matrix phase to a significant degree, and are thereby time-dependent. However, Eq. (12.27) shows that for quasi-isotropic laminates, $Q_{22}$ always appears in combination with $Q_{11}$, in the form of $Q_{11}+Q_{22}$. In view of the fact that $Q_{11}$ exceeds $Q_{22}$ by two orders of magnitude, it is possible to neglect the contribution of the time-dependent variation of $Q_{22}$ to the stress-strain relation shown in Eq. (12.27) and attribute all creep to the temporal dependence of $Q_{66}$. The above considerations were discussed in detail in an earlier work on the time-dependent behavior of the crossply composite, ${ }^{20}$ where the timedependent form of $Q_{66}$ was shown to have the following form:

$$
\frac{1}{Q_{66}(t)}=\frac{1}{Q_{66}(0)}+\left(\frac{4}{Q_{11}+Q_{22}+2 Q_{12}}+\frac{1}{Q_{66}(0)}\right) \frac{D_{1} t^{n}}{D_{o}} .
$$

Upon employing $D_{\mathrm{o}}=4.18 \times 10^{-5} \mathrm{MPa}^{-1}, D_{1}=6.6 \times 10^{-6} \mathrm{MPa}^{-\mathrm{n}} \min ^{-\mathrm{n}}$, and $n=0.245$ as power-law creep parameters that fall within the range of values that fit the creep data for the crossply composite, it is possible to predict the creep behavior of the quasi-isotropic composite by substituting Eq. (12.28) into Eq. (12.27). An example for such a prediction is shown in Fig. 12.21. Although the values of the instantaneous strain are subject to some uncertainty that is attributable to sample-to-sample variability in the value of $Q_{11}+Q_{22}$, the predicted timedependent portion of strain falls parallel to the recorded data, exhibiting excellent agreement with experimental results.

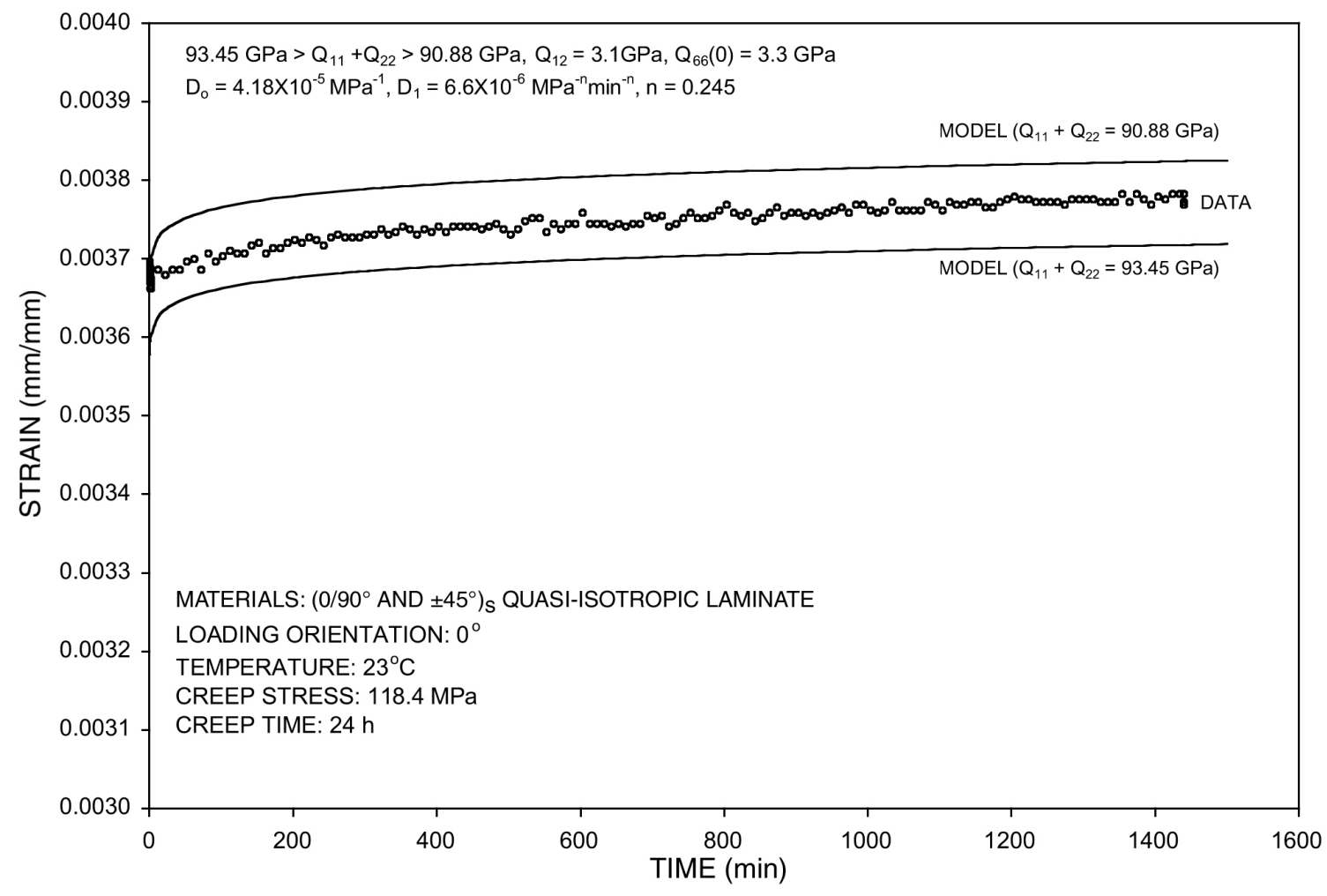

Fig. 12.21. Prediction of creep behavior of quasi-isotropic composite based on crossply viscoelastic characterization. 


\subsection{CONCLUDING REMARKS}

This chapter shows that the response of the quasi-isotropic composite can be related by the well-established mechanics theories of plasticity and viscoelasticity in conjunction with classical laminate theory. Although data scatter increases rather substantially with both stress and temperature, the above theories appear to provide an adequate and suitable framework for the modeling of the mechanical behavior of the quasi-isotropic composite and more complex layups made of the constituent materials.

A novel aspect of mechanical behavior, which seems to have never been explored before, is the loss of quasi-isotropy due to material nonlinearity. This phenomenon has been noticed experimentally, perhaps for the first time, in the stress-strain response and could be rationally attributed to the plasticity of the resin phase. 
$12-26$ 


\title{
13. EFFECTS OF CIRCULAR HOLES
}

\author{
J. M. Corum and V. Kunc*
}

\subsection{INTRODUCTION}

Circular holes typify stress concentrations, and they have consequently received wide attention. Several investigators have shown that the length of a discontinuity, not its shape, is the governing parameter, at least in fiber-dominated layups. ${ }^{27-29}$ Thus, holes can be used to characterize the effect of other discontinuities, including slits. Further, it is shown in Chap. 14 that the effect of a circular hole on strength degradation conservatively bounds that of an impact damage area of irregular shape having the same area. Thus, circular holes play a significant role in the recommended damage tolerance evaluation procedures given in Chap. 5 of Part 1.

The study of circular hole effects reported here was motivated by the above and by the fact that automotive structures typically have a multitude of holes. Their effect on structural strength and stiffness must be assessed.

\subsection{TEST PROGRAM}

Two carbon-fiber layups were tested:

- the reference crossply composite, $\left[{ }^{2} 45^{\circ}\right]_{3} \mathrm{~S}$, with specimens having either a $0 / 90^{\circ}$ fiber orientation or $\mathrm{a} \pm 45^{\circ}$ orientation, and

- the quasi-isotropic composite, $\left[0 / 90^{\circ} / \pm 45^{\circ}\right]_{\mathrm{S}}$.

The specimen layout for each composite/fiber orientation is illustrated in Fig. 13.1. Four sets of duplicate specimens were cut from a single plaque of each material and orientation. The width, w, and hole diameter, a, of specimens within each set are tabulated below (going from left to right in Fig. 13.1).

\begin{tabular}{cccc}
$\mathbf{w}(\mathbf{m m})$ & & $\mathbf{a}(\mathbf{m m})$ \\
\cline { 1 - 1 } 25.4 & & 3.18 \\
50.8 & & 12.7 \\
25.4 & & 6.35 \\
76.2 & & 25.4 \\
$25.4^{\dagger}$ & & 0
\end{tabular}

Two sets of specimens in each case were instrumented with strain gages for measuring strains to compare with finite-element results. A third set of specimens was loaded in steps. After each step, the specimens were unloaded, and X-ray photographs were made to locate cracking. The results of these parts of the study are presented in a separate topical report. ${ }^{30}$

\footnotetext{
*Graduate student, Department of Mechanical and Nuclear Engineering, Kansas State University.

† Specimens without holes were dogboned to a width of $20.3 \mathrm{~mm}$.
} 


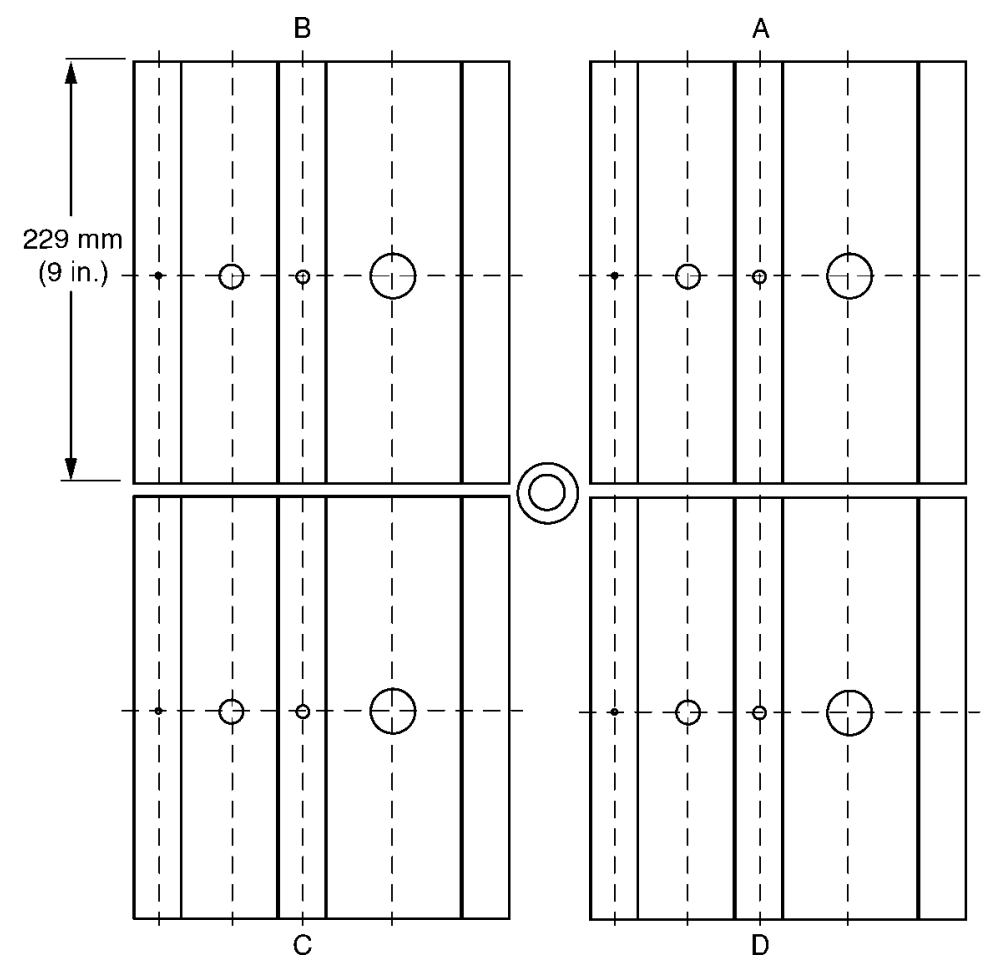

Fig. 13.1. Layout for four groups of specimens from a single plaque. This layout was used for quasi-isotropic and $\pm 45^{\circ}$ crossply composite specimens. For $0 / 90^{\circ}$ crossply specimens, the layout was rotated $45^{\circ}$ on the plaque, with the surface fibers oriented parallel to the specimen axes.

\subsection{TEST RESULTS}

The test results, tabulated as the averages from four test specimens in each case, are given in Table 13.1. The gross stress, $\bar{\sigma}$, is the average stress away from the hole in the actual finite-width plates. The gross stress in an equivalent infinitely wide plate was calculated by the following relationship,

$$
\bar{\sigma}_{\infty}=\frac{1}{3}\left[2+(1-\mathrm{a} / \mathrm{w})^{3}\right] \bar{\sigma} /(1-\mathrm{a} / \mathrm{w})
$$

which is based on an empirical formula for the stress concentration factor in an elastic, isotropic plate of arbitrary width. ${ }^{31}$ Equation (13.1) was derived by equating the maximum stress in an infinitely wide plate to that in the finite-width plate. Although it has been shown that isotropic finite-width corrections can be applied to anisotropic plates containing center cracks to obtain stress intensity factors, their application to circular holes has not been shown conclusively. ${ }^{31}$

Note that the notched strength/UTS in Table 13.1 is just the reciprocal of the apparent stress concentration factor, $\mathrm{SCF}_{\infty}=\mathrm{UTS} / \bar{\sigma}_{\infty}$. 
Table 13.1. Average hole specimen tensile test results

\begin{tabular}{|c|c|c|c|c|c|c|}
\hline $\mathbf{w}(\mathbf{m m})$ & $\mathbf{a}(\mathrm{mm})$ & $\mathbf{t}(\mathbf{m m})$ & $\begin{array}{c}\text { Gross failure } \\
\text { stress, } \\
\bar{\sigma}(\mathrm{MPa})\end{array}$ & $\begin{array}{c}\text { Gross failure } \\
\text { stress, } \\
\bar{\sigma}_{\infty}(\mathrm{MPa})\end{array}$ & $\mathrm{SCF}_{\infty}$ & $\begin{array}{c}\text { Notch } \\
\text { strength/UTS }\end{array}$ \\
\hline \multicolumn{7}{|c|}{ Quasi-isotropic composite (plaque Q20) } \\
\hline 20.3 & 0 & 2.16 & 355 & 355 & 1.00 & 1.00 \\
\hline 25.4 & 3.18 & 2.14 & 244 & 248 & 1.43 & 0.70 \\
\hline 25.4 & 6.35 & 2.16 & 213 & 230 & 1.55 & 0.65 \\
\hline 50.7 & 12.7 & 2.14 & 187 & 201 & 1.77 & 0.57 \\
\hline 76.1 & 25.4 & 2.16 & 153 & 175 & 2.03 & 0.49 \\
\hline \multicolumn{7}{|c|}{ 0/90 ${ }^{\circ}$ crossply (plaque $\mathrm{C29}$ ) } \\
\hline 20.4 & 0 & 2.96 & 435 & 435 & 1.00 & 1.00 \\
\hline 25.5 & 3.18 & 2.96 & 392 & 399 & 1.09 & 0.92 \\
\hline 25.3 & 6.35 & 2.97 & 318 & 343 & 1.28 & 0.79 \\
\hline 50.8 & 12.7 & 2.98 & 244 & 263 & 1.66 & 0.61 \\
\hline 76.1 & 25.4 & 2.98 & 182 & 209 & 2.09 & 0.48 \\
\hline \multicolumn{7}{|c|}{ $\pm 45^{\circ}$ crossply (plaque $\mathrm{C} 30$ ) } \\
\hline 20.5 & 0 & 3.05 & 145 & 145 & 1.00 & 1.00 \\
\hline 25.3 & 3.18 & 3.03 & 129 & 131 & 1.11 & 0.90 \\
\hline 25.3 & 6.35 & 3.04 & 102 & 109 & 1.33 & 0.76 \\
\hline 50.8 & 12.7 & 3.01 & 110 & 118 & 1.23 & 0.82 \\
\hline 76.1 & 25.4 & 3.05 & 96 & 110 & 1.31 & 0.76 \\
\hline
\end{tabular}

\subsection{FAILURE MODES AND LOCATIONS}

It is obvious that the maximum stress at holes in the quasi-isotropic composite occurs at $\theta=0^{\circ}$, and because the strength is almost the same in all directions, failure would be expected to initiate there. The situation in the crossply composite is not as clear. Laminated plate analyses performed earlier at the University of Tennessee determined the variation of circumferential stress around the edge of holes in specimens with the $0 / 90^{\circ}$ and $\pm 45^{\circ}$ fiber orientations and compared that with the variation of UTS with orientation. ${ }^{32}$ In the $0 / 90^{\circ}$ case, the circumferential stress around the edge of the hole is highest at $\theta=0^{\circ}$, but so is the UTS in that orientation. Failure was predicted to occur at an angle, $\theta$, ranging from about $7^{\circ}$ for the smallest holes to about $10.5^{\circ}$ for the largest holes. In the $\pm 45^{\circ}$ case, the circumferential stress around the edge of a hole peaks at about $\theta=35^{\circ}$, but the UTS is a minimum at $\theta=0^{\circ}$, and that is where failure is predicted to occur.

A digital video camera was set up to monitor the failure process in one set of 50.8- and 76.2-mm-wide specimens for each composite. Results for the 76.2-mm-wide specimens are typified by the single frames shown in Figs. $13.2-13.4$ for the quasi-isotropic $0 / 90^{\circ}$ crossply and $\pm 45^{\circ}$ crossply, respectively.

In the quasi-isotropic case, a major crack popped in suddenly, at $\theta=0^{\circ}$ as predicted, accompanied by a debris cloud of either fine powder or fast-moving larger particles [see Fig. 13.2(a)]. This cloud appeared only in one frame as the crack popped in; the following frame showed larger or slower moving fragments coming from the crack [Fig. 13.2(b)].

In the $0 / 90^{\circ}$ crossply case, a damage zone of vertical ply failures first occurred between about $\theta=10^{\circ}$ and $20^{\circ}$ [Fig. 13.3(a)]. A major crack emanating from the damage zone quickly followed [Fig. 13.3(b)]. The location of the initial damage zone is in general agreement with the predicted angle of $\theta=10.5^{\circ}$. 


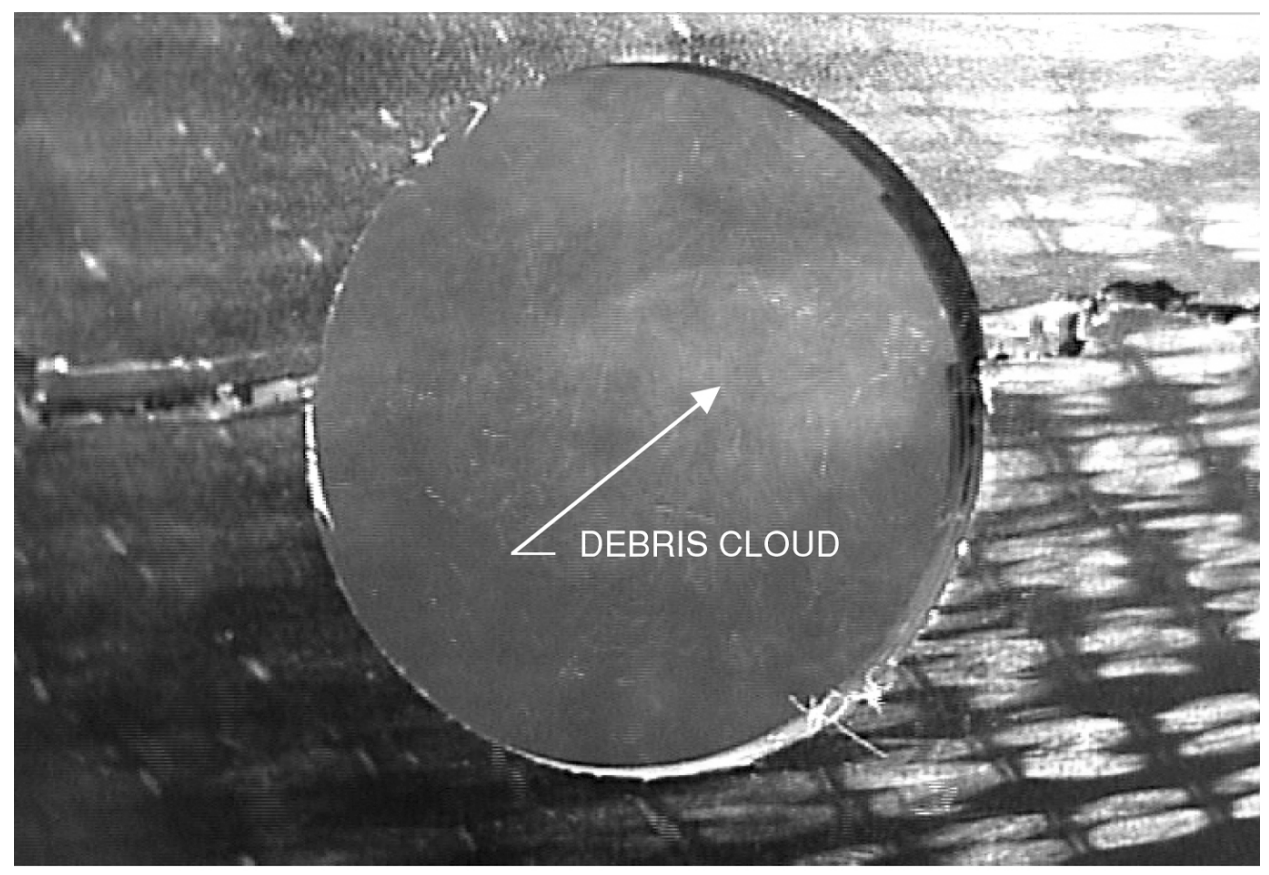

(a) Debris cloud at moment of crack pop-in

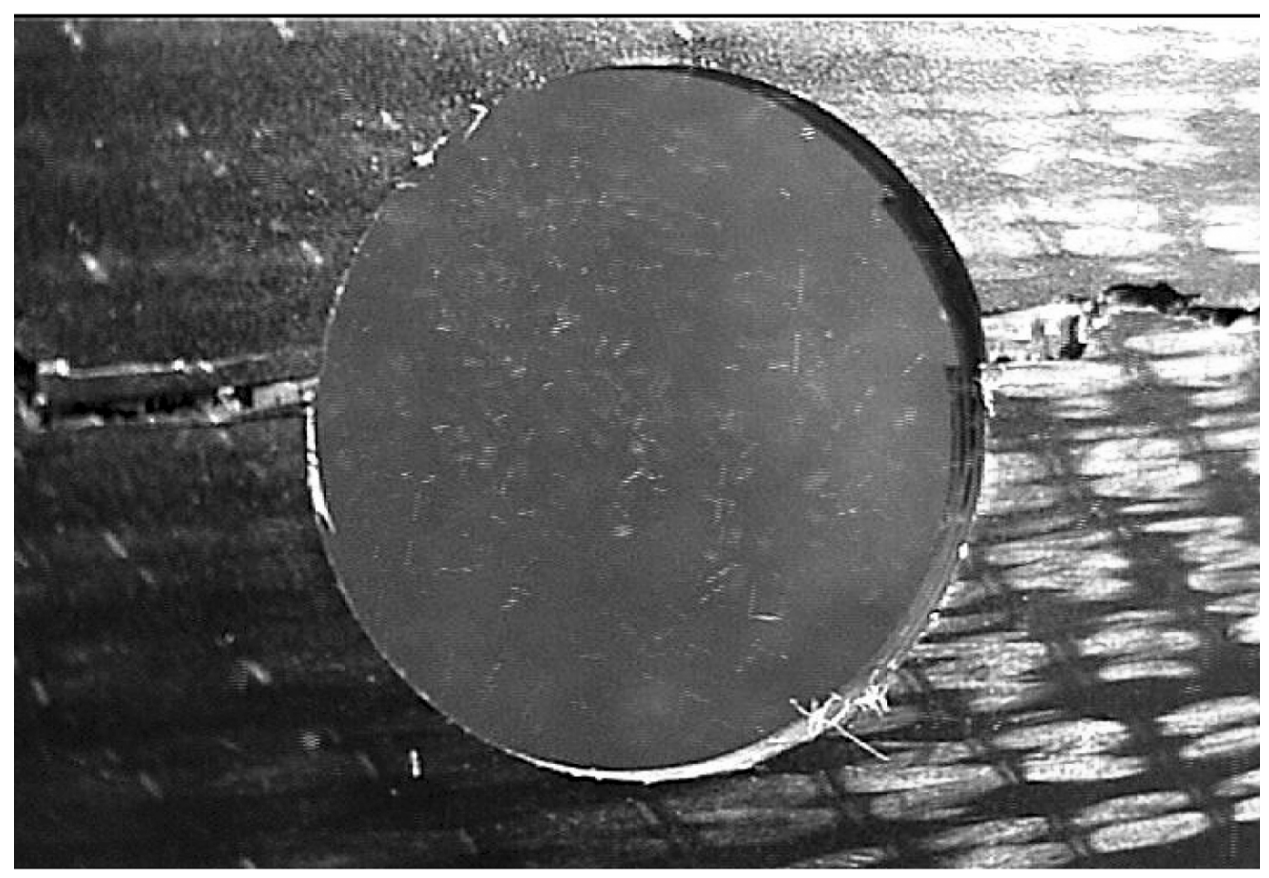

(b) Subsequent release of small fragments

Fig. 13.2. Failure progression in 76.2-mm-wide (3-in.) quasi-isotropic specimen with 25.4-mmdiam (1-in.) hole. 


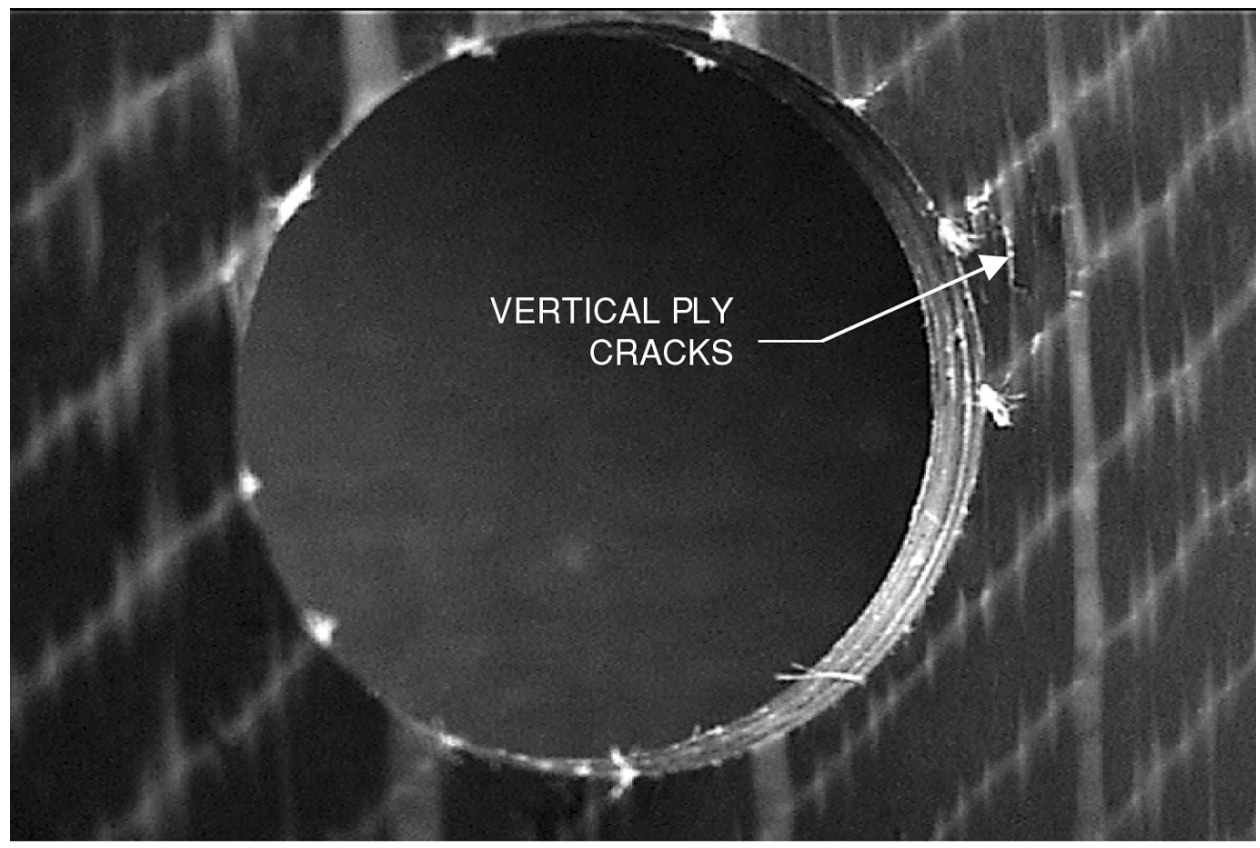

(a) Damage zone at $10-20^{\circ}$

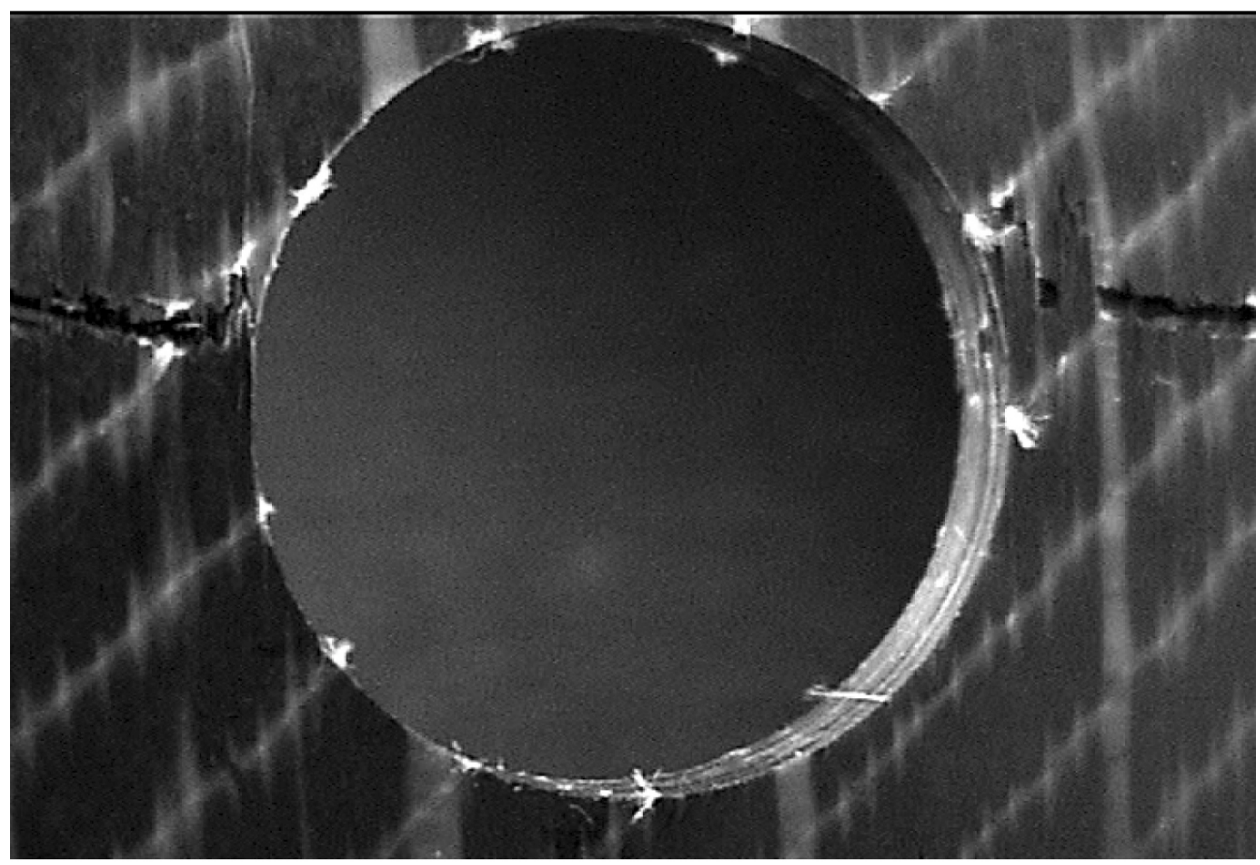

(b) Crack eminating from damage zone

Fig. 13.3. Failure progression in 76.2 -mm-wide (3-in.) crossply composite specimen with $0 / 90^{\circ}$ fiber orientation and 25.4-mm-diam (1-in.) hole. 


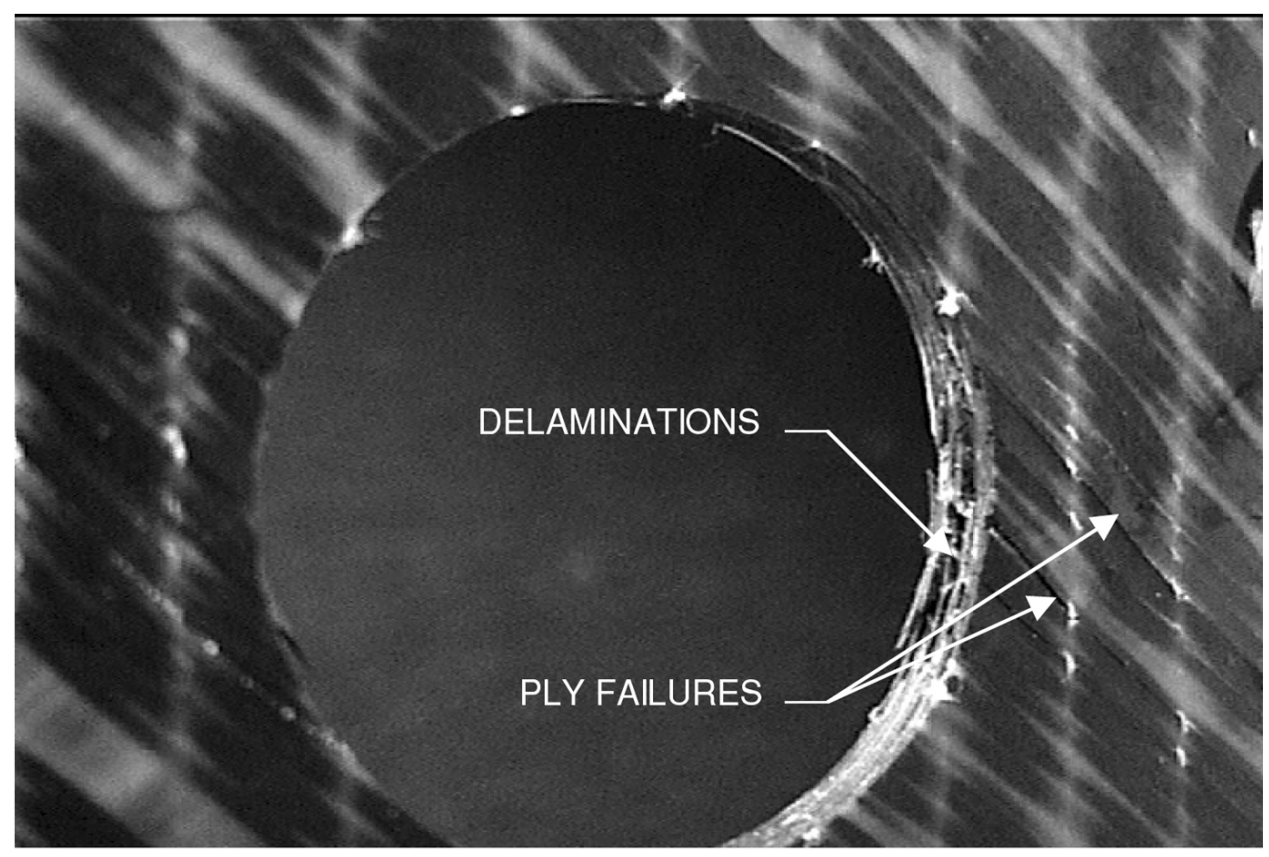

(a) Initial damage zone

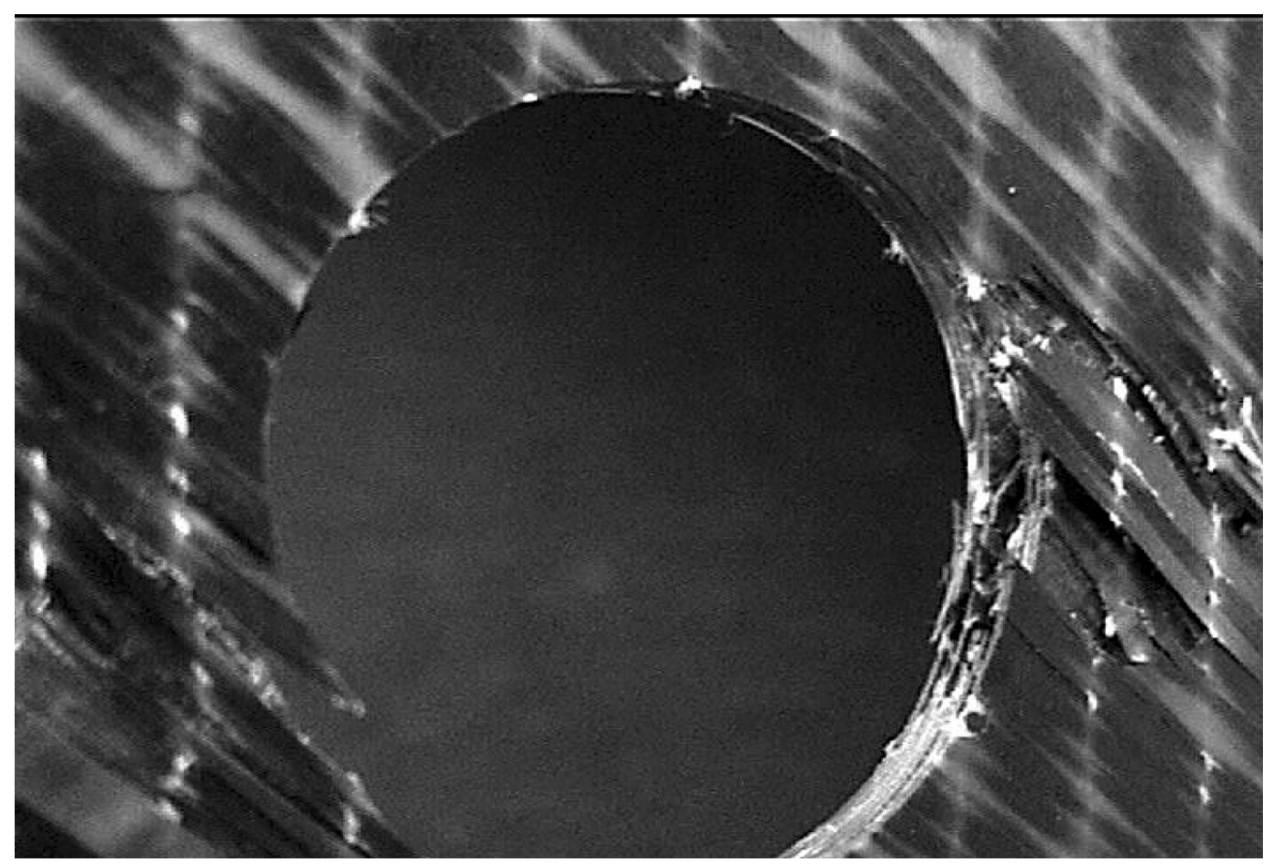

(b) Major cracking emanating from damage zone

Fig. 13.4. Failure progression in 76.2 -mm-wide (3-in.) crossply composite specimen with $\pm 45^{\circ}$ fiber orientation and 25.4-mm-diam (1-in.) hole. 
In the case of the $\pm 45^{\circ}$ crossply, damage began to occur at $\theta=0^{\circ}$. Both delaminations and ply failures appeared to occur simultaneously [Fig. 13.4(a)]. The damage grew and relatively slowly developed into the scissors pattern of cracks typical of $\pm 45^{\circ}$ failed specimens.

\subsection{EFFECTS OF HOLE SIZE}

Stress concentrations at holes in composites, and thus the gross failure stress, depend on hole size. Very small holes produce practically no apparent stress concentration, while larger holes have a SCF approaching the predicted value, which is independent of size. This hole size effect was found in the isotropic chopped-glass-fiber composite, and it is apparent in the data of Table 13.1. Methods for characterizing the hole size effect include two criteria proposed by Whitney and Nuismer 27,31 and a power law relation that is loosely related to fracture mechanics. ${ }^{33}$

Fracture mechanics assumes a single dominant crack that grows in a self-similar fashion. Thus, application to composites with a damage zone consisting of many cracks is questionable, even for sharp initial slits. This is even more true for holes. Nonetheless, the concept has been applied. It has been observed that the following linear-elastic fracture mechanics relation between gross stress and stress intensity factor for a slit of length $2 \mathrm{c}$ in an infinitely wide plate has the form of a power law.

$$
\bar{\sigma}_{\infty}=\frac{\mathrm{K}}{\sqrt{\pi}} \mathrm{c}^{-1 / 2}
$$

Here, $\mathrm{c}$ is the half-length of the slit, and $\mathrm{K}$ is the stress intensity factor. Using a fracture mechanics model, Mar and $\operatorname{Lin}^{34}$ proposed the following equation for the fracture stress of notched fiber-dominated composites:

$$
\bar{\sigma}_{\infty}=\mathrm{H}(2 \mathrm{R})^{-\mathrm{m}}
$$

where $2 \mathrm{R}$ is the notch length or hole diameter. They found that only the length of a discontinuity (i.e., slits, holes) is important, not its shape. Regardless of the theoretical validity of Eq. (13.3), Fig. 13.5 shows that power laws provide good fits to the results in Table 13.1, except for very small hole sizes. Lagace ${ }^{33}$ suggested capping the relations by horizontal lines corresponding to the UTS values, which are plotted on the ordinate of Fig. 13.5. Caprino ${ }^{29}$ suggested that fracture of unnotched material is precipitated by an intrinsic flaw of length $2 \mathrm{~L}_{0}$. Values of $\mathrm{L}_{0}$ can be determined from Fig. 13.5.

Mar and $\operatorname{Lin}^{34}$ suggest that the coefficient $\mathrm{H}$ in Eq. (13.3) is akin to a fracture toughness, and further that $\mathrm{H}$ may be approximately correlated with the number of $0^{\circ}$ plies in the layup. Examining the equations in Fig. 13.5, it is seen that indeed the coefficient for the $0 / 90^{\circ}$ crossply, which has $50 \%$ of its plies in the $0^{\circ}$ orientation is nearly twice that of the quasi-isotropic material,which has only $25 \%$ of its plies in the $0^{\circ}$ orientation. The $\pm 45^{\circ}$ plies in the quasiisotropic material do make some contribution, as can be seen from the coefficent for the $\pm 45^{\circ}$ material.

The two closely related criteria of Whitney and Nuismer are based on the nature of the predicted stress distributions adjacent to large and small holes, as illustrated in Fig. 13.6. In the first approach it is assumed that failure occurs when the predicted stress over some distance, $d_{o}$, away from the hole is equal to or greater than the UTS. This is referred to as the "point criterion". The second criterion assumes that failure occurs when the average stress over some distance, $\mathrm{a}_{0}$, equals the UTS. This is referred to as the "average criterion." These criteria lead to the following relations. $^{31}$ 


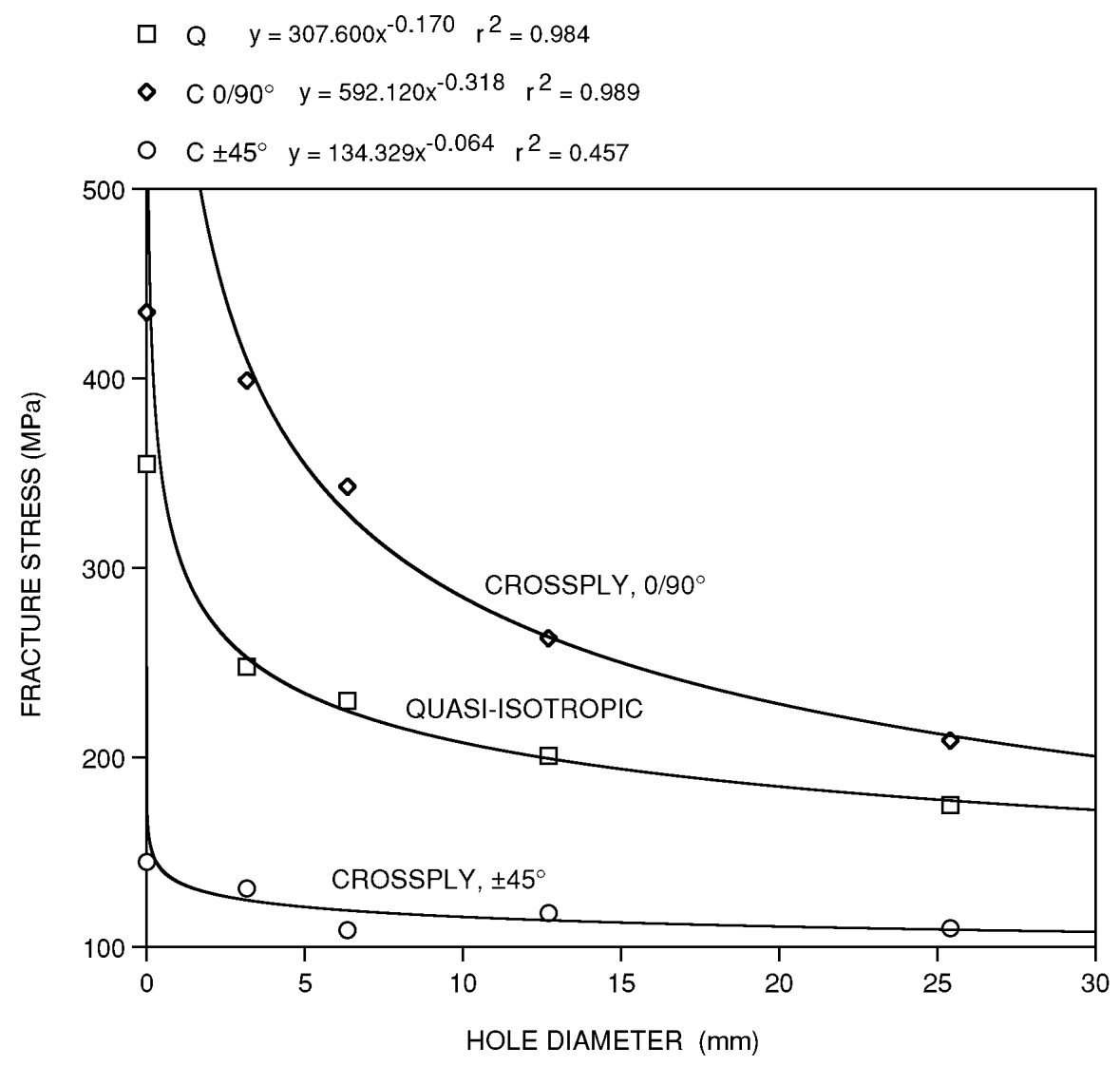

Fig. 13.5. Notched strength (for infinite plate) vs hole diameter, with power-law curve fits. The data points on the ordinate for specimens without holes were not used in the curve fits.

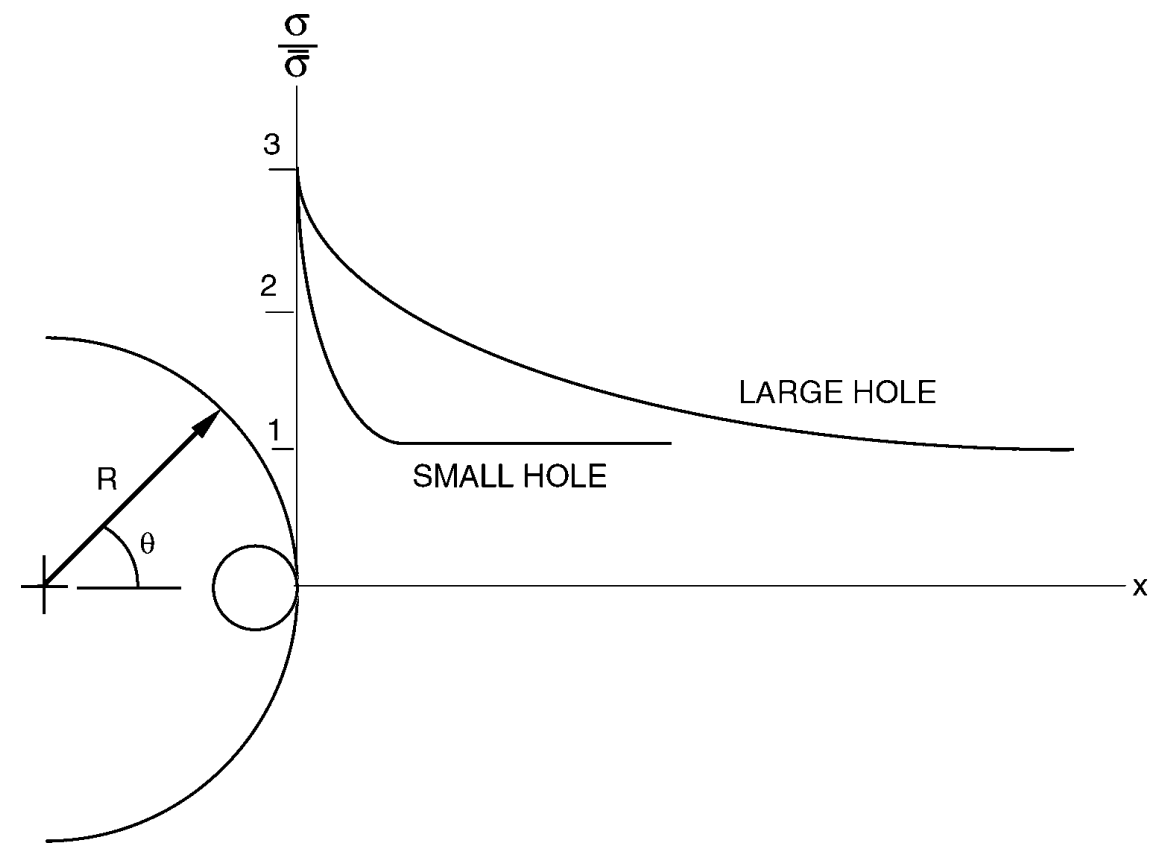

Fig. 13.6. Schematic representation of predicted axial stress distributions at large and small holes in a uniaxially loaded, infinitely wide plate. 
Point criterion:

$$
\frac{\bar{\sigma}_{\infty}}{\mathrm{UTS}}=2 /\left[2+\xi_{1}{ }^{2}+3 \xi_{1}{ }^{4}-\left(\mathrm{K}_{\mathrm{t}}-3\right)\left(5 \xi_{1}{ }^{6}-7 \xi_{1}{ }^{8}\right)\right]
$$

where

$$
\xi_{1}=\mathrm{R} /\left(\mathrm{R}+\mathrm{d}_{0}\right)
$$

and $\mathrm{K}_{\mathrm{t}}$ is the othotropic stress concentration factor for an infinitely wide plate, given by

$$
\mathrm{K}_{\mathrm{T}}=1+\left\{2\left[\left(\mathrm{E}_{11} / \mathrm{E}_{22}\right)^{1 / 2}-\mathrm{v}_{12}\right]+\mathrm{E}_{11} / \mathrm{G}_{12}\right\}^{1 / 2}
$$

\begin{tabular}{|c|c|}
\hline Material & $\mathbf{K}_{\mathbf{T}}$ \\
\hline Quasi-isotropic & 3.00 \\
\hline $0 / 90^{\circ}$ crossply & 5.20 \\
\hline $\pm 45^{\circ}$ crossply & 1.97 \\
\hline
\end{tabular}

All of the required elastic constants are available for the composites represented in Table 13.1. The resulting calculated values of $\mathrm{K}_{\mathrm{T}}$ are given below.

Average criterion:

$$
\frac{\bar{\sigma}_{\infty}}{\mathrm{UTS}}=2\left(1-\xi_{2}\right) /\left[2-\xi_{2}{ }^{2}-\xi_{2}{ }^{4}+\left(\mathrm{K}_{\mathrm{T}}-3\right)\left(\xi_{2}{ }^{6}-\xi_{2}{ }^{8}\right)\right]
$$

where

$$
\xi_{2}=\mathrm{R} /\left(\mathrm{R}+\mathrm{a}_{0}\right)
$$

Nonlinear curve fitting was used to determine the best fits of Eqs. (13.4) and (13.7) to the three data sets in Table 13.1. The results are shown in Figs. 13.7-13.9 for the quasi-isotropic,

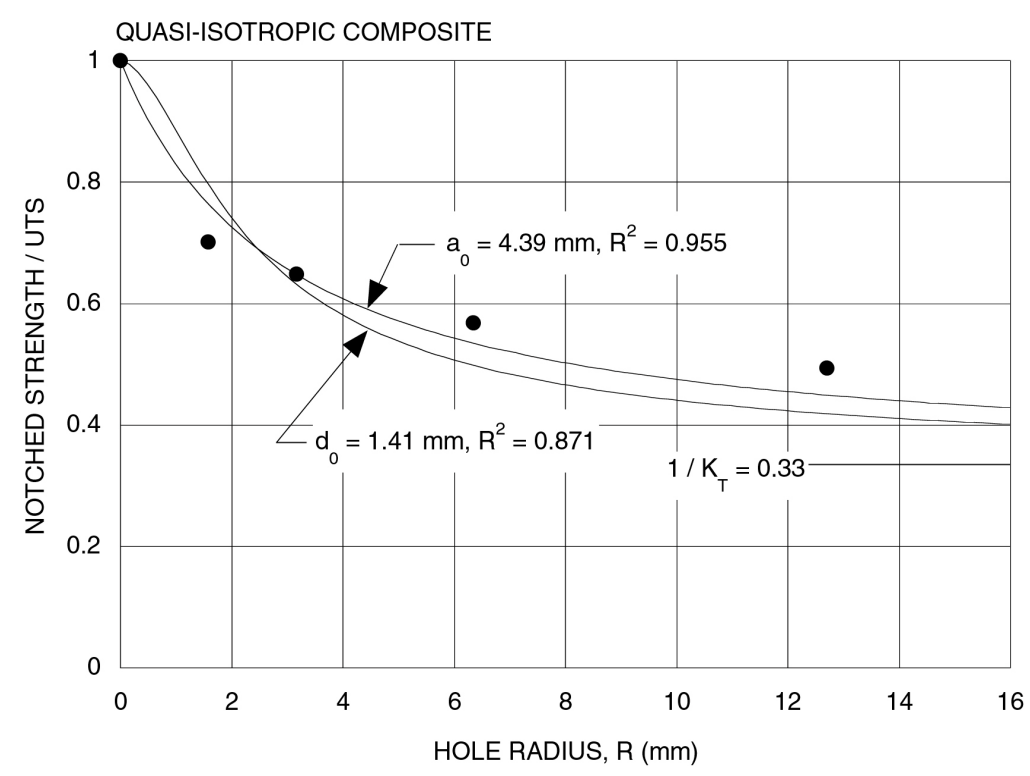

Fig. 13.7. Notched strength to UTS ratio vs hole radius for quasi-isotropic composite. Average experimental data are compared to Whitney-Nuismer point stress $\left(\mathrm{d}_{0}\right)$ and average stress $\left(\mathrm{a}_{0}\right)$ criteria (nonlinear curve fits to data). 


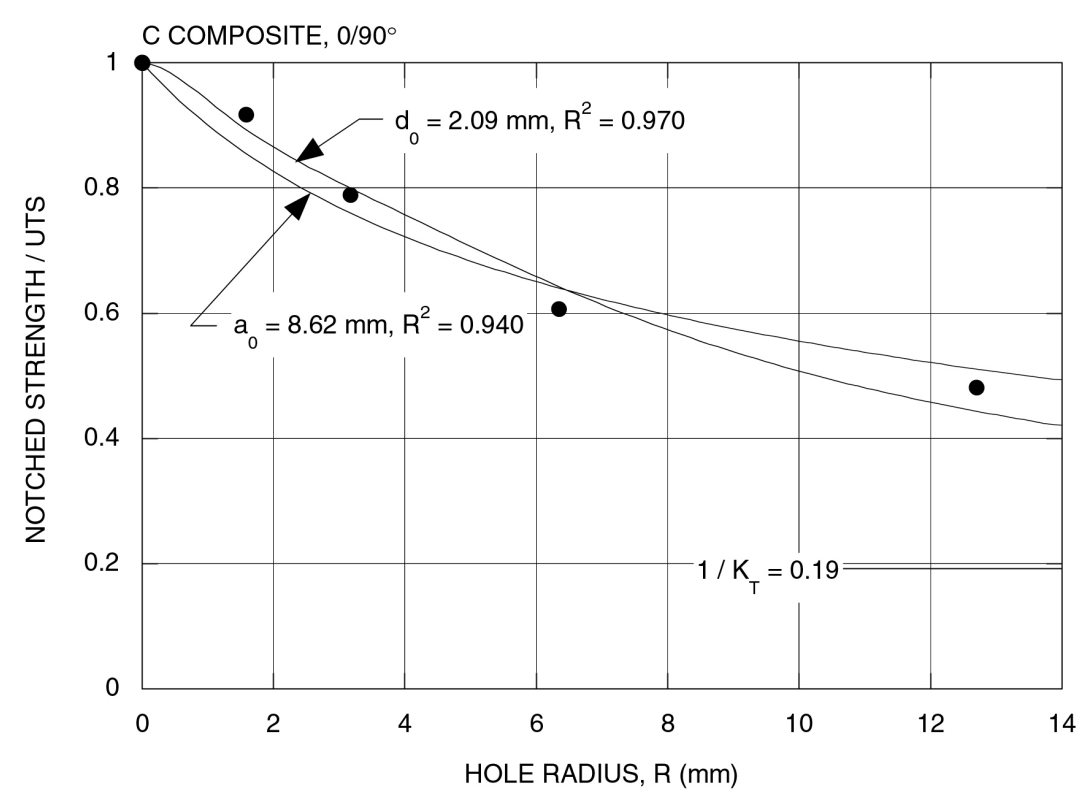

Fig. 13.8. Notched strength to UTS ratio vs hole radius for $0 / 90^{\circ}$ crossply composite. Average experimental data are compared to Whitney-Nuismer point stress $\left(\mathrm{d}_{0}\right)$ and average stress $\left(\mathrm{a}_{0}\right)$ criteria (nonlinear curve fits to data).

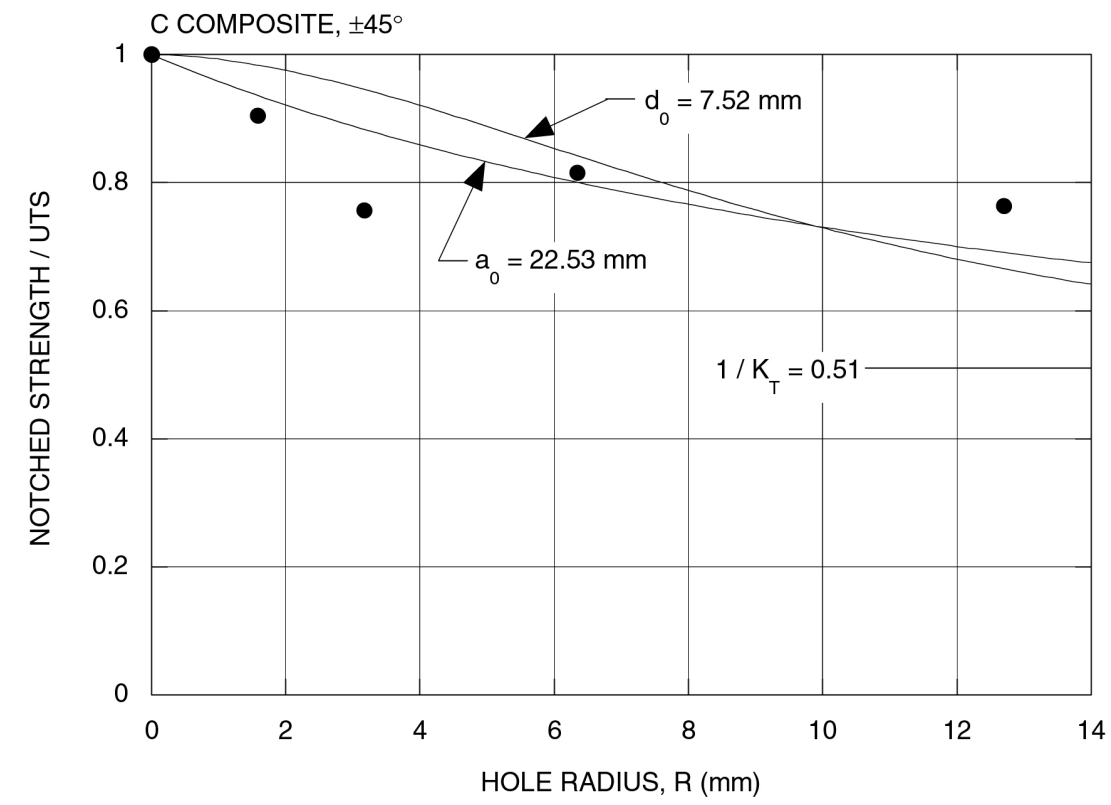

Fig 13.9. Notched strength to UTS ratio vs hole radius for $\pm 45^{\circ}$ crossply composite. Average experimental data are compared to Whitney-Nuismer point stress $\left(\mathrm{d}_{0}\right)$ and average stress $\left(\mathrm{a}_{0}\right)$ criteria (nonlinear curve fit to data). Coefficients of determination, $\mathrm{r}^{2}$, values could not be calculated for this data set. 
$0 / 90^{\circ}$ crossply and $\pm 45^{\circ}$ crossply composite specimens, respectively. Both criteria represent the data fairly well, except perhaps for the $\pm 45^{\circ}$ crossply case. There, failure occurred well beyond the elastic range, invalidating the various relations and also resulting in an interaction between the holes and specimen edges as cracking progressed toward ultimate failure.

Judging from the coefficients of determination, $\mathrm{r}^{2}$, the average criterion does a better job for the quasi-isotropic composite. For the $0 / 90^{\circ}$ crossply composite, the point criterion was somewhat better.

\subsection{DISCUSSION}

It has been shown that for fiber-dominated cases, both a power-law relation and the Whitney-Nuismer criteria correlate reasonably well with failure data from tensile tests of specimens containing circular holes of various sizes. Any of the correlations could be used for purposes of design. Based on data from a number of investigations, these same correlations can probably be used to approximate the effects of defects having shapes differing from circular holes.

However, the results presented in this chapter apply only to uniaxial tension stress states. Special compressive tests of 76.2-mm-wide (3-in.) specimens with circular holes were performed on the quasi-isotropic composite. ${ }^{*}$ These tests are presented in the next chapter, Sect. 14.3.4, where the results are compared with the results of similar tests on impact-damaged specimens and with the quasi-isotropic tensile results reported in this chapter. Although the compressive strength of specimens without holes was only $88 \%$ of the corresponding tensile strength, once holes were introduced, the tensile and compressive strengths were comparable.

\footnotetext{
*A compression-after-impact specimen design with special antibuckling plates was used.
} 
13-12 


\title{
14. DAMAGE TOLERANCE
}

\author{
J. M. Corum, R. L. Battiste, and M. B. Ruggles-Wrenn
}

\subsection{INTRODUCTION}

The damage tolerance assessment procedures in Chap. 5 of Part 1 consist of two parts: (1) demonstrating structural adequacy in the presence of a 6.4-mm-diam hole in the worst possible location and (2) determining the damage area and strength degradation for specified lowenergy impacts such as kickups of roadway debris, tool drops, and load drops in a pickup truck box. This chapter provides the background data and correlations for these procedures.

Baseline impact damage area correlations were based on the results of tests in a pendulum impact facility and an air-gun facility, representing events such as tool drops and kickups of roadway debris, respectively. Specimens were the same in both cases-nominally 2.2-mm-thick by 229 -mm-square plates. The facilities are the same as used previously for random-glass-fiber composites and the crossply carbon-fiber composite. They are described in Ref. 7. The specimens were clamped on 203-mm-diam circles and impacted at the center. A 12.7-mm-diam hemispherical impactor point was used in both facilities.

In addition to baseline tests, tests were performed to assess the effects of impacts at a low temperature $\left(-40^{\circ} \mathrm{C}\right)$. Also, brick-drop tests were performed to determine the ability of the baseline correlations to cover that event. Finally, each impact specimen was cut into either conventional compressive specimens or special CAI specimens that were tested to determine property degradation as a function of damage area. Hole specimens having the special CAI configuration were also tested, and the results were compared to those of impacted specimens. These tests and the results are presented in the following sections.

\subsection{IMPACT TESTS}

\subsubsection{Baseline Results}

Table 14.1 lists all of the impact tests performed on the quasi-isotropic carbon-fiber composite. The table lists the velocity of the impactor just prior to impact, the calculated kinetic energy of the impactor, and the measured impact damage area. In the pendulum case, the maximum force reached during the impact, as measured by a miniature load cell mounted behind the impactor point, is also listed. Finally, the "property tests" column indicates the type of mechanical property test specimens cut from each impacted plate specimen. While special CAI specimens were cut from most of the impacted plates, ordinary compression test specimens were cut from some.

The pendulum impactor mass was $11.52 \mathrm{~kg}$ with a 12.7 -mm-diam hemispherical hardenedsteel impactor point. The air-gun projectile was a $12.7-\mathrm{mm}$-diam hardened-steel cylinder with a hemispherical point. The projectile mass was $0.0224 \mathrm{~kg}$.

Damage areas were determined from ultrasonic C-scans of the impacted plate specimens. The damage areas generally extended further in the direction of the surface fibers, and four of the air-gun specimens exhibited fairly long narrow delaminations running along the surface ply fibers on their back side. This tendency to delaminate was not as pronounced as in the crossply carbonfiber composite; none of the pendulum specimens exhibited this tendency. 
Table 14.1. List of impact tests

\begin{tabular}{|c|c|c|c|c|c|}
\hline $\begin{array}{c}\text { Specimen } \\
\text { No. }\end{array}$ & Property tests & $\begin{array}{c}\text { Velocity } \\
(\mathrm{m} / \mathrm{s})\end{array}$ & $\begin{array}{c}\text { Energy } \\
\text { (J) }\end{array}$ & $\underset{\text { force }(N)}{\operatorname{Maximum}}$ & $\begin{array}{l}\text { Damage area } \\
\quad\left(\mathrm{mm}^{2}\right)\end{array}$ \\
\hline \multicolumn{6}{|c|}{ Pendulum baseline (12.7-mm diam, 11.52 kg) } \\
\hline Q21-1 & $\mathrm{CAI}^{a}$ & 0.72 & 2.96 & 1485 & 56 \\
\hline Q21-4 & Compression & 0.69 & 2.74 & 1485 & 28 \\
\hline Q22-1 & CAI & 1.02 & 6.01 & 1716 & 163 \\
\hline Q22-4 & Compression & 0.98 & 5.49 & 1840 & 354 \\
\hline Q23-1 & CAI & 1.20 & 8.34 & 2170 & 331 \\
\hline Q23-4 & Compression & 1.16 & 7.76 & 2096 & 370 \\
\hline Q24-1 & CAI & 1.39 & 11.17 & 2063 & 752 \\
\hline Q24-4 & CAI & 1.43 & 11.82 & 1956 & 937 \\
\hline Q25-1 & CAI & 0.87 & 4.39 & 1799 & 152 \\
\hline Q25-4 & Compression & 0.87 & 4.39 & 1766 & 163 \\
\hline Q26-1 & Compression & 1.10 & 6.97 & 1807 & 286 \\
\hline Q26-4 & CAI & 1.13 & 7.40 & 1857 & 309 \\
\hline \multicolumn{6}{|c|}{ Pendulum, $-40^{\circ} \mathrm{C}(12.7-\mathrm{mm}$ diam, $11.52 \mathrm{~kg})$} \\
\hline Q27-1 & Compression & 0.99 & 5.66 & 1791 & 258 \\
\hline Q27-4 & CAI & 0.98 & 5.50 & 1857 & 281 \\
\hline \multicolumn{6}{|c|}{ Air gun baseline (12.7-mm diam, $0.02244 \mathrm{~kg})$} \\
\hline Q21-2 & CAI & 38.14 & 16.32 & & 825 \\
\hline Q21-3 & CAI & 36.11 & 14.63 & & 703 \\
\hline Q22-2 & CAI & 39.94 & 17.90 & & 1123 \\
\hline Q22-3 & CAI & 40.66 & 18.55 & & 1095 \\
\hline Q23-2 & CAI & 33.20 & 12.37 & & 376 \\
\hline Q23-3 & Compression & 33.54 & 12.62 & & 331 \\
\hline Q24-2 & Compression & 27.02 & 8.19 & & 179 \\
\hline Q24-3 & CAI & 26.53 & 7.90 & & 239 \\
\hline Q25-2 & CAI & 19.66 & 4.33 & & 23 \\
\hline Q25-3 & Compression & 18.88 & 4.00 & & 17 \\
\hline Q26-2 & CAI & 35.68 & 14.28 & & 545 \\
\hline Q26-3 & CAI & 35.91 & 14.47 & & 522 \\
\hline \multicolumn{6}{|c|}{ Air gun, $-40^{\circ} \mathrm{C}(12.7-\mathrm{mm}$ diam, $0.02244 \mathrm{~kg})$} \\
\hline Q27-2 & CAI & 33.22 & 12.38 & & 505 \\
\hline Q27-3 & Compression & 33.25 & 12.40 & & 370 \\
\hline \multicolumn{6}{|c|}{ Brick drop } \\
\hline Q28-1 & CAI & 3.46 & 10.37 & & 281 \\
\hline Q28-2 & & 3.46 & 10.37 & & 168 \\
\hline Q28-3 & CAI & 4.89 & 20.74 & & 1470 \\
\hline Q28-4 & CAI & 3.87 & 12.95 & & 443 \\
\hline
\end{tabular}

$a_{\text {Special compression-after-impact. }}$ 
Figure 14.1 depicts the back side of a typical specimen impacted by the pendulum. No extensive delaminations are present. Figure 14.2 is the corresponding C-scan image of the specimen. Figure 14.3 shows one of the air-gun specimens that did exhibit a surface-ply failure and delamination.

The corresponding C-scan image is shown in Fig. 14.4, with the delamination extending to the right. More significant delaminations showed up as white in the $\mathrm{C}$-scan images, and they were included in the areas recorded in Table 14.1. Some of the smaller damage areas tabulated in Table 14.1 were clearly indicated in the $\mathrm{C}$-scan images but were not visible on the specimens.

There are 12 baseline pendulum tests and 12 baseline air-gun tests tabulated in Table 14.1. The corresponding results are plotted in Fig. 14.5, where damage area vs impactor kinetic energy is shown. Also shown, for comparison, are the results of the baseline impact tests on the crossply carbon-fiber composite ${ }^{4}$ and on the P4 chopped-glass fiber composite. ${ }^{3}$ Recall that the crossply carbon-fiber composite and the chopped-glass-fiber composite were nominally the same thickness $-3.2 \mathrm{~mm}$. The difference in damage in the two cases was attributed to delaminations in the crossply composite and, more importantly, to the increased stiffness of the crossply composite, which resulted in higher impact forces (see Fig. 14.6). The higher damage levels and lower impact force values in the quasi-isotropic composite case result from the fact that it was thinner-2.2 $\mathrm{mm}$ compared to $3.2 \mathrm{~mm}$.

As was the case for the crossply composite, a single correlation does not describe both the pendulum and air-gun data, which indicates that kinetic energy is not an adequate correlating parameter. An improved correlating parameter is used in Fig. 14.7, where damage area is expressed as a power-law function of the parameter mass ${ }^{0.535} \times$ velocity. $^{*}$ The solid curve represents all of the data, while the dashed and dotted curves represent the pendulum and air-gun data alone, respectively. The fact that all three curves are close attests to the suitability of the correlating parameter chosen.

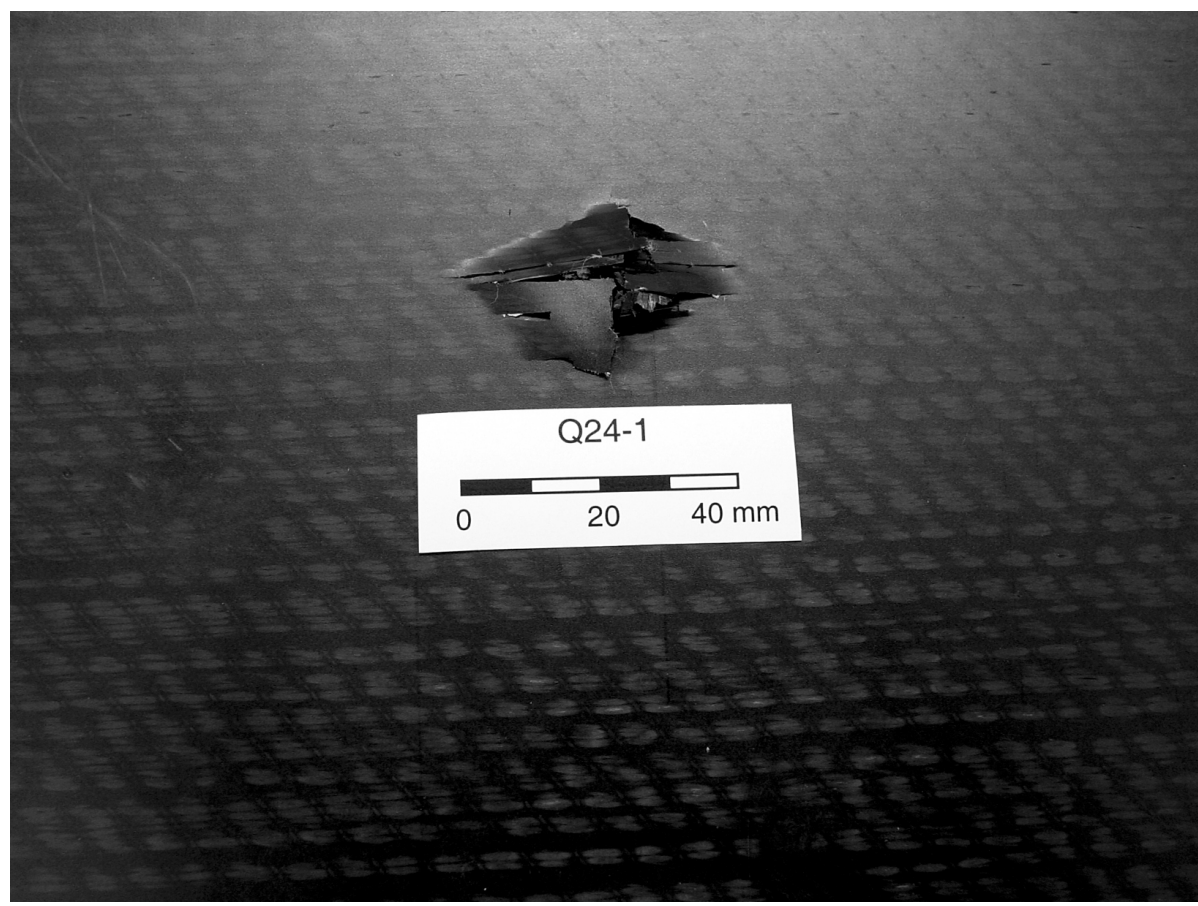

Fig. 14.1. Photograph of back of specimen Q24-1, impacted by pendulum.

\footnotetext{
*While the power law represents the data over the range shown, it is likely invalid below some threshold, where no damage occurs, and above some energy level where damage is probably limited.
} 


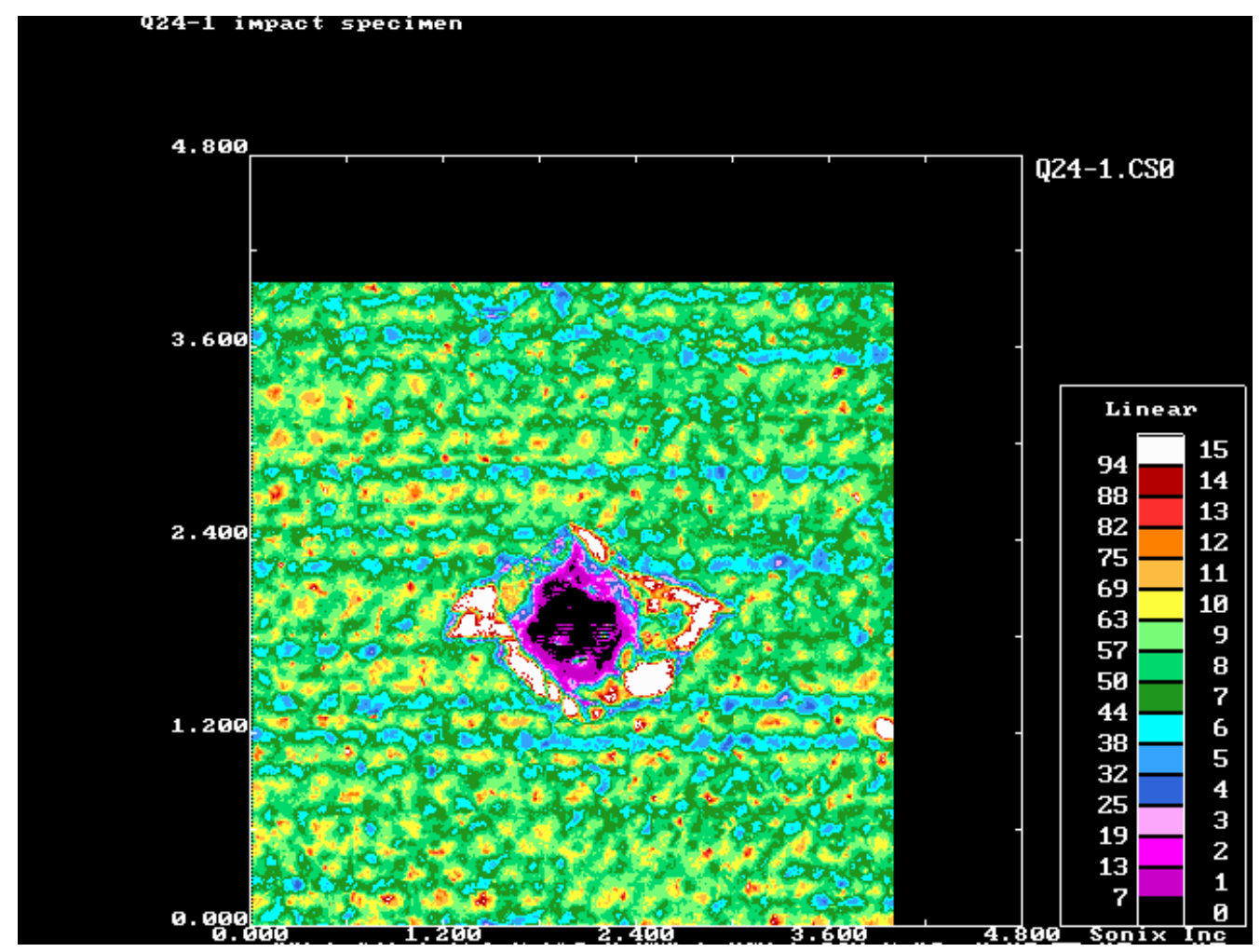

Fig. 14.2. C-scan of impact specimen Q24-1. Image is flipped horizontally from that in Fig. 14.1.

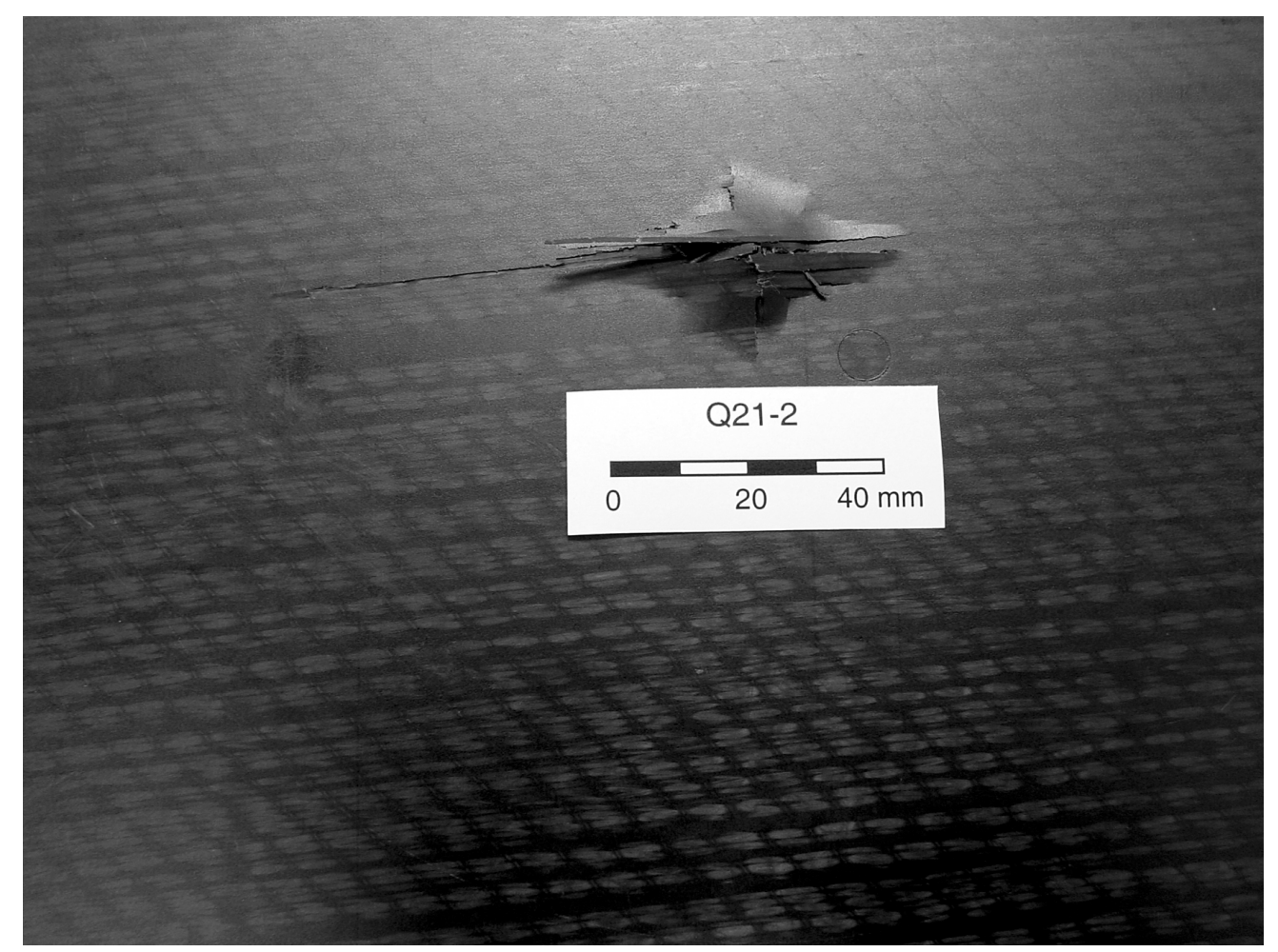

Fig. 14.3. Photograph of back of specimen Q21-2, impacted by air-gun projectile. 


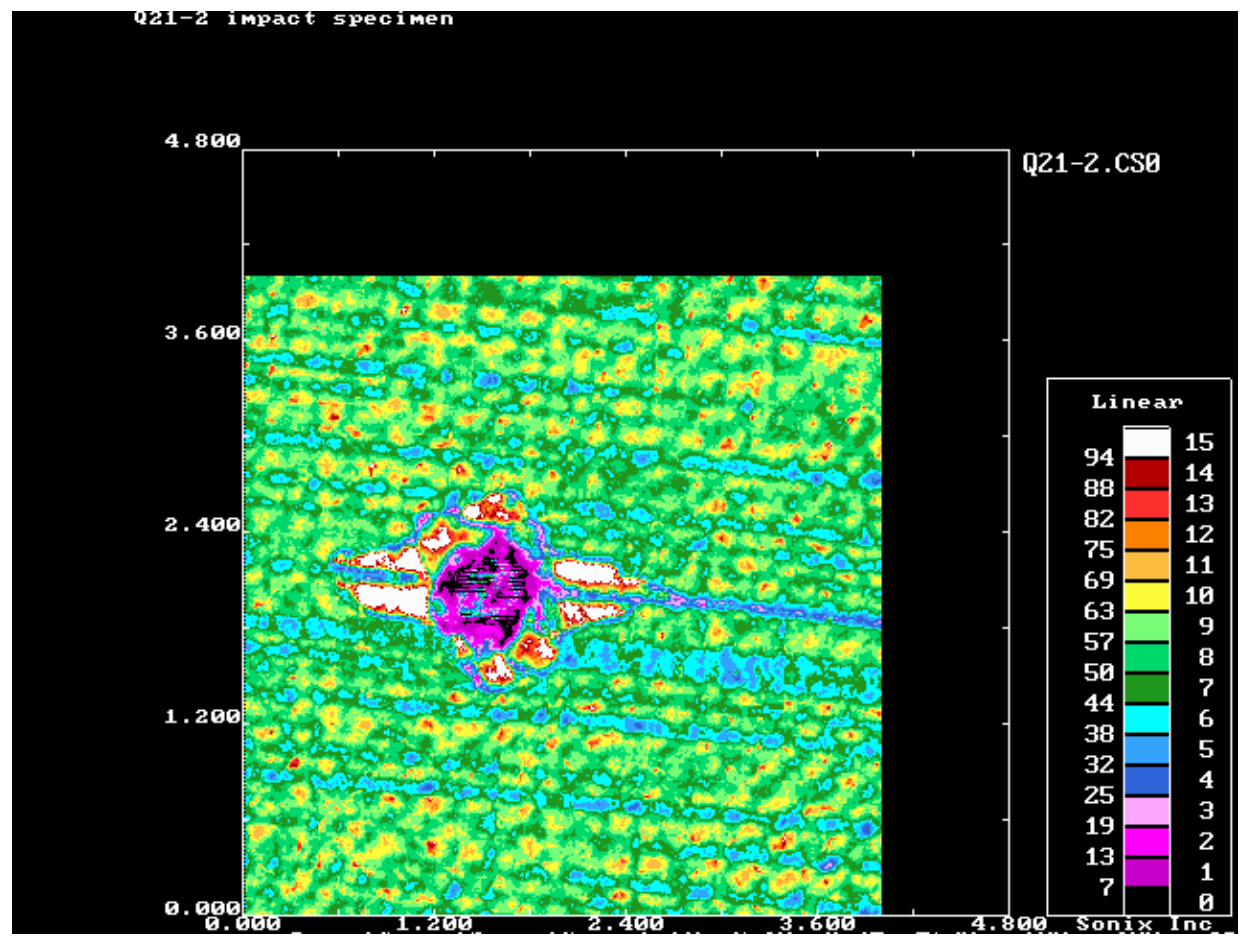

Fig. 14.4. C-scan of impact specimen Q21-2. Image is flipped horizontally from that in Fig. 14.3.

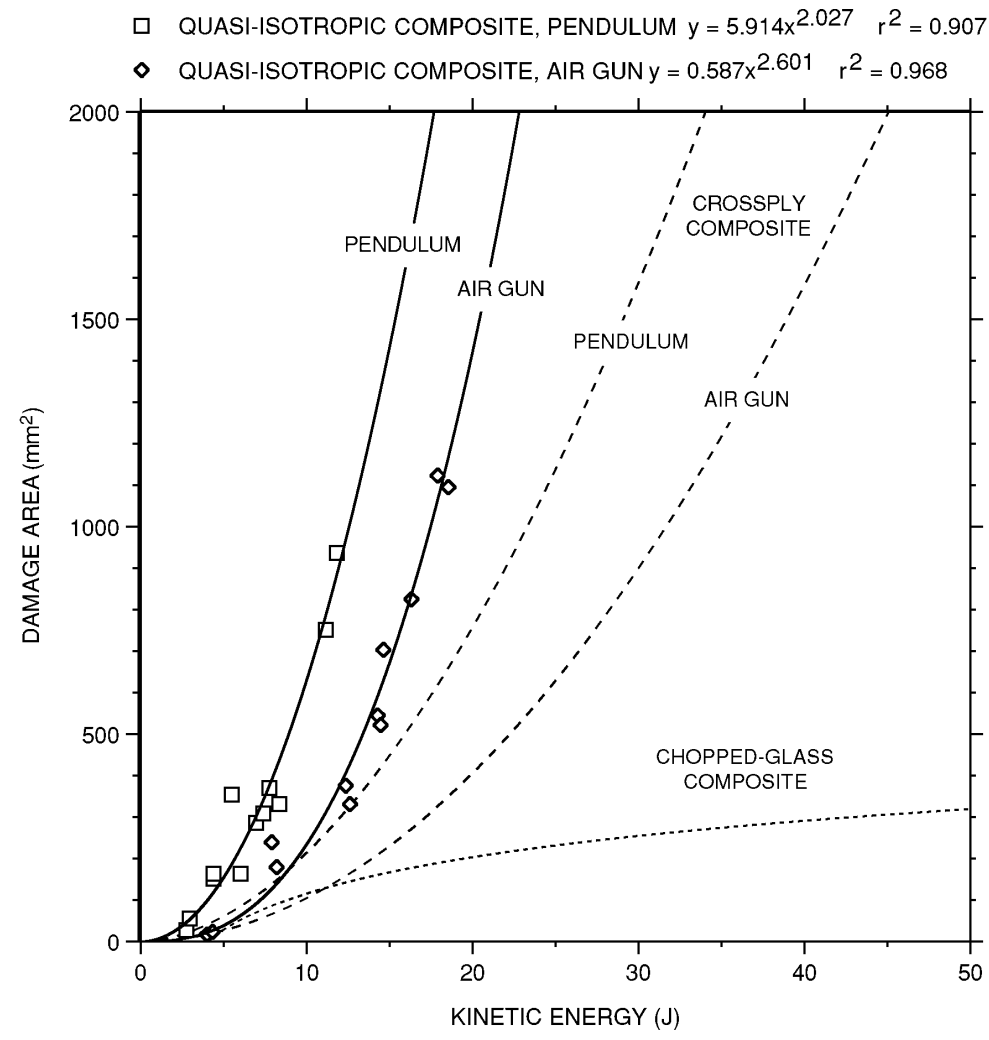

Fig. 14.5. Baseline impact damage areas vs kinetic energy. Crossply carbon-fiber composite correlations (long dashes) and chopped-glass-fiber composite correlations (short dashes) are shown for comparison. 


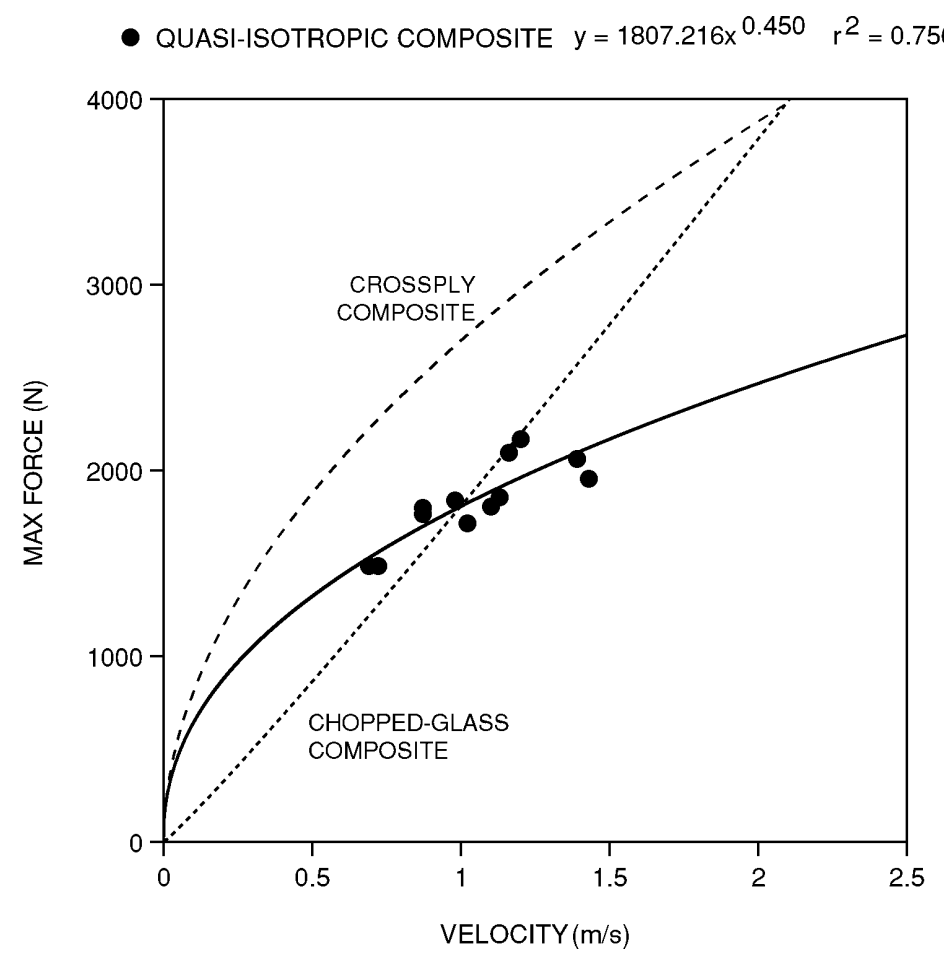

Fig. 14.6. Comparison of peak impact forces measured in pendulum tests of quasi-isotropic carbon-fiber composite and those of crossply carbon-fiber composite and glass-fiber composite.

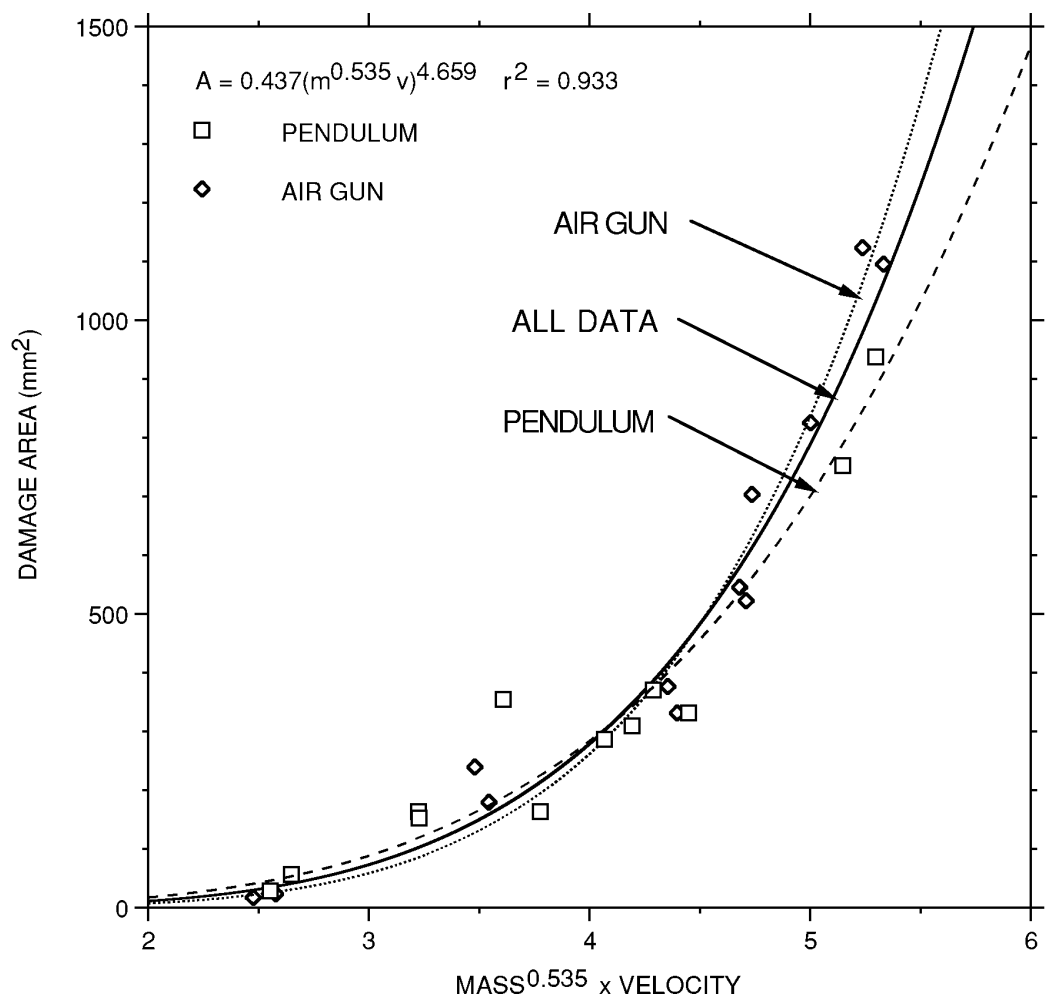

Fig. 14.7. Baseline impact damage areas vs mass $0.535 \times \mathrm{v}($ mass in $\mathrm{kg}$ and velocity in $\mathrm{m} / \mathrm{s})$. The solid curve and equation represent all of the data, the dashed curve represents the pendulum data alone, and the dotted curve represents the air-gun data alone. 


\subsubsection{Effects of Low Temperature}

Four tests - two pendulum and two air gun - were performed on specimens at a temperature of $-40^{\circ} \mathrm{C}$ to determine if the damage results were affected by the low temperature. Recall from Chap. 7 that for this material the tensile strength at $-40^{\circ} \mathrm{C}$ is less than at room temperature. The results of these four tests were included in Table 14.1.

The resulting damage areas are depicted in Fig. 14.8 relative to the baseline results at room temperature. Consistent with the lower tensile strength at $-40^{\circ} \mathrm{C}$, three of the four damage areas obtained at $-40^{\circ} \mathrm{C}$ do seem to be slightly greater than the room-temperature baseline correlation.

\subsubsection{Brick-Drop Tests}

The test results presented in the previous sections were all for smooth hemispherical steel impactor points. Brick drops, which are one of the loadings specified for composite pickup boxes, provide an opportunity to determine if the results can be used to predict damage areas due to impacts from more irregular objects.

Four brick-drop tests were performed, as tabulated in Table 14.1. The bricks had an average mass of $1.73 \mathrm{~kg}$, and they were dropped from heights of $0.61 \mathrm{~m}$ (first two in Table 14.1), $1.22 \mathrm{~m}$, and $0.76 \mathrm{~m}(2,4$, and $2.5 \mathrm{ft})$. The new bricks were dropped so that they hit on a sharp corner, with the center of gravity in line with the impact point. The same clamped specimen configuration was used as in the pendulum and air-gun impacts.

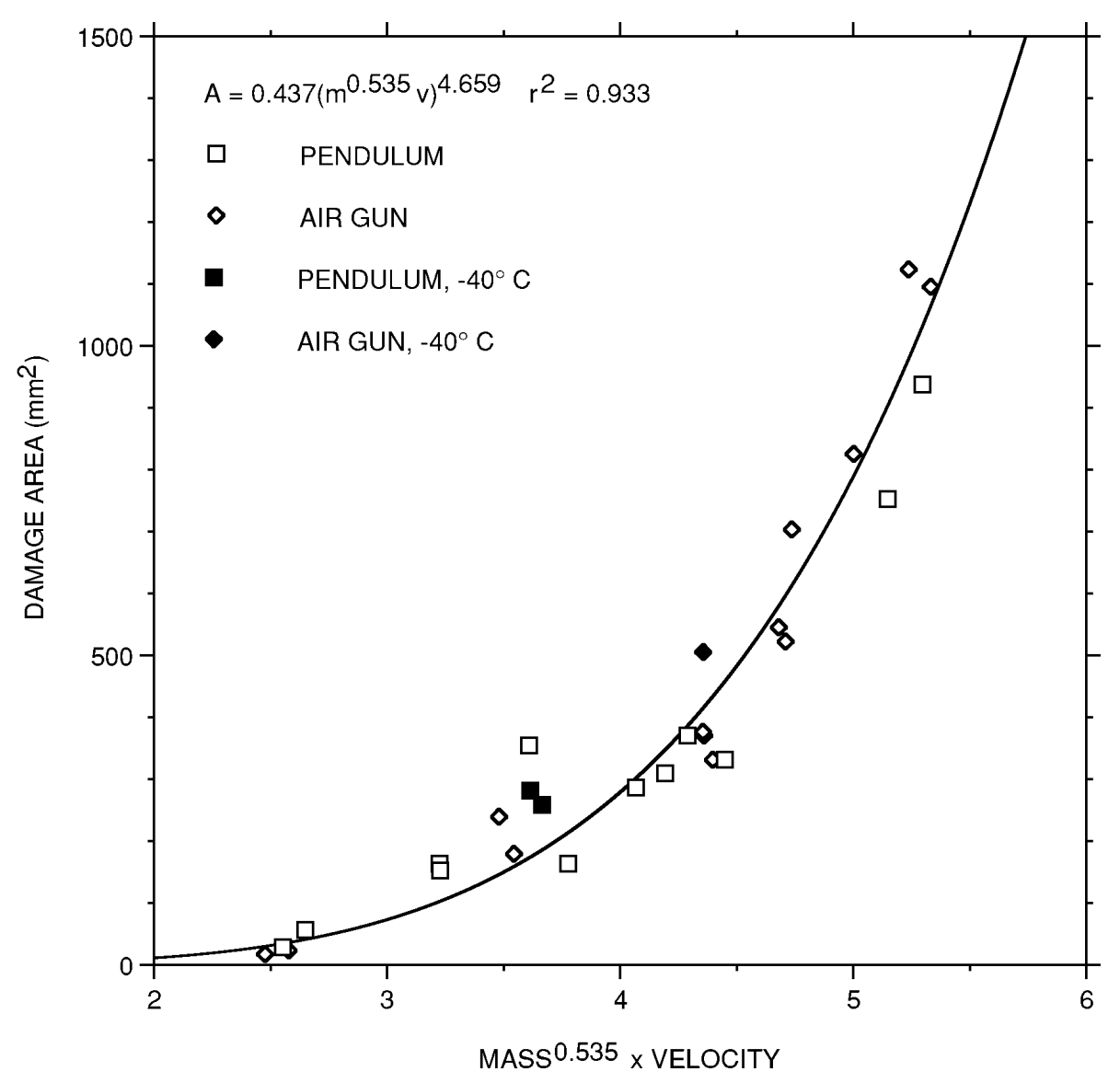

Fig. 14.8. Effect of test temperature of $-40^{\circ} \mathrm{C}$ on impact damage. 
The C-scans of the brick-drop specimens looked very similar to those from the pendulum and air gun. There were no indications of long delaminations. Figure 14.9 compares damage areas produced by the brick drops with the baseline correlation and data from the pendulum and air-gun tests. The four brick data points are well below the baseline data and correlation, which indicates that the correlation can be conservatively applied to bricks and presumably to other irregularly shaped objects as well.

\subsection{DEGRADATION OF STRENGTH PROPERTIES}

\subsubsection{Introduction}

As was indicated in Table 14.1, every impact specimen, except one, was subsequently cut into mechanical property test specimens for determining strength degradation. Contrary to what was done for earlier composites, where both tension and compression strengths were evaluated, the decision was made to focus on compressive strength degradation. For this purpose, a special CAI test was adopted. ${ }^{35}$ This test, along with the strength degradation results obtained, is described in Sect. 14.3.2.

To provide a tie with the results from the earlier composites evaluated (i.e., crossply carbonfiber, ${ }^{4}$ chopped-glass-fiber, ${ }^{3}$ and continuous-strand-mat glass-fiber ${ }^{2}$ ), conventional compressive specimens were also cut from some of the impacted plate specimens and tested. These results are presented in Sect. 14.3.3, where they are compared with the CAI results.

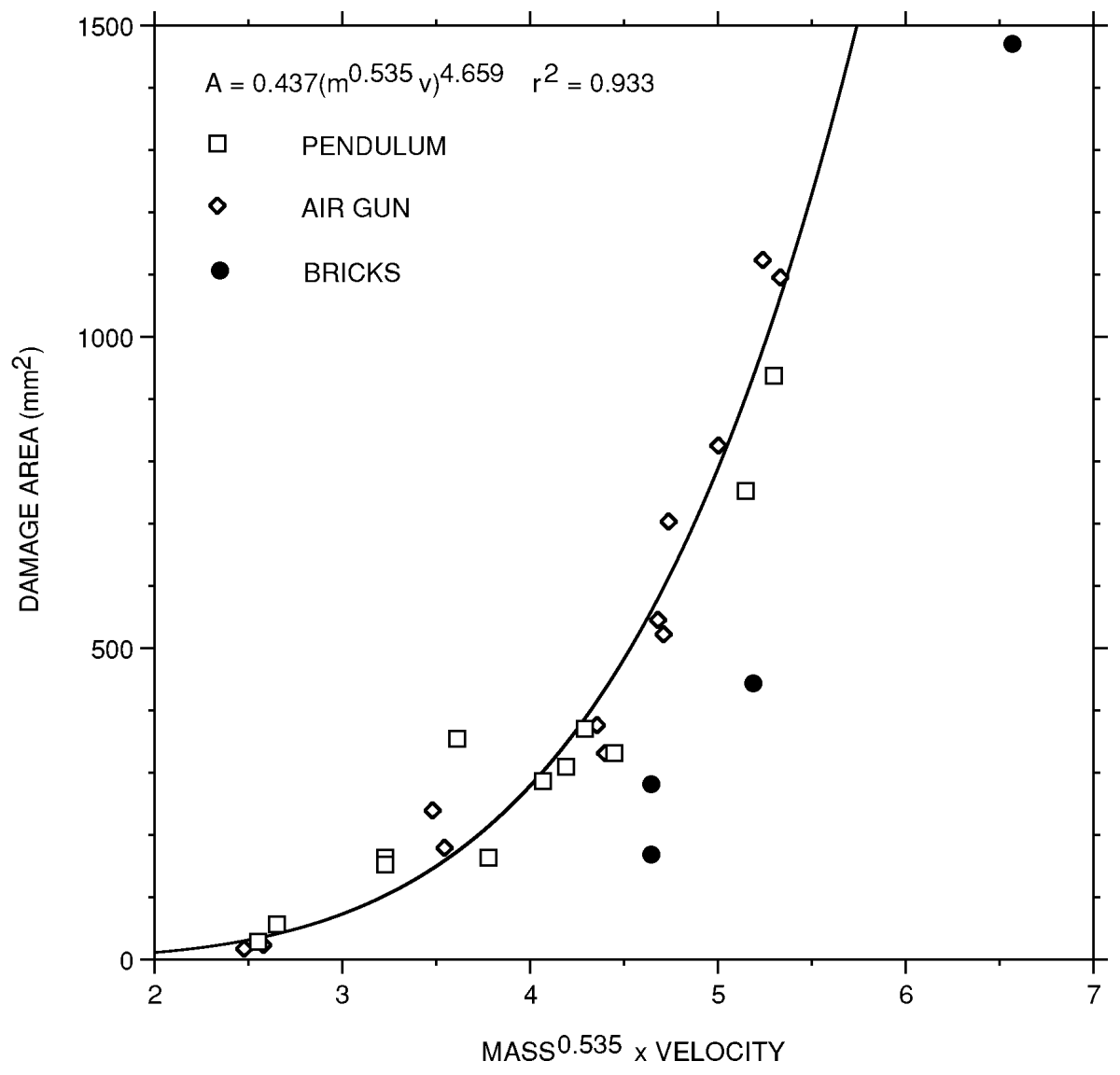

Fig. 14.9. Impact damage data for specimens subjected to brick drops compared to baseline correlations. 
A comparison is presented in Sect. 14.3.4 between the effect of impact damage and that of circular holes. Circular holes were machined into several undamaged CAI specimens to provide data for this comparison. The compressive hole data are also compared with the tensile data that were presented in Chap. 13.

\subsubsection{Compression-After-Impact}

The search for a simple new CAI test was dictated by (1) a desire to have a wider test geometry where the width would not be dominated by damage and (2) the need to guard against specimen buckling as candidate carbon-fiber composites for automotive applications become increasingly thin. A test proposed by Sjöblom and Hwang ${ }^{35}$ at the University of Dayton was adapted to meet these needs.

The test arrangement used is depicted in Fig. 14.10. The CAI specimen is 76.2-mm wide by 177.8-mm long, with 38.1-mm-long tabs at each end. Antibuckling plates with a 38.1-mm-diam circular hole at the center are used to restrain the specimen against lateral deflections. Bolts holding the plates were secured just barely finger tight. Figure 14.11 shows a specimen mounted in the 50.8-mm-wide hydraulic wedge grips of a test machine.

The antibuckling plates appeared to work well. Failures of impact-damaged specimens occurred transversely through the damaged region. As explained in the following paragraph, baseline undamaged CAI-type specimens were also cut from the impacted plates and tested. Failure of these undamaged specimens was generally transverse and straight across. They often occurred at the center (see Fig. 14.12) but also occurred at other axial locations. In four cases, these undamaged specimens failed at the tab in a buckling mode. The early buckling failures were found to be due to excessive flexibility of the load train, which allowed a hinge to form. The load train, was subsequently stiffened, and this solved the problem. The buckling failures were not used in the final analysis.

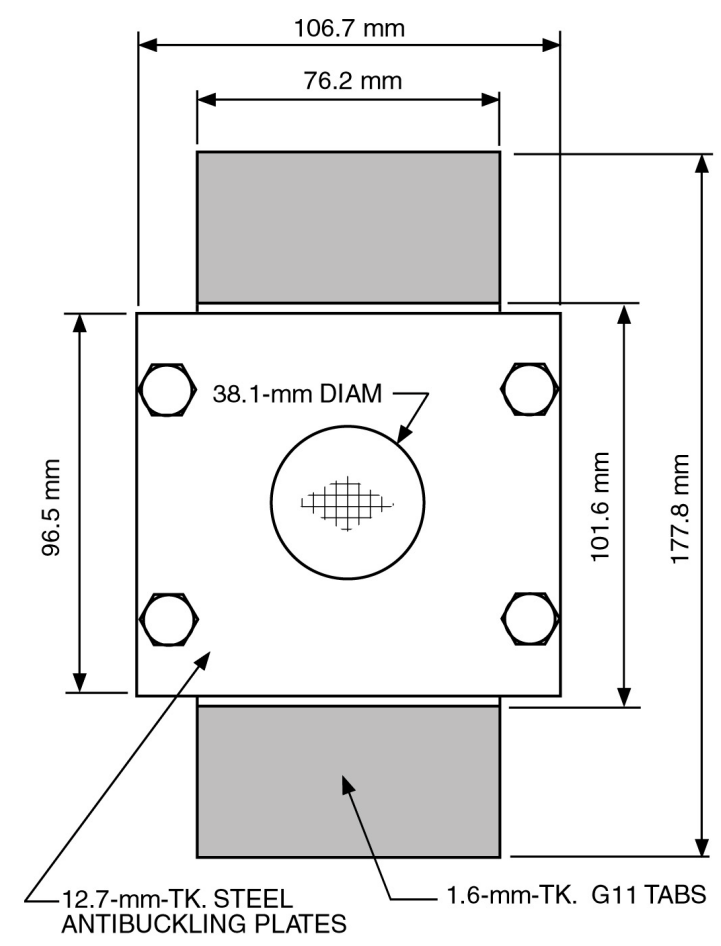

Fig. 14.10. CAI specimen and high-strength steel antibuckling face plates. 


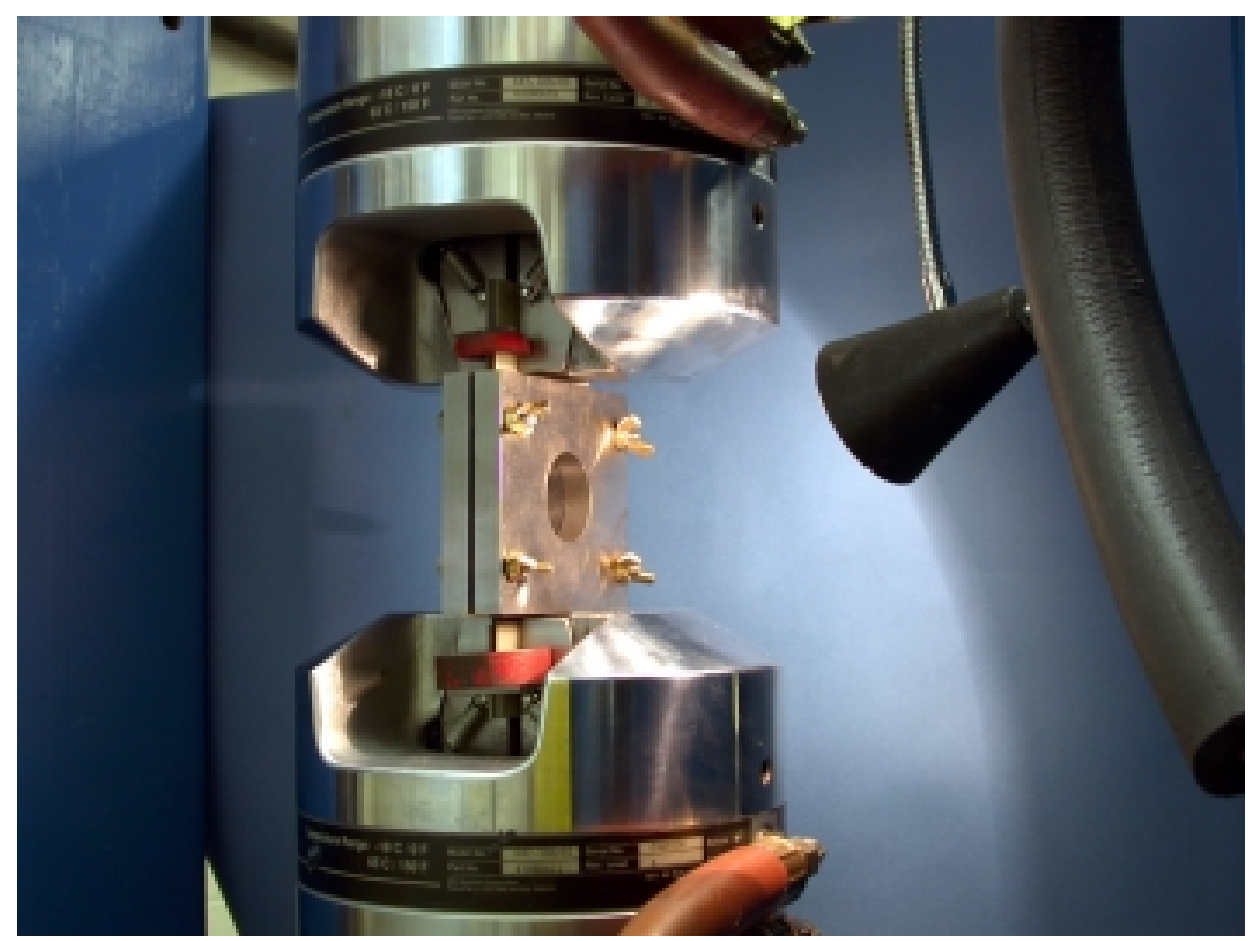

Fig. 14.11. CAI specimen with antibuckling face-support plates installed in hydraulic wedge grips of test machine.

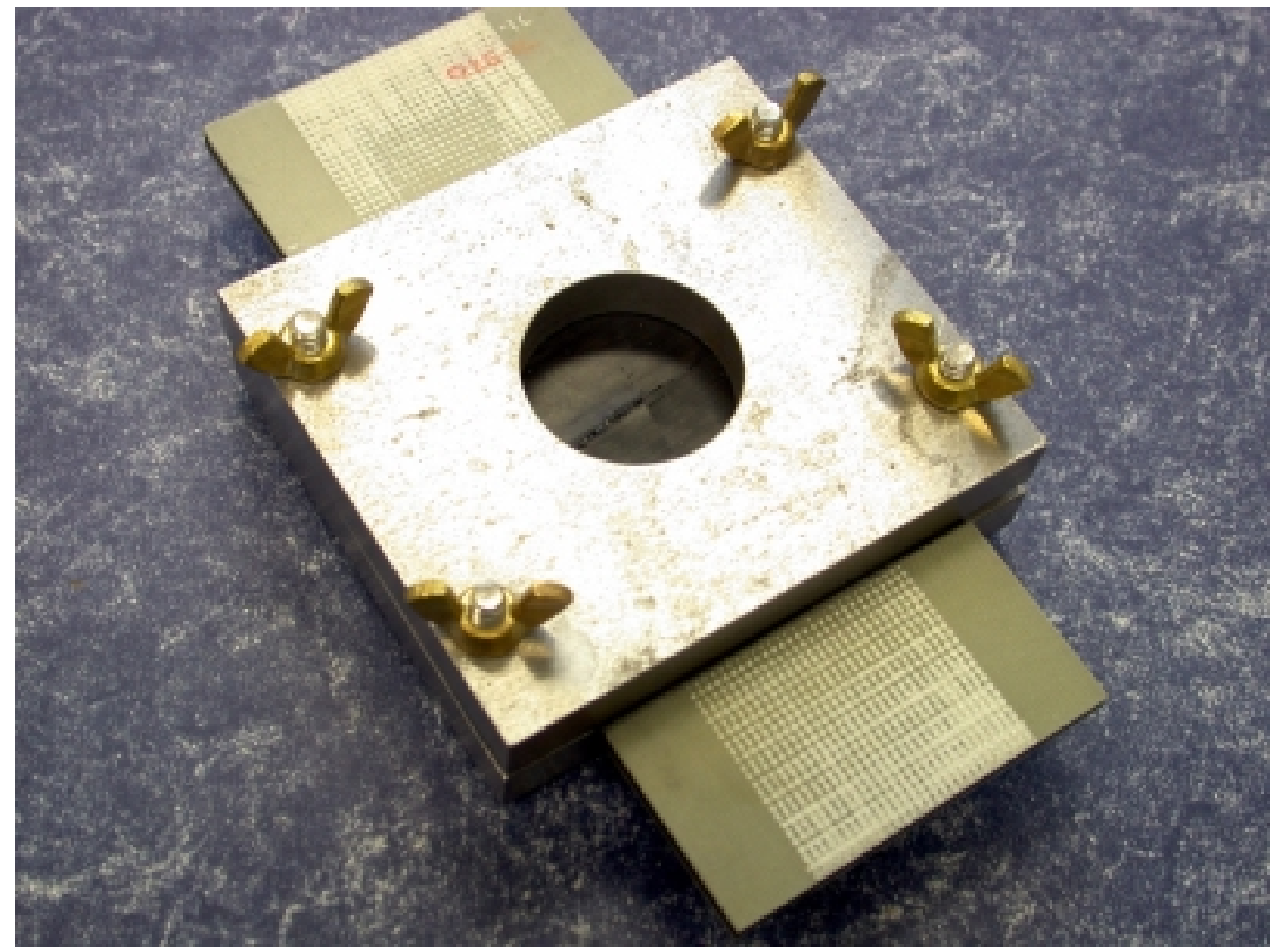

Fig. 14.12. Failed undamaged CAI specimen. 
Figure 14.13 shows the layout used for cutting CAI specimens from the 228.6- by 228.6-mm-square (9- by 9-in.) impacted plates. The center 76.2-mm-wide (3-in.) specimen was centered on the impact damage area. An undamaged baseline specimen was cut from the left side, and a specimen with a circular hole was cut from the right side. These latter two specimens were slightly less than 76.2-mm (3-in.) wide because of dimensional variations and the saw kerf. The specimens were oriented so that surface fibers were oriented transverse to the specimen axis.

The average CAI compressive strength of the undamaged baseline specimens was $312 \mathrm{MPa}$. This is substantially higher than the 225-MPa average conventional compressive strength of the quasi-isotropic composite, and it is almost as high as the $336-\mathrm{MPa}$ average tensile strength. The increased strength is attributed to the lateral constraining effects of the steel plates.

Figure 14.14 shows the ratio of the CAI strengths measured on center specimens that had impact damage to the average value of $312 \mathrm{MPa}$ for undamaged specimens plotted as a function of the damage area. The open points are from baseline pendulum and air-gun impact specimens. The power-law curve fit correlations were derived from these points only. Also shown in the figure are data points corresponding to impact specimens tested at $-40^{\circ} \mathrm{C}$ and those subjected to brick drops.

The correlations suggest that, for a given damage area, the pendulum specimens lost somewhat more strength than did the air-gun specimens. This seemed also to be the case for the retained $0 / 90^{\circ}$ strength (both tensile and compressive) for impacted specimens of the crossply carbon-fiber composite. ${ }^{4}$ The data points in Fig. 14.14 from specimens tested at $-40^{\circ} \mathrm{C}$ both lie above the correlation curves; two brick-drop data points lie above, and one lies below, the correlations. Overall, all of the data fall within a relatively small band.

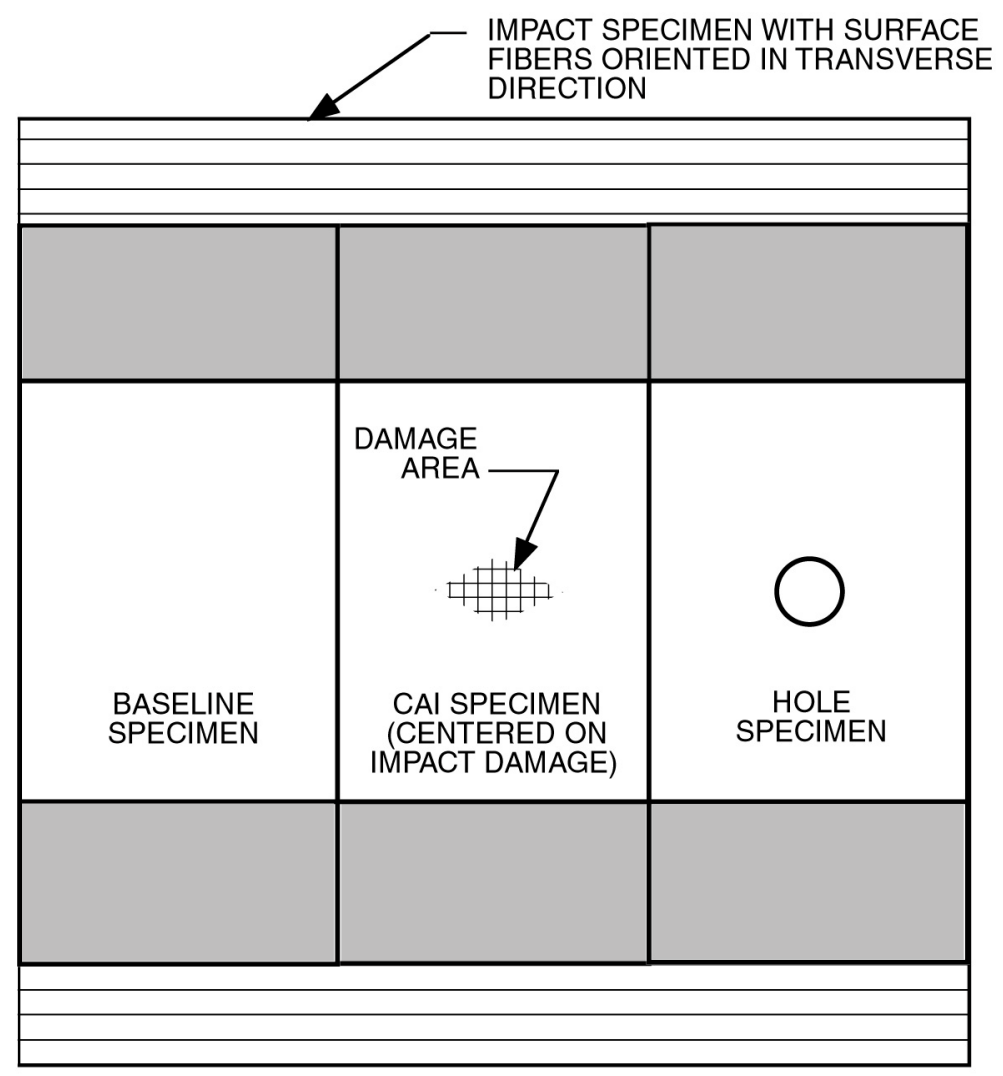

Fig. 14.13. Layout used for cutting CAI specimens from impacted plate specimens. 


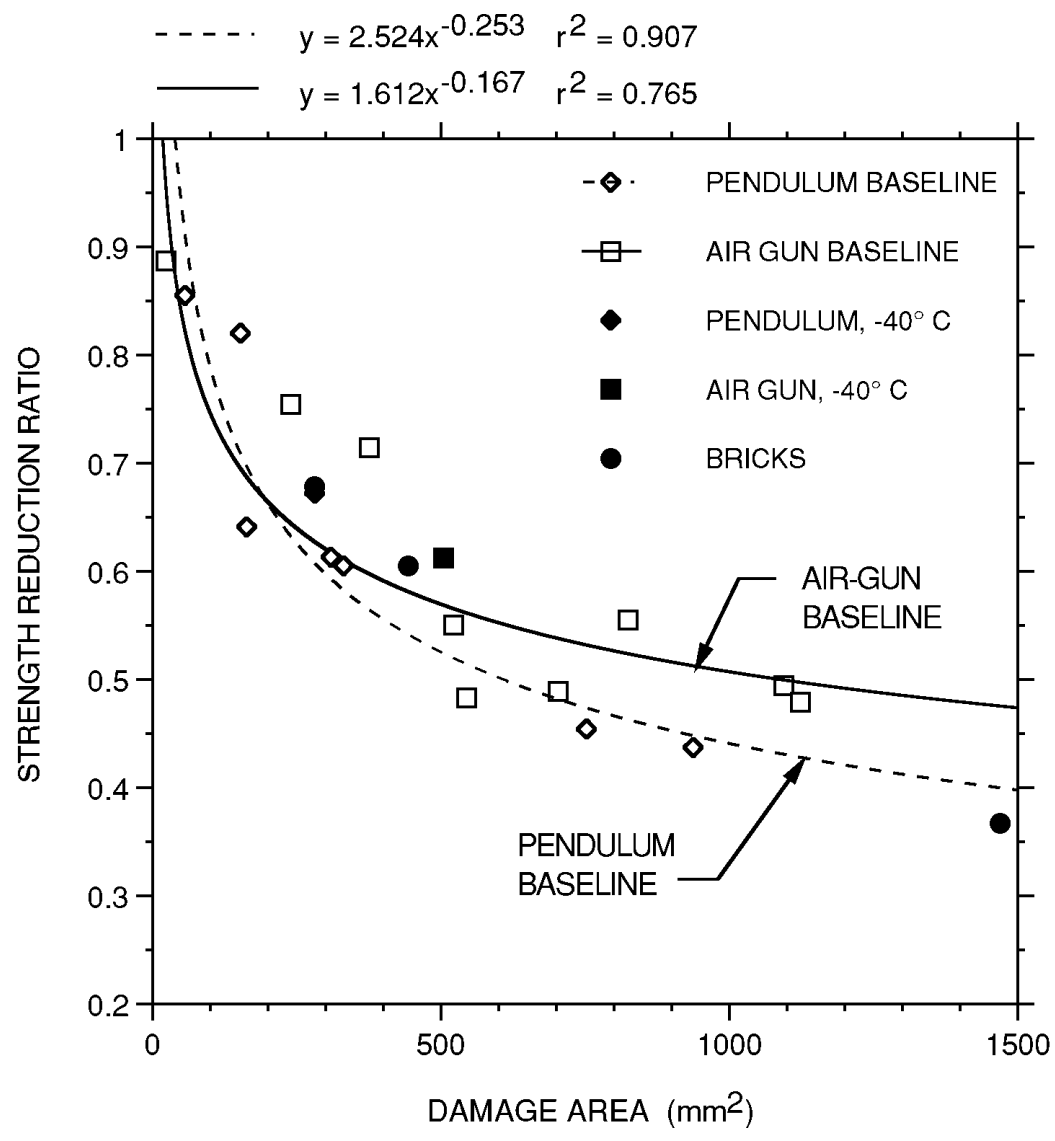

Fig. 14.14. Relative retained CAI strength vs damage area. Curve fits are for baseline data only.

\subsubsection{Comparison with Conventional Compressive Strength Reductions}

As shown in Table 14.1, ten impacted plate specimens were cut into conventional compressive test specimens. Conventional compressive tests were used in each of the previous three composites studied to determine impact-induced strength degradation, so, as previously stated, testing conventional specimens provides a tie to the earlier results and a means of transitioning to the CAI test.

Figure 14.15 shows the cutting plan used to obtain the conventional compressive specimens. All specimens were oriented so that surface fibers were transverse to the specimen axis. The average compressive strength from all of the undamaged baseline specimens was $218 \mathrm{MPa}$, which is just $70 \%$ of the CAI compressive strength.

The strengths of the damaged specimens were ratioed to the undamaged average, and the resulting ratios are compared in Fig. 14.16 with the curve fit correlations obtained from the CAI tests. While there is considerable scatter in the conventional compressive results, the baseline reduction ratios appear to be reasonably in line with the CAI ratios. Note that a pendulum result for $-40^{\circ} \mathrm{C}$, which was indicated in Table 14.1, is missing from Fig. 14.16. A valid result from that test was not obtained. The one result for $-40^{\circ} \mathrm{C}$ plotted in Fig. 14.16 is well below the other data. 


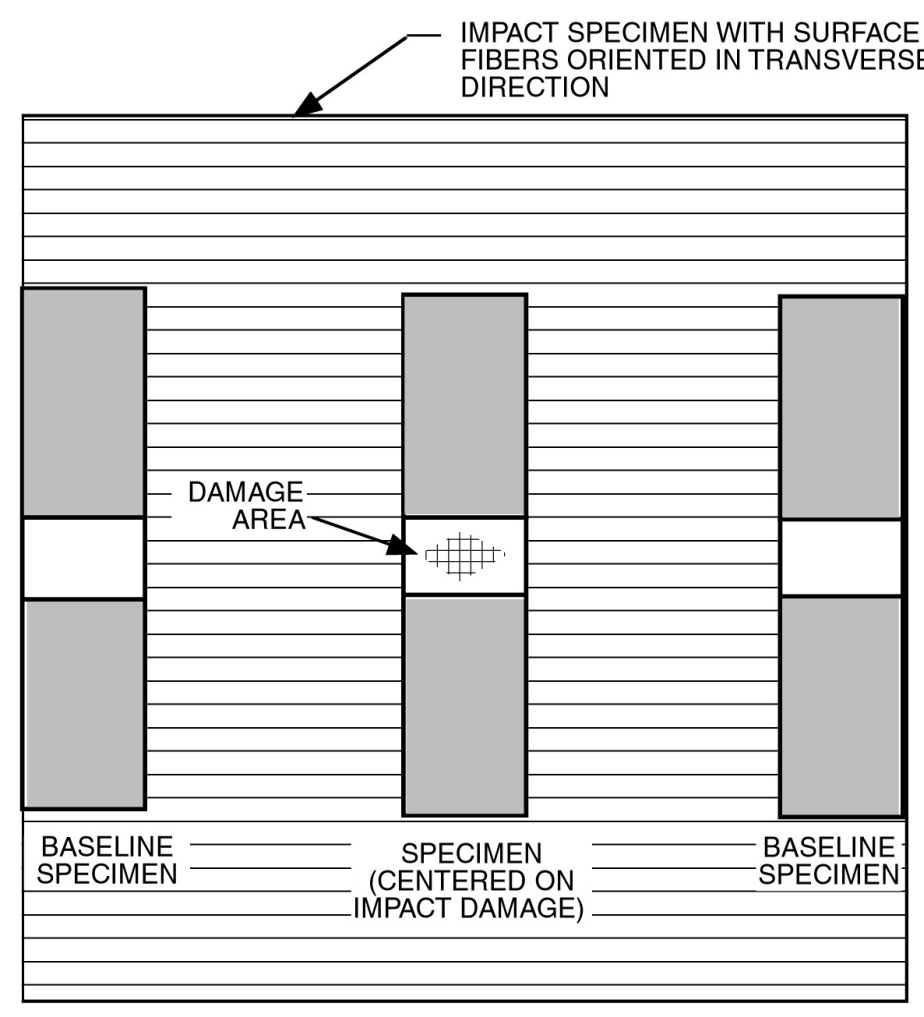

Fig. 14.15. Layout used for cutting regular compressive specimens from impacted plate specimens.

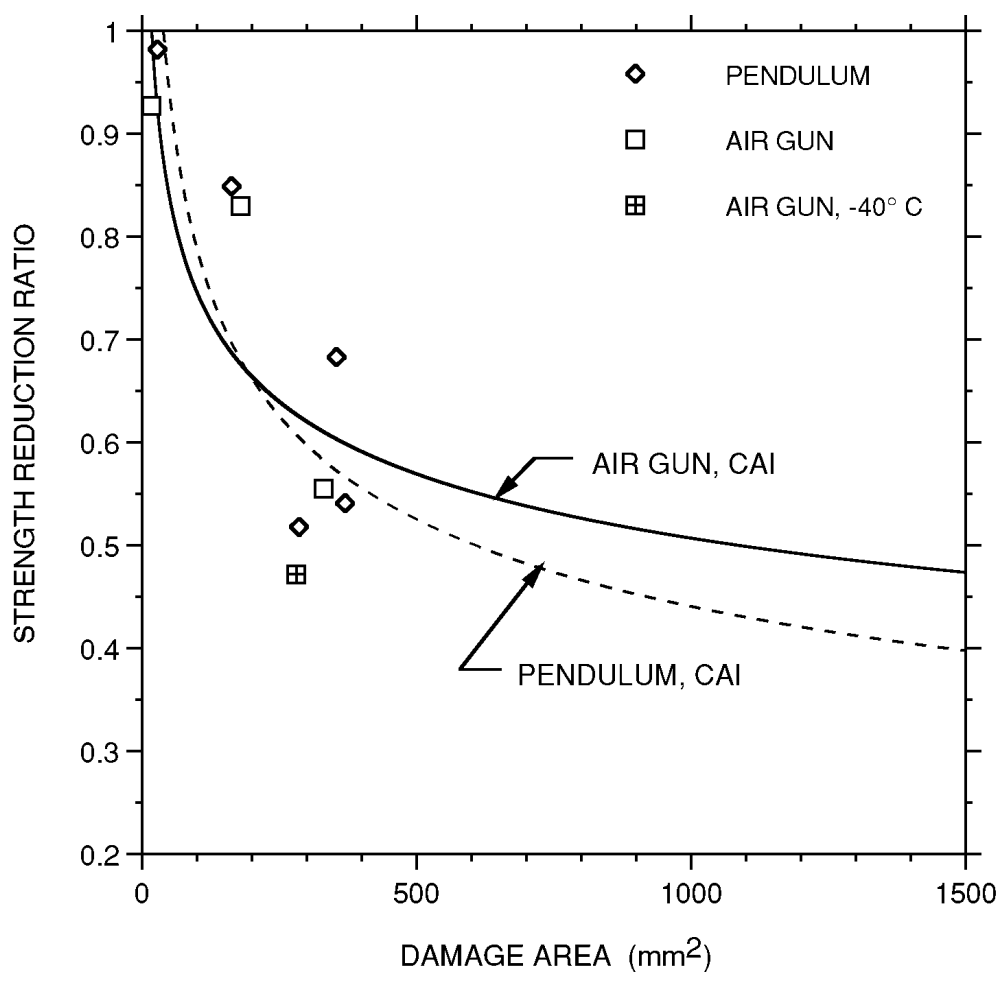

Fig. 14.16. Relative retained conventional compressive strength compared to CAI correlations. 


\subsubsection{Similarity to Hole Effects}

As was shown in Fig. 14.13, an undamaged CAI specimen that contained a central circular hole was cut adjacent to each CAI specimen that had an impact damage area. The range of hole diameters was chosen so that the corresponding areas spanned the measured impact damage areas of interest. The hole diameters, the corresponding number of specimens tested, and the average resulting strengths are tabulated in Table 14.2.

Table 14.2. Average hole specimens compressive test results

\begin{tabular}{cccc}
\hline $\begin{array}{c}\text { Hole diameter } \\
(\mathbf{m m})\end{array}$ & $\begin{array}{c}\text { Number of } \\
\text { specimens }\end{array}$ & $\begin{array}{c}\text { Gross failure stress, } \\
\overline{\boldsymbol{\sigma}}(\mathbf{M P a})\end{array}$ & $\begin{array}{c}\text { Gross failure stress, } \\
\overline{\boldsymbol{\sigma}}_{\boldsymbol{\infty}}(\mathbf{M P a})\end{array}$ \\
\hline 0 & 16 & 312 & 312 \\
6.35 & 4 & 227 & 229 \\
9.53 & 3 & 198 & 202 \\
12.7 & 4 & 179 & 185 \\
19.0 & 4 & 165 & 177 \\
25.4 & 3 & 145 & 166 \\
\hline
\end{tabular}

The results of the CAI-type tests of specimens with circular holes are compared in Fig. 14.17 with the results of the CAI tests of specimens containing impact damage. The power-law curve fit through the impact data points is based on all tests of specimens from the pendulum- and air-gunimpacted plate specimens. It does not include the brick test results shown in the figure nor the test data for the undamaged specimens. Likewise, the hole test correlation does not include the results for undamaged specimens without holes. The latter are plotted in Fig. 14.17 only for reference.

- IMPACT DAMAGE $\mathrm{y}=574.617 \mathrm{x}^{-0.191} \mathrm{r}^{2}=0.782$

- CIRCULAR HOLES $y=387.511 x^{-0.156} \mathrm{r}^{2}=0.871$

- UNDAMAGED / NO HOLES (NOT INCLUDED IN CURVE FITS)

$\oplus$ BRICK DROPS

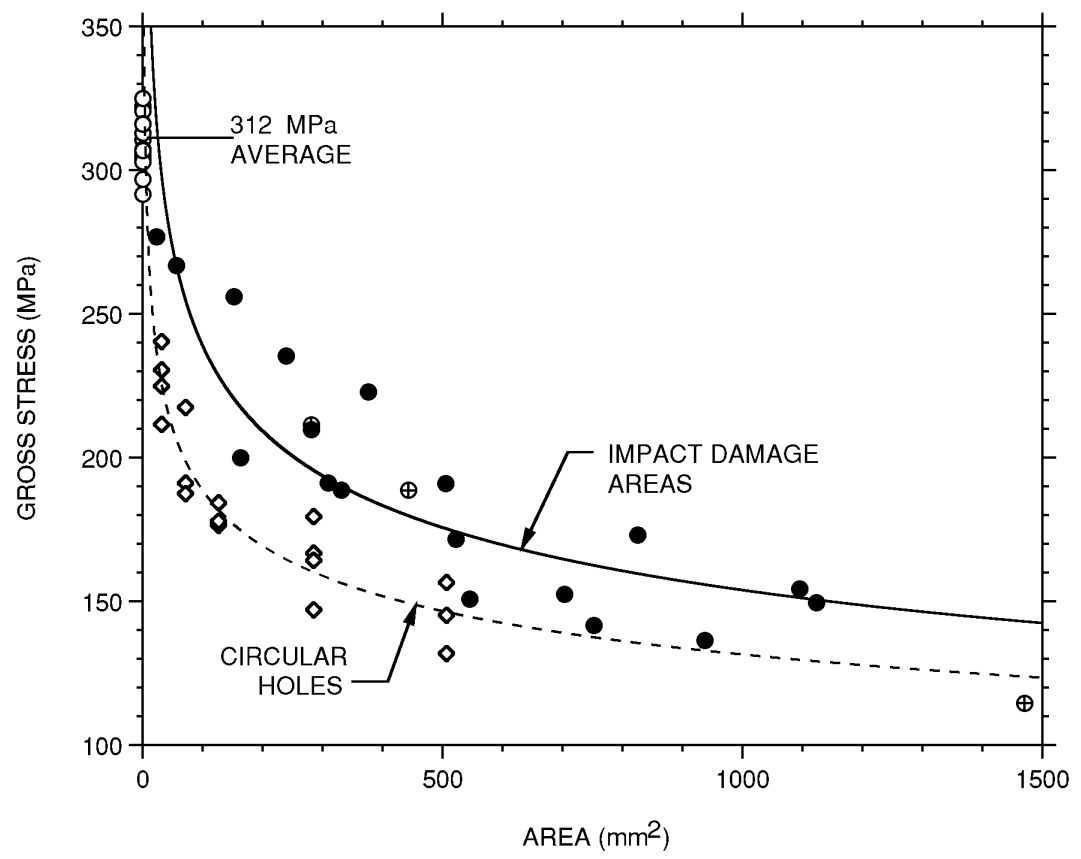

Fig. 14.17. Comparison of strength of CAI hole specimens with CAI results for impactdamaged specimens. 
As would be expected, for a given area the hole specimen failure stress is less than that for a specimen with impact damage. However, the trend is the same, and the hole correlation forms a reasonable lower bound for the impact damage results. This supports the guidance in Chap. 5 of Part 1 that impact damage in a structure can be represented by a circular hole to determine the effect on structural integrity.

How do the results of the CAI compressive tests of specimens with holes compare with the tensile test results of hole specimens reported in Chap. 13? To facilitate this comparison, the CAI hole results were converted to results for an infinite plate by using the approximate Eq. (13.1) given in Chap. 13. These converted values are shown in the right-hand column of Table 14.2. Figure 14.18 shows the average gross stress values for both tensile and compressive results as a function of hole diameter. The open circle and triangle on the ordinate represent the average tensile and CAI compressive strengths for specimens without holes. Despite the significant difference in these latter unnotched values, the gross failure stresses for specimens with holes are in fairly close agreement. When plotted as a strength reduction ratio, as shown in Fig. 14.19, the tensile strength degradation is larger than the CAI compressive strength degradation.

\subsection{SUMMARY AND RECOMMENDATIONS}

Fourteen pendulum impact tests, simulating tool drops, and fourteen air-gun tests, simulating kickups of roadway debris, were performed along with four brick-drop tests. Impact damage area

$\oplus$ TENSILE $y=307.600 x^{-0.170} \quad r^{2}=0.984$

○ TENSILE BASELINE

A CAl $y=338.370 x^{-0.224} r^{2}=0.965$

$\Delta \quad$ CAI BASELINE

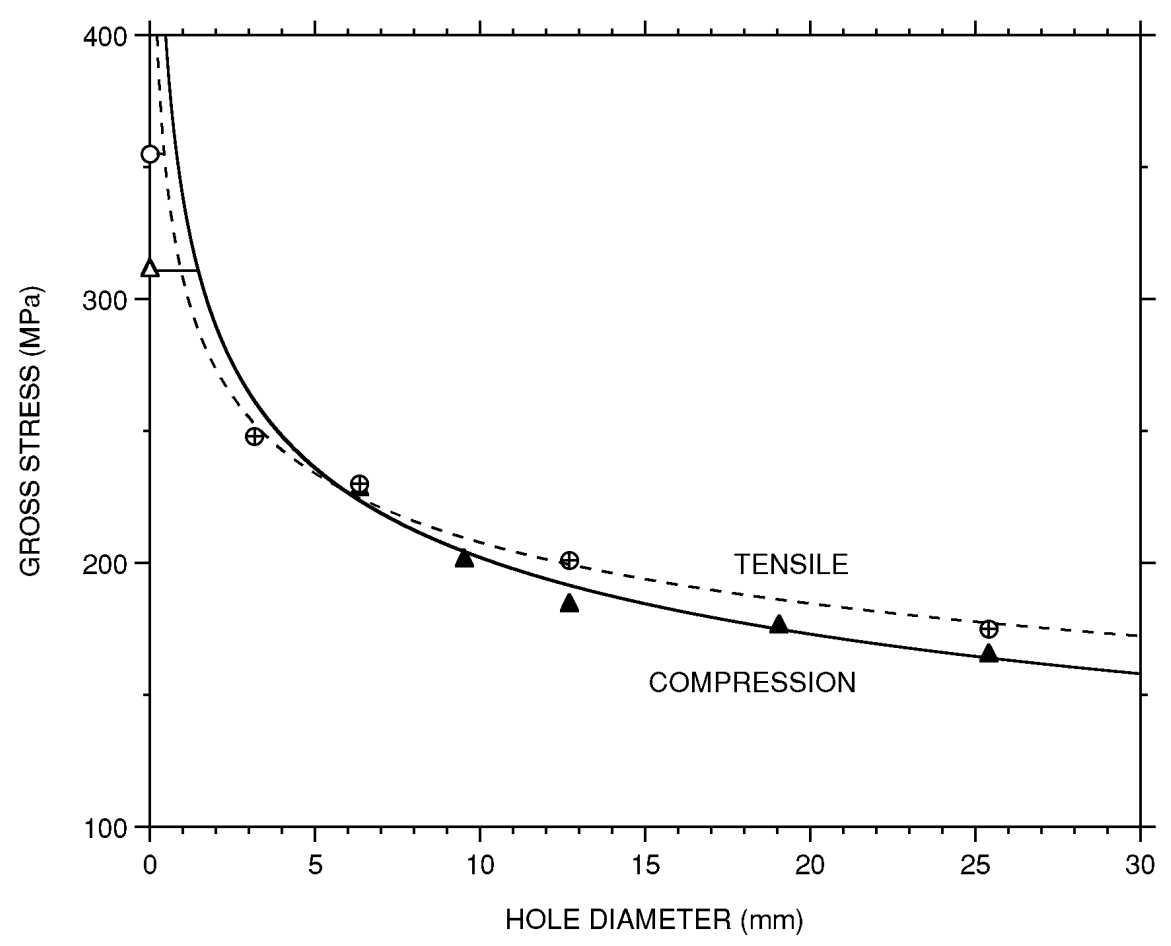

Fig. 14.18. Comparison of tensile and CAI compressive strengths of hole specimens. Both sets of data have been converted to equivalent infinitely wide plates. 


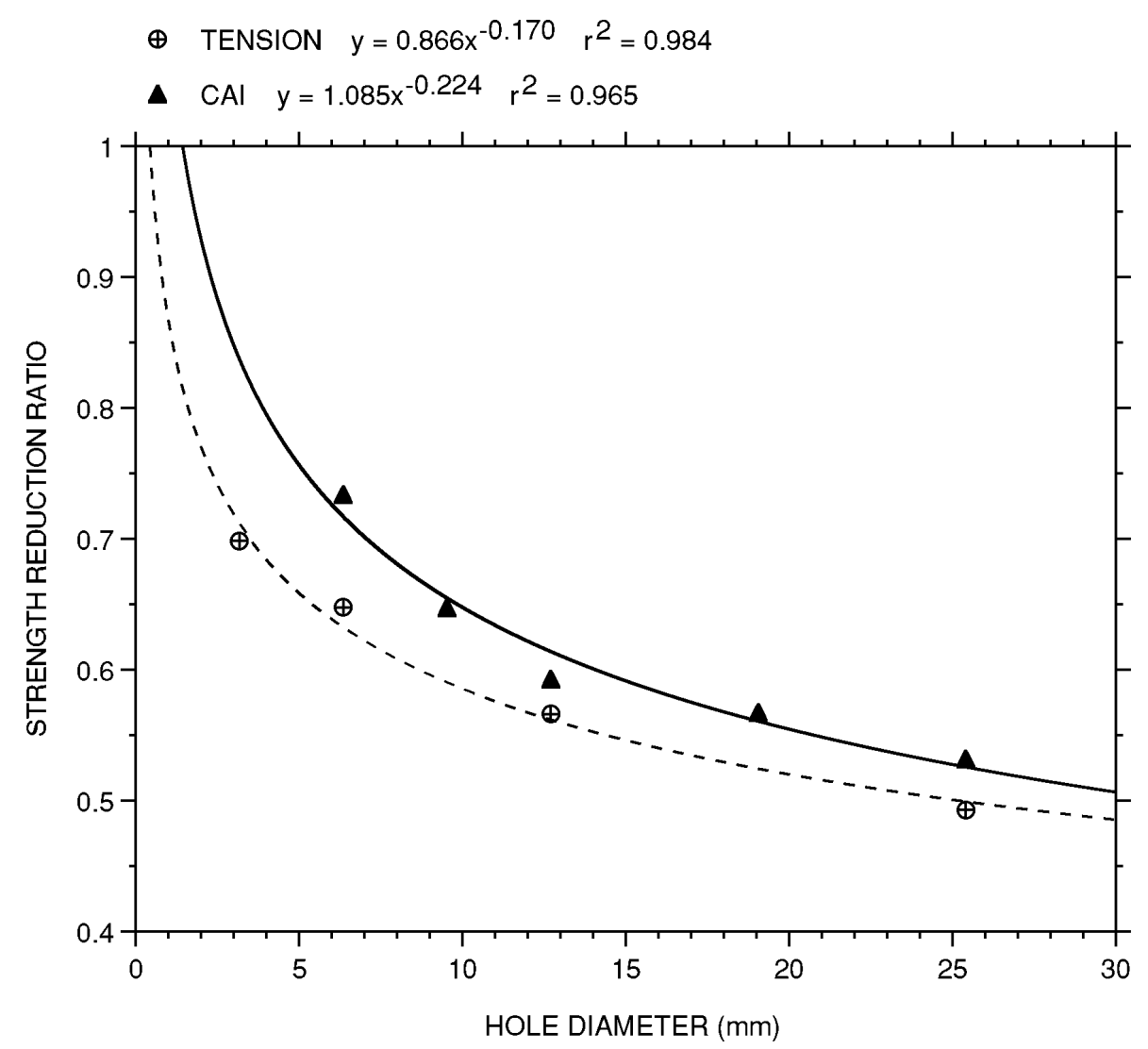

Fig. 14.19. Strength reduction ratio vs hole diameter for tensile and CAI compressive tests. Results are for infinitely wide plates.

was correlated with the quantity $\mathrm{m}^{0.535} \mathrm{v}$, where $\mathrm{m}$ is impactor mass in kilograms, and $\mathrm{v}$ is velocity in meters per second. The "design curve" given in Chap. 5 of Part 1 for conservatively estimating damage area was established from the data as shown in Fig. 14.20. The curve provides an upper bound for all of the observed damage, including that due to impacts at a temperature of $-40^{\circ} \mathrm{C}$ and to brick drops. The curve suggests that below a threshold of about 2.2 for $\mathrm{m}^{0.535} \mathrm{v}$, no detectable damage is expected.

A direct comparison between the damage assessment design curves for the carbon-fiber and glass-fiber composites that have been studied is difficult because the exponent on mass is different in each case. Looked at on the basis of kinetic energy, however, the two random-glassfiber composites (i.e., continuous-strand-mat and P4 chopped-glass-fiber) sustained about the same levels of damage; the crossply carbon-fiber composite exhibited significantly more damage; and the quasi-isotropic composite, being thinner, exhibited the greatest damage.

Property degradation tests of two types were performed: (1) a special CAI test on 76.2-mmwide specimens and (2) conventional compressive tests on 25.4-mm-wide specimens. In terms of strength reduction ratio, results from the two sets of tests were in reasonable agreement, although the CAI tests exhibited much less scatter. All of the compressive strength reduction data are plotted together in Fig. 14.21, and a design curve, which provides a lower bound to the data, is suggested. This curve was given in Chap. 5 of Part 1.

The design curve in Fig. 14.21 is not as low as the corresponding curve developed previously for the crossply carbon-fiber composite. ${ }^{4}$ The latter was based on both tensile and compressive strength reduction tests, and it was pulled down particularly by a few tensile results 


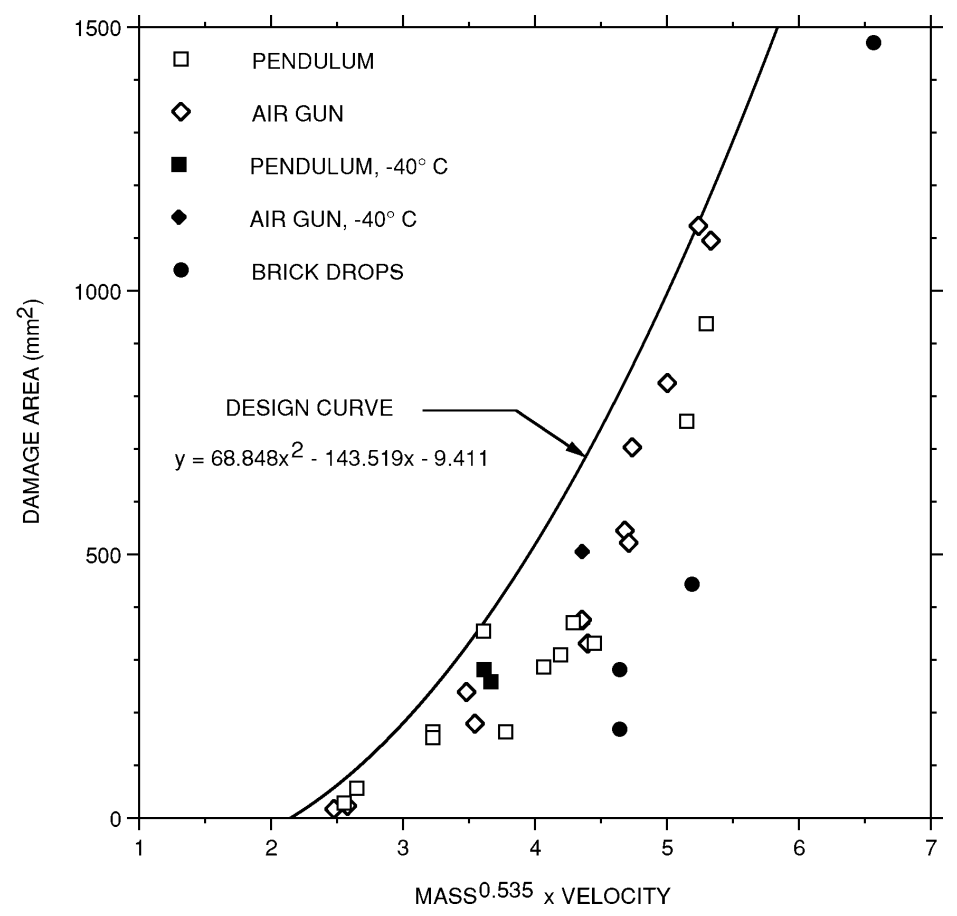

Fig. 14.20. Curve for conservatively estimating impact damage areas. Data points shown include tests at $-40^{\circ} \mathrm{C}$ and brick drops.

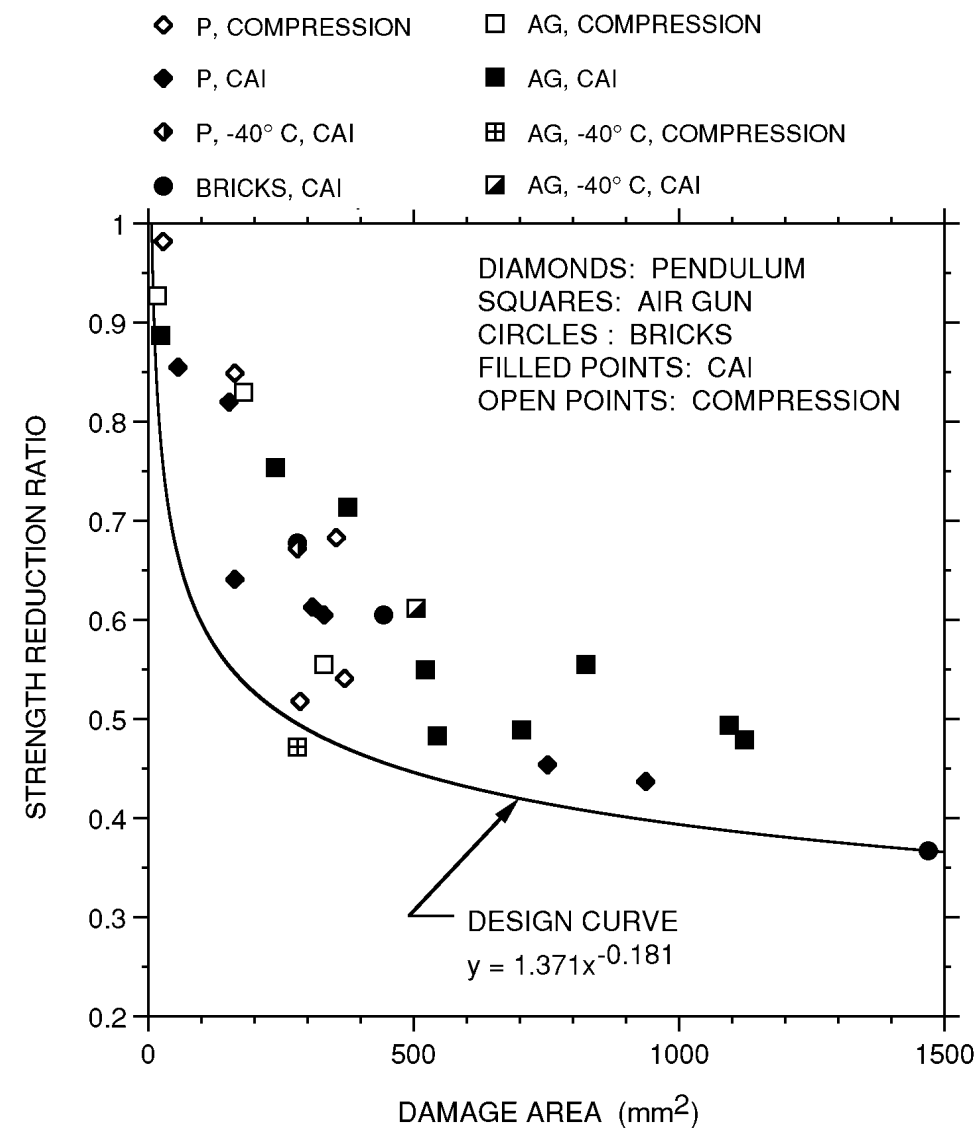

Fig. 14.21. Curve for conservatively estimating strength loss. All data points, both CAI and conventional compression, are shown. 
from pendulum-impacted specimens. At the higher values of damage area, the crossply composite strength degradation, both tensile and compressive, was clearly greater than for the quasiisotropic composite. The P4 chopped-glass-fiber composite strength reduction was governed by the loss of compressive strength; the reduction was significantly greater than that shown in Fig. 14.21. 


\section{REFERENCES}

1. J. M. Corum et al., Durability-Based Design Criteria for an Automotive Structural Composite: Part 1. Design Rules, ORNL-6930, Oak Ridge National Laboratory, Oak Ridge, Tenn., February 1998.

2. J. M. Corum et al., Durability-Based Design Criteria for an Automotive Structural Composite: Part 2. Background Data and Models, ORNL-6931, Oak Ridge National Laboratory, Oak Ridge, Tenn., February 1998.

3. J. M. Corum, R. L. Battiste, W. Ren, and M. B. Ruggles, Durability-Based Design Criteria for a Chopped-Glass-Fiber Automotive Structural Composite, ORNL/TM-1999/182, Oak Ridge National Laboratory, Oak Ridge, Tenn., November 1999.

4. J. M. Corum et al., Durability-Based Design Properties of Reference Crossply CarbonFiber Composite, ORNL/TM-2000/322, Oak Ridge National Laboratory, Oak Ridge, Tenn., April 2001.

5. The Composite Materials Handbook-MIL 17, Volume 1, Guidelines for Characterization of Structural Materials, Revision MIL-HDBK-17-1E, Technomic Publishing Co., Inc., Lancaster, Pennsylvania, January 1997.

6. National Materials Advisory Board, Life Prediction Methodologies for Composite Materials, NMAB-460, National Research Council, Washington, D.C., October 1991.

7. J. M. Corum, R L. Battiste, W. Ren, and M. B. Ruggles, Recommended Minimum Test Requirements and Test Methods for Assessing Durability of Random-Glass-Fiber Composites, ORNL-6953, Oak Ridge National Laboratory, Oak Ridge, Tenn., June 1999.

8. ASTM Standard D 3410-87, Standard Test Method for Compressive Properties of Unidirectional or Crossply Fiber-Resin Composites, American Society for Testing and Materials.

9. J. Gao and Y. J. Weitsman, The Tensile Mechanical Properties and Failure Behavior of Stitched T300 Mat/Urethane 420 IMR Composite, MAES98-2.0-CM, The University of Tennessee, July 1998.

10. E. M. Hagerman, ACC/GM, personal communication to J. M. Corum, Oak Ridge National Laboratory, August 2, 2001.

11. ASTM Standard D 790, Test Methods for Flexural Properties of Unreinforced and Reinforced Plastics and Electrical Insulating Materials, American Society for Testing and Materials.

12. R. Talreja, "Fatigue of Composite Materials," Chap. 3, Durability of Polymer Matrix Composites for Automotive Structural Applications: A State-of-the-Art Review, ORNL-6869, Oak Ridge National Laboratory, Oak Ridge, Tenn. (July 1995).

13. A. Conle and J. P. Ingall, "Effects of Mean Stress on the Fatigue of Composite Materials," Journal of Composite Technology and Research, 7(1), 3-11 (Spring 1985).

14. M. J. Owen and T. R. Smith, "Some fatigue properties of chopped-strand-mat/polyester resin laminates," Plastics and Polymers, 33-44 (February 1968).

15. Y. Weitsman, "Moisture in Composites: Sorption and Damage," Chap. 9, Fatigue of Composite Materials (ed. K. L. Reifsnider), Elsevier Science Publishers, B.V. (1991), pp. 385429.

16. C. H. Shen and G. S. Springer, "Moisture Absorption and Desorption of Composite Materials," Environmental Effects on Composite Materials (ed. G. S. Springer), Technomic Publishing Co., Westport, Connecticut (1981), pp. 15-33.

17. H. Kraus, Creep Analysis, John Wiley and Sons, New York, 1980.

18. S. Deng and Y. Weitsman, Mechanical Response of Stitched T300 Mat/Urethane 420

IMR Composite Laminates; Property/Orientation Dependence and Damage Evolution, ORNL/TM-2000/103, Oak Ridge National Laboratory, Oak Ridge, Tenn., February 2000. 
19. S. Deng and Y. Weitsman, "The Deformation of Carbon Fiber/Urethane Resin Composite under Load and Temperature," pp. 145-154 in Proceedings of the SAMPE-ACCEDOE-SPE Midwest Advanced Materials and Processing Conferences, Dearborn, Michigan, September 12-14, 2000 (ed. M. Rokosz et al.).

20. S. Deng and Y. Weitsman, "Time-Dependent Deformation of Stitched T300 Mat/Urethane 420 IMR Cross-ply Composite Laminates," Mechanics of Time Dependent Materials (to appear).

21. J. M. Corum et al., Basic Properties of Reference Crossply Carbon-Fiber Composite, ORNL/TM-2000/29, Oak Ridge National Laboratory, Oak Ridge, Tenn., March 2000.

22. I. M. Daniel and O. Ishai, Engineering Mechanics of Composite Materials, Oxford University Press, 1994.

23. C. T. Sun and J. L. Chen, "A Simplified Flow Rule for Characterizing Nonlinear Behavior of Fiber Composites," J. Comp. Mater., 23, 1009-1020 (October 1989).

24. C. T. Sun and K. J. Yoon, "Elastic-Plastic Analysis of AS4/PEEK Composite Laminate Using a One-Parameter Plasticity Model," J. Comp. Mater., 26(2), 293-308 (1992).

25. R. A. Schapery, "Nonlinear Viscoelastic and Viscoplastic Constitutive Equations Based on Thermodynamics," Mechanics of Time-Dependent Materials, 1(2), 209-240 (1997).

26. V. M. Winn and S. Sridharan, "An Investigation into the Accuracy of a One-Parameter Nonlinear Model for Unidirectional Composites," J. Comp. Mater., 16, 1491-1507 (2001).

27. J. M. Whitney and R. J. Nuismer, "Stress Fracture Criteria for Laminated Composites Containing Stress Concentrations," J. Composite Materials, 8, 253-265 (1974).

28. J. W. Mar and K. Y. Lin, "Fracture of Boron/Aluminum Composites with Discontinuities," J. Composite Materials, 11, 405-421 (1977).

29. G. Caprino, "On the Prediction of Residual Strength of Notched Laminates," J. Materials Science, 18, 2269-2273 (1983).

30. V. Kunc, J. M. Corum, and X. J. Xin, Investigation of Strength of Stitched CarbonFiber Mat/Urethane Composites with Holes, ORNL/TM-2001/245, Oak Ridge National Laboratory (to be published).

31. R. J. Nuismer and J. M. Whitney, "Uniaxial Failure of Composite Laminates Containing Stress Concentrations," Fracture Mechanics of Composites, ASTM STP 593, American Society of Testing and Materials, 1975, pp. 117-142.

32. Y. J. Guo, Stresses and Failure Analysis of Composite Laminates with Hole, University of Tennessee, March 9, 2000 (unpublished).

33. P. A. Lagace, "Notch Sensitivity and Stacking Sequence of Laminated Composites," Composite Materials: Testing and Design (Seventh Conference), ASTM STP 893, ed. J. M. Whitney, American Society for Testing and Materials, 1986, pp. 161-176.

34. J. W. Mar and K. Y. Lin, "Fracture Mechanics Correlation for Tensile Failures of Filamentary Composites with Holes," J. Aircraft, 14(7), 703-704 (1977).

35. P. Sjöblom and B. Hwang, "Compression-After-Impact: The $\$ 5000$ Data Point," 34th International SAMPE Symposium, 1411-1421 (May 1989). 
Appendix A

THE MODELING OF PLASTIC NONLINEARITY IN POLYMERIC COMPOSITES 
A-2 


\section{Appendix A. THE MODELING OF PLASTIC NONLINEARITY IN POLYMERIC COMPOSITES}

This appendix summarizes the three-parameter plasticity model proposed by Sun and Chen.* The model assumes the distortional energy in a unidirectionally reinforced composite lamina for the state of plane stress to be given by

$$
2 f\left(\sigma_{i j}\right)=\sigma_{22}^{2}+2 a \tau_{12}^{2} \leq k
$$

where $a$ is an empirical plastic parameter, $\sigma_{22}$ is the in-plane stress transverse to the fiber direction, and $\tau_{12}$ is the in-plane shear stress. Also $f$ is the yield function, and $k$ represents the yield surface at which plastic flow occurs. The incremental plastic strain is given by

$$
d \varepsilon_{i j}^{p}=\frac{\partial f}{\partial \sigma_{i j}} d \lambda
$$

In Eq. (A.2), $d \lambda$ is a proportionality factor, termed the plastic multiplier.

Substituting Eq. (A.1) into (A.2), the plastic strain components may be expressed in an expanded form:

$$
\left\{\begin{array}{l}
d \varepsilon_{11}^{p} \\
d \varepsilon_{22}^{p} \\
d \gamma_{12}^{p}
\end{array}\right\}=\left\{\begin{array}{c}
0 \\
\sigma_{22} \\
2 a \tau_{12}
\end{array}\right\} d \lambda .
$$

Consider incremental plastic work per unit volume,

$$
d W^{p}=\sigma_{i j} d \varepsilon_{i j}^{p}=2 f d \lambda .
$$

Based on equivalent plastic work, a measure of plasticity may be related by effective stress and effective plastic strain, which are defined as

$$
\bar{\sigma}=\sqrt{3 f} \quad \text { or } \quad f=\frac{\bar{\sigma}^{2}}{3}
$$

and thus

$$
d \bar{\varepsilon}^{p}=\frac{2}{3} \bar{\sigma} d \lambda
$$

An empirical model, expressed in power-law form, was found to provide a reasonable representation for the plastic behavior of composites. ${ }^{*}$ Because nonlinearity in the stress-strain response of many composites appears to occur at the onset of loading, one has

$$
\bar{\varepsilon}^{p}=A \bar{\sigma}^{n} .
$$

Combining Eqs. (A.1) and (A.5), one obtains

${ }^{*}$ C. T. Sun and J. L. Chen, "A Simplified Flow Rule for Characterizing Nonlinear Behavior of Fiber Composites," J. Comp. Mater., 23, 1009-1020 (October 1989). 


$$
\bar{\sigma}=\left[\frac{3}{2}\left(\sigma_{22}^{2}+2 a \tau_{12}^{2}\right)\right]^{\frac{1}{2}}
$$

Substitution of Eq. (A.8) into (A.7) yields

$$
\bar{\varepsilon}^{p}=A\left[\frac{3}{2}\left(\sigma_{22}^{2}+2 a \tau_{12}^{2}\right)\right]^{\frac{n}{2}} .
$$

Equations (A.1) and (A.7) through (A.9) suggest that the plastic response of polymeric composites may be characterized by the three constants $n, a$, and $A$.

For an off-axis unidirectional composite under uniaxial load $N_{\mathrm{X}}$ oriented at an angle $\theta$ about the fiber direction, the stress components relative to the principal directions of symmetry are

$$
\left\{\begin{array}{l}
\sigma_{11} \\
\sigma_{22} \\
\tau_{12}
\end{array}\right\}=\left\{\begin{array}{c}
\cos ^{2} \theta \\
\sin ^{2} \theta \\
-\sin \theta \cos \theta
\end{array}\right\} \sigma_{x} .
$$

Also, the plastic strain in the loading direction is

$$
d \varepsilon_{x}^{p}=\cos ^{2} \theta d \varepsilon_{11}^{p}+\sin ^{2} \theta d \varepsilon_{22}^{p}-\sin \theta \cos \theta d \gamma_{12}^{p} .
$$

Combination of Eqs. (A.3), (A.10), and (A.11) leads to

$$
d \varepsilon_{x}^{p}=\frac{2}{3}[h(\theta)]^{2} \sigma_{x} d \lambda
$$

where $h(\theta)$ is given by

$$
h(\theta)=\left[\frac{3}{2}\left(\sin ^{4} \theta+2 a \sin ^{2} \theta \cos ^{2} \theta\right)\right]^{\frac{1}{2}} .
$$

In conjunction with the transformation function $h(\theta)$, the effective stress and effective plastic strain may also be expressed in terms of $\sigma_{\mathrm{x}}$. From Eqs. (A.6), (A.8), and (A.10), one obtains

$$
\bar{\sigma}=h(\theta) \sigma_{x}
$$

and

$$
d \bar{\varepsilon}^{p}=\frac{2}{3} h(\theta) \sigma_{x} d \lambda .
$$

Comparison of Eqs. (A.15) and (A.12) yields

$$
d \bar{\varepsilon}^{p}=\frac{d \varepsilon_{x}^{p}}{h(\theta)},
$$

whereby, upon integration 


$$
\bar{\varepsilon}^{p}=\frac{\varepsilon_{x}^{p}}{h(\theta)}
$$

Substituting Eqs. (A.14) and (A.17) into Eq. (A.7) one obtains

$$
\varepsilon_{x}^{p}=[h(\theta)]^{n+1} A \sigma_{x}^{n} .
$$

Equation (A.18) expresses the plastic strain-stress relation in an off-axis unidirectional composite under a uniaxial load. This shows that under a certain stress level the corresponding plastic strain is determined by the material plastic properties $n, A$, and $a$, where $a$ is embedded in $h(\theta)$.

In the case of laminates, all individual plies, oriented at different angles about the load direction, are assumed to undergo the same strains $\varepsilon_{x}, \varepsilon_{y}$, and $\gamma_{x y}$. To ascertain this commonality of deformation at each stage of loading, with $h(\theta)$ varying from ply to ply, it is necessary to perform an incremental computation because the plastic components of strain vary nonlinearly with stress. 
Appendix B

OPTIMAL NONLINEAR LEAST-SQUARE DATA FITTING SCHEME TO DETERMINE THE PLASTIC PARAMETERS $a, A$, AND $n$ 
B-2 


\section{Appendix B. OPTIMAL NONLINEAR LEAST-SQUARE DATA FITTING SCHEME TO DETERMINE THE PLASTIC PARAMETERS $a, A$, AND $n$}

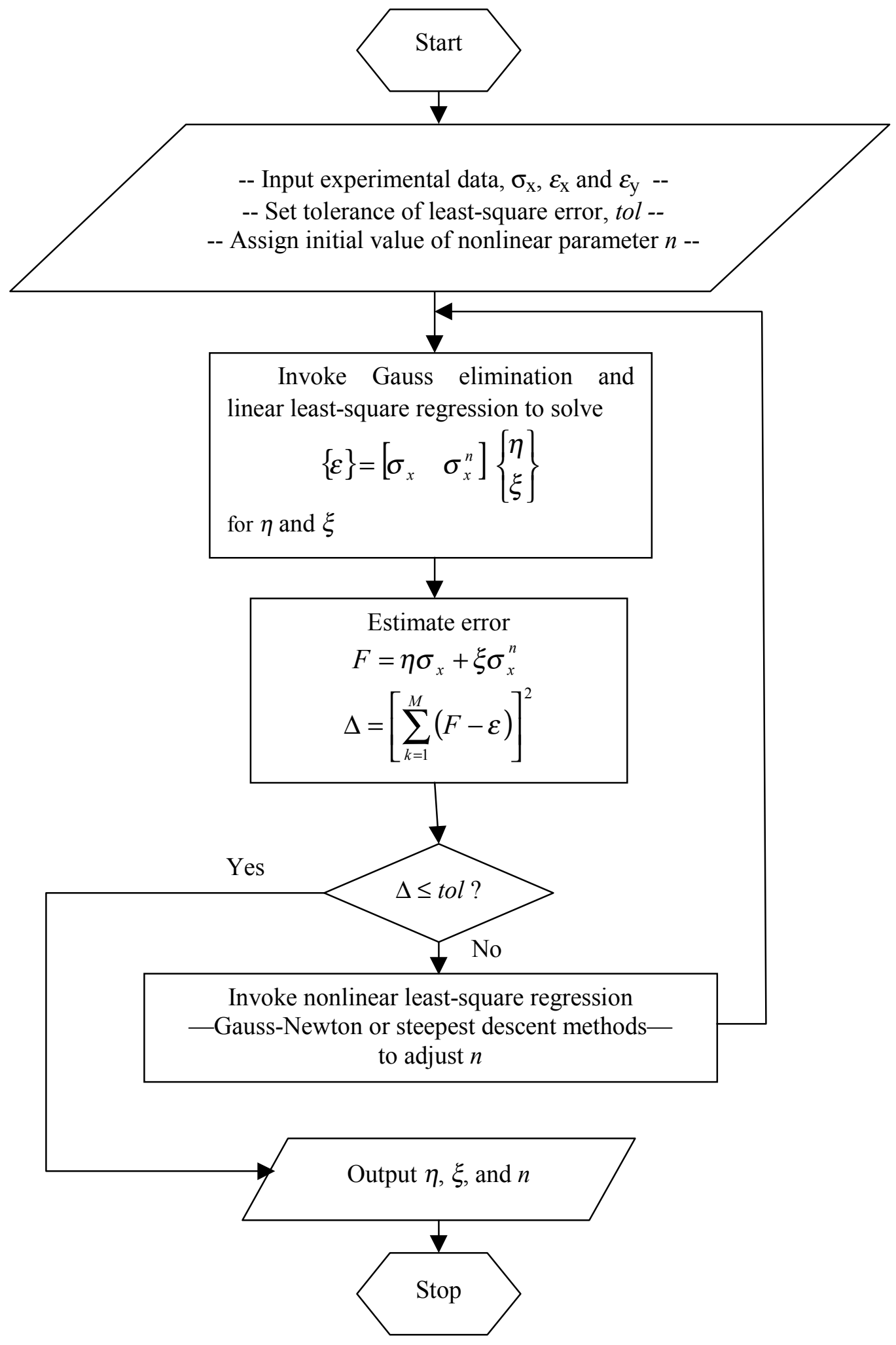


B-4 
Appendix $\mathrm{C}$

A MATHEMATICAL DEMONSTRATION FOR THE DEPARTURE FROM QUASI-ISOTROPY CAUSED BY NONLINEARITY 


$$
\text { C-2 }
$$




\section{Appendix C. A MATHEMATICAL DEMONSTRATION FOR THE DEPARTURE FROM QUASI-ISOTROPY CAUSED BY NONLINEARITY}

Though not supported by experimental data, it is possible to provide a straightforward demonstration for the fact that the response of quasi-isotropic laminates becomes orientationdependent in the nonlinear range of stress-strain behavior by means of a simplified nonlinear formulation.

For this purpose, assume that the basic stress-strain relations of a unidirectional ply are given by

$$
\begin{aligned}
& \sigma_{1}=Q_{11} \varepsilon_{1}+Q_{12} \varepsilon_{2} \\
& \sigma_{2}=Q_{12} \varepsilon_{1}+Q_{22} \varepsilon_{2} \\
& \sigma_{6}=f\left(\varepsilon_{6}\right) .
\end{aligned}
$$

Thus, Eq. (C.1) presumes that all nonlinearity dwells in the stress-strain response in shear alone. Obviously, $f\left(\varepsilon_{6}\right)=-f\left(-\varepsilon_{6}\right)$, and $\lim _{\varepsilon_{6} \rightarrow 0} f\left(\varepsilon_{6}\right)=Q_{66}$.

Straightforward manipulations of Eq. (C.1) yield the following expressions for the response of a quasi-isotropic laminate under uniaxial stress applied at an angle $\phi$ about the $X_{1}$ axis:

$$
\begin{aligned}
\sigma_{x} & =\left[\frac{1}{2}\left(m^{4}+n^{4}\right)\left(Q_{11}+Q_{22}\right)+2 m^{2} n^{2} Q_{12}\right] \varepsilon_{x} \\
& +\left[m^{2} n^{2}\left(Q_{11}+Q_{22}\right)\left(m^{4}+n^{4}\right) Q_{12}\right] \varepsilon_{y} \\
& +m n\left\{f\left[\left(m^{2}-n^{2}\right) \gamma_{x y}+2 m n\left(\varepsilon_{x}-\varepsilon_{y}\right)\right]-f\left[\left(m^{2}-n^{2}\right) \gamma_{x y}-2 m n\left(\varepsilon_{x}-\varepsilon_{y}\right)\right]\right\},
\end{aligned}
$$

where $\mathrm{m}=\cos \phi$, and $\mathrm{n}=\sin \phi$.

In the special case that $\phi=22.5^{\circ}$, the above expression reduces to

$\sigma_{\mathrm{x}}=\frac{1}{8}\left[3\left(Q_{11}+Q_{22}\right)+2 Q_{12}\right] \varepsilon_{\mathrm{x}}$

$$
+\frac{1}{8}\left[\left(Q_{11}+Q_{22}\right)+6 Q_{12}\right] \varepsilon_{\mathrm{y}}+\frac{\sqrt{2}}{2} \widetilde{f}\left[\frac{\sqrt{2}}{2}\left(\varepsilon_{x}-\varepsilon_{y}\right)\right] .
$$

While, for $\phi=0^{\circ}$, one obtains

$$
\sigma_{\mathrm{x}}=\frac{1}{8}\left[3\left(Q_{11}+Q_{22}\right)+2 Q_{12}\right] \varepsilon_{\mathrm{x}}+\frac{1}{8}\left[\left(Q_{11}+Q_{22}\right)+6 Q_{12}\right] \varepsilon_{\mathrm{y}}+\frac{1}{2} f\left(\varepsilon_{x}-\varepsilon_{y}\right) .
$$

Note that under uniaxial tension $\varepsilon_{6}=0$ for both $\phi=0^{\circ}$ and $\phi=22.5^{\circ}$.

The essential theme of the above expressions is that they clearly demonstrate that Eqs. (C.3) and (C.4) predict different results. The difference is entirely due to the fact that, in view of the 
nonlinear character of $f(x), \frac{1}{\alpha} f(\alpha x) \neq f(x)$. It also follows that in the linear range, that is, as $f(x) \rightarrow Q_{66} x$, the inequality becomes an equality and quasi-isotropy prevails.

Nevertheless, while demonstrating the departure from quasi-isotropy due to nonlinearity, it can be shown that the current formulation predicts that the response at $22.5^{\circ}$ is stiffer than that at $\phi=0^{\circ}$. Such a prediction is, of course, contradicted by data. 
Appendix D

\section{PLAQUE RECORDS}


D-2 


\section{Appendix D. PLAQUE RECORDS}

Twenty-eight quasi-isotropic carbon-fiber composite plaques were provided to the ORNL Durability of Carbon-Fiber Composites Project by ACC. Plaque fabrication followed the same process as that described previously for the crossply carbon-fiber composite. ${ }^{*}$ The thickness of each plaque was measured at each of the points shown in the sketch in Fig. D.1. These measurements are given in Table D.1, together with the resulting average plaque thickness and the maximum measured thickness variation for each plaque. The thickness variation is defined as the maximum thickness measurement minus the minimum, divided by the average, and is given in percent. Note that the thickness variation pattern is generally consistent for each of the plaques in a molding trial, (given by the three-letter ACC designation). Furthermore, the thickness variation for each plaque in a trial generally has about the same magnitude. Molding trial TZP has the largest variation (average of $42.4 \%$ ), while TFZ has the smallest (average of 14.4\%).

All of the plaques except for Q1 through Q6 and Q17 had the following symmetric layup relative to the plaque number and the $0^{\circ}$ direction shown in Fig. D.1: $\left[90^{\circ} / 0 / \pm 45^{\circ}\right]_{\mathrm{S}}$. Plaques Q1 through Q6 had the outer stitch-bonded mats rotated $90^{\circ}$ relative to the plaque number and the $0^{\circ}$ direction shown on Fig. D.1: $\left[0 / 90^{\circ} / \pm 45^{\circ}\right]_{S}$. The outer mats of plaque Q17 were nonsysmetrically oriented; that is, the top surface ply was oriented at $90^{\circ}$, while the bottom surface ply was at $0^{\circ}$.

Table D.2 lists the fiber volume of each plaque (calculated from the fiber preform and plaque weights), the use made of each plaque, and the average plaque strength and stiffness. Plaque average strengths come from four reference tensile tests, except for plaques Q11, Q12, Q13, and Q18, where six reference tensile tests were conducted. Virgin stiffnesses were measured for all tensile-type specimens. Thus, the plaque average stiffness values are often based on more than just four reference tensile specimens. The unweighted averages for all plaques were calculated assuming that the tabulated plaque averages were the true plaque values, regardless of how many specimens were used to determine them.

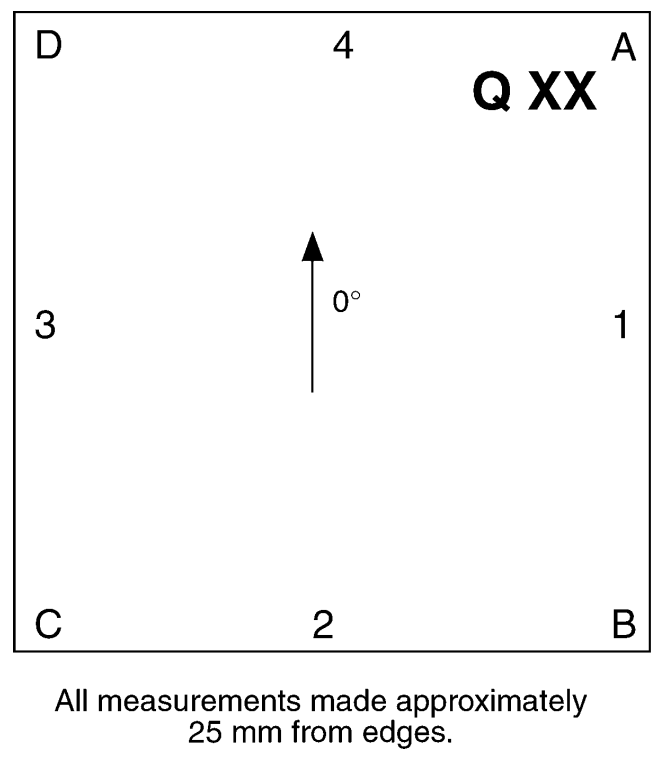

Fig. D.1. Location of thickness measurements relative to plaque designation and reference orientation.

*J. M. Corum et al., Durability-Based Design Properties of Reference Crossply Carbon-Fiber Composite, ORNL/TM-2000/322, Oak Ridge National Laboratory, Oak Ridge, Tenn., April 2001. 
Table D.1. Thickness data for quasi-isotropic composite plaques used in the durability study

\begin{tabular}{|c|c|c|c|c|c|c|c|c|c|c|c|}
\hline \multirow{2}{*}{$\begin{array}{c}\text { ORNL } \\
\text { designatio }\end{array}$} & \multirow{2}{*}{$\begin{array}{c}\text { ACC } \\
\text { designation }\end{array}$} & \multicolumn{9}{|c|}{ Thickness (mm) } & \multirow{2}{*}{$\begin{array}{c}\text { Thickness } \\
\text { variation } \\
(\%)\end{array}$} \\
\hline & & $\mathbf{A}$ & 1 & B & 2 & $\mathrm{C}$ & 3 & D & 4 & $\overline{\text { Average }}$ & \\
\hline$\overline{\mathrm{Q} 1}$ & TJB 57 & 3.200 & 2.700 & 2.224 & 2.384 & 2.483 & 2.532 & 2.658 & 2.995 & 2.647 & 36.87 \\
\hline Q2 & TJB 58 & 2.847 & 2.446 & 2.064 & 2.318 & 2.470 & 2.413 & 2.430 & 2.704 & 2.461 & 31.82 \\
\hline $\mathrm{Q}^{a}$ & TJB 59 & 2.819 & 2.347 & 1.980 & 2.189 & 2.260 & 2.225 & 2.258 & 2.607 & 2.336 & 35.92 \\
\hline Q4 & TJB 61 & 2.799 & 2.342 & 1.922 & 2.113 & 2.212 & 2.212 & 2.292 & 2.619 & 2.314 & 37.90 \\
\hline Q5 & TJB 62 & 2.868 & 2.405 & 1.975 & 2.129 & 2.212 & 2.206 & 2.283 & 2.635 & 2.339 & 38.18 \\
\hline Average & $\mathrm{TJB}$ & 2.929 & 2.473 & 2.046 & 2.236 & 2.344 & 2.341 & 2.416 & 2.738 & 2.419 & 36.14 \\
\hline Q6 & TZP 10 & 2.111 & 2.094 & 2.089 & 2.631 & 3.169 & 2.775 & 2.456 & 2.327 & 2.456 & 43.97 \\
\hline Q7 & TZP 69 & 2.233 & 2.141 & 2.055 & 2.611 & 3.098 & 2.793 & 2.579 & 2.446 & 2.494 & 41.82 \\
\hline Q8 & TZP 65 & 2.283 & 2.137 & 1.962 & 2.503 & 2.981 & 2.742 & 2.591 & 2.487 & 2.461 & 41.41 \\
\hline Average & $\mathrm{TZP}$ & 2.209 & 2.124 & 2.035 & 2.582 & 3.082 & 2.770 & 2.542 & 2.420 & 2.471 & 42.40 \\
\hline Q9 & TFZ 14 & 2.714 & 2.447 & 2.174 & 2.155 & 2.023 & 2.214 & 2.407 & 2.623 & 2.345 & 29.47 \\
\hline Q10 & TFZ 15 & 2.386 & 2.201 & 2.041 & 2.093 & 2.038 & 2.130 & 2.219 & 2.356 & 2.183 & 15.94 \\
\hline Q11 & TFZ 16 & 2.365 & 2.203 & 2.026 & 2.097 & 2.054 & 2.139 & 2.226 & 2.352 & 2.183 & 15.53 \\
\hline Q12 & TFZ 17 & 2.361 & 2.174 & 1.994 & 2.069 & 2.050 & 2.134 & 2.240 & 2.353 & 2.172 & 16.90 \\
\hline Q13 & TFZ 18 & 2.409 & 2.247 & 2.073 & 2.102 & 2.040 & 2.135 & 2.236 & 2.376 & 2.202 & 16.76 \\
\hline Q14 & TFZ 19 & 2.338 & 2.198 & 2.073 & 2.122 & 2.083 & 2.145 & 2.205 & 2.329 & 2.187 & 12.12 \\
\hline Q15 & TFZ 20 & 2.319 & 2.158 & 2.009 & 2.101 & 2.090 & 2.170 & 2.253 & 2.347 & 2.181 & 15.50 \\
\hline Q16 & TFZ 21 & 2.170 & 2.184 & 2.203 & 2.322 & 2.323 & 2.231 & 2.134 & 2.203 & 2.221 & 8.51 \\
\hline Q17 & TFZ 22 & 2.300 & 2.173 & 2.009 & 2.062 & 2.024 & 2.101 & 2.187 & 2.308 & 2.146 & 13.93 \\
\hline Q18 & TFZ 23 & 2.303 & 2.178 & 2.028 & 2.090 & 2.059 & 2.121 & 2.177 & 2.308 & 2.158 & 12.97 \\
\hline Q19 & TFZ 24 & 2.334 & 2.192 & 2.042 & 2.089 & 2.042 & 2.066 & 2.173 & 2.311 & 2.156 & 13.54 \\
\hline Q20 & TFZ 25 & 2.356 & 2.201 & 2.037 & 2.087 & 2.045 & 2.122 & 2.197 & 2.330 & 2.172 & 14.69 \\
\hline Q21 & TFZ 26 & 2.299 & 2.219 & 2.121 & 2.187 & 2.159 & 2.151 & 2.159 & 2.289 & 2.198 & 8.10 \\
\hline Q22 & TFZ 27 & 2.256 & 2.104 & 1.974 & 2.056 & 2.041 & 2.109 & 2.165 & 2.273 & 2.122 & 10.93 \\
\hline Q23 & TFZ 28 & 2.435 & 2.250 & 2.054 & 2.115 & 2.055 & 2.168 & 2.280 & 2.424 & 2.223 & 17.14 \\
\hline Q24 & TFZ 29 & 2.422 & 2.301 & 2.144 & 2.189 & 2.121 & 2.197 & 2.262 & 2.410 & 2.256 & 13.34 \\
\hline Q25 & TFZ 30 & 2.332 & 2.188 & 2.019 & 2.089 & 2.057 & 2.137 & 2.223 & 2.338 & 2.173 & 14.68 \\
\hline Q26 & TFZ 31 & 2.314 & 2.168 & 2.021 & 2.078 & 2.047 & 2.106 & 2.177 & 2.297 & 2.151 & 13.62 \\
\hline Q27 & TFZ 32 & 2.334 & 2.191 & 2.031 & 2.083 & 2.035 & 2.107 & 2.177 & 2.308 & 2.158 & 14.04 \\
\hline Q28 & TFZ 33 & 2.308 & 2.201 & 2.075 & 2.113 & 2.068 & 2.109 & 2.150 & 2.282 & 2.163 & 11.10 \\
\hline Average & TFZ & 2.353 & 2.209 & 2.057 & 2.115 & 2.073 & 2.140 & 2.212 & 2.341 & 2.187 & 14.44 \\
\hline \multicolumn{2}{|c|}{ Overall average } & & & & & & & & & 2.259 & 21.31 \\
\hline
\end{tabular}

$a_{\mathrm{ACC}}$ thickness measurements. 
Table D.2. Disposition of quasi-isotropic composite plaques in the durability study

\begin{tabular}{|c|c|c|c|c|c|}
\hline $\begin{array}{c}\text { ORNL } \\
\text { designation }\end{array}$ & $\begin{array}{c}\text { ACC } \\
\text { designation }\end{array}$ & $\begin{array}{c}\text { Fiber } \\
\text { volume } \\
\text { fraction } \\
(\%) \\
\end{array}$ & Use & $\begin{array}{c}\text { Average } \\
\text { UTS } \\
\text { (MPa) }\end{array}$ & $\begin{array}{c}\text { Average } \\
\text { stiffness } \\
\text { (GPa) }\end{array}$ \\
\hline Q1 & TJB 57 & 34.94 & Cantilever beams & N. A. ${ }^{a}$ & 26.8 \\
\hline Q2 & TJB 58 & 37.20 & Not used & & \\
\hline Q3 & TJB 59 & 39.20 & Time-dependent modeling & N. A. & N. A. \\
\hline Q4 & TJB 61 & 38.80 & Time-dependent modeling & N. A. & N. A. \\
\hline Q5 & TJB 62 & 38.80 & Time-dependent modeling & N. A. & N. A. \\
\hline Average & TJB & 37.79 & & & \\
\hline Q6 & TZP 10 & 37.52 & Not used & & \\
\hline Q7 & TZP 69 & 35.93 & Not used & & \\
\hline Q8 & TZP 65 & 37.20 & Not used & & \\
\hline Average & TZP & 36.88 & & & \\
\hline Q9 & TFZ 14 & 38.46 & Mean-stress fatigue & 299 & 30.6 \\
\hline Q10 & TFZ 15 & 40.98 & Short-time creep & 325 & 32.3 \\
\hline Q11 & TFZ 16 & 41.37 & Basic properties & 358 & 32.2 \\
\hline Q12 & TFZ 17 & 42.14 & Basic properties & 348 & 32.8 \\
\hline Q13 & TFZ 18 & 40.60 & Basic properties & 329 & 31.9 \\
\hline Q14 & TFZ 19 & 41.75 & Fatigue & 328 & 32.9 \\
\hline Q15 & TFZ 20 & 41.37 & Fatigue & 344 & 32.2 \\
\hline Q16 & TFZ 21 & 40.98 & Long-term creep & 333 & 31.9 \\
\hline Q17 & TFZ 22 & 41.76 & Not used & & \\
\hline Q18 & TFZ 23 & 41.76 & Basic properties & 342 & 34.2 \\
\hline Q19 & TFZ 24 & 41.76 & Flexure (uniaxial, biaxial) & 346 & 34.8 \\
\hline Q20 & TFZ 25 & 39.85 & Hole specimens & 355 & 34.1 \\
\hline Q21 & TFZ 26 & 40.98 & Impact & 359 & 33.3 \\
\hline Q22 & TFZ 27 & 41.78 & Impact & 356 & 36.2 \\
\hline Q23 & TFZ 28 & 40.98 & Impact & 319 & 33.2 \\
\hline Q24 & TFZ 29 & 40.23 & Impact & 338 & 31.7 \\
\hline Q25 & TFZ 30 & 41.37 & Impact & 329 & 33.6 \\
\hline Q26 & TFZ 31 & 42.54 & Impact & 330 & 34.0 \\
\hline Q27 & TFZ 32 & 41.37 & Impact & 317 & 31.5 \\
\hline Q28 & TFZ 33 & 41.76 & Impact & 329 & 33.2 \\
\hline Average & TFZ & 41.19 & & 336 & $33.0^{b}$ \\
\hline
\end{tabular}

$a_{\text {Not available. }}$

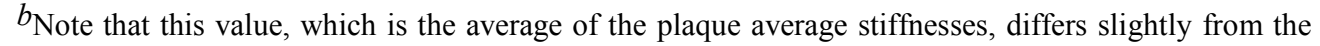
average stiffness of $32.4 \mathrm{GPa}$ given in Chaps. 2 and 7. There the average was based on each individual test stiffness. 
D-6 
ORNL/TM-2002/39

\section{INTERNAL DISTRIBUTION}

\author{
1-2. R. L. Battiste \\ 3. R. G. Boeman \\ 4-13. J. M. Corum \\ 14. D. L. Erdman \\ 15. J. G. Hansen \\ 16. A. Ionita \\ 17. L. D. Klett \\ 18. V. Kunc \\ 19. E. Lara-Curzio \\ 20. R. E. Norris
}

\author{
21-22. M. B. Ruggles-Wrenn \\ 23. S. Simunovic \\ 24. P. A. Sklad \\ 25. J. M. Starbuck \\ 26. C. D. Warren \\ 27-28. Y. J. Weitsman \\ 29. R. E. Ziegler \\ 30. Central Research Library \\ 31. ORNL Laboratory Records-RC \\ 32. ORNL Laboratory Records-OSTI
}

\section{EXTERNAL DISTRIBUTION}

33. M. Abdallah, Hexcel Carbon Fibers, Research and Technology, P.O. Box 18748, Salt Lake City, UT 84118-0748

34. S. Deng, University of Tennessee, Department of Mechanical and Aerospace Engineering, 307 Perkins Hall, Knoxville, TN 37996-2030

35. M. M. Fisher, American Plastics Council, 1300 Wilson Boulevard, Suite 800, Arlington, VA 22209

36. R. B. Freeman, The Budd Company, 1515 Atlantic Boulevard, Auburn Hills, MI 48326

37. R. Gjerde, Textron Automotive Company, 100 Brady Road, Americus, GA 31709

38-67. L. Berger, Automotive Composite Consortium, General Motors, 30500 Mound Road, Mail Code 480-106-710, Box 9055, Warren, MI 48090-9055

68. J. M. Henshaw, Department of Mechanical Engineering, The University of Tulsa, 600 S. College Avenue, Tulsa, OK 74104-3189

69. G. A. Holmes, National Institute of Standards and Technology, Bldg. 224, Room B116, Mail Stop: Room B108, Gaithersburg, MD 20899

70. P. K. Johnson, Zoltek Corporation, 3101 McKelvey Road, St. Louis, MO 53044

71. S. H. Johnson, BP Amoco Polymers, Inc., 4500 McGinnis Ferry Road, Alpharetta, GA 300053914

72. D. Kossak, Cambridge Industries, 29333 Stephenson Highway, Madison Heights, MI 48071

73. F. G. Krautz, Vetrotex Certainteed, 4515 Allendale Road, Wichita Falls, TX 76310-2199

74. X. Li, University of Tennessee, Department of Mechanical and Aerospace Engineering, 307 Perkins Hall, Knoxville, TN 37996-2030

75. G. R. Miesel, Ashland Chemical Company, 900 Wilshire Drive, Suite 100, Troy, MI 48084

76. E. Ostwald, Dow Automotive, 1600 Harmon Road, Auburn Hills, MI 48326

77. S. R. Reeve, National Composite Center, 2000 Composite Drive, Kettering, OH 45420

78. C. R. Schultheisz, National Institute of Standards and Technology, Building 224, Room A209, Gaithersburg, MD 20899

79. T. D. Seagrave, Bayer Corporation, 100 Bayer Road, Pittsburgh, PA 15205

80. D. R. Secrist, Fortafil Fibers, Inc., 121 Cardiff Valley Road, Rockwood, TN 37854

81. L. V. Smith, Washington State University, School of Mechanics and Materials Engineering, Pullman, WA 99164-2920

82. D. Stewart, Stewart Automotive Research, LLC, 1260 Shotwell Street, Houston, TX 77020

83. X. J. Xin, Department of Mechanical and Nuclear Engineering, Kansas State University, 338 Rathbone Hall, Manhattan, KS 66506-5205

84. S. J. Winckler, Cyclics Corporation, 747 Pierce Road, Clifton Park, NY 12065 
85-88. J. A. Carpenter, U.S. Department of Energy, 1000 Independence Avenue, SW, Washington, DC 20585

89. M. Rowlins, U.S. Department of Energy, Oak Ridge Site Office, Oak Ridge, TN 37831

90. S. Diamond, U.S. Department of Energy, 1000 Independence Avenue, SW, Washington, DC 20585 